\title{
An Evolving
}

Paradigm of

Agricultural

Mechanization

Development

\section{How Much Can Africa}

Learn from

Asia? 


\section{About IFPRI}

The International Food Policy Research Institute (IFPRI), a CGIAR Research Center established in 1975, provides research-based policy solutions to sustainably reduce poverty and end hunger and malnutrition. IFPRI's strategic research aims to foster a climate-resilient and sustainable food supply; promote healthy diets and nutrition for all; build inclusive and efficient markets, trade systems, and food industries; transform agricultural and rural economies; and strengthen institutions and governance. Gender is integrated in all the Institute's work. Partnerships, communications, capacity strengthening, and data and knowledge management are essential components to translate IFPRI's research from action to impact. The Institute's regional and country programs play a critical role in responding to demand for food policy research and in delivering holistic support for country-led development. IFPRI collaborates with partners around the world.

\section{About IFPRI's Peer Review Process}

IFPRI books are policy-relevant publications based on original and innovative research conducted at IFPRI. All manuscripts submitted for publication as IFPRI books undergo an extensive review procedure that is managed by IFPRI's Publications Review Committee (PRC). Upon submission to the PRC, the manuscript is reviewed by a PRC member. Once the manuscript is considered ready for external review, the PRC submits it to at least two external reviewers who are chosen for their familiarity with the subject matter and the country setting. Upon receipt of these blind external peer reviews, the PRC provides the author with an editorial decision and, when necessary, instructions for revision based on the external reviews. The PRC reassesses the revised manuscript and makes a recommendation regarding publication to the director general of IFPRI. With the director general's approval, the manuscript enters the editorial and production phase to become an IFPRI book. 



\section{An Evolving Paradigm of Agricultural Mechanization Development}

How Much Can Africa Learn from Asia?

Edited by

Xinshen Diao, Hiroyuki Takeshima, and Xiaobo Zhang

A Peer-Reviewed Publication

International Food Policy Research Institute

Washington, DC 
Copyright (c) 2020 International Food Policy Research Institute (IFPRI).

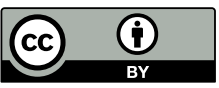

This publication is licensed for use under a Creative Commons Attribution 4.0 International License (CC BY 4.0). Subject to attribution, you are free to share (copy and redistribute the material in any medium or format), adapt (remix, transform, and build upon the material) for any purpose, even commercially.

Third-party content: The International Food Policy Research Institute does not necessarily own each component of the content contained within the work. The International Food Policy Research Institute therefore does not warrant that the use of any third-party-owned individual component or part contained in the work will not infringe on the rights of those third parties. The risk of claims resulting from such infringement rests solely with you. If you wish to re-use a component of the work, it is your responsibility to determine whether permission is needed for that re-use and to obtain permission from the copyright owner. Examples of components can include, but are not limited to, tables, figures, or images.

Recommended citation: Diao, X., H. Takeshima, and X. Zhang, eds. 2020. An Evolving Paradigm of Agricultural Mechanization Development: How Much Can Africa Learn from Asia? Washington, DC: International Food Policy Research Institute. https://doi.org/10.2499/9780896293809.

This is a peer-reviewed publication. Any opinions expressed herein are those of the authors and are not necessarily representative of or endorsed by the International Food Policy Research Institute (IFPRI). The boundaries and names shown and the designations used on the maps do not imply official endorsement or acceptance by IFPRI.

International Food Policy Research Institute, 1201 Eye Street, NW, 12th floor, Washington, DC 20005 USA, Telephone: +1-202-862-5600, www.ifpri.org

ISBN: 978-0-89629-380-9

DOI: https://doi.org/10.2499/9780896293809

Library of Congress Cataloging-in-Publication Data may be found on page viii. 
List of Figures xvii

Abbreviations and Acronyms xxiii

Foreword xxvii

$\begin{array}{ll}\text { Abstract } & \text { xxix }\end{array}$

Acknowledgments $\quad$ xxxi

Part 1: Synthesis of the Lessons

Chapter 1 An Evolving Paradigm for Africa and Synthesis of the Lessons from Asia

Xinshen Diao, Jed Silver, Hiroyuki Takeshima, and Xiaobo Zhang

Part 2: Early-Adopter Asian Countries

Chapter 2 Mechanization Outsourcing Clusters and Division of Labor in Chinese Agriculture 
Chapter 3 Farm Machinery Use and the Agricultural Machinery Industries in India: Status, Evolution, Implications, and Lessons Learned

Madhusudan Bhattarai, Gajendra Singh,

Hiroyuki Takeshima, and Ravindra S. Shekhawat

Chapter 4 The Evolution of Agricultural Mechanization in Sri Lanka

Fredrick Abeyratne and Hiroyuki Takeshima

Chapter 5 Evolution of Agricultural Mechanization

in Thailand

Rob Cramb and Viboon Thepent

Chapter 6 Evolution of Agricultural Mechanization in Viet Nam

Hiroyuki Takeshima, Yanyan Liu, Nguyen Van Cuong, and Ian Masias

\section{Part 3: Late-Adopter Asian Countries}

Chapter 7 Evolution of Agricultural Mechanization

in Bangladesh: The Case of Tractors

for Land Preparation

Mansur Ahmed and Hiroyuki Takeshima

Chapter 8 Myanmar's Rapid Agricultural Mechanization:

Demand and Supply Evidence

Myat Thida Win, Ben Belton, and Xiaobo Zhang

Chapter 9 Evolution of Agricultural Mechanization in Nepal

Hiroyuki Takeshima and Scott E. Justice

Part 4: African Countries

Chapter 10 The Rapid-but from a Low Base-Uptake of Agricultural Mechanization in Ethiopia: Patterns, Implications, and Challenges

Guush Berhane, Mekdim Dereje, Bart Minten, and Seneshaw Tamru 
Chapter 11 Agricultural Mechanization in Ghana: Alternative Supply Models for Tractor Hiring Services

Xinshen Diao and Hiroyuki Takeshima

Chapter 12 Evolution of Agricultural Mechanization in Kenya

Hugo De Groote, Cliff Marangu, and Zachary M. Gitonga

Chapter 13 Evolution of Agricultural Mechanization in Nigeria

Hiroyuki Takeshima and Akeem Lawal

Chapter 14 Agricultural Mechanization in Tanzania

Geoffrey C. Mrema, David G. Kahan,

and Andrew Agyei-Holmes

Contributors

Index 


\section{Library of Congress Cataloging-in-Publication Data}

Names: Diao, Xinshen, editor. | Takeshima, Hiroyuki, editor. |Zhang, Xiaobo, 1966- editor.

Title: An evolving paradigm of agricultural mechanization development : how much can Africa learn from Asia? / edited by Xinshen Diao, Hiroyuki Takeshima, Xiaobo Zhang.

Description: Washington, DC : International Food Policy Research Institute, 2020. | Includes bibliographical references and index.

Identifiers: LCCN 2020025874 (print) | LCCN 2020025875 (ebook) | ISBN 9780896293809 (paperback) | ISBN 9780896293816 (epub)

Subjects: LCSH: Farm mechanization-Government policy-Africa. | Farm mechanization-Government policy-Asia.

Classification: LCC S760.A35 A54 2020 (print) | LCC S760.A35 (ebook) | DDC 338.1/61096-dc23

LC record available at https://lccn.loc.gov/2020025874

LC ebook record available at https://lccn.loc.gov/2020025875 


\section{LIST OF TABLES}

1.1 Key aspects of theoretical framework covered in country chapters

1.2 Focus of empirical analyses in selected chapters 25

1.3 Share (percentage) of agricultural area with different levels of soil workability constraints

2.1 Average agricultural production and input at the household level, China, 2009-2012

2.2 Ordinary least squares estimation of production function for three crops, China, 2009-2012

2.3 Estimation of production function for three crops using

Levinsohn and Petrin method, China, 2009-2012

2.4 Use of machinery in Chinese agricultural production, percentages, 2008 and 2012

2.5 Summary statistics of combine service enterprise survey in Peixian county, China, 2013

3.1 Change in use of farm machinery and related factors of Indian agriculture, 1960-2012/2013

3.2 Trends of farm holdings in India, 1983 to 2010/2011

3.3 Distribution of tractors across selected states in India, 1982 and 2012

3.4 Major farm machinery used and annual market size of farm machinery in India, 2014/2015 
3.5 Percentage of mechanization by major crop and by operation in India, 2013

3.6 Correlation coefficients between tractor density and selected factors in India, 1982 and 2012

3.7 Leading tractor manufacturers in India, 2009/2010 to $2015 / 2016$

3.8 Status of farm mechanization industry in India, 2014

3.9 Tractor investment and farm size dynamics in semi-arid villages in India, 2001-2014

3.10 Effects of tractor use for land preparation on the use of human labor and animal (bullock) traction for land preparation (per year, all production seasons combined)

3.11 Effects of combine harvester use on the use of human labor for harvesting and threshing (per year, all production seasons combined)

3.12 Effects of tractor use on overall labor and animal use at the household level

3.13 Effects of tractor use for land preparation on the use of chemical fertilizer per acre (per year, all production seasons combined)

3.14 Yield effects of tractor and combine harvester use on key crops

3.15 Wage rates for agricultural labor (by sex), bullocks, and tractors in a typical dryland village in Andhra Pradesh, India, 2011

4.1 Evolution of economic structure, employment structure, and mechanization in Sri Lanka, 1960s-2010s

4.2 Declining farm sizes in Sri Lanka, 1960-2002 147

4.3 Holding size and use of machinery for paddy land preparation and harvesting, selected districts, Sri Lanka, 2013/2014

4.4 Labor and machinery costs for selected crops, Sri Lanka, 1979/1980-2013

4.5 Power sources used for selected operations in maize production in Monaragala district

4.6 Awareness, affordability, and use of farm implements for land preparation in finger millet production in study locations 
4.7 Annual sales of farm machinery, Sri Lanka, 2011/20122013/2014

5.1 Number of holdings using farm machinery and equipment by source, Thailand, 2013

5.2 Holding size and land use by region, Thailand, 2013

5.3 Number of agricultural machinery businesses, Thailand, $2009 \quad 186$

5.4 Production of agricultural machinery in Thailand, 2001 and 2012

6.1 Mechanization level and economic structure in Viet Nam, 1960-2020

6.2 Proportion of machine rental by region, Viet Nam, 1992-2008 208

6.3 Median total land cultivated per household (in square meters) by region, Viet Nam, 1992-2008

6.4 Tractor ownership by region, Viet Nam, 1992-2008

6.5 Tractors per 1,000 farm households, by region, Viet Nam, 2007209

6.6 Real median daily wage of male agricultural labor, Viet Nam, 1992-2008 ('000 VND)

6.7 Regression results on machine use

7.1 Evolution of economic and employment structure and mechanization in Bangladesh, 1980s-2010s

7.2 Profile of farm machines of farm households, Bangladesh, 2000-2010

7.3 Characteristics of tractor/power tiller adopter and owner households, Bangladesh, 2000-2010

7.4 Determinants of adoption and ownership/service provision of tractors, Bangladesh, 2000-2010

7.5 Determinants of adoption of tractors and/or power tillers, Bangladesh, 2000-2008

7.6 Probit model and linear regression models (including correlated random effects variables)

8.1 Share of farm households using machinery for land preparation and harvesting, Myanmar, 2006-2016 (percentages)

8.2 Real purchase value of selected machinery and average annual growth rate, Myanmar, 2000-2015 
8.3 Share of households using owned versus rented machinery for land preparation and combine harvesting, by farm size category, Myanmar, 2015/2016

8.4 Cumulative number of agricultural machinery dealers selling different types of machine, Myanmar, 1995-2016

8.5 Annual sales of selected machinery by dealerships in Mingalar Than Myint compound, Myanmar, 2012-2016

8.6 Share of 2016 sales of selected machinery, by type of finance, Myanmar

9.1 Evolution of different scales of mechanization in Nepal, 19702016

9.2 Land-to-labor ratio, terrain ruggedness, and draft animal holdings, Nepal, 2010

9.3 Share (percentage) of farm households using tractors, by year and agroecological belt, Nepal, 1995-2010

9.4 Mechanization and cropping patterns (percentage of farmers growing each crop), Nepal, 2010

9.5 Farm household characteristics, Nepal, 1995-2010

9.6 Daily agricultural wages (in kg of milled rice a day of labor purchases), Nepal, 1995 and 2010

9.7 Types of hiring service providers interviewed, Nepal, 2016

9.8 Size of landholdings by interviewed tractor service providers, Nepal, 2016

9.9 Extent of custom hiring service operations, in number of days used per year, ${ }^{a}$ Nepal, 2016

9.10 Sources of financing for tractors and power tillers

9.11 Breakdown of key cost components for four-wheel tractors and power tiller operations (US dollars ${ }^{a}$ per year per machine), excluding costs for attachments, Nepal, 2016

9.12 Median owned and annually cultivated farm size (ha) of tractor owners, differentiated by hiring-out status, Nepal Terai, 2003 and 2010

9.13 Change in owned farm size and operational size, by tractor owners and non-owners (panel samples), Nepal, 1995, 2003, 2010 
9.14 Effects of adopting tractors on household income (total income and agricultural income), Nepal, 1995, 2003, 2010

9.15 Effects of tractor use on livestock revenue, land rental revenue, and off-farm income, Nepal Terai and Hills, 1995, 2003, 2010

9.16 Effects of tractor use on off-farm income-earning activities (person-hours within 12 months), Nepal Terai and Hills, 1995, 2003, 2010

9.17 Effects of mechanization on agricultural input use (land, fertilizer, labor), Nepal Terai and Hills, 1995, 2003, 2010

9.18 Effects of mechanization on real revenue per hectare, Nepal Terai and Hills, 1995, 2003, 2010

9.19 Effects of tractor custom hiring service on agricultural returns to scale in Nepal Terai, 2010

9A.1 Significance ( $\mathrm{p}$-values) of differences in averages between tractor adopters and non-adopters for each variable used in inverse probability-weighted regression

10.1 Ownership of machinery, Ethiopia, 2013

10.2 Use of machinery, percentage of plots, Ethiopia, 2013

10.3 Use of machinery by crop, percentage of plots, Ethiopia, 2013

10.4 Share of households that use machines, by zone, as reported by focus groups, Ethiopia, 2013

10.5 Comparison of some characteristics of mechanizationintensive zones with other zones, Ethiopia, 2013

10.6 Importance of machine rental services, by farm size, Ethiopia, 2013

10.7 Labor and land productivity in the wheat cluster in southeast Ethiopia, 2013

10.8 Regressions to examine the association of the use of machines for harvesting and threshing on wheat yield in southeast Ethiopia, 2013, quintals/ha

10.9 Labor and land productivity by tractor use in mechanizationintensive zones, Ethiopia, 2013

10.10 Regressions to examine the association of the use of tractors on wheat yield in mechanization-intensive zones, quintals/ha, Ethiopia, 2013 
11.1 Crop area per rural person, by region, 2000 and 2010

11.2 Changes in the farm size distribution, 2005/2006 and $2012 / 2013$

11.3 Agricultural wages and annual average growth rate in Ghana, 1991-2012, by type of work

12.1 Sampling design of the four surveys, Kenya, 1992-2012

12.2 Factors affecting the adoption of farm mechanization, Kenya, farm household survey of 2012

13.1 Farmland endowments, farm sizes, labor, and animal use by region, Nigeria, 2010 and 2012

13.2 Percentage of farmers using tractors or animal traction in 2010 and 2012 rainy seasons in Nigeria

13.3 Percentage of area using tractors or animal traction in 2010 and 2012 rainy seasons in Nigeria

13.4 Farm size distribution in Nigeria and corresponding mechanization levels, 2010-2012

13.5 Estimated area and area shares of tractor use in Nigeria, 2010-2012

13.6 Major characteristics of each type of farm household in Nigeria, 2010

13.7 Real male wages per day in Nigeria for land clearing and land preparation (in kilograms of local rice grain at local purchase price), 2010-2012

13.8 Determinants of the area cultivated by tractors (pseudo-panel double hurdle model; marginal effects evaluated at the mean of observations), Nigeria, 2010-2012

13.9 Sources of tractor services in 2010 rainy season (percentages), Nigeria

13.10 Area cultivated annually per tractor (hectares per year), Nigeria, 2013

13.11 Average annual tractor use by farming activity (all tractors combined), Nigeria, 2013

13.12 Profitability differences between types of tractor owneroperators (in US $\$ 1,000$ s), Nigeria, 2013 
13.13 Effects of tractor adoption on animal traction use, Nigeria, 2010,2012

13.14 Effects of tractor adoption on chemical fertilizer use, crop revenues, and household income, Nigeria, 2010, 2012

13.15 Effects of tractor adoption on household labor use and offfarm income, Nigeria, 2010, 2012

13.16 Soil types and tractor use in Nigeria, 2010, 2012

13B.1 Balancing properties of propensity score matching 455

13B.2 First-stage regression of propensity score matching method 456

14.1 Significant difference in utilization rates per price of machines between Siam Kubota and Amec power tillers in Mbarali district, Tanzania, 2012/2013

14.2 Number of tractors and implements in surveyed districts, Tanzania, 2015 



\section{LIST OF FIGURES}

1.1 Overview of sequential adoption of mechanization according to Pingali, Bigot, and Binswanger (1987)

2.1 Number of agricultural workers and amount of machinery power, China, 1978-2012

2.2 Average cost of cooperative ownership of combine harvesters 84

2.3 Demand for mechanization services

2.4 Cost per hectare and area harvested by combine service enterprises, Peixian county, China, 2013

3.1 Two-wheel and four-wheel tractor sales in India between 2005 and 2015

3.2 Breakdown by horsepower of tractors sold in India between 2000 and 2012

3.3 Map showing major agroclimatic zones of India

3.4 Tractor density and agricultural labor density across the states of India, 2012

4.1 Holding size and use of machinery for paddy land preparation and harvesting

5.1 Regions of Thailand

5.2 Monthly wage rates in Thailand by sector, 1980-1995

5.3 Agricultural land, agricultural employment, and land-toworker ratio in Thailand, 1971-2014 
5.4 Imports and exports of agricultural machinery and parts, Thailand, 2009-2014

5.5 Use of two-wheel tractor to power an axial flow pump to irrigate a rice field in Central region, Thailand

6.1 Trend of tractor ownership, machine renting, and labor hiring for all farming operations in Viet Nam, 1992-2008

6.2 Tractor ownership and machine rental for larger- and smallerholders, based on rice planting area, Viet Nam, 1992-2008

6.3 Relationship between tractor ownership and rice planting area, Viet Nam, 1992 and 2008

6.4 Relationship between machine rental and rice planting area, Viet Nam, 1992 and 2008

6.5 Trend of total land cultivated per household and total annual cropland cultivated per household, Viet Nam, 1992-2008

6.6 Kernel density of total cultivated area, Viet Nam, 1992 and 2008

6.7 Kernel density of total annual cropland, Viet Nam, 1992 and 2008

6.8 Kernel density of rice planting area, Viet Nam, 1992 and 2008

6.9 Median daily real male and female agricultural wage, Viet Nam, 1992-2008

6.10 Proportions of samples providing tractor rental services, conditional on rice planting area, among tractor owners, Viet Nam, 2004-2008

7.1 Agricultural labor, cattle/buffalo, machinery, and real wages, Bangladesh, 1992-2013

7.2 Agricultural machinery use in South Asian countries

7.3 Kernel density of land distribution among adopters and owners of machinery, Bangladesh, 2000-2010

7.4 Landownership and adoption of agricultural machinery, Bangladesh, 2000-2010

7.5 Percentage of owners hiring out their tractors/power tillers, Bangladesh, 2000-2010

7.6 Mean adoption rate of tractors/power tillers by ecology, Bangladesh, 2000-2008 
7.7 Mean adoption rate of tractors/power tillers by division, Bangladesh, 2000-2008

8.1 Location of village tracts surveyed, Myanmar, 2016

8.2 Machinery and draft animal use in paddy cultivation, Myanmar, 2015/2016

8.3 Cumulative purchases of selected machinery, Myanmar, 1990-2015

8.4 Share of households using machinery for land preparation and harvesting, by farm size group, Myanmar, 2015/2016

8.5 Use of owned or rented machinery for land preparation and for harvesting in paddy cultivation, Myanmar, 2006-2016

8.6 Number and location of machinery suppliers, Myanmar, 2010, 2013, and 2016

9.1 Agroecological belts in Nepal

9.2 Share of Terai farm households renting tractors or using only draft animals, by farm size (left $=$ tractor renters; right $=\mathrm{draft}$ animals only), Nepal, 2003 and 2010

9.3 Correlation between village development committee-level share (percentage) of tractor-using farm households and share of households engaged in farming, Nepal, 1995-2010

9A.1 Balancing properties of inverse probability-weighted regressions

10.1 Real daily wages of unskilled laborers in rural areas of Ethiopia, 2003 to 2016 (left panel), and rural wage data from other developing countries (right panel)

10.2 Real prices of oxen in Ethiopia, 2004-2016

10.3 Evolution of farm sizes of smallholders (less than $25 \mathrm{ha}$ ), Ethiopia, 2004-2015

10.4 Commercial farms in Ethiopia, 2014/2015: Crops grown by percentage (left panel) and area under commercial farms by zone, '000 ha (right panel)

10.5 Rainfall patterns in Ethiopia

10.6 Imports of agricultural machines into Ethiopia, three-year moving averages - value of main agricultural machines, 20012014 (left panel); number of four-wheel tractors, 2005-2014 (right panel) 
10.7 Tractor sales by Adama Agricultural Machinery Industry (part of Metals and Engineering Corporation), Ethiopia, 2012/2013-2015/2016

10.8 Imports of combine harvesters into Ethiopia, three-year moving averages, by value, 2001-2014 (left panel); by number, 2007-2014 (right panel)

10.9 Farm size and grain area, by zone, Ethiopia, 2014/2015

10.10 Mechanization and daily wage rates, Ethiopian birr/day, 2015

10.11 Seasonal changes in use of combine harvesters (left panel) and in harvesting charges (right panel), Ethiopia, 2015/2016

10.12 Seasonal movement of tractors between the Arsi, Bale, Borena, and Harari zones, Ethiopia, 2015/2016

10.13(a) Seasonal movement of combine harvesters in Arsi, Bale, and neighboring areas, Ethiopia, November 2015 to February 2016-Route 1

10.13(b) Seasonal movement of combine harvesters in Arsi, Bale, and neighboring areas, Ethiopia, November and December 2015Route 2

10.14 Density functions on association of combine harvesters with labor productivity (left) and with crop yields (right), Ethiopia, 2013

10.15 Density functions on the association of tractor use and labor productivity, Ethiopia, 2013

10.16 Seasonal movements in real rural wages in Ethiopia, July 2004-June 2014, monthly wage index (average yearly wage is 1.00)

11.1 R-value measure of farming system evolution in Ghana, 1961-2014

11.2 Tractor imports in Ghana, 2003 to 2012

12.1 Map with primary sampling units of different surveys, Kenya, 1992-2012

12.2 Farm implements used, by agroecological zone, farm households, Kenya, 2014

12.3 Evolution of farm mechanization in Kenya from 1992 to 2012 
12.4 Evolution of farm mechanization in Kenya from 1992 to 2012, by agroecological zone and year

12.5 Evolution of farm mechanization in Kenya from 1992 to 2012, by year and by agroecological zone

13.1 Seasonality of tractor use, hours per month, by tractor owners (left panel); average distance between home district and where hiring services are provided (right panel); Nigeria, 2014

14.1 Tractors in use in Tanzania in different years, 1950-2015 459

14.2 Draft animals in use in different regions, Tanzania, $2005 \quad 464$

14.3 Four-wheel tractors in use in different regions in Tanzania, 2005

14.4 Four-wheel tractors in use in different regions in Tanzania, 2015

14.5 Age of four-wheel tractors in Tanzania, $2005 \quad 468$

14.6 Number of two-wheel tractors imported by Tanzania, 2005-2014

14.7 Distribution of two-wheel tractors in different regions, $2014 \quad 469$

14.8 Level of mechanization in the four case study districts, Tanzania, 2015

14.9 Size of farms operated by four-wheel tractor owners in the case study districts, Tanzania, 2015

14.10 Size of farms in Mbarali district, Tanzania, farmed by tractor owners in 2013

14.11 Distances from home to shops selling spare parts, Mbarali district, Tanzania, 2013 



\section{ABBREVIATIONS AND ACRONYMS}

$\begin{array}{ll}\text { AAMI } & \text { Adama Agricultural Machinery Industry (Ethiopia) } \\ \text { ADB } & \text { Asian Development Bank (Nepal) } \\ \text { AED } & \text { Agricultural Engineering Division (Thailand) } \\ \text { AEHE } & \text { Agricultural Equipment Hiring Enterprises (Nigeria) } \\ \text { AERI } & \text { Agricultural Engineering Research Institute (Thailand) } \\ \text { AGITF } & \text { Agriculture Inputs Trust Fund (Tanzania) } \\ \text { AMD } & \text { Agricultural Mechanization Department (Myanmar) } \\ \text { AMSEC } & \text { Agricultural Mechanization Services Enterprise Center } \\ & \text { (Ghana) } \\ \text { ASDP } & \text { Agricultural Sector Development Program (Tanzania) } \\ \text { ASDS } & \text { Agricultural Sector Development Strategy (Tanzania) } \\ \text { ATA } & \text { Agricultural Transformation Agency (Ethiopia) } \\ \text { AUC } & \text { African Union Commission } \\ \text { BDT } & \text { Banglashi taka (Bangladesh) } \\ \text { BOI } & \text { Thailand Board of Investment (Thailand) } \\ \text { Br } & \text { Ethiopian birr (Ethiopia) } \\ \text { CAADP } & \text { Comprehensive Africa Agriculture Development } \\ \text { CAMARTEC } & \begin{array}{l}\text { Programme } \\ \text { Centre for Agricultural Mechanisation and Rural }\end{array} \\ \text { CBU } & \text { Technology (Tanzania) } \\ \text { CHS } & \text { completely built-up units (Ethiopia) } \\ \text { CHSC } & \text { custom hiring service } \\ & \text { custom hiring service center (India) }\end{array}$


CIF cost, insurance, and freight (Nepal)

CIMMYT International Maize and Wheat Improvement Center

CKD completely knocked-down

CNC

CRS computer numerical control (Thailand)

CSA

DAP

EAs

ESAP

ESS

FACASI

FAO

FMRC

FOB

4WTs

$\mathrm{FtF}$

GDP

GGS

GMM

GS

ha

HIES

HIMIs

hp

HTT

HYVs

ICRISAT

IFPRI

IMF

IPW

IRRI

IV

$\mathrm{KD}$

KES

LGA

LMIs

Central Statistical Agency (Ethiopia)

draft animal power enumeration areas (Myanmar) economic structural adjustment program (Tanzania) Ethiopia Socioeconomic Survey (Ethiopia) Farm Mechanization and Conservation Agriculture for Sustainable Intensification project (Tanzania)

Food and Agriculture Organization of the United Nations Farm Mechanization Research Centre (Sri Lanka) free on board (Nepal)

four-wheel tractors Feed the Future (Ethiopia) gross domestic product (Ethiopia) Great Groundnut Scheme (Tanzania) generalized method of moments (India) government sourced (Nigeria) hectare Household Income and Expenditure Survey (Bangladesh) high- and intermediate-mechanization implements (Ethiopia) horsepower hand-tool technology (Tanzania) high-yielding varieties International Crops Research Institute for the Semi-Arid Tropics (India)

International Food Policy Research Institute International Monetary Fund (Ghana) inverse probability weighting (Nepal) International Rice Research Institute (Thailand) instrumental variables (India) knocked-down (Ethiopia) Kenya shillings (Kenya) local government area (Nigeria) low-mechanization implements (Ethiopia) 
LP

LPG

LSFs

LSMS-ISA

LSP

MAAS

MASL

METEC

MIP

MMK

MNCs

MoANR

MS

MSFs

NARI

NC

NCAM

$\mathrm{NE}$

NGN

NGO

NGV

NLSS

NTM

NW

OFCs

OFY

OLS

PAN

PBAM

PBB

PIM

PSFs

PSM

QFP

$\mathrm{R} \& \mathrm{D}$

RCRE

Rs
Levinsohn and Petrin (2003)

liquefied petroleum gas (Thailand)

large-scale farms (Tanzania)

Living Standards Measurement Study-Integrated Surveys on Agriculture (Nigeria)

local service provider (India)

Myanmar Aquaculture-Agriculture Survey (Myanmar)

meters above sea level (Ethiopia)

Metals and Engineering Corporation (Ethiopia)

mechanization implementation program (Nigeria)

Myanmar kyats (Myanmar)

multinational corporations (Tanzania)

Ministry of Agriculture and Natural Resources (Ethiopia)

market sourced (Nigeria)

medium-scale farms (Tanzania)

National Agricultural Research Institute (Sri Lanka)

North Central region (Nigeria)

National Center for Agricultural Mechanization (Nigeria)

North East region (Nigeria)

Nigerian naira (Nigeria)

nongovernmental organization

natural gas for vehicles (Thailand)

Nepal Living Standards Survey (Nepal)

Nigeria Truck Manufacturers (Nigeria)

North West region (Nigeria)

other field crops (Sri Lanka)

Operation Feed Yourself (Ghana)

ordinary least squares

Peugeot Automobile Nigeria Limited (Nigeria)

Peixian Bureau of Agricultural Mechanization (China)

Pingali, Bigot, and Binswanger (1987)

Policies, Institutions, and Markets (CGIAR Research

Program)

peasant subsistence farms (Tanzania)

propensity score matching (Nigeria)

Quality Food Products Ltd (Tanzania)

research and development

Research Center for the Rural Economy (China)

rupees 


$\begin{array}{ll}\text { SAMA } & \text { Sustainable Agricultural Mechanization in Africa } \\ \text { SAP } & \text { Structural Adjustment Program } \\ \text { SE } & \text { standard error (Kenya) } \\ \text { SKD } & \text { semi-knocked-down } \\ \text { SMAM } & \text { Sub-Mission on Agricultural Mechanization (India) } \\ \text { SMS } & \text { short message service } \\ \text { SSA } & \text { Africa south of Sahara } \\ \text { SSCFs } & \text { small-scale commercial farms (Tanzania) } \\ \text { SSFs } & \text { small-scale farms (Tanzania) } \\ \text { SUMA-JKT } & \text { National Service Corporation Sole Agri-Machinery Project } \\ & \text { (Tanzania) } \\ \text { SUR } & \text { seemingly unrelated regressions (Nepal) } \\ \text { SW } & \text { South West region (Nigeria) } \\ \text { TAMS } & \text { Tanzania Agricultural Mechanization Strategy (Tanzania) } \\ \text { THB } & \text { Thai baht (Thailand) } \\ \text { THS } & \text { tractor hiring services } \\ \text { THU } & \text { tractor hiring unit (Nigeria) } \\ \text { TRAMA } & \text { Tanzania Tractor Manufacturing Company (Tanzania) } \\ \text { 2WTs } & \text { two-wheel tractors } \\ \text { VAT } & \text { value-added tax } \\ \text { VDC } & \text { village development committee (Nepal) } \\ \text { VDSA } & \text { Village Dynamics in South Asia (India) } \\ \text { VEAM } & \text { Viet Nam Engine and Agricultural Machinery Corporation } \\ & \text { (Viet Nam) } \\ \text { VHLSS } & \text { Vietnamese Household Living Standard Survey (Viet Nam) } \\ \text { VLSS } & \text { Vietnamese Living Standard Survey (Viet Nam) } \\ \text { VND } & \text { Vietnamese dong (Viet Nam) } \\ \text { VWON } & \text { Volkswagen of Nigeria Limited (Nigeria) } \\ \text { ZOI } & \text { zone of influence (Ethiopia) }\end{array}$




\section{FOREWORD}

Agricultural mechanization plays an important role in economic transformation. In recent years, rapid urbanization, increased food demand, rising rural wages, and seasonal labor bottlenecks have led to a resurgence of policy support to promote agricultural mechanization in Africa south of the Sahara. The African Union's Agenda 2063 commits countries to banishing the hand hoe by 2025 as part of the goal of achieving overall productivity and food security improvements through a modern and environmentally sustainable agriculture sector.

This book makes an important contribution to our understanding of the development of mechanization in Africa. The authors emphasize that appropriate strategies in Africa should be guided by better knowledge of mechanization supply and demand, as seen through a lens that combines farming-system evolution and induced innovation theories, as well as knowledge of the paradigm shift that has been occurring in Africa over the past three decades.

The book's case studies show that this "new paradigm" raises new challenges in Africa. As demand for mechanization has risen in Africa, including among smallholders, the supply-side gaps compared to Asia have become more pronounced. Significant opportunities exist for supply-side reform, including the identification of appropriate machinery for different locations, dissemination of knowledge about such types of machines, mitigation of coordination failures, exploitation of the multifunctionality of machines, and facilitation of migratory service provision. A range of policies can be helpful, such as import policies and promotion policies, as well as institutional and capacity development policies. To be effective, such policies will need to strike the right balance between direct and indirect interventions-adhering to key principles of 
prioritizing market-led hiring services, eliminating distortions, and providing relevant public goods.

The policies and challenges highlighted in this book have implications not only for agricultural production but also, at a broader level, for agrifood system transformation and rural revitalization, which are essential for achieving inclusive, sustainable growth in Africa. The book's analytical framework and empirical results promise to be valuable for both policymakers and researchers.

Johan Swinnen

Director General 
Over the last few decades, urbanization, increased food demand, rising rural wages, and seasonal labor bottlenecks have led to the resurgence of policymaker and development stakeholder interest in promoting agricultural mechanization in Africa south of Sahara (SSA). Unlike the predictions based on farming system intensification and on the induced innovation framework used by Pingali, Bigot, and Binswanger in their 1987 book Agricultural Mechanization and the Evolution of Farming Systems in Sub-Sabaran Africa, however, the supply of mechanization in SSA has failed to meet demand, due to both market failures associated with various characteristics that are unique to the continent (such as complementary technologies, infrastructure, and machine size) and improper government interventions. Meanwhile, lessons from Asia-where significant mechanization growth has occurred despite smallholder dominance-are becoming increasingly relevant to SSA. The potential for such South-South knowledge exchange has so far been limited due to the insufficient empirical information in both regions. In SSA, there is little knowledge regarding in-country variations of demand potential and adoption of mechanization. In Asia, despite the large overall body of knowledge of the continent's experience, the literature has not coherently documented how and when mechanization grew and what impacts it had, nor has it provided sufficient quantitative evidence on these issues.

This book attempts to fill this knowledge gap. In so doing, the book revisits the approach paradigm of Pingali, Bigot, and Binswanger (1987), emphasizing the market failures that can cause the undersupply of mechanized services and assessing potential government failures based on evidence from some recent government interventions in mechanization in studied SSA 
countries. The book also emphasizes the divergent patterns of mechanization between Asian and African countries, pointing out the challenges specific to SSA and their policy implications. The book begins with a chapter describing the farming systems approach, the importance of functional mechanization hiring markets and supportive policies, and key differences between SSA and Asian mechanization, including the market failures specific to SSA. The rest of the book is structured with stand-alone case studies for 13 countries -8 Asian and 5 African - to document the evolution of mechanization in these countries. Two of the key underlying questions are what SSA policymakers can draw from the Asian mechanization experience and whether there is a need to develop a new paradigm that better accounts for the Africa-specific experience. This book makes at least four significant contributions to the literature, with important policy implications. First, based on solid country evidence, it provides a detailed overview of the development and current state of mechanization in African and Asian developing countries. Second, using a similar structure for case studies in the country chapters, it allows the reader to easily draw comparisons between countries and between Asian and SSA mechanization in a clearer light. Third, it endows national policymakers and the development community with broader knowledge that can be adapted to local contexts, helping them to learn from successes and avoid replicating past failures. Finally, as a whole, the book serves as a precursor for further research and a call to create an updated paradigm of mechanization development. 


\section{ACKNOWLEDGMENTS}

The editors wish to acknowledge the valuable contributions of researchers and stakeholders at the International Conference on South-South Knowledge Sharing on Agricultural Mechanization, held in Ethiopia in 2017, and programs by the CGIAR Research Program on Policies, Institutions, and Markets (PIM), led by the International Food Policy Research Institute (IFPRI) and funded by CGIAR Fund donors. Editors and authors are also grateful for the constructive comments and suggestions from the external reviewers, Jerry Shively and other IFPRI Publications Review Committee members, which significantly improved the book. Special thanks go to Gershon Feder, Paul Dorosh, Steve Biggs, and the late Hans BinswangerMkhize for their feedback and comments on the conceptualization of issues and the development of the framework. Editors also benefited greatly from the valuable insights of Frédéric Baudron, Lidia Cabral, Josef Kienzle, M. A. Sattar Mandal, Keijiro Otsuka, and David Spielman, among others. Authors of various chapters benefited from the support of in-country collaborators, including IFPRI and International Maize and Wheat Improvement Center (CIMMYT) country offices and local field teams. Editors also thank Mia Ellis for editing various chapter manuscripts. China and Kenya chapters consist largely of materials that have already been published in the journals China Economic Review and Agricultural Mechanization in Asia, Africa and Latin America. Finally, the writing of this book would not have been possible without the financial support of PIM, the United States Agency for International Development, and the Regional Strategic Analysis and Knowledge Support System in Asia. 



\section{PART 1}

\section{Synthesis of the Lessons}





\title{
AN EVOLVING PARADIGM FOR AFRICA AND SYNTHESIS OF THE LESSONS FROM ASIA
}

\author{
Xinshen Diao, Jed Silver, Hiroyuki Takeshima, and Xiaobo Zhang
}

\begin{abstract}
Africa has experienced a paradigm shift in mechanization in the past three decades. The "new paradigm" has also given rise to new challenges and policy issues. By synthesizing the recent experiences in African and Asian countries, this chapter draws lessons from Asia and Africa under this new African paradigm. In doing so, the chapter first lays out the guiding theoretical framework used in 1987 by Pingali, Bigot, and Binswanger (PBB), based on the literature on farming systems evolution and induced technological change. The chapter then describes the "new paradigm," which builds on PBB but also integrates the additional dimension of market failures associated, on the supply side, with custom hiring services, which have become the most common mode of mechanization among smallholders in developing countries. Applying this expanded framework, the chapter then reviews the Asian experience first. It highlights how mechanization has grown in the continent, having largely avoided supply-side market failures, thanks to several factors: smaller machine sizes; ${ }^{1}$ increased opportunities for multifunctional uses of machines; more secure land tenures that allow integration with formal credit markets; and the supportive, rather than distortive, nature of government subsidy policies. The chapter then turns to the experiences in Africa south of the Sahara ("Africa" hereafter) and highlights the emerging patterns of spatial variations in demand that are still largely consistent with the PBB framework. However, the chapter also stresses that market failures associated with custom hiring services on the supply side are substantial due to features unique to Africa, including the dominant types of large tractors, in addition to higher financial constraints on tractor ownership resulting from lack of secure land tenures and weak penetration of formal credit markets, as well as other barriers due to limited multifunctionality, lack of migratory
\end{abstract}

1 In this book, we use the term "size," in relation to tractors, to refer loosely to horsepower. Our definition of size is not based on any clear-cut engineering threshold. Rather, we focus on size aspects when we highlight the differences in typical tractor horsepower between Africa and Asia that are relatively universal, as described in the later section, and their implications for the nature of constraints and market failures that Africa is facing. 
services due to insufficient infrastructure and coordination failures, and insufficient technologies complementary to mechanization. Based on country experiences in Asia and Africa, the chapter also highlights key government policies that have not always been successful, including import restrictions (or removal thereof), inefficient technology and skill promotion, and insufficient provision of public goods. Last, given the country experiences and the identified appropriate roles of governments, the chapter concludes by describing the key lessons that are important for Africa's mechanization pathway forward, including (1) understanding the emerging nature of demand, (2) actively promoting private hiring services, (3) eliminating or reducing distortions, and (4) prioritizing the mechanization technologies appropriate for African contexts.

\section{Introduction}

Agricultural transformation is imperative for growth and poverty reduction in Africa. Yet the desired progress has been elusive. The region is a net food importer despite the fact that agriculture accounts for 60 percent of employment. Main food crop yields are estimated at about half the world average, and rural poverty, hunger, and malnutrition are persistent (AfDB 2016). Recently, increased (albeit still insufficient) attention has been paid to promoting a Green Revolution-style agricultural intensification, focusing on improved seed varieties, fertilizer, and agrochemicals that increase the land productivity. In comparison, much less emphasis has been placed on addressing seasonal labor constraints and rising rural wages through mechanization to promote agricultural transformation.

Mechanization is a labor-saving technology that enables farmers to expand cultivation area and free up labor for other agricultural functions or nonfarm income generation. ${ }^{2}$ Early efforts to promote mechanization in Africa often failed due to abundance of rural laborers within most rural farm households

2 In this book, the term "mechanization" is defined in a broad sense, including both technologies themselves and processes that involve their use. The term "tractorization" is used where the focus is specifically on tractors, and mechanization is used if the focus is generally on increased mechanical power. Mechanization can sometimes encompass tractorization if, for example, the process happens to involve a switch from draft animals to tractors. The term "farm power" is used where the focus is more on motive energy inputs in farming, which are provided through either human labor, animal work, or machinery (these all take the form of motive energy, as opposed to energy embedded in other types of inputs, such as fertilizer). The term "agricultural machinery" is used where the focus is on the physical capital items that convert energy inputs into the desired form of energy outputs. The term "agricultural implements" is used in a similar way, but specifically for machine attachments, such as plows and harrows.

Similarly, "labor-saving" is defined in a broad way, including both in economic terms (for example, saving on the cost of labor) and ergonomic terms (for example, reduced labor 
that limited farmer incentives to intensify production (Pingali, Bigot, and Binswanger 1987, hereafter "PBB"). However, agricultural mechanization has gained renewed attention recently in Africa. Some indications suggest that farming systems have evolved sufficiently in many locations of Africa for farmers to demand mechanization (Mrema, Baker, and Kahan 2008; Diao, Silver, and Takeshima 2016; Binswanger-Mkhize 2017) and that increased mechanization adoption has occurred in new pockets across Africa recently (FAO 2016; Malabo Montpellier Panel 2018). Despite recent progress, however, the spread of mechanization in Africa has lagged far behind that of Asia, where mechanization has been widely adopted in most countries in recent years, including in many low-income and labor-abundant Asian countries. Moreover, research on mechanization in developing countries, and in Africa in particular, is scarce, and knowledge and insight about mechanization in Africa, in terms of both collecting statistics about it and understanding its drivers and impacts, remains limited.

Although different opinions exist in the literature for understanding factors affecting mechanization in Africa, the framework developed by PBB in 1987, based on the farming systems evolution hypothesis, which emphasizes the demand side of mechanization, remains one of the most important guiding frameworks, together with other guiding strategies, for pursuing mechanization development. In their seminal volume, Agricultural Mechanization and the Evolution of Farming Systems in Sub-Saharan Africa, PBB argued that widespread public efforts to promote mechanization often failed because African farming systems had simply not intensified enough to generate sufficient demand for mechanization among farmers. Their theory also fits the patterns observed in Asia, where farming systems had already undergone widespread intensification and draft animal power (DAP) had been in use for a much longer period (Lawrence and Pearson 2002). Twenty years after publication of the PBB book, Pingali further asserted that "where the demand side factors are in place, agricultural intensification and the adoption of mechanical power occurs in Africa in a similar pattern to Asia and Latin America" (2007, 2787). Broadly speaking, farming systems have intensified in many places in Africa, with a shortened fallow period and an increasing share of annual crop areas among total agricultural land. However, as the rest of this chapter and the African case studies in this book show, the characteristics of demand for mechanization remain complex. Moreover, supply does not appear

requirement and reduced drudgery), both of which are becoming increasingly important motivations in Africa to address the mechanization challenge (for example, Kormawa et al. 2018). 
to have responded at nearly the levels observed in Asia. As a result, the farming systems hypothesis alone has been insufficient to explain mechanization in Africa (Binswanger-Mkhize 2017). Altogether, with the intensifying farming system and growing relevance of modern mechanization technologies, there is a need for a closer understanding of not only demand but also, most important, the increasing relevance of supply-side constraints on mechanization in Africa, which we describe as a "new paradigm" for mechanization in Africa.

Mechanization could help farmers overcome the labor constraints present in agriculture, reduce drudgery in various farming operations, expand farm sizes where land is available, and permit higher levels of intensification in more labor-intensive farming activities. Although tractor plowing per se is not directly associated with yield growth, it enables key operations to be done on time, which is especially relevant for rainfed agriculture in areas with short planting windows. Evidence from Asian as well as some African countries also suggests that tractor use is associated with higher cropping intensity and use of fertilizer. Combine harvesters have also become part of mechanization practice. As shown in the case studies of Asian countries and Ethiopia, use of combine harvesters has the potential to significantly reduce postharvest losses, thus increasing outputs per unit of land. In a highly optimistic scenario, these effects of mechanization can contribute to Africa's forestalled agricultural transformation. However, for this to occur, substantial improvements in agricultural engineering research; varietal development; and market development for inputs, credit, and outputs would likely have to take place to complement mechanization. In many African countries, supply elasticity is limited partly due to technological backwardness, leading to persistently high reliance on food imports despite relatively high food prices (for example, in the case of rice, Gyimah-Brempong, Johnson, and Takeshima 2016). It is essential to understand and address these complex issues hindering mechanization development in Africa.

It has often been suggested that Africa can learn from Asian experiences of agricultural transformation, including mechanization. Asian experiences in mechanization are diverse, and distinct patterns of mechanization across Asian countries could offer many lessons to Africa. One thing that seems to be common among many Asian countries is that mechanization has often started with little direct intervention from the governments. Manufacturing of spare parts and simple tools often grew out of innovations by local entrepreneurs at the early stages of manufacturing-sector development (Diao et al. 2014). In some countries where governments did get involved, they primarily attempted to overcome market constraints for the private supply to meet 
existing farmer demand, and provided key public goods to overcome market failures as well as education (Rijk 1986). As is described later in this chapter, despite the limited successes of the African government-led mechanization programs three decades ago (as diagnosed by $\mathrm{PBB}$ ), recent efforts by a few African governments suggest that the past lesson is still relevant for today's issues. These issues include limited machine utilization rates and the insufficient provision of soil and machinery technological knowledge to the private sector, among others (Kormawa et al. 2018). The challenge to African policymakers is how to appropriately address key market failures that prevent the private sector's supply from meeting emerging demand, and how to better identify the characteristics of demand that help overcome supply bottlenecks. Later sections of the chapter describe market failures that lead to risks and uncertainty about making machine investments due to spatially and temporally variable demand in hiring markets, uncertainty about and limited opportunities for multifunctional use of machines, and insufficient machinery and oil information and knowledge that can be provided by the government as public goods (Diao et al. 2017). ${ }^{3}$

This book aims to update the PBB framework by integrating an additional dimension - market failures on the supply side of mechanization associated with custom hiring services, the most common mode of mechanization among smallholders in developing countries - in order to account for the recent mechanization patterns observed in Africa alongside those in Asia. By doing so, we intend not to dispute the underpinnings of PBB's hypothesis, but rather to capture the emerging challenges of mechanization, particularly those highlighted by recent experiences in Africa. An updated framework is not only important for further research but also a crucial tool for African policymakers to develop judicious approaches to supporting mechanization development.

3 PBB hypothesized that the supply-side constraints are rarely binding, and although there are many grounds to expect this hypothesis to hold in general (such as the private sector's ability to innovate mechanical technologies compared with biological technologies), testing it formally has been challenging. Further, despite the improved understanding and recognition of market failures (including those in information, risk, and finance) and of the role public-sector institutions play in sustaining private sector-led growth (Rodrick 2007; Naudé 2011), these new perspectives have not been applied sufficiently to understand how the public sector can "speed up" and "raise efficiency" of the private sector's responses to meet demand. The potential roles of the public sector to assist the private sector in such ways in the short run is important because African governments and international communities are under pressure to meet development goals that are becoming increasingly time-sensitive (for example, 2025 goals for mechanization achievements envisaged under the African Union's Agenda 2063, and 2030 goals under more general Sustainable Development Goals, among others). 
This book presents evidence from 13 countries in Asia and Africa to lay the foundations for the new paradigm. These chapters largely avoid policy prescriptions, and instead aim to provide a thorough overview of where mechanization stands in each country and how it has developed to that point. They are intended as resources for policymakers, academics, and lay readers to draw upon when considering how to encourage the development of mechanization in specific contexts. This book's approach of focusing on individual countries for case studies differs from that of PBB, which focused on the African continent as one geographic region and drew collective lessons from various locations within it.

The book also contributes to the efforts in integrating mechanization into the mainstream Africa-wide agenda, including the African Union's Agenda 2063 (a strategic framework for the socioeconomic transformation of the continent over the next 50 years), the Comprehensive Africa Agriculture Development Programme (CAADP), and the Malabo Declaration. Under Agenda 2063, Aspiration \#1, "To achieve a prosperous Africa based on inclusive growth and sustainable development," Goal \#5 commits countries to banish the hand hoe by 2025 as part of the goal of achieving overall productivity and food security enhancement through a modern and environmentally sustainable agriculture sector (Malabo Montpellier Panel 2018). Although this is a political goal and its economic rationale remains to be investigated, it symbolizes the growing interest in mechanization within the African community. The CAADP platform, which commits African countries to spend 10 percent of national budgets on the agriculture sector to achieve a 6 percent annual growth rate in the sector, recognizes the importance of agricultural mechanization in promoting intensification (Diao, Silver, and Takeshima 2016; FAO 2016). Increasingly, agricultural mechanization has been integrated into CAADP’s Pillar \#4, Integrated Research, Technology Dissemination and Adoption (Malabo Montpellier Panel 2018). The Malabo Declaration further recognizes the slow pace of mechanization along the agriculture value chain and emphasizes the importance of investments into suitable, reliable, and affordable mechanization and energy supplies in order to double productivity by 2025 (Malabo Montpellier Panel 2018). In October 2018, after intensive expert consultations with a broad range of stakeholders, the African Union Commission (AUC) and Food and Agriculture Organization of the United Nations (FAO) launched the Sustainable Agricultural Mechanization in Africa (SAMA) framework, which has been integrated into CAADP and the Malabo Declaration (Kormawa et al. 2018) and recognizes that agricultural mechanization in Africa is an indispensable pillar for attaining the 
Zero Hunger vision by 2025, as stated in the Malabo Declaration of 2014 (AUC 2018).

The book is written at a crucial time, and its recommendations are expected to become part of the policy dialogue and debate on how to develop and disseminate modern agricultural technologies in order to double agricultural productivity in Africa. The book emphasizes mechanization promotion as an important component of agricultural technology, together with agricultural research and development $(\mathrm{R} \& \mathrm{D})$, irrigation, and so on, which requires the public sector to increase its investment while avoiding the creation of new market and trade distortions that can discourage private investment. We expect the insights of the book to be consistent with the spirit of CAADP to prioritize and coordinate investments (World Bank 2007, 24). We also expect the book to inform the implementation of SAMA, launched by the AUC and FAO in 2018 (Kormawa et al. 2018). SAMA consists of 10 elements, including (but not limited to) appropriate technologies, business models, financing mechanisms, manufacturing growth, technology development and transfer, and inclusiveness focusing on smallholders and their organizations-all of which are highly relevant for mechanization policy and promotion. Moreover, by providing concrete examples and experiences from what Asian countries have achieved, this book tries to promote South-South learning and AfricaAsia collaboration in searching for the proper pathways for African countries to adopt mechanization.

This book is edited mostly from economists' perspectives, although chapters are written by a mixture of agricultural economists and agricultural engineers. The book is intended for a range of stakeholders. For policymakers at higher levels, the book will be useful for any ministry of agriculture that oversees direct policies on agricultural engineering and the governance of agrifood systems that encompass the farm sector as well as upstream and downstream sectors (such as machine industries and agricultural machinery service providers on the one hand, and rural transportation of harvests on the other). However, our interpretations of PBB (and updating thereof) that highlight the roles of a broad set of economywide factors, including macroeconomic factors, provide useful insights to other policymaking institutions, such as ministries of finance, trade and industry, or education, into how their policies can have profound effects on agricultural mechanization, and further offer a useful common base of knowledge on which they may coordinate their policies toward unified development strategies. The descriptions in this book, which distinguish the modern sector and the more traditional small businesses involved with mechanization, also provide better understanding 
for policymakers at an operational level and establish more realistic expectations of the impact of their programs and interventions; in this way, this book can serve as a reference for them to better communicate these expectations to stakeholders. Furthermore, the book offers useful historical perspectives to the newer and younger generation of policymakers, who are increasingly assuming political positions in Africa. This book also offers detailed descriptions of mechanization adoption at the subregional level and of the structure of the existing mechanization market sector. These can be useful for the private sector and specific industries that are interested in assessing the potential market opportunities of mechanization in Africa. The book also serves as an important document that communicates economic perspectives on agricultural mechanization in comprehensive and holistic ways to the agricultural engineering research community. Last, the book can be useful for researchers and students in the agricultural economics research community who are interested in learning about and conducting empirical research on economic issues surrounding agricultural mechanization.

The remainder of this chapter is structured as follows. First, we describe the analytical scope of the book. We then develop our updated theoretical framework for mechanization. This updated framework integrates PBB's hypothesis, centered around the theory of farming systems development by Boserup (1965) and the induced innovation theory of Hayami and Ruttan $(1970,1985)$, and expands it to account for common market failures in agricultural machinery investment and mechanized service provision. We then describe the selection of case study countries and their linkages with the framework. Next, we apply this framework to help explain the divergence between mechanization trends in Asia and those in Africa. We then pay attention to the role of government policies in shaping mechanization, before concluding with some recommendations that provide context for the remainder of the book.

\section{Analytical Scope of the Book}

This book primarily focuses on tractors-both four-wheel tractors (4WTs) and power tillers, also known as walk-behind tractors-though some chapters also cover combine harvesters, another example of a motive, power-intensive mechanization technology, mainly because highly specialized hiring service providers have emerged in some countries, which allow smallholders to get access to the services of combine harvesters. We acknowledge that agricultural mechanization is not just tractor use and that it involves the use of many other types of equipment. Although future studies need to investigate these broader 
categories of mechanization to provide a more holistic view of agricultural mechanization in Africa, many other types of commonly used agricultural machinery in Africa are less associated with the development of the hiring service markets that have eased smallholders' access to mechanization, one reason why we did not cover them in this book.

There are several other reasons that justify this book's focus on tractors and the important role they play in agricultural mechanization. First, tractors have historically been considered one of the major mechanical innovations in agriculture that can replace animal and human power for the toughest part of farming operations-land preparation. Replacing animal and human power with a tractor makes it possible for farm size to expand and for more and more land to be brought under cultivation. Moreover, tractors as a substitution for animal and human power make it much easier to command more power per worker and significantly raise labor productivity in agriculture (Hayami and Ruttan 1970). Hayami and Ruttan (1970) went as far as to consider the tractor the single most important mechanical innovation. In an extreme case like that of the United States, tractors alone have historically raised gross domestic product by significant margins (Steckel and White 2012).

Second, partly related to the first point, the adoption of tractors generally means a considerable leap from human or animal power because of the great difference in horsepower, and thus is likely to have significant effects in reducing drudgery associated with manual farm work and in enhancing welfare, as well as a modernizing effect on the agricultural sector. Third, among major farming operations, the use of tractors for land preparation often precedes significant mechanization of other operations. Land preparation is the most energydemanding farming operation in rainfed agriculture (Lal 2004; Baudron et al. 2015), and primary tillage is one of the first operations to be mechanized when a new source of mobile power becomes available (Binswanger 1986).

Fourth and finally, tractors are unique in various dimensions and face distinct challenges not encountered by other machines. For example, because threshing is less time-bound than some other operations, the rental market for threshing machines developed in the United States in the 19th century and in Asia in the 20th, with fewer timeliness constraints than was the case for tractors (Binswanger and Donovan 1987, 15). Multifunctionality of tractors, intensively exploited in Asia, also makes tractors unique because tools for other operations, such as planters, weeders, sprayers, and carts for transportation, are often attached to tractors when the latter are introduced. Also, tractors have served as an important source of power to run stationary equipment such as irrigation pumps and threshers (Diao, Silver, and Takeshima 2016), 
especially before the widespread adoption of cheaper machines such as diesel pumps (IRRI 1983) or the emergence of modern substitutes such as solar pumps. Because tractors are relatively unique, with few substitutes (compared with other types of equipment), information is relatively more available across countries about tractors than about other farm implements. Focusing on tractors therefore provides us one way to see more clearly the gaps between Asia and Africa. Furthermore, for many African countries, tractors may be one of the most important binding constraints on the current stage of mechanization, especially where intermediate technologies such as animal traction have spread relatively widely.

Although agricultural mechanization encompasses not only crop production but also fishery and livestock production, the focus of this book is mechanization for crop production. This is not only because crop production accounts for the most significant part of agriculture in both Africa and Asia, but also because mechanization of crop production often represents the first stage of mechanization development. The share of crop production remains greater than 75 percent of the gross production value of agriculture in Africa, and 70 percent in Asia (FAO 2019a). The share of rural households engaged in crop production is also high and dominant in both Africa and Asia. Focusing primarily on crop production therefore still captures the important aspects of agricultural mechanization at both continents' current stage of agricultural development.

In fact, focusing on tractors as the core of crop-related mechanization can implicitly cover some power-intensive activities associated with fishery and livestock production, such as on-farm production of fodder (from maize and so on), transportation of fodders or water, and transportation of animals for slaughtering or sales. However, due to data availability on the use of machinery in livestock raising, we cannot do any empirical analysis explicitly on livestock mechanization in this book. Similarly, as with crop production, more control-intensive activities, such as identification, medication, vaccination, evisceration, and processing and packaging, may be mechanized only after the mechanization of power-intensive activities has been widely adopted. Such adoption represents a more advanced stage of mechanization and is not covered by this book, although mechanization in these areas is likely to be increasingly important in the future in both Asia and Africa.

Last, the book focuses primarily on production and does not directly address issues associated with postharvest and storage activities, or with processing and marketing along the value chain of agriculture (Breuer, Brenneis, and Fortenbacher 2015), except where we touch on the multifunctionality of 
tractors (for example, their use for transport). We make this choice because most mobile operations, which constitute one type of power-intensive operation, occur at the production stage, whereas most operations in postharvest stages are stationary (PBB). The mechanization of mobile operations typically faces a different set of constraints than that of stationary operations. For example, activities such as milling, grinding, pounding, pressing, crushing, and threshing typically do not face the timeliness problems associated with plowing, and so efficient rental markets are relatively easily established (PBB; Binswanger and Donovan 1987). Similarly, these service providers often provide other postharvest services. For example, in Ghana, many rice mills provide drying and storage services (Takeshima, Agandin, and Kolavalli 2017). As long as there are still challenges associated with the mechanization of these activities, treating them together with mechanization for mobile operations, such as that provided by tractors, may be difficult in a single book. At the same time, mechanization of some activities, such as packaging and grading, may be adopted at later stages when demand for high-value processed foods rises substantially, at which point mechanization of power-intensive activities would have sufficiently spread. Nevertheless, as is shown in this chapter, some of the recommendations in the book may also apply to postproduction stages, and therefore our book provides a useful framework that can be adopted for analyses of postharvest mechanization issues in the future.

\section{A Theoretical Framework for the Evolving Paradigm}

Demand for mechanization depends on the level of agricultural intensification, land-labor ratios, labor costs, and the development of a hiring market. We first summarize the theoretical framework around these components and describe how our framework builds on elements of the conventional framework, before examining how it explains trends in Asia and Africa.

\section{Farming Systems Evolution}

One of the elements of the conventional framework is Boserup's theory of endogenous farming systems evolution, established in her seminal work, The Conditions of Agricultural Growth (1965). PBB's hypothesis can be seen as an extension of this theory. Boserup argued that the evolution of farming systems is an interactive, endogenous process driven by increasing population pressure and rising demand for agricultural products through market development. Farmers respond to this process by shortening fallow periods and intensifying 
production by adopting modern inputs, such as improved seeds, fertilizers, and agrochemicals, to increase land productivity (Boserup 1965). The hypothesis was further developed in Ruthenberg's 1971 book, Farming Systems in the Tropics, which saw its third edition published in 1980. Ruthenberg specified that when farming systems move from long fallows to short fallows (at most two years of fallow per year of cultivation) or annual cultivation, plowingwhether with animals or tractors - becomes necessary to limit weed growth as well as to bring nutrients to the surface of the soil (Ruthenburg 1980). Before this stage, stumps and other field obstacles make plowing more challenging, especially where the use of appropriate plows (such as disc plows) is not profitable (PBB). However, once this stage is reached, the grasses that emerge between seasons cannot be removed by burning. Consequently, labor requirements become too high for manual hoeing alone (Boserup 1965; Ruthenburg 1980). The crux of PBB's hypothesis focused on emphasizing that demand for plowing is insufficient if viewed from the evolution stage of such a farming system in significant parts of Africa, and that this principle had largely constrained adoption of mechanization until recently.

PBB further hypothesized that mechanization is a sequential process adopted at different stages of agricultural intensification, with a shift from human muscle to animal power to machinery. The most power-intensive operations, such as plowing and threshing, are mechanized before harvesting is mechanized. Figure 1.1 illustrates these sequences according to intensification level, power source, and functions mechanized. In PBB's view, in the areas where animal traction is feasible, bypassing it to move directly from hand hoes to tractors is not cost-effective due to the costs of destumping fields and forgoing the benefits of animal by-products. They demonstrate that although trypanosomiasis is a major constraint to developing draft animals, it becomes less of a problem as population density increases and more forests are converted to crop fields. This book's online Appendix 1D discusses in greater detail how the patterns in Figure 1.1 have, in fact, been widely observed in Asia and elsewhere.

PBB's fundamental explanation of the low adoption of mechanization in Africa focused on African small farmers, for whom farming systems had not evolved sufficiently for them to demand plowing using tractors. However, some African countries did have more tractors than many Asian countries prior to the 1960 s, because of their colonial history and related farmland distribution in which large-scale farming was carried out mostly by white settlers who had a long history of mechanization (Acemoglu, Johnson, and Robinson 2002). Excluding such large-scale farms that still existed after independence, 
FIGURE 1.1 Overview of sequential adoption of mechanization according to Pingali, Bigot, and Binswanger (1987)

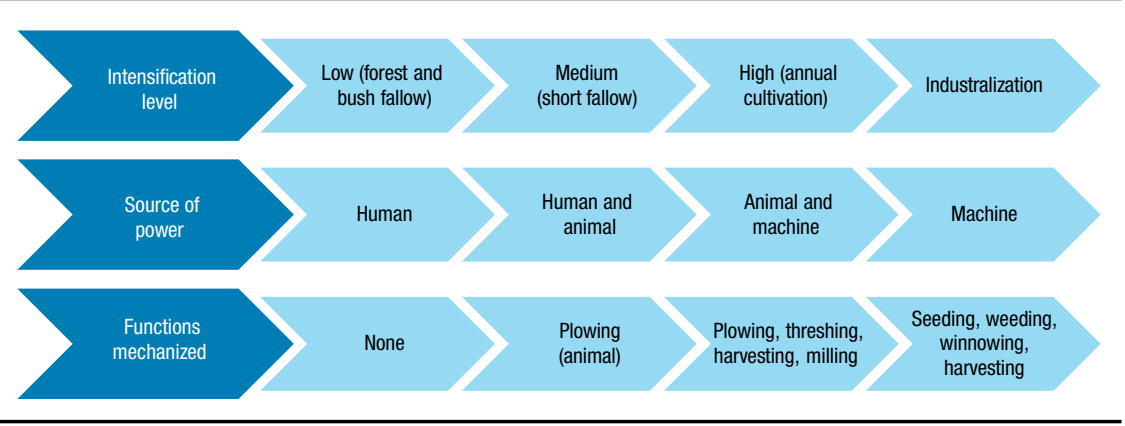

Source: Adapted from Pingali, Bigot, and Binswanger (1987).

the smaller African farmers continued to follow farming systems characterized by long- to medium-fallow stages, and their agricultural products faced relatively inelastic demand due to low population density, lack of urbanization, and poor market access. Thus, there was limited market demand for mechanization among the majority of African farmers, and mechanized services were predominantly provided by the public tractor hiring scheme. In the few systems in which mechanization was concentrated, PBB found it to be highly correlated with intensification levels and to have developed with limited government intervention.

\section{Induced Technological Change}

Equally important for understanding mechanization is Hayami and Ruttan's induced technological innovation theory $(1970,1985)$. The simple intuition behind this theory is that the public and private sectors are driven to develop and adopt technologies that can help to overcome constraints caused by the scarcity of factor endowments-land or labor. Under this theory, in addition to technology innovation, institutional innovations, which include agricultural $\mathrm{R} \& \mathrm{D}$ as well as changes in property rights, tenancy, and labor arrangements, are expected to respond similarly to agricultural endowments. The induced innovation theory explains why mechanization, a labor-saving technology, was adopted much earlier in land-abundant North and South American countries than elsewhere; it also explains why Japan and some other land-constrained Asian countries first adopted land-saving technologies such as high-yielding varieties and intensive use of fertilizer, before machine power replaced animal power. 
The intensification process described by $\mathrm{PBB}$ requires greater labor input in the beginning, in response to a growing labor endowment resulting from the growing population density. At the later stage, the industrial sector's pull of labor out of agriculture and emigrants' remittances to rural areas cause a labor shortage in agriculture and a rising rural wage rate, which lead to more modern mechanization development, as has been experienced in the United States, Japan, and more recently, other Asian countries (Hayami and Ruttan 1970; Binswanger-Mkhize 2017). This outline shows the importance of an overall economic transformation process for agricultural mechanization. Importantly, however, the mechanization process also varies across countries and regions. For example, many African countries have already experienced rapid urbanization and a growing service sector that leads to labor movement out of the agricultural sector, but their domestic food production responds to such transformation less through agricultural intensification than through other means. That is, despite the fact that urbanization leads to growth in domestic demand for food, that demand is increasingly met by imports. Understanding the full mechanisms underpinning the relationship between overall economic transformation and agricultural mechanization, including why some Asian countries have seen greater mechanization compared with some in Africa as a response to structural transformation, is therefore important.

For mechanical technologies, market incentives have generally been considered more effective than biological technology in inducing innovation, including in countries such as the United States (Hayami and Ruttan 1985). Unlike the farming systems theory, the induced innovation theory explicitly considers public institutions as part of the technology development and adoption process, recognizing that technological change is unlikely to originate solely and automatically from the evolution of farming systems, and instead is likely also to require institutional innovations within both the public and private sectors.

\section{DISTINCTION BETWEEN PBB FRAMEWORK AND INDUCED INNOVATION THEORY}

Micro-elements of the PBB framework are consistent with induced innovation theory, yet there are important distinctions between the two. For example, conventional induced innovation theory does not explain explicitly why mechanization (or innovation toward mechanization) did not emerge in Africa before the farming system evolution, when land was more abundant than labor.

Induced innovation theory, such as that described by Hayami and Ruttan $(1970,1985)$, is largely founded on the existence of a highly intensified 
farming system, such as that of the United States and Japan. Whereas the premise of the theory is that relative land abundance induces innovation in land-complementary technologies, authors such as Hayami and Ruttan (1970, 1985) have shown that this pattern holds in already highly intensified farming systems. The theory does not imply that mechanization could emerge wherever land is abundant, regardless of farming system. At the preintensification stage, the traditional land-complementary strategy for farming is shifting cultivation and fallowing, rather than developing mechanical technologies. Mechanical technologies, which are labor-saving and land-complementary, require sufficient market demand for agricultural outputs, which comes from increased population density and urbanization, as described in PBB.

To understand mechanization in Africa in the early days, it is important to integrate induced innovation theory with the PBB framework because induced innovation alone cannot explain when and why mechanization occurred or did not occur in Africa, even though many countries in the continent are relatively more land abundant than Asia. To explain the evolution of the land-complementarity of mechanical technologies, induced innovation theory has to rely on the PBB framework, which draws on the farming systems evolution hypothesis.

Both induced innovation theory and the farming systems evolution hypothesis relate to the broader demand-side drivers of technological change, and the PBB framework focuses specifically on the demand-side factors applicable to mechanization. We now turn to supply-side factors, which are less prominently considered as binding factors in PBB's framework.

\section{The Supply Side of Mechanization: Hiring Markets and Market Failures}

One of the important components of our updated framework does not trace back to any particular strand of literature; instead, it focuses on the supplyside issue of mechanization, addressing market failures relating to agricultural machinery investment and mechanization custom hiring services-the most common mode of mechanization among smallholders in developing countries. In developing countries dominated by smallholders with limited wealth, most farmers are unlikely to be able to afford a tractor or other large machinery. Hiring in services often becomes the only way for many farmers to access mechanization. At the same time, farm sizes are often not large enough for tractor owners to fully utilize their machinery. Thus, hiring out services becomes necessary for owners to be able to recoup their investments. In this mechanized service market, private owner-operators are almost invariably the 
most efficient way of supplying hiring services. First, private owner-operators have incentives for maximizing tractor utilization, which may not be the case for government hiring schemes. Second, on-farm benefits of tractor ownership ensure that owners can conduct plowing and other field operations on time for their own land. Third, farmer owner-operators have low risk associated with machine damage caused by irresponsible behaviors of some hired operators.

The ability of the supply of hiring services to meet the growing demand for mechanization among small- and medium-scale farmers depends on the many factors affecting the decision of a few would-be buyers to invest in a tractor. For investment in a tractor to be viable, the revenues from hiring out services plus the timeliness benefits from using a tractor on one's own fields, less the costs of fuel, maintenance, repairs and spare parts, payment to operators (when they are hired), machinery depreciation, and loan interest payments, must be enough to offset the investment over the course of the tractor's useful life (Houssou, Diao, and Kolavalli 2014). The opportunities for hiring out services are therefore key to maximizing utilization rates in a way that ensures profitable ownership of a tractor or combine harvester. Although tractors can theoretically operate for $800-1,200$ hours per year, short plowing periods determined by rainfall and temperature conditions can reduce this capacity to 300 hours per year (Hunt 1983; Culpin 1988).

In addition to the length of the plowing season, achieving a break-even rate for the investment depends on many economic and technical factors that affect the development of the hiring market. First, without sufficient demand among farmers for mechanization services in their home areas, ownership of a tractor is unlikely to be profitable for a medium- or even large-scale farmer. On the other hand, farmers' demand for hiring services depends not only on farming system evolution and the relative scarcity of labor at the national level, but also on whether the expected benefit of mechanization services outweighs the service charges, a payoff that requires a high enough productivity level. The market price of hiring services, in turn, depends on the competitiveness of service markets with enough service providers and, further, the providers' operating costs. If agricultural returns are low due to low productivity, then demand for paid services may be low. Given that returns on investment in tractors are determined by the utilization rate, low or uncertain demand in the local hiring market negatively affects the decision of a would-be buyer to invest in a tractor, particularly when long-distance mobility in service provision is limited.

Second, the utilization rate of a tractor-and hence opportunities for profitable tractor ownership in rainfed systems-greatly depends on the length 
of the planting window, which may be as short as 30 days in semi-arid areas (Mrema, Kienzle, and Mpagalile 2018). This makes it extremely difficult in such contexts to reach a break-even point in investment and magnifies the cost of a tractor breakdown or other delay. Therefore, opportunities for providing multifunctional hiring services with a tractor, beyond plowing, can be vital. This may be achieved by using the tractor for water pumping, maize shelling, or processing of other crops, or for other functions such as transport, although certain stationary power applications such as pumping may be less relevant in areas where general motorized pumps or solar pumps are emerging as alternatives. Opportunities for multifunctional tractor use depend on farmers' demand for additional hiring services, which may be low in the places where an irrigation system is beyond reach for most farmers or where small-scale irrigation technologies are underdeveloped. Farmers in these areas may not have adopted a practice, such as harrowing or multiple plowing, that requires tractor use multiple times in land preparation. Migratory service provision in plowing increases utilization by allowing tractor owners to use their machines for a longer period of the year by exploiting geographical variation in seasons. However, these opportunities may not currently exist in many African countries. Migratory services rely on better road infrastructure, which depends on public investment. Migratory services are also subject to coordination failures, and it is unlikely for individual tractor owners to gauge the service demand and connect with customers in locations beyond their home areas. These issues can be particularly serious in Africa, more so than in Asia, because road infrastructure is poorer and service market networks are underdeveloped at an early stage of mechanization in Africa. Transporting tractors over long distances can be prohibitively costly where physical infrastructure is poor. Alternatively, identifying medium-scale commercial farmers and encouraging their growth in a way that raises returns on machinery can also stimulate the growth of potential suppliers of custom hiring services (Mpanduji 2000; Agyei-Holmes 2014).

Even within a locality, significant obstacles hinder the efficient utilization of tractors, especially where plots are small and fragmented. In an area with small farm sizes, especially if the timing of production among small farmers is not uniform, traveling between plots, as well as turning and other maneuvers in a small plot, increases time and fuel consumption. Again, this can be especially serious in Africa, where the dominant types of tractors are larger and the road infrastructure is poorer than in Asia. These obstacles all cut into the margins of tractor operation. One way to offset this disadvantage of scale in farm size is for small farmers to coordinate planting and to jointly hire a 
tractor for plowing their fields at once, but this would require coordination efforts beyond tractor owners' capacity. Moreover, there is a steep learning curve for both the technical and business aspects of tractor ownership and operation in hiring markets, which implies additional risks for tractor investment. The complex soil and field conditions across small farms require experience, which takes time for owners or hired operators to acquire. Otherwise, stumps and other obstacles hidden in unfamiliar fields can easily damage tractors.

Apart from these risks, traditional land tenure systems can not only limit the consolidation of farmland but also prevent the land from being used as collateral, making credit for tractor purchases unavailable to many would-be buyers who are farmers. This is especially prevalent in countries with particularly weak land tenure security. Thus, the lump-sum investment required becomes unfeasible for many potential owners. Even where credit is available, interest rates are often too high to be attractive for would-be buyers.

The availability of appropriate technology is also imperative for hiringmarket development. All of the potential market failures described above are exacerbated when tractor sizes are large. Larger, higher-horsepower tractors are generally more expensive, require higher utilization rates for breakeven, and possess higher barriers to entry than smaller models. Thus, larger tractor size exposes owners to greater hiring-market risk because any major delay or coordination failure has greater consequences in terms of recouping the higher investment cost. Thus, it is important to strike a balance between a tractor powerful enough to effectively plow local soils and one small and cheap enough to be owned and operated cost-efficiently in areas where those smaller tractors would be in fact more suitable. However, in Africa, with hiring markets in the early stages, the tractors available are manufactured for and previously owned in other countries. With limited knowledge of the suitability of different tractors for different within-country soil conditions, achieving the balance between size and efficiency of tractors is beyond the capacity of individual owners or the private sector. These challenges are more severe in Africa, where soil conditions and other production environments are generally more diverse than in Asia (World Bank 2007), yet the public information to address them is limited. The evidence is still insufficient as to what the optimal size of tractors is in Africa, although small tractors, including two-wheel tractors, have been promoted in Africa from time to time over the course of several centuries. Continuous research is needed to shed more light on this issue and provide information to policymakers and stakeholders about the size of tractors. 
Familiarity with animal traction can facilitate the adoption of tractors beyond the sequential nature of farming systems evolution, because in this case tractors are adopted simply to substitute for animal traction. Although the transition from animal traction to tractors requires learning a new technology, in the places where farmers go straight from hand hoes to tractors, they must learn not only the new technology but also new land preparation practices. In a society with established animal traction, formal or informal hiring markets already exist for draft animal services. Moving from a tradition of hiring animals for land preparation to hiring tractors for plowing is therefore a much faster process, in terms of both new technology adoption and tractor hiring market development. Having used animal traction also helps new tractor owner-operators shorten their learning period for service provision. Of course, the potential of draft animals must also be evaluated against the risks of owning the animals, such as disease and competition with the growing demand for livestock products. Where feasible, leapfrogging draft animal technology should remain as one of the options (Kormawa et al. 2018). However, as is described in this book, animal power often preceded the growth of mechanical power in developing countries in the 20th century and has spread considerably in parts of Africa in the last few decades, suggesting that lessons from these experiences can be applied to other parts of Africa in the future.

To summarize, we integrate induced technological innovation theory and market failure challenges in the development of markets for hiring services with PBB's farming systems hypothesis to better explain contemporary mechanization trends under the new paradigm. $\mathrm{PBB}$ focused on the relative efficiency of the private sector compared with the public sector in overcoming some of the aforementioned challenges associated with hiring-service operations. In contrast, we emphasize that the private sector continues to face the remaining challenges, and the public sector must still play an active role in mitigating these challenges, not through direct interventions in hiringservice schemes, but instead through other measures. Demand is still a necessary precondition for adoption. Demand depends not only on farming systems but also on the availability of labor relative to land in the context of broader economic transformation. The development of mechanization hiring markets is constrained by many factors that can slow down the spontaneous supply response of mechanization services. Our framework recognizes that certain market failures associated with investment risk and hiring market development are significant, with some form of public support required to overcome them. One key difference from PBB is that we highlight more 
the complex nature of the demand for mechanization of specific activities, such as land preparation. Whereas PBB illustrated the nature of demand in a broader scheme, including its sequential nature, they focused relatively less on, for example, its variations across farm households or at the intensive margins (for example, the number of times each plot is plowed). The key will be understanding the extent and determinants of such variation.

\section{Case Study Countries in the Book}

The validity of the theoretical framework presented in the previous section is assessed drawing on collective evidence from a set of countries. Key aspects of this framework are further investigated through focused empirical analyses from a subset of countries.

\section{Theoretical Framework and Country Chapters}

Countries covered in this book are selected based on various criteria. First, we focus on countries in which substantial research has been done by the International Food Policy Research Institute and other CGIAR centers so that we can make the best use of existing research results. In addition, Asian countries are selected to represent diversity in mechanization experiences with different levels of economic development and manufacturing capacity, and various mechanization-sector development patterns. Selected Asian countries have also developed various mechanization supply models (for example, Bangladesh, China, and India, as highlighted in Diao et al. 2014). Although some Asian countries are not included due to the unavailability of substantial research with relatively detailed empirical assessments, the information that is available for excluded Asian countries (for example, in FAO and CSAM 2014) is generally consistent with the key patterns described in this book. Although China and India are much larger than other Asian countries included, their lessons can potentially be useful for subregional approaches within Africa, which have been promoted in recent years (Kormawa et al. 2018).

African countries are selected from East Africa (Ethiopia, Kenya, and Tanzania) and West Africa (Ghana and Nigeria). Four of these countries are among the largest countries in Africa in terms of economically active population in agriculture, and they together (plus Ghana) account for 40 percent of all of the economically active population in Africa's agriculture sector and more than 30 percent of Africa's arable land, including the nation of South Africa and some northern African countries (USDA ERS 2018; GGDC 
2019). South Africa and some countries in northern Africa (such as Egypt) are much more advanced in mechanization than other areas due to domination of either large-scale commercial farms (in the case of South Africa) or irrigated agriculture (in the case of Egypt). Therefore, they are excluded from this book, which focuses, in the case of African countries, on smallholders and rainfed agriculture. For similar reasons, Latin America is not covered by the book.

Although a general framework is provided in the previous section, many chapters of the book adopt different approaches to addressing this framework. Table 1.1 summarizes how the case study countries covered in this book are collectively linked to each key aspect of the theoretical framework described in the previous section.

In addition, an online appendix, Appendix $1 \mathrm{C}$, that provides a brief review of other African countries' experiences, particularly Francophone countries and Lusophone countries, as well as experiences of some Latin American countries, is included as a supplement to the book. As is described in the overview in Appendix 1C, although the experiences in the countries have been by no means identical, they do have much in common with those of the countries explicitly covered in this book.

\section{Empirical Framework and Approaches}

The empirical approach also differs across chapters also because of the available primary data. Table 1.2 summarizes the types of data covered in each chapter's empirical analysis. Note that Table 1.2 omits five country chapters (Chapters 4, Sri Lanka; 5, Thailand; 8, Myanmar; 11, Ghana; and 14, Tanzania), which include no quantitative empirical analyses due to the unavailability of data.

The Viet Nam, Bangladesh, Kenya, and Nigeria chapters focus on the determinants of mechanization adoption. The China chapter focuses on the importance of machine rental, assessing the effect of machine rental on agricultural production using a structural production function. Similarly, the Nepal chapter focuses on the effects of machine rental on production technology characteristics and provides further insights into the effects on returns to scale. The India, Nepal, and Nigeria chapters focus on detailed aspects of the associations between tractor adoption and agricultural input uses (land, labor, draft animals, and other inputs such as chemical fertilizer or irrigation). The Bangladesh, Nepal, and Nigeria chapters assess the associations between tractor adoption and off-farm labor supply or incomes. The Nepal and Nigeria chapters also assess the associations between tractor adoption and agricultural 
TABLE 1.1 Key aspects of theoretical framework covered in country chapters

\begin{tabular}{|c|c|c|c|c|c|c|c|c|c|c|c|c|c|}
\hline \multirow[b]{3}{*}{ Key aspect of the theoretical framework } & \multicolumn{13}{|c|}{ Chapter } \\
\hline & 2 & 3 & 4 & 5 & 6 & 7 & 8 & 9 & \multicolumn{2}{|c|}{1011} & \multicolumn{2}{|c|}{1213} & \\
\hline & 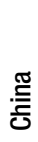 & $\stackrel{\text { 뜸 }}{\underline{E}}$ & 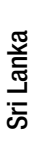 & 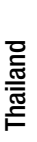 & 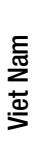 & 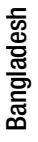 & $\begin{array}{l}\text { ত } \\
\text { E } \\
\text { స̃ } \\
\text { ¿ }\end{array}$ & $\frac{\text { 증 }}{\text { 는 }}$ & 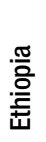 & 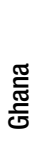 & ্ָত্ড & & \\
\hline \multicolumn{14}{|l|}{ Farming systems evolution } \\
\hline Farming systems intensification & & & & & & & & & $x$ & $\mathrm{x}$ & $\mathrm{x}$ & $x$ & $\mathrm{x}$ \\
\hline Sequential nature of mechanization & $x$ & $x$ & $\mathrm{x}$ & $x$ & & & $x$ & & $x$ & $\mathrm{x}$ & $x$ & & \\
\hline \multicolumn{14}{|l|}{ Induced technological change } \\
\hline Land endowments and mechanization & $x$ & $x$ & $x$ & $x$ & $x$ & $x$ & $x$ & $\mathrm{x}$ & $x$ & $\mathrm{x}$ & $x$ & $\mathrm{x}$ & $x$ \\
\hline Labor scarcity due to economic transformation & $\mathrm{x}$ & $\mathrm{x}$ & & $x$ & $x$ & & $\mathrm{x}$ & $\mathrm{x}$ & $\mathrm{x}$ & $\mathrm{x}$ & & $\mathrm{x}$ & \\
\hline Actual impacts of mechanization & $\mathrm{x}$ & $\mathrm{x}$ & & & & $\mathrm{x}$ & & $\mathrm{x}$ & $\mathrm{x}$ & & & $\mathrm{x}$ & $\mathrm{x}$ \\
\hline \multicolumn{14}{|l|}{ Supply-side issues: Market failures } \\
\hline Risk and uncertainty in economics of service provision & $x$ & $\mathrm{x}$ & & & $\mathrm{x}$ & $x$ & $\mathrm{x}$ & $\mathrm{x}$ & $x$ & $\mathrm{x}$ & & $x$ & $\mathrm{x}$ \\
\hline $\begin{array}{l}\text { Insufficient knowledge of machinery, operations, repairs, } \\
\text { mechanization }\end{array}$ & & $x$ & $x$ & $x$ & & & & $x$ & $x$ & $x$ & $x$ & $x$ & \\
\hline \multicolumn{14}{|l|}{$\begin{array}{l}\text { Supply-side issues: Complementary efforts by the gov- } \\
\text { ernment (or shortage thereof) }\end{array}$} \\
\hline Public goods and complementary technologies & $\mathrm{x}$ & $\mathrm{x}$ & $\mathrm{x}$ & $\mathrm{x}$ & $\mathrm{x}$ & $\mathrm{x}$ & & $\mathrm{x}$ & & $\mathrm{x}$ & & $\mathrm{x}$ & \\
\hline Research and development on mechanization & & $\mathrm{x}$ & $\mathrm{x}$ & $x$ & $x$ & & & & & $\mathrm{x}$ & & $\mathrm{x}$ & $\mathrm{x}$ \\
\hline Financial sector reform (for example, land tenure reform) & & $\mathrm{x}$ & & & & & $\mathrm{x}$ & & $\mathrm{x}$ & & & & $\mathrm{x}$ \\
\hline Coordinating roles (or shortage thereof) & $\mathrm{x}$ & & & & $\mathrm{x}$ & & $\mathrm{x}$ & & & $\mathrm{x}$ & & & \\
\hline \multicolumn{14}{|l|}{$\begin{array}{l}\text { Supply-side issues: Government failures (or absence } \\
\text { thereof) }\end{array}$} \\
\hline Subsidies (fairness or distorting nature of) & $\mathrm{x}$ & $\mathrm{x}$ & & $x$ & $\mathrm{x}$ & & & $\mathrm{x}$ & & $\mathrm{x}$ & & $\mathrm{x}$ & \\
\hline Excessive import restrictions (or absence thereof) & & $x$ & $\mathrm{X}$ & & & $x$ & $\mathrm{x}$ & $x$ & $x$ & $\mathrm{x}$ & $\mathrm{x}$ & $x$ & $\mathrm{x}$ \\
\hline Arbitrary selection of service providers & & & & & $\mathrm{x}$ & & & & & $\mathrm{x}$ & & $x$ & \\
\hline Excessive regulations (or absence thereof) & & & & & & $x$ & $\mathrm{x}$ & $\mathrm{x}$ & & & & & \\
\hline
\end{tabular}

Source: Authors.

incomes or revenues. The Ethiopia chapter provides a more detailed assessment of the effects on wheat yields of using tractors and harvester-threshers. Finally, regarding the types of machines used, the chapters on Bangladesh, Nepal, Kenya, and Nigeria focus specifically on tractors, the India and Ethiopia chapters consider tractors and harvester-threshers, and the China, Viet Nam, and Kenya chapters consider agricultural machinery in general. 
TABLE 1.2 Focus of empirical analyses in selected chapters

\begin{tabular}{|c|c|c|c|c|c|c|c|c|}
\hline \multirow[b]{3}{*}{ Focus area in mechanization } & \multicolumn{8}{|c|}{ Chapter } \\
\hline & 2 & 3 & 6 & 7 & 9 & 10 & 12 & 13 \\
\hline & China & India & $\begin{array}{l}\text { Viet } \\
\text { Nam }\end{array}$ & Bangladesh & Nepal & Ethiopia & Kenya & Nigeria \\
\hline Adoption & & & $x$ & $x$ & & & $x$ & $x$ \\
\hline \multicolumn{9}{|l|}{ Impact on production, farm resource use } \\
\hline Production function & $x$ & & & & $x$ & & & \\
\hline Farm size/area & & $x$ & & & $x$ & & & $x$ \\
\hline Yield & & $x$ & & & $x$ & $x$ & & \\
\hline Labor use & & $x$ & & & $x$ & & & $x$ \\
\hline Animal use & & $\mathrm{x}$ & & & & & & $x$ \\
\hline Other inputs use-fertilizer & & $x$ & & & $x$ & & & $x$ \\
\hline \multicolumn{9}{|l|}{ Impact on incomes } \\
\hline Income-agriculture & & & & & $x$ & & & $x$ \\
\hline Income_-overall, other & & & & & $x$ & & & \\
\hline Off-farm labor supply, income & & & & $x$ & $x$ & & & $x$ \\
\hline Analysis by crops/farming operations & $x$ & $x$ & & & & $x$ & & \\
\hline \multicolumn{9}{|l|}{ Types of mechanization technologies } \\
\hline Tractor & & $x$ & & $\mathrm{x}$ & $x$ & $x$ & $x$ & $x$ \\
\hline Combine thresher & & $x$ & & & & $x$ & & \\
\hline Machinery in general & $\mathrm{x}$ & & $\mathrm{x}$ & & & & $\mathrm{x}$ & \\
\hline
\end{tabular}

Source: Authors.

These empirical analyses fill the gap in the mechanization literature and build on early studies (for example, Jayasuriya, Te, and Herdt 1986) by providing updated evidence while taking into account the changes in technological and socioeconomic conditions and the farming systems evolution that have occurred within the last few decades. Further, some empirical analyses offer evidence based on more rigorous estimation methods that address issues such as endogeneity of mechanization adoption decisions, which were not always adequately addressed in earlier studies.

\section{VARIATIONS IN EMPIRICAL SPECIFICATIONS ACROSS CHAPTERS}

Different empirical specifications and approaches are used for different chapters, based on data availability and data quality. First, there are differences with regard to the definitions of "mechanization". For some countries, 
information was available only for "machines," whereas more specific information on "tractors" was available for other countries. Generally, we provided more results in the latter case (for example, for India, Nepal, and Nigeria).

Second, in the African country chapters, quantitative analyses are limited due to generally low mechanization adoption levels at the national level. The exceptions are Ethiopia and Nigeria, both of which have either detailed nationally representative samples or detailed information on machine use. In contrast, although Tanzania also has Living Standards Measurement Studytype data, the adoption rate of tractors captured in the survey is very low. Similarly, for Ghana, data such as those from the Ghana Living Standards Survey provide information only on "equipment" rather than "tractors," terms that are often exchangeable in the country. Quantitative analyses are also not conducted for three Asian countries (Sri Lanka, Thailand, and Myanmar) due to lack of data. These countries are nonetheless included, given the rich qualitative evidence.

Specifications are selected to best fit the available data and adapted to the differences in data quality that exist across countries. Where data quality is considered less than satisfactory, we often use techniques such as propensity score-based models, rather than linear regression models. Linear models try to answer more questions (producing coefficients for each variable) given the number of variables, whereas approaches such as propensity score-based models that focus on one variable (here, the number of tractor/machine adoptions) may be more suitable in cases with poorer data quality (Heckman and Vytlacil 2007). Production functions are estimated only in the China and Nepal chapters. Insights on production functions are important and relevant for mechanization (especially to assess properties such as returns to scale), but estimations require both strong instrumental variables and good data quality. The China data are considered to have especially good quality. Similarly, data from the lowland area of Nepal are considered suitable because, despite the homogeneity of the agroclimatic environment, prices can vary considerably depending on the distance to the Indian border and thus serve as good instrumental variables.

Analyses by crop or farming activity are limited to the cases in which information is available and there is a sufficient sample size for a particular crop or farming activity. Only China, India, and Ethiopia (wheat) meet these criteria.

Last, where applicable, data in Asian chapters are selected with a particular focus on drawing lessons for Africa. For example, the analyses in the India chapter rely on datasets from semi-arid tropical regions that largely practice 
rainfed farming, comparable to the majority of agricultural production environments in Africa, so that the findings can be more relevant to African countries.

\section{Reviewing Country Experiences through the Updated Framework}

Armed with this updated framework, we examine the development patterns of agricultural mechanization in eight Asian and five African countries. The objective is to provide a detailed, clear, and consistent summary of mechanization in each country. Unlike some books that have a uniform conceptual framework for all chapters, this book, rather, takes the approach of synthesizing common messages from each country study and using them as concrete, illustrative examples that help update the PBB framework. We do our best to provide each chapter with a similar structure, enabling easy comparisons across countries. Each chapter first reviews the history of mechanization in the country. The chapters then analyze the demand for mechanization at the system and household levels, paying attention to differential farming systems, land-labor ratios, farm size distribution, and labor market dynamics, among other elements. This leads to an assessment of the extent to which the demand for mechanization has emerged, and its spatial patterns. The next section of each chapter then turns to a supply-side analysis for machines-in terms of import, subsidy, and promotion policies-by looking, where relevant, at manufacturing, and more important, at service provision through hiring markets. Attention is again paid to spatial variation within countries. Each chapter analyzes how mechanization has factored into broader agricultural transformation in the country, through its effects on farm size, land productivity (through complementarities with yield-enhancing technological inputs and reduction in postharvest losses), and agricultural employment.

We first review some of the trends from Asia and Africa, which further demonstrate the need for our updated framework as described above to explain the slower adoption of mechanization in Africa, despite emerging demand. Whereas lack of demand was an appropriate diagnosis for low levels of mechanization in Africa before the 1980s, in many parts of African countries this no longer appears to be the case. The farming systems have changed and the pressure on agricultural labor has increased. In the parts of African countries where we do observe increasing adoption of mechanization, the supply has not fully met emerging demand due to the market failures described above; elsewhere in the continent, demand for mechanization has not grown 
significantly. Meanwhile, in Asia, the shift from draft animals to tractors and the adoption of other agricultural mechanization after the Green Revolution seem to be mainly driven by agricultural intensification, industrialization, and overall structural transformation. Tractor hiring markets have developed over time to respond to emergent demand in a wide range of Asian countries, with relatively few obstacles, first in the favorable regions in response to agricultural intensification (at a relatively early stage), and later at greater scale in response to structural transformation (at a later stage). Therefore, PBB's hypothesis needs to be augmented to fully account for the divergence between mechanization in Asia and in Africa. Our updated framework, described above, tries to explain this divergence by identifying obstacles that are relatively more unique in Africa's developing mechanization hiring markets, while also highlighting the role of government policies.

\section{Asia}

In general, mechanization has been widespread in Asia, given relatively conducive conditions. In all eight Asian countries covered in this book, intensified farming systems have long been established and the tradition of animal plowing and use of some small and simple agricultural machinery can be traced back hundreds of years, and at times even longer. ${ }^{4}$ In a few Asian countries, such as Sri Lanka, the adoption of tractors had reached significant levels by as early as the 1970s (see respective chapters). The key issue in Asia is not the adoption of plowing as part of the farming practice but the substitution of tractors and power tillers for animal draft power and the adoption of engine-powered machinery such as combine harvesters or threshers for harvesting or postharvest processing. Thus, the induced technological innovation theory is much more relevant than the theory of farming system evolution for explaining the sequences of mechanization in Asia.

Rapid mechanization in developing countries of Asia largely came as part of broader economic transformation processes. Although the Green Revolution of the 1970s further intensified agricultural production and created demand for irrigation-related mechanization, the replacement of animal traction with tractors for plowing and the development of mechanization for planting, weeding, harvesting, and postharvest operations came later and was

4 Various information for other Asian countries not included in this book (for example, Bhutan, Cambodia, Indonesia, Laos, Pakistan, the Philippines) has been provided in other studies, including FAO and CSAM (2014). Many of those countries' experiences are similar in one way or another to experiences in the eight Asian countries covered in this book. 
mainly a response to rising labor costs. The Asian country case studies indicate that mechanization truly began to accelerate when the pace of industrialization started to accelerate, and when the development of labor-intensive manufacturing and the rural nonfarm economy put upward pressure on wage rates, albeit at different times in different countries (Zhang, Yang, and Wang 2011; Wei, Xie, and Zhang 2017). However, distinct patterns between countries still exist in terms of when mechanization was adopted on various types of farms.

\section{TYPICAL CASES}

In China, India, Thailand, and Viet Nam, mechanization has followed a fairly predictable path. For India and Thailand, farmers with small and relatively larger-scale farm sizes have coexisted for decades, while in China and Viet Nam the distribution of farm sizes became more diversified in the years following their economic reforms. Whereas larger farmers had traditionally used tractors for land preparation long before the shift from animal draft to tractor power among smallholders, the pattern of the spread of mechanization among smallholders seems to be similar among these four countries. In each of these countries, increased returns on farm power use in general, which were led by the overall agricultural intensification process, industrialization and economic growth, and the subsequent urbanization that pulled labor out of agriculture, all created demand for mechanization because of rising labor costs that induced labor-saving technological change. Smaller $4 \mathrm{WT}$ or power tillers with lower horsepower have dominated mechanization in land preparation, while small to medium-size combine harvesters have been widely adopted, even among smallholders. As detailed in their chapters, these countries have all developed various extents of capacity to manufacture a broad variety of different sizes of equipment, much of it affordably priced, to meet demand from farmers with different farm sizes. Government subsidies have been used to support both manufacturers and farmers, but these subsidies were rarely targeted to specific groups of farmers. Still, machinery is typically concentrated among a small number of farmers, with the majority accessing services through the hiring market. Although not covered in this book, tractor rental markets have been relatively efficient in some other Asian countries such as the Philippines (Takahashi and Otsuka 2009). Whereas markets for plowing services are typically local, harvesting services commonly involve migration across the country to reach farmers in different agroecological zones. These patterns have also been consistent with experiences at the early stage of mechanization in countries such as the United States (Olmstead and Rhode 2001). 


\section{ATYPICAL CASES}

Agriculture in Bangladesh, Nepal, and Sri Lanka is dominated by small-scale farmers - even by the Asian standard (FAO 2019b) — with relatively abundant rural labor, especially the former two countries. The average small size of farms would intuitively make them seem less suitable for exploiting scale economy advantages through engine-powered mechanization as a substitute for animal traction. However, land preparation in both Bangladesh and Sri Lanka is highly mechanized through power tillers. For example, 89 percent of farm households in Bangladesh had adopted tractors or power tillers for land preparation by 2008, 80 percent of whom had less than 1 ha of farmland. However, only about 4 percent of farm households owned the machinery, highlighting the wide adoption and robustness of the hiring market. Most of this development occurred over a short period after the late 1980s, following the removal of import restrictions on Chinese power tillers when a typhoon decimated the draft animal population (Mandal 2017). An estimated 80 percent of tillage is also mechanized in Sri Lanka, again mostly through power tillers (Biggs and Justice 2017), and farmers in most districts also use combine harvesters. Although Nepal, a country with mountainous and hilly terrain, is the least mechanized among the eight Asian countries studied in this book, and indirect evidence suggests significant market failures in its tractor hiring markets, tractor adoption in Nepal has been growing rapidly since the 1990s. This is particularly evident in the Terai plains, and mini-tillers have also started spreading in the hilly/mountainous regions in the most recent decade (Nepal chapter). Finally, Myanmar has been undergoing an extremely rapid transition in mechanization, with growth in the adoption of $4 \mathrm{WTs}$ and power tillers for plowing, as well as combine harvesters, accelerating following major economic reforms in 2012. Between 2006 and 2016, the share of farm households in Ayeyarwady and Yangon regions using mechanized land preparation rose from 36 to 97 percent, and the share using mechanized harvesting rose from 5 to 57 percent (Myanmar chapter).

\section{COMMON FACTORS}

Although the need to overcome labor constraints may have driven the substantial progress in mechanization in all eight Asian countries, physical and market conditions seem to have provided few impediments to the development of mechanization-hiring markets, which emerged organically as the dominant form of service provision to smaller farmers in these countries. 
Government subsidies and public goods played a key role in mechanization development in most Asian countries. As will be discussed in the section on government policy, these interventions mostly played a supportive role in facilitating the development of machinery and implements to support farmers' needs, increasing access to machinery, and overcoming coordination failures. In other words, they supported the private sector's supply response to rising demand, rather than attempting to create demand or directly intervene in the supply of mechanization.

Small and relatively low-cost tractors, power tillers, and harvesters, typically manufactured domestically or imported from China, India, Thailand, or other nearby Asian countries, are among the agricultural machinery most commonly adopted in Asia. Power tillers are dominant throughout Bangladesh, Sri Lanka, and Myanmar, and are common in rice-producing areas elsewhere. More important, the smaller size of tractors in Asia is not only due to the common presence of power tillers. Even where larger 4WTs have been adopted, they rarely exceed $50 \mathrm{hp}$. With rising rural incomes, the cost of machines has been low enough that some small- and medium-scale farmers could afford to buy them and become service providers in the hiring market. Moreover, though subsidized credit was widely available in a few countries, farmers could also use their land as collateral to acquire machines. Recent land reforms appear to have been one of the major catalysts of the spread of smaller tractors and combine harvesters in Myanmar in the past few years (Myanmar chapter). The role of land tenure security in Myanmar might have been particularly strong because of rising demand for mechanization, which stands in contrast to its role in some African countries, such as Kenya, where a relatively sophisticated land tenure system played a limited role due to slower farming system intensification and slower growth of mechanization demand.

In irrigated cereal systems, climate conditions have led farmers to plant their crops simultaneously, which helps overcome the scale issues associated with mechanization services on small farms. In addition to irrigation's overall role in intensification, long-established irrigation systems and the rapid spread of shallow-water irrigation have presented opportunities for multifunctional tractor use, such as powering water pumps with tractor engines, particularly at early stages of mechanization, before the arrival of cheaper diesel pumps. Using tractors for carting agricultural and nonagricultural goods has also been common in rural Asia. In larger countries, climate patterns and infrastructure have enabled migratory service provision, increasing opportunities for greater utilization of agricultural machinery. 


\section{Africa}

\section{CONTINENTAL AND COUNTRY TRENDS}

After cases of Asian mechanization development, the focus of the book turns to Africa. The five African countries covered also differ significantly in their patterns of mechanization, but most of them are relatively mechanized compared with the rest of low-income African countries. In many other countries, mechanization levels are often too low or data are too scarce to justify the inclusion of detailed descriptions. However, the online Appendix 1C of this book provides a brief overview of the experiences in Francophone and Lusophone countries to supplement this chapter. Analysis of the available data from the country chapters and elsewhere shows that there has been a resurgence in mechanization, but with significant variations across countries. According to a study published by the FAO and AUC (Kormawa et al. 2018, Figure 2), the share of farm areas primarily prepared by tractors in the whole of Africa was possibly around 10-20 percent in 2005. Though there might have been some growth in tractor adoption since then, that growth has been slow in some major countries, including Nigeria (Nigeria chapter), which has the largest amount of arable land in Africa. It is therefore expected that tractor use in Africa is still far behind the levels seen in Asia.

All five African countries covered in this book contain regions that have experienced significant mechanization adoption, despite slow mechanization growth at the national level. Of these countries, demand seems to be most widespread in Ghana, where many medium-scale farmers have acquired tractors and one-third of agricultural households now use some form of mechanization (Ghana chapter). However, demand for mechanization is concentrated in the northern savannah zones (including Upper West region, where the adoption rate is 88.5 percent). Because tractor use is not feasible in most of the forest zones, the adoption rates range from 2 to 10 percent in the forest zones. However, tractor operators often receive requests for plowing from more farmers than they can serve, indicating that supply has not kept up with demand. Likewise, although the value of agricultural machinery imports into Ethiopia increased sevenfold between 2005/2006 and 2013/2014, it did so from a very low base, and still less than 1 percent of agricultural plots in 2013/2014 were plowed by tractor. The rapid adoption of tractors and combine harvesters appears to have been generally concentrated in wheat-barley systems in the southeast of the country, which has bimodal rainfall and where terrains are relatively flat and larger farmers and smallholders are intermingled (Ethiopia chapter). Tanzania seems to exhibit generally similar patterns 
of mechanization growth; the tractor population nearly doubled from 2005 to 2015, plowing about 14 percent of cultivated land nationwide, but 64 percent of tractors were located in six contiguous regions that are relatively dry and land-abundant, with good market access. Power tillers tend to be generally concentrated in grain-surplus areas of the southern highlands, particularly in rice cultivation areas. In Kenya, tractor ownership remains generally low, at 2 percent of farm households in 2012 (Kenya chapter), although it appears higher in the tropical highlands and in the coastal lowlands. In Nigeria, the area plowed by tractors declined to 7 percent in 2012 (Nigeria chapter), and it appears fairly concentrated in input-intensive systems in remote areas with high wages, for rice in the south and a variety of cereals in the north.

The nature of demand is complex as well, because adoption appears to be relatively extensive but not intensive. Although it is not discussed in all the chapters, we see little evidence of the intensive use of tractors and draft animals. Rather, adoption tends to be at the extensive margin, with tractors being used for only a single plowing. Observations from Ghana and Ethiopia suggest that there appear to be many cases in which tractors are generally not used for multiple plowings, unless there is a tradition of using animal draft for a second plowing (Ghana and Ethiopia chapters). This issue could relate to the learning curve and behavioral factors associated with technology adoption, or it may simply reflect low perceived returns from multiple plowings. Nevertheless, the effects of lower demand for multifunctional use, which is discussed below as a market failure because it constrains profitable ownership of tractors, are an important component of demand itself.

We now turn to the separate components of our framework, to explain these divergent patterns between Africa and Asia.

\section{Components of the Framework}

\section{DEMAND-SIDE FACTORS}

A key demand-side factor in Africa today is that overall demand for mechanization has risen, and thus it has become important to dig deeper and better understand its complexity. Farming systems in Africa have intensified significantly over the past 30 years, albeit at varying speeds and with different patterns. Population density and market access have induced the shift to permanent cropping, even in sparsely populated areas such as the savannah zones of West Africa (Binswanger-Mkhize and Savastano 2014). At the same time, despite the increased farming intensity, the level of agricultural development has remained unclear. For example, much of Africa has not experienced 
any type of Asian-style Green Revolution at a large scale (Diao, Headey, and Johnson 2008; Woodhouse 2009; Nin-Pratt and McBride 2014). Adoption rates of improved seeds, fertilizers, pesticides, and other inputs remain relatively low, and opportunities for irrigation development are quite limited and underexploited (You et al. 2011). Increased agricultural production has primarily come from land expansion, and crop yield growth has been extremely modest. Compared with the eight Asian cases in this book, it appears that at least at a national level, the five African countries in the book still have not reached the overall level of agricultural intensification that already existed in Asia a few decades ago when its mechanization started growing.

There is also much spatial variation in the availability of land among African countries. The majority of Africa's virgin land suitable for cultivation is in remote regions of a handful of countries, while in most systems farms are declining in size and fragmenting as rural populations grow (Chamberlin, Jayne, and Headey 2014). Virgin land in northern Ghana is still available; most surveyed tractor owners who acquired farmland recently were able to get access to such land, and some were given land freely by relatives or community chiefs (Chapoto et al. 2014). In contrast, land is scarce in much of Kenya and Ethiopia, where farm sizes have been declining. Though a general rise in population density and intensification of farming systems are preconditions for mechanization demand growth, land remains scarce if much of the population remains in the agricultural sector, which can depress land expansion, one of the motivations for investments in tractors. This is especially true if land markets are weak.

On the other hand, the low adoption of yield-enhancing technologies may mean agriculture is simply not profitable enough to justify the cost associated with mechanization adoption. This may be particularly the case in Nigeria, where the stagnant agricultural sector described in the country chapter limits incentives to invest in a tractor.

Africa also has many more systems than does Asia in which tree crops and root crops, which can be less conducive to plowing, are dominant (Diao, Silver, and Takeshima 2016; Mrema, Kienzle, and Mpagalile 2018). This partly explains the very low adoption of tractors in forest zones such as southern Ghana and Nigeria, where roots and cereals are often planted among cocoa and other tree crops.

Spatial variation in the demand for general labor-saving technology in African agriculture is also closely related to the patterns of economic growth. Although parts of Africa have undergone substantial economic growth and structural change over the past three decades (McMillan, Rodrik, and 
Verduzco-Gallo 2014; Rodrik 2016; Diao, McMillan, and Rodrik 2017), Africa's recent growth trajectory is much different from the one Asia went through at similar stages of development. In Asia, rising agricultural productivity essentially drove the process of structural transformation, industrialization, and urban growth (Johnston and Mellor 1961). There, the agricultural productivity growth, coupled with Engel's law, had also caused declining employment in the agricultural sector (Timmer 1988) and raised farm wages, partly by stimulating the growth of the industrial sector through backward and forward linkages, which absorbed workers away from the agricultural sector (Haggblade, Hazell, and Reardon 2007). In contrast, urbanization in Africa has been driven by neither a substantial increase in agricultural productivity nor industrialization. Rather, urbanization has been driven by the growth of consumption in cities dominated by nontradable services, which are often driven by natural resource revenues (Gollin, Jedwab, and Vollrath 2016). There has been substantial growth in the rural nonfarm economy, linked to growing urban demand (Diao, Silver, and Takeshima 2016), suggesting that similar effects of service-led nonagricultural growth may occur in rural areas. Such trends, where they take place, may accelerate the rise of rural wages more so than the typical model of industrialization-led structural transformation. In parts of Africa, the demand for mechanization is likely to have been raised substantially by rising food demand that has increased not only food imports but also purchases from the domestic farm sector (AGRA 2019), as well as by labor productivity growth (Diao, Hazell, et al. 2019; Diao, Kweka, and McMillan 2019) and land productivity-enhancing intensification (Christiaensen 2017; Otsuka 2019). However, in other parts of Africa, rising food prices and food imports have not necessarily induced sufficient agricultural productivity growth, and effects on demand for mechanization have been limited. These somewhat unique conditions in Africa today can complicate the nature of the demand for mechanization and magnify market uncertainty, risks, and other market failures, as discussed in the later section.

Where economic growth and urbanization have progressed, the overall trend has been a pronounced shift of labor out of agriculture, involving migration to urban areas and diversification of households into farming and nonfarm income generation, with youth exiting agriculture much more rapidly. Such economic transformation could further raise demand for mechanization in the near future (Diao, Silver, and Takeshima 2016). Shifting food demand to higher-value and more labor-intensive crops, associated with urbanization, can also exert upward pressure on agricultural labor demand (Tschirley et al. 2015; Binswanger-Mkhize 2017). In Ghana, increased demand for maize as 
both food and fodder crop has entailed a higher concentration of labor costs in land preparation, relative to other costs (Ngeleza et al. 2011). In a growing number of African countries, labor constraints are becoming more binding and inducing further demand for mechanization. For example, in Ghana, land is abundant, yet over 50 percent of the population now lives in urban areas. Farmland per agricultural worker has been rising over the past several decades and the sizes of small, medium, and large farms have all been growing (Diao et al. 2014). In contrast, countries like Kenya are still largely rural and dense in regions with high agricultural potential. Farm size per worker has declined as rural population growth remains high. Whereas some areas have shifted to high-value horticulture production, the harvested areas under vegetables and fruits have remained at about 6 percent of the total harvested area in the country (FAO 2018).

Another contrast exists between Ethiopia and Nigeria-in Ethiopia, rapidly rising rural wages and the rising cost of keeping livestock have been inducing the substitution of tractors for animal draft power even on small wheat-barley farms. However, low real wages in northern Nigeria and the relative availability of grazing lands have contributed to growth in animal traction alongside stagnation in tractor plowing (Nigeria chapter).

Considering the diverse patterns of farming system evolution and factor endowments in African agriculture, there is likely to be much spatial heterogeneity in the demand for mechanization. It is clear that in some areas, farming systems and labor scarcity have induced significant demand for tractors and, in some cases, combine harvesters. However, the viability of animal traction appears limited to areas with favorable conditions for keeping livestock, low wages, and available grazing land. In areas where demand for tractors has not developed and animal traction is not feasible, attempts to create demand may remain ill-advised. Therefore, we now turn our attention to market failures hindering the supply response in places where demand for mechanization has emerged, which justifies public-sector mechanization-related interventions.

\section{SUPPLY-SIDE FACTORS}

As described above, under the new paradigm with greater overall demand for mechanization, an updated framework that more closely analyzes supply-side factors than does the PBB framework is needed. Factors that are unique to mechanization and factors that are relatively unique to Africa both exacerbate the market failures on the supply side. These market failures show why supply is unlikely to respond fully and spontaneously to emergent demand for mechanization. 


\section{Tractor size}

Tractor sizes are often much larger in Africa than in Asian developing countries. According to World Bank (2014) studies of seven countries, the average horsepower of 4WTs is more than $100 \mathrm{hp}$ in Ethiopia and Kenya; between 60 and $85 \mathrm{hp}$ in Ghana, Mozambique, Nigeria, and Zambia; and between 40 and $60 \mathrm{hp}$ in Burkina Faso. This stands in contrast to Asia, where power tillers for rice cultivation dominate in countries with small landholdings, and among $4 \mathrm{WTs}$, medium-size tractors dominate, with a range of 30-50 hp.

Farmers in Africa frequently cite heavy soils as a reason for preferring large tractors. Although direct evidence is scarce, assessments based on soil data from FAO and others (2012) suggest that a greater share of the agricultural area in Africa may have relatively high constraints in terms of soil workability. Table 1.3 suggests that in Asia, when weighted by the size of the agricultural area in each country, 74 percent of soil may have either no constraints or only slight constraints, whereas this ratio drops to 58 percent in Africa. However, these ratios may vary considerably across subregions; for example, the share of soils with workability constraints is considerably higher in South Asia, compared with East or Southeast Asia (Table 1.3). Similarly, soil conditions in rural Africa are highly heterogeneous even within a locality (Turner 2016), and soil knowledge may still be very limited due to weak capacity for soil research and soil mapping across different agroecological zones within a country. This implies that for some areas, soil conditions may not require tractors as large as those typically used. Moreover, interviews with farmers in both Ethiopia and Ghana show that they often prefer deep plowing, which uses a large disc plow that requires a more powerful tractor, even when it is not ideal for their soil conditions (Diao, Silver, and Takeshima 2017). More important, African farmers might have been more exposed to large and high-horsepower tractors than to smaller types due to the government's introduction and continued promotion of secondhand tractors. As a result, it could be that tractor owners, operators, and mechanics have become experienced only with these large tractor models, and perhaps the supply chain for both tractors and spare parts has developed only for the few popular brands of large tractors. This market failure could persist because this path dependence may not be easily overcome in the short run.

Prices of tractors are highly correlated with their sizes; larger tractors, the purchase of which is usually self-financed in Africa, require greater financial investments, have higher break-even utilization rates, and have lower maneuverability on small farms. Farmers might be willing to adopt smaller tractors to some degree. In recent focus group discussions, Ghanaian farmers expressed 
TABLE 1.3 Share (percentage) of agricultural area with different levels of soil workability constraints

\begin{tabular}{lcccc}
\hline Area & $\begin{array}{c}\text { No or slight } \\
\text { constraints }\end{array}$ & $\begin{array}{c}\text { Moderate } \\
\text { constraints }\end{array}$ & $\begin{array}{c}\text { Severe } \\
\text { constraints }\end{array}$ & $\begin{array}{c}\text { Very severe } \\
\text { constraints }\end{array}$ \\
\hline East/South Asia & 74 & 12 & 7 & 7 \\
SSA & 58 & 22 & 12 & 8 \\
\hline East Asia & 84 & 8 & 4 & 4 \\
Southeast Asia & 70 & 24 & 5 & 2 \\
South Asia & 50 & 15 & 16 & 19 \\
East Africa & 59 & 20 & 12 & 9 \\
Middle Africa & 73 & 11 & 10 & 6 \\
West Africa & 49 & 31 & 14 & 7 \\
Southern Africa & 56 & 20 & 13 & 11 \\
\hline
\end{tabular}

Source: Authors' calculations based on FAO et al. (2012) and FAO (2018).

Note: SSA = Africa south of the Sahara. The figures are based on the assumption that distribution of soil workability is equal between agricultural land and other land. Therefore, these figures need to be interpreted with caution.

willingness to purchase $45-55 \mathrm{hp}$ tractors if they were 20 percent cheaper than the 65-70 hp tractors that are the most commonly used. However, they would not consider a tractor of less than $40 \mathrm{hp}$ at any price, because they believe such a tractor to be too weak to plow heavy soils (Diao et al. 2018). Nevertheless, other than the power tillers used in irrigated areas, few such tractors are imported into Ghana.

More still must be known about why farmers prefer large tractors and under what conditions they would adopt smaller machines. With scarce knowledge of soil conditions, it is difficult to determine the optimal level of horsepower required for different soil conditions in different areas. Without such knowledge and information on different plowing methods, farmers are unlikely to change their preferences and adopt smaller machines. It is also difficult for manufacturers in tractor-exporting countries to design new equipment suitable for the local conditions in Africa.

\section{Barriers to tractor ownership}

Even where significant demand for plowing does exist, the number of medium- to large-scale farmers who are capable of purchasing tractors may still be suppressed because of the indivisibility of such investments, and this can limit the supply in hiring markets (Houssou et al. 2015; Takeshima 2015). In Africa, such constraints can be exacerbated by the aforementioned large tractor sizes. Put differently, though the number of medium- to large-scale farmers investing in tractors and providing hiring services has been growing in 
Africa, the pace of this growth could have been even faster if market failures had been mitigated.

Even though tractors acquired through private channels tend to be more of the secondhand type in Africa, the cost of these tractors is still quite high, especially when compared with the tractors that were adopted by Asian farmers at the early stages of mechanization. In addition, although tractors can be imported secondhand, plows and other implements have to be imported new, and these implements for large tractors are also more expensive than those for smaller tractors.

Historically, both private and government credit was important in the adoption of mechanization in some Asian countries. Whereas the up-front cost for a tractor in Africa is significantly higher than in Asia, there is little use of credit for tractor purchases in Africa. For example, only 2 percent of surveyed tractor owners in northern Ghana used any formal credit to purchase tractors, and 87 percent were completely self-financing (Chapoto et al. 2014). This stands in contrast to India, where up to 95 percent of tractor sales are made on credit. This likely relates to the reluctance of African private banks to lend to farmers, which is associated with the poor performance and low repayment of agriculture-related loans. African countries can potentially learn from experiences in India, including its relative success in directing a significant fraction of credit to the agricultural sector. It is, however, important to note that Indian success might have been endogenous; that is to say, it might have been enabled by rising overall demand for mechanization and the resultant growing density of potential would-be buyers of tractors, which reduced transaction costs per unit of credit provided and lowered interest rates. Another key factor seems to be the difficulty of registering land as collateral, as well as general concerns about the viability of the commercial value of agricultural products. In contrast, Myanmar allowed farmers to use land use right certificates as collateral for loans from private banks after its land reform. Credit thereby played a huge role in the rapid adoption of mechanization technology in Myanmar. Importantly, as was discussed above, the potential role of stronger land tenure is conditional on the presence of significant demand, and thus may be less relevant for parts of Africa where demand is still insufficient due to the low level of farming system intensification. However, where the farming system has sufficiently intensified, the role of land tenure may be significant.

Tanzania has been trying to resolve such financing issues by establishing an agriculture window at the Tanzania Investment Bank, as well as establishing the Tanzania Agricultural Development Bank in 2014, although the 
extent to which farmers have been able to take advantage of these services needs to be formally evaluated in more rigorous studies. Leasing schemes for machinery in Africa are underdeveloped (Ströh de Martinez, Feddersen, and Speicher 2016), and joint liability schemes, often implemented through cooperatives, have been riddled with collective action problems; the performance of loan guarantee schemes in this context is also mixed (Zander, Miller, and Mhlanga 2013). One promising case is a contract farming scheme in Zambia that facilitates access to credit for tractor purchases to its emergent farmers, who are guaranteed to have other nearby members of the outgrower scheme as customers for plowing services (Ströh de Martinez, Feddersen, and Speicher 2016). Such schemes can potentially help address both the credit and uncertainty constraints in the equipment hiring market.

\section{Coordination and information failures}

Small farmers with fragmented plots are common in both Asia and Africa. But the lack of coordination among farmers seems to be a bigger issue for agricultural machinery hiring in Africa than in Asia. Consolidating demand within the locality to attract service providers seems harder in Africa than in Asia, due to greater heterogeneity even within the relatively small geographical area, including soil types and cropping systems (World Bank 2007; Turner 2016). Most agricultural areas in Asia have grain-dominant crop systems, with a relatively homogeneous crop calendar within a locality, in which planting or harvesting occur at similar times. Generally higher adoption rates of relatively more homogeneous improved seed varieties in Asia may also be a contributing factor for such homogeneity in farming operations. On the other hand, when cropping systems are diverse within the locality, such as in the root crop-dominant systems or the root, legume, and maize mixed cropping systems found in many African countries, nearby farmers may not necessarily plant and harvest their crops following a similar calendar. The dominance of rainfed agriculture in Africa, with relatively long planting windows in some tropical conditions, causes farmers in the same community to plant at different times. As a result, operators of tractors or combine harvesters are reluctant to provide hiring services to small farmers in a community when their fields are not ready for plowing together (see Ghana chapter), because dispersed plots consume more time and fuel. These constraints can be binding at early stages of mechanization growth, although they can be partly overcome as the overall demand for mechanization rises to a sufficiently high level.

The challenges due to heterogeneity in land preparation timing within a locality should be distinguished from such heterogeneity at a regional level. 
As is discussed elsewhere, the latter can help with increasing utilization rates of machines for service providers because demand is more spread out within a year. However, similar heterogeneity within a locality poses constraints rather than opportunities because economies of scale in the hiring service become compromised.

Moreover, farming system intensification and the use of animal traction is relatively new and has a short history in much of Africa. This limits the existing knowledge and skills in plowing that are easily transferable to tractor ownership. Historically, animal traction has been constrained by trypanosomiasis in many African countries (Alsan 2015), although some of this disease has been eradicated through the expansion of human settlement recently. Although crop-livestock integration had progressed to the point that knowledge on animal traction and appropriate animal rearing has been accumulated (McIntire, Bourzat, and Pingali 1992), livestock is still owned by pastoralists in other parts of Africa and crop-livestock integration has started only recently there (Ehui and Polson 1993; Mrema, Kienzle, and Mpagalile 2018). Of the countries covered in this book, Ethiopia, drier areas of Kenya, northern Nigeria, some regions of Tanzania, and Sahelian Francophone countries have had some history of animal traction, but this is only relatively recent for most countries. In Africa, only Ethiopia and Mali have a long history of widespread plowing and animal traction (Mrema, Kienzle, and Mpagalile 2018). Therefore, though animal traction is not always a precondition for eventual tractor adoption, the limited spread of animal traction in many areas suggests significant knowledge constraints for mechanized plowing service provision, which can also constrain efficient tractor use.

Observations of new tractor owners and operators in Ghana show that many still lack basic knowledge, not only of the machines, but also of plowing practices and soil characteristics (Diao et al. 2018). In contrast, the authors' own field visits and conversations with farmers in Ethiopia indicate that farmers who had experience with animal traction were able to avoid such challenges when moving from draft animals to tractors. In such areas, farmers combine animal traction and tractor plowing. Plowing before the first rain, when the soil is too hard for animal traction, is done with tractors, and then second and third plowing and harrowing are done with animal traction. In areas of Ghana without animal traction, multiple plowing is rarely practiced (Diao et al. 2018). Without a tradition of animal traction, the technical and business learning curves may be much steeper and limit the efficiency of service providers in a hiring market. More broadly, the evidence on the role of 
plowing intensity on productivity and overall profitability is limited in Africa, and such evidence likely has to be generated by public-sector R\&D.

Taking advantage of information and communication technology could also present an opportunity for the private sector to help farmers overcome hiring market coordination failures, as has been the case in India (see chapter). Some companies in Ghana (Diao et al. 2018), Nigeria, and Kenya (Ströh de Martinez, Feddersen, and Speicher 2016) have developed relatively new platforms that make tractor hiring services more easily accessible through SMS and mobile apps. Uber-type hiring modalities such as Hello Tractor are also potentially promising in the long run. However, more evidence is needed to evaluate their impact on efficiency, long-term viability, and outcomes for farmers.

\section{Opportunities for migratory service provision}

Whereas migratory service provision has become common for combine harvesters in China, Myanmar, and Thailand, few tractor owners engage in migratory service provision in Africa. In Ghana and Nigeria, the few migratory tractor owners tend to be clustered in a small number of areas. In addition to the challenges described earlier within local hiring markets in Africa, migratory service provision can face the additional challenges of market information asymmetry, lack of customer networks, and other coordination failures. These challenges may be more constraining at the early stage of hiring market growth, when potential customers are still few and sparsely located. Asia overcame these challenges over time, and now Africa will face these challenges. Furthermore, because tractors need to be loaded on trucks to be transported around the country, rural road networks and trucking services need to be sufficiently developed for this to be viable. Such infrastructure and institutional capacity are much less common in Africa than they are in Asia. Without established client networks and well-developed trucking service logistics systems, migratory service providers risk not being able to find customers in unfamiliar areas. This coordination failure often requires a third party to intervene, as county governments have done in China. However, not all local governments in Africa have this capacity. In such cases, there may be opportunities for private information and communication technology platforms to provide the necessary coordination. For parts of Africa, including eastern and southern Africa, Kormawa and colleagues (2018) advocated a more regional approach, encouraging migratory services that extend beyond country borders to take advantage of greater variability in peak demand season and enhance the utilization rate of machines. In such a setting, the 
aforementioned public-sector role in coordination, including cross-country coordination, is likely to be even more critical.

\section{Types and uses of machinery}

The selection, in both size and function, of machinery available to African farmers also tends to be limited. Farmers purchasing tractors in Africa frequently opt for cheaper secondhand imports. The average age of tractors in most countries is quite high and, in some cases, exceeds the useful life of a tractor (Diao, Silver, and Takeshima 2016). However, evidence from Ghana suggests that these tractors perform as well as, if not better than, new tractors (Houssou, Diao, and Kolavalli 2014). Because secondhand imports tend to be of several common brands, markets for spare parts and maintenance services develop much more robustly for these tractors than for the new tractor brands often imported by governments. This makes secondhand tractors more attractive investments. In contrast, new tractors that are mostly acquired by large commercial farms or imported under government programs are widely reported to be less efficient than secondhand tractors acquired by farmers through their own means, often because of the lack of maintenance services and spare parts supply. This difference makes it hard to compare the performance of used and new tractors. It could be that if smaller, cheaper machinery were available, then owners acquiring it through private channels would use it more efficiently, particularly as tractor fleets continue to age.

Opportunities for multifunctional use of tractors also appear limited in Africa compared with Asia, with some exceptions, such as tractor-powered maize shellers that have become common in Ghana and elsewhere. Although multiple plowing and harrowing is commonly practiced in Asia, including the rainfed area in Bangladesh (Aboagye et al. 2016), and in small parts of Africa to improve overall soil quality given the rainfall patterns (for example, Temesgen et al. 2008), this practice is still rare among most African farmers, limiting the demand at the intensive margins by individual farmers. Additionally, irrigation potential is much lower in Africa than in Asia, limiting opportunities for tractor-powered irrigation. Whereas tractors are used in carting harvested produce in Africa, they are less commonly used for other transport purposes than in Asia. There is also increasing competition from three-wheel motorcycles that are cheaper, more comfortable, and faster than tractors for passenger transportation. Though the three-wheel motorcycles certainly offer important alternatives for rural mechanization, the point here is the changing nature of the multifunctionality potential of tractors. 
There is a need for more in-depth examination of whether and how such multifunctionality can be exploited to enhance utilization from tractor owners' perspective.

Whereas tractor assembly plants in a few African countries have been operated to varying degrees of success, the manufacturing of agricultural machinery has not taken off in Africa on a large scale. In Asia, even in smaller countries without domestic tractor manufacturing such as Bangladesh, Myanmar, Nepal, and Sri Lanka, manufacturers in nearby countries have been able to develop and distribute machinery suitable for local conditions, and most implements other than plows and harrows are often made locally now. In Africa, although such cross-border diffusion of technology should be possible, market failures persist due to various factors. The distance between global manufacturers in emerging countries and Africa, in addition to relatively low aggregate demand continentwide, may still lead to significant transaction costs for the private sector to transfer knowledge and innovate mechanization technology appropriate for Africa.

\section{Implications of the Empirical Analyses}

Importantly, empirical analyses conducted in several chapters of this book support the discussions so far. As described above, the focus areas of empirical analyses covered by selected chapters in this book (Table 1.2) largely fall into three categories: (1) adoption of mechanization, (2) impacts of mechanization (associations between mechanization adoption and various production characteristics such as the production function, productivity, and the use of other inputs), and (3) impacts on income (associations between mechanization adoption and farm/household incomes). Evidence on (1) generally suggests that both conventional demand-side factors (highlighted in PBB) and various supply-side factors are important determinants of mechanization adoption. Furthermore, the importance of agroclimatic conditions, including soil types, for adoption (as shown in the Bangladesh and Nigeria chapters) is linked to the provision of public goods such as better knowledge of spatial distributions of agroclimatic conditions (for example, soil maps).

Evidence on (2) suggests that mechanization is generally associated with more intensive production systems, including greater land cultivation intensity as well as use of yield-enhancing inputs such as irrigation or fertilizer. Quite often, mechanization adoption is associated with greater overall labor use, because the effect of intensification outweighs the substitution effects between machinery and labor. These sets of evidence are linked to various policy recommendations, including public goods such as the development 
of complementary technologies-for example, high-yielding varieties. Furthermore, effects on returns to scale (see the Nepal chapter) suggests that scale effects typically associated with machines are also present, pointing to the importance of developing more efficient land markets that facilitate the exploitation of such scale effects in the medium term.

Evidence on (3) suggests that mechanization often has positive income effects on smallholders. Significant effects of mechanization evidenced by both (1) and (2) have been largely realized through custom hiring services of machines provided by individual machinery owners, suggesting that private custom hiring services are efficient given the currently prevailing knowledge constraints and existing market distortions. These sets of evidence are linked to the importance of further focusing on the efficient promotion of custom hiring services with reduced market distortions, as discussed in this section and the next. Moreover, overall, these sets of evidence suggest that mechanization can be promoted (in an appropriate way) to support smallholders in Africa, and it is also important for achieving inclusive agricultural transformation.

\section{The Role of Government Policy}

Comparing mechanization development in Africa and Asia underscores the many preconditions for the supply of mechanization to meet emerging demand. Although PBB accurately diagnosed the inappropriateness of government schemes to promote mechanization in Africa when demand had not emerged, recent trends do not suggest that supply will spontaneously respond adequately when demand does emerge. Even in Asia, which faced relatively fewer obstacles in supply responses to mechanization than Africa, governments played a critical role in creating an enabling environment and providing public goods in many countries. Although this demonstrates the importance of supportive government policies, recent policies and interventions in Africa have not fared much better than those discussed by PBB. Therefore, such efforts must be judicious and aim to resolve key market failures without distorting private supply channels.

In Asia, governments generally have limited direct interventions to the provision of subsidies and subsidized credit for machinery, and in most cases, such as in India, China, and Thailand, governments have minimized the distortive nature of subsidies by keeping them open to a wide range of equipment and implements and to all who met a transparent set of qualifications (Singh 2006; Diao et al. 2014). 
Rather than emphasizing direct interventions, many governments in Asia focused their efforts on R\&D, whether through developing machinery and implements as a mandate for agricultural engineering institutes or through performing other types of agricultural R\&D such as the development of new seed varieties that make the use of mechanization more efficient. In both Nepal and Nigeria, the adoption of mechanization by smallholders has been positively associated with the availability of improved varieties suitable for their production environment (Takeshima 2017; Takeshima and Liu 2018). As agricultural machinery manufacturers have benefited from the government subsidy policy, subsidies, in turn, have created incentives for manufacturers to develop more varieties of machinery suitable for local conditions, to stimulate demand among farmers. Training and extension in some countries provided by both the public and private sectors helped familiarize farmers with different types of machinery, creating more demand for mechanization. Because of this, government policies that include a subsidy rarely limit the types of machines that farmers adopt or who can become the beneficiaries of the policies, which relatively efficiently avoids distortion in the markets, both for imports and for hiring services, as well as rent-seeking behaviors.

In cases in which early restrictive government policies were in place, mechanization rapidly accelerated when liberalization removed these restrictions. For example, after the liberalization of the Vietnamese economy in the late 1980s, mechanization levels skyrocketed in the following decade. The rapid spread of mechanization in Bangladesh is also generally attributed to the lifting of import restrictions on cheap Chinese engines used to power shallow tube wells and on Chinese-made power tillers (Biggs and Justice 2017; Mandal 2017), although other factors, such as the disaster-triggered decimation of many draft animals, general interest in tractors, and the authoritarian regime at that time, might have also indirectly affected the process. Although the government originally restricted cheaper Chinese engines and power tillers because they were perceived to be of inferior quality to Japanese models, farmers overwhelmingly opted for the "cheap but good enough" Chinese models when liberalization lifted the restrictions (Biggs and Justice 2017). Most recently, the liberalization of the banking system in Myanmar and the country's 2011 land reforms unleashed nascent demand for mechanization that led a majority of farmers in surveyed regions to adopt mechanization for land preparation and 40 percent to do so for harvesting. All of this machinery, which was predominantly low-cost Chinese equipment, was imported from other Asian countries by the private sector. 


\section{Import Policies}

Given that tractors and combine harvesters are not manufactured in Africa, the availability of various options for the importation of machinery is critical. As the Asian cases demonstrate, mechanization typically succeeds in the absence of restrictions and tariffs on machinery. These policies are often put in place to ensure that only high-quality equipment reaches farmers and to protect domestic manufacturing industries where they exist. However, they may limit the uptake of mechanization at key early stages. This is relevant for countries such as Ethiopia, where an enterprise must prove it is an agribusiness enterprise in order to qualify to obtain foreign exchange for importation; both of these policies make the importation process more cumbersome.

Currently, few African countries have import duties on agricultural machinery, but many still have taxes on imported spare parts. Given limited potential to manufacture many of these spare parts in most African countries, there is little justification for such taxes, which can impede the market for spare parts. The import tariff on agricultural machinery parts can affect not only the tractor owner's service provision but also the farmers who hire tractor services. Removing obstacles to dealers' building up of their stocks is very important. Import procedures for machinery also cause delays; in Ethiopia, importing tractors requires an investment license, and machinery must be cleared and purchased within six months for import duties to be waived (World Bank 2012). Although the actual implementation of tax policies, including differentiation between agricultural purposes and others, faces its own challenges, there will likely be a need to consider adjusting tax rates and to better balance tax revenues with improved spare parts availability in the country.

\section{Promotion Policies}

The distortionary effects of premature government promotion of mechanization from the colonial period up to the 1980s are well documented by PBB and others. As they note, government efforts to manufacture, distribute, and hire out tractors were unsuccessful attempts to induce intensification where demand conditions were not sufficient.

Whereas governments' direct involvement in mechanization service provision decreased during the 1990s, some different types of government involvement have picked up in recent years. However, not all of this involvement has been judicious. For example, at least 11 African countries have had government-run or subsidized tractor hiring services this century (Diao, 
Silver, and Takeshima 2016). Such services not only face inherently higher barriers to profitability than those operated by the private sector (including farmers) due to operating costs and the lack of own-farm benefits, but may also crowd out potential private service providers, especially when service charges are below market rates.

Recent attempts by governments to subsidize private hiring schemes have been met with a similar set of challenges. For example, initial iterations of Ghana's Agricultural Mechanization Services Enterprise Center (AMSEC) program and Nigeria's Agricultural Equipment Hiring Enterprise program provided nonfarm enterprises with subsidized loans to purchase tractors for hiring-out services. However, such programs appear to suffer from the same cost disadvantages and misaligned incentives that purely public programs did. In Ghana, there is no evidence that AMSEC programs reduce service charges for plowing, enable farmers to plow greater areas and adopt more modern inputs, or encourage them to acquire similar tractors through a demonstration effect (Benin 2013). Many of the entrepreneurs who obtained governmentimported machinery using AMSEC loans have defaulted because their operations were not profitable (Diao et al. 2014; Houssou, Diao, and Kolavalli 2014). Though formal evaluation of these programs in rigorous studies is needed to shed more light, the potential efficiency consequence of selective targeting of beneficiaries in these programs, among others, remains relevant.

As suggested above, the market failures in African mechanization call for looking for second-best solutions through public sector engagement, particularly in the early stages of mechanization development. Countries can learn from past mistakes and avoid creating government failures in their attempts to replace failed markets in the mechanization process. One example of such learning is discussed in the Ghana chapter, which describes the way the AMSEC program was refined through reducing the barriers to qualify for the subsidy program, widening the selection of machinery available, and introducing a training program for operators under a new concessional loan facility. Though such a program is unlikely to be a panacea for Ghana's mechanization issues, the effort to refine this subsidy program is quite encouraging.

Although government failures have been less pronounced in Asian countries, they have not been free from them, either. Although not included in the set of studied countries in this book, in Pakistan, unexpected changes in the interest rates of government loans to farmers for tractor purchases, as well as uncertainty about tariffs and other pricing policies, reportedly have constituted a significant source of demand uncertainty in the tractor manufacturing industry, leading to efficiency losses (Andrabi, Ghatak, and Khwaja 2006). 
Government failures like the creation of such uncertainty should be avoided as much as possible in African countries as well.

\section{Public Goods Policies}

One area of government support that played a key role in Asian mechanization and is unlikely to have distortionary effects is the provision of public goods. In Asia, this has consisted of government support to R\&D institutions, which develop and adapt wide varieties of locally appropriate machinery, often in collaboration with domestic private sectors, as has been the case in India (Singh 2006; Diao et al. 2014), Sri Lanka, and Thailand (see chapters), as well as in international organizations (Thailand chapter).

$\mathrm{R} \& \mathrm{D}$ elsewhere in agriculture has also been important for mechanization. For example, as was mentioned earlier, improvements in rice varieties appear to have stimulated demand for tractor plowing in Nepal, Viet Nam, and Thailand (see chapters). This occurs both through technical improvements that make mechanization feasible-such as improved varieties that respond better to more intensive tillage, are suitable for mechanical reaping, or permit more frequent cropping-as well as through yield increases that promote further intensification. Investment in broader agricultural R\&D, including the continuous development and commercialization of a newer generation of improved seed varieties, has been limited in most African countries compared with Asia (Beintema and Stads 2017), which can further limit opportunities for intensification and thus mechanization. R\&D on agronomy is also relevant even for the rainfed one-crop systems that dominate Africa. For example, the transfer of intensive land preparation to the rainfed rice system in Ghana has raised the returns on mechanization (deGraft-Johnson et al. 2014).

Coordination, which was briefly touched upon earlier, is also an intangible public good that governments could provide to overcome market failures in certain cases. Although the private sector also plays a role in providing efficient coordination at the local level, such coordination at a more regional level or coordination combined with public goods, such as information and infrastructure, tend to be undersupplied by the private sector alone. Yang and others (2013); Zhang, Yang, and Reardon (2017); and the China chapter describe local governments' involvement in enabling combine harvester owners to link with customers in remote provinces, transport their machines, and distribute free harvesting information. Moreover, when the number of migratory service providers rose, the local government devolved its role from directly escorting combine operators to helping them to form groups. This is not to say that such a model would be easily adoptable in Africa; certainly, demand for combine 
harvesting is scarce except in a few cereal systems. However, local governments could learn from this case as an example of providing commonsense, demanddriven services to help meet demand by overcoming previous market failures. This could be especially relevant given the pervasiveness of hiring market failures in Africa compared with Asia. Lack of coordination at the rural community level among smallholders in farming will be an increasingly significant barrier for mechanization as more farming activities are mechanized. Local governments can adopt a problem-solving approach, helping farmers overcome collective action problems where they arise. Farm-based organizations, cooperatives, and other types of collective actions are encouraged and promoted by African countries' governments. Encouraging such organizations to own tractors is shown in the literature to be less efficient than encouraging individual ownership, due to the moral hazard issue and other failures in collective actions. Instead, such organizations can be considered as institutional mechanisms for promoting local coordination in crop planting and harvesting. This will possibly help small farmers access hiring services.

There have also been mechanization R\&D success stories in Africa, such as the ASI thresher in Senegal, as well as some cases such as Tinkabi and Kabanyolo tractors. Tanzania has a government institution dedicated to designing and modifying equipment for local use, although it is unclear how successful its designs have been. Nevertheless, most countries lack institutions with the mandate and capability for such functions. However, the development and introduction of more appropriate types of equipment depend heavily on knowledge that is largely missing, such as knowledge of specific localized soil conditions. Investments in soil mapping not only could help in adapting machinery to local conditions and determining optimal tractor sizes, but also could help countries move from a blanket promotion of fertilizer to integrated soil fertility strategies. Similarly, increased R\&D on ergonomics, or more broadly the R\&D on demand for drudgery reduction, among other topics, is likely to be important for Africa from a welfare enhancement perspective (Kahan, Bymolt, and Zaal 2018).

Public investments for raising smallholder productivity remain important also given the patterns of farmland investments in Africa. The concerns regarding growing commercial farmland investments after the global food price hike (for example, Byerlee and Deininger 2013) have been partly tempered as domestic, rather than foreign, actors have become major investors (Jayne et al. 2016), and these medium-size farmers have become important providers of mechanization services to neighboring smallholders (Diao, Silver, 
and Takeshima 2016). At the same time, the system that has evolved has been the coexistence of medium-scale farmers and smallholders, rather than a more rapid takeover by larger-scale farmers, and such coexistence has been partly facilitated by the custom hiring market for mechanization services. To the extent that exogenously raising smallholder productivity raises the returns from more intensive land preparation and thus raises demand for custom hiring of mechanization services, public investments to raise smallholder productivity are likely to complement private investments in machinery by medium-size farmers in Africa (Byerlee and Deininger 2013).

\section{Institutional Development and Capacity Enhancement Policies}

As discussed earlier in this chapter, both market failures and government failures can affect mechanization development, and the public sector (national government, regional and international organizations, and so on) plays important roles in mitigating the market failures. In Asia, the national governments and national agricultural research institutes often played important roles in monitoring the status of agricultural mechanization in countries, through means including a tractor census or collection of other data describing the status of various aspects of mechanization-sector development. Asia also had a greater number of advanced educational institutions in agriculture, including state agricultural universities, which had been established as early as the 1950s and 1960s, often more than three decades prior to such development in Africa, and which contributed to the generation of new agricultural knowledge tailored to local conditions (Lele and Goldsmith 1989; FARA 2014). Professional bodies of agricultural engineers, agricultural economists, or commercial farmers had also long been established in Asian countries, often dating back to the 1940s and the 1950s, and can play important roles in policy advocacy for agricultural mechanization. Capacity of similar bodies is relatively weak in Africa and needs to be strengthened, through means including greater regional concentration and enhanced analytical capacity to generate required evidence on mechanization-sector issues with methodological rigor (Lantin 2013; FARA 2014).

At the same time, the rich set of information generated by the national organizations has been extensively exchanged at the forums offered by international and regional organizations. These organizations have included the Regional Network for Agricultural Machinery (established in 1974 with support of the United Nations Development Programme, FAO, and the United Nations Industrial Development Organization), the United Nations Asian 
and Pacific Centre for Agricultural Engineering and Machinery (a regional institution of the United Nations Economic and Social Commission for Asia and the Pacific, which became the Centre for Sustainable Agricultural Mechanization in 2004), and the Asian Productivity Organization. The CGIAR system, including centers such as the International Rice Research Institute and the International Crops Research Institute for the Semi-Arid Tropics, also contributed not only to conducting R\&D on machine designs and performance but also to knowledge transfer across countries (outcomes of which were documented extensively in reports such as IRRI 1978, 1983, 1986). Sufficient capacity of the national organizations to gather, process, and sometimes analyze relevant mechanization information in the countries has complemented investments in international/regional organizations. Substantial national-level information on the mechanization sector and other information on the agricultural sector is also likely to have enabled regional and institutional organizations to effectively assist each country in formulating sound agricultural mechanization strategies.

Importantly, these institutional efforts in Asia have also been complemented by significant private-sector R\&D and innovation. Scholars have argued that mechanical research, compared with biological research such as plant breeding, has been driven significantly more by the private sector than the public sector (Evenson and Binswanger 1978, 201). This is because the mechanization research is generally less tied to basic science and instead relies significantly on long-established physical and metallurgical principles that do not vary much across geographic regions. As a result, the private sector in each country is given much scope to conduct applied research using those longestablished principles (Evenson and Binswanger 1978, 201). The process of such adaptive research has been documented from early on in India, where significant exposures to foreign mechanical technologies through importation stimulated later manufacturing of indigenous tractors that are more suitable for Indian conditions (Morehouse 1980; Ito 1986; IRRI 1983; Bell, Dawe, and Douthwaite 1998). An older history of power tiller manufacturing is also documented in Japan (Francks 1996). Such active innovations in the private sector in Asia are likely to have complemented the regional institutions as well, by providing more knowledge and relevant information about the technologies that can be transferred across countries. The efforts to strengthen similar institutions that can effectively support mechanization in Africa will require substantially mobilizing the potential of private-sector innovations, including those that originate from traditional small businesses. 


\section{Africa's Path Forward: Lessons from Asia and the Past}

The evolution of farming systems in Africa over the past 30 years and deepening labor constraints suggest that there is a rising demand for agricultural mechanization across a wide geographical area, which has not been sufficiently met by mechanization supply. This stands in stark contrast to Asia, where in many countries even the smallest farms have been rapidly mechanized. This raises the question of whether such a rapid transformation is possible in Africa, and if so, how it can be achieved.

PBB's hypothesis that supply-side constraints are less binding than those from the demand side may hold in the long run, but evidence on this has been weak or, rather, absent, particularly for effects in the short to medium run. Even in some late-adopting countries such as Nepal, indirect evidence suggests that lack of access to custom hiring services may still be a significantly binding constraint, particularly in lowland Nepal, where 4WTs are more common and indivisibility of technologies is still relevant (Nepal chapter). These experiences suggest that in locations where $4 \mathrm{WT}$ are more suitable and common, the overall spread of tractor use requires market development to support a substantial increase in tractor population as well as efficiency improvements in the custom hiring service market. It appears that mechanization growth in Africa is likely to be constrained in the near future at least partly due to the supply-side market failures-and in some cases, policies that exacerbate rather than ameliorate such failures-discussed above. Significantly greater efforts are needed to overcome these market failures while judiciously avoiding the distortionary effects of past interventions. Importantly, as in Asia, mechanization needs in Africa are not uniform and there is no unique solution that can apply to all contexts. These needs will differ not only between countries but among agricultural systems within countries as well. Appropriate solutions will require focusing not only on the needs of farmers in different systems but also on the constraints faced by a group of farmers who are potential suppliers of mechanization. Their acquisition, operation, and hiring out of agricultural machinery services must be facilitated. Therefore, the aim of this book is to provide policymakers and researchers with more detailed accounts of mechanization development in Asian and African countries, and to identify where cross-country learning is relevant and where country-specific solutions must be developed. Nevertheless, the following recommendations can be considered across different contexts. 


\section{Demand Must Be Closely Assessed}

First, PBB's predictions have largely held regarding the growth of demand for mechanization in the past three decades. As also described in Appendix 1D, PBB hypothesized that whether tractors can be more profitable than animal traction varies on a case-by-case basis, even if farming systems have reached sufficient intensification levels and animal traction or tractors have become more relevant technologies (PBB's hypothesis 10). Similarly, PBB hypothesized that in relatively land-scarce endowments, including many African countries, advancement in biological technologies may drive the adoption of mechanical technologies (PBB's hypothesis 14). Experiences described in many Asian chapters (for example, Bangladesh, India, Nepal, Thailand, Viet $\mathrm{Nam}$ ) suggest consistent indirect evidence that substantial public $\mathrm{R} \& \mathrm{D}$ in biological technologies, as well as other infrastructure such as roads and irrigation to the extent that they contribute indirectly to biological technologies, preceded and contributed to enhancing demand for mechanization in landscarce, smallholder-dominated environments and, particularly, raised mechanization demand at the intensive margins. Where such investments have been made, experiences suggest that mechanization can be used not only for crops like rice and wheat, but also for crops like sugarcane and maize, as well as root crops, such as cassava (for example, Thailand), even though the mechanization potential for these crops in Africa has been questioned. Whereas rising farm wages are observed across various pockets of African countries, public $R \& D$ and infrastructure investments have remained relatively insufficient. This might have made the demand for mechanization volatile and risky from hiring service providers' perspectives, even though overall demand is rising. Further efforts are needed to investigate whether and where it is beneficial to enhance public investments in technologies that are complementary to mechanization technologies.

\section{Market-Led Hiring Services Must Be Prioritized}

As described above, private hiring services are almost invariably the most efficient method of supplying mechanization services for smaller farms. Hiring markets enable relatively larger-scale (often called "medium-scale") farmers to profitably invest in machines, and smaller farmers to access services. The viability of mechanization service provision depends on the ability of owners to make a substantial lump-sum investment in a machine and achieve efficient utilization rates. Experiences in Africa, including Ghana and Nigeria, suggest that service providers selected by governments have often faced challenges in reaching the break-even level of utilization rates, incurred losses overall 
(including the machine depreciation costs), and been unable to reach an economically sustainable level, while service providers not targeted by the government have been more efficient and achieved utilization rates above break-even points (Ghana and Nigeria chapters). Efforts to make ownership and service provision more viable could focus on widening the selection of available machinery, addressing coordination failures that pose barriers between hiring service providers and consumers, and promoting access to agricultural finance. However, the specifics of such efforts will depend on highly localized factors, and none of these potential solutions are likely to be universally applicable.

Highlighting the market-led hiring services remains important for African countries because many African governments feel pressure to intervene more directly in the selection of beneficiaries for their support programs, including programs that promote hiring-service businesses (for example, Ghana and Nigeria chapters). Targeted subsidies to selected beneficiaries, who are not always selected transparently, can waste public funds by providing machines to owners who do not use them efficiently or could afford them without the subsidy. The experience described in the Viet Nam chapter attests to this phenomenon as well; the significant involvement of government in tractor hiring services intensified during the 1980s through collectivization, but it did not lead to significant tractor use growth, in contrast to the growth in tractor use under the more liberalized system of subsequent decades.

The public sector's role becomes rather important in coordinating functions, as is showcased in the China chapter, such as linking service providers and customers, providing free harvest information, linking with other service providers (such as mobile companies), and waiving of highway tolls, which can potentially induce the emergence of more hiring service providers in competitive ways. Similarly, the role of the development of an enabling environment has been highlighted in the chapter on Myanmar, where improvements in access to financial services following post-2011 reforms led to a surge of machine investments. As the demand for mechanization rose, the strengthening of the land tenure system through issuance of transferable land use rights that can be used as loan collateral, together with partial relaxation of restrictions on the banking sector, is likely to have removed significant constraints on the supply side.

\section{Eliminate Distortions}

On the other hand, programs that arbitrarily select beneficiaries, limit technology choices, and do not provide incentives for machines to be properly 
utilized and maintained are likely to exacerbate existing market failures and encourage rent-seeking behaviors. For the most part, duties on imported machinery have been removed, but it is still important also to exempt spare parts where possible. If subsidies are pursued, they should be wide-ranging and aimed to increase rather than limit exposure to new brands, types of machinery, and implements. As was mentioned earlier, in some Asian countries where subsidies have been provided, subsidy levels have been relatively low and instead been extended to cover a wide range of machines in terms of brands and sizes, among other factors (for example, China and India chapters). Asian countries have also promoted the importation of a broad range of machines at the early stage of mechanization growth, often with fewer trade restrictions. This helped expose the local population to a variety of machines and provided ideas later on for local manufacturing of machines (for example, India and Sri Lanka chapters) or spare parts and attachments (for example, Bangladesh chapter). It also led to a significant inflow of cheaper, "good enough" machines, such as power tillers from manufacturers in neighboring countries (for example, Myanmar chapter). At an early stage, tractor use grew even where regulatory policies were weak in terms of machine quality controls, and appropriate regulatory policies become more relevant to the sector once adoption reached a sufficient scale (for example, Nepal chapter). In contrast, government importation of tractors through concessional loans in Africa in recent years has required equipment to be imported from the donor country and resulted in a limited range of brands, for which supply chains of spare parts and repairs were not developed; these actions risked crowding out private supply channels and led to importing tractors for which supply channels were difficult to develop (Diao et al. 2014; Diao, Silver, and Takeshima 2016). The experiences in countries like Bangladesh and Nepal suggest that African countries can also first focus on liberalizing machine imports to allow the inflow of various types of tractors and machines, and then start investing in regulatory capacity once the adoption reaches certain levels.

Sometimes, focusing the government's intervention on specific brands has the potential to reduce the unit price of tractors due to economies of scale, especially when combined with regional approaches that overcome the small market sizes in certain African countries. Such efforts should, however, still be based on an understanding of the demand in the market for a different set of brands based on a range of factors, including not only the suitability for different soils, but also existing operational and maintenance/repair knowledge, spare parts availability, and so on. For cases in which such analytical capacity of the government is limited, the government's interventions in 
brand selection may need to be seriously questioned against more market-led machine importation.

As mentioned above, mechanization services provided by the private sector, including traditional small business-type service providers, have consistently been more efficient than those provided or subsidized by the government (PBB; Kienzle, Ashburner, and Sims 2013; Diao et al. 2014; Houssou, Diao, and Kolavalli 2014; Diao, Silver, and Takeshima 2016). The experiences described in the Thailand chapter also suggest that the government has often been more effective by keeping private small businesses active, rather than solely through direct intervention focusing on the more modern sector. Providing subsidies to individual farmers to purchase tractors may therefore be more efficient than aiming to promote so-called professional service provision enterprises. When subsidies are in place, care should be taken to widen the range of machinery available to farmers and not crowd out private suppliers. For example, the frequent changes in brands and models imported under different concessional loan arrangements can disrupt the current private supply chains for machines and spare parts, and create uncertainty for private dealers.

We also recognize that efficient, traditional small businesses are important in the processing sectors, although the book does not directly address postharvest operations. For example, some African countries have tried to promote large-scale modern processing facilities, without recognizing that traditional small business-type processors were expected to be more efficient given local constraints such as unreliable paddy supplies-as in the case of rice milling in Nigeria (Gyimah-Brempong, Johnson, and Takeshima 2016). Such attempts to promote large-scale facilities were made despite the fact that the milling sector in Asia has continued to rely on efficiency improvements of small-scale mills (for example, Bangladesh; Reardon et al. 2012).

\section{Identify Appropriate Technology}

Ensuring that appropriate technology can reach farmers and service providers is likely to involve a blend of direct imports of some technologies and their local adaptation. Whereas evidence has been accumulating regarding the agronomic effects of different tillage methods in Africa, the overall evidence was rather mixed in early years (for example, Lal 1993) and has been generally scarce (for example, Sithole, Magwaza, and Mafongoya 2016). Economic studies of different tillage methods, including those comparing different types of tractors, seem scarcer. More research is required to understand whether the tractors used in most African countries are larger than necessary, and 
whether deep plowing by big disc plows is more prevalent than needed, despite its higher cost and possibly damaging effect on soil. While it may take time to change farmers' perceptions of mechanization technology, governments can nevertheless influence the adoption of appropriate technology through demonstration, experiments, and other incentive-promoting interventions for new, more efficient types of machinery and mechanization practices. Agricultural machinery is often sensitive to local conditions, and for many new machines that are less popular in Africa now, such as planters and small harvesters, adaptation to local conditions will be necessary. With proper policy and public funding support, local R\&D institutions can play an important role in adapting imported models to local conditions, developing new designs, educating engineers, and offering extension programs, often in collaboration with the private sector, as is documented in some Asian chapters (for example, the Thailand chapter). The capacity of local artisans to fabricate various implements, such as maize shellers, exists in many countries, but their capacity to fabricate more advanced implements, such as plows or harrows, may need time to develop. Small artisans and manufacturers in low-income Asian countries like Bangladesh and Myanmar have played an important role in local adaptation of many implements, including those that are imported. With proper policies from the government, including financial and technical support, small local manufacturers can play a role equally as important in Africa as the one they played in Asia. Finally, the development of complementary technologies, such as irrigation and rural infrastructure, can also be important for mechanization development.

Although past policy failures show the types of interventions that are unlikely to succeed, relatively little is known about how government interventions can effectively complement the private sector in Africa. To develop an effective government policy to support mechanization, it is important to both identify market failures in mechanization and recognize the risk that inappropriate government interventions may create market distortions that disincentivize the private sector's role in developing mechanization supply chains. As described above and in the country chapters, there have also been cases in which private entrepreneurs and farmer-investors have emerged as relatively efficient mechanization service providers. Gathering more information about these cases, many of which occurred among the traditional small businesses; understanding their business models; and sharing their knowledge is likely to remain an important domain of the government. A deeper understanding of the suitability of different sizes and types of machines under different conditions, of the progression of hiring market dynamics, of better practices 
in mechanization-especially for the promotion of other intensified farming technologies - and of alternatives for overcoming credit constraints are much needed. Given that solutions are likely to be highly localized, effective public-sector support requires not only accounting for different climatic conditions and factor endowments, but also broader economic transformation pathways that effect agricultural transformation, frequent exchanges of experimental knowledge, and mutual learning among African countries.

\section{References}

Aboagye, P. O., A. G. Abubakar, A. I. Adama, A. O. Lawal, and A. A. Musa. 2016. Agricultural Mechanization and South-South Knowledge Exchange: What Can Ghanaian and Nigerian Policymakers and Private Sector Learn from Bangladesh's Experience? Ghana Strategy Support Program Policy Note No. 6 and Nigeria Strategy Support Program Policy Note No. 36. Washington, DC: International Food Policy Research Institute.

Acemoglu, D., S. Johnson, and J. A. Robinson. 2002. "Reversal of Fortune: Geography and Institutions in the Making of the Modern World Income Distribution." Quarterly Journal of Economics 117 (4): 1231-1294.

AfDB (African Development Bank Group). 2016. Feed Africa: Strategy for Agricultural Transformation in Africa 2016-2025. Abidjan, Côte d'Ivoire.

AGRA (Alliance for a Green Revolution in Africa). 2019. The Hidden Middle: A Quiet Revolution in the Private Sector Driving Agricultural Transformation. Africa Agriculture Status Report 7. Nairobi, Kenya.

Agyei-Holmes, A. 2014. "Tilling the Soil in Tanzania: What Do Emerging Economies Have to Offer?" PhD dissertation, International Development Economics, The Open University, UK.

Alsan, M. 2015. "The Effect of the Tsetse Fly on African Development." American Economic Review 105 (1):382-410.

Andrabi, T., M. Ghatak, and A. I. Khwaja. 2006. "Subcontractors for Tractors: Theory and Evidence on Flexible Specialization, Supplier Selection, and Contracting." Journal of Development Economics 79: 273-302.

AUC (African Union Commission). 2018. "African Union Commission Launches the Sustainable Agricultural Mechanization Framework." Press release, October 9. https://au.int/en/press releases/20181009/auc-launches-sustainable-agricultural-mechanization-framework.

Baudron, F., B. Sims, S. Justice, D. Kahan, R. Rose, S. Mkomwa, P. Kaumbutho, J. Sariah, R. Nazare, G. Moges, and B. Gérard. 2015. "Re-examining Appropriate Mechanization in Eastern and Southern Africa: Two-Wheel Tractors, Conservation Agriculture, and Private Sector Involvement." Food Security 7 (4): 1-16. 
Beintema, N., and G. Stads. 2017. A Comprehensive Overview of Investments and Human Resource Capacity in African Agricultural Research. Agricultural Science and Technology Indicators Synthesis Report. Washington, DC: International Food Policy Research Institute.

Bell, M. A., D. Dawe, and M. B. Douthwaite. 1998. Increasing the Impact of Engineering in Agricultural and Rural Development: Deliberations of a Think Tank, 26-28 February 1998, IRRI, Los Bafios, Philippines. IRRI Discussion Paper Series No. 30. Manila, Philippines: International Rice Research Institute.

Benin, S. 2013. Impact of Ghana's Agricultural Mechanization Services Center Program. IFPRI Discussion Paper 01330. Washington, DC: International Food Policy Research Institute.

Biggs, S. D., and S. E. Justice. 2017. "Rural and Agricultural Mechanization: A History of the Spread of Small Engines in Selected Asian Countries." In Rural Mechanisation: A Driver in Agricultural Change and Rural Development, edited by M. A. S. Mandal, S. D. Biggs, and S. E. Justice, 23-76. Dhaka, Bangladesh: Institute for Inclusive Finance and Development.

Binswanger, H. 1986. “Agricultural Mechanization: A Comparative Historical Perspective.” World Bank Research Observer 1 (1): 27-56.

Binswanger, H., and G. Donovan, eds. 1987. Agricultural Mechanization: Issues and Options. Washington, DC: World Bank.

Binswanger-Mkhize, H. P. 2017. "Agricultural Mechanization in Sub-Saharan Africa: A Review." Unpublished draft, Accelerating African Poverty Reduction.

Binswanger-Mkhize, H. P., and S. Savastano. 2014. Agricultural Intensification: The Status in Six African Countries. Policy Research Working Paper No. 7116. Washington, DC: World Bank Group.

Boserup, E. 1965. The Conditions of Agricultural Growth: The Economics of Agrarian Change under Population Pressure. New Brunswick, NJ, US: Transaction Publishers.

Breuer, T., K. Brenneis, and D. Fortenbacher. 2015. "Mechanization-A Catalyst for Rural Development in Sub-Saharan Africa." Rural 2149 (2): 16-19.

Byerlee, D., and K. Deininger. 2013. "Growing Resource Scarcity and Global Farmland Investment." Annual Review of Resource Economics 5:1, 13-34.

Chamberlin, J., T. S. Jayne, and D. Headey. 2014. "Scarcity amidst Abundance? Reassessing the Potential for Cropland Expansion in Africa." Food Policy 48:51-65.

Chapoto, A., N. Houssou, A. Mabiso, and F. Cossar. 2014. Medium and Large-Scale Farmers and Agricultural Mechanization in Ghana: Survey Results. Accra, Ghana: Ghana Strategy Support Program of the International Food Policy Research Institute and Savanna Agricultural Research Institute. 
Christiaensen, L. 2017. “Agriculture in Africa-Telling Myths from Facts: A Synthesis.” Food Policy 67: 1-11.

Culpin, C. 1988. Profitable Farm Mechanization, 2nd ed. Hertfordshire, UK: Granada Publishing. deGraft-Johnson, M., A. Suzuki, T. Sakurai, and K. Otsuka. 2014. "On the Transferability of the Asian Rice Green Revolution to Rainfed Areas in Sub-Saharan Africa: An Assessment of Technology Intervention in Northern Ghana." Agricultural Economics 45 (5): 555-570.

Diao, X., J. Agandin, P. Fang, S. E. Justice, D. S. Kufoalor, and H. Takeshima. 2018. Agricultural Mechanization in Ghana: Insights from a Recent Field Study. IFPRI Discussion Paper 1729. Washington, DC: International Food Policy Research Institute.

Diao, X., F. Cossar, N. Houssou, and S. Kolavalli. 2014. "Mechanization in Ghana: Emerging Demand and the Search for Alternative Supply Models." Food Policy 48: 168-181.

Diao, X., P. Fang, E. Magalhaes, S. Pahl, and J. Silver. 2017. Cities and Rural Transformation: A Spatial Analysis of Rural Youth Livelihoods in Ghana. IFPRI Discussion Paper 1599. Washington, DC: International Food Policy Research Institute.

Diao, X., P. Hazell, S. Kolavalli, and D. Resnick. 2019. Ghana's Economic and Agricultural Transformation: Past Performance and Future Prospects. Oxford, UK: Oxford University Press.

Diao, X., D. Headey, and M. Johnson. 2008. Toward a Green Revolution in Africa: What Would It Achieve and What Would It Require? Agricultural Economics 39 (Supp.): 539-550.

Diao, X., J. Kweka, and M. McMillan. 2019. "Economic Transformation in Africa from the Bottom Up." In The Oxford Handbook of Structural Transformation, edited by C. Monga and J. Y. Lin. Oxford, UK: Oxford University Press.

Diao, X., M. McMillan, and D. Rodrik. 2017. The Recent Growth Boom in Developing Economies: A Structural Change Perspective. NBER Working Paper 23132. Cambridge, MA, US: National Bureau of Economic Research.

Diao, X., J. Silver, and H. Takeshima. 2016. Agricultural Mechanization and Agricultural Transformation. IFPRI Discussion Paper 1527. Washington, DC: International Food Policy Research Institute.

- 2017. Agricultural Mechanization in Africa: Insights from Ghana's Experience. IFPRI Issue Brief. Washington, DC: International Food Policy Research Institute.

Ehui, S., and R. Polson. 1993. "A Review of the Economic and Ecological Constraints on Animal Draft Cultivation in Sub-Saharan Africa." Soil and Tillage Research 27 (1-4): 195-210.

Evenson, R. E., and H. Binswanger. 1978. Technology Transfer and Research Resource Allocation. In Induced Innovation: Technology, Institutions, and Development, edited by H. P. Binswanger and V. W. Ruttan, 164-211. Baltimore: Johns Hopkins University Press. 
FAO (Food and Agriculture Organization of the United Nations). 2016. Agricultural Mechanization: A Key Input for Sub-Saharan African Smallholders. Rome.

- 2018. FAOSTAT database. Accessed May 2018. http://faostat.fao.org.

_.2019a. AQUASTAT database. Accessed December 2019. www.fao.org/nr/water/aquastat /data/query/index.html?lang=en.

- 2019b. World Census of Agriculture. Rome.

FAO, IIASA (International Institute for Applied Systems Analysis), ISRIC (International Soil Reference and Information Centre), ISSCAS (Institute of Soil Science-Chinese Academy of Sciences), and JRC (Joint Research Centre of the European Commission). 2012. Harmonized World Soil Database, vers. 1.2. Rome: FAO; Laxenburg, Austria: IIASA. http://webarchive .iiasa.ac.at/Research/LUC/External-World-soil-database/HTML/.

FAO and CSAM (Centre for Sustainable Agricultural Mechanization). 2014. "Country Pages." Accessed July 2, 2019. http://un-csam.org/cp_index.htm.

FARA (Forum for Agricultural Research in Africa). 2014. Science Agenda for Agriculture in Africa: "Connecting Science" to Transform Agriculture in Africa. Accra, Ghana.

Francks, P. 1996. “Mechanizing Small-Scale Rice Cultivation in an Industrializing Economy: The Development of the Power-Tiller in Prewar Japan." World Development 24 (4): 781-791.

GGDC (Groningen Growth and Development Center). 2019. Africa Sector Database. Accessed on March 28, 2019. www.rug.nl/ggdc/productivity/10-sector/other-releases/africa-sector -database.

Gollin, D., R. Jedwab, and D. Vollrath. 2016. “Urbanization with and without Industrialization.” Journal of Economic Growth 21 (1): 35-70.

Gyimah-Brempong, K., M. Johnson, and H. Takeshima. 2016. The Nigerian Rice Economy: Policy Options for Transforming Production, Marketing, and Trade. Philadelphia: University of Pennsylvania Press. http://ebrary.ifpri.org/utils/getfile/collection/p15738coll2/id/130481 /filename/130692.pdf.

Haggblade, S., P. B. R. Hazell, and T. Reardon. 2007. Transforming the Rural Nonfarm Economy: Opportunities and Threats in the Developing World. Baltimore: Johns Hopkins University Press.

Hayami, Y., and V. Ruttan. 1970. "Factor Prices and Technical Change in Agricultural Development: The United States and Japan." Journal of Political Economy 78 (5): 1115-1141. _. 1985. Agricultural Development: An International Perspective. Baltimore: Johns Hopkins University Press. 
Heckman, J., and E. Vytlacil. 2007. “Econometric Evaluation of Social Programs, Part I: Causal Models, Structural Models and Econometric Policy Evaluation." In Handbook of Econometrics. Vol. 6, 4779-4874. Amsterdam: Elsevier.

Houssou, N., C. Asante-Addo, X. Diao, and S. Kolavalli. 2015. Big Tractors but Small Farms: Tractor Hiring Services as a Farmer-Owner's Response to an Under-Developed Agricultural Machinery Market. Ghana Strategy Support Program Working Paper No. 39. Washington, DC, and Accra, Ghana: International Food Policy Research Institute.

Houssou, N., X. Diao, and S. Kolavalli. 2014. Economics of Tractor Ownership under Rainfed Agriculture with Applications in Ghana. IFPRI Discussion Paper 01387. Washington, DC: International Food Policy Research Institute.

Hunt, D. R. 1983. Farm Power and Machinery Management. Ames: Iowa State University Press. IRRI (International Rice Research Institute). 1978. Proceedings of the International Agricultural Machinery Workshop. Los Baños, Philippines.

- 1983. Consequences of Small-Farm Mechanization. Los Baños, Philippines.

_ 1986. Small Farm Equipment for Developing Countries. Los Baños, the Philippines.

Ito, S. 1986. "Modifying Imported Technology by Local Engineers: Hypotheses and Case Study of India." Developing Economies 24 (4): 334-348.

Jayasuriya, S., A. Te, and R. Herdt. 1986. "Mechanization and Cropping Intensification: Economics of Machinery Use in Low-Wage Economies." Journal of Development Studies 22: $327-335$.

Jayne, T. S., J. Chamberlin, L. Traub, N. Sitko, M. Muyanga, F. K. Yeboah, W. Anseeuw, A. Chapoto, A. Wineman, C. Nkonde, and R. Kachule. 2016. “Africa’s Changing Farm Size Distribution Patterns: The Rise of Medium-Scale Farms." Agricultural Economics 47 (S1): $197-214$.

Johnston, B. F., and J. Mellor. 1961. "The Role of Agriculture in Economic Development." American Economic Review 51: 566-593.

Kahan, D., R. Bymolt, and F. Zaal. 2018. “Thinking Outside the Plot: Insights on Small-Scale Mechanization from Case Studies in East Africa." Journal of Development Studies 54 (11): 1939-1954.

Kienzle, J., J. E. Ashburner, and B. G. Sims, eds. 2013. Mechanization for Rural Development: A Review of Patterns and Progress from around the World. Integrated Crop Management vol. 20-2013. Rome: FAO.

Kormawa, P., G. Mrema, N. Mhlanga, M. K. Fynn, J. Kienzle, and J. Mpagalile, eds. 2018. Sustainable Agricultural Mechanization: A Framework for Africa. Rome: FAO; Addis Ababa: African Union Commission. 
Lal, R. 1993. "Tillage Effects on Soil Degradation, Soil Resilience, Soil Quality, and Sustainability." Soil and Tillage Research 27 (1-4): 1-8.

—. 2004. “Carbon Emission from Farm Operations." Environment International 30:981-990.

Lantin, R. 2013. “Information Exchange and Networking: The RNAM Experience.” In Mechanization for Rural Development: A Review of Patterns and Progress from around the World, edited by J. Kienzle, J. E. Ashburner, and B. G. Sims. Rome: FAO.

Lawrence, P. R., and R. A. Pearson. 2002. "Use of Draught Animal Power on Small Mixed Farms in Asia." Agricultural Systems 71 (1): 99-110.

Lele, U., and A. A. Goldsmith. 1989. “The Development of National Agricultural Research Capacity: India's Experience with the Rockefeller Foundation and Its Significance for Africa." Economic Development and Cultural Change 37 (2): 305-343.

Malabo Montpellier Panel. 2018. Mechanized: Transforming Africa’s Agriculture Value Chains. Dakar, Senegal.

Mandal, M. A. S. 2017. "Growth of Mechanization in Bangladesh Agriculture: Role of Policies and Missing Links." In Rural Mechanization: A Driver in Agricultural Change and Rural Development, edited by M. A. S. Mandal, S. D. Biggs, and S. E. Justice. Dhaka, Senegal: Institute for Inclusive Finance and Development.

Mclntire, J., D. Bourzat, and P. Pingali. 1992. Crop Livestock Interactions in Sub-Saharan Africa. Washington, DC: World Bank.

McMillan, M., D. Rodrik, and I. Verduzco-Gallo. 2014. "Globalization, Structural Change, and Productivity Growth, with an Update on Africa." World Development 63: 11-32.

Morehouse, W. 1980. “Technology and Enterprise Performance in the Indian Tractor Industry: Does Self-Reliance Measure Up?” Economic and Political Weekly 15 (51): 2139-2152.

Mpanduji, S. M. 2000. "Repair Cost of Tractors and Comparison of Mechanization Strategies under Tanzanian Conditions." PhD dissertation, Technical University of Munich, Germany.

Mrema, G. C., D. Baker, and D. G. Kahan, eds. 2008. Agricultural Mechanization in SubSaharan Africa: Time for a New Look. Agricultural Management, Marketing and Finance Service Occasional Paper No. 22. Rome: Rural Infrastructure and Agro-industries Division, FAO.

Mrema, G., J. Kienzle, and J. Mpagalile. 2018. "Current Status and Future Prospects of Agricultural Mechanization in Sub-Saharan Africa (SSA)." Agricultural Mechanization in Asia, Africa and Latin America 49 (2): 13-30.

Naudé, W. A. 2011. "Entrepreneurship Is Not a Binding Constraint on Growth and Development in the Poorest Countries." World Development 39 (1): 33-44. 
Ngeleza, G. K., R. Owusua, K. Jimah, and S. Kolavalli. 2011. Cropping Practices and Labor Requirements in Field Operations for Major Crops in Ghana. IFPRI Discussion Paper 01074. Washington, DC: International Food Policy Research Institute.

Nin-Pratt, A., and L. McBride. 2014. "Agricultural Intensification in Ghana: Evaluating the Optimist's Case for a Green Revolution." Food Policy 48: 153-167.

Olmstead, A. L., and P. W. Rhode. 2001. "Reshaping the Landscape: The Impact and Diffusion of the Tractor in American Agriculture, 1910-1960." Journal of Economic History 61 (3): 663-698.

Otsuka, K. 2019. "Technology Transfer and Agricultural Development: A Comparative Study of Asia and Africa." In Paths to the Emerging State in Asia and Africa, edited by K. Otsuka and K. Sugihara, 35-54. Amsterdam: Springer.

Pingali, P. 2007. “Agricultural Mechanization: Adoption Patterns and Economic Impact." In Handbook of Agricultural Economics. Vol. 3, edited by R. Evenson and P. Pingali, 2779-2805. Amsterdam: Elsevier.

Pingali, P., Y. Bigot, and H. Binswanger. 1987. Agricultural Mechanization and the Evolution of Farming Systems in Sub-Saharan Africa. Baltimore: Johns Hopkins University Press.

Reardon, T., K. Z. Chen, B. Minten, and L. Adriano. 2012. The Quiet Revolution in Staple Food Value Chains in Asia: Enter the Dragon, the Elephant, and the Tiger. Manila, Philippines: Asian Development Bank; Washington, DC: International Food Policy Research Institute.

Rijk, A. G. 1986. "The Role of Farm Mechanization in Developing Countries: Experiences in Asian Countries." In Small Farm Equipment for Developing Countries, 3-22. Los Baños, Philippines: International Rice Research Institute.

Rodrik, D. 2007. One Economics, Many Recipes: Globalization, Institutions and Economic Growth. Princeton, NJ, US: Princeton University Press.

Rodrik, D. 2016. “An African Growth Miracle?” Journal of African Economies 27 (1): 10-27.

Ruthenberg, H. 1980. Farming Systems in the Tropics, 3rd ed. Oxford, UK: Clarendon Press.

Singh, G. 2006. Agricultural Machinery Industry in India (Manufacturing, Marketing and Mechanization Promotion). New Delhi: Indian Agricultural Statistics Research Institute.

Sithole, N. J., L. S. Magwaza, and P. L. Mafongoya. 2016. "Conservation Agriculture and Its Impact on Soil Quality and Maize Yield: A South African Perspective." Soil and Tillage Research 162: 55-67.

Steckel, R. H., and W. J. White. 2012. Engines of Growth: Farm Tractors and Twentieth-Century US Economic Welfare. NBER Working Paper 17879. Cambridge, MA, US: National Bureau of Economic Research. 
Ströh de Martinez, C., M. Feddersen, and A. Speicher. 2016. Food Security in Sub-Sabaran Africa: A Fresh Look on Agricultural Mechanization. Study 91. Bonn: German Development Institute.

Takahashi, K., and K. Otsuka. 2009. "The Increasing Importance of Nonfarm Income and the Changing Use of Labor and Capital in Rice Farming: The Case of Central Luzon, 19792003." Agricultural Economics 40 (2): 231-242.

Takeshima, H. 2015. Market Imperfections for Tractor Service Provision in Nigeria. IFPRI Discussion Paper 01424. Washington, DC: International Food Policy Research Institute.

- 2017. The Roles of Agroclimatic Similarity and Returns to Scale in Demand for Mechanization: Insights from Northern Nigeria. IFPRI Discussion Paper 01692. Washington, DC: International Food Policy Research Institute.

Takeshima, H., J. Agandin, and S. Kolavalli. 2017. Growth of Modern Service Providers for the African Agricultural Sector: An Insight from a Public Irrigation Scheme in Ghana. IFPRI Discussion Paper 01678. Washington, DC: International Food Policy Research Institute.

Takeshima, H., and Y. Liu. 2018. The Role of Plant-Breeding R\&D in Tractor Adoption among Smallholders in Asia: Insights from Nepal Terai. IFPRI Discussion Paper 01719. Washington, DC: International Food Policy Research Institute.

Temesgen, M., J. Rockstrom, H. H. G. Savenije, W. B. Hoogmoed, and D. Alemu. 2008.

"Determinants of Tillage Frequency among Smallholder Farmers in Two Semi-Arid Areas in Ethiopia." Physics and Chemistry of the Earth, Parts A/B/C 33 (1-2), 183-191.

Timmer, P. 1988. “Agricultural Transformation." Handbook of Development Economics 1:275-331.

Tschirley, D., T. Reardon, M. Dolislager, and J. Snyder. 2015. “The Rise of a Middle Class in East and Southern Africa: Implications for Food System Transformation.” Journal of International Development 27 (5): 628-646.

Turner, M. D. 2016. "Rethinking Land Endowment and Inequality in Rural Africa: The Importance of Soil Fertility." World Development 87: 258-273.

USDA ERS (United States Department of Agriculture Economic Research Service). 2018. International Agricultural Productivity Project. Washington, DC.

Wei, S., Z. Xie, and X. Zhang. 2017. “From 'Made in China' to 'Innovated in China': Necessity, Prospects, and Challenges." Journal of Economic Perspective 31 (1): 49-70.

Woodhouse, P. 2009. “Technology, Environment and the Productivity Problem in African Agriculture: Comment on the World Development Report 2008." Journal of Agrarian Change 9 (2): 263-276.

World Bank. 2007. World Development Report 2008: Agriculture for Development. Washington, DC. -2012. Agribusiness Indicators: Ethiopia. Washington, DC. 
- 2014. Agribusiness Indicators: Synthesis Report. Agriculture Global Practice Discussion Paper 01. Washington, DC.

Yang, J., Z. Huang, X. Zhang, and T. A. Reardon. 2013. “The Rapid Rise of Cross-Regional Mechanization Services in China." American Journal of Agricultural Economics 95 (5): 1-7.

You, L., C. Ringler, U. Wood-Sichra, R. Robertson, S. Wood, T. Zhu, G. Nelson, Z. Guo, and Y. Sun. 2011. "What Is the Irrigation Potential for Africa? A Combined Biophysical and Socioeconomic Approach." Food Policy 36 (6): 770-782.

Zander, R., C. Miller, and N. Mhlanga. 2013. Credit Guarantee Systems for Agriculture and Rural Enterprise Development. Rome: FAO.

Zhang, X., J. Yang, and T. A. Reardon. 2017. "Mechanization Outsourcing Clusters and Division of Labor in Chinese Agriculture." China Economic Review 43: 184-195.

Zhang, X., J. Yang, and S. Wang. 2011. "China Has Reached the Lewis Turning Point." China Economic Review 22 (4): 542-554. 



\section{PART 2}

\section{Early-Adopter Asian Countries}





\title{
MECHANIZATION OUTSOURCING CLUSTERS AND DIVISION OF LABOR IN CHINESE AGRICULTURE
}

Xiaobo Zhang, Jin Yang, and Thomas Reardon

\begin{abstract}
Despite small landholdings, a high degree of land fragmentation, and rising labor costs, agricultural production in China has steadily increased. If one treats the farm household as the unit of analysis, it is difficult to explain the conundrum. When seeing agricultural production through the lens of the division of labor, the puzzle can be easily solved. In response to rising labor costs, farmers outsource some power-intensive stages of production, such as harvesting, to specialized mechanization service providers, which are often clustered in a few counties and travel throughout the country to provide harvesting services at competitive prices. Through such an arrangement, smallholder farmers can stay viable in agricultural production.
\end{abstract}

\section{Introduction}

In The Wealth of Nations, Adam Smith ([1776] 1976) emphasized the gains from specialization arising from two types of division of labor. The first type is division of labor within the firm, as famously illustrated in the example of pin making in a workshop, where 10 workers, each doing a specialized task of the set of tasks to make a pin, could make hundreds of times more per day than the 10 workers working independently, each doing all the tasks. The second type refers to division of labor across producers, as shown in the linen shirt example in Smith's book. The production of linen shirts is dispersed over many workshops. Smith posited that market size determines the division of labor. Due to a lack of scale, the division of labor in agricultural production is not as common as in industrial production.

Marshall echoed Smith's viewpoints in his Principles of Economics:

In agriculture there is not much division of labor, and there is no production on a very large scale; for a so-called "large farm" does not employ a tenth part of the labor which is collected in a factory of moderate dimensions. $(1920,167)$ 
The latter vision of farming - and its implications for the division of labor and mechanization - was manifest again in Asia from the 1950s to the present. Ruttan (2001) put forward nearly the same ideas and terms as Smith and Marshall. He emphasized that using machines for the series of short tasks on tiny farms would imply costly investment in specialized machinery that small farmers would be loath to make. Though recognizing the important role of mechanization in various steps of agricultural production, Pingali held a similarly pessimistic view on rice harvesting mechanization in Southeast Asian countries:

In the absence of land consolidation and the re-design of the rice land to form large contiguous fields, the prospects for large-scale adoption of the harvester-combines are limited. $(2007,2790)$

Otsuka (2012) went further along those lines to note that only on larger farms would the mechanization investment, at least for large machines, pay off to farmers-and thus the path to efficient mechanization must have as a first step a sharp increase in Asian farm size from the current 1- to 3-ha average to considerably more. Given that China's farm size is only one-third that of Japan, he warned that Chinese agriculture would likely repeat the path of Japan, relying heavily on subsidies and experiencing low growth in labor productivity.

Standing in contrast to the above prognosis for the Asian small farm sector to develop a division of labor and to mechanize, this chapter shows that China - with farm sizes averaging only about 0.5 ha-has both evolved a division of labor and experienced rapid farm mechanization. There is a paradox: despite rapid increase in real wages in the past decade, China has seen steadily climbing farm output and yields. We show that the explanation for the paradox is that since circa 2004, there has been rapid farm mechanization in the form of both ownership and rental of machines, plus rapid development of farm mechanization "outsourcing" services that combine the provision of specialized labor and the services of large harvesting machines. The increasing trend of outsourcing mechanization services primarily reflects the second type of division of labor defined by Adam Smith. Although at the farm level the scale of production is small, certain stages of production, such as harvesting, can be undertaken at a much larger scale, allowing for a division of labor between farmers and mechanization service providers to take place.

This chapter focuses on the second type of division of labor in Chinese agricultural production, in particular the emergence of a cluster of farmer cooperatives that sell outsourced harvesting services (because harvesting is 
the most "heavy" of the tasks in agricultural production) across provinces for up to eight months a year. By participating in a national labor-cum-machine services market, these migratory specialized mechanization service providers have overcome the small scale of agricultural production at the farm level logically identified by the economists cited above. This has precedent; for example, Akinola (1987) documented how the operators of tractors traveled across regions to provide land preparation services in the 1970s and 1980s in Africa. Even in the United States, where farm size is much larger than in many developing countries, migratory wheat harvesting services were present a century ago, serving farms that were smaller than those in existence today and farmers who did not yet own their own machinery (Olmstead and Rhode 1995). ${ }^{1}$

This chapter makes two contributions. First, the chapter shows that for China, agricultural production can be as divisible as industrial production; this point has been largely neglected in the literature. When looking at production of small farmers through this lens, one can see that farm size becomes less of a limiting factor on scaling up production if some steps of production can be outsourced. Although our chapter is about China, the findings may shed some light on the debate as to whether smallholder farmers are efficient in developing countries in general and countries in Africa south of the Sahara in particular, a topic much debated recently, for example by Collier and Dercon (2013).

Second, the chapter contributes to the literature on agricultural mechanization. In the 1980s there was a wave of literature on mechanization and farming systems change in the wake of the Green Revolution (for example, Binswanger 1986; Jayasuriya and Shand 1986; Jayasuriya, Te, and Herdt 1986). After a mainly dormant period of some three decades, there has been a second wave of literature on mechanization (for example, Takahashi and Otsuka 2009; Pingali 2007; Diao et al. 2012). An important motivation for the second wave of literature has been, as, for example, Takahashi and Otsuka (2009) noted, that a spur toward and acceleration of mechanization have been driven, on the capacity side, by investment from the investable surplus from the Green Revolution and in labor market development from the rapid spread of rural nonfarm and migration employment, and on the incentive side, by the rural wage increase prompted by this labor market development. This second wave has treated the surge in machine ownership and conventional rental,

1 See, for example, US Custom Harvesters Inc., at uschi.com. Interestingly, farmers in the United States outsource not only mechanization services but also pollination services. Migratory beekeepers provide pollination services to commercial fruit and nut producers from one area to another (Chang 1973; Muth et al. 2003). 
but not yet the relatively new arrangement of outsourced services provided pan-territorially and pan-seasonally by clusters of service providers, as has been the case in China over the past two decades. This chapter extends Yang and colleagues (2013) by offering more detailed information about the inner workings of mechanization harvesting service clusters, and by developing a conceptual framework to understand the underlying mechanism.

The chapter proceeds as follows. The following section explores in greater detail the three trends noted above. The next section explains the economics of mechanized harvesting services, followed by a section that describes the supply of mechanized services based on a primary survey in Peixian county in Jiangsu province, China. The survey covers farmer cooperatives supplying migratory labor-cum-machine services to a number of provinces in China. A final section concludes.

\section{The Chinese Agricultural Paradox and Mechanization}

There is a paradox in Chinese agriculture in the past three decades-despite the small farm size and massive exodus of labor out of agricultural production, farm output has steadily gained over time. This section explores and explains this paradox and its relation to mechanization.

\section{Farm Labor Drain}

In 1978, more than 92 percent of the Chinese population worked in agriculture, on farms; this rural population density and high share of population in agriculture was partly because the country was much poorer at that time than now (and the share of population in agriculture is typically inversely related to countries' income per capita; see Timmer 1988) and partly due to the restriction of labor mobility by the household registration system implemented in the 1950s (Lin et al. 2008).

Although the country's rural population density is still relatively high, and farms average about 0.5 ha (one of the lowest sizes in the world), from 1978 to today, there has been a massive drop in the share of the population operating farms. In 2005, the Organization for Economic Co-Operation and Development estimated that only 40 percent of China's labor was in agriculture (McGregor 2005). This change has happened for three reasons.

First, in the past three decades there has been a rapid rise in rural nonfarm employment, complementing farm household incomes but also pulling labor time from farms and farm households out of farming. This has 
been spurred at least in part by the emergence of "rural industrialization." Lin and Yao (2001) noted that from 1978 to 1997, the number of rural enterprises (owned by individuals and by the government) jumped from 1.5 million to 20.2 million. Moreover, rural industry was less than 10 percent of rural employment and 8 percent of rural income in 1978, but by 1996 it accounted for 30 percent of rural employment and 34 percent of rural income (Lin and Yao 2001). (Note that these figures underestimate rural nonfarm employment because in addition to rural manufacturing there is also substantial rural service-sector activity.)

Second, as China's cities grew and manufacturing and services boomed in the cities, there was a massive rural-to-urban migration over the 1990s and 2000s. Before 1990, the government had strict limits on urban household registration, greatly blocking rural migration to cities (Green 2008). During the 1990 s, the government gradually liberalized urban household registration restrictions, with a nearly full liberalization by the end of the 1990s. Besides this "rural labor release" factor, there was a push factor for migration, to wit, tiny farms, kept small by disallowance of farm sales and limitations on land rental. ${ }^{2}$ There was also a large pull factor for migration - the rapid growth of cities, and urban industry and construction. The result was that the stock of rural-to-urban migrants went from around 30 million in the late 1980s to 150-180 million by the late 2000s (Fan 2009).

Third, China's stringent one-child policy, introduced in the late 1970s, caused the natural population growth rate to decline from 2.58 percent in 1970 to 0.48 percent in 2012. As a result, China's working-age labor force, including workers in rural areas, started to shrink in $2012 .^{3}$

That shift of labor out of agriculture induced many media reports on labor shortages. It also contributed to wage increases: Zhang, Yang, and Wang (2011) reported that real wages had started to accelerate in 2003/2004, suggesting that the era of Lewis-type surplus labor had come to an end. ${ }^{4}$

\section{Farm Output Growth}

The above narrative chronicles a massive loss of rural people working on farms, in both the coastal and the interior provinces. This was not much

2 Deininger and Jin (2009) noted, however, that these rental limitations were gradually reduced in the 2000s.

3 See https://www.economist.com/free-exchange/2012/01/23/one-billion-workers.

4 For the original idea, see Lewis (1954). 
compensated by rural population increase. Moreover, most of those who left farming were younger workers, the most physically productive.

Despite the fall in farm labor and rise in wages, rice yields in tons ${ }^{5}$ per hectare went up from about 4 in 1978 to 6.8 in 2012; wheat yields increased by 178 percent, from about 1.8 tons per hectare in 1978 to 5.0 tons per hectare in 2012; and maize yields more than doubled, from 2.8 tons to 6.0 tons per hectare (NBS 2013).

The decrease in farming labor per se does not lower agricultural output. Some early literature (Lewis 1954; Pingali 2007) contended that declining farm labor does not necessarily cause a fall in farm production in developing countries. In fact, Lewis (1954) argued that the farm (and nonfarm) sector in underdeveloped economies employs a large number of "messengers," whose contribution to production is almost negligible and hence the marginal productivity of their labor is negligible. When the supply of rural labor to the manufacturing sector is unlimited, the marginal productivity of labor in farming remains negligible.

However, when a country passes the so-called Lewis turning point, when surplus labor is exhausted, a drop in the farm labor force would in principle harm agricultural productivity. Since 2003/2004, real wages in China have grown by more than 10 percent per year, indicating that the era of Lewis-type surplus labor has come to an end (Zhang, Yang, and Wang 2011), meaning that decreasing labor input to farm fields during this stage should cause little harm to land productivity. Despite rapidly rising real wages since 2003/2004, agricultural productivity has grown at the same pace as in the period prior to the arrival at the Lewis turning point. In principle, rising labor cost would have significantly increased the cost of agricultural production, dragging down its growth. This is a puzzle.

\section{The Puzzle Explained: The Rapid Rise of Farm Mechanization}

Figure 2.1 shows that from 1978 to 2012, farm machinery usage, proxied by kilowatts of energy expended by the machines, rose sevenfold, from about 150 million $\mathrm{kW}$ in 1978 to more than 1 billion $\mathrm{kW}$ in 2012. In a rough calculation, noting that each unit of mechanical horsepower is equal to 0.75 $\mathrm{kW}, 1$ billion $\mathrm{kW}$ comes to about 750 million hp of farm machinery. A smallish power tiller operates on $6 \mathrm{hp}$, so that would mean the equivalent of 118 million small tillers. In any case, the increase in farm machine use was massive. Interestingly, the increase in machinery use was a fairly smooth trend

5 "Tons" refers to metric tons throughout the chapter. 
FIGURE 2.1 Number of agricultural workers and amount of machinery power, China, 1978-2012

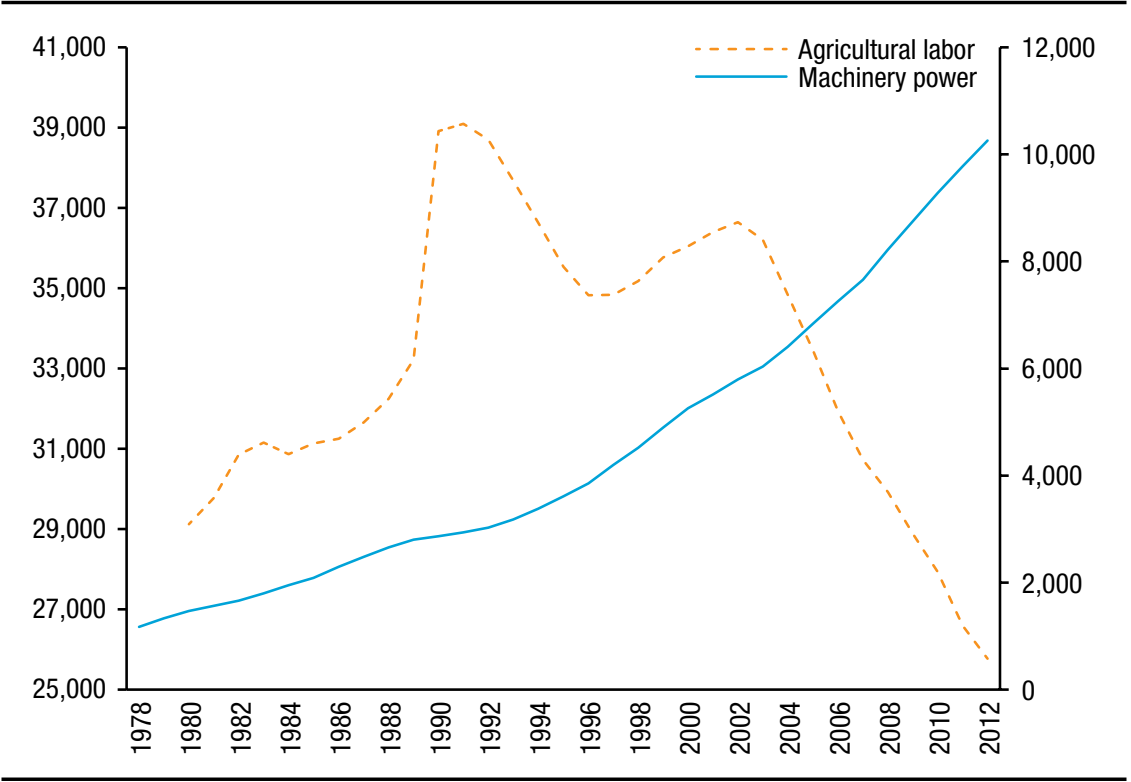

Source: Authors, based on data from China Statistical Yearbook (NBS 2011).

Note: Unit of machinery power is $100,000 \mathrm{~kW}$. Number of workers (left axis) is in 10,000.

over those decades, implying that machinery use was rising quickly in the 1980s and 1990s, as off-farm labor use rose. Yet that rise of machine use did not accelerate in the mid-2000s, when farm wages started to rise sharply in what has been identified as the Lewis turning point in China (Zhang, Yang, and Wang 2011). This suggests that rural households were facing farm-level labor constraints in the agricultural peak seasons before the arrival at the Lewis turning point.

We posit that mechanization services are provided by outside sources to farmers who do not own machinery. To test this hypothesis, we use data from the panel household survey done by the Research Center for the Rural Economy (RCRE) of the Ministry of Agriculture. The RCRE dataset includes detailed information on actual input use in agricultural production. Machinery use was not added to the questionnaire until 2004. In the empirical analysis, we use panel data from 2009 to 2012, covering 49,301 households.

When evaluating the effect of mechanization input on agricultural production, we also need to control for other input factors (Pingali 2007), such 
as seed, fertilizer, and pesticide. Table 2.1 presents the summary statistics of both output and input variables used in the regressions. As shown in Panel A for wheat, both output and planting area declined from 2009 to 2012, by 1.24 percent and 2.13 percent per year, respectively. Yield increased by 0.91 percent per year in the sample period.

The contraction of rice production was more pronounced than that of wheat. Total production per farm dropped by 3.43 percent per year, whereas rice acreage per farm declined by 3.35 percent per year. Rice yields witnessed a decline from 7.25 tons per hectare in 2009 to 7.23 tons in 2012. In comparison, maize output, planting area, and yield all experienced growth in the same period. The annual growth rate of maize yield was 3.94 percent. This is likely associated with the demand shift as per capita consumption of wheat and rice declined, whereas meat consumption, which drives up demand for maize, increased.

In the same period, labor input actually declined from 36 days to 33 days in wheat, from 55 to 48 days in rice, and from 46 to 42 days in maize production. The expenditure on machinery use jumped by 9.14 percent, 13.28 percent, and 13.96 percent per year for wheat, rice, and maize, respectively. Apart from machinery expenditures, other nonlabor inputs (seed, fertilizer, and pesticide) have also grown rapidly, in particular pesticide cost for wheat, and seed expenditure for rice and maize. It appears that the increasing expenditure on nonland inputs has offset the decline in labor use.

Using the RCRE panel dataset, we estimate the following Cobb-Douglas production function at the household level and quantify the contribution of various inputs to agricultural production:

$$
\begin{aligned}
& y=\beta_{0}+\beta_{1} \text { land }+\beta_{2} \text { labor }+\beta_{3} \text { seed }+\beta_{4} \text { fertilizer }+\beta_{5} \text { pesticide } \\
& +\beta_{6} \text { machine }+\beta_{7} \text { demographic }+\varepsilon,
\end{aligned}
$$

where land is the cropping area of grain; seed, fertilizer, and pesticide inputs are measured in value terms in constant 2009 US dollar-based prices; and machine refers to the machinery rental cost. These variables are all in natural logarithms. In addition, we include the household head's age and education to reflect household characteristics.

Table 2.2 presents the ordinary least squares (OLS) estimation of production functions for three crops, wheat, rice, and maize. All three regressions include province fixed effects, year fixed effects, and their interactions. The results are rather consistent across the three regressions. Land has the largest elasticity with respect to output, followed by fertilizer. For rice, machinery use has the third-largest elasticity, while for wheat and maize it ranks fourth in 
TABLE 2.1 Average agricultural production and input at the household level, China, 2009-2012

\begin{tabular}{|c|c|c|c|c|c|}
\hline Variable & 2009 & 2010 & 2011 & 2012 & Annual growth rate \\
\hline \multicolumn{6}{|l|}{ Panel A: Wheat } \\
\hline Output (kg) & $1,145.23$ & $1,143.99$ & $1,128.89$ & $1,103.01$ & $-1.24 \%$ \\
\hline Land size (ha) & 0.22 & 0.22 & 0.21 & 0.21 & $-2.13 \%$ \\
\hline Yield (kg/ha) & $5,219.32$ & $5,264.38$ & $5,307.70$ & $5,362.97$ & $0.91 \%$ \\
\hline Labor input (days) & 35.58 & 37.05 & 36.76 & 32.93 & $-2.55 \%$ \\
\hline Seed fee (\$) & 18.84 & 20.00 & 21.21 & 21.60 & $4.67 \%$ \\
\hline Fertilizer fee (\$) & 51.35 & 51.64 & 55.31 & 62.01 & $6.49 \%$ \\
\hline Pesticide fee (\$) & 5.91 & 6.96 & 7.16 & 8.60 & $13.29 \%$ \\
\hline Machinery fee (\$) & 34.88 & 36.04 & 36.87 & 45.35 & $9.14 \%$ \\
\hline \multicolumn{6}{|l|}{ Panel B: Rice } \\
\hline Output (kg) & $1,493.27$ & $1,403.35$ & $1,320.29$ & $1,344.74$ & $-3.43 \%$ \\
\hline Land size (ha) & 0.21 & 0.20 & 0.19 & 0.19 & $-3.35 \%$ \\
\hline Yield (kg/ha) & $7,248.35$ & $7,025.61$ & $6,835.60$ & $7,230.45$ & $-0.08 \%$ \\
\hline Labor input (days) & 55.01 & 54.59 & 51.54 & 48.11 & $-4.37 \%$ \\
\hline Seed fee (\$) & 12.82 & 13.89 & 15.95 & 17.42 & $10.75 \%$ \\
\hline Fertilizer fee (\$) & 54.64 & 50.88 & 52.48 & 56.49 & $1.12 \%$ \\
\hline Pesticide fee (\$) & 16.72 & 16.65 & 16.63 & 19.33 & $4.96 \%$ \\
\hline Machinery fee (\$) & 25.86 & 26.88 & 30.75 & 37.59 & $13.28 \%$ \\
\hline \multicolumn{6}{|l|}{ Panel C: Maize } \\
\hline Output (kg) & $1,740.05$ & $1,786.08$ & $1,846.85$ & $1,953.74$ & $3.94 \%$ \\
\hline Land size (ha) & 0.25 & 0.26 & 0.26 & 0.26 & $0.34 \%$ \\
\hline Yield (kg/ha) & $6,849.50$ & $6,857.71$ & $7,137.54$ & $7,612.33$ & $3.58 \%$ \\
\hline Labor input (days) & 45.60 & 45.78 & 45.17 & 42.49 & $-2.33 \%$ \\
\hline Seed fee (\$) & 19.02 & 21.17 & 23.25 & 26.71 & $11.98 \%$ \\
\hline Fertilizer fee (\$) & 58.13 & 58.76 & 64.75 & 75.12 & $8.92 \%$ \\
\hline Pesticide fee (\$) & 6.61 & 7.52 & 7.96 & 9.20 & $11.67 \%$ \\
\hline Machinery fee (\$) & 21.76 & 23.53 & 24.55 & 32.20 & $13.96 \%$ \\
\hline
\end{tabular}

Source: Calculated by authors based on China Ministry of Agriculture Research Center for the Rural Economy household surveys (2009-2012).

Note: Monetary values are in constant 2009 US dollars.

elasticity. The table also displays the $p$-value of a $t$-test on constant returns to scale (the sum of the coefficients for all the inputs equals one). The test does not reject the null hypothesis of constant returns to scale for all three crops. However, the OLS estimations may be subject to endogeneity problems. For instance, productive farmers may intentionally choose better seeds and 
TABLE 2.2 Ordinary least squares estimation of production function for three crops, China, 2009-2012

\begin{tabular}{llll}
\hline Variable & Wheat & Rice & Maize \\
\hline Land & $0.467^{\star \star \star}$ & $0.811^{\star \star \star}$ & $0.426^{\star \star \star}$ \\
& $(0.06)$ & $(0.02)$ & $(0.07)$ \\
Labor & 0.04 & $(0.01)$ & 0.04 \\
& $(0.02)$ & $(0.02)$ & $(0.02)$ \\
Seed & $0.052^{\star \star}$ & $0.006^{\star \star}$ & $0.169^{\star \star \star}$ \\
& $(0.02)$ & $(0.00)$ & $(0.04)$ \\
Fertilizer & $0.331^{\star \star \star}$ & $0.010^{\star \star \star}$ & $0.312^{\star \star \star}$ \\
& $(0.05)$ & $(0.00)$ & $(0.04)$ \\
Pesticide & $0.060^{\star \star \star}$ & 0.00 & $0.024^{\star \star}$ \\
Machinery use & $(0.01)$ & $(0.00)$ & $(0.01)$ \\
& $0.032^{\star \star \star}$ & $0.008^{\star \star \star}$ & $0.015^{\star \star \star}$ \\
Age of household head & $(0.01)$ & $(0.00)$ & $(0.01)$ \\
& $0.000^{\star \star}$ & 0.00 & 0.00 \\
Education of household head & 0.00 & 0.00 & $(0.00)$ \\
& 0.00 & 0.00 & $0.006^{\star \star}$ \\
Test CRS ( $p$-value) & $(0.00)$ & $(0.00)$ & $(0.00)$ \\
Year effect & 0.15 & 0.18 & 0.31 \\
Province effect & yes & yes & yes \\
Province * year effect & yes & yes & yes \\
\hline$N$ & yes & yes & yes \\
Adjusted $R^{2}$ & 14,622 & 11,802 & 25,539 \\
\hline Sources & 0.99 & 0.99 & 0.99 \\
\hline
\end{tabular}

Source: Calculated by authors based on China Ministry of Agriculture Research Center for the Rural Economy household surveys (2009-2012).

Note: Dependent variable and independent variables are in logarithms. Robust standard errors are in parentheses. The symbols ${ }^{*},{ }^{\star \star}$, and ${ }^{\star \star \star}{ }^{\star}$ represent levels of significance at 10 percent, 5 percent, and 1 percent, respectively. CRS = constant returns to scale.

hire more harvesting services to increase crop yields. To address the problem, we repeat Table 2.2 following the method of Levinsohn and Petrin (2003), shortened as "LP method" hereafter. In the context of the Chinese economy, Yu (2014) applied the LP method by using a firm's export status as a proxy for its unobserved productivity. In the field of agricultural economics, Brambilla and Porto (2005) employed the share of cotton cropping area to infer a farmer's cotton productivity when applying the LP method. Following the same spirit, here we use whether a farmer rents in land as 
TABLE 2.3 Estimation of production function for three crops using Levinsohn and Petrin method, China, 2009-2012

\begin{tabular}{|c|c|c|c|}
\hline Variable & Wheat & Rice & Maize \\
\hline \multirow[t]{2}{*}{ Land } & $0.492^{* \star *}$ & $0.811^{\star \star \star}$ & $0.481^{* \star *}$ \\
\hline & $(0.02)$ & $(0.01)$ & $(0.02)$ \\
\hline \multirow[t]{2}{*}{ Labor } & $0.024^{\star \star \star}$ & $-0.012^{\star}$ & $0.025^{\star \star \star}$ \\
\hline & $(0.01)$ & $(0.01)$ & $(0.01)$ \\
\hline \multirow[t]{2}{*}{ Seed } & $0.051^{\star \star \star}$ & $0.007^{\star \star \star}$ & $0.148^{\star \star \star}$ \\
\hline & $(0.01)$ & $(0.00)$ & $(0.01)$ \\
\hline \multirow[t]{2}{*}{ Fertilizer } & $0.319^{\star \star \star}$ & $0.010^{\star \star \star}$ & $0.277^{\star \star \star}$ \\
\hline & $(0.02)$ & $(0.00)$ & $(0.01)$ \\
\hline \multirow[t]{2}{*}{ Pesticide } & $0.052^{\star \star \star}$ & 0.00 & $0.025^{\star \star \star}$ \\
\hline & $(0.00)$ & $(0.00)$ & $(0.00)$ \\
\hline \multirow[t]{2}{*}{ Machinery use } & $0.034^{\star \star \star}$ & $0.008^{\star \star \star}$ & $0.014^{\star \star \star}$ \\
\hline & $(0.00)$ & $(0.00)$ & $(0.00)$ \\
\hline \multirow[t]{2}{*}{ Age of household head } & $0.001^{\star \star}$ & $0.000^{*}$ & $0.000^{\star}$ \\
\hline & 0.00 & 0.00 & 0.00 \\
\hline \multirow[t]{2}{*}{ Education of household head } & $0.002^{\star \star}$ & 0.00 & $0.004^{\star \star \star}$ \\
\hline & $(0.00)$ & $(0.00)$ & $(0.00)$ \\
\hline Year effect & yes & yes & yes \\
\hline Province effect & yes & yes & yes \\
\hline Province * year effect & yes & yes & yes \\
\hline$N$ & 14,622 & 11,802 & 25,539 \\
\hline Wald test CRS $=1(p$-value $)$ & 0.58 & 0.43 & 0.14 \\
\hline
\end{tabular}

Source: Calculated by authors based on China Ministry of Agriculture Research Center for the Rural Economy household surveys (2009-2012).

Note: Dependent variable and independent variables are functions of natural logarithm. The estimation method is based on Levinsohn and Petrin (2003). Robust standard errors are in parentheses. The symbols ${ }^{*}$, ${ }^{\star *}$, and ${ }^{* \star *}$ represent levels of significance at 10 percent, 5 percent, and 1 percent, respectively.

a proxy for unobserved idiosyncratic crop productivity. A more productive farmer is more likely to rent in land than is a less productive farmer. As shown in Table 2.3, the main findings from the earlier OLS estimations remain in force under the LP estimations. Land still has the largest elasticity with respect to output. The coefficient for machinery use is positive and statistically significant in all three regressions. Both the OLS and LP estimations indicate that mechanization plays an important role in determining wheat, rice, and maize production. 


\section{Economics of Cross-Regional Mechanization Services}

In the previous two sections, we have documented the rapid rise of farm mechanization and its impact on the growth of agricultural production. Interestingly, the increase in farm mechanization is through provision of cross-regional mechanization services rather than more widespread ownership of agricultural machinery. In this section, we analyze the economic mechanisms behind the flourishing cross-regional mechanization services from both the supply and the demand side.

\section{Supply Side}

For simplicity, we assume an average farm household operates one unit of land. The price of outsourcing mechanization services is $P_{m}$ per unit of land. The purchase cost of machinery, say a combine harvester, is $M$. The depreciation rate of a combine harvester is $\beta$. The variable cost of operation per unit of land (such as fuel, communication cost, meals, and accommodation) is $\alpha$.

If the farmer sells the combine harvester in the $\gamma$ th year, the annualized fixed cost is

$$
m=\frac{M\left[1-(1-\beta)^{\gamma}\right]}{\gamma} \text {. }
$$

If the combine harvester harvests $n$ units of land, the total variable cost would be $n \alpha$. Overall, the average cost per unit of land per year is

$$
c_{s}=(m+n \alpha) / n=\frac{M\left[1-(1-\beta)^{\gamma}\right]}{\gamma n}+\alpha .
$$

Only when the price of the harvesting service, $P_{m}$, is higher than the cost, $c_{s}$, is it profitable for one to own a combine harvester. The supply function of the mechanization service can be written as

$$
\left\{\begin{array}{l}
S=1, \text { if } P_{m} \geq \frac{M\left[1-(1-\beta)^{\prime}\right]}{\gamma n}+\alpha \\
S=0, \text { if } P_{m}<\frac{M\left[1-(1-\beta)^{\prime}\right]}{\gamma m}+\alpha .
\end{array}\right.
$$

\section{Demand Side}

Because of the short window of time for harvesting, farmers often cannot harvest their own crop on time. In this situation, they face three choices:

\section{Own a combine harvester.}

If the operator of a combine harvester uses the combine only for his own harvesting, the total cost is $m+\alpha$. If he also provides harvesting services 
to other local farmers, provided that the maximum unit of land a combine can harvest in the limited local harvest season is $f$, then the total annual cost drops to $m / f+\alpha$. If he can travel to other parts of China, the total harvest time would be much longer. Suppose he can harvest up to $n$ units of land (much larger than $f$ ) by providing cross-regional harvesting services. The average cost will further decline to $m / n+\alpha$.

\section{Form a cooperative.}

On average a Chinese farm is too small to solely support a combine harvester. However, if farmers form a cooperative to increase the de facto farm size and share the cost of machinery purchase, the cost of operation drops. But due to the narrow window of local harvesting time, even if a combine runs at full capacity, it can only harvest $f$ units of land. So the optimal farm size of a cooperative for owning a combine (without sourcing service out to other famers) is $f$ (or $2 f$ for owning two combines, or $3 f$ for having three combines, and so on). Under the optimal farm size, the average cost is $m / f+\alpha$. Figure 2.2 plots the average cost curve to own combine harvesters in relation to farm size. As shown in the figure, forming a cooperative does not bring about more cost advantage than owning a combine harvester as an individual and hiring out services.

\section{Purchase services.}

If a farmer hires labor for harvesting, the cost is determined by market wages, $w$. If the farm is hiring mechanized harvesting services, the average cost per unit of land is $m / n+\alpha$. As discussed in choice 1 , the cost of hiring labor-cum-machine harvesting services is lower than that of forming a cooperative $(m / n+\alpha<m / f+a)$. Therefore, farmers prefer hiring in these services to forming a mechanization cooperative. In the past decade, real wages have rapidly gone up, making it more costeffective for farmers to hire in cross-regional mechanized harvesting services $(m / n+\alpha<<\mathrm{w})$ than to own a combine harvester.

When both the supply and demand conditions are fulfilled, the market for cross-regional mechanization services emerges:

$$
\frac{M\left[1-(1-\beta)^{*}\right]}{\gamma n}+\alpha \leq P m \leq w .
$$




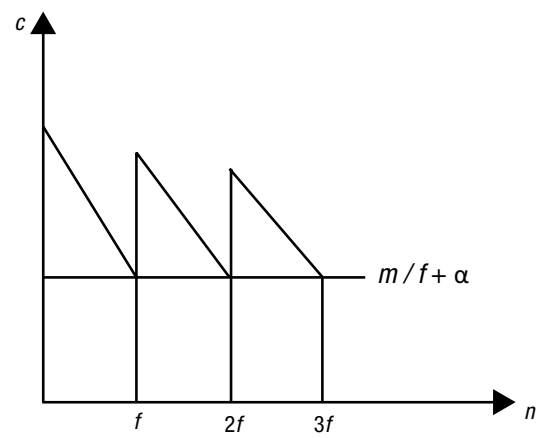

Source: Drawn by authors.

Note: $\alpha=$ variable cost of operation per unit of land; $c=\operatorname{cost} ;=$ maximum units of land a combine can harvest in the limited local harvest season; $m=$ annualized fixed cost of owning a combine harvester; $n=$ units of land a combine can harvest by providing cross-regional services.

Only when there are enough farms $(n)$ to hire the service is there a possibility for the market to exist. The minimum number of farms is determined by

$$
\begin{aligned}
& \frac{M\left[1-(1-\beta)^{\gamma}\right]}{\gamma n}+\alpha=w \text { and } \\
& n_{\text {min }}=M \frac{\left[1-(1-\beta)^{r}\right]}{\gamma(w-\alpha)}=m /(w-\alpha) .
\end{aligned}
$$

This is the minimum feasible scale over which to spread the cost of machinery, as suggested by Jayasuriya, Te, and Herdt (1986). We can draw several predictions from the above exercise.

First, the minimum feasible scale of mechanization services is positively correlated with the cost of machinery $(m)$. Combines are generally much more expensive than plows, which are attached to tractors. For example, rice combines cost between $\$ 11,000$ and $\$ 25,000 .{ }^{6}$ In comparison, a plow is normally less than $\$ 1,000$. As a result, those who own combines are more likely to travel farther over a longer period to sell services to recoup the cost than are those with plows. In fact, the plowing market is primarily local. In the RCRE 2013 survey, we attached a supplementary survey on the use of machinery in rice, wheat, and maize production in six provinces in 2008 and 2012. Table 2.4 shows the prevalence of machinery use in land preparation, planting,

6 Dollar figures are US dollars throughout the chapter.

7 We randomly selected 100 households from each of the 11 major cereal-producing provinces (Anhui, Fujian, Hebei, Hubei, Hunan, Jiangsu, Jiangxi, Liaoning, Shandong, Shannxi, and Sichuan). The final effective sample size was 1,094 . 
TABLE 2.4 Use of machinery in Chinese agricultural production, percentages, 2008 and 2012

\begin{tabular}{|c|c|c|c|c|c|c|c|}
\hline \multirow[b]{2}{*}{ Year } & \multirow[b]{2}{*}{ Operation } & \multicolumn{2}{|c|}{ Rice } & \multicolumn{2}{|c|}{ Wheat } & \multicolumn{2}{|c|}{ Maize } \\
\hline & & $\begin{array}{l}\text { Using } \\
\text { machinery }\end{array}$ & $\begin{array}{c}\text { Hiring } \\
\text { mechanization } \\
\text { service }\end{array}$ & $\begin{array}{c}\text { Using } \\
\text { machinery }\end{array}$ & $\begin{array}{c}\text { Hiring } \\
\text { mechanization } \\
\text { service }\end{array}$ & $\begin{array}{l}\text { Using } \\
\text { machinery }\end{array}$ & $\begin{array}{c}\text { Hiring } \\
\text { mechanization } \\
\text { service }\end{array}$ \\
\hline \multirow[t]{3}{*}{2012} & Plow & 86 & 82 & 90 & 83 & 62 & 74 \\
\hline & Plant & 10 & 91 & 68 & 89 & 48 & 63 \\
\hline & Harvest & 74 & 99 & 86 & 98 & 28 & 99 \\
\hline \multirow[t]{3}{*}{2008} & Plow & 72 & 80 & 89 & 82 & 55 & 70 \\
\hline & Plant & 6 & 96 & 65 & 88 & 41 & 67 \\
\hline & Harvest & 52 & 98 & 80 & 97 & 14 & 94 \\
\hline
\end{tabular}

Source: Data from a complementary module of China Ministry of Agriculture Research Center for the Rural Economy survey (2013).

Note: The numbers in the column "Using machinery" represent the percentage of farm households who have used machinery. The figures in the column "Hiring mechanization service" stand for the percentage of farmers hiring mechanization among those who used machinery.

and harvesting. If a farmer used machinery, we further asked whether the machinery was on a contract-hire basis. Take rice as an example. In 2012, 86 percent of rice farmers used machinery for plowing, with 74 percent using combine harvesters. Of the harvesting combines, 99 percent were used on a contract-hire basis. In comparison, among those who used mechanical plows, 82 percent rented in the service, a rate lower than the hire-in rate of harvesting services. Because plows are cheaper than combines, more farmers own disc plows than combines. Apart from own-use, those who own plows also provide land preparation services to other farmers in their own or neighboring villages.

Second, cross-regional migratory harvesting services are more likely to occur in countries with large seasonal variation and more flat land. Seasonality is a defining feature of agricultural production. The time for harvesting is often constrained to a narrow window, sometimes as short as a few days, by imminent rain or pest invasion. Although it is possible for a large to medium tractor/combine to provide harvesting services in the local area, it may be difficult for its owner to find the needed number of clients in the local catchment area in such a short harvesting window. In a small country without much variation over regions in production seasons, then, it would be hard to develop a viable national labor-cum-machine service market because of the limited number of days available for harvesting. However, China is large, with big regional differences in cropping periods in terms of number of seasons in a year and length of a given season. For instance, there are up to three production seasons in some parts of southern China, yet northeastern China 
crops only one season. By taking advantage of harvests for crops at different times and locations, the service providers can travel all over China to chase production seasons to maximize the number of working days and harvesting areas. From equation (7), only when $n$ exceeds $n_{\text {min }}$ do labor-cum-machine services become a viable business model. This allows the expansion of the market size, and thus a division of labor-with specialized labor-cum-large tractor/ combine services used to realize that division. The large regional variation in seasonality probably is another reason behind the rapid diffusion of crossregional harvesting services.

The phenomena demonstrated above are explained by the insight of Stigler (1951) that the division of labor is limited by the extent of the market. We can further use a diagram to illustrate Stigler's point. For simplicity, assume there are only two steps in production, nonharvesting and harvesting. We plot the average cost curves of the two steps ( $Y_{1}$ and $Y_{2}$, respectively) in Figure 2.3. The horizontal axis is acreage harvested. The providers of harvesting services charge fees based on acreage harvested. Because the unit price per acre is largely fixed, the acreages harvested marked on the horizontal axis can be regarded as a proxy for the total output of combine harvesters. If a farmer finishes both steps with own labor and machinery, the total cost curve would be $A C$, the sum of $Y_{1}$ and $Y_{2}$. Suppose now a cheaper cross-regional harvesting service is available and $Y_{2}^{\prime}$ is the new average cost curve for renting in the mechanization services. $Y_{2}^{\prime}$ is lower than the previous $Y_{2}$. Consequently, the average cost curve moves down, as shown by the dashed line $A C^{\prime}$. Therefore, by hiring in labor-cum-machine harvesting services, it is possible for small farmers to stay in business despite a small production scale.

Because it is more difficult to use machinery on hills than on plains, the share of flat areas will determine the size of the machine plowing and harvesting market for a given crop. Compared with rice and wheat, maize is more likely to be planted on hilly areas in China. The penetration rate of mechanized plowing for wheat in 2012 was 90 percent, higher than for maize (62 percent). Wheat harvesting relied heavily on combine harvesters (86 percent), most of which were labor-cum-machine services (98 percent). In comparison, the incidence of maize mechanized harvesting was only 28 percent. The popular models of maize combine harvesters in the United States, where there are strict requirements on the height and row spacing of maize, do not apply well to China because smallholder farmers use diverse seeds and do not follow standard row spacing. Some Chinese maize combine harvesters adapted to Chinese cropping patterns have been developed, but they did not go on the market until recently. 


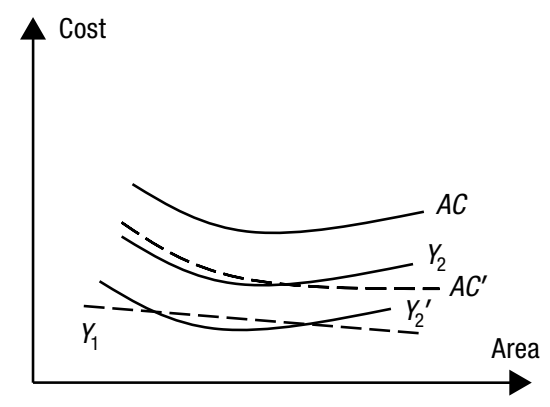

Source: Drawn by authors based on Stigler (1951).

Note: $A C=$ beginning cost curve; $A C^{\prime}=$ cost curve with cheaper, hired-in harvesting service; $Y_{1}=$ cost of nonharvesting step; $Y_{2}=$ cost of doing own harvesting step; $Y_{2}^{\prime}=$ cost of cheaper, hired-in harvesting service.

\section{The Evolution of Cross-Regional Mechanization Services}

In this section, we discuss a case study of a cluster of labor-cum-machine harvesting services based in Peixian county, Jiangsu province. This is one of the first and largest cross-regional mechanization service clusters. Peixian is in the extreme north of Jiangsu province, bordering two other provinces (Shandong and Henan). The county is well connected to the national transportation network. Peixian is composed of 16 townships. There are 36 cross-regional mechanization service cooperatives in Peixian. The county seat alone has 7 cooperatives. The mechanization service providers form their own cooperatives (separate from farm cooperatives per se). They mainly specialize in wheat and rice harvesting. Peixian has about 2,100 combine harvesters, and more than 1,000 of them are involved in cross-regional harvesting.

The idea of cross-regional services originated in 1997. The Peixian Bureau of Agricultural Mechanization (PBAM) selected eight directors from 18 agricultural mechanization service stations dispersed in different townships in the county and organized a study tour to Weifang, a city in Shandong province, to learn about the mechanization experience there. The directors also visited Anhui, Henan, Hebei, and Tianjin provinces to meet with the staff of local agricultural mechanization bureaus and farmers to explore the potential of cross-regional harvesting services. After the directors returned home from the tour, PBAM organized free demonstration and training sessions for farmers and technicians at the township agricultural mechanization service stations. After completing training, trainees were issued a PBAM certificate allowing 
them to drive trucks and combines to provide harvesting services. In addition, PBAM gathered harvest information nationwide, printed a pocket-size harvest calendar covering major cropping areas, and distributed it to potential combine harvest operators for free.

In the first two years (1998 and 1999), PBAM helped form a harvest team composed of nearly 50 combines. Each combine had three or four operators. Led by a deputy director of PBAM, the group traveled to Zhumadian, a city in neighboring Henan province, to harvest wheat. At the time, the two major models of combines were Xinjiang No. 2 and Futian. However, they were too heavy to be transported by truck, so they could be only driven slowly to nearby regions. Moreover, they were not reliable and often broke down. To cope with the repair and maintenance problems, the county invited a few technicians from the combine manufacturers to join the harvest team. The service expedition to Henan was a success. On average, a combine brought the owner a net profit of $\$ 8,571$, much higher than farm annual incomes at the time. The word of cross-regional harvesting services as a profitable business model quickly spread. Following suit, more entrepreneurs purchased combines and entered the business.

As the business grew, it was impossible for PBAM to escort all the harvesting teams. By the year 2000, PBAM stopped escorting any teams. Instead, it facilitated operators to form their own small groups and selected experienced team leaders. On average, each group included 10 combines and about 40 operators. All the members in a team traveled together following the same route.

Traveling in a group offers several advantages. The first advantage is security. When traveling far away from home, one often faces various unexpected challenges, such as extortion from gangs. By staying in groups, they faced a smaller chance of facing extortion because a team of 40 or so strong, young workers is a natural deterrent to potential harassment.

Second, traveling in a group can help teams cope with repair problems, one of the largest risks associated with long-distance cross-regional harvesting. It is cumbersome and expensive for an individual combine to bring all the commonly broken parts. When traveling in a group, although each person carries only a few parts, pooling them helps deal with most of the common problems. In rare cases when a group runs out of spare parts, it can call other teams nearby for help. Some large teams with more than 50 combines even bring their own service truck.

Third, traveling as a team lowers the search cost. It is common for a cooperative to hire a scout with a motorcycle to search for new harvesting orders 
while operators focus on harvesting. ${ }^{8}$ Because all the team members share the scout cost, each individual bears only a small proportion of the total search cost.

Initially, because the combines pulled by tractors were too heavy to travel long distances, their radius of harvesting services was limited to only a few counties in Jiangsu province and neighboring Henan and Shandong provinces. Beginning in 2003, a more reliable and smaller model, Kubota, made in Japan, gradually replaced the old models in the market. Because of its small size, a truck can carry it for long distances. The diffusion of small combines quickly revolutionized cross-regional harvesting services.

When traveling in a group, coordination among team members is a key challenge. In the first several years, cooperative leaders spent a lot of money on cell phone calls because changes in schedule, route, or meeting places had to be relayed to all the members one by one. They complained about the problem to PBAM. In response, PBAM worked with China Mobile, one of the largest telecommunication companies in China, to set up a group message service for the harvesting teams in 2011. As a result, the telecommunication cost dropped dramatically.

When the migratory harvesting service providers travel to villages far away, it is challenging for them to coordinate with farmers for synchronized harvesting. Intermediaries in villages play a key role in linking farmers and the operators of combine harvesters. The intermediaries are more knowledgeable about local demand than the service providers from outside. They normally charge a 10 percent commission fee out of the total service charges. Operators rely heavily on intermediaries only when they first come to a village. However, after a few times of providing satisfactory services, their reliance on intermediaries weakens. More often than not they directly contact known farmers to schedule harvesting service.

Most Chinese highways charge tolls. For long-distance travel, the toll cost can be prohibitive. Starting in 2004, the central government waived the tolls for all the trucks carrying combines or tractors that are engaged in crossregional harvesting services (Ministry of Transport 2004).

As noted above for the country as a whole, the biggest driver behind the rising demand for outsourced mechanization services was probably the spike in labor costs; that also applies here. From 2003 to 2011, the appreciation of real wages escalated, with a double-digit annual increase (Zhang, Yang,

8 In a sense, this is very similar to honeybee scouts, who are specialized in looking for suitable sites for new hives (Seeley 2010). 
and Wang 2011). Rising wages induced farmers to substitute machinery for laborers to do the power-intensive production steps, such as plowing and harvesting.

On the supply side of machines for this service cluster, subsidies played a role. Beginning in 2004, the central government started to provide subsidies for farmers to purchase agricultural machinery (Bai 2004). The subsidy amount has increased over time. Farmers who purchase tractors with greater than $100 \mathrm{hp}$ are entitled to a subsidy from the central government as high as $\$ 21,428$, whereas the subsidy for a 200 hp tractor caps at $\$ 35,714$ (Ministry of Agriculture 2013). In addition, mechanization service cooperatives can apply for subsidies, which range from $\$ 4,285$ to $\$ 14,285$, to build warehouses for their machinery.

However, the subsidy may also exert a negative impact on cross-regional mechanization service providers. With a lower effective purchasing cost thanks to the subsidy, owners of combines do not need to travel as far as before to recoup the machinery cost. When farmers in many other regions purchased their own combines under the support of subsidy, the Peixian service cluster faced greater numbers of competitors. This is perhaps why the total number of combines in Peixian has declined in the past several years.

In sum, both the rising labor cost and the active roles of local and central government, followed by intense local private investment by farmers, have contributed to the rapid development of the Peixian mechanization service cluster.

In 2011, we conducted qualitative interviews with combine operators, cooperative leaders, and local officials. Based on the qualitative interviews, we designed a questionnaire and first tested it in Anhui province. ' After the test, we further revised the questionnaire. In March 2012, we formally launched our survey in Peixian. We randomly selected 8 from 31 mechanization service cooperatives and interviewed the members of the chosen cooperatives. In total, we completed 124 interviews.

Table 2.5 reports the median income and cost among the interviewed cooperative members. On average, a combine harvest owner earned $\$ 14,286$ per year, which is seven times the per capita rural net annual income in Jiangsu province. Wages $(\$ 7,937)$ accounted for 35 percent of the total cost. Fuel was the second-most-expensive item, constituting 28 percent of the total cost. Food and lodging consumed 21 percent of total expenses. Repair and maintenance cost $\$ 3,175$, or 14 percent of total expenses. Telecommunication

9 We did not test it in Peixian county of Jiangsu province to avoid contaminating the sample. 
TABLE 2.5 Summary statistics of combine service enterprise survey in Peixian county, China, 2013

\begin{tabular}{lrc}
\hline Variable & Median & Observations \\
\hline 1. Net income (\$) & $14,285.71$ & 103 \\
2. Total costs (\$) & $22,539.68$ & n.a. \\
a. Repair and maintenance & $3,174.60$ & 102 \\
b. Employee wages & $7,936.51$ & 87 \\
c. Telephone & 317.46 & 103 \\
d. Food/lodging while traveling & $4,761.90$ & 65 \\
e. Gasoline/diesel & $6,349.21$ & 89 \\
3. Area served (ha) & 133.33 & 89 \\
4. Days working away from home & 179.00 & 107 \\
\hline
\end{tabular}

Source: Calculated by authors based on authors' survey (2013).

Note: Monetary values are in US dollars. n.a. = not applicable.

represented only 1.4 percent of the overall cost. Each combine harvested 133 ha of land, serving more than 250 farmers, given that the average farm size in China is around 0.5 ha.

Figure 2.4 plots the average cost per hectare versus total hectares of land harvested. As shown in the figure, the average cost per hectare comes down as the harvested area increases. This is consistent with the prediction of equation (4). Indeed, cross-regional harvesting exhibits increasing returns to scale. The longer time one harvests, the higher the net profit. In our sample, the operators travel on average 179 days (about six months), with some as long as eight months.

\section{Conclusions}

Lack of production scale has been long regarded in the literature as a major constraint on smallholder farmers. In this chapter, we show this conventional wisdom may not be true. Agricultural production can be divided into multiple steps. When the nonfarm job opportunities are limited and wages are low, farmers tend to undertake most steps of production by themselves. However, as real wages increase, it becomes cheaper for farmers to outsource some of the power-intensive steps to professional service providers, such as labor-cummachine service providers, than to manually harvest crops. Because China is a large country with diversified production seasons, labor-cum-machine service providers can travel widely for a long period, greatly lowering their unit 
FIGURE 2.4 Cost per hectare and area harvested by combine service enterprises, Peixian county, China, 2013

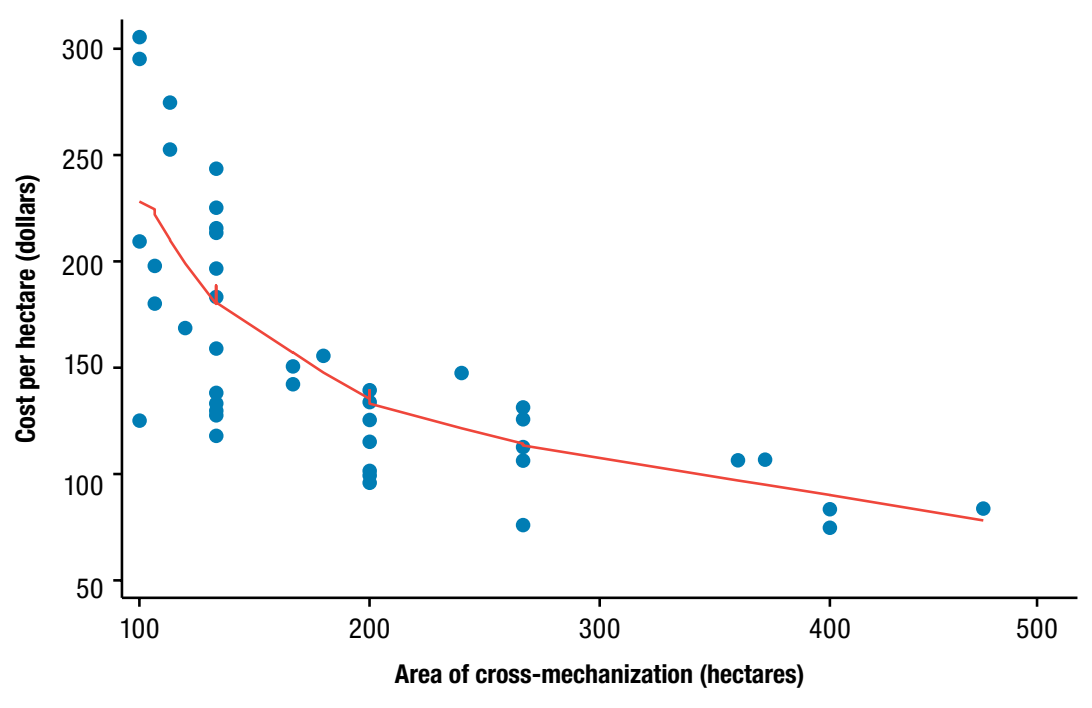

Source: Drawn by authors based on authors' Peixian survey (2013).

Note: Dollars are US dollars.

cost of operation and essentially substituting for the more expensive manual harvesting. This is an important reason why, despite the declining labor input in agricultural production, land productivity in China has not declined. The availability of the cheaper option of labor-cum-machine services is a key reason.

The emergence of the national labor-cum-machine service market may also help the nonfarm sector. When mechanization services are absent, migratory workers have to return home to help harvest crops, disrupting the normal production in the nonfarm sector. Now that the service is readily available for hire, migratory workers do not need to rush home during the peak seasons. This in turn may help boost labor productivity in the nonfarm sector; that is a hypothesis to test in future research.

By outsourcing the labor- and power-intensive steps of production to others, smallholder farmers can maintain their competitiveness despite their small and fragmented land size. However, as the current old-generation farmers with low opportunity cost of labor die out in the near future, land consolidation will become inevitable. 
The Chinese experience highlights that agricultural production can be divisible in the same way as industrial production. If we ignore the fine division of labor, we may draw a less precise assessment of the competitiveness and potentials of Chinese agriculture. Paying greater attention to the structure of production can help us better understand the working economy (Coase and Wang 2011).

As for policy recommendations, China's experiences offer important lessons for mechanization promotion in African countries. Although the agricultural and economic conditions of China differ from those of many African countries, China's recent experiences demonstrate good practices in many aspects that offer useful principles African countries can follow.

First, China's experiences demonstrate that constraints due to small farm size, combined with land fragmentation, can still be overcome, and mechanization can spread in such an environment if the right conditions (technological, institutional, and political) hold. Second, subsidies introduced in 2004 have been successful partly because they were less selective and thus less distorting than some subsidies in Africa. Although different caps were placed on tractors with different horsepower, no particular brands were favored, unlike the recent subsidies implemented in many African countries.

Third, as is described in the case study of a cluster of labor-cum-machine harvesting services based in Peixian county, Jiangsu province, the governments at various administrative layers played important coordinating roles, which is one of the key public goods. These coordination roles included linking service providers and customers, providing free harvest information, linking with providers of other services (mobile companies), and waiving of highway tolls, among others. These coordinating roles were complemented by investments in road infrastructure as well as irrigation infrastructure, which facilitated the expansion of production seasons where climatically feasible, lengthening the windows of harvesting seasons during which migratory harvesting services could recoup machine investment costs. If African countries were to develop similar migratory mechanization services, it would be critical that governments play similar coordinating roles and provide key infrastructures.

\section{References}

Akinola, A. 1987. "Government Tractor Hire Service Scheme as a Tractorization Policy in Africa: The Nigerian Experience." Agricultural Administration and Extension 25 (2): 63-77. Bai, R. 2004. Research on the Policy of Subsidy for Purchasing Agricultural Machinery. Beijing: China Agricultural Science and Technology Press. 
Binswanger, H. 1986. “Agricultural Mechanization: A Comparative Historical Perspective.” World Bank Economic Observer 1: 27-56.

Brambilla, I., and G. G. Porto. 2005. Farm Productivity and Market Structure: Evidence from Cotton Reforms in Zambia. Economic Growth Center Discussion Paper No. 919. New Haven, CT, US: Yale University.

Chang, S. N. S. 1973. “The Fable of Bees: An Economics Investigation." Journal of Law and Economics 16 (1): 11-33.

Coase, R. H., and N. Wang. 2011. “The Industrial Structure of Production: A Research Agenda for Innovation in an Entrepreneurial Economy." Entrepreneurship Research Journal 1: 1-13.

Collier, P., and S. Dercon. 2013. "African Agriculture in 50 Years: Smallholders in a Rapidly Changing World?” World Development 63: 92-101.

Deininger, K., and S. Jin. 2009. “Securing Property Rights in Transition: Lessons from Implementation of China's Rural Land Contracting Law.” Journal of Economic Behavior and Organization 70: 22-38.

Diao, X., F. Cossar, N. Houssou, S. Kolavalli, K. Jimah, and P. Aboagye. 2012. “Mechanization in Ghana: Searching for Sustainable Service Supply Models.” IFPRI Discussion Paper 1237. Washington, DC: International Food Policy Research Institute.

Fan, C. 2009. "Flexible Work, Flexible Household: Labor Migration and Rural Families in China." In Work and Organizations in China after Thirty Years of Transition, edited by Lisa Keister, 377-408. Research in the Sociology of Work, Vol. 19. Bingley, UK: Emerald Group Publishing Limited.

Green, S. 2008. On the World's Factory Floor: How China's Workers Are Changing China and the Global Economy. Special Analysis of Key Topics. London: Standard Chartered Bank.

Jayasuriya, S., and R. Shand. 1986. “Technical Change and Labor Absorption in Asian Agriculture: Some Emerging Trends.” World Development 14: 415-428.

Jayasuriya, S., A. Te, and R. Herdt. 1986. "Mechanization and Cropping Intensification: Economics of Machinery Use in Low-Wage Economies.” Journal of Development Studies 22: 327-335.

Levinsohn, J., and A. Petrin. 2003. "Estimating Production Functions Using Inputs to Control for Unobservables." Review of Economic Studies 70 (2): 317-342.

Lewis, W. A. 1954. "Economic Development with Unlimited Supplies of Labor.” The Manchester School 22 (2): 139-191.

Lin, Y., F. Cai, and Z. Li. 2008. The China Miracle: Development Strategy and Economic Reform, 3rd ed. Hong Kong: Chinese University of Hong Kong Press. 
Lin, Y., and Y. Yao. 2001. "Chinese Rural Industrialization in the Context of the East Asian Miracle." In Rethinking the East Asian Miracle, edited by J. E. Stiglitz and S. Yusuf, 143196. Washington, DC: The World Bank.

Marshall, A. 1920. Principles of Economics, 8th ed. London: Macmillan.

McGregor, R. 2005. “China Must Cut Farming Population, Says OECD.” Financial Times, November 15.

Ministry of Agriculture of the People's Republic of China. 2013. Guidance of the Policy of Subsidy for Purchasing Agricultural Machinery. Beijing. http://jiuban.moa.gov.cn/zwllm/zwdt /201301/t20130125_3208634.htm.

Ministry of Transport of the People's Republic of China. 2004. Regulation on the Administration of Toll Roads. Beijing. http://www.gov.cn/zwgk/2005-05/23/content_241.htm.

Muth, M. K., R. R. Ruckers, W. N. Thurman, and C. T. Chuang. 2003. “The Fable of Bees Revisited: Causes and Consequences of the US Honey Program." Journal of Law and Economics 46 (2): 479-516.

NBS (National Bureau of Statistics of the People's Republic of China). 2011. China Rural Statistical Yearbook. Beijing: China Statistics Press.

- 2013. China Rural Statistical Yearbook. Beijing: China Statistics Press.

Olmstead, A. L., and P. W. Rhode. 1995. "Beyond the Threshold: An Analysis of the Characteristics and Behavior of Early Reaper Adopters." The Journal of Economic History 55 (1): 27-57.

Otsuka, K. 2012. "Food Insecurity, Income Inequality, and the Changing Comparative Advantage in World Agriculture." Presidential address at the 27th International Conference of Agricultural Economists, Foz do Iguaçu, Brazil, August 18-24.

Pingali, P. 2007. "Agricultural Mechanization: Adoption Patterns and Economic Impact." In Handbook of Agricultural Economics. Vol. 3, edited by R. Evenson and P. Pingali, 2779-2805. Amsterdam: Elsevier.

Ruttan, V. W. 2001. Technology, Growth and Development: An Induced Innovation Perspective. New York: Oxford University Press.

Seeley, T. D. 2010. Honeybee Democracy. Princeton, NJ, US: Princeton University Press.

Smith, A. (1776) 1976. The Wealth of Nations. New York: Oxford University Press.

Stigler, G. J. 1951. “The Division of Labor Is Limited by the Extent of the Market." Journal of Political Economy 59: 185-193.

Takahashi, K., and K. Otsuka. 2009. "The Increasing Importance of Nonfarm Income and the Changing Use of Labor and Capital in Rice Farming: The Case of Central Luzon, 19792003." Agricultural Economics 40: 231-242. 
Timmer, C. P. 1988. “The Agricultural Transformation." In Handbook of Development Economics. Vol. 1, edited by H. Chenery and T. N. Srinivasan, 275-331. Amsterdam: North-Holland.

Yang, J., Z. Huang, X. Zhang, and T. Reardon. 2013. “The Rapid Rise of Cross-Regional Agricultural Mechanization Services in China." American Journal of Agricultural Economics 95 (5): $1245-1251$.

Yu, M. 2014. "Processing Trade, Tariff Reductions and Firm Productivity: Evidence from Chinese Firms." Economic Journal 125: 943-988.

Zhang, X., J. Yang, and S. Wang. 2011. “China Has Reached the Lewis Turning Point.” China Economic Review 22: 542-554. 


\title{
FARM MACHINERY USE AND THE AGRICULTURAL MACHINERY INDUSTRIES IN INDIA: STATUS, EVOLUTION, IMPLICATIONS, AND LESSONS LEARNED
}

\author{
Madhusudan Bhattarai, Gajendra Singh, Hiroyuki Takeshima, \\ and Ravindra S. Shekhawat
}

\begin{abstract}
Over the last several decades, India has seen a continuous spread of tractor use as well as growth in its domestic tractor manufacturing industry, despite relatively slow wage growth and a slow decline in the employment share of the agricultural sector. By now, arguably as much as 90 percent of the country's farm area may be prepared by tractors. India is now the largest tractor market in the world, purchasing more than 90 percent of the 660,000 tractors it produces per year. The annual value of tractors sold in India is more than US $\$ 5$ billion per year. This study reviews the evolution of agricultural mechanization, particularly tractors, in India. In doing so, it provides some rough indicators of the extent of mechanization (particularly the spread of tractor use) at different historical phases, emphasizing that India's experiences up to 1990 are as important as the lessons since then. Substantial infrastructure endowments (in terms of roads, for example), which were already high in the 1960s, and investments into rural electrification, as well as knowledge accumulation through the importation of a large number of tractors early on, are likely to have helped the growth of domestic tractor manufacturing. Diverse custom hiring services for tractors and combine harvesters have emerged to serve areas that are profitable, with relatively little direct support from the government. The private sector has also stepped up to provide facilitating services to connect service providers and farmers. Empirical analyses of the impact of tractor ownership and tractor/combine harvester use confirms many hypotheses about the farm-level impact of mechanization in India. Despite the typically small landholding in India, tractor ownership is led by the motive to expand farm size. Tractors are more bullock saving than labor saving, whereas combine harvesters are more strongly labor saving. Combine harvesters are more yield enhancing than tractors, but land preparation by tractors may indirectly enhance yields through the increased use of chemical fertilizer.
\end{abstract}


All of these patterns provide important lessons for other countries that are still at an early stage of mechanization.

\section{Historical Background and Evolution of Farm Mechanization in India}

This section takes a historical perspective on the development and evolution of farm machinery use in India, supplemented by numerical data and facts from across the states of India as well as information on changes that have taken place over the years.

Table 3.1 summarizes growth in the use of farm machinery and related agricultural factors, as well as selected agricultural performance metrics, over recent decades. Agricultural land in India has expanded by only 5 percent since 1960 , but grain yields have increased by 300 percent, partly due to the growth in land-saving technologies (irrigation and fertilizers). However, the use and density of farm tractors has also increased considerably during this time.

Information is scarce regarding the extent of tractor use, in terms of the share of agricultural area prepared by tractors. However, various sources of information and back-of-the-envelope calculations, detailed in the note accompanying Bhattarai et al. (2018 Table 2.1), can offer likely estimates. The share was likely to have been about 10 percent in 1980 and 20 percent in 1990 . Therefore, by 1990, India was likely to have exceeded many African countries in its extent of tractor adoption for land preparation. Thus, for African countries today, the experiences in India up to 1990 may be particularly important.

Tractors were first introduced in India in 1914 by the British government for reclaiming land and clearing lands of brush and shrubs. The tractor industry in India has grown particularly fast in the last 50 years, especially since the early 1990s, when Indian industrial sectors (including the production, import, and export of tractors and their parts) became liberalized. ${ }^{1}$

The historical development of tractor and other farm machinery use in India can be separated into five different phases (Bhattarai et al. 2018, Table 2.2). In parallel, there were also major shifts in national and regional

1 As described in the section of this article titled "Machinery Purchase, Manufacturing, and Import Policies," before 1992/1993, a government permit and license were necessary to manufacture, import, or export tractors. After 1992/1993, all of these restrictions were lifted. At present, anybody can set up a tractor factory in India without any license or permit. 
TABLE 3.1 Change in use of farm machinery and related factors of Indian agriculture, 1960-2012/2013

\begin{tabular}{|c|c|c|c|c|c|c|c|c|}
\hline Item & Unit & 1960 & 1970 & 1980 & 1990 & 2000 & 2010 & $\begin{array}{l}2012 / \\
2013\end{array}$ \\
\hline $\begin{array}{l}\text { Agricultural land } \\
\text { (net cropped area) }\end{array}$ & million ha & 133 & 140 & 140 & 143 & 143 & 142 & 140 \\
\hline Irrigated area & $\%$ & 18.32 & 23.04 & 28.84 & 34.03 & 41.11 & 44.99 & 47.62 \\
\hline Cropping intensity & $\%$ & 115 & 118 & 123 & 130 & 133 & 136 & 139 \\
\hline Grain yield & $\mathrm{kg} / \mathrm{ha}$ & 700 & 860 & 1,000 & 1,300 & 1,600 & 1,950 & 2,130 \\
\hline $\begin{array}{l}\text { Nutrient use (N, } \mathrm{P} \text {, } \\
\text { and } \mathrm{K} \text { ) }\end{array}$ & $\mathrm{kg} / \mathrm{ha}$ & 2.00 & 13.61 & 31.95 & 67.55 & 90.12 & 142.35 & 131.36 \\
\hline $\begin{array}{l}\text { No. of irrigation } \\
\text { pumps }\end{array}$ & million & 0.4 & 3.3 & 6.2 & 12.9 & 19.5 & 28.0 & 52.8 \\
\hline No. of draft animals & million & 80 & 83 & 73 & 71 & 60 & 50 & 48 \\
\hline Agricultural labor & million & 131.1 & 125.7 & 148.0 & 185.3 & 234.1 & 263.1 & - \\
\hline Total no. of tractors & 1,000 & 37 & 146 & 531 & 1150 & 2633 & 5005 & 5811 \\
\hline $\begin{array}{l}\text { Tractors per } 1,000 \\
\text { ha of net crop area }\end{array}$ & $\begin{array}{l}\text { no./ } \\
1,000 \text { ha }\end{array}$ & 0.3 & 1.0 & 3.8 & 8.1 & 18.6 & 35.4 & 41.5 \\
\hline $\begin{array}{l}\text { Crop area per } \\
\text { tractor }\end{array}$ & ha & 3,594 & 959 & 264 & 124 & 54 & 28 & 24 \\
\hline No. of power tillers & 1,000 & - & 9.6 & 16.2 & 32.3 & 114.7 & 259.2 & 312.7 \\
\hline $\begin{array}{l}\text { Approximate share } \\
\text { of area plowed by } \\
\text { tractors }\end{array}$ & $\%$ & 一 & 3 & 10 & 20 & 40 & 80 & 90 \\
\hline
\end{tabular}

Source: Bhattarai et al. (2018, Table 2.1).

Note: $-=$ data not available $; \mathrm{K}=$ potassium; $\mathrm{N}=$ nitrogen; $\mathrm{P}=$ phosphorus.

policies as well as shifts in macroeconomic policies, which also affected the adoption and use of farm machinery.

At present, even small and medium-size farmers, with 2-3 ha of landholdings, have started to own tractors on an individual basis. These owners hire out their tractors to fellow farmers and others in their villages for both farm and nonfarm uses, making their tractor purchasing decision more of an entrepreneurial move, based on a prospectus of its benefits from rental services, than a simple investment in plowing their own lands. This phenomenon has led to an extraordinary growth in tractor use in India during the last 40 years. Further discussions on the growth pattern of the tractor market, factors associated with the growth of tractor use in India, and the entry of new tractor manufacturers since 1961 can be found in Bhattarai and others (2017) and in Singh (2015). 


\section{Demand for Mechanization in India}

\section{Trends in Machinery Use and Ownership by Farm Size}

Table 3.2 shows the change in average landholding size of five types of farmers from 1983 to 2010/2011, as well as a snapshot of tractor ownership among medium to large farmers in 2009 . Over time, the farm size distribution has shifted toward small and marginal (in terms of both average size and share of farmers), whereas, as shown above, adoption of tractors has continued rising during the same period. This pattern roughly suggests that tractor use for land preparation has spread in India without a significant increase in farm size.

In 2009, tractor ownership was still concentrated among medium to large farms, with 38 percent of large farmers (those with more than $10 \mathrm{ha}$ ) owning tractors, 18 percent of medium-size farmers (with 2-10 ha), and less than 1 percent of smallholding and marginal farmers (those with less than 2 ha of land). The large and medium-size farmers with tractors have been providing hiring services to enable tractor use among smallholders.

Tractor usage varies spatially across India as well. Table 3.3 shows the distribution of tractor availability across the states of India in 1982 versus 2012. In 1982, almost 60 percent of the tractors in India were concentrated in three northern states: Uttar Pradesh (27 percent), Punjab (21 percent), and Haryana (12 percent). This share had shrunk to less than 40 percent by 2012 . However, the concentration is still high in these three states because they accounted for only 18 percent of the cropped area in India in 2010.

In many respects, the development path of farm machinery use in India is unique, with growth in the use of other farm machinery mirroring that of tractors. India is one of the largest markets for four-wheel tractors (4WTs) in the world (both in volume of annual production and in sales). Likewise, the pace of growth in the use of combine harvesters, mechanical threshers, and other farm machinery in the country has also expanded at a massive scale during recent years. Table 3.4 summarizes the annual sales (or market size) of tractors and related farm machinery in India in recent years.

\section{TYPES OF TRACTORS}

Most tractors purchased in India are 4WTs, and the share of two-wheel tractors (2WTs) remained low from 2005 from 2015, while sales of 4WTs more than doubled (Figure 3.1). In general, less than 10 percent of total tractor sales are $2 \mathrm{WTs}$, in contrast to many other countries in Southeast Asia, despite the fact that more than 80 percent of farmers in India are smallholders, with less than 2 ha of landholdings. In fact, the expansion and diffusion of 2 WTs has 
TABLE 3.2 Trends of farm holdings in India, 1983 to 2010/2011

\begin{tabular}{|c|c|c|c|c|c|c|c|c|c|}
\hline \multirow[b]{2}{*}{ Category of holdings } & \multicolumn{4}{|c|}{ No. of holdings (million) } & \multirow{2}{*}{$\begin{array}{c}\text { Tractor } \\
\text { penetration } \\
\text { (2009) }\end{array}$} & \multicolumn{4}{|c|}{ Total area (million ha) } \\
\hline & 1983 & $\begin{array}{l}2000 / \\
2001\end{array}$ & $\begin{array}{l}2005 / \\
2006\end{array}$ & $\begin{array}{l}2010 / \\
2011\end{array}$ & & 1983 & $\begin{array}{l}2000 / \\
2001\end{array}$ & $\begin{array}{l}2005 / \\
2006\end{array}$ & $\begin{array}{l}2010 / \\
2011\end{array}$ \\
\hline Marginal (< 1 ha) & 44.5 & 75.4 & 83.7 & 92.4 & - & 17.5 & 29.8 & 32.0 & 35.4 \\
\hline Small (1-2 ha) & 14.7 & 22.7 & 23.9 & 24.7 & - & 20.9 & 32.1 & 33.1 & 35.1 \\
\hline Semi-medium (2-4 ha) & 11.6 & 14.0 & 14.1 & 13.8 & $18 \%$ & 32.4 & 38.2 & 37.9 & 37.5 \\
\hline Medium (4-10 ha) & 8.2 & 6.6 & 6.4 & 5.9 & & 49.6 & 38.2 & 36.6 & 33.7 \\
\hline Large (> $10 \mathrm{ha})$ & 2.4 & 1.2 & 1.1 & 1 & $38 \%$ & 42.9 & 21.1 & 18.7 & 17.4 \\
\hline All holdings & 81.4 & 119.9 & 129.2 & 137.8 & - & 163.3 & 159.4 & 158.3 & 159.1 \\
\hline Ha/holding & n.a. & n.a. & n.a. & n.a. & - & 2.01 & 1.33 & 1.23 & 1.15 \\
\hline $\begin{array}{l}\text { Share of marginal and } \\
\text { small farmers (\%) }\end{array}$ & 72.6 & 81.8 & 83.3 & 85.0 & - & 23.5 & 38.8 & 41.1 & 44.3 \\
\hline
\end{tabular}

Source: Shah and Kanodia (2015); Goel and Kumar (2013).

Note: $-=$ data not available; n.a. $=$ not applicable.

TABLE 3.3 Distribution of tractors across selected states in India, 1982 and 2012

\begin{tabular}{lccccc}
\hline & \multicolumn{2}{c}{1982} & & \multicolumn{2}{c}{2012} \\
\cline { 2 - 3 } \cline { 5 - 6 } State & Number $(\mathbf{1 , 0 0 0})$ & \% of India & & Number $(1,000)$ & \% of India \\
\hline Uttar Pradesh & 141.4 & 27.16 & & $1,106.1$ & 19.03 \\
Rajasthan & 54.3 & 10.43 & & 699.9 & 12.04 \\
Madhya Pradesh & 24.5 & 4.71 & & 660.6 & 11.37 \\
Punjab & 106.7 & 20.50 & & 517.7 & 8.91 \\
Haryana & 61.5 & 11.81 & & 516.6 & 8.89 \\
Gujarat & 27.8 & 5.34 & & 495.1 & 8.52 \\
Maharashtra & 21.5 & 4.13 & & 419.2 & 7.21 \\
Karnataka & 20.4 & 3.92 & & 363.9 & 6.26 \\
Andhra Pradesh & 20.9 & 4.01 & & 342.4 & 5.89 \\
Bihar & 14.2 & 2.73 & & 266.6 & 4.59 \\
Tamil Nadu & 14.2 & 2.73 & & 186.7 & 3.21 \\
Odisha & 1.2 & 0.23 & & 83.1 & 1.43 \\
West Bengal & 1.6 & 0.31 & & 35.5 & 0.61 \\
Kerala & 1.3 & 0.25 & & 11.6 & 0.20 \\
All India & 520.6 & 100.00 & & $5,811.1$ & 100.00 \\
\hline
\end{tabular}

Source: Data from India Ministry of Road Transport and Highways (personal communication March 2, 2018). 
TABLE 3.4 Major farm machinery used and annual market size of farm machinery in India, 2014/2015

\begin{tabular}{lcccc}
\hline & $\begin{array}{c}\text { Market } \\
\text { Size annually } \\
\text { (units) }\end{array}$ & $\begin{array}{c}\text { Average } \\
\text { per-unit cost in } \\
\text { US dollars }\end{array}$ & $\begin{array}{c}\text { Average } \\
\text { per-unit cost in } \\
\text { Indian rupees }\end{array}$ & $\begin{array}{c}\text { Annual } \\
\text { industry size in } \\
\text { billion rupees }\end{array}$ \\
\hline Tractor & 600,000 & $7,000-12,000$ & 570,000 & 342.00 \\
Power tiller & 56,000 & 2,100 & 126,000 & 7.06 \\
Combine harvester & $4,000-5,000$ & $22,000-35,000$ & $1,710,000$ & 7.70 \\
Thresher & 100,000 & $1,600-2,500$ & 123,000 & 12.30 \\
Rotavator & $60,000-80,000$ & $1,300-2,000$ & 99,000 & 6.93 \\
Rice transplanter & $1,500-1,600$ & $1,500-2,500$ & 150,000 & 0.62 \\
$\quad$ Walking type & - & $2,500-4,200$ & 201,000 & - \\
$\quad$ Riding type & - & $3,300-16,600$ & 597,000 & - \\
Self-propelled reaper & $4,000-5,000$ & $1,300-2,000$ & 99,000 & 0.45 \\
Zero-till seed drill & $25,000-30,000$ & $750-850$ & 48,000 & 1.32 \\
Multicrop planter & $1,000-2,000$ & $850-1,000$ & 55,500 & 0.08 \\
Laser land leveler & $3,000-4,000$ & $5,800-6,500$ & 369,000 & 1.29 \\
Power weeder & 25,000 & 8,500 & 510,000 & 12.75 \\
\hline
\end{tabular}

Source: CSAM (2014); Shah and Kanodia (2015); Singh (2015).

Note: US\$1 = 65 Indian rupees in 2014/2015. — = data not available.

been confined to only a few states, such as Karnataka, Kerala, Odisha, and some states in the northeast.

Although formal analyses of the reasons for the dominance of $4 \mathrm{WTs}$ among tractors in India have been limited, informal interactions with local experts suggest the following potential reasons. First, in India, 2WTs are well accepted by farmers in paddy-growing states (eastern and southern India), but not in dry regions due to the need for engines with higher horsepower for plowing. Second, in India, registration is not available for $2 \mathrm{WTs}$, so they are not permitted on highways and busy roads, limiting their nonfarm or hauling uses during the off-season. Furthermore, despite the expansion of irrigation, 60 percent of farmland in India is still rainfed (FAO 2018) or under farming systems that rotate rice cultivation with rainfed nonrice crops (Pingali 2007).

The typical horsepower of a $4 \mathrm{WT}$ in India is $30-40 \mathrm{hp}$ (Figure 3.2). Although the share of higher-horsepower tractors has gradually increased since the period 2000-2009, more than 80 percent of 4WTs were still of less than $50 \mathrm{hp}$ in 2012. The average horsepower among tractors in India has therefore been lower than that of the 50-70 hp 4WTs boasted by African governments. 
FIGURE 3.1 Two-wheel and four-wheel tractor sales in India between 2005 and 2015

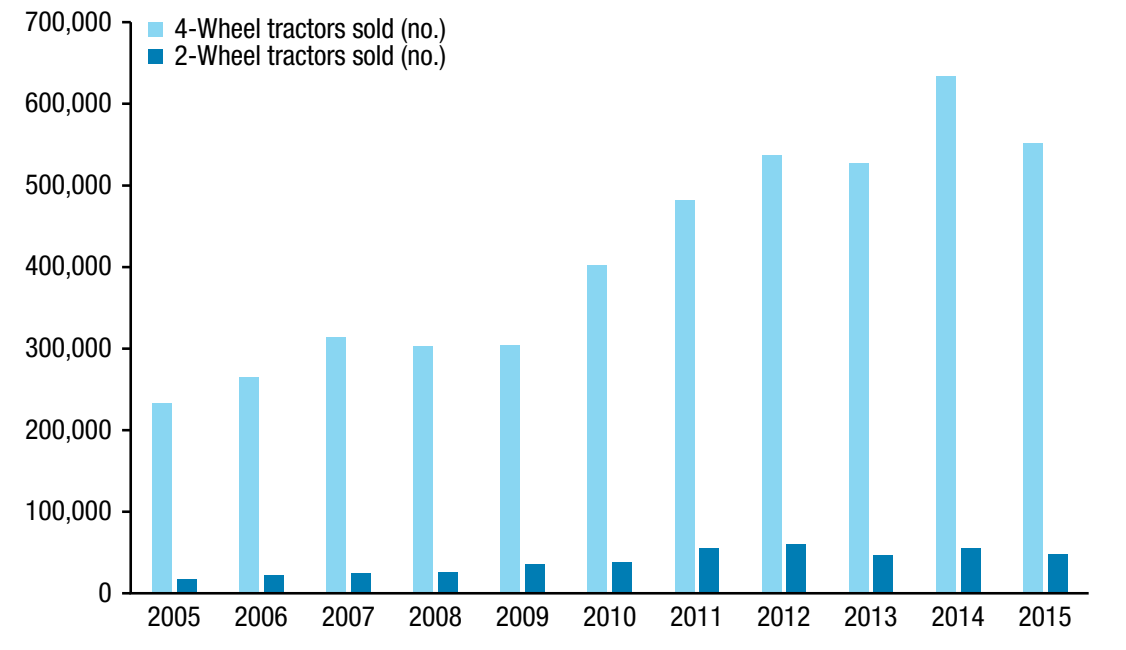

Source: Shah and Kanodia (2015).

FIGURE 3.2 Breakdown by horsepower of tractors sold in India between 2000 and 2012

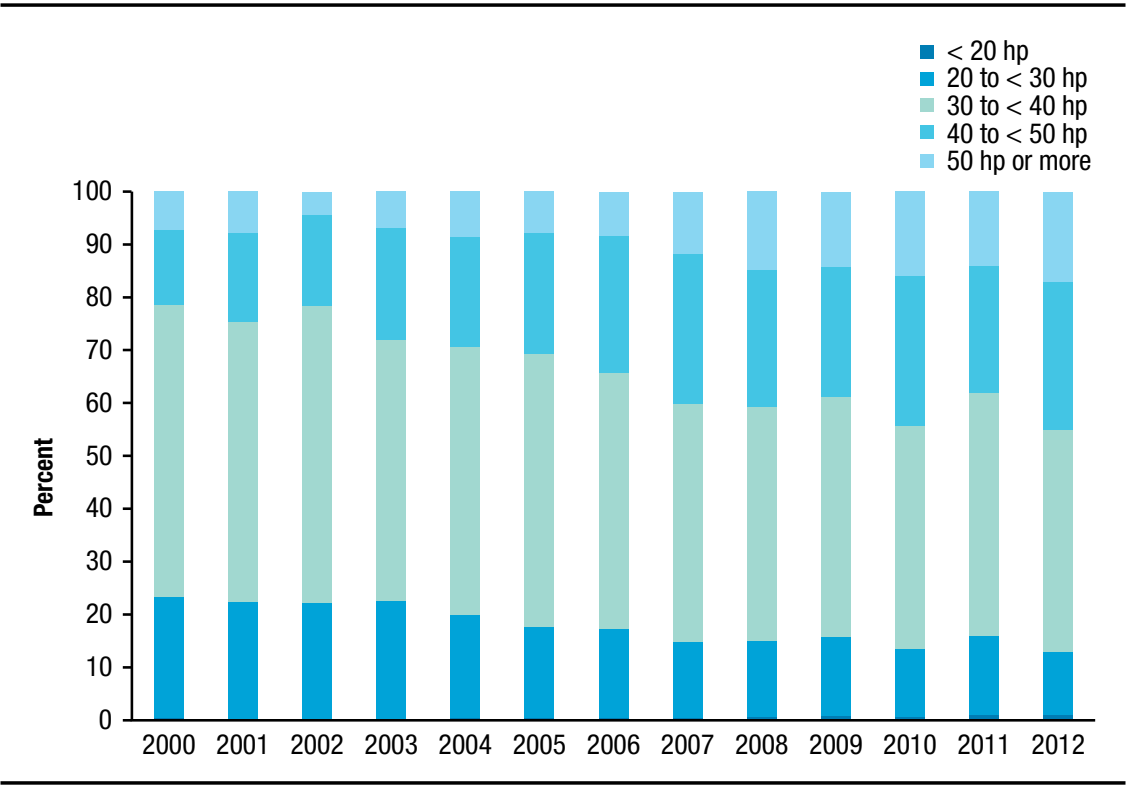

Source: CSAM (2014); Bhattarai et al. (2017). 


\section{Agroecological Conditions, Cropping Systems, and the Spread of Farm Machinery}

The adoption levels of farm mechanization vary greatly by crop type and operation type. Generally, mechanization is more common for paddy and wheat cultivation than for other crops, except planting for paddy (Table 3.5). Land plowing, seedbed preparation, and spraying of pesticides for all major crops in India have been more mechanized than other operations.

Compared with paddy and wheat, harvesting of coarse cereals (such as sorghum and pearl millet), pulses, and vegetables is much less mechanized (Table 3.5). If the rate of mechanization does not speed up for several operations on these crops, farmers may lose any comparative advantage in growing them. In fact, the acreage of many of the pulses and coarse cereals (notably sorghum) has already been declining in India in recent years.

The agricultural production pattern in India can be divided into more than 20 distinct agroecological zones, with distinct cropping patterns and cropping intensities in each zone (Figure 3.3). Currently, tractors, combine harvesters, and other farm machinery are used more intensively in Haryana, Punjab, and the western part of Uttar Pradesh (that is, the western part of the Indo-Gangetic Basin), as well as in central India (the major rice-wheat cultivation belt), than elsewhere. Likewise, soybeans are cultivated widely in central India (the states of Madhya Pradesh and Maharashtra), with their crop area expanding partly due to the ready availability of combine harvesters, which allow timely harvesting and land preparation for the following season.

\section{Labor-Land Ratio and Tractor Density}

In principle, farm mechanization should grow faster in places with less availability of labor per unit of landholding - that is, where the labor force is scarce-due to substitution effects among the factors of production for agricultural commodities. In India, the evidence on this relationship is mixed, as reflected in Figure 3.4. India itself is a region with one of the highest densities of rural population, where tractors (and power tillers in close neighbor Bangladesh) have spread rapidly in the recent past. Agricultural labor density is also very high in most parts of India, as in the South Asia region as a whole. On the other hand, Haryana and Punjab, two of the states with the highest tractor densities, also have some of the lowest agricultural labor densities in India. Still, several states with agricultural labor densities as low as those of Haryana and Punjab (Gujarat, Karnataka, Kerala, and Rajasthan) have lower tractor densities. 
TABLE 3.5 Percentage of mechanization by major crop and by operation in India, 2013

\begin{tabular}{lcccc}
\hline Crop & Seedbed preparation & $\begin{array}{c}\text { Sowing/planting/ } \\
\text { transplanting }\end{array}$ & $\begin{array}{c}\text { Weed and pest } \\
\text { control }\end{array}$ & $\begin{array}{c}\text { Harvesting and } \\
\text { threshing }\end{array}$ \\
\hline Paddy & $85-90$ & $5-10$ & $80-90$ & $70-80$ \\
Wheat & $90-95$ & $80-90$ & $70-80$ & $80-90$ \\
Potatoes & $90-95$ & $80-90$ & $80-90$ & $70-80$ \\
Cotton & $90-95$ & $50-60$ & $50-60$ & 0 \\
Maize & $90-95$ & $80-90$ & $70-80$ & $50-60$ \\
Gram & $90-95$ & $50-60$ & $60-70$ & $30-40$ \\
Sorghum & $80-90$ & $30-50$ & $60-70$ & $20-30$ \\
Millet & $80-90$ & $30-40$ & $60-70$ & $20-30$ \\
Oilseeds & $80-90$ & $30-40$ & $60-80$ & $20-30$ \\
Vegetables & $70-80$ & $5-10$ & $80-90$ & $<1$ \\
Horticultural crops & $60-70$ & $30-40$ & $40-50$ & $<1$ \\
\hline
\end{tabular}

Source: FICCI (2015).

Note: ${ }^{\text {a }}$ The reported harvester use on paddy, wheat, and potatoes seems high, and this may be the case for a few states in the north, but not for the country as a whole.

Table 3.6 shows correlation coefficients between tractor density and selected variables across the states, estimated for 1982 and 2012. The strength of spatial correlation between tractor density and agricultural labor wage declined over this period; it remained the same between tractor density and agricultural labor density. However, the strength of the correlation has increased for the average operational agricultural landholding, with its correlation coefficient with tractor density having slightly increased in 2012 over that of 1982.

Overall, mechanization growth in India has reflected key demand characteristics. First, tractor use in India has grown without significant farm size growth and even with continued land fragmentation. This trend is consistent with the hypothesis that the demand for mechanization was to meet the increasing farm power requirements for land productivity improvement, rather than to improve productivity by expanding scale. Second, the speed of growth in tractor use has been heterogeneous across regions and states within India, although the growth curves have gradually converged, with lagging regions starting to catch up. Third, $4 \mathrm{WTs}$ are still common, possibly due to the rice-nonrice crop rotation that is still common in India, as well as certain soil characteristics. 


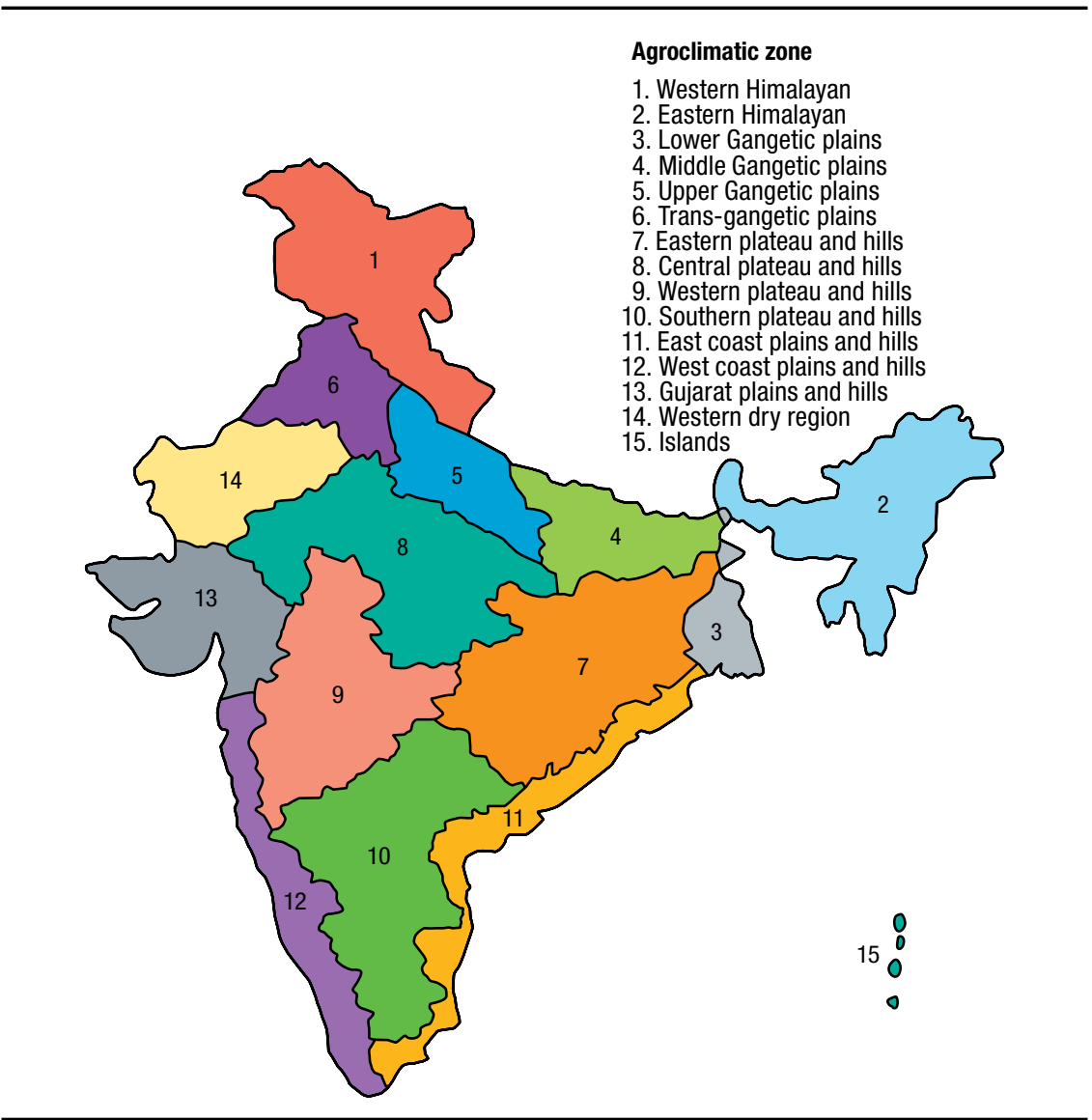

Source: India, MOEIT (2018).

\section{Supply-Side Factors}

This section describes supply-side factors for growth and expansion in the use of farm machinery such as tractors, harvesters, and other major farm implements, including (1) development and dissemination of farm machinery technologies; (2) support and incentives for effectively engaging the private sector in the adoption and diffusion of farm machinery technology; and (3) the private sector's role in developing machinery technology, markets, and custom hiring services. In the federal structure of India, issues related to agricultural and farm machinery support fall under state jurisdiction. As a result, each state of India is pursuing its own farm machinery support policies and related 
FIGURE 3.4 Tractor density and agricultural labor density across the states of India, 2012

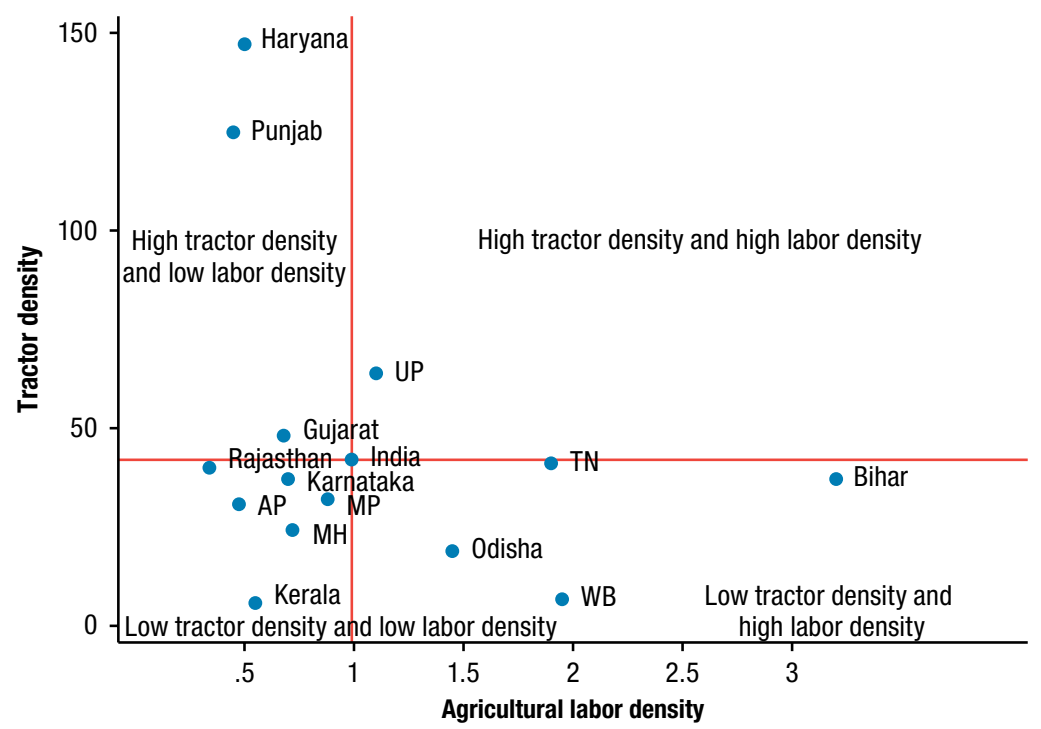

Source: Bhattarai et al. (2017).

Note: For the vertical axis, density is in units per 1,000 hectares; for the horizontal axis, density is in units per hectare. AP = Andhra Pradesh; MH = Maharashtra; MP = Madhya Pradesh; TN = Tamil Nadu; UP = Uttar Pradesh; WB = West Bengal.

TABLE 3.6 Correlation coefficients between tractor density and selected factors in India, 1982 and 2012

\begin{tabular}{lcc}
\hline & \multicolumn{2}{c}{ Correlation coefficient $(\mathbf{r})$} \\
\cline { 2 - 3 } Factor associated with changes in tractor density & 1982 & 2012 \\
\hline Real wage rate (Indian rupees/day) & $0.60^{\star \star}$ & 0.02 \\
Agricultural labor density (no. of ag. laborers/ha) & -0.38 & -0.37 \\
Average operational holding (ha) & 0.438 & $0.639^{\star \star}$ \\
Intensity of irrigation (\%) & $0.714^{\star \star \star}$ & $0.468^{\star}$ \\
Cropping intensity (\%) & $0.794^{\star \star \star}$ & $0.594^{\star \star}$ \\
Scheduled commercial bank credit (Indian rupees/ha) & 0.382 & 0.053 \\
\hline
\end{tabular}

Source: Adapted from Bhattarai et al. (2017, Table 4.3).

Note: Asterisks indicate the statistical significance: ${ }^{\star \star \star} 1 \%,{ }^{\star \star} 5 \%,{ }^{\star} 10 \%$. 
other inducements (subsidy programs) to promote farm machinery in its jurisdiction in line with location-specific constraints.

\section{Machinery Purchase, Manufacturing, and Import Policies}

In India, importing a diverse set of foreign tractors constituted an important part of technology transfer policies, which helped the country raise its knowledge levels, later inducing the growth of domestic manufacturing. This process was partly led by the premise that an inappropriate foreign technology can be a powerful stimulus to indigenous technology generation (Morehouse 1980). Throughout the 1950s, the Indian government's policy was to permit the import of "conventional" technologies, including tractors, on the condition that these technologies did not exist in the country (Morehouse 1980, 2143). Tractor imports grew throughout the 1960 s, from 3,000 tractors per year in 1961 to 16,000 per year in 1970, with a total of about 50,000 tractors imported in 10 years (Patel and Gandhi 1996; Singh, Verma, and Tandon 1984). In 1970, tractors were imported from various countries, including the USSR (3,621), Czechoslovakia (3,247), Poland $(3,131)$, the UK $(2,845)$, and Romania (1,743), among others (Patel and Gandhi 1996). Imports were largely led by the private sector, although there were also often concessional agreements. ${ }^{2}$ For example, Escorts Ltd., which started as an importer and domestic agent for Massey Ferguson, built up a dealer network in North India and, after Massey Ferguson moved to South India, formed a joint venture with Ford Motor Company USA (Morehouse 1980). By 1979, after the Indian government's shift toward technological self-reliance in the 1970s, the Escorts $35 \mathrm{hp}$ tractor (manufactured through a mixture of the original Polish technologies and substantial indigenous modification) became a leader, with 21 percent of the market share (Morehouse 1980). The important message here is that the growth of domestic tractor manufacturing in India was preceded by the importation of a large number of tractors, which helped the private sector build its knowledge about tractors and their design, setting the stage for the growth of private-sector research and development $(R \& D)$ for further modifications in the 1970s.

The Indian government shifted its focus toward technological self-reliance in the 1970s and set up more regulatory trade policies. These included import duties (30 percent) and an eventual ban on imports in 1973 (Binswanger 1978), an excise duty (about 18 percent), and central and state sales taxes

2 For example, Aurora and Morehouse (1972) mentioned that some of the imported tractor components from Czechoslovakia were subsidized. 
(about 4 percent and 7 percent, respectively), as well as a 40-120 percent import duty and an ad valorem duty on imported tractor components and raw materials in the mid- to late 1970s, among other miscellaneous taxes (Singh 1978). However, it is important to note that these increased duties and taxes were the government's attempt to raise tax revenues, taking advantage of the growing demand for tractors. In addition, a gift program was introduced, allowing citizens residing abroad to buy a tractor in foreign currency and send it free of taxes to friends or relatives in India (Farrington 1986).

\section{SUBSIDIES ON TRACTORS}

Since the 1960s, subsidies had been provided for pump sets in India (Singh 1978). The history of subsidies on tractors in India before the 1980s is somewhat sketchy, but they are thought to have had generally more limited effects on tractor purchases than in some other countries, such as Pakistan (Binswanger 1978). ${ }^{3}$ By the early 1980s, government subsidies for machinery such as tractors were 25-33 percent (Binswanger and Donovan 1987) of the purchase price. It is important to note that the subsidy rates in India have historically been lower than rates in other countries that provided similar subsidies. The subsidies on tractors and other agricultural machines have remained until now, although maximum subsidy rates by machine, type of buyer, and region have changed. ${ }^{4}$ On top of the fixed subsidy offered under various central government programs, depending upon local conditions, the state-level agency will often grant a further level of subsidy.

\section{FINANCING}

As in other countries, the Indian government has also provided financial support for the purchase of tractors and other agricultural machines. Although evidence is generally scarce regarding the actual impacts of these supports, it is noteworthy that in India, the share of tractors purchased with bank credit has historically been high. For example, in the early 1980s, 90 percent of tractors in India had been purchased using bank credit (Singh, Verma, and Tandon 1984), and this share has remained high.

In the 1970s, to encourage mechanization, the government directed banks to offer loans of up to 85 percent for farmers to purchase tractors and implements, with a repayment period of $7-10$ years and at concessionary

3 For example, Pakistan had been providing 40-50 percent subsidies on tractors since the 1960s (Binswanger 1978).

4 For example, the maximum subsidy rates are 25 percent for tractors, 40 percent for power tillers and all other agricultural machines, 50 percent for machinery purchased by women farmers and scheduled castes and tribes, and 90 percent for purchases in the northeastern states. 
rates of 10-14 percent per year (Suri 1978; Singh 1978; Farrington 1986). Similarly, the government encouraged banks to extend equipment manufacturers credit at 10-15 percent interest rates (Singh 1978). After 1975, the National Bank for Agriculture and Rural Development granted \$175 million ${ }^{5}$ (at the then-current exchange rate, amounting to perhaps $\$ 500$ million to $\$ 600$ million at the 2010 rate) for refinancing tractor loans (Farrington 1986). In the 1980s, the government continued to direct banks to reserve 11 percent of their total credit for tractor purchases by medium-size and large farmers at interest rates of 10-11 percent (Singh, Verma, and Tandon 1984).

The support for financing has continued since then. Recognizing the importance of the agricultural sector in India's development, the government and the Reserve Bank of India have played a vital role in creating a broadbased institutional framework for meeting the increasing credit requirements of the sector. Agricultural policies in India have been reviewed from time to time to maintain pace with the changing requirements of the agricultural sector, one of the priority sectors for lending among scheduled commercial banks. The government has stipulated a target of 18 percent net bank credit for the sector. Microfinance and the Kisan (Farmer) Credit Card Scheme have emerged as the major policy developments to address the distributional aspects of credit in recent years.

Cooperative banks currently have a major share ( 51.5 percent $)$ in providing loans to farmers, followed by commercial banks (36.9 percent). About 95 percent of tractor sales in India are on credit. Various institutions provide credit for tractors and machinery-public-sector banks, private-sector banks, publically funded financial institutions, cooperative banks, and private sector-operated financial institutions (usually subsidiaries of the same tractor companies selling tractors to farmers).

\section{IMPORT POLICIES}

Once India had reached near-self-sufficiency in tractors in the late 1970s, as mentioned above, the focus of trade policies shifted to imports of tractor components and spare parts. ${ }^{6}$ Until the 1980s, the Indian government placed tighter restrictions on imports of tractor components than did other South Asian countries (Farrington 1986). ${ }^{7}$ Imports of specialized sophisticated

5 Dollar figures are US dollars throughout the chapter.

6 Although Indian tractor exports have also grown, the majority of markets for Indian tractors have been domestic. For example, in 2008, exports accounted for only 14 percent of total tractor sales in India (Sarkar 2013).

7 Tractor imports dropped to marginal levels after 1978, as India's domestic manufacturing matured (Singh, Verma, and Tandon 1984). 
agricultural machines and certain spare parts to the collaborative manufacturers and actual consumers were allowed, but with an import duty of 40 percent and a countervailing duty of 10 percent (Singh, Verma, and Tandon 1984). Nonetheless, tractor manufacturing in India kept growing fast in the 1980s, with annual production growing from around 80,000 in 1980 to about 150,000 in 1991, immediately before liberalization (Singh 1998). Thus, it is important to note that even before liberalization in the early 1990s, both the demand for and the supply of tractors had already grown considerably in India, and therefore the growth in India up to the 1980s offers important lessons for African countries today. After 1991, licenses and permits were no longer needed to import or manufacture tractors, other farm machinery, or their parts and engines. In addition, the quota on imports was replaced by a uniform, transparent tax. This liberalization is likely to have helped sustain the momentum of growth that had already occurred in the 1980s (Pray and Nagarajan 2014).

Today, under the government's import policy, India levies full duty on the import of spare parts and components for agricultural implements, made up of a customs duty part and an excise duty part. For finished agricultural implements, the countervailing duty, chargeable on assessable value, is nil; the basic customs duty, chargeable on the same, is 7.5 percent; and the additional duty chargeable is 4 percent. These import duties and tariffs are still set by the Central Excise Tariff Act of 1985, which also sets a 0 percent rate of excise duty for these items. However, recently, certain machinery parts and components are being classified by the Central Excise Department under other headings that attract excise duty of about 12 percent even if they are used for agriculture. ${ }^{8}$

\section{LICENSING, REGULATIONS, AND REGISTRATION}

As mentioned above, since 1991/1992, no licensing has been needed in India for setting up a new tractor manufacturing plant. Moreover, until 2014, by which time the use of machines such as tractors had already spread widely across the country, only four testing centers offered quality testing and certification of new tractors and implements.

8 Specifically, they include power take-off shafts and gear boxes (used in agricultural implements such as rotary tillers, rotary slashers, rotary harrows, post-hole diggers, and balers), hooks (used in agricultural implements such as harrows and agricultural trailers), springs (used in agricultural implements such as cultivators, harrows, and rotary tillers), spindles and hubs (used in agricultural implements such as disc plows, disc ridgers, and disc harrows), and others. 
Farmers have to register their tractors with local road and transportation departments even for agricultural and local transport use in the villages. Nowadays, almost all tractor owners register their tractors so that they can drive them on roads and highways for nonfarm-sector uses. Unlike tractors, some other machines, such as power tillers, are not registered, preventing them from moving on the highways and roads outside of villages. This is a major difference between India and other countries in South Asia, where power tillers are often used for hauling farm and nonfarm goods from villages to urban centers and back.

\section{POLICIES ON FUELS}

Fuel policies in India, in particular those on diesel, have gradually shifted from taxation before the oil shocks of the 1970s and 1980s to subsidization since then. Before the first oil shock, in the early 1970s, high-speed diesel oil was taxed because it was used by road transportation that competed with government-owned railways; gasoline was also taxed because it was assumed to be the fuel of wealthy automobile owners. Central taxes on diesel would usually amount to 300 percent (Desai 1981). In addition, until 1974, a 100 percent import duty was imposed on diesel fuel (Binswanger 1978).

Until the 1980s, the government controlled production and pricing in the energy sectors (Sarkar and Kadekodi 1988). After the second oil shock, in 1980, and the consequent price spikes in diesel, the Indian government shifted its emphasis to meeting the energy requirements of the agricultural sector (Moulik 1988). Diesel subsidies expanded gradually throughout the 1980s, and diesel prices were also kept low by relaxing a major portion of the excise duty (Singh, Verma, and Tandon 1984). However, the pace of subsidy expansion was uneven across states. For example, whereas diesel for running a pump was already subsidized as early as 1981 in some states (Srinivasan 1981), in some states in South India, diesel fuel, unlike electricity, was not subsidized even by the late 1980s (Babu and Hallam 1989). By the 1990s, at the national level, India was providing about $\$ 1.3$ billion (in 1990s dollars) in subsidies for diesel (Larsen 1994). Fuel subsidies continued until 2015, after which they were gradually removed.

India has also invested substantially in rural electrification. In spite of limited empirical evidence about the effects of rural electrification on the prices of substitutes such as diesel, it is likely that electrification helped diesel prices

the country, the government now plans to open more than 30 such machinery quality testing centers in the country within a few years. 
remain relatively stable and lower than without electrification. Electrification started in the early 1950s, and by $1975 / 1976$, one-third of the approximately 600,000 villages in India had been electrified (Mukherjee 1978); this share increased to 57 percent by 1980 and to almost 90 percent by 1994 (Fan, Hazell, and Thorat 2000). In the 1980s, the rate for electricity used for agriculture was also kept at approximately 50 percent of that charged for industrial and domestic use (Singh, Verma, and Tandon 1984).

Partly due to these factors, the price of diesel at the pump in India has been lower than in other developing countries, at $\$ 0.23$ per liter in 1991 as opposed to about $\$ 0.55$ per liter among low-income countries, and $\$ 0.91$ as opposed to about $\$ 1.10$ to about $\$ 1.20$ in 2014 (World Bank 2017).

\section{RESEARCH AND DEVELOPMENT}

In India, as in other countries, the private sector has led a significant portion of the $\mathrm{R} \& \mathrm{D}$ related to agricultural mechanization. In the late 1970 s, most major manufacturers in India had some R\&D unit or units associated with the parent mechanical engineering company when a separate joint venture was created to make tractors with foreign collaboration (Morehouse 1980). This trend continued toward the 1980s. By the mid-1980s, capital investments in $\mathrm{R} \& \mathrm{D}$ facilities and recurring $\mathrm{R} \& \mathrm{D}$ expenditures by Indian manufacturers had reached $\$ 5$ million and $\$ 2$ million, respectively (Mohan 1986), equivalent to perhaps $\$ 10$ million and $\$ 4$ million at today's prices. The agricultural machinery industries almost doubled their R\&D spending between the mid-1980s and the mid-1990s (Pray and Nagarajan 2014). By 2008/2009, the industry was spending about $\$ 40$ million (in 2005 prices), of which about half was spent by Indian firms and the remainder by multinational companies (Pray and Nagarajan 2014). Throughout the 1990s and the following decade, the agricultural machinery industry devoted about 1.0 percent of the value of its sales to agricultural spending-low from a global standpoint (with a global average of about 2.7 percent) but still substantial (Pray and Nagarajan 2014). Although the private sector has contributed greatly to this $R \& D$, the public sector has also played a complementary role by developing designs for new equipment, educating engineers, and offering extension programs (Singh, Verma, and Tandon 1984).

\section{POLICIES TOWARD INCLUSIVE GROWTH OF AGRICULTURAL MECHANIZATION}

As noted in the previous sections, the growth of mechanization, including the use of tractors, has been uneven in India, in terms of regional variations of tractor growth, with the level of mechanization growth lagging especially in the eastern and northeastern regions. Therefore, in 2014, the Indian 
government initiated a program called the Sub-Mission on Agricultural Mechanization (SMAM) in its 12th five-year plan (for 2012-2017) (India, MOAFW 2015). The sub-mission will primarily help with modernizing mechanization in areas that are lagging or using old technologies, through financial subsidies on acquiring machinery or establishing machinery rental service centers, among other activities. The proposed funding outlay for this mission during the period of the 12th plan is 35 billion Indian rupees (Rs), or about $\$ 550$ million. ${ }^{10}$ It is important to note that addressing inequality in access to mechanization has been challenging even in countries such as India, and the recent approach of the Indian government may suggest that addressing inequality may be more feasible once overall mechanization (in terms of tractor use) has reached a sufficient level that lagging areas and regions can be more easily identified.

\section{Agricultural Machinery Manufacturing Policies}

India has seen remarkable growth in its domestic manufacturing sector for agricultural machines, including tractors. It is difficult to point out specific policies that led to this growth because there were no specific policies that promoted it. However, the Indian government did contribute to the creation of an enabling environment. Binswanger and Donovan (1987) listed three areas in which the public sector contributes to the development of the machinery manufacturing industry: (1) providing communication and transportation infrastructure, (2) directly assisting the industry through training and $\mathrm{R} \& \mathrm{D}$, and (3) establishing the regulatory framework within which the industry operates. The Indian government has generally performed many of these functions.

In terms of infrastructure, both rural electrification (mentioned earlier) and expansion of the road network have been substantial. Although estimates vary, road density in India has generally been higher than in other countries, with estimates of about $388 \mathrm{~km}$ of roads per $1,000 \mathrm{~km}^{2}$ of area at the beginning of the Green Revolution in the 1960s (Bationo et al. 2011), doubling between 1970 and 1990 (Fan, Hazell, and Thorat 2000). These densities are substantially higher than, for example, those of African countries today, which range from $4 \mathrm{~km}$ in Ethiopia to $11 \mathrm{~km}$ in Kenya to $46 \mathrm{~km}$ in Ghana (World Bank 2017).

Regarding training and $\mathrm{R} \& \mathrm{D}$, as mentioned above, imports of a large number of tractors in the 1960s helped the domestic private sector to study

10 At the 2011/2012 exchange rate of US $\$ 1=$ Rs 45 . 
the machines and develop ideas for modifications and adaptions, as well as manufacturing. Furthermore, India had already had a long history of manufacturing tractor parts; its engine manufacturing industry began in the 1930s, and by 1950, 6 companies were manufacturing 20,000 engines per year (Bell, Dawe, and Douthwaite 1998). These numbers had increased to 32 companies producing 141,000 engines by 1975 . With such an accumulation of local expertise, combined with a long history of manufacturing parts such as engines, the protectionism of the 1970s (regulations on and banning of tractor imports) helped the domestic manufacturing sector grow by facilitating smooth replacement of imported with domestic tractors in the market, without the substantial negative effects of reduced technology transfer speed that also sometimes result from protectionism (Ito 1986). Unlike in many small developing countries elsewhere, the Indian manufacturing sector also benefited from the country's large domestic market, in which annual demand for tractors had already reached 10,000 by the early 1970 s.

Several international tractor manufacturers (such as Ford and Escorts) entered into Indian tractor markets in the 1970s and 1980s. By 1992, there were more than 15 tractor manufacturers producing tractors in India. Since liberalization in the early 1990 s, several mergers among the manufacturers have taken place. Also since then, a few new international (global brand) tractor manufacturing and trading companies have started to produce tractors, combine harvesters, laser land levelers, and other implements in India. The actual market size of each tractor manufacturer varies from year to year (Table 3.7).

Tractor manufacturers in India are usually not allowed to produce attachments and the like; rather, another entity is encouraged to produce these farm implements. As a result, there is a vibrant farm implement and attachment industry in India, with more than 10,000 small-scale farm implement manufacturers scattered all over the country (Table 3.8).

\section{Ownership and Market Institutions for Mechanization Service Provision}

In the early 1970s, public sector-operated custom hiring service centers (CHSCs) were established in many places in India by state-level agricultural inputs corporations to promote farm machinery use along with application of fertilizer and other inputs. But in most states, these public rental service centers could not cover their operating costs. As a result, within a few years of their opening, many were closed down when state governments tightened their budgets. By 1980, most of them had ceased to operate. 
TABLE 3.7 Leading tractor manufacturers in India, 2009/2010 to 2015/2016

\begin{tabular}{lccccccc}
\hline & \multicolumn{7}{c}{ Percentage share in annual production } \\
\cline { 2 - 8 } Manufacturer & $\mathbf{2 0 0 9 /}$ & $\mathbf{2 0 1 0 /}$ & $\mathbf{2 0 1 1 /}$ & $\mathbf{2 0 1 2 /}$ & $\mathbf{2 0 1 3 /}$ & $\mathbf{2 0 1 4 /}$ & \multicolumn{2}{c}{ 2015/ } \\
\hline Mahindra \& Mahindra & $\mathbf{2 0 1 0}$ & $\mathbf{2 0 1 1}$ & $\mathbf{2 0 1 2}$ & $\mathbf{2 0 1 3}$ & $\mathbf{2 0 1 4}$ & $\mathbf{2 0 1 5}$ & \multicolumn{1}{c}{ 2016 } \\
TAFE & 39.55 & 39.84 & 38.60 & 38.47 & 40.08 & 37.72 & 37.71 \\
Escorts & 22.59 & 20.80 & 23.51 & 24.73 & 24.88 & 23.96 & 22.99 \\
Sonalika & 13.12 & 12.04 & 9.78 & 10.27 & 10.13 & 9.55 & 9.00 \\
John Deere & 8.21 & 8.58 & 9.79 & 10.35 & 0.83 & 12.36 & 11.94 \\
New Holland & 8.74 & 9.77 & 9.50 & 7.15 & 9.63 & 7.40 & 8.92 \\
SAME Deutz-Fahr & 4.92 & 6.00 & 5.63 & 6.04 & 7.42 & 5.80 & 5.56 \\
VST Tillers Tractors Ltd. & 0.79 & 1.05 & 1.08 & 0.89 & 5.24 & 1.36 & 1.55 \\
HMT Tractors & 0.87 & 0.84 & 1.13 & 1.37 & 1.10 & 1.01 & 1.37 \\
Force Motors & 1.07 & 0.88 & 0.69 & 0.44 & 0.22 & 0.18 & 0.13 \\
\hline
\end{tabular}

Source: Adapted from Singh, Singh, and Singh (2015).

TABLE 3.8 Status of farm mechanization industry in India, 2014

\begin{tabular}{lc}
\hline Equipment manufacturer & $\begin{array}{c}\text { Number of production } \\
\text { units in India }\end{array}$ \\
\hline Agricultural tractors & 22 \\
Power tillers & 5 \\
Irrigation pumps & 600 \\
Plant protection equipment & 300 \\
Combine harvesters & 48 \\
Reapers & 60 \\
Threshers & 6,000 \\
Seed drills and planters & 2,500 \\
Diesel oil engines & 200 \\
Plows, cultivators, harrows & 5,000 \\
Chaff cutters & 50 \\
Rural artisans & $>1$ million \\
\hline
\end{tabular}

Source: CSAM (2014). 
Over the years, a variety of forms of custom hiring service providers have emerged in the leading states and regions of India, each with a different operational modality. The pace of the growth of custom hiring services for farm machinery has been fast, especially from 2000 onward. The development of vibrant markets for these services in India is one of the reasons for the massive growth of farm machinery use in the last two to three decades. Even marginal and smallholding farmers in India have been effectively using tractors, combine harvesters, and other farm machinery, including the costly laser land leveler, through the development of rental services. The rental market has made the use of these huge and costly machines possible by aggregating services across farmers. Types of ownership and rental services for farm machinery in India can be categorized into the following major groups:

- Individual farmers as owners. Machinery has become more widespread than ever and is available in every village of India. As individual farmers purchase different pieces of equipment, a farmer-to-farmer system of service provision may develop at the local level. Then, as entrepreneurship develops, the farmer-owners may start working together as local service providers (LSPs), renting out several types of machinery. ${ }^{11}$ Eventually, some farmers take on rental services for farm machinery as a major business activity.

- Cooperative and joint ownership among farmers. Cooperative ownership of farm machinery has been most successfully adopted in Punjab, where, since 2010/2011, more than 1,250 farmers' cooperatives have been effectively providing rental services through CHSCs. Though other states (Karnataka and others) have recently attempted such initiatives, none have been as successful as Punjab's.

- Machinery owned and rented out by rural entrepreneurs (LSPs). Several public projects and private businesses are supporting individual rural entrepreneurs to operate as LSPs for rental services. For example, the Cereal Systems Initiative for South Asia supported such LSPs in Bihar, Haryana, Odisha, and eastern Uttar Pradesh.

11 Custom hiring services for grain combines are unique because the equipment goes where the work is, starting in the north for a season, going to the south for a season, and then returning to the north again. Custom hiring rates differ from place to place. An elaborate description of custom hiring services for harvesters, their movements across India, and the economics of their use in wheat cultivation is offered by Bhattarai et al. (2015). 
- Big business (corporation)-owned machinery for bigfarms. Rental programs of this type are initiated in intensively cultivated agricultural pockets of southern India. Examples include (1) rentals from Coromandel Agrico Group, (2) Yanmar Coromandel Agrisolutions Service Centre in Tamil $\mathrm{Nadu}$, and (3) rental services from sprayer manufacturer UPL Ltd. in North India.

- Big private firm-owned farm machinery for organized custom hiring services. In addition to large corporations, individual private firms have also recently started to operate CHSCs with a range of farm machinery at one place, offering services to farmers through various business models. For example, Zamindara Farm Solutions operates a rental program for farm machinery in the state of Punjab.

- Government-promoted CHSCs under a public-private partnership model. Recently some state governments (Andhra Pradesh, Karnataka, and Madhya Pradesh) have provided encouragement and funding support to private industry or nongovernmental organizations (NGOs) through a public-private partnership mode of operation. CHSCs are set up with 50-75 percent of the cost of farm implements supported by the government, with their ownership, operation, and management carried out by a private business or NGO. In this model, a large portion of the investment cost is subsidized by the government. Many other state governments are attempting to replicate Karnataka's recent successful CHSC program.

- Direct government-implemented rental services, such as the Yantradoot program in Madhya Pradesh. Under the Yantradoot Villages Scheme in Madhya Pradesh (in central India), district-level officers of the Department of Agriculture Engineering periodically demonstrate the use of farm implements to farmers in selected villages spread throughout the state and make these implements available for hire to the agricultural community at nominal prices. The designated villages are rotated each year so that all farmers can get the benefit of observing demonstrations of new farm machine technologies within their villages.

There is also an increasing trend toward using smartphone and Web-based technologies to coordinate the demand from the large number of farmers in rural areas with the rental services available to them. CHSCs represent a new business model of rental services for agricultural machinery in India, making machinery and technology accessible to hundreds of smallholding farmers at affordable prices. 
Importantly, these service providers have largely emerged informally, with little direct promotion by the government, because support programs have only recently been initiated (including the aforementioned SMAM, launched in 2014).

Custom hiring service providers have also been emerging for nonconventional machines. Combine harvester service providers have been emerging in Punjab (Singh, Kingra, and Sangeet 2013), where the number of self-propelled and tractor-driven combines has increased from 3,000 and 5,000, respectively, in 2000/2001 to 8,000 and 6,000, respectively, in 2010/2011 (CSAM 2014). Custom hiring services with tractor-pulled zero-till machines have also been emerging, albeit with 60 percent subsidies on machines that typically cost Rs 55,000 (about \$1,000) (Keil, D’Souza, and McDonald 2016). Out of approximately 13 million ha of rice-wheat systems in the Indo-Gangetic Plains, as much as 5 million ha was under zero-till technologies in 2008 (Chauhan et al. 2012). Finally, the number of service providers and contractors for laser land leveling increased from only about 8 in 2005 to an estimated 2,000-4,000 in India by 2010 (IRRI 2010; CSAM 2014) and has kept growing since then. In Punjab, the area under laser land leveling increased from about 1,000 ha in 2005 to 600,000 ha in 2010 (CSAM 2014).

\section{Farm-Level Impacts of Agricultural Mechanization}

This section presents some empirical evidence on the effects of farm machinery use on various outcomes of interest (agricultural performance, crop yield, land size, and so on) in India, using farm household-level panel data from the Village Dynamics in South Asia (VDSA) project of the International Crops Research Institute for the Semi-Arid Tropics (ICRISAT) (ICRISAT 2017). For short, we call this the "ICRISAT-VDSA dataset" or simply "VDSA data." The panel form of household data provides us the opportunity to isolate and quantify more meaningfully the net effects of farm machinery use on key agricultural performance metrics (the outcomes of interest).

The ICRISAT-VDSA dataset has been collected through the support of various donors over the years since the 1970s. The data used in this study were collected from 2001 through 2014. Details of the survey are described in Rao and others (2011a, 2011b) for the 2001-2008 period and on the VDSA project website ${ }^{12}$ for the 2009-2014 period as well as all previous periods. The scope of the ICRISAT-VDSA dataset was to collect detailed information 
on households' agricultural production activities; economic activities including farming, livestock, and nonfarm activities; household resource use; receipts from welfare programs; and coping mechanisms, among other data. The VDSA data contain details on agronomic production practices gathered through a longitudinal survey of farm households across various locations in the semi-arid regions of India. The data are therefore suitable for estimating the impact of mechanization (particularly tractor and combine harvester use) on different indicators of agricultural performance, including crop yield, labor use in farming, and production practices, as well as farm size dynamics.

The sampling frame of the data consists of a total of six villages in Andhra Pradesh and Maharashtra states, which were covered in the first-generation VDSA study conducted between 1975 and 1985. Based on the census of households in these six villages, households were classified into four groups according to farm size and landownership, from which a predetermined number of households were randomly selected for interviews. A total of 446 farm households were selected for interviews in 2001. All of these households, including any that spun off from the original households, were interviewed again annually from 2002 to 2008 . The same households were interviewed again after 2009, when the VDSA project added coverage in eastern India and Bangladesh. Our analyses use only the samples from Andhra Pradesh and Maharashtra states throughout the period 2001-2014, to maintain consistency.

From these samples, we constructed an unbalanced panel, because some households were not always interviewed every year. We analyzed more than 880 farm households as part of these unbalanced panel data. After missing observations were removed, our final sample was 5,692 households for most specifications, although for some models, such as land dynamics analysis, sample sizes were reduced because certain lagged observations had to be used as independent variables.

The results are summarized by topic under the different subheadings below. Technical discussions of empirical methods are provided in this chapter's appendix.

\section{Effects on Farm Size and Farm Size Dynamics}

Table 3.9 summarizes results on farm size dynamics and the effects of tractor ownership. The dependent variable is the growth rate in area cultivated between the current year and the previous year. The significantly positive coefficients of the number of tractors owned, or the binary indicator of owning a tractor at time $t-1$, indicates that these factors significantly increase the 
TABLE 3.9 Tractor investment and farm size dynamics in semi-arid villages in India, 2001-2014

\begin{tabular}{|c|c|c|c|c|c|}
\hline $\begin{array}{l}\text { Dependent variable }= \\
\ln (\text { cultivated })(t)-\ln (\text { cultivated })(t-1)\end{array}$ & Model 1 & Model 2 & Model 3 & Model 4 & Model 5 \\
\hline \multicolumn{6}{|l|}{ Endogenous variable } \\
\hline $\ln ($ cultivated $)(t-1)$ & $\begin{array}{l}-.707^{\star \star \star} \\
(.035)\end{array}$ & $\begin{array}{l}-.573^{\star \star \star} \\
(.053)\end{array}$ & $\begin{array}{l}-.707^{\star \star \star} \\
(.035)\end{array}$ & $\begin{array}{l}-.571^{\star \star \star} \\
(.054)\end{array}$ & $\begin{array}{l}-.802^{\star \star \star} \\
(.074)\end{array}$ \\
\hline In(cultivated)2 $(t-1)$ & n.a. & n.a. & n.a. & n.a. & $\begin{array}{l}.051^{\star \star} \\
(.019)\end{array}$ \\
\hline $\ln ($ land owned $)(t-1)$ & $\begin{array}{l}.417^{\star \star \star} \\
(.061)\end{array}$ & $\begin{array}{l}.390^{\star \star \star} \\
(.056)\end{array}$ & $\begin{array}{l}.419^{\star \star \star} \\
(.060)\end{array}$ & $\begin{array}{l}.392^{\star \star *} \\
(.056)\end{array}$ & $\begin{array}{l}.476^{* \star \star} \\
(.043)\end{array}$ \\
\hline Number of tractors owned $(t-1)$ & $\begin{array}{l}.313^{\star \star *} \\
(.098)\end{array}$ & $\begin{array}{l}.213^{\star \star} \\
(.104)\end{array}$ & n.a. & n.a. & $\begin{array}{l}.115 \dagger \\
(.069)\end{array}$ \\
\hline Owns tractor $(y e s=1)(t-1)$ & n.a. & n.a. & $\begin{array}{l}.306^{\star \star \star} \\
(.097)\end{array}$ & $\begin{array}{l}.199^{\star \star} \\
(.093)\end{array}$ & n.a. \\
\hline \multicolumn{6}{|l|}{ Exogenous variable } \\
\hline Other household characteristics & Included & Included & Included & Included & Included \\
\hline Year dummies & Included & Included & Included & Included & Included \\
\hline 0 -value dummies & Included & Included & Included & Included & Included \\
\hline Number of observations & 3,839 & 3,839 & 3,839 & 3,839 & 3,839 \\
\hline Number of panels & 625 & 625 & 625 & 625 & 625 \\
\hline Number of instruments & 246 & 211 & 246 & 211 & 426 \\
\hline \multicolumn{6}{|l|}{$p$-value } \\
\hline $\mathrm{H}_{0}$ : Model jointly insignificant & .000 & .000 & .000 & .000 & .000 \\
\hline $\mathrm{H}_{0}$ : Overidentified (Hansen test) & .142 & .223 & .136 & .229 & .716 \\
\hline $\mathrm{H}_{0}$ : Autocorrelation & .529 & .778 & .534 & .776 & .364 \\
\hline $\begin{array}{l}\text { Closest lag of endogenous variables } \\
\text { used as instrumental variables }\end{array}$ & 1 & 2 & 1 & 2 & 1 \\
\hline
\end{tabular}

Source: Authors' calculations based on ICRISAT (2017).

Note: Asterisks indicate the statistical significance: ${ }^{\star \star \star} 1 \%,{ }^{\star \star} 5 \%,{ }^{\star} 10 \%, \dagger 15 \%$. Other explanatory variables include $\ln$ (household size —working age), In(household size—dependents), In(completed education of household head, years), $\ln ($ experience of household head). n.a. $=$ not applicable.

growth rate of the operational farm size between $t-1$ and $t$. For the sample at hand, owning a tractor at $t-1$ increases the growth rate of the operational farm size by about 10-30 percentage points, which is potentially substantial. The positive effects of tractor ownership on the growth of operational size hold even after controlling for the dynamics in operational sizes through the variable $\ln$ (cultivated) $(t-1)$ and its squared term, as well as the size of land owned at time $t$. 


\section{Effects on Land Productivity and Adoption of Other Modern Technologies}

\section{EFFECTS ON LABOR AND DRAFT ANIMAL USE}

Table 3.10 presents the household-level effects of tractor use on the use of human labor and of bullocks for land preparation, ${ }^{13}$ estimated through the same panel data specifications as those described above. Similarly, Table 3.11 presents the household-level effects of combine harvester use on the use of labor and bullocks for harvesting and threshing. In both tables, figures for the random-effects tobit model correspond to responses at a sufficiently high level of labor or bullock use (not at a marginal level).

Generally, tractor use for land preparation is mostly bullock saving (Table 3.10), although it is also somewhat labor saving. In the sample at hand, 1.00 hour of using a tractor for land preparation leads to about a 0.84 -hour reduction in the use of bullocks. However, this effect is for all households, including those not using bullocks. Among households actually using bullocks for land preparation, 1.00 hour of tractor use for land preparation substitutes for about 1.04 hours of bullock use for land preparation. The effect on labor use for land preparation is relatively small and generally statistically insignificant.

These patterns are generally consistent with early mechanization experiences in the United States and Japan, where much of the farm power for land preparation had been provided by animals (horses and so on) and the use of tractors substituted for more animal power than human labor.

In contrast, the combine harvester is strictly labor saving (Table 3.11). ${ }^{14}$ On average, 1.00 hour of combine harvester use reduces the labor for harvesting and threshing by approximately 28-29 hours. The use of labor for these activities is also highly responsive to wages, unlike the case for land preparation, shown in Table 3.10. This result is consistent with the generalization in Binswanger (1986) that mechanization of harvesting is profitable only when the wages are sufficiently high and rising, whereas mechanization of land preparation can be profitable even at low wages.

The use of tractors substitutes for animal and human power only in specific operations, rather than for their aggregate use over the whole farming

13 Although some rounds of the ICRISAT-VDSA categorize certain activities as "land preparation," the term is not clearly defined for other rounds. We identify all activities such as harrowing, plowing, land clearing, puddling, and any other land-related preparation, aggregating all of them as "land preparation" to calculate the total labor use, bullock use, and tractor use for land preparation.

14 The use of bullocks for harvesting or threshing was minimal in the samples. 
TABLE 3.10 Effects of tractor use for land preparation on the use of human labor and animal (bullock) traction for land preparation (per year, all production seasons combined)

\begin{tabular}{|c|c|c|c|c|}
\hline \multirow{3}{*}{$\begin{array}{l}\text { Dependent variable } \\
\text { Estimation model }\end{array}$} & \multicolumn{4}{|c|}{ (Hours/year) } \\
\hline & \multicolumn{2}{|c|}{$\begin{array}{l}\text { Labor use for land } \\
\text { preparation }\end{array}$} & \multicolumn{2}{|c|}{$\begin{array}{l}\text { Bullock use for land } \\
\text { preparation }\end{array}$} \\
\hline & $\begin{array}{l}\text { Fixed-effects } \\
\text { SURE }\end{array}$ & $\begin{array}{c}\text { System of } \\
\text { panel tobit } \\
\text { regressions }\end{array}$ & $\begin{array}{l}\text { Fixed-effects } \\
\text { SURE }\end{array}$ & $\begin{array}{c}\text { System of } \\
\text { panel tobit } \\
\text { regressions }\end{array}$ \\
\hline Tractor used for land preparation (hours) & .118 & .076 & $-.837^{\star \star \star}$ & $-1.041^{\star \star \star}$ \\
\hline Farmland owned (acres) & $4.435^{\star \star \star}$ & $4.184^{\star \star \star}$ & $4.358^{\star \star \star}$ & $4.850^{\star \star \star}$ \\
\hline In(bullock rental costs) & n.a. & n.a. & -2.098 & -5.404 \\
\hline In(male labor wage for land preparation) & -1.447 & 2.342 & n.a. & n.a. \\
\hline Other household characteristics & Included & Included & Included & Included \\
\hline Year dummies & Included & Included & Included & Included \\
\hline Village dummies & Included & Included & Included & Included \\
\hline Year * village dummies & Included & Included & Included & Included \\
\hline Intercept & Included & Included & Included & Included \\
\hline Household fixed effects & Fixed effects & CRE & Fixed effects & CRE \\
\hline Number of observations & 5,057 & 5,057 & 5,057 & 5,057 \\
\hline Number of panels & 1,054 & 1,054 & 1,054 & 1,054 \\
\hline$\%$ of uncensored observations & n.a. & 81 & n.a. & 65 \\
\hline $\mathrm{H}_{0}$ : Variables are exogenous & Yes & n.a. & Yes & n.a. \\
\hline
\end{tabular}

Source: Authors' calculations based on ICRISAT (2017).

Note: Asterisks indicate the statistical significance: ${ }^{\star \star \star} 1 \%,{ }^{\star \star} 5 \%,{ }^{\star} 10 \%$. CRE $=$ correlated random effects; n.a. $=$ not applicable; SURE = seemingly unrelated regression.

operation. This point becomes clearer if we assess the effects of overall tractor use (including activities other than land preparation) on the overall use of draft animals or human labor for farming. Table 3.12 presents these results: 1.00 hour of tractor use reduces the overall use of bullocks by about 0.33 hours, which is considerably smaller than the effect of tractors on bullock use for land preparation alone. For human labor, the effects are even weaker and generally insignificant. Thus, the effects of tractor use on animal and labor use vary across farming operations and are more pronounced for land preparation than for other operations. ${ }^{15}$

15 Evidence on gendered labor use in India is scarce, except for one study. Carranza (2014) showed that in contemporary India, plow technology is more likely to be adopted for deep, loamy soils than for shallow, clayey soils, and that tractors are associated with less participation of women in agriculture because in India, deep tillage reduces the use of human labor for subsequent activities (transplanting, fertilizing, weeding, and the like), particularly reducing female labor demand. 
TABLE 3.11 Effects of combine harvester use on the use of human labor for harvesting and threshing (per year, all production seasons combined)

\begin{tabular}{lcc}
\hline Dependent variable & \multicolumn{2}{c}{$\begin{array}{c}\text { Labor use for harvesting and threshing } \\
\text { (hours/year) }\end{array}$} \\
\hline Estimation model & $\begin{array}{c}\text { Fixed-effects } \\
\text { SURE }\end{array}$ & $\begin{array}{c}\text { System of panel tobit } \\
\text { regressions }\end{array}$ \\
\hline Combine harvester use (hours) & $-28.556^{\star \star}$ & $-28.138^{\star \star \star}$ \\
Farmland owned (acres) & $59.616^{\star \star \star}$ & $58.742^{\star \star *}$ \\
In(male labor wage) & $-134.941^{\star \star}$ & $-234.671^{\star \star}$ \\
Used irrigation (yes $=1$ ) & $222.852^{\star \star *}$ & n.a. \\
Other household characteristics & Included & Included \\
Year dummies & Included & Included \\
Village dummies & Included & Included \\
Year * village dummies & Included & Included \\
Intercept & Included & Included \\
Household fixed effects & Fixed effects & CRE \\
\hline Number of observations & 5,057 & 5,057 \\
Number of panels & 1,054 & 1,054 \\
$\%$ of uncensored observations & n.a. & 98 \\
$\mathrm{H}_{0}$ : Variables are exogenous & Yes & n.a. \\
\hline
\end{tabular}

Source: Authors' calculations based on ICRISAT (2017).

Note: Asterisks indicate the statistical significance: ${ }^{\star \star \star} 1 \%,{ }^{\star \star} 5 \%,{ }^{\star} 10 \%$. CRE $=$ correlated random effects; n.a. $=$ not applicable; SURE = seemingly unrelated regression.

These findings are consistent with other recent findings that the adoption of tractors does not simply substitute for human labor or animal traction, but changes the overall returns to scale in production, and the use of labor or animals is also affected more profoundly by such transformations of overall production technologies than by piecemeal adoption for a single process (Takeshima 2017).

\section{EFFECTS ON CHEMICAL FERTILIZER USE INTENSITY}

Table 3.13 presents the estimated effects of tractor use for land preparation on chemical fertilizer use intensity. Generally, 1-hour per acre increase in tractor use for land preparation (approximately a 50 percent increase on average) is associated with increased chemical fertilizer use by about $1-2 \mathrm{~kg} / \mathrm{acre}$, or approximately 3 percent. Therefore, although the effects are significantly positive, they are modest. This result is consistent with the conventional view that tractor use leads to yield-enhancing operations only modestly or not at all (for example, Jayasuriya, Te, and Herdt 1986). However, a recent study in the 
TABLE 3.12 Effects of tractor use on overall labor and animal use at the household level

\begin{tabular}{lccc}
\hline & Bullock use/hour & & Labor use/hour \\
\cline { 2 - 3 } Variable & $\begin{array}{c}\text { System of panel tobit } \\
\text { regressions }\end{array}$ & & $\begin{array}{c}\text { Fixed-effects } \\
\text { SURE }\end{array}$ \\
\hline Tractor use (hours) & $-.327^{*}$ & 2.862 \\
Farmland owned (acres) & $11.024^{\star \star \star}$ & $118.629^{\star \star *}$ \\
In(bullock rental costs) & $-26.190^{\star}$ & $-267.111^{*}$ \\
In(male labor wage) & -15.597 & $-329.656^{\star}$ \\
Other household characteristics & Included & Included \\
Year dummies & Included & Included \\
Village dummies & Included & Included \\
Year * village dummies & Included & Included \\
Household fixed effects & Fixed effects & CRE \\
Intercept & Included & & Included \\
\hline Number of observations & 5,057 & 5,057 \\
Number of panels & 1,054 & & 1,054 \\
$\%$ of uncensored observations & 95 & & n.a. \\
$R$-squared & .621 & & .554 \\
\hline
\end{tabular}

Source: Authors' calculations based on ICRISAT (2017).

Note: Asterisks indicate the statistical significance: ${ }^{\star \star \star} 1 \%,{ }^{\star \star} 5 \%,{ }^{\star} 10 \%$. CRE $=$ correlated random effects; n.a. $=$ not applicable; SURE = seemingly unrelated regression.

Terai zone of Nepal, adjacent to Bihar state in India, suggests that mechanization may raise the returns on chemical fertilizer use at the intensive margins (Takeshima et al. 2017). Future studies in India, especially in areas bordering Nepal and sharing common agroecological conditions, should investigate whether similar effects hold in India.

\section{EFFECTS OF TRACTOR AND COMBINE HARVESTER USE ON YIELDS OF KEY CROPS}

We next consider how tractor and combine harvester use affects the yields of key crops. Given the prevalence of various crops in the areas covered by the VDSA, we select rice and cotton in kharif season, wheat in rabi season, and sugarcane (an annual) to investigate. Utilizing detailed information from the VDSA, we estimate effects on yields, controlling for fixed effects of plot, season, and variety.

Table 3.14 summarizes the estimated yield effects. Generally, the use of tractors does not seem to affect yield. Only for cotton does tractor use appear to exhibit weakly significant effects on yield (statistical significance at the 
TABLE 3.13 Effects of tractor use for land preparation on the use of chemical fertilizer per acre (per year, all production seasons combined)

\begin{tabular}{lccc}
\hline & \multicolumn{3}{c}{ Chemical fertilizer use } \\
\cline { 2 - 4 } Dependent variable & $\begin{array}{c}\text { (kg per acre/ } \\
\text { year) }\end{array}$ & $\begin{array}{c}\text { In } \begin{array}{c}\text { (kg per acre/ } \\
\text { year) }\end{array} \\
\text { (kg per acre/ } \\
\text { year) }\end{array}$ \\
\hline Estimation model & $\begin{array}{c}\text { Fixed-effects } \\
\text { SURE }\end{array}$ & $\begin{array}{c}\text { Fixed-effects } \\
\text { SURE }\end{array}$ & $\begin{array}{c}\text { System of panel } \\
\text { tobit regressions }\end{array}$ \\
\hline Tractor use for land preparation (hours per acre) & .678 & $.054^{\star \star \star}$ & $1.725^{\star \star}$ \\
In(male labor wage for land preparation) & -1.187 & -.017 & $19.111^{\star}$ \\
In(fertilizer price) & $-18.086^{\star \star \star}$ & $-.370^{\star \star *}$ & $-10.312^{\star \star}$ \\
Used irrigation (yes =1) & $14.010^{\star \star \star}$ & $.151^{\star \star *}$ & 3.933 \\
Other household characteristics & Included & Included & Included \\
Year dummies & Included & Included & Included \\
Village dummies & Included & Included & Included \\
Year * village dummies & Included & Included & Included \\
Household fixed effects & Fixed effects & Fixed effects & CRE \\
Intercept & Included & Included & Included \\
\hline Number of observations & 5,057 & 5,057 & 5,057 \\
Number of panels & 1,054 & 1,054 & 1,054 \\
$\%$ of uncensored observations & n.a. & n.a. & 80 \\
$p$-value & n.a. & n.a. & n.a. \\
$\mathrm{H}_{0}$ : Model jointly insignificant & .000 & .000 & .000 \\
$\mathrm{H}_{0}$ : Variables are exogenous & Yes & Yes & n.a. \\
\hline
\end{tabular}

Source: Authors' calculations based on ICRISAT (2017).

Note: Asterisks indicate the statistical significance: ${ }^{\star \star \star} 1 \%,{ }^{\star \star} 5 \%,{ }^{\star} 10 \%$. CRE $=$ correlated random effects; n.a. $=$ not applicable; SURE $=$ seemingly unrelated regression.

15 percent level). This result may be partly because of significant adoption of Bt cotton varieties in India observed lately in areas including those covered by VDSA data. Bt cotton may be more suitable for production on large farms than on smaller ones because its resistance to major pests can reduce the labor cost for pest control, particularly on large farms (Deininger and Byerlee 2012). Although the exact mechanisms need to be investigated in future studies, the results suggest potential interactions between tractors and certain improved varieties.

The adoption of combine harvesters seems to have mixed effects. Although yield effects on wheat are insignificant, those for rice in kharif season are significant, with the adoption of combine harvesters leading to about 
TABLE 3.14 Yield effects of tractor and combine harvester use on key crops

\begin{tabular}{lcccc}
\hline Dependent variable & \multicolumn{3}{c}{ Growth rate of yield $(1=100 \%$ increase) } \\
\hline Crop and season & $\begin{array}{c}\text { Rice } \\
\text { (kharif } \\
\text { season) }\end{array}$ & $\begin{array}{c}\text { Cotton } \\
\text { (kharif } \\
\text { season) }\end{array}$ & $\begin{array}{c}\text { Wheat } \\
\text { (rabi } \\
\text { season) }\end{array}$ & $\begin{array}{c}\text { Sugarcane } \\
\text { (annual) }\end{array}$ \\
\hline Whether using tractor or not (yes $=1$, no $=0)$ & .041 & .093 & -.080 & .045 \\
Whether using combine harvester or not (yes $=1$, no $=0)$ & $.235^{\star}$ & -.122 & -.191 & n.v. \\
Price of crop (natural log) & $.006^{\star *}$ & -.042 & .032 & .020 \\
Other household characteristics & Included & Included & Included & Included \\
Year dummies & Included & Included & Included & Included \\
Village dummies & Included & Included & Included & Included \\
Year * village dummies & Included & Included & Included & Included \\
Household fixed effects & Included & Included & Included & Included \\
Intercept & Included & Included & Included & Included \\
Number of observations & 443 & 601 & 422 & 479 \\
\hline
\end{tabular}

Source: Authors' calculations based on ICRISAT (2017).

Note: Asterisks indicate the statistical significance: ${ }^{\star \star \star} 1 \%,{ }^{\star \star} 5 \%,{ }^{*} 10 \%$. n.v. $=$ variables are dropped because there is no variation among the samples.

a 23.5 percent increase in yield, given the prevailing yield levels in the sample. This finding is consistent with the hypothesis that adopting combine harvesters can raise rice yield through reduced harvest loss associated with improved harvesting and threshing precision enabled by machines, among other things. The insubstantial effects for wheat indicate that the yield effects of combine harvester use could vary by crop.

\section{Effects on Seasonal Wage Variability}

To analyze seasonal wage variability, we use monthly microlevel VDSA data on seasonal wage rates in a particular Andhra Pradesh village, Aurapally. We analyze the seasonal and monthly variations in agricultural wages by taking the average rate in the village for each of four types of labor in each month of 2011 (Table 3.15).

Interestingly, the seasonal fluctuation (coefficient of variation) in the wage rate for female agricultural labor is six times higher than that of male labor. This result suggests that employment is more stable for men than women, who are hired largely for peak-season work; indeed, we see more fluctuation in demand for female labor than for male labor across the sampled 18 villages. Furthermore, the wage rate for women in India is almost 50 percent 
TABLE 3.15 Wage rates for agricultural labor (by sex), bullocks, and tractors in a typical dryland village in Andhra Pradesh, India, 2011

\begin{tabular}{lcccc}
\hline & \multicolumn{4}{c}{ Rupees per hour } \\
\cline { 2 - 5 } Month & $\begin{array}{c}\text { Bullock pair + } \\
\text { driver wage }\end{array}$ & $\begin{array}{c}\text { Female } \\
\text { labor wage }\end{array}$ & $\begin{array}{c}\text { Male } \\
\text { labor wage }\end{array}$ & $\begin{array}{c}\text { Tractor + } \\
\text { driver }\end{array}$ \\
\hline January & 600 & 118 & 200 & 600 \\
February & 610 & 88 & 190 & 465 \\
March & 610 & 93 & 200 & 430 \\
April & 570 & 84 & 200 & 550 \\
May & 650 & 93 & 210 & 510 \\
June & 775 & 138 & 200 & 585 \\
July & 580 & 141 & 194 & 568 \\
August & 610 & 127 & 210 & 570 \\
September & 640 & 135 & 205 & 520 \\
October & 610 & 124 & 200 & 600 \\
November & 610 & 126 & 200 & 520 \\
December & 570 & 104 & 200 & 550 \\
Average & 623 & 118 & 201 & 540 \\
Standard deviation & 55 & 21 & 6 & 53 \\
Coefficient of variation & 9 & 18 & 3 & 10 \\
\hline
\end{tabular}

Source: Authors' calculations based on ICRISAT (2017).

lower than that for men, except in the peak season of farm operation, June to November. The rate for a bullock pair and male operator for a day in 2011 was substantially higher than the rate for either a male or female worker, and the same as hiring a tractor and driver for a mere hour. A typical tractor of $40 \mathrm{hp}$ can plow almost 50 percent more area in an hour than a pair of animals can plow in a day. These findings illustrate the field-level economics behind the astonishing increase in tractor rentals among Indian farmers.

\section{Conclusions and Implications}

Historical review of the evolution of mechanization growth in India reveals important lessons about the drivers and impacts of mechanization. The spread of tractors despite the continuous decline in average farm size indicates that mechanization can grow even in a smallholder-dominated society through extensive custom hiring services, at least in the medium term, before the 
comparative advantage starts shifting toward larger farms as mechanization deepens. The speed of mechanization growth can vary considerably across regions, depending on agroecological conditions and farming and cropping systems. Although $4 \mathrm{WTs}$ are more common than power tillers, due possibly to the prevalence of rice-nonrice rotation and other soil-related constraints, a popular horsepower for $4 \mathrm{WTs}$ has been $30-50 \mathrm{hp}$.

Substantial infrastructure endowments (in terms of roads, for example), which were already high in the 1960s, as well as investments into rural electrification, were likely to have been important for the growth in domestic manufacturing of tractors. The promotion of importing tractors in the early days was likely to have helped farmers and technicians in India accumulate knowledge about tractors and parts. This knowledge, again, may have contributed to the growth of the domestic tractor manufacturing sector even as import restrictions in the 1970s were negatively affecting the continuous transfer of foreign tractor technologies. Over time, diverse models of providing custom hiring services for tractors and combine harvesters have begun to serve areas where such services are profitable, with relatively little direct support from the government. The government's direct support has instead concentrated on recent efforts to achieve inclusive growth by providing services to those left behind. With some subsidies, service providers for zero-till technologies and laser land leveling have also emerged. The private sector has also stepped up to provide facilitating services that connect service providers and farmers.

Empirical analyses of the impact of tractor ownership and tractor/combine harvester use confirm many of our hypotheses. Despite the typically small landholding in India, tractor ownership is led by the motive to expand farm size. Tractors are more bullock saving than labor saving, whereas combine harvesters are more strongly labor saving. This finding is consistent with the hypothesis that power requirements in Indian farming are much greater than can be met by human labor only, so that the returns on substituting tractors for human labor are substantial. These returns are an important precondition for custom hiring service providers to earn enough profit to provide services. Combine harvesters are more yield enhancing than tractors because the former are likely to directly reduce harvesting losses. Tractor adoption for land preparation, however, induces greater chemical fertilizer use, which may then lead to yield increases.

As for policy recommendations, Indian experiences offer a number of lessons to African countries. First, although India eventually developed domestic manufacturing industries for tractors and other major agricultural machinery, 
at an early stage the country followed less distorting tractor importation policies. Through such an approach, the country imported a diverse set of foreign tractors. The availability of such great diversity in designs, brands, and functions of machines stimulated learning by local engineers and fabricators, as well as local adaptations, and eventually helped the emergence of strong and vibrant manufacturing industries. Although taxes, tariffs, or both had been placed to raise government revenues, they were introduced only after overall demand and imports had grown sufficiently and the local manufacturing capacity had been raised sufficiently.

Second, though subsidies have long been provided for agricultural machinery, India has kept subsidy levels relatively low (25-33 percent) and instead has expanded the types of machines (including brands and designs) for which subsidies are applicable. Consequently, its subsidies have been less selective and distorting, and have contributed more to increasing the range of machines available in the market.

Third, significant support for finance, such as directing banks to reserve 11 percent of total credit for tractor purchases (in the 1980s) coincided with a significantly high share of tractors purchased with bank credit over time. The direction of causality remains unclear and the cost-effectiveness of this approach needs further investigation. The prevalence of relatively small 4WTs (with an average horsepower of 30) in India might have brought in more buyers who were wealthy enough to buy those tractors with some credit but not wealthy enough to buy larger, more expensive tractors-unlike in African countries, where only larger tractors are available, which can be bought only by wealthy individuals, who need no credit at all.

Last, the government has provided significant public goods. It has facilitated private-sector $\mathrm{R} \& \mathrm{D}$ in machines by developing designs for new equipment, educating engineers, and offering extension programs. Furthermore, significant public investments have been provided over time in infrastructure (road, irrigation) and complementary technologies (improved varieties and so on).

Though the economic, institutional, and political conditions in India differ from those of many African countries, the Indian experiences have been closer to the principles of a significant government focus on public goods provision and facilitation, with fewer distortions of the markets. These are likely to be important principles that African countries must follow in reforming their mechanization support policies. 


\section{References}

Arellano, M., and S. Bond. 1991. "Some Tests of Specification for Panel Data: Monte Carlo Evidence and an Application to Employment Equations." Review of Economic Studies 58: 277-297.

Arellano, M., and O. Bover. 1995. "Another Look at the Instrumental Variables Estimation of Error-Components Model." Journal of Econometrics 68: 29-52.

Aurora, G. S., and A. Morehouse. 1972. "Dilemma of Technological Choice: The Case of the Small Tractor." Economic and Political Weekly 7 (31/33): 1633-1644.

Babu, S. C., and A. Hallam. 1989. "Evaluating Agricultural Energy Policies under Uncertainty: The Case of Electricity in South India." Agricultural Economics 3 (3): 187-198.

Bationo, A., B. Waswa, J. M. Okeyo, F. Maina, and J. M. Kihara, eds. 2011. Innovations as Key to the Green Revolution in Africa. Vol. 1, Exploring the Scientific Facts. New York: Springer Science + Business Media.

Bell, M. A., D. Dawe, and M. B. Douthwaite. 1998. Increasing the Impact of Engineering in Agricultural and Rural Development: Deliberations of a Think Tank, 26-28 February 1998, IRRI, Los Baños, Philippines. Discussion Paper 30. Manila: International Rice Research Institute.

Bhattarai, M., P. K. Joshi, R. S. Shekhawat, and H. Takeshima. 2017. The Evolution of Tractorization in India's Low-Wage Economy: Key Patterns and Implications. IFPRI Discussion Paper 01675. Washington, DC: International Food Policy Research Institute.

Bhattarai, M., G. Singh, H. Takeshima, and S. Shekhawat. 2018. Farm Machinery Uses and Agricultural Industries in India: Status, Evolution, Implications, and Lessons Learned. IFPRI Discussion Paper 01715. Washington, DC: IFPRI.

Bhattarai, M., B. L. Varalakshmi, P. R. Pandey, A. B. Dhumale, and C. Bantilan. 2015. "Whether Combine Harvester Is Speeding Up Rural Transformation in India?" Poster presented at Village Dynamics in South Asia workshop at International Crops Research Institute for the Semi-Arid Tropics, Hyderabad, India, March. http://vdsa.icrisat.ac.in/Include/posters /Poster28.pdf.

Binswanger, H. 1978. The Economics of Tractors in South Asia: An Analytical Review. New York: Agricultural Development Council; Hyderabad: International Crops Research Institute for the Semi-Arid Tropics.

_. 1986. "Agricultural Mechanization: A Comparative Historical Perspective." World Bank Research Observer 1 (1): 27-56.

Binswanger, H., and G. Donovan. 1987. Agricultural Mechanization: Issues and Options. Washington, DC: World Bank. 
Blundell, R., and S. Bond. 1998. "Initial Conditions and Moment Restrictions in Dynamic Panel Data Models." Journal of Econometrics 87: 115-143.

Carranza, E. 2014. "Soil Endowments, Female Labor Force Participation, and the Demographic Deficit of Women in India." American Economic Journal: Applied Economics 6 (4): 197-225.

Chamberlain, G. 1984. "Panel Data." In Handbook of Econometrics. Vol. 2, ed. Z. Grilliches and M. D. Intriligator, 1247-1318. Amsterdam: North-Holland.

Chauhan, B. S., G. Mahajan, V. Sardana, J. Timsina, and M. L. Jat. 2012. "Productivity and Sustainability of the Rice-Wheat Cropping System in the Indo-Gangetic Plains of the Indian Subcontinent: Problems, Opportunities, and Strategies." Advances in Agronomy 117 (1): $315-369$.

CSAM (Centre for Sustainable Agricultural Mechanization). 2014. "Country Pages: India.” Accessed February 25, 2018. http://un-csam.org/PPT/in-index.htm.

Deininger, K., and D. Byerlee. 2012. "The Rise of Large Farms in Land-Abundant Countries: Do They Have a Future?” World Development 40 (4): 701-714.

Desai, A. 1981. Interfuel Substitution in the Indian Economy. Energy in Developing Countries Discussion Paper D-73B. Washington, DC: Resources for the Future.

Fan, S., P. Hazell, and S. Thorat. 2000. "Government Spending, Agricultural Growth and Poverty in Rural India." American Journal of Agricultural Economics 82 (4): 1038-1051.

FAO (Food and Agriculture Organization of the United Nations). 2018. AQUASTAT database. Accessed March 2. www.fao.org/nr/water/aquastat/main/index.stm.

Farrington, J. 1986. "Mechanization Policy and the Impact of Tractors in South Asia: A Review." In Small Farm Equipment for Developing Countries: Proceedings of the International Conference on Small Farm Equipment for Developing Countries: Past Experiences and Future Priorities, 2-6 September 1986, 85-124. Los Baños, Philippines: International Rice Research Institute.

FICCI (Federation of Indian Chambers of Commerce and Industry). 2015. Transforming Agriculture through Mechanization: A Knowledge Paper on Indian Farm Equipment Sector. New Delhi: Grant Thornton India. http://ficci.in/spdocument/20682/agrimach.pdf.

Goel, H., and V. Kumar. 2013. Automobiles: Sixth Gear. Mumbai: Kotak Securities Ltd.

Henderson, H., L. Corral, E. Simning, and P. Winters. 2015. "Land Accumulation Dynamics in Developing Country Agriculture.” Journal of Development Studies 51 (6): 743-761.

ICRISAT (International Crops Research Institute for the Semi-Arid Tropics). 2017. Village Dynamics in South Asia Dataset 2001-2014. Hyderabad, India. http://vdsa.icrisat.ac.in /vdsa-database.aspx. 
India, MOAFW (Ministry of Agriculture and Farmers' Welfare). 2015. Agricultural Mechanization Sub-Mission (SMAM): A Brief. New Delhi.

India, MOEIT (Ministry of Electronics and Information Technology). 2018. "Agro Climatic Zones in India." Accessed March 2. http://vikaspedia.in/agriculture/crop-production /weather-information/agro-climatic-zones-in-india.

IRRI (International Rice Research Institute). 2010. Rice in the Global Economy: Strategic Research and Policy Issues for Food Security. Los Baños, Philippines.

Ito, S. 1986. "Modifying Imported Technology by Local Engineers: Hypotheses and Case Study of India." Developing Economies 24 (4): 334-348.

Jayasuriya, S. K., A. Te, and R. H. Herdt. 1986. "Mechanization and Cropping Intensification: Economics of Machinery Use in Low-Wage Economies." Journal of Development Studies 22 (2): 327-335.

Keil, A., A. D’Souza, and A. McDonald. 2016. “Growing the Service Economy for Sustainable Wheat Intensification in the Eastern Indo-Gangetic Plains: Lessons from Custom Hiring Services for Zero-Tillage." Food Security 8 (5): 1011-1028.

Larsen, B. 1994. World Fossil Fuel Subsidies and Global Carbon Emissions in a Model with Interfuel Substitution. Policy Research Working Paper 1256. Washington, DC: World Bank.

Mohan, C. 1986. "Establishment of the Tractor Industry in India." In Small Farm Equipment for Developing Countries: Proceedings of the International Conference on Small Farm Equipment for Developing Countries: Past Experiences and Future Priorities, 2-6 September 1986, 161172. Los Baños, Philippines: International Rice Research Institute.

Morehouse, W. 1980. “Technology and Enterprise Performance in the Indian Tractor Industry: Does Self-Reliance Measure Up?” Economic and Political Weekly 15 (51): 2139-2152.

Moulik, T. K. 1988. “Energy and Development Options: The Case of India." Journal of Energy and Development 13 (2): 239-273.

Mukherjee, S. K. 1978. Energy Consumption in India: Recent Trends and the Problem of Demand Forecasting. Working Paper 198. Ahmedabad: Indian Institute of Management.

Patel, N. T., and M. Gandhi. 1996. Profile and Impacts of Tractorization. Working Paper 1305. Ahmedabad: Indian Institute of Management.

Pingali, P. 2007. “Agricultural Mechanization: Adoption Patterns and Economic Impact." In Handbook of Agricultural Economics. Vol. 3, Agricultural Development: Farmers, Farm Production and Farm Markets, edited by R. Evenson and P. Pingali, 2779-2805. Amsterdam: Elsevier.

Pray, C. E., and L. Nagarajan. 2014. "The Transformation of the Indian Agricultural Input Industry: Has It Increased Agricultural R\&D?” Agricultural Economics 45 (S1): 145-156. 
Rao, Y. M., K. Ravi Chand, V. R. Kiresur, and M. C. S. Bantilan. 2011a. Documentation of Second-Generation Village-Level Studies (VLS) in India (Part I: 2001-02 to 2004-05). Patancheru, India: International Crops Research Institute for the Semi-Arid Tropics.

- 2011b. Documentation of Second-Generation Village-Level Studies (VLS) in India, 2005-06 to 2008-09. Patancheru, India: International Crops Research Institute for the Semi-Arid Tropics.

Roodman, D. 2009. "How to Do xtabond2: An Introduction to Difference and System GMM in Stata." Stata Journal 9 (1): 86-138.

Sarkar, A. 2013. "Tractor Production and Sales in India, 1989-2009." Review of Agrarian Studies 3 (1): $55-72$.

Sarkar, H., and G. K. Kadekodi. 1988. Energy Pricing in India: Perspective, Issues, and Options. Geneva, Switzerland: International Labour Organization.

Shah, C. J., and S. Kanodia. 2015. Farm Mechanisation: Way Forward for Indian Agriculture. Mumbai: ICICI Securities Ltd. http://content.icicidirect.com/mailimages/IDirect_ FarmMechanisation_ThematicReport.pdf. Accessed April 17.

Shonkwiler, J. S., and S. T. Yen. 1999. “Two-Step Estimation of a Censored System of Equations.” American Journal of Agricultural Economics 81 (4): 972-982.

Singh, C. P., S. R. Verma, and S. K. Tandon. 1984. "Status of Agricultural Mechanization in India." In Development of the Agricultural Machinery Industry in Developing Countries: Proceedings of the 2nd International Conference, Amsterdam, 23-26 January 1984, edited by A. Moens and A. H. J. Siepman, 99-115. Wageningen, Netherlands: Center for Agricultural Publishing and Documentation.

Singh, G. 1998. "Production and Use of Tractors in India." In Increasing the Impact of Engineering in Agricultural and Rural Development, edited by M. A. Bell, D. Dawe, and M. B. Douthwaite, 49-60. Discussion Paper 30. Los Baños, Philippines: International Rice Research Institute.

- 2015. "Agricultural Mechanization Development in India." Indian Journal of Agricultural Economics 70 (1): 64-82.

Singh, K. N. 1978. "Status of Agricultural Mechanization in Southeast and East India." In Proceedings of the International Agricultural Machinery Workshop, 43-58. Los Baños, Philippines: International Rice Research Institute.

Singh, R. S., S. Singh, and S. P. Singh. 2015. "Farm Power and Machinery Availability on Indian Farms." Agricultural Engineering Today 39 (1): 45-56.

Singh, S., H. S. Kingra, and Sangeet. 2013. "Custom Hiring Services of Farm Machinery in Punjab: Impact and Policies." Indian Research Journal of Extension Education 13 (2): 45-50. 
Srinivasan, T. N. 1981. Food Security: Indian Perspective. Discussion Paper 373. New Haven, CT, US: Economic Growth Center, Yale University.

Suri, M. M. 1978. “Agricultural Mechanization in India." In Proceedings of the International Agricultural Machinery Workshop, 33-42. Los Baños, Philippines: International Rice Research Institute.

Takeshima, H. 2017. "Custom-Hired Tractor Services and Returns to Scale in Smallholder Agriculture: A Production Function Approach." Agricultural Economics 48 (3): 363-372. Takeshima, H., R. Adhikari, S. Shivakoti, B. D. Kaphle, and A. Kumar. 2017. "Heterogeneous Returns to Chemical Fertilizer at the Intensive Margins: Insights from Nepal.” Food Policy 69: 97-109.

\section{Appendix 3A: Empirical Methods}

\section{Effects on Farm Size and Farm Size Dynamics}

The role of tractor ownership in farm size dynamics is estimated by modifying the specifications provided by Henderson and colleagues (2015) for the dynamic growth patterns of farms in Paraguay. The regression equations and the empirical results of the regression models are provided below.

Specifically, we estimate the equation

$$
\begin{aligned}
& \Delta \ln y_{i t}=\alpha+\beta_{1} \ln y_{i, t-1}+\beta_{2}\left(\operatorname{lny}_{i, t-1}\right)^{2}+\beta_{3} \ln (\text { land owned })_{i, t-1} \\
& +\beta_{4} \text { tractor }_{i, t-1}+\beta_{5} z_{i t}+\varepsilon_{i t},
\end{aligned}
$$

where

- $y_{i t}=$ the operational land size of farm household $i$ in year $t$,

- $\Delta=$ the difference in variables between years $t$ and $t-1$,

- tractor $_{i, t-1}=$ the number of tractors owned in $t-1$, and

- $z_{i t}=$ the other socioeconomic characteristics of the households.

Other variables include labor endowments (working-age household members), dependency (the number of children and elders), education of the household head, household members' ages, and so on. The other characteristics added are similar to those used by Henderson and others (2015). As in Henderson and others (2015), equation (1) is estimated using the dynamic 
panel methods developed by Arellano and Bond (1991), Arellano and Bover (1995), and Blundell and Bond (1998), which also address the peculiar endogeneity issues between variables $y_{i, t-1}$ and tractor $_{i, t-1}$.

Specifically, we estimate equation (1) using system generalized method of moments (GMM) methods, which are often considered more efficient than difference GMM methods (Roodman 2009). The models are estimated using the xtabond 2 command in Stata. We use lagged values of the differences between $y_{i, t-1}$ and $\left(y_{i, t-1}\right)^{2}$, and of tractor $_{i, t-1}$, up to a certain period, as the excluded instrumental variables (IVs) to instrument the potentially endogenous variables, together with all the exogenous variables included in the model. The bottom row of Table 3.9 displays the specific lag periods used as IVs. The validity of the instruments is tested by a Hansen test of overidentification, and autocorrelation is also tested, with results of both tests shown near the bottom of Table 3.9. The $p$-values indicate that the model satisfies the conditions of these tests.

\section{Effects on Land Productivity and Adoption of Other Modern Technologies}

The effects of mechanization (tractor and combine harvester use) on farmers' various behaviors are assessed in the following panel data equation framework:

$$
y_{i t}=\alpha+c_{i}+M_{i t} \beta+A_{i t} \gamma+z_{i t} \delta+\varepsilon_{i t},
$$

where $y_{i t}$ is the outcome of interest (labor use, bullock use, use of modern inputs such as chemical fertilizer, or yield), $M_{i t}$ is the use of machines (tractors or combine harvesters), $A_{i t}$ is the area cultivated, and $z_{i t}$ is the vector of other exogenous variables. Variable $z_{i t}$ includes time-variant household characteristics, such as household size (breaking out working-age members and dependents), completed education of the household head (in years), farming experience of the household head (years), gender and age of the household head, prices of various inputs or services (chemical fertilizer price, male labor wages, land purchase or rental price, tractor rental price), whether using irrigation or not (yes $=1$ ), value of agricultural capital, and year-village interaction terms to control for other village-specific shocks in each year. ${ }^{16}$

16 Year-village interaction dummies account for various shocks that may affect many households within the village. They may include weather-related shocks, local-level government interventions, or technological shocks such as the diffusion of new varieties in the area, all of which can affect outcomes separately from the effects of tractor or combine harvester use. 
Variables $M_{i t}$ and $A_{i t}$ are potentially endogenous, so we also estimate this relationship using IV estimation methods. ${ }^{17}$ We find, however, that the fixed-effects model generally eliminates the endogeneity bias. Equation (2) is also estimated using a censored regression model, as several outcome variables contain values of 0 . Importantly, the outcomes of interest-labor use, bullock use, chemical fertilizer, and yield — are correlated with each other, including correlation among idiosyncratic errors, $\varepsilon_{i t}$, across equation (2) for each outcome. We therefore estimate (2) as a system of equations, rather than estimating it separately for each outcome. Specifically, equation (2) is estimated in two ways. First, we estimate a seemingly unrelated regression using within-transformed variables, which is equivalent to a system of fixed-effects panel, ordinary least squares regressions. Second, we estimate a system of the censored regression model (Shonkwiler and Yen 1999) combined with Chamberlain (1984)-type correlated random effects approximated by average values of exogenous variables over time, which is essentially a system of panel tobit regressions.

\section{EFFECTS OF TRACTOR AND COMBINE HARVESTER USE ON YIELDS OF KEY CROPS}

We estimate

$$
y_{i j t}=\alpha+c_{i j}+M_{i j t} \beta+P_{i j t}+z_{i t} \delta+\varepsilon_{i t}
$$

in which $y_{i j t}$ is the natural $\log$ of the yield of the crop grown by household $i$ in year $t$. Here, notation $j$ is added to indicate that the model controls for plot, season, and variety. The set of variables is similar to those for equation (2), except that here we drop area, $A_{i t}$, which is part of the dependent variable, and add $P_{i j t}$, the price of the crop, which is specific to variety, plot, and season.

17 Generally, the IVs used include the rental fees for the respective machines and the land value per acre. Their natural log transformations are also included to account for potentially nonlinear relations between these price variables and the values for the use of machines or the area cultivated. 



\title{
THE EVOLUTION OF AGRICULTURAL MECHANIZATION IN SRI LANKA
}

Fredrick Abeyratne and Hiroyuki Takeshima

\begin{abstract}
Sri Lanka's unique geography and its distinct experiences with machine use in rice and field crop production offer valuable insights into different patterns of mechanization. Rice in Sri Lanka has a substantial irrigation infrastructure, a strong plant breeding system, and historical examples of success in location-specific breeding strategies (Pain 1986). Furthermore, tractor use in rice cultivation grew very quickly, especially given the relatively small amount of arable land in the country and the lack of direct subsidies, but with certain incentives. Though mechanization initially spread for paddy cultivation, machinery has also become popular in varying degrees in the production of other field crops. This chapter explores the spread of mechanization in Sri Lanka, with a focus on the use of four- and two-wheel tractors, and combine harvesters. It first looks at the process of mechanization from a historical perspective. It then conducts demand- and supply-side analysis to identify the opportunities and challenges facing adoption of machinery in agriculture. It concludes with a brief discussion of the implications of the Sri Lankan experience for African countries starting the process of mechanization.
\end{abstract}

\section{History of Mechanization Evolution in Sri Lanka}

In Sri Lanka, the historical evolution of mechanization can be split into two periods by looking at the trends pre- and post-1970. In the pre-1935 period, which consisted of precolonial and colonial times, dry agricultural zones in the country were relatively neglected and mechanization was limited to the processing of plantation crops in the wet zone. From 1935 to 1970, dry-zone irrigation systems were rehabilitated, and farmers were resettled in those areas. Furthermore, four-wheel tractors (4WTs) - characterized as those with greater than $25 \mathrm{hp}$-were introduced through government-run pools as well as private ownership and incentive schemes for importation. This led to considerable growth in tractor use, especially on paddy fields. 
In the period from 1970 to 1977 , imports of tractors and other equipment were restricted. From 1977 to 2000, liberalization led to the lifting of these restrictions, which resulted in the further mechanization of rice production and the gradual rise of mechanization in the production of other field crops (OFCs). From 2000 onward, mechanization spread further among certain OFCs. Additionally, following the end of the country's civil war in 2009, there was an expansion of production and the use of combine harvesters, especially in the eastern part of the country and a gradual spread of combine harvesters for paddy harvesting and threshing.

\section{Up to the 1960s}

In Sri Lanka, paddy has predominantly been grown under irrigated conditions, while subsidiary food crops or OFCs have been grown under slash-andburn (chena) conditions without irrigation. Small homesteads have produced perennial crops such as coconut and fruit trees, and were mostly prevalent in the dry zone of the country.

From the mid-16th century through the mid-20th century, foreign occupation was accompanied by massive transformation in the agricultural sector. Plantation crops such as coffee, tea, rubber, and coconuts were introduced to the southwestern parts of the country known as the wet zone (areas with annual rainfall exceeding 2,500 $\mathrm{mm}$ ). These plantation crops had long been cultivated using manual labor, and machinery had historically been used only for processing outputs. At the same time, in the dry zone (areas with annual rainfall of 1,200-1,800 $\mathrm{mm}$ ), paddy-based agriculture was neglected and the ancient irrigation works disturbed, if not destroyed.

Just prior to Sri Lanka's independence in 1948, however, there was a revival of paddy-based agriculture in the dry zone, and previously neglected tank irrigation systems were restored. The government led land development and resettled people from the densely populated wet zone to newly opened lands in the dry zone, which had previously been under forest cover. In these new settlements, initial land allocations consisted of 5-acre plots of irrigated land for paddy cultivation and 3 acres of highland. Later allocations were reduced to 2 acres of land for paddy cultivation and 1 acre of highland (Ellman et al. 1976). Whereas the highlands were home to perennial crops such as jackfruit and coconuts, annual field crop cultivation had been mainly restricted to slash-and-burn methods in state-owned forestlands. Under the new settlement schemes, large amounts of these lands began to be used for paddy cultivation using both manual labor and draft animal power (DAP). 
In the mid-1940s, demand was rising for draft power and, though the figures are not available, it is known that draft animals were widely used by the 1960s (Siriweera 1989). To meet the increasing demand for plowing the first $4 \mathrm{WTs}$, initially with $25 \mathrm{hp}$, were introduced into the country. As dependence on draft animals grew, so too did the eagerness to substitute tractors for their use. In the 1950s and 1960s, large-scale imports began of the 25 to $65 \mathrm{hp}$ class of $4 \mathrm{WTs}$, and the 35 to $45 \mathrm{hp}$ class began to gain more popularity (Pillainayagam 1972). During these two decades, approximately 800 $4 \mathrm{WT}$ and a few hundred two-wheel tractors (2WTs) were imported annually (Harriss 1977), which was substantial for a country with less than 1 million ha of arable land. By 1962 the total number of registered 4WTs had reached 2,080 (Farrington and Abeyratne 1982a).

In some periods, the import of tractors was facilitated by foreign aid. Between 1965 and 1969, more than 6,100 4WTs and nearly 3,500 2WTs were imported, primarily through foreign aid arrangements (Raj 1972). Part of the increased tractor importation was also induced by lobbying. In the 1950s, there were several occasions when large-scale farmers in the Eastern province demanded to import tractors in order, then, to sell them to private individuals (Farrington 1984). Incidentally, as will be shown later, it was these same farmers who pioneered today's modern use of sophisticated machinery such as combine harvesters, due to their large landholdings.

Tractor use first spread among larger farms. The 1962 Census of Agriculture showed that the intensity of tractor use was greater in areas with a higher proportion of larger holdings (Raj 1972). However, the same census figure suggests that tractor use had also started to spread among relatively smaller farms, including rice farms of 5 acres or less (Raj 1972). In the 1960s, approximately 15 percent of rice area was likely to have been plowed by tractors (Table 4.1). This share is comparable to levels of adoption in some African countries today, an issue that we will return to in our conclusions.

\section{Since the 1970s}

The number of tractors and mechanized areas grew considerably following the late 1960s. By 1976, the number of 4WTs had reached 12,873 (Farrington and Abeyratne 1982a, 1982b). Whereas 4WTs had been introduced earlier, 2WTs, or power tillers ( $5 \mathrm{hp}$ ), had only truly begun to spread across Sri Lanka in the latter part of the 1960s. The first popular model was the Sri Lankan-designed, British-made Landmaster; later, Japanese models such as Kubota gained prominence. By the mid-1970s, around 5,000 2WTs had 
TABLE 4.1 Evolution of economic structure, employment structure, and mechanization in Sri Lanka, 1960s-2010s

\begin{tabular}{|c|c|c|c|c|c|c|}
\hline Variable & 1960s & 1970s & $1980 \mathrm{~s}$ & 1990s & $2000 s$ & 2010s \\
\hline \multicolumn{7}{|l|}{ Sector share of GDPa } \\
\hline Agriculture & 30 & 29 & 27 & 23 & 13 & 11 \\
\hline Manufacturing/industry & 21 & 26 & 27 & 27 & 29 & 30 \\
\hline Service & 48 & 44 & 45 & 50 & 57 & 61 \\
\hline \multicolumn{7}{|l|}{ Employment share (\%)* } \\
\hline Agriculture & $53^{b}$ & $50^{\mathrm{b}}$ & 50 & 42 & 37 & 30 \\
\hline Manufacturing/industry & $12^{b}$ & $13^{b}$ & 20 & 23 & 28 & 26 \\
\hline Service & $35^{b}$ & $37^{b}$ & 30 & 35 & 35 & 44 \\
\hline Share $(\%)$ of rice area plowed by tractors ${ }^{\star \star}$ & $15^{\star \star \star}$ & $45^{c}$ & $43^{\mathrm{d}}$ & $63^{c}$ & $85^{c}$ & $\begin{array}{c}98^{\mathrm{e}} \\
\text { (70-2WTs } \\
28-4 \mathrm{WTs})\end{array}$ \\
\hline Share $(\%)$ of rice area plowed by animals ${ }^{\star \star}$ & - & $37^{c}$ & $43^{d}$ & $34^{c}$ & $8^{c}$ & 2 \\
\hline $\begin{array}{l}\text { Share (\%) of rice area to total arable land } \\
\text { and permanent crops }\end{array}$ & 29 & 37 & 42 & 42 & 44 & 47 \\
\hline Number of 4WTs $(1,000)$ & $2-12^{\dagger}$ & $12-13^{9}$ & $19^{h}$ & - & $15^{c}$ & - \\
\hline Number of 2WTs $(1,000)$ & $0-4^{\dagger}$ & $5-10^{i}$ & $17^{j}$ & - & $100^{k}$ & $150^{\mathrm{k}}$ \\
\hline $\begin{array}{l}\text { Number of irrigation pumps in dry zone } \\
(1,000)^{\prime}\end{array}$ & - & 3 & 15 & 60 & 107 & - \\
\hline $\begin{array}{l}\text { Number of combine harvesters sold annu- } \\
\text { ally }(1,000)^{\mathrm{m}}\end{array}$ & - & - & - & - & - & $1-2$ \\
\hline Share of rice area (\%) under irrigation & - & - & $60^{n}$ & - & - & - \\
\hline
\end{tabular}

been registered in the country. In 1977, 13,300 4WTs and 6,150 2WTs were registered, and by 1980 the numbers of $4 \mathrm{WTs}$ and $2 \mathrm{WTs}$ had increased to more than 21,000 and 13,000, respectively (Abeyratne 1984). Based on a rough approximation, the share of rice area plowed by either $2 \mathrm{WTs}$ or $4 \mathrm{WTs}$ had reached 45 percent by the 1970s-1980s (Table 4.1). ${ }^{1}$ This was significant because, by the 1980 s, rice area accounted for more than 40 percent of

1 The use of tractors for land preparation of paddy plots still varied between agroecological zones. For example, in the 1980 s, the adoption rates of tractors for paddy in the wet zone were around 10 percent, as opposed to 70 percent in the dry zone (Kathirkamathamby 1984). 


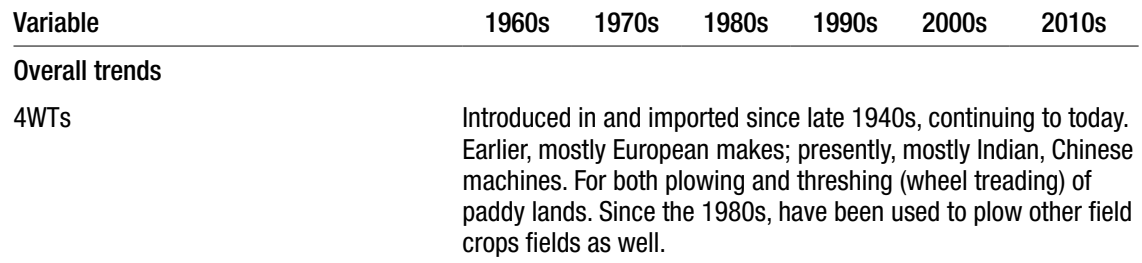

2WTs

Threshers (rice)/winnowers

Threshers (other field crops)

Combine harvesters

n.a. Sri Lankan-designed British Landmaster introduced in later 1960s. Thereafter, Japanese, Chinese, Indian makes became very popular. Used for plowing, transportation, threshing, and so on.

n.a. 2WT-driven threshers for paddy introduced in 1970s. Farm Mechanization Research Centre-designed and locally manufactured.

n.a. n.a. n.a.

n.a. In early 2000 s, green gram and maize threshing machines introduced.

n.a. n.a. n.a. n.a. n.a. Introduced for paddy after the civil war ended.

n.a. Mainly driven by 2WT engines, introduced in 1970s and used extensively since 2000 for other field crops.

Source: a World Bank (2016). b Figures are for 1963 and 1971, respectively, based on Department of Census and Statistics, reported in Athukorala and Jayasuriya (2004, Table 11). c Figures in later sections of this chapter. d Figures in later sections of this chapter, as well as IRRI $(1986,108)$. e CSAM and UNESCAP (2015). f Raj (1972). g Raj (1972) and IRRI (1986, 109). h IRRI (1986). i Raj (1972) and figures in later section. j Kathirkamathamby (1984). k Biggs and Justice (2013). I Kikuchi et al. (2001). Figure for the 2000s is the figure from year 2000. m Bandara (2013). $n$ IRRI (1986).

Note: $-=$ data not available; $2 \mathrm{WT}=$ two-wheel tractor; $4 \mathrm{WT}=$ four-wheel tractor; GDP = gross domestic product; $n$.a. = not applicable. * Because the figures from World Bank (2016) do not add up to 100 percent, each category was adjusted proportionately so that their sums are 100 percent. ${ }^{*}$ It is also important to note that paddy-harvested area almost doubled between the 1960s and the 2010s, from 523,296 ha to 1,057,406 ha (FA0 2018a). This makes the growth of the estimated share of mechanized paddy area milder than the area indicated by the growth of the number of tractors. ${ }^{\star \star \star}$ The figures are very roughly estimated using a back-of-the-envelope method, as described in the appendix.

farm area in Sri Lanka. This means that as early as the 1970s, Sri Lanka had surpassed the mechanization levels of most African countries today. At the same time, the use of DAP declined, with the share of farm households owning water buffalo falling to 40 percent by the mid-1980s (Kathirkamathamby 1984). The share of paddy area that uses tractors for land preparation has consistently risen since then, to around 60 percent in the $1990 \mathrm{~s}, 85$ percent in the 2000s, and close to 100 percent in the 2010s (Table 4.1).

The growth of tractors during the early 1970 s occurred in spite of restrictions on foreign exchange allocated for imports, with a levy of 55 percent imposed on foreign exchange entitlements for $4 \mathrm{WT}$ imports and a 25 percent 
import duty on 2 WTs. Though restrictive, these were still concessionary compared with levies on other imports. In the latter part of the 1970s, the economy liberalized, and tractor use grew as a result. As part of the liberalization, levies for foreign exchange entitlements on imports were removed and the full value of imported tractors used for agricultural purposes was made tax deductible (Farrington and Abeyratne 1982a, 1982b). By the early 1980s, the average duty on imported items had been reduced to about 5 percent and the business turnover tax that an importer had to pay was reduced to 1-2 percent (Kathirkamathamby 1984).

Tractors were not only useful for land preparation, and their multipurpose uses were well established by the 1970s; 40 percent of all tractor use time in the early 1970s was for nonagricultural work (Harriss 1977). Similarly, a 1979 survey showed that for every 1,000 hours of tractor use per year, 500 were devoted to nonagricultural activities (Kathirkamathamby 1984).

Though 4WTs were widely used only for land preparation, threshing of paddy by treading it with the wheels, and transport, by the 1990s 2WTs had become popular for many other purposes. These included land preparation; powering of threshers, winnowers, and water pumps; and use of the rotovator to chop straw and spread it into the field. In addition, 2WTs also became a popular method for transport of goods and people. Use of $2 \mathrm{WT}$ s increased even more after local manufacturing began and the Farm Mechanization Research Centre (FMRC) designed a portable thresher. Hiring of tractors became common during this period as well, and studies done in the early 1990s show that 65 percent of owners of $4 \mathrm{WT}$ s hired out their machines, as did 57 percent of 2WT owners (GTZ 1991).

Initially, tractors were mostly used for irrigated paddy agriculture, whereas cultivation and harvesting of OFCs continued to employ manual labor. In the early 1970s, only 25 percent of all tractors in the dry and intermediate zones were being used on nonrice commercial estates (Harriss 1977). Tractor use for OFCs was low partly because these crops were still largely cultivated under slash-and-burn conditions, in which soil fertility could be restored through fallowing rather than tillage (Farrington 1984).

In the 1980s, as slash-and-burn cultivation became less common and fallow periods shortened, it became clear that mechanical sources of farm power were needed for increasing field crop production (Abeyratne, Gunasena, and Tennakoon 1986). For example, by the early 1990s, 31 percent of chili farmers in Sri Lanka has switched to mechanical land preparation (GTZ 1991). This rise in the mechanization of OFC production was supported by legal changes. The first was a ban on forest clearing, which further reduced slash-and-burn 
cultivation. The second was the removal of a restriction on using paddy land for OFC cultivation during the yala season (when water is inadequate for paddy cultivation), which had previously been in place in order to prioritize paddy production. This removal led to increased OFC cultivation on paddy lands, especially during the yala season. ${ }^{2}$ By the 2000 s, $4 \mathrm{WTs}$ were used for land preparation and as threshing machines, water pumps, micro-irrigation systems, and sprayers for many different OFCs.

Beginning in the early 1980 s, economic transformation accelerated, partly induced by the liberalization of the economy. Growth increased in the manufacturing and service industries and led to large-scale migration of youth into new sectors. Furthermore, more workers joined security forces. These labor flows, combined with decreasing fertility rates and increased labor migration to Middle Eastern and European countries, gradually led to labor scarcities in agriculture. These trends have been associated with further mechanization expansion since the 1980s (Thilakaratne and Somaratne 2011).

Public-sector investments into infrastructure and plant breeding are also likely to have played significant roles in inducing the overall growth in mechanization. The country's density of paved roads was historically one of the highest in South Asia, and as early as 1980 had reached 282 meters per $\mathrm{km}^{2}$ of land area and 1,177 meters per 1,000 people (World Bank 1994, FAO 2018a), which is likely to be higher than in most countries in Africa south of the Sahara today. This allowed for greater transport and use of machinery. The National Agricultural Research Institute (NARI) made substantial investments into adaptive research, and as a result, all of the widely used rice varieties in Sri Lanka by the 2000s were NARI-developed, as opposed to imported (Hossain et al. 2003, Table 5.3). Improved varieties often raise the returns on more intensive tillage and transportation of harvest, inducing greater use of tractors (for example, Takeshima and Liu 2018).

Following the end of the civil war in 2009, large extents of land were recultivated, especially those in the Eastern province that had not been cultivated for nearly three decades. This revival led to increased demand for mechanization in the region. The use of combine harvesters and other accessories such as threshers in rice cultivation grew. For example, in Ampara district 60 percent of farm households used combine harvesters by 2010 and 40 percent used

2 Seasonal variation in rainfall is determined by the southwest monsoon (occurring in March to August, the agricultural season of yala) and the northeast monsoon (occurring in September to February, the agricultural season of maha). 
combine threshers (Epasinghe 2010). ${ }^{3}$ In some instances, these services were provided by Indian workers who migrated looking for work operating large machines, as the required skills often did not exist locally. By 2014, most farm areas underwent mechanized land leveling and land preparation, provided by power tillers and 4WTs (CSAM and UNESCAP 2015).

When one analyzes this timeline, one sees that agricultural mechanization in Sri Lanka has gone through an evolutionary process, rather than a simple upward trend in machinery use over time. The types of machinery (and power) in use have been based on changes in incentive and trade policies, evolving crop technology, and economic transformation. The key takeaway is that although use of tractors and combine harvesters has spread widely across Sri Lanka, there remain a number of constraints to mechanization, including the persistence of smallholders and land fragmentation; quality issues associated with imported machines; insufficient competition among custom hiring service providers in some areas; and limited operating and repair knowledge, especially among the youth population. The following sections will take first a demand perspective and then a supply perspective to discuss these opportunities and challenges within mechanization in more depth.

\section{Demand-Side Analysis}

A demand-side analysis shows that although mechanization has spread in a smallholder-dominated environment, farm size and mechanization adoption are positively correlated. Furthermore, the demand for machines varies across cropping systems, and recently, rising incomes and labor costs have fueled demand for mechanization. Overall, despite many constraints to mechanization, demand-side factors have been strong enough to consistently induce further use of machinery, and this is likely to persist going forward. These issues are further discussed below.

\section{Holding Size and Machinery Use}

The average holding size in Sri Lanka has declined continuously over the last several decades, falling from 1.61 ha in 1960 to 1.08 ha in 1980 and to 0.47 ha in 2002 (Table 4.2). This rate of decline is one of the fastest in South Asia.

3 It is interesting to note that the rice varieties (apart from MI-273) that were popular in 1970 were susceptible to shattering, so engine-powered mechanized harvesting was not recommended for them; even small combine harvesters were tested and found unsuitable, due to small holding sizes and undulating terrain (Pillainayagam 1982). However, breeding of nonshattering varieties has gradually enabled the use of mechanical harvesting. 
TABLE 4.2 Declining farm sizes in Sri Lanka, 1960-2002

\begin{tabular}{lllll}
\hline Year & 1960 & 1970 & 1980 & 2002 \\
\hline Average holding size (ha) & 1.61 & 1.24 & 1.08 & 0.47 \\
\hline
\end{tabular}

Source: FAO (2018b).

Therefore, the spread of mechanization (especially the growth in tractor use) observed during the last several decades has occurred alongside a continuous decrease in farm sizes.

Current machinery use in irrigated paddy farming is extensive, though its use in OFC cultivation varies and is relatively less in dryland cropping areas. ${ }^{4}$ In Sri Lanka today, the average holding size for irrigated paddy is around 2.6 acres, which is generally arranged in contiguous tracts that allow for easy mechanization. On the other hand, the farm size for OFCs varies from 0.5 to 2 acres, and its organization is more scattered (Sri Lanka, DOA 2015). These characteristics are not much changed from earlier years. In 2002, for example, 60 percent of smallholder agricultural operations in Sri Lanka operated less than 2 acres of land, 31 percent operated less than 1 acre, and only 1.4 percent operated more than 10 acres (Sri Lanka, DCS 2002). In addition to smaller holding size, each holding is divided into small plots (liyaddas) based on the slope of the land, limiting the use of large machines and the development of economies of scale. In general, farm size has been one of the major constraints to owning large machines such as $4 \mathrm{WT}$, and thus farmers have relied on hiring them. In the 1980s, ownership of large machinery was therefore skewed toward owners of large holdings (Farrington and Abeyratne 1982a, 1982b), and this pattern has persisted.

Size of holdings has a relationship with the type of machinery used for land preparation, as shown in Table 4.3 and Figure 4.1. As a result, the recent growth of $2 \mathrm{WTs}$ relative to $4 \mathrm{WTs}$ (Table 4.1) can be associated with the persistence of smallholder farmers in Sri Lanka. Table 4.3 and Figure 4.1 show that with smaller holding size, the use of $2 \mathrm{WT}$ s is more prominent. In fact, most farmers, except those in Ampara (both eastern and western), Mannar, Polonnaruwa, and Trincomalee, use $2 \mathrm{WTs}$ for land preparation of smaller holdings, and the availability of single-axle 2WTs can help speed farming

4 Though in the past field crops were exclusively cultivated as rainfed (dryland) crops, increasing numbers of farms are adopting irrigation methods such as drip, sprinkler, and pumped well water. 
TABLE 4.3 Holding size and use of machinery for paddy land preparation and harvesting, selected districts, Sri Lanka, 2013/2014

\begin{tabular}{lcccc}
\hline & \multicolumn{3}{c}{ Percentage reporting * 10} & \\
\cline { 2 - 4 } District & 4WTs & 2WTs & Combine harvesters & Av. holding size (acres) \\
\hline Ampara-eastern & 10.0 & 0.0 & 10.0 & 4.9 \\
Ampara-western & 6.4 & 3.6 & 9.0 & 2.2 \\
Anuradhapura & 6.2 & 3.8 & 6.6 & 2.4 \\
Gampaha & 2.0 & 8.0 & 8.0 & 1.3 \\
Kalutara & 2.6 & 7.4 & 4.2 & 0.9 \\
Kurunegala & 0.0 & 10.0 & 5.0 & 1.0 \\
Mahaweli System H & 3.2 & 6.8 & 6.4 & 2.1 \\
Mahaweli System B & 4.2 & 5.8 & 7.8 & 2.9 \\
Mannar & 8.0 & 2.0 & 10.0 & 5.0 \\
Polonnaruwa & 7.4 & 2.6 & 8.0 & 3.0 \\
Trincomalee & 6.2 & 3.8 & 10.0 & 3.0 \\
\hline
\end{tabular}

Source: Sri Lanka, DOA (2015).

Note: $2 \mathrm{WT}$ = two-wheel tractor; $4 \mathrm{WT}$ = four-wheel tractor.

FIGURE 4.1 Holding size and use of machinery for paddy land preparation and harvesting

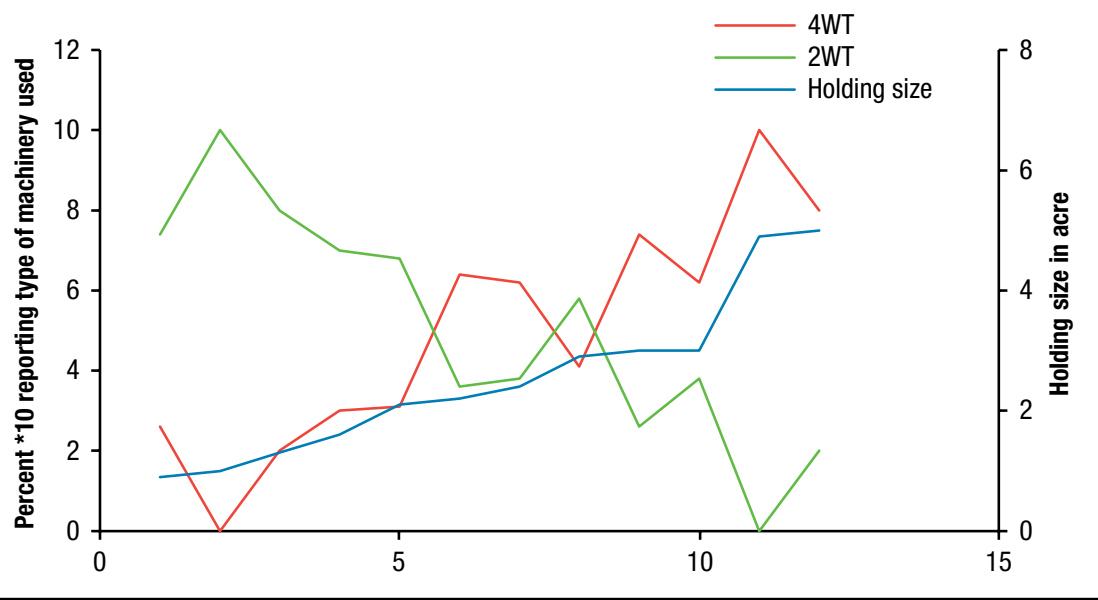

Source: Sri Lanka, DOA (2015). 
operations. Furthermore, a significant number of farmers in most districts now use combine harvesters for harvesting and pulling loads.

\section{Farming System and Machinery Use}

In the 1970s, about 50 percent of the time use of tractors was dedicated to nonfarm purposes (Kathirkamathamby 1984). Such multipurpose use of tractors continued in later years, and by the 1990s, 2WTs were used by farmers and others in a mix of entrepreneurial operations and services (Biggs, Kelly, and Balasuriya 1993; Kienzle, Ashburner, and Sims 2013). Within the farming sector, machinery use initially developed because of demand from paddy farmers but over time also increased in the field crop sector, largely due to decreasing labor availability and the resulting higher cost of labor. Table 4.4 gives information on labor and machinery costs for the cultivation of selected crops in major production areas across Sri Lanka.

Table 4.4 provides several insights on machinery and labor use over time. For irrigated paddy cultivation, the share of hired labor in total costs rose and fell significantly over the last two decades, going from 32 percent in 1995 to 55 percent in 2005 , and finally declining to a period low of 20 percent in 2013. This trend has naturally been coupled with a rising share of machinery costs in paddy cultivation. For OFCs, machinery costs vary based on the type of crop and location. In 2000, machinery was not used for maize production; however, by 2013 it accounted for 31 percent of total costs. This rapid increase in machinery use is likely explained by the introduction of new highproductivity technologies such as hybrid seeds and the increased demand for maize from the livestock feed industry.

Production of the green gram bean, on the other hand, has seen a declining share of machinery costs relative to labor costs. Machinery's share in the total cost of production declined from 36 percent in 2000 to just 15 percent in 2013. Green gram beans must be harvested often, which is a labor-intensive operation. Mechanization of harvesting operations appears to have been slow, so that rising wages resulted in a higher share of costs attributable to labor. Similarly, for red onions (grown mainly in the Jaffna district) the share of machinery in total costs has not changed from 11 percent since 1995, whereas hired labor's share in costs has increased. The case of red onions differs from that of green gram beans, however, because the former's trend was partly due to greater labor availability in the Jaffna district following the decline in war hostilities. Similarly for potatoes, which are mainly grown in the wet zone of Sri Lanka, the use of machinery has been minimal. This is because the wet 
TABLE 4.4 Labor and machinery costs for selected crops, Sri Lanka, 1979/1980-2013

(Rs. per acre)

\begin{tabular}{|c|c|c|c|c|c|c|c|}
\hline Crop/Expense & $1979 / 1980$ & 1990 & 1995 & 2000 & 2005 & 2010 & 2013 \\
\hline Paddy, area (irri) & Apura & Apura & Apura & Apura & Apura & SL & SL \\
\hline Labor (hired) & 384 & 1,050 & 2,121 & 3,462 & 4,511 & 7,671 & 5,293 \\
\hline $\begin{array}{l}\text { Labor wage index } \\
\text { (Rs. / day) }\end{array}$ & 20 & 66 & 135 & 213 & 347 & 697 & 945 \\
\hline $\begin{array}{l}\text { Machine hire cost } \\
\text { (buff) }\end{array}$ & 552 & 1,199 & 2,132 & 3,163 & 4,883 & 7,955 & 14,830 \\
\hline TC without FL & 1,312 & 3,413 & 6,271 & 10,021 & 12,870 & 20,763 & 26,959 \\
\hline TC with FL & 1,694 & 5,599 & 10,654 & 15,217 & 22,535 & 35,165 & 39,917 \\
\hline Maize, area (RF) & Mgala & Mgala & n.a. & Apura & Apura & Apura & Apura \\
\hline Labor, hired & 235 & n.a. & n.a. & 921 & 3,728 & 11,081 & 9,880 \\
\hline Labor wage index & 17 & - & - & 185 & 335 & 693 & 988 \\
\hline Machine hire cost & 0 & - & - & 0 & 3,201 & 5,628 & 8,861 \\
\hline TC without FL & 253 & - & - & 1,448 & 11,146 & 29,443 & 29,011 \\
\hline TC with FL & 597 & - & - & 8,664 & 22,087 & 42,727 & 45,814 \\
\hline Green gram, area & - & Kgala & Mgala & Mgala & Mgala & Putl & $\mathrm{H}$ area \\
\hline Labor, hired & - & 667 & 726 & 2,765 & 3,410 & 9,002 & 17,730 \\
\hline Labor wage index & 一 & 50 & 131 & 173 & 310 & 801 & 985 \\
\hline Machine hire cost & - & 39 & 0 & 2,179 & 3,009 & 2,626 & 4,814 \\
\hline TC without FL & 一 & 754 & 1,599 & 5,932 & 7,995 & 15,968 & 24,666 \\
\hline TC with FL & 一 & 2,500 & 6,105 & 7,583 & 15,912 & 30,707 & 38,738 \\
\hline Chilies, area & Apura (DC) & Apura (DC) & Apura (DC) & Apura (DC) & Apura (GC) & Apura (GC) & Apura (GC) \\
\hline Labor, hired & 294 & 3,830 & 1,240 & 1,051 & 8,818 & 21,417 & 27,132 \\
\hline Labor wage index & 16 & 66 & 126 & 191 & 309 & 449 & 969 \\
\hline Machine hire cost & 0 & 0 & 0 & 0 & 0 & 4,430 & 7,022 \\
\hline
\end{tabular}

zone has more hills and uneven terrain, and so machinery use has been more difficult than in the dry zone.

Apart from terrain, the price of crops has also triggered changes in the cropping system. For lower-priced crops such as green gram, importing is a cheap option and as a result, the amount under cultivation has reduced. Such reductions have been accompanied by lower use of machinery. However, with higher productivity and prices guaranteed by strong demand from the livestock feed market, maize production has gone up, leading to increased machinery use. Furthermore, the availability of both motor-driven threshers and tractors for land preparation has increased machinery use. Hence, the 


\begin{tabular}{|c|c|c|c|c|c|c|c|}
\hline Crop/Expense & $1979 / 1980$ & 1990 & 1995 & 2000 & 2005 & 2010 & 2013 \\
\hline TC without FL & 448 & 6,802 & 8,406 & 4,949 & 15,636 & 50,246 & 50,116 \\
\hline TC with FL & 1,729 & 9,927 & 20,541 & 26,247 & 42,433 & 101,925 & 117,926 \\
\hline Red onion, area & n.a. & Jaf & Mgala & Putl & Putl & Putl & Jaf \\
\hline Labor, hired & - & 7,580 & 8,520 & 15,108 & 22,535 & 32,160 & 61,133 \\
\hline $\begin{array}{l}\text { Labor wage index } \\
\text { (Rs./day) }\end{array}$ & - & 55 & 132 & 157 & 279 & 536 & 818 \\
\hline Machine hire cost & - & 4,767 & 4,790 & 9,161 & 1,1854 & 16,603 & 21,628 \\
\hline $\mathrm{TC}$ without FL & - & 33,343 & 41,923 & 75,524 & 86,342 & 139,737 & 203,876 \\
\hline TC with FL & - & 37,672 & 52,654 & 77,385 & 93,853 & 153,956 & 239,305 \\
\hline Potato, area (irri) & Badul & Badul & Badul & Badul & Badul & Badul & Badul \\
\hline Labor, hired & 540 & 6,420 & 9,537 & 17,507 & 23,624 & 21,488 & 36,000 \\
\hline Labor wage index & 20 & 81 & 142 & 195 & 340 & 564 & 720 \\
\hline $\begin{array}{l}\text { Machine hire cost } \\
\text { (spra) }\end{array}$ & 54 & 0 & 0 & 3,600 & 3,506 & 5,273 & 8,094 \\
\hline TC without FL & 11,745 & 44,236 & 95,081 & 87,230 & 130,154 & 178,726 & 212,799 \\
\hline TC with FL & 13,256 & 56,568 & 112,576 & 99,412 & 163,956 & 248,563 & 270,661 \\
\hline Potato, area (irri) & NE & NE & NE & $\mathrm{NE}$ & NE & $\mathrm{NE}$ & NE \\
\hline Labor, hired & 1,961 & 18,085 & 13,398 & 21,442 & 36,422 & 47,903 & 71,261 \\
\hline Labor wage index & 18 & 116 & 130 & 203 & 382 & 628 & 996 \\
\hline $\begin{array}{l}\text { Machine hire cost } \\
\text { (spra) }\end{array}$ & 171 & 2,177 & 1,900 & 3,600 & 4,083 & 4,558 & 14,791 \\
\hline TC without FL & 14,580 & 119,109 & 109,145 & 122,991 & 162,815 & 282,810 & 301,495 \\
\hline TC with FL & 15,619 & 121,078 & 126,529 & 138,461 & 197,597 & 312,975 & 337,279 \\
\hline
\end{tabular}

Source: Sri Lanka DOA (2015).

Note: $-=$ data not available; Apura $=$ Anuradhapura; Badul $=$ Badulla; buff $=$ buffalo hire cost; $D C=$ dry chilies; $F L=$ family labor; $\mathrm{GC}=$ green chilies; $\mathrm{H}$ area $=$ Mahaweli System $\mathrm{H}$ area; irri = irrigated; Jaf = Jaffna; Kgala = Kurunegala; Mgala = Monaragala; n.a. = not applicable; NE = Nuwara Eliya; Putl = Puttalam; RF = rainfed; SL = Sri Lanka; spra = sprayers; TC = total cost.

evidence shows that changes in both technological and economic factors can affect the intensity of machine use.

The growth in mechanization for some nonrice field crops has also been associated with the development of a system in which just one crop is grown on the same land over time, also known as monocropping. In the past, the cropping systems in rainfed lands (chenas) were mixed, with the different crop requirements and timing making it more difficult to use machinery. However, with the transition to monocropping, machinery became more popular in the cultivation of OFCs. The shift toward monocropping was partially led by government initiatives. As the country's goal of rice self-sufficiency was achieved, 
policies have been redirected to encourage production of OFCs under rainfed and micro-irrigation systems, as well as under major irrigation systems during the yala season, when water is not adequate for a full crop of rice. For the 2016 maha season, the Ministry of Agriculture decided to produce maize, soybeans, and green gram, most of which are still largely imported, to a great extent under monocropping systems. The area used for OFC cultivation, which was 107,792 ha in the year 2009, is projected to increase to 300,000 ha by 2030 (Colombage 2011).

Corroborating the macro information from the Department of Agriculture, a study by Kumara, Weerakkody, and Epasinghe (2016) showed gradual replacement of draft power by mechanized operations over the years. Table 4.5 provides an example of the Monaragala district, showing that over time the level of mechanization in maize production has grown.

On the other hand, only a small percentage of farmers engaging in finger millet cultivation in the Monaragala and Ampara districts use machinery (unlike for maize cultivation in Ampara), despite the fact that a large percentage are willing (Table 4.6). In Monaragala district, millet cultivation is primarily for commercial sale. Those with machines use them for production, and those without them employ their own manual labor. The relatively high willingness to use machinery suggests that there are barriers to their use in the region, likely due to either availability or cost. These facts, along with low market value for millet, means that this commercial production has not led to greater hiring.

Another noteworthy feature in the demand for machinery is the relationship between total household income and type of machine used. A recent study showed that for higher-income households, there is a tendency to use more high-tech machinery, such as combine harvesters, whereas lower-income households use less sophisticated techniques, such as Agrimec threshing machines (Epasinghe 2010). In agricultural households, a higher percentage of total income comes from nonagricultural sources, and in rural households the average income from nonfarm activities is estimated to be more than twice as high as that from farm activities (Bandara 2013). With an increasing number of youths earning more from engaging in nonagricultural pursuits, machinery use for commercial purposes has increased on their family farms. However, households operating near subsistence levels on smallholdings continue to use manual labor and simple machines.

Finally, even though the growth of mechanization has continuously progressed in Sri Lanka, imported machines have at times been unsuitable for certain locations and have led farmers to dis-adopt mechanized operations (Kumara, Weerakkody, and Epasinghe 2016). Extension services intended to 
TABLE 4.5 Power sources used for selected operations in maize production in Monaragala district

\begin{tabular}{|c|c|c|c|c|c|c|c|c|}
\hline \multirow[b]{2}{*}{ Operation } & \multicolumn{4}{|c|}{$\begin{array}{l}\text { Share (\%) of farmers using } \\
\text { labor or draft power }\end{array}$} & \multicolumn{4}{|c|}{$\begin{array}{l}\text { Share }(\%) \text { of farmers } \\
\text { using machinery }\end{array}$} \\
\hline & $\begin{array}{l}2008 / \\
2009\end{array}$ & $\begin{array}{l}2009 / \\
2010\end{array}$ & $\begin{array}{l}2010 / \\
2011\end{array}$ & $\begin{array}{l}2011 / \\
2012\end{array}$ & $\begin{array}{l}2008 / \\
2009\end{array}$ & $\begin{array}{l}2009 / \\
2010\end{array}$ & $\begin{array}{l}2010 / \\
2011\end{array}$ & $\begin{array}{l}2011 / \\
2012\end{array}$ \\
\hline General land preparation & 48 & 50 & 74 & 40 & - & - & - & - \\
\hline 1st and 2nd plow & - & - & - & - & 74 & 80 & 100 & 94 \\
\hline 2nd plow only & 26 & 20 & - & 6 & - & - & 54 & - \\
\hline Preparation of ridges & - & 36 & 36 & - & 68 & 64 & 74 & 88 \\
\hline Digging holes \& seeding & 100 & 100 & 100 & 100 & - & - & - & - \\
\hline Weeding \& earthing up & 100 & 100 & 100 & 100 & - & - & - & - \\
\hline Fertilizer application & 98 & 100 & 100 & 100 & - & - & - & - \\
\hline Harvesting \& pulling loads & 100 & 100 & 100 & 100 & - & - & - & - \\
\hline \multicolumn{9}{|l|}{ Threshing \& processing } \\
\hline 2WT-driven thresher & - & - & - & - & 64 & 70 & 46 & 58 \\
\hline 4WT-driven thresher & 22 & - & - & - & 14 & 30 & 54 & 42 \\
\hline
\end{tabular}

Source: Sri Lanka Department of Agriculture (various years), as quoted in Kumara, Weerakkody, and Epasinghe (2016). Note: $-=$ data not available.

TABLE 4.6 Awareness, affordability, and use of farm implements for land preparation in finger millet production in study locations

\begin{tabular}{|c|c|c|c|c|c|c|c|c|}
\hline \multirow[b]{2}{*}{ Farm implement } & \multicolumn{4}{|c|}{$\begin{array}{l}\text { Share (\%) of farmers } \\
\text { in Ampara district }\end{array}$} & \multicolumn{4}{|c|}{$\begin{array}{l}\text { Share }(\%) \text { of farmers } \\
\text { in Monaragala district }\end{array}$} \\
\hline & $\begin{array}{c}\text { Aware } \\
\text { of }\end{array}$ & Affordable & Used & $\begin{array}{l}\text { Willing } \\
\text { to use }\end{array}$ & $\begin{array}{c}\text { Aware } \\
\text { of }\end{array}$ & Affordable & Used & $\begin{array}{l}\text { Willing } \\
\text { to use }\end{array}$ \\
\hline Disc plow & 100 & - & - & 50 & 100 & - & 15 & 60 \\
\hline Tine tiller & 100 & - & - & 54 & 100 & - & 18 & 70 \\
\hline $\begin{array}{l}\text { Agrimec paddy machine, } \\
\text { altered }\end{array}$ & 18 & - & - & - & 100 & - & 18 & 18 \\
\hline
\end{tabular}

Source: Hector Kobbekaduwa Agrarian Research and Training Institute survey data (2014), as quoted in Kumara, Weerakkody, and Epasinghe (2016).

Note: $-=$ data not available.

make farmers aware of the locally available machinery to mechanize field crop production have at times been inefficient and further restricted machine use.

\section{Labor Market and Machinery Use}

Rising labor costs have been one of the underlying forces for mechanization growth in Sri Lanka. With universal primary education and increased completion of higher education, there is an unwillingness to join the labor-intensive 
and relatively less profitable farming industry. This has led to a scarcity of labor, and as a result, a higher cost of agricultural labor. For example, the nominal labor wage rate in the year 2000 was just 200 Sri Lankan rupees (Rs) but had risen to Rs 700 to Rs 1,000 by 2013 . Though these wages are still lower than those offered for similarly skilled positions in the manufacturing and service sectors, the increases have nonetheless made it more difficult to afford agricultural labor and have motivated farmers to substitute machinery for labor (Table 4.4).

Another factor driving mechanization is the aging population in Sri Lanka. According to the 2002 census, the youth (15- to 29-year-old) population has been decreasing over time; young people made up 26.8 percent of the population in 2001 and just 23 percent in 2012 (Sri Lanka, DCS 2018; UNDP 2014). Along with that, the population older than 60 is increasing; in 2001 it was only 10.2 percent, but by 2051 it is projected to hit 55.8 percent (De Silva 2007). With fertility declining and life expectancy increasing it is predicted that by 2030, Sri Lanka will have one of the highest proportions of people over 60 years old in Asia (Siddhisena and DeGraaf 2009). These trends further decrease labor availability and motivate increased use of machinery.

In conclusion, some of the major demand-side factors influencing current machinery use in Sri Lanka are holding size, type and value of crop, terrain, import policy for crops, stability of demand and prices for crops, availability of new varieties and technologies, total household income, awareness about availability and suitability of machinery, and labor shortages. In general, changes in technology, land conditions, and the labor market seem to have played the biggest role. Technological innovations allowing for higher yields, and cropspecific market conditions, such as the high demand for maize, have induced greater use of machinery. Increases and changes in land use, such as the rise of monocropping, have also led to an increase in mechanization across different crop types. Finally, rising household incomes combined with the many factors reducing availability of agricultural labor have supported the spread of mechanization.

\section{Supply-Side Issues}

In this section, we discuss supply-side issues related to mechanization, with a particular focus on ownership, the hiring market, and local manufacturing of agricultural machinery. There is little documentation of subsidies related to agricultural machinery in Sri Lanka before the 1980s (Raj 1972; Kathirkamathamby 1978). This suggests that the spread of tractor use on rice 
TABLE 4.7 Annual sales of farm machinery, Sri Lanka, 2011/2012-2013/2014

\begin{tabular}{lccccc}
\hline Year & $\begin{array}{c}\text { 2-wheel } \\
\text { tractors }\end{array}$ & $\begin{array}{c}\text { 4-wheel } \\
\text { tractors }\end{array}$ & $\begin{array}{c}\text { Combine } \\
\text { harvesters }\end{array}$ & Sprayers & Transplanters \\
\hline $2011 / 2012$ & 14,445 & 7,184 & 2,160 & 26,093 & - \\
$2012 / 2013$ & 9,664 & 5,141 & 1,099 & 6,240 & 23 \\
$2013 / 2014$ & 2,783 & 1,479 & - & - & 87 \\
\hline
\end{tabular}

Source: Bandara (2013).

Note: $-=$ data not available.

farms leading up to the 1970s, as shown in Table 4.1, occurred without substantial provision of subsidies. However, there were many other supply-side factors that led to increased machine use.

\section{Sources of Machinery}

One of the factors that precipitated the growth in tractor use in Sri Lanka was the formation of state-run tractor pools for hire, which began with 150 tractors gifted from the departing British military. By 1952, the main expansion of tractor services came from the cooperative agricultural production and sales societies' importation of 241 tractors.

By the mid-1960s, however, the official policy shifted toward the promotion of private ownership of tractors, largely sourced through imports. During the 1950s and 1960s, Sri Lanka was importing about 800 tractors annually. The dominance of imports was partially due to policy decisions including preferential import duties ( 1 percent for tractors), preferential allocation of foreign exchange, and low-interest credit.

In recent years, both the incentives and restrictions governing machine imports have largely been removed. However, imports continue to rise. In Table 4.7, we present statistics on recent annual sales of certain machines, showing that some machine types, such as combine harvesters, have been coming into the country in large numbers. The spike in imports in 2011 is because more land, especially in the northern and eastern areas, came under cultivation after cessation of the civil war. This shows that despite issues with quality of imported machines and a growing base of local manufacturers, imports continue to be an important source of farm machinery supply.

\section{Regulation}

The majority of imported machinery is not well regulated, and inflows of low-quality machinery are frequent (Bandara 2013). It is expected that improving the quality of imported machinery could contribute to increased 
mechanization of OFCs (Kumara, Weerakkody, and Epasinghe 2016). Meanwhile, it is worth recognizing that despite the issues with quality, machine imports have remained significant over the years.

The effects on local manufacturers of low taxes and other incentives that supported importation of machinery are ambiguous. It is possible that these policies acted as disincentives for local manufacturers, but at the same time it is likely that the availability of cheap, imported machines provided materials for local manufacturers to use for reverse engineering and modifications of imported machines.

\section{Research and Development}

One of the mechanization-related policies pre-1980 was the establishment of a machinery designs testing unit in the mid-1960s (Kathirkamathamby 1978). In the 1970s, a public research unit called the Engineering Research and Development Division (later renamed as Farm Mechanisation Research Center [FMRC]) was established. Its responsibilities included machinery design and development, machinery testing and evaluation, field trials and experiments, machinery extension evaluation, and machinery production. The main aim of the research has been to develop equipment that is suitable for varying production environments in Sri Lanka. However, this adaptive research intensified only after the 1970 s, by which time tractor use had already spread considerably through the use of imported tractors.

\section{Ownership and Hiring Services}

Almost all machinery is privately owned by individuals. This high rate of private ownership has persisted despite varying constraints, including poor purchasing power of individuals, seasonality of use, lack of infrastructure facilities, and a shortage of repair and maintenance services (Bandara 2014). It was through custom hiring services (CHS) offered by these private individuals that agricultural mechanization really spread in the country. Although in some rare cases the state-run agrarian service centers owned a limited quantity of machinery for hiring purposes, their share was largely insignificant. Given how much tractor use spread through hiring services, it is useful to investigate incentives behind such services and the potential effects of machinery ownership concentration among so few owners.

\section{THE MACHINERY HIRING MARKET}

Now that Sri Lanka has reached near-universal use of tractors for land preparation, investigating the efficiency of the hiring market is becoming 
increasingly important. Studies have shown that farmers' awareness of the availability of new land preparation technologies is imperfect, and the spatial concentration of machinery continues to make hiring fees uneven across locations (Bandara 2011; Kumara, Weerakkody, and Epasinghe 2016). Larger machinery, such as combine harvesters and $4 \mathrm{WTs}$, is mostly owned by large farmers and businesses, whose distributions-and consequently the availability of machines-do not always match the demand for CHS in the local area. It is unlikely that reviving CHS run through cooperatives or stateowned enterprises is a good strategy, given their poor performance in the past. However, it is important to further explore how much more efficiency can be brought into CHS through a mix of individual and group ownership, publicprivate enterprises, and the effective use of modern technologies such as information and communication technologies.

Combine harvester provision services have also been growing. They are, however, not free from constraints. In certain areas, there is excess supply (in some cases, more than 500 concentrated in one area) and thus reduced hiring rates; estimates suggest that prices have fallen from Rs 15,000 per ha to just Rs 7,500. In other instances, rising labor wages of operators, rising costs of fuel and of repair and maintenance, significant reliance on brokers, and climatic problems such as floods and droughts can pose serious constraints to combine harvester use.

In spite of these issues, there are many options for raising the efficiency of Sri Lanka's hiring market for tractors and combine harvesters (Bandara 2014). For example, establishing government support for private machinery hiring centers through public-private partnerships and also through subsidies or soft loans may have significant benefits, as would training machinery operators free of charge at the FMRC. Also, estimating and enforcing fair market hiring rates that allow for reasonable profit margins could help. Machinery owners would also benefit greatly from better access to the latest technologies, which could occur through coordination between the FMRC and the Farm Mechanization Training Centre. Finally, introducing an effective regulatory system that safeguards all relevant stakeholders would go a long way toward improving the CHS market.

\section{Local Manufacturing of Machinery}

In Sri Lanka, the machinery available for purchase by farmers has been of three kinds: (1) locally manufactured equipment, (2) imported equipment or fabricated versions of imported equipment, and (3) imported equipment 
modified by innovative farmers to suit their own needs. Of these, imported machinery has consistently made up the majority.

Imported machinery has generally been imperfectly suitable for the different land classes, operations, and types of crops grown in Sri Lanka. This may have resulted in reduced productivity and profitability of farms, even though using these machines is still more profitable than using manual labor. In combine harvester operations, the rate of grain loss remains high, at 20-30 percent. It is true that some innovative farmers have modified available machinery to meet their unique needs. However, in order for these modified versions to be commercially produced, the FMRC would need to test and certify them. Due to long delays in these procedures, such innovations have never reached large-scale commercial production levels (Kumara, Weerakkody, and Epasinghe 2016).

Local manufacturing of agricultural machinery has emerged in Sri Lanka over time. There are several manufacturers in Sri Lanka who produce agriculture machinery, sometimes on a commercial scale, based on the designs of the FMRC as well as their own innovations. There are currently seven such manufacturers supplying various types of machines, including a 2WT-operated disc plow, a 2WT-operated seeder, an altered combine harvester for maize threshing, an Agrimec paddy thresher altered for threshing of finger millet, a SeedMaster (seeder-cum-fertilizer drill), a rotovator altered for earthing up, and a modified FMRC maize thresher.

These local manufacturers have emerged in Sri Lanka despite serious constraints. These include the scarcity of skilled labor and the risk averseness of farmers toward machinery usage (Kumara, Weerakkody, and Epasinghe 2016). Further growth of the local manufacturing industry can benefit from joint ventures with foreign manufacturers, continued and improved political stability, and significant increases in local demand. The Sri Lankan government is also currently promoting local capacity through policies such as exemptions from the corporate income tax, customs duty, value-added tax, and ports and airports development levy. The government is also placing emphasis on raising skill levels for manufacturing and testing, and on establishing business and technology development centers that aim to create awareness, adaptive testing, and demonstrations of machinery.

\section{Conclusions}

The spread of agricultural mechanization in Sri Lanka occurred despite several constraints, including the quality of imported machines, persistence of 
smallholders, low market value of crops, low productivity of crop production, hilly terrain, and insufficient awareness of available mechanical technologies. As some of these constraints have been removed, mechanization has grown even further. However, it remains important for the Sri Lankan government to address the issues of machine quality, lack of skilled workers, spatial concentration, insufficient incentives for small and medium enterprises and for technology development, and the large farm-dominated machine ownership that leads to an uncompetitive CHS market. However, the example of Sri Lanka has shown that even in the face of considerable barriers, agricultural mechanization can spread rapidly.

The experiences in Sri Lanka offer useful insights for African countries. Sri Lanka initially saw substantial growth in 4WT use, which continued until the 1980s, followed by the gradual takeover of 2WTs. Importantly, during the accelerations in tractor use leading up to the 1970s, relatively few direct subsidies were involved. During the early stage of mechanization growth in the second half of the 20th century, Sri Lanka focused on stimulating imports of a substantial quantity of tractors and other machines, while making significant investments in complementary technologies such as improved crop varieties and irrigation infrastructure. These patterns suggest the importance of technology-induced mechanization at an early stage, which African countries may have to follow. In particular, Sri Lanka has invested considerably in local $\mathrm{R} \& \mathrm{D}$ to adapt these technologies to its tropical, low-latitude nature and to its soil types and physiographic conditions, which are different from the rest of Asia but somewhat similar to West Africa, especially in its rice-growing areas (Moormann and van Breemen 1978). Consequently, the early stages of mechanization occurred while agricultural wages remained low and the sector continued to account for a large share of employment. These early investments may have set the stage for further spread of mechanization later on, which become more driven by income growth of farm households and increases in labor costs.

\section{References}

Abeyratne, F. 1984. “Changing Patterns of Farm Technology in Sri Lanka." In Farm Power and Employment in Asia, edited by F. Farrington, F. Abeyratne, and G. Gill. Bangkok: Agricultural Development Council.

Abeyratne, F., H. P. M. Gunasena, and D. Tennakoon. 1986. Shifting Farming towards Stability. Research Study 66. Colombo, Sri Lanka: Agrarian Research and Training Institute. 
Athukorala, P. C., and S. Jayasuriya. 2004. Complementarity of Trade and FDI Liberalization in Industrial Growth: Lessons from Sri Lanka. Acton, Australia: Australian National University.

Bandara, M. H. M. 2011. “Country Report.” Presentation at Sustainable Agricultural

Mechanization Roundtable: Moving Forward on the Sustainable Intensification of

Agriculture, United Nations Asia Pacific Center for Agricultural Engineering and

Machinery, Bangkok, December 8-9.

_ 2013. "Updates on Sustainable Agricultural Mechanization Technology." Paper

presented at Ninth Session of Technical Committee, Centre for Sustainable Agricultural

Mechanization, Bhopal, India, October 17-18.

_. 2014. "Status of Custom Hiring System of Farm Machinery in Sri Lanka." Presentation at Second Regional Forum on Sustainable Agricultural Mechanization in Asia and the Pacific, Serpong, Indonesia, September 9-11.

Biggs, S., and S. Justice. 2013. "Rural and Agricultural Mechanization in Bangladesh and Nepal:

Status, Processes and Outcomes." In Mechanization for Rural Development: A Review of Patterns and Progress from around the World, edited by J. Kienzle, J. Ashburner, and B. Sims, 67-98. Integrated Crop Management, vol. 20. Rome: Food and Agriculture Organization of the United Nations.

-2015. Rural and Agricultural Mechanization: A History of the Spread of Small Engines in Selected Asian Countries. Discussion Paper 01443. Washington, DC: International Food Policy Research Institute.

Biggs, S. D., A. P. Kelly, and G. Balasuriya. 1993. Rural Entrepreneurs, Two-Wheel Tractors and Marketsfor Services: A Case from Sri Lanka. Discussion Paper No. 242. Norfolk, UK: School of Development Studies, University of East Anglia.

Colombage, S. 2011. "Long-Term Outlook for Non-plantation Agriculture in the Macroeconomic Context." In Agriculture and Rural Development in Sri Lanka, ed. W. Wimalaratne, ch. 16. Colombo, Sri Lanka: University of Colombo.

CSAM (Centre for Sustainable Agricultural Mechanization) and UNESCAP (United Nations Economic and Social Commission for Asia and the Pacific). 2015. Agricultural Mechanization and Testing of Agricultural Machinery in the Asia-Pacific Region. Beijing.

De Silva, W. I. 2007. A Population Projection of Sri Lanka for the Millennium, 2001, 2101: Trends and Implications. Colombo, Sri Lanka: Institute of Health Policy.

Ellman, A. O., D. De S. Ratnaweera, K. T. Silva, and G. Wickramasinghe. 1976. Land Settlement in Sri Lanka. Research Study 16. Colombo, Sri Lanka: Agrarian Research and Training Institute.

Epasinghe, S. 2010. "The Impact of Use of Machinery for Paddy Harvesting: The Social, Economic and Environment," unpublished manuscript in Sinhala, Hector Kobbekaduwa Agrarian Research and Training Institute, Colombo, Sri Lanka. 
FAO (Food and Agriculture Organization of the United Nations). 2018a. FAOSTAT database.

Accessed April 17, 2018. http://faostat.fao.org. 2018b. World Census of Agriculture. Rome.

Farrington, J. 1984. “Technology, Growth and Distribution in Sri Lanka’s Paddy Sub-Sector," PhD dissertation, University of Reading, UK.

Farrington, J., and F. Abeyratne. 1982a. Farm Power in Sri Lanka. Development Study 22. Reading, UK: University of Reading.

_ 1982b. "The Impact of Small Farm Mechanization in Sri Lanka." In Farm Power and Employment in Asia, ed. J. Farrington, F. Abeyratne, and G. J. Gill, 113-137. Bangkok: Agricultural Development Council.

GTZ (German Society for Technical Cooperation). 1991. Mechanization Survey Report. Eschborn, Germany.

Harriss, B. 1977. “Paddy and Rice Statistics in Sri Lanka.” In Green Revolution?, edited by B. H. Farmer, 20-29. London: Palgrave Macmillan.

Hossain, M., D. Gollin, V. Camanilla, E. Cabrera, N. Johnson, G. S. Kush, and G. McLaren. 2003. "International Research and Genetic Improvement in Rice: Evidence from Asia and Latin America." In Crop Variety Improvement and Its Effect on Productivity: The Impact of International Agricultural Research, edited by R. Evenson and D. Gollin, 71-108. Wallingford, UK: Centre for Agriculture and Bioscience International.

IRRI (International Rice Research Institute). 1986. Small Farm Equipment for Developing Countries. Los Baños, Philippines.

Kathirkamathamby, S. 1978. "Status of Agricultural Mechanization in Sri Lanka." In Proceedings of the International Agricultural Machinery Workshop, 161-170. Los Baños, Philippines: International Rice Research Institute.

_ 1984. "Agricultural Mechanization in Sri Lanka." In Development of the Agricultural Machinery Industry in Developing Countries, edited by A. Moens and A. H. J. Siepman. Wageningen, Netherlands: Center for Agricultural Publishing and Documentation.

Kienzle, J., J. E. Ashburner, and B. G. Sims. 2013. Mechanization for Rural Development: A Review of Patterns and Progress from around the World. Rome: Food and Agriculture Organization of the United Nations.

Kikuchi, M., P. Weligamage, R. Barker, M. Samad, H. Kono, and H. M. Somarathna. 2001. "Agro-Well and Pump in Irrigation Schemes in the Dry Zone of Sri Lanka: Past Diffusion, Present Status and Future Prospects." In Use of Groundwater for Agriculture in Sri Lanka: Symposium Proceedings, edited by S. Pathmarajah, 1-9. Peradeniye, Sri Lanka: Agricultural Engineering Society of Sri Lanka. 
Kumara, S. K., R. Weerakkody, and S. Epasinghe. 2016. "Mechanization in the Field Crop Sector: Situation Analysis," unpublished draft, Hector Kobbekaduwa Agrarian Research and Training Institute, Colombo, Sri Lanka.

Moormann, F. R., and N. van Breemen. 1978. Rice, Soil, Water, Land. Los Baños, Philippines: International Rice Research Institute.

Pain, A. 1986. “Agricultural Research in Sri Lanka: An Historical Account.” Modern Asian Studies 20 (4): $755-778$.

Pillainayagam, M. G. 1972. "A Comparative Study of 2 Wheel and 4 Wheel Tractor Operations and Performance in the Dry Zone." Unpublished.

_ 1982. "Research into Farm Power and Equipment in Sri Lanka." In Farm Power and Employment in Asia, edited by J. Farrington, F. Abeyratne, and G. J. Gill. Bangkok: Agricultural Development Council.

Raj, K. N. 1972. "Mechanization of Agriculture in India and Sri Lanka (Ceylon)." International Labor Review 106: 315-334.

Siddhisena, K. A. P., and D. DeGraaf. 2009. “A Pace of Its Own: The Demography of Ageing Sri Lanka." Journal of Population Ageing 2: 77-99.

Siriweera, W. I. 1989. "Role of Draft Buffalo in Rural Sri Lanka." In Draft Animals in Rural Development: Proceedings of an International Research Symposium, edited by D. Hoffmann, J. Nari, and R. J. Petheram. Cipanas, Indonesia: Australian Center for International Agricultural Research.

Sri Lanka, DCS (Department of Census and Statistics). 2002. Population Census. Battaramulla.

- Various years. Labor Force Survey. Battaramulla.

Sri Lanka, DOA (Department of Agriculture). 2015. 2013/14 Maha, Cost of Cultivation of Agricultural Crops. Battaramulla.

Takeshima, H., and Y. Liu. 2018. The Role of Plant-Breeding R\&D in Tractor Adoption among Smallholders in Asia: Insights from Nepal Terai. IFPRI Discussion Paper 01719. Washington, DC: International Food Policy Research Institute.

Thilakaratne, I. G., and H. M. Somaratne. 2011. "Strategies to Overcome the Scarcity of Agriculture Labor: An Empirical Study of Rural Village in the Dry Zone." Annals of the Sri Lanka Department of Agriculture 4: 399-406.

World Bank. 1994. World Development Report 1994: Infrastructure for Development. Washington, DC. 2016. World Development Indicators database. https://data.worldbank.org/indicator/. Accessed May 21. 


\section{Appendix 4A: Back-of-the-Envelope Calculation of the Share (Percentage) of Rice Area Plowed by Tractors}

The share (percentage) of rice area plowed by tractors in the 1960s in Table 4.1 is calculated in the following way.

First, the population of $4 \mathrm{WTs}$ in the 2010s is estimated as 20,000. This is based on the figure of 15,000 in 2002 (as is shown in this chapter), and assuming that it increased only slightly, unlike the increase for $2 \mathrm{WTs}$ observed during this period. The figures for $2 \mathrm{WTs}$ in the 2010s are estimated as 150,000 , based on Biggs and Justice (2015). For the 1960s, the average number of $4 \mathrm{WT}$ is estimated as 5,000, based on various estimates (for instance, the figure for 1962 in this chapter comes from Raj 1972). The average number of 2WTs in the 1960s is estimated as 1,000, based on the fact that importation of several hundred 2WTs per year began in the late 1950s (Harriss 1977), and the number of 2WTs was negligible until 1965 and then increased to 3,500 by 1969 (Raj 1972).

Applying the figures of total harvested area of rice (1,057,406 ha) in 20102014, shares of area plowed by $4 \mathrm{WTs}$ and $2 \mathrm{WTs}$ ( 28 percent and 70 percent of 1,057,406 ha, respectively; see CSAM and UNESCAP 2015), and estimated numbers of $4 \mathrm{WTs}$ and $2 \mathrm{WTs}$ as above, we calculate the approximate areas plowed corresponding to each unit of 4WTs and 2WTs in Sri Lanka as 14.8 ha and 4.9 ha, respectively, of paddy area. Note that this is not the actual area plowed by each unit, but rather simply proportions between the mechanically plowed rice areas and the numbers of $4 \mathrm{WT}$ s and $2 \mathrm{WT}$, which allow us to extrapolate roughly the areas plowed in the 1960s, given the numbers of $4 \mathrm{WTs}$ and 2WTs in the country in the 1960s.

Using the figures obtained above, mechanically plowed rice areas in the 1960 s were estimated by simply multiplying the aforementioned 14.9 ha and 4.9 ha to the estimated numbers of $4 \mathrm{WTs}(5,000)$ and $2 \mathrm{WTs}(1,000)$, respectively, which led to the estimated mechanically plowed rice area of about 80,000 ha. Based on the average harvested rice area in the 1960s of 523,296 ha, the approximate share of mechanically plowed area is estimated as about 15 percent $(=80,000 / 523,296)$. However, it should be noted that, given the number of assumptions made, this figure should be interpreted with caution. 

Chapter 5

\title{
EVOLUTION OF AGRICULTURAL MECHANIZATION IN THAILAND
}

Rob Cramb and Viboon Thepent

\begin{abstract}
Evidence from Asia indicates that mechanization can play a vital role in poverty-reducing small-scale agricultural and rural development. The case of Thailand is especially pertinent because it illustrates both the development of accessible small-scale machinery and the provision of large-scale machinery to smallholders through contract hiring services. This chapter reviews the specific demand and supply factors that have given rise to the pattern of mechanization in Thailand over the past half century. It is argued that rapid mechanization resulted from the conjuncture of several key elements from the 1960s to the 1990s-the dominance of smallholders in the landscape, cultivating rice and field crops for both domestic and export markets; dramatic demographic changes, contributing to a growing scarcity of agricultural labor; a boom in manufacturing, drawing labor out of farming; the development of infrastructure, facilitating agricultural commercialization and labor mobility; a technological and business environment encouraging competition among small and medium firms to develop suitable and affordable machines for farmers; and a policy environment broadly supportive of smallholder agriculture, agribusiness, industrial development, and trade. The Thailand case provides important evidence for policy debates about small-scale mechanization in other Southeast Asian countries and Africa south of the Sahara.
\end{abstract}

\section{Introduction}

Over the past five decades, the agricultural sector in Thailand has experienced one of the most rapid and extensive processes of mechanization in Southeast Asia, in which the distinguishing feature has been the development of locally adapted small-scale machinery to meet the needs of agricultural smallholders. This began in the 1960s and 1970s with the importation and local manufacture of pumps and two-wheel tractors (2WTs) used in rice cultivation, particularly in the central plain of the Chao Phraya River, in the Central region (Figure 5.1). Mechanization was extended progressively to the use of small 
rice mills, sprayers, threshers, and combine harvesters, not only in the central plain but also in the lowland rice-growing and upland field-crop zones of the Khorat Plateau in the Northeast region (Figure 5.1). The number of 2WTs in use increased from around 90,000 in 1975 to 2.7 million by 2008, representing a growth rate of 11 percent and a density in 2008 of 0.14 per hectare of agricultural land, or just over 7 ha per machine (Chancellor 1983; Coxhead and Plangpraphan 1998; Thepent 2000, 2015). Correspondingly, the number of buffalo, the main source of draft power in rice farming before the advent of the 2WT, declined from a peak of 6.4 million in 1982 to just over 1.0 million in 2014 (FAO 2017).

The current usage of machinery and equipment on farms in Thailand is recorded in Table 5.1, showing that 41 percent of holdings use $2 \mathrm{WTs}$, 41 percent use four-wheel tractors (4WTs), 20 percent use planters, 30 percent use small water pumps, 44 percent use sprayers, 37 percent use weeders, and 29 percent use combine harvesters. Apart from $4 \mathrm{WTs}$, threshers, and combine harvesters, which are predominantly sourced from private service providers, most of this machinery and equipment is owned by the landholder, notably in 75 percent of cases for 2WTs and 76 percent of cases for engine-powered pumps. Moreover, most is manufactured in Thailand by a large number of small to medium-size private engineering firms, some of which now export machines to neighboring countries. In 2009 there were reported to be 275 firms manufacturing 2WTs, 386 firms manufacturing combine harvesters, and 1,192 firms providing repairs and maintenance for agricultural machines (Thepent 2015).

The explanation for this rapid mechanization of Thai agriculture lies in the conjuncture of several key elements:

- The nature of farming in Thailand, dominated by smallholders, with farms averaging around 3 ha, cultivating rice and field crops for both domestic and export markets;

- Dramatic demographic changes, especially a rapid drop in birth rates, contributing to a growing scarcity of agricultural labor;

- A boom in manufacturing and construction in the 1980s and 1990s, drawing labor out of farming, particularly in younger age groups, a process that has continued at a slower rate in subsequent decades;

- The development of transport and communication infrastructure, facilitating agricultural commercialization and labor mobility; 
FIGURE 5.1 Regions of Thailand

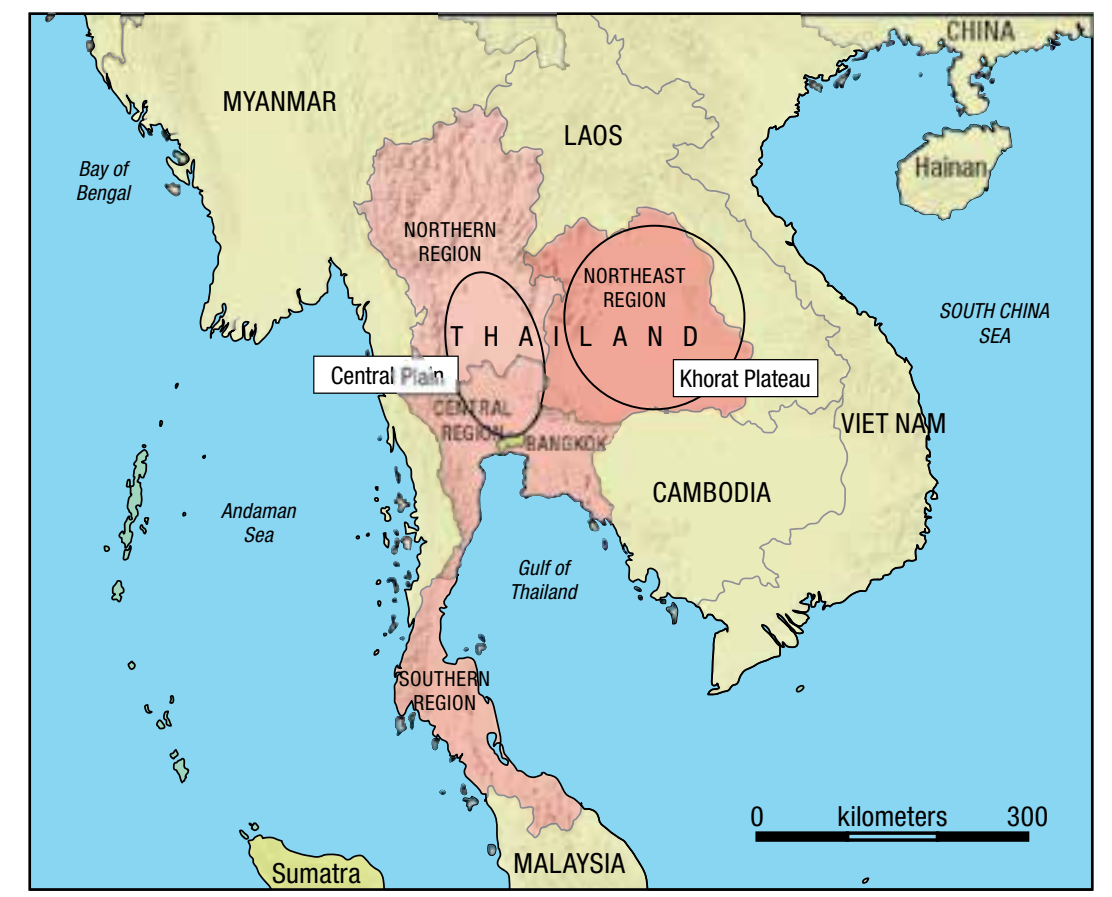

Source: Australian National University (2019).

- A technological and business environment encouraging competition among small and medium-size firms to develop suitable and affordable machines for farmers;

- A policy environment generally supportive of smallholder agriculture, agribusiness, industrial development, and trade.

This chapter elaborates on this historical conjuncture, examining both the demand and supply sides of the story. First, the chapter describes the longterm economic and demographic changes that have given rise to labor scarcity in agriculture, and the trends in agricultural development that have led farmers to make greater use of machinery, focusing on the crops for which mechanization has been in greatest demand and had the greatest impact, namely, rice and commercial field crops. Second, the story of mechanization itself is outlined and the factors enabling the rapid growth in the supply of suitable farm machinery and machinery services are analyzed. The chapter concludes with 
TABLE 5.1 Number of holdings using farm machinery and equipment by source, Thailand, 2013

\begin{tabular}{|c|c|c|c|c|c|c|c|}
\hline \multirow[b]{2}{*}{ Type of machinery } & \multirow[b]{2}{*}{$\begin{array}{c}\text { No. of } \\
\text { holdings }\end{array}$} & \multirow[b]{2}{*}{$\begin{array}{c}\% \text { of } \\
\text { holdings }\end{array}$} & \multicolumn{5}{|c|}{ Source of machinery or equipment } \\
\hline & & & $\begin{array}{l}\text { Owned by } \\
\text { landholder }\end{array}$ & $\begin{array}{l}\text { Co-op or } \\
\text { farmer } \\
\text { group }\end{array}$ & $\begin{array}{l}\text { Service } \\
\text { provider }\end{array}$ & $\begin{array}{l}\text { Govern- } \\
\text { ment } \\
\text { agency }\end{array}$ & Other \\
\hline \multicolumn{8}{|l|}{ Tractor } \\
\hline 4-wheel tractor & $2,427,001$ & 41.1 & 336,735 & 4,869 & $2,056,174$ & 2,966 & 6,361 \\
\hline 2-wheel tractor & $2,438,848$ & 41.3 & $1,827,555$ & 5,631 & 643,863 & 1,884 & 14,359 \\
\hline \multicolumn{8}{|l|}{ Water pump } \\
\hline Engine & $1,376,690$ & 23.3 & $1,049,403$ & 11,340 & 316,503 & 9,892 & 13,871 \\
\hline Electrical motor & 330,474 & 5.6 & 283,443 & 2,767 & 48,364 & 11,309 & 1,789 \\
\hline Natural energy & 32,758 & 0.6 & 17,989 & 1,125 & 14,589 & 2,442 & 1,690 \\
\hline \multicolumn{8}{|l|}{ Sprayer } \\
\hline Manually operated & $1,273,177$ & 21.5 & 856,546 & 2,264 & 418,894 & 1,049 & 8,082 \\
\hline Machine-powered & $1,323,153$ & 22.4 & 845,773 & 2,476 & 489,336 & 1,266 & 6,104 \\
\hline \multicolumn{8}{|l|}{ Weeder } \\
\hline Manually operated & $1,053,087$ & 17.8 & 673,112 & 1,778 & 373,144 & 803 & 8,699 \\
\hline Machine-powered & $1,155,443$ & 19.5 & 748,969 & 1,542 & 379,050 & 1,155 & 5,880 \\
\hline \multicolumn{8}{|l|}{ Planter/seeder } \\
\hline Manually operated & 720,999 & 12.2 & 268,000 & 2,140 & 497,155 & 827 & 17,764 \\
\hline Machine-powered & 167,413 & 2.8 & 62,600 & 438 & 110,424 & 163 & 682 \\
\hline Att. to 2-wheel tractor & 131,381 & 2.2 & 73,237 & 357 & 60,179 & 161 & 858 \\
\hline Att. to 4-wheel tractor & 192,569 & 3.3 & 37,120 & 427 & 156,223 & 258 & 639 \\
\hline \multicolumn{8}{|l|}{ Harvester } \\
\hline Reaper (sugar) & 82,044 & 1.4 & 3,047 & 686 & 78,953 & 238 & 258 \\
\hline Combine harvester & $1,639,016$ & 27.7 & 33,095 & 3,123 & $1,588,239$ & 2,456 & 2,646 \\
\hline \multicolumn{8}{|l|}{ Thresher } \\
\hline Rice/cereal thresher & 542,887 & 9.2 & 14,512 & 2,652 & 526,713 & 1,449 & 2,544 \\
\hline Corn sheller & 173,568 & 2.9 & 4,027 & 1,328 & 168,737 & 256 & 1,077 \\
\hline Rice/cereal winnower & 207,718 & 3.5 & 4,777 & 3,302 & 201,873 & 714 & 1,969 \\
\hline Rice mill & $1,808,871$ & 30.6 & 40,515 & 59,847 & $1,752,898$ & 9,130 & 25,564 \\
\hline Milking machine & 11,707 & 0.2 & 7,622 & 102 & 4,091 & 28 & 96 \\
\hline \multicolumn{8}{|l|}{ Transportation } \\
\hline 4-wheel truck & $1,744,370$ & 29.5 & 799,979 & 3,177 & 931,162 & 1,772 & 15,695 \\
\hline 6-wheel (and over) truck & $1,037,262$ & 17.5 & 84,563 & 2,483 & 951,690 & 1,379 & 3,112 \\
\hline Boat & 29,256 & 0.5 & 26,362 & 44 & 2,733 & 42 & 161 \\
\hline Farm truck & 943,220 & 16.0 & 499,030 & 3,001 & 459,441 & 1,427 & 9,521 \\
\hline
\end{tabular}

Source: Thailand, NSO (2013). 
a summary of key lessons for the debate on agricultural mechanization and its contribution to rural development.

\section{Factors Affecting the Demand for Mechanization}

\section{Economywide Structural and Demographic Change}

Thailand has experienced remarkable economic growth in the past five decades, raising its economic status from that of a low-income to an upper-middleincome country (Warr 2007; World Bank 2016). Economic growth accelerated to around 8 percent from the mid-1980s to the mid-1990s due mainly to a surge of Japanese investment in labor-intensive manufacturing industries such as garments, textiles, and footwear in and around Bangkok. The automotive and electronics industries also began to expand, and urban property development boomed. Hence a significant gap opened up between agricultural and nonagricultural wage rates, especially nonagricultural wages in Bangkok (Figure 5.2). The Asian financial crisis caused a major reversal in 1997/1998, but by 1999 rapid economic growth had resumed, continuing for another decade until the global financial crisis of 2007/2008. Since then growth has continued, albeit falteringly due to a combination of domestic and global instability, with growth in 2015 recorded at 2.8 percent (World Bank 2016).

This long-term growth trajectory has been associated with major structural change in the Thai economy (Coxhead and Plangpraphan 1998; Poapongsakorn 2006; Warr 2007, 2014; Leturque and Wiggins 2011; Cramb and Newby 2015; Klyuev 2015; Ouyyanont 2016; World Bank 2016). Although the agricultural sector also experienced steady growth, as noted above, its share of GDP declined. Agriculture's value-added grew at 3-4 percent in real terms from 1960 to 2014, but it declined as a proportion of gross domestic product, from 37 percent in 1960 to 8 percent in 1993, and has hovered around 10 percent since then. At the same time, agriculture's share of total employment fell from 71 percent in 1980 to around 42 percent in 2004, also fluctuating around the same proportion in the succeeding decade. This proportion is considered high for a country of Thailand's economic status (Klyuev 2015), possibly reflecting an overstatement of the degree to which rural households still depend primarily on agriculture; the number of full-time farmers declined from 16.3 million in 1992 to 9.6 million in 2010, which was about 27 percent of total employment (World Bank 2016, 27).

The long-term decline in agricultural employment in Thailand has been partly offset by an influx of migrant workers from surrounding countries 
FIGURE 5.2 Monthly wage rates in Thailand by sector, 1980-1995

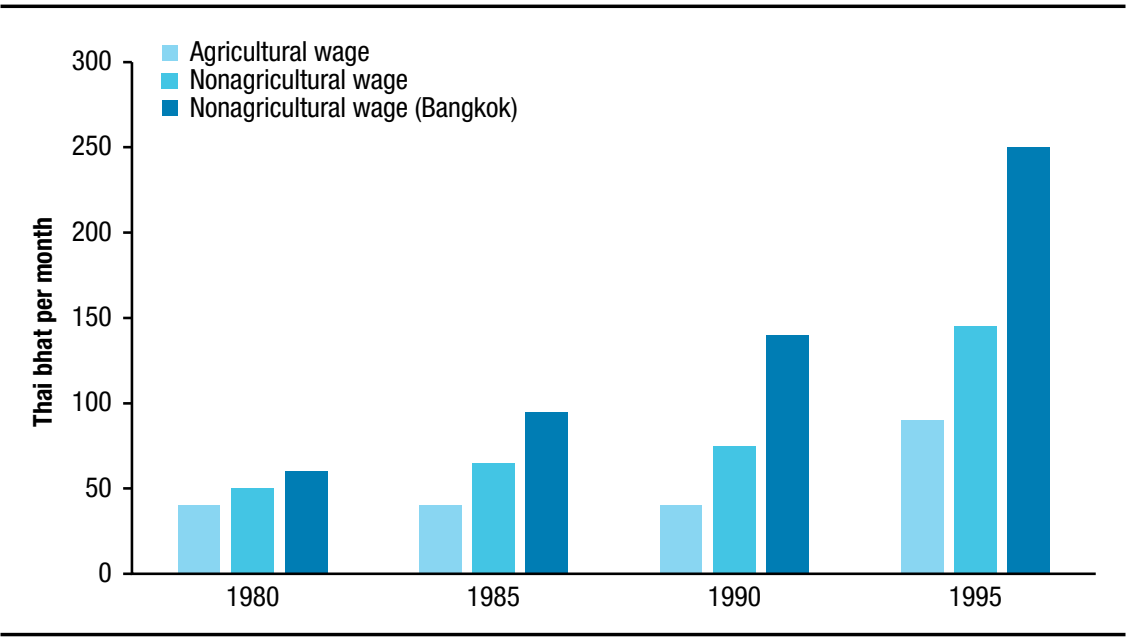

Source: Coxhead and Plangpraphan (1998).

(Myanmar, Laos, and Cambodia) in recent decades, who are paid lower wages than Thai workers. Thailand currently has about 3.7 million migrant workers, accounting for almost 10 percent of total employment (World Bank 2016, 28). However, it is estimated that migrant workers contribute only about 5 percent of the agricultural workforce, mainly working on specialized commercial farms, and have not greatly affected the trend toward mechanization on the majority of smallholder crop farms.

Alongside this economic transformation has been a major demographic transition (De Koninck and Rousseau 2012; Rigg 2012; Cramb and Newby 2015). In the 1960s Thailand was experiencing rapid population growth (around 3 percent) due to a high birth rate and a much reduced death rate. Given that more than 80 percent of the population was rural and a similar proportion of the workforce was engaged in agriculture, this was creating concern about, on the one hand, population pressure in the central lowlands, causing land fragmentation and increased landlessness (Ramsay 1985), and on the other, the spread of lowland Thai rice farmers into the forested uplands of the Northern region (Chapman 1978). It also gave rise to concern in some quarters about the labor-displacing effects of mechanization.

However, a complex of factors (economic growth, urbanization, and an effective family planning policy) led to a sharp drop in the birth rate from the mid- to late 1960 s, such that the population growth rate fell to only 
0.3 percent in 2013 (World Bank 2016). This dramatic slowing in the rate of population growth, combined with the movement of labor from agriculture to urban-based industry and services, led to reduced growth and then, beginning around 2000, an absolute decline in the rural population such that, by 2015, the urban population just exceeded the rural population in a total population of 68 million.

\section{Pattern of Agricultural Development}

\section{LANDHOLDINGS AND FARMING SYSTEMS}

Thailand has a land area of 51 million ha, of which 43 percent is agricultural land, allocated mainly to lowland rice ( 51 percent); field crops such as maize, cassava, and sugarcane (22 percent); and tree crops, notably rubber and oil palm (22 percent) (Table 5.2). The high percentage of agricultural land results in a ratio of 0.3 ha per person, more than in most Southeast Asian countries (Cramb 2015). Thus, although Thailand is not a "land-abundant" economy, it has a relatively favorable land endowment.

There were almost 6 million agricultural holdings recorded in the 2013 agricultural census (Thailand, NSO 2013). The number of holdings had increased by 2.0 percent since the 2003 census, and the total area had increased by 1.9 percent, so the average holding size remained stable at 3.2 ha-again, relatively large by Asian standards. Almost all holdings (98.9 percent) were held by individual households, accounting for 98.5 percent of the total area. Most holdings (91.0 percent) comprised 1-3 parcels, representing 75.1 percent of the total area.

The incidence of ownership was high in 2013, with 78.7 percent of holdings owned, 11.3 percent non-owned (borrowed or rented), and 10.0 percent comprising both owned and non-owned parcels. About 63 percent of land parcels were registered, providing secure tenure, though unregistered rights are also considered relatively secure, except in forest reserves and areas at risk of land expropriation by developers (USAID 2011).

The size distribution of holdings was somewhat unequal. Whereas the middle 50 percent of holdings, in the range 1.45-6.24 ha, contained 50 percent of the area, the upper 12 percent of holdings contained 41 percent of the area, mostly in the 6.25-80 ha range, and the lower 37 percent of holdings $(<1.45 \mathrm{ha})$ contained 9 percent of the area. Nevertheless, it is true to say that the overall agrarian structure is "unimodal" (Tomich, Kilby, and Johnston 1995), dominated by independent farm households operating their own, relatively compact smallholdings. 
TABLE 5.2 Holding size and land use by region, Thailand, 2013

\begin{tabular}{lrrrrr}
\hline & \multicolumn{5}{c}{ \% of total area in region } \\
\cline { 2 - 6 } Variable & Central & North & Northeast & South & Thailand \\
\hline Rice & 42.4 & 50.1 & 67.5 & 5.7 & 51.3 \\
Rubber & 8.5 & 3.2 & 8.2 & 66.7 & 14.5 \\
Permanent crops & 13.1 & 7.7 & 0.9 & 24.2 & 7.5 \\
Field crops & 27.2 & 34.8 & 20.5 & 0.3 & 22.4 \\
Horticultural crops & 2.0 & 1.1 & 0.3 & 0.6 & 0.8 \\
Forest (planted) & 1.5 & 1.5 & 0.6 & 0.2 & 0.9 \\
Freshwater culture & 2.9 & 0.2 & 0.2 & 0.4 & 0.7 \\
Other & 2.4 & 1.4 & 1.8 & 2.0 & 1.8 \\
Total & 100.0 & 100.0 & 100.0 & 100.0 & 100.0 \\
\hline Mean area/holding (ha) & 3.7 & 3.4 & 3.2 & 2.3 & 3.2 \\
\hline
\end{tabular}

Source: Thailand, NSO (2013).

The type of land operated by these smallholders varies considerably across the country's four main regions (Figure 5.1). The Central region includes the historical rice bowl, with fertile soil, 60 percent irrigable land, high population density, and good access to markets. It was also the first region to commercialize and diversify into crops such as sugarcane, rubber, and horticultural crops. The number of agricultural holdings in this region declined between 2003 and 2013; so too did the average holding size-from 3.9 to 3.7 ha-which nevertheless remains the highest in the country (Table 5.2). Despite its historical significance, the region accounts for only 14 percent of all holdings in the country and 17 percent of total area.

The Northern region is largely mountainous, with low population density. It was traditionally associated with long-fallow swidden agriculture but has seen an increase in the area of lowland rice cultivation in the upper part of the central plain and in inland valleys ( 34 percent of the region's arable land is irrigable) and an expansion of field crops (especially maize) and horticultural crops on sloping land. It has also seen a decline in the number of holdings but an increase in the average holding size, from 3.0 ha in 2003 to 3.4 ha in 2013, not far below the Central region average (Table 5.2). Overall, the region accounts for 22 percent of holdings and 24 percent of farm area.

The Northeast region has poor, often sandy soils, less reliable rainfall, and low productivity but accommodates almost half of Thai farm households. Rainfed lowland rice is the dominant crop (only 13 percent of the 
region's arable land is irrigable), but the region has seen significant growth of export-quality rice and expansion of cassava, sugarcane, and rubber in recent decades, particularly in the northern part (Ekasingh et al. 2007; Grandstaff et al. 2008; Table 5.2). The number of holdings has been increasing, but the average holding size has remained constant at 3.2 ha (Table 5.2). The Northeast accounts for 46 percent of holdings and 47 percent of area.

The Southern region has little flat land but has ideal agroecological conditions for tropical tree crops, notably rubber and oil palm, which take up 91 percent of agricultural land (Table 5.2). The number of holdings has been increasing and the average area decreasing, from 2.8 to $2.3 \mathrm{ha}$. This region accounts for 17 percent of holdings but only 13 percent of total farm area.

\section{PHASES OF AGRICULTURAL GROWTH}

Agricultural growth was relatively rapid in the 1960s and 1970s, averaging 4-5 percent, but slowed with the boom in manufacturing beginning in 1985 and has fluctuated around 2-3 percent in the past decade. There have been two distinct phases in Thailand's postwar agricultural growth-extensive growth up to 1990, followed by intensive growth since then (Poapongsakorn 2006; Leturque and Wiggins 2011). As can be seen in Figure 5.3, in the 1970s and 1980s, both the area of agricultural land and the size of the agricultural workforce increased as a rapidly growing rural population pushed out the agricultural frontier, particularly in the Northern and Northeast regions, contributing to extensive deforestation. However, the expansion of farmland could not prevent the ratio of agricultural land per worker from falling, from about 1.8 ha in the early 1970 s to just over 1.0 ha in the late 1980 s. The turning point was around 1990, which marked the peak of agricultural land expansion and the beginning of an absolute decline in the agricultural workforce. Hence agricultural land per worker began to rise, slowed by the Asian financial crisis in $1997 / 1998$, but returning to nearly 1.8 ha in 2014 .

Whereas the pre-1990 phase of agricultural growth was dependent on increases in aggregate inputs of land and labor, the post-1990 phase has been driven by increased productivity resulting from investment in capital (particularly mechanization) and technological improvement (particularly improved crop varieties), roughly in the ratio 60:40 (Leturque and Wiggins 2011). Hence value-added per agricultural worker, which had been unchanging in the 1970 s and 1980 s, rose sharply, from $\$ 530^{1}$ in 1990 to $\$ 1,260$ in

1 Dollar amounts are in US dollars throughout the chapter. 
FIGURE 5.3 Agricultural land, agricultural employment, and land-to-worker ratio in Thailand, 1971-2014

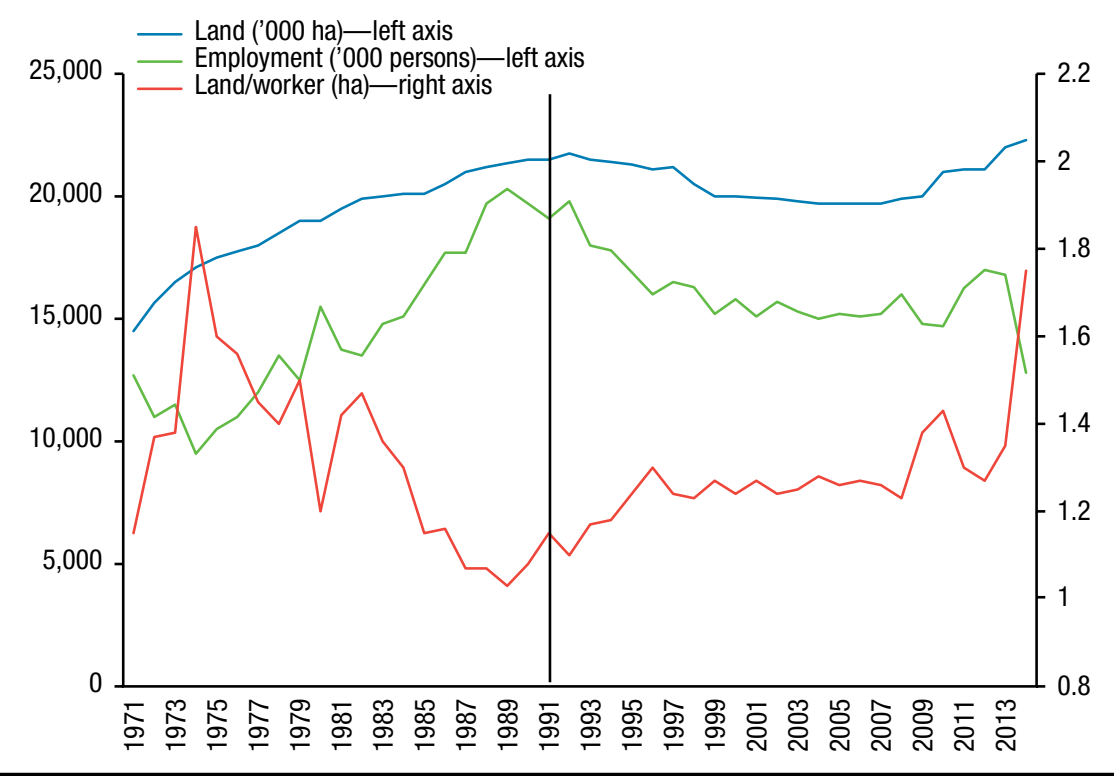

Source: World Bank (2017).

2013, though still well below valued-added per worker in the industrial sector. Farmers sourced the capital for this investment from their savings and by borrowing from the highly successful Bank for Agriculture and Agricultural Cooperatives and other formal and informal sources (including dealer credit for larger items of machinery). This phase of agricultural growth has not only been characterized by intensification of land use (notably, a shift to two or more crops per year in the irrigated central plain) but also greater diversification into high-value nonrice crops (fruit, vegetables, and flowers) particularly in the Central and Northern regions. It has also seen the emergence of more specialized, professional farmers, estimated to account for 20 percent of all farmers in 2004, many of them in contract-farming arrangements with agribusiness firms (Poapongsakorn 2006, 40-43; Leturque and Wiggins 2011, 22-23).

Throughout these two periods, Thai agriculture has been strongly export oriented, with rice, sugar, cassava, rubber, palm oil, poultry, and aquaculture all contributing. Before the manufacturing boom of the 1980s, most exports were of agricultural origin, and agriculture still contributes 25 percent of total exports by value (Poapongsakorn 2006; Singhapreecha 2014). 


\section{Crop-Specific Factors Affecting Demand for Mechanization}

The mechanization of agriculture has been largely a story of lowland rice and the major commercial field crops-sugarcane, cassava, and maize. Mechanization of the major tree crops-rubber and oil palm—has proved more elusive. The impetus for mechanization came not only from the declining availability and increasing cost of farm labor due to the exogenous economic and demographic trends described above, but also from trends within the crop subsectors that increased the demand for labor, adding to its cost. In the case of rice, the impetus for mechanization came from the shift to more intensive production, especially double cropping, made possible by irrigation and Green Revolution technologies, in the context of a growing export market (Fujimoto, Adulavidhaya, and Matsuda 1990). In the case of the major field crops, the impetus came from export booms that made areal expansion (and eventually increased yields) profitable (De Koninck and Rousseau 2012). This combination of relatively elastic demand for farm output and an increasing cost of labor induced farmers to demand suitable labor-saving capital inputs in order to reduce costs and maintain profitability (Binswanger 1986; Pingali 2007).

\section{RICE}

Rice is still the most important crop in Thailand, accounting for just over half of agricultural land (Table 5.2). Rice is mainly grown in the central plain, of which a high proportion is irrigated, enabling double cropping, and on the Khorat Plateau, where it is mainly rainfed, permitting only a single wet-season crop. From the 1960 s to the 1980 s, growth in rice production was largely due to expansion of the area cultivated (from about 6 million ha to 10 million ha), especially in the Northern and Northeastern regions, with little improvement in yields, which were low by Asian standards, averaging 1.8 tons/ha. ${ }^{2}$ In the 1990s, area expansion ceased but average yields increased at about 2.5 percent, continuing through to the present-they now average 3.0 tons/ha. This was due to the ongoing and widespread use of high-yielding varieties (HYVs), increased fertilizer application, and improvements in irrigation. Total rice production has increased at a rate of more than 10 percent since 1990 due to a combination of increased yield and (since 2000) greater cropping intensity. Thailand has long been one of the two or three major exporters of rice, peaking at 10.8 million tons of milled rice, valued at \$5.4 billion, in 2014 . Rice exports were heavily taxed up to the late 1990 s, but in recent years the

\footnotetext{
2 "Tons" refers to metric tons throughout the chapter.
} 
state has introduced price-support schemes (with disastrous political and economic consequences).

Up to the 1950s, most rice farming in Thailand used a traditional set of labor-intensive and time-consuming technologies-land preparation by buffalo-drawn shovel-plow and harrow; irrigation (where feasible) using scoops, water wheels, or a wooden water-lift trough; pulling and transplanting seedlings by hand; weeding with a knife or sickle; harvesting by sickle (or a finger knife in the Southern region); threshing sheaves with hand-held sticks or by animal trampling; and dehusking the grain (as required) using a wooden mortar and pestle (Jongsuwat 1980; Chinsuwan and Cochran 1986). The peak labor demands were for transplanting and harvesting, with land preparation a slow and laborious process. Beginning in the 1960 s, all of these operations, except transplanting, were progressively mechanized, beginning in the central plain.

The earliest machines used were 2WTs for land preparation and low-lift axial flow pumps for irrigation, powered by single-cylinder engines. Farmers acquired these machines themselves, given their low cost and their multiple functions, ${ }^{3}$ but there was also some localized renting, particularly in the Northeast. As Pingali (2007) pointed out, such machines are generally the first to be utilized because they contribute to power-intensive rather than controlintensive tasks. Though land preparation was not the major labor peak, the advent of double cropping in the irrigated areas created a major bottleneck in the turnaround from the wet-season to the dry-season crop. A survey in the early 1970s found that "the increase in tractor use and ownership were wholly due to double cropping since the use of buffalo was too slow given the existing farm size and household labor supply" (Jongsuwat 1980, 23). Threshing and transportation were also highly mechanized for the same reason. Jongsuwat concluded that "the use of tractors and other farm machines is a matter of necessity in double cropping" $(1980,23)$. Thus mechanization (through both tractors and pumps) allowed the advantages of the HYVs to be realized.

Rather than mechanize transplanting (a control-intensive task), farmers almost universally reverted to direct seeding to save labor, using hand broadcasting of presoaked seed in irrigated areas or dry seed in rainfed areas (Kupkanchanakul 2000; Rerkasem 2015). This was in preference to direct seeding with devices such as seed drills or drum seeders, or using

3 The tractors could be used for transportation as well as powering pumps, threshers, and other equipment. The pumps could be used to power boats. 
rice transplanters, which were expensive and required greater precision and control. However, in recent years some farmers in the Central region have started to hire contractors who use imported rice transplanters (Thepent and Chamsing 2009), and there has been limited use of a seed drill in parts of the Northeast region. Hand weeding was progressively augmented or replaced by herbicides applied with hand-operated or powered backpack sprayers.

Imported Chinese reapers were tried in the early 1980s but were generally unsuccessful. However, mobile threshers were successfully introduced in the 1970s and 1980s, mostly on a contract service basis, threshing being another power-intensive task. Threshers were superseded in the central plain beginning in the 1990s by combine harvesters, also provided by contractors, and these contract harvesting services have since spread to the Northeast region (Poungchompu and Chantanop 2016).

The dehusking of rice, whether for home consumption or sale, is now universally undertaken at local rice mills rather than in the home. With the use of combine harvesters, the grain is harvested with high moisture content and is no longer left in the field to dry. Hence now almost 90 percent of collectors and millers in the major rice production areas own mechanical dryers. Attempts to promote the use of small dryers among farmer groups were generally unsuccessful.

\section{SUGARCANE}

The area of sugarcane expanded from 63,000 ha in 1961 to 1.35 million ha in 2014, occupying 6.1 percent of agricultural land, mainly in the Central region, the southern part of the Northern region, and the Northeast region. Sugarcane was first planted in the 1950s on higher land in the central plain, and subsequently spread to the Northern and Northeast regions. Most of the growth in total production has been due to this more-than-twentyfold expansion in area rather than increased yields, which have about doubled since 1980. Sugar is produced for both domestic and export markets, and the industry has negotiated significant protection in the form of a "home price scheme" that subsidizes exports (Leturque and Wiggins 2011). In addition, the government's promotion of fuel ethanol, largely derived from molasses, is adding to the demand for sugarcane (USDA 2016). Cane production reached a new record of 105.7 million tons in 2014. Thailand is the world's second-largest sugar exporter, with exports valued at $\$ 2.6$ billion in 2015, accounting for 12 percent of world sugar trade (Weerathaworn 2015).

The expansion of sugarcane in the upland areas of the central plain in the 1950s and 1960s was limited by the lack of animal or machine power 
and consequent dependence on manual labor for land clearing and cultivation. However, by the 1970 s, imported and locally assembled 4WTs drawing disc plows and harrows were used for the heavy work of land preparation, facilitating the area expansion in the 1970s and 1980s. Srijantr reported for a sugar-growing subdistrict in the western part of the central plain that "an agricultural revolution occurred in Thung Luk Nok in 1975. In sugarcane production, farmers started to use high-yield varieties, farm machines such as four-wheel tractors for land preparation, and big trucks for transportation to factories" $(2003,129)$. Srijantr observed that "only the rich farmers or those who had accumulated enough capital could invest in the new means of production such as four-wheel tractors and big trucks" $(2003,129)$. These large farmers became entrepreneurs, hiring out their tractors and trucks to small farmers, extending credit, and buying their sugarcane to meet allocated quotas from the mills.

As labor costs continued to increase, large farmers in the central plain began to use mechanical harvesters, as well as mechanizing other operations, including planting, fertilizing, and weed control. However, among smaller farmers and in the Northeast region, to which the industry expanded, manual planting and harvesting have remained dominant (Ekasingh et al. 2007). Ding, Tangwongkit, and Tangwongkit found that "manual harvesting remained popular due to its low cost, low soil compaction, and low damage to cane roots and the subsequent ratoon crop" $(2004,33)$. Vorasayan and Pathumnakul (2014) reported that with rising wages (doubling between 1998 and 2013), mechanical harvesting was becoming more feasible and the amount harvested in this way was increasing rapidly. However, widespread use was restricted by the prevalence of small farms with short fields (giving rise to field inefficiencies) and the need to have a truck alongside the harvester at all times to collect the chopped cane, whereas with manual harvesting, trucks can come to pick up the cane at any time.

\section{CASSAVA}

Cassava was a boom crop of the 1970s and 1980s, taking advantage of an advantageous EU market for animal feed (Curran and Cook 2008). Production and exports grew rapidly, almost entirely due to expansion of cultivated area in the Northeast region, where geopolitical concerns during the Indochina conflict had prompted US funding of extensive road infrastructure. The Northeast, with its sandy soils and undulating land, accounts for about 80 percent of total cassava production (Ekasingh et al. 2007; Leturque and Wiggins 2011). In the 1990s the loss of the export window to Europe led 
to a reduction in area and output, but the development of domestic processing (for example, for ethanol) and, especially, the growth of demand from China for both starch and dried cassava led to a resurgence in production beginning in around 2000 (Tijaja 2010). Although yields showed some improvement in this period (averaging 22 tons/ha in 2014 compared with around 15 tons/ ha in the 1970s and 1980s), the growth in production was again mainly due to areal expansion in the Northeast. By 2014, cassava was planted on a record area of 1.4 million ha (6.1 percent of agricultural land), producing 30 million tons of fresh roots. These were processed into dried chips and starch for use in domestic industries (about a third) and export (about two-thirds), mainly to China. Thailand has dominated global exports of cassava products since the 1980s, in 2013 exporting 5.8 million tons of dried cassava worth $\$ 1.3$ billion and 2.4 million tons of cassava starch worth $\$ 1.1$ billion.

A recent survey in the Central, Northern, and Northeast regions found that the common methods of land preparation involved primary and secondary tillage using a 4WT drawing a standard disc plow and disc tiller (Chamsing 2013). Many farmers in the Northeast also practiced ridging by removing the two front discs from the standard plow. These activities were almost all undertaken by contractors at a rate of 200-250 Thai baht (THB) per rai $(\$ 35-\$ 44 / \mathrm{ha})$. However, planting was done manually in all regions. About half the surveyed farmers planted directly into the plowed soil and half planted into preformed ridges (thought to prevent waterlogging and make harvesting easier). There was a widespread demand for a cassava planter, but current prototypes did not meet farmers' preference for vertical planting of cassava stakes. Pre-emergence herbicides were sprayed after planting to control weeds. Farmers used manual backpack sprayers, powered backpack sprayers, and high-pressure pumps to apply the herbicides; in the Northeast, 94 percent of farmers used a manual sprayer. Mechanical weeding was not observed.

Harvesting involved first manually cutting the cassava stems, which were collected for planting material, stacked for burning, or otherwise removed from the field. Most farmers then hired labor to lift the cassava roots using a locally developed harvesting tool that has spread to other Asian countries (Howeler and Aye 2014, 39). However, 37 percent of farmers in the Northern region, 27 percent in the Northeast region, and 24 percent in the Central region used a cassava digger attached to a 4WT (Chamsing 2013). Whether the roots were dug manually or with a tractor-drawn digger, the remaining tasks of collecting the lifted plants, cutting the roots from the stems, and loading the harvest into trucks were all done manually. There was interest from farmers in a prototype combined digger and hauler, but this needed further 
development. The cassava roots were loaded into small trucks, some owned by the farmer but most owned by collectors or contractors, for transportation to local factories. The roots were mechanically chopped and either sun-dried for production of chips or processed into starch.

\section{MAIZE}

In the 1950s, maize was planted on a small scale as a subsistence crop (for food and animal feed), mainly in the uplands and highlands of the Northern region. From 1961, maize was promoted as a commercial enterprise as part of the government's export-oriented diversification strategy (Ekasingh et al. 2004). It was increasingly planted as a rainfed crop on the undulating uplands, lower mountain slopes, foothills, and highlands of the Northern region (where its expansion was associated with extensive deforestation and soil erosion), as a rainfed crop on the upland plain of the Northeast region, and as a dry-season irrigated crop following wet-season rice on the lowland plain of the Central and lower Northern regions. The rainfed crop is almost entirely feed maize, whereas the irrigated crop includes sweet corn and baby corn. About half the maize area is in the Northern region and a quarter in each of the Central and Northeast regions. Almost 90 percent of maize is produced as a rainfed upland crop in the wet season (Ekasingh et al. 2004, 2007).

Maize production expanded rapidly in the 1970s and 1980s, almost entirely due to expansion in cultivated area. Most of this production was for export, which reached 4 million tons, valued at \$359 million, by 1986 . Beginning in the 1990s the area planted in maize declined as many upland farmers switched to other crops such as cassava and fruit trees, settling at about 1.1 million ha in the 2000s, but yields began to rise with increased use of improved varieties and fertilizers so that production has continued on an increasing trend. However, exports of maize plummeted from their peak in the late 1980s to be close to zero in the 1990s. The rapid growth of the domestic poultry and livestock sectors, which themselves have grown into export industries, increased the demand for feed within Thailand. Hence Thailand has been at times a net importer of maize, drawing on contract farming arrangements in neighboring countries.

Ekasingh and colleagues (2004) conducted a survey of maize producers in the main agroecological zones in 1999/2000. They found that all farmers used large 4WTs for land preparation, at least for the first pass, mostly on a contract basis. A majority of the surveyed areas were using various types of mechanical seeder, especially on large farms in flatter areas. However, on smaller farms on sloping land, the seed was planted manually. Farmers in the 
Central region planting maize in the dry season necessarily irrigated using the axial flow pumps that had become pervasive. Farmers sprayed pre-emergence herbicides after planting using manual or powered backpack sprayers, and followed up with mechanical weeding. In all the surveyed villages, harvesting was done manually, which was regarded by farmers as a significant cost. Often harvesting teams were contracted from other provinces or regions, particularly from the Northeast region. The harvested cobs were shelled mechanically by mobile machines provided on contract by the traders who purchased the grain. Ekasingh and others observed that "across Thailand, mechanization of farm operations is becoming a necessity for maize farmers, especially for land preparation, sowing, fertilizer application, and weeding. Small trucks are also used for transporting farm inputs and outputs" $(2004,19)$. Subsequently, Thai-made combine harvesters have been developed for maize, in response to demand from farmers to overcome the last remaining labor bottleneck. In the last decade these have been commercially produced and are increasingly used in flatter areas on a contract basis (Chiaranaikul n.d.).

\section{Factors Affecting the Supply of Mechanization}

As described above, the demand for agricultural mechanization came from millions of smallholder farmers engaged in production of rice and field crops for expanding global markets. These farmers were faced with increasing labor costs due to increased requirements for labor (arising from intensification of rice production and expansion of field crop production) and a declining agricultural labor force (due to slowing of population growth and rapid rural-to-urban migration resulting from industrialization). That the supply of mechanization was able to meet this demand, particularly in rice production, was due to the emergence and growth of local manufacturing capacity characterized by large numbers of small- to medium-scale enterprises and a few large firms in close communication with farmers and public-sector researchers. Small machinery firms typically employed 4 or 5 workers occupying a workshop of 50 square meters. They were located in close proximity to rice farms in the central plain. Large firms with 100 or more workers, occupying 3,000 square meters, also sprang up in the industrializing provinces to the north of Bangkok. The remarkable development of this agricultural machinery industry in Thailand has been outlined by Anchan (1983), Chancellor (1983), Rijk (1986, 1989), Thepent and Chamsing (2009), Thepent (2015), and Soni (2016). 
Imports of small-scale machinery from East Asia were also an important part of the mechanization story-as a direct source of supply, as models for local adaptation, and (crucially) providing components for incorporation in locally made machines. In particular, small, single-cylinder engines (of less than $16 \mathrm{hp}$ ) imported from Japan played a critical role in the early stages of the industry from the 1950 s to the 1970 s. These engines could be flexibly incorporated in locally designed pumps and tractors and thus used to power irrigation, cultivation, threshing, and transportation. By the early 1980s, about 80 percent of the single-cylinder diesel engines sold in the country were supplied by two local manufacturers under license from Japanese parent companies. ${ }^{4}$ These engines were more expensive but also more durable; they could be used for tractors, water pumping, boat propulsion, and powering a locally made transport vehicle (Chancellor 1983). The preference for diesel over gasoline engines reflected the lower price for diesel fuel (Biggs and Justice 2015).

\section{Policy Context}

Throughout Thailand's successive National Economic and Social Development Plans, beginning with the First Plan (1962-1966), there was no explicit policy regarding agricultural mechanization. Indeed, mechanization was not mentioned until the Sixth Plan (1987-1991). However, in 1979, the National Committee for Agricultural Mechanization was established to formulate a policy and strategy, which was approved by the cabinet in 1985 . This essentially affirmed the process that was already well underway, encouraging mechanization that increased productivity, with affordable machines of good quality that were suitable to the conditions of Thai farmers. This was despite concerns in some quarters about the capacity of mechanization to displace agricultural labor and cause excessive rural-to-urban migration (Anchan 1983), as well as to reduce agriculture's capacity to reabsorb labor during economic downturns (Coxhead and Plangpraphan 1998). The strategies involved collaboration between public and private sectors in research and development, standardization of machinery to enable certification, training of farmers and manufacturing workers, and facilitation of long-term credit for farmers and machinery businesses.

4 Siam Kubota Diesel Co. Ltd. and Yanmar Thailand Co. Ltd., both established in 1978 in Pathum Thani province, just north of Bangkok.

5 Standardization and certification have had limited impact. Testing is not feasible for smalland medium-scale manufacturers without assembly lines and, in any case, the local market disciplines these manufacturers without the need for formal certification. Testing is, however, enforced for the small one-cylinder engines that form an essential component of other 
The Seventh Plan (1992-1996) reiterated this general support for mechanization and promotion of local manufacturing and extension to farmers, but there was no explicit policy in this or subsequent plans. The Tenth and Eleventh Plans (spanning 2007 to 2016) made a significant shift to the notion of a "sufficiency economy," emphasizing sustainable agriculture, food security, bioenergy production, energy efficiency, and environmentally appropriate technologies, but none of these emphases has been interpreted or applied in a way to affect ongoing developments in mechanization.

Nevertheless, government institutions have played an important role in the development of the agricultural machinery industry since the 1950s, particularly in research and development. The Agricultural Engineering Division (AED), now the Agricultural Engineering Research Institute (AERI), under the Ministry of Agriculture and Cooperatives, developed blueprints and prototypes, linked with international research programs (for example, through a joint farm machinery development project with the International Rice Research Institute, or IRRI, from 1975 to 1985), and interacted closely with innovative private-sector manufacturers. ${ }^{6}$ The Small Industry Finance Corporation was established in 1964 and was a potential source of support to the emerging farm machinery industry, though it was "hampered by limited funds, which were dependent on state budget allocations, and cumbersome and inflexible government procedures and regulations" (SME Development Bank 2017). Its successor since 2002, the Small and Medium Enterprise Development Bank of Thailand (SME Development Bank), is much better resourced. The Thailand Board of Investment (BOI) also plays a role by offering tax breaks and other incentives to attract new projects from domestic and foreign manufacturers (Thepent 2015).

Though government institutions have been broadly supportive of mechanization, policy settings were not always favorable to the local industry. Reflecting on the first two decades of mechanization, Sukharomana remarked:

The farm power strategy of Thailand is remarkable in the sense that it has worked despite formidable handicaps... The government's most important contribution to the development of [the] farm machinery industry appears to be the initial importation of small tractors

machines, whether locally manufactured or imported. Certification for other machinery imports and exports is voluntary.

6 Professional and industry organizations have provided important links between the private sector, researchers, and government, including the Thai Society of Agricultural Engineers, established in 1976; the Agricultural Machinery Manufactures Industry Club, established in 1980; and the Thai Machinery Association, established in 2001 (Thepent 2015). 
from which local manufacturers borrowed [their] present technology. Having successfully borrowed, their industry has flourished with little government support-despite prevailing hostile fiscal policies and the government's indifference to industry needs. $(1983,31)$

According to Sukharomana, cheap credit through the Small Industry Finance Corporation had been "made available in a trickle" $(1983,6)$, with only three agricultural machinery firms acquiring loans. Sukharomana (1983) was particularly critical of the impacts of trade policy on local manufacturing, with low tariffs on imported machinery (including secondhand tractors) and excessive duties on components, particularly the imported diesel engines that were essential to the local industry. Donovan, Binswanger, and Pingali (1986) also pointed out that in the 1970s, local tractor production increased at 14 percent while the import share dropped below 7 percent- "despite negative protection." However, in 1981 imports of secondhand 2WTs from Japan surged, seriously undermining the domestic industry. ${ }^{7}$ In response to pressure from local manufacturers, in 1982 the government increased tariffs on imported machines and engines (from 5 to 35 percent) and established restrictive import quotas. In Anchan's words at the time, "clearly, the local manufacturing firms are now well protected" $(1983,12)$. This was consistent with policy toward the automotive industry (and industrial policy in general), which was protectionist from the 1960s to the 1980s, before the general liberalization of trade beginning in 1991 (Natsuda and Thoburn 2011), by which time the agricultural machinery industry was well established and starting to export locally made $2 \mathrm{WT}$ s and equipment to neighboring countries.

A broader aspect of the policy context relates to energy costs. As in many Asian countries, Thailand has long subsidized energy consumption via a complex set of measures (ADB 2015). Retail prices for diesel, liquefied petroleum gas (LPG), and natural gas for vehicles (NGV) are capped-in the case of automotive diesel at THB 30 (\$0.85) per liter, which is of considerable advantage to farmers using diesel pumps, tractors, and pick-ups. Price subsidies for diesel and NGV apply to all consumers, whereas LPG prices vary with the consuming sector. Electricity prices are subsidized for low-consuming households, as is the cost of providing electricity to rural and remote areas (where coverage is now close to 100 percent). Modeling suggests that removal of these subsidies without compensation or increased government spending on services

7 These $18 \mathrm{hp} 2 \mathrm{WTs}$ were recycled after perhaps only 2,000 hours of use, enabling importers to undercut the local product. 
would reduce the consumption levels of agricultural households and increase rural poverty, particularly in the Northern and Northeast regions, but only marginally, indicating that farmers are benefiting somewhat from the current regime (ADB 2015, 14-16). However, subsidy removal would benefit the agricultural machinery sector most, but harm the motor vehicle and vehicle repair sectors (ADB 2015, 17). This implies that the current regime has been, on balance, unfavorable to the agricultural machinery industry, though not greatly.

\section{Industry Size and Structure}

The agricultural machinery industry has been part of the growth and diversification of the manufacturing sector in Thailand. The Department of Industrial Works reported 2,809 businesses producing and repairing agricultural machinery in 2009 (Table 5.3). A survey in 2001 by the AERI found that 46 percent of agricultural machinery firms were small (with fewer than 10 employees), 34 percent were medium (10-30 employees), and 20 percent were large (more than 30 employees). Small firms typically have minimal equipment such as a simple lathe, follow flexible designs such that their products cannot be checked against a template, and employ workers on a daily wage without any fixed job descriptions or assignments. Medium firms have jigs and fixtures in addition to a simple lathe but still follow flexible designs and employ daily-paid labor. Large firms use computer numerical control (CNC) machining and possibly an automated machining center, follow a systematic manufacturing process that can be checked, and employ monthly-paid staff with specified job descriptions and assignments as well as daily-paid staff and contractors. ${ }^{8}$

The businesses enumerated in Table 5.3 produced mainly 2 WTs and tillage equipment, sprayers, and combine harvesters. More than 40 percent provided repairs and maintenance in small workshops scattered through the countryside. A survey of the top 70 agricultural machinery factories in Thailand in 2001 gave an indication of the production capacity, emphasizing the importance of $2 \mathrm{WTs}$, small tillage implements, sprayers, and pumps (Table 5.4). Two-wheel tractors and threshers last about 10 years, diesel engines about 7 years, and irrigation pumps and power sprayers about 6 years (Thepent 2000). Hence the output of 80,000 2WTs implies the capacity to maintain a stock of 800,000 on farms. This is just under half of the recorded

8 It is likely that the size distribution of machinery firms has shifted in the succeeding two decades, but no up-to-date study is available. 
TABLE 5.3 Number of agricultural machinery businesses, Thailand, 2009

\begin{tabular}{lc}
\hline Type of machinery & $\begin{array}{c}\text { No. of } \\
\text { businesses }\end{array}$ \\
\hline Two-wheel tractors & 275 \\
Tillage equipment & 329 \\
Planters & 16 \\
Sprayers & 447 \\
Harvesters & 386 \\
Other machinery & 164 \\
Repairs and maintenance & 1,192 \\
\hline
\end{tabular}

Source: Thepent (2014).

stock on rice farms in 2000, underlining the fact that imports of tractors and a range of other agricultural machinery remained important (Table 5.4).

Indeed, the Thai agricultural machinery industry has become increasingly integrated into the regional economy, with both imports and exports rising rapidly (Figure 5.4). According to Thailand BOI (2016), the value of agricultural machinery imports tripled between 2009 and 2014, to a total value of $\$ 1.11$ billion. The main sources of imports were Japan, China, and Malaysia. The largest imports by value were water pumps, tractor vehicles and parts, and mechanical sprayers. ${ }^{9}$ In the same period the value of agricultural machinery exports increased more than five times, to $\$ 0.79$ billion, led by $2 \mathrm{WTs}$ and equipment for cleaning, sorting, and grading seeds and grains (Thepent 2015; Thailand BOI 2016). The major export destinations were Cambodia, Myanmar, and Indonesia. Agricultural machinery and parts accounted for 7 percent of imports and 10 percent of exports of all machinery and parts in 2014 (Thailand BOI 2016).

\section{Development and Supply of Machinery}

\section{IRRIGATION PUMPS}

After the establishment of the Rice Department in 1953, the AED began work on improving imported machines and inventing machines suited to local conditions (Jongsuwat 1980). In the mid-1950s the AED developed a submersible low-lift axial flow pump (tho phayanak) powered by a small diesel

9 Electric-powered pump sets produced in southern China (Qiuqiong, Rozelle, and Hu 2007) have gradually replaced locally produced diesel-powered axial flow pumps as rural electrification has progressed. 
TABLE 5.4 Production of agricultural machinery in Thailand, 2001 and 2012

\begin{tabular}{lcc}
\hline & \multicolumn{2}{c}{ Production (units/year) } \\
\cline { 2 - 3 } Type of machinery & 2001 & 2012 \\
\hline Four-wheel tractors & - & 40,000 \\
Two-wheel tractors & 80,000 & - \\
Large tillage implements & 3,000 & - \\
Small tillage implements & 90,000 & - \\
Threshing machines & 2,000 & - \\
Combine harvesters & 600 & 3,000 \\
Hand-operated sprayers & 60,000 & - \\
Irrigation pumps & 55,000 & - \\
\hline
\end{tabular}

Source: BAC (2011) for 2001; Thepent (2014) for 2012.

Note: $-=$ data not available.

FIGURE 5.4 Imports and exports of agricultural machinery and parts, Thailand, 2009-2014

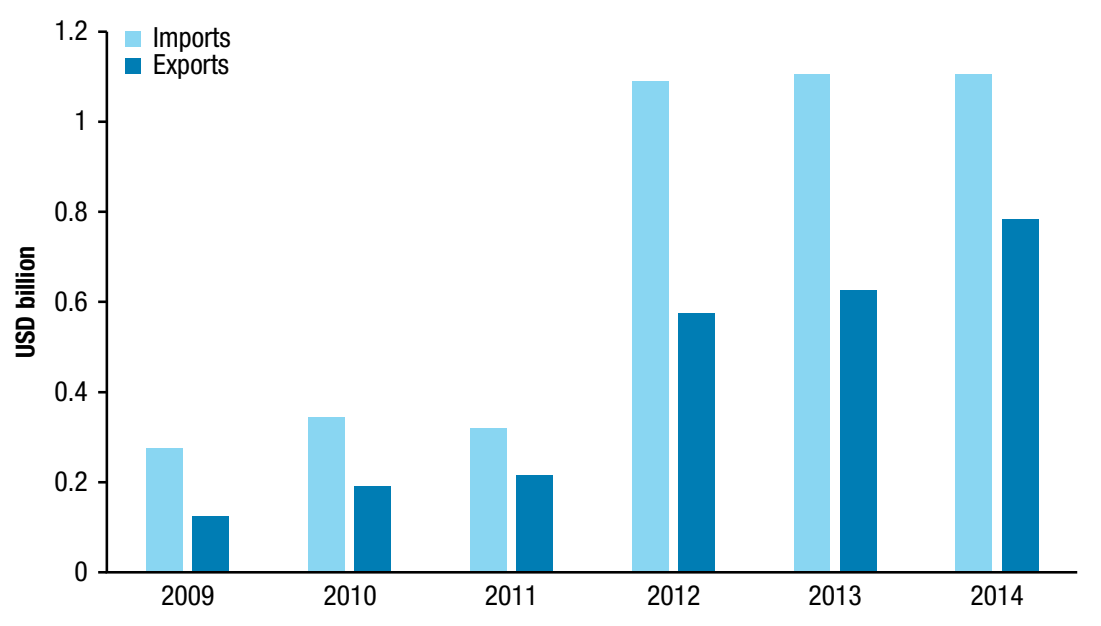

Source: Thailand BOI (2016).

Note: USD = US dollars.

engine of $4.5 \mathrm{hp}$, and in 1957 the design was released for local manufacture (Jongsuwat 1980). This "Debaridhi pump" (named after its inventor, M. R. Debaridhi Thevakul) was commercially produced and widely purchased or hired by farmers to lift water from rivers, canals, and ponds, and to drain rice fields. It very quickly replaced the traditional water wheels and scoops, and complemented (or compensated for) the large government-operated pumps in 
irrigation projects in the Chao Phraya delta (Molle, Shah, and Barker 2003). It was more efficient and cheaper to run than centrifugal pumps and could be easily transported. By enhancing their ability to irrigate, the pump helped to make dry-season cropping of rice and field crops economically attractive to lowland farmers. ${ }^{10}$

Versions of the Debaridhi pump are still widely used, often powered by 2WT engines (Figure 5.5). In 2001, 80 percent of irrigation pumps were in the Chao Phraya basin ( 55 percent in the Central region and 25 percent in the Northern), 15 percent in the Northeast, and 5 percent in the Southern region. By 2008 there were reported to be 1.43 million irrigation pumps in use, averaging THB 4,500 (\$126) per unit, for a total value of THB 6,439 million (\$180 million) (Thepent 2015). The 2013 agricultural census (Thailand, NSO 2013) found that 1.7 million holdings (29 percent) used an irrigation pump, 81 percent powered by a diesel engine and 19 percent by an electric motor (Table 5.1). Of these holdings, 78 percent of farmers owned a pump and 21 percent accessed a pump through a "service provider," often a neighboring farmer (Table 5.1).

\section{TRACTORS}

As in many countries even today (Pingali 2007; Animaw et al. 2016), there was initially a bias in official circles in favor of large tractors as the symbol of modernized agriculture (Chakkaphak and Cochran 1986). In 1891 the government imported some steam-powered tractors and rotary hoes, but these were expensive and unsuitable for use in paddy fields. In the early 1920s, further agricultural machines were imported for research and development, but there was little progress before the onset of World War II. In the early 1950s $4 \mathrm{WTs}$ were imported for use on the Rice Research Station and promoted through contract services to nearby farmers, but the project was unsuccessful. In 1958 the AED released the design of a small $25 \mathrm{hp} \mathrm{4WT} \mathrm{(the} \mathrm{"Iron}$ Buffalo") to two firms for commercial production, but the machine could not compete with imported tractors. In 1960 Ford established an assembly line for 4WTs, followed in 1964 by Massey Ferguson, but these were for use in dryland farming, not in rice production.

Two-wheel tractors were also imported in the decade after the war. In 1947, a single-axle tractor with rotary hoes powered by a $5.9 \mathrm{hp}$ gasoline engine was imported from Japan, but its low chassis made it unsuitable for

10 A similar development occurred in the Mekong delta in the 1960s, apparently independently of the Thai innovation (Biggs 2012). 
FIGURE 5.5 Use of two-wheel tractor to power an axial flow pump to irrigate a rice field in Central region, Thailand

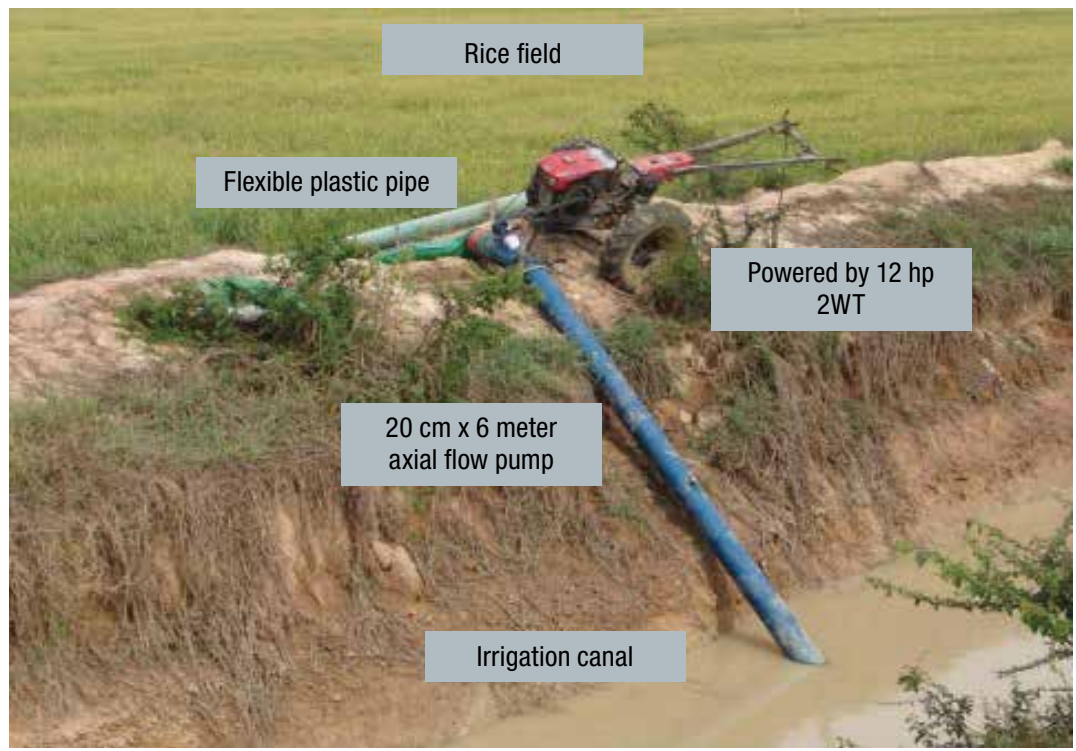

Photo: Scott Justice

Source: Scott Justice

paddy fields. Later, in the 1950s, a Japanese 2WT was imported and appeared more suitable. However, the major surge in the supply of tractors for rice farming began in the mid-1960s, when workshops around Bangkok began to modify the design of the imported 2WTs to meet farmers' demands for a cheaper and better-adapted version. One workshop succeeded in simplifying the gearbox and adapting other parts of the tractor, notably by lengthening the handles to enable easier turning in the muddy paddy fields. ${ }^{11}$ In 1966 several firms began producing these modified 2WTs, using imported air-cooled, singlecylinder gasoline engines. Their lower price relative to the imported tractors and their suitability to local conditions (for example, their greater maneuverability) made them popular with farmers, and they soon spread to all parts of the central plain. In a 1981/1982 survey of 222 farmers in an irrigated area of Suphanburi province, reasons given for using the 2WT were "save time

11 The producer of this first successful model was a village chief, Kamnan Prung Farkaew of the Singkru Dsahagrum factory in Phra Pradaeng, now part of Greater Bangkok (Jongsuwat 1980). 
in farm work" (22.8 percent), "can plant on time" (20.3 percent), "easy and reduces drudgery" (18.6 percent), "better plowing” (12.3 percent), "increases output" (5.6 percent), "no animal and human labor available" ( 4.2 percent), and "reduces weeding" (3.7 percent) (Sukharomana 1983).

The high demand led to the establishment of many farm machinery firms in this region. By the mid-1970s there were about 90,000 2WTs in use in Thailand, mostly (76 percent) in the Central region, and by 1981 there were more than 284,000 (Chancellor 1983; Sukharomana 1983). Almost all (95 percent) were locally manufactured by small firms, of which there were about 100 in 1979 (Sukharomana 1983). Small engineering workshops located in rural areas needed only a basic tool kit of an oxyacetylene torch for cutting and welding and an angle grinder to smooth cuts and joins. Mechanics learned their trade on the job and often subsequently set up their own small businesses. As the workshops were nearby the paddy fields, there was close interaction between farmers and mechanics in developing the tractors. Workshops would freely copy and adapt designs from existing machines and combine parts from different sources, and farmers would compare the performance of the machines and seek out better models. The tractors of the 1960s and 1970s incorporated the imported single-cylinder engines referred to above. By the 1980 s, they were mostly equipped with locally manufactured, liquid-cooled 8 hp diesel engines. These engines were more expensive but also more durable; they could be used also for water pumping, boat propulsion, and powering a locally made transport vehicle when not being used on the tractor (Chancellor 1983).

The 2WT was "so common and so simple in construction that any wellequipped workshop could effect repairs" (Chancellor 1983, 6). During the peak seasons, mechanical workshops worked long hours to repair farmers' machines. Mechanics' services were charged at THB $12.5(\$ 0.36)$ per hour in 1980/1981 (about twice the minimum wage for nonmetropolitan areas at that time). An excellent road network allowed rapid distribution of spare parts. Owners of the small, locally made tractors did about 30 percent of their own repairs and called on workshops for 60 percent (Chancellor 1983). Chancellor concluded that agricultural machinery systems in Thailand were marked by "an extensive general knowledge of machine repair techniques, a wide availability of low-cost machine repair services and a well-developed network of spare-parts supplies from import and domestic sources, so that repairs could be quickly effected" $(1983,6)$.

As reported in Table 5.1, by the 2013 agricultural census (Thailand, NSO 2013), 2.4 million holdings (41 percent) used 2 WTs, and in 75 percent 
of these holdings the tractor was owned by the landholder. Most of these holdings were rice farms. By this time a similar number of holdings used 4WTs, also mainly now manufactured or assembled in Thailand. These holdings were typically dryland farms growing field crops such as sugarcane, cassava, or maize. However, in the case of the larger tractors, 85 percent of holdings relied on service providers, typically larger landholders in the same district who gained extra income by renting out their tractors for land preparation. Larger tractors were more effective in cultivating the harder dryland soils but too expensive for most smallholders to own. However, the distinct uses of $2 \mathrm{WTs}$ and $4 \mathrm{WT}$ are becoming blurred. Thepent reported that "there is a growing market for a four-wheel tractor of less than $40 \mathrm{hp}$ with rotary implements which will replace two-wheel tractors for rice cultivation in the central plain region and the lower part of the Northern region" $(2015,4)$.

\section{PLANTERS}

Transplanting rice was a major bottleneck. As discussed above, farmers' main response was to move to direct seeding by hand broadcasting, in both irrigated and rainfed areas, first in the central plain, then spreading to the Northeast (Konchan and Kono 1996). In 1978, a rice transplanter was imported from China by a local firm, which also began manufacturing it (Chamsing and Singh 2000,3). The transplanter was power operated and capable of handling 12 rows. However, it could not be sold in large numbers because farmers preferred the simpler and cheaper broadcasting method. In recent years there has been renewed interest in the use of transplanters in parts of the central plain due to problems with contamination of rice varieties and weed control under direct seeding. Rice transplanters of less than $10 \mathrm{hp}$ include 4-row and 6-row walking types, and those of more than $10 \mathrm{hp}$ include 6-row and 8-row ride-on types. Sales of these transplanters have been increasing since 2010, though they still account for a small proportion of planted area (Ken Research 2016). All transplanters are imported from the Republic of Korea, Japan, and China, and are accessed through service providers.

Planting of dryland crops was also a peak labor requirement. Larger sugarcane farmers in the Central region had begun to use imported planters to reduce labor costs, as had larger maize farmers on flatter land in the Northern and Northeast regions. Maize seeders could be attached to $2 \mathrm{WTs}$ or $4 \mathrm{WTs}$, and some combined seeding and fertilizer application. However, despite the demand from farmers, there has been no commercial production of a cassava planter. 


\section{HARVEST AND POSTHARVEST MACHINERY}

The harvesting of rice, including the operations of reaping and threshing, constituted a second period of peak labor demand, especially where double cropping was practiced, and hence there was strong farmer interest in mechanizing these tasks. In 1975, the AED constructed a prototype axial flow rice thresher using a blueprint from the IRRI (Mongkoltanatas 1986). It was released to selected firms in Chachoengsao province (east of Bangkok) for commercial production, and 10 units were immediately sold. However, the design proved unsuccessful. Later, in 1975, a new blueprint was released to three firms for commercial production, and this version was rapidly and widely taken up by farmers. In 1977 IRRI sent a blueprint for a portable rice thresher. It was produced by one firm but not widely used due to its low capacity. Subsequent experimentation came up with a Thai thresher that doubled the capacity (from 1 to 2 tons per hour) and was self-propelled so it could be driven to the site (Sukharomana 1983; Mongkoltanatas 1986). This made it ideal for service provision by contractors.

During 1981/1982 about 1,000 Chinese reapers were imported and sold for rice harvesting. However, the long-stemmed Thai rice varieties were not suitable for reaping and, in any case, farm workers had to collect and bind the harvested rice as for manual harvesting, requiring more labor. In addition, the weight of the machines made field operations difficult. Hence the reapers were finally abandoned.

In the period 1985 to 1987, however, local machinery firms near Bangkok began to fabricate small track-type rice combine harvesters that could go into muddy and even flooded fields (Chiaranaikul n.d.). By the early 1990s, these firms had successfully launched a range of these track-type combine harvesters that were acceptable to farmers. They had a capacity of 0.4 to 0.9 ha per hour, providing a substantial saving, and were quickly taken up in the central plain through service providers. In 1997, there were about 2,000 harvesters, mainly in the central plain. As more contractors entered the industry, hiring rates came down. A survey by AERI for 1999/2000 found that 57 percent of rice farmers harvested with sickles, 35 percent used a combine, and 8 percent used a reaper; most farmers (88 percent) used a power thresher (Thepent 2000). Combine harvesters have since spread to the major rice-growing area of the Northeast, at first through itinerant contractors from the Central region who trucked their combines to the region and used local brokers to line up groups of adjacent farmers, then through local contractors in the Northeast who were capable of directly negotiating with neighboring farmers (Poungchompu and 
Chantanop 2016). According to the 2013 agricultural census, 1.6 million holdings ( 28 percent) used a combine harvester, in 97 percent of cases accessed through a contractor (Thailand, NSO 2013). Thus the spread of combines, even without land consolidation, has been more rapid and extensive than many analysts predicted (for example, Pingali 2007).

As the use of combines has spread, the domestic demand for reapers and threshers has understandably diminished (Table 5.1), though threshers are still produced for export to neighboring countries, using the same parts as are incorporated in the combine. At the same time, the high moisture content of grain harvested by combines has stimulated the development of a range of mechanical driers. The higher moisture content was because farmers could not dictate the date of harvesting, having to fit in with the contractor's schedule, and because the grain was no longer dried in the field as it was when threshing was conducted separately. The AERI has made a significant contribution to the design of these driers. In the late 1990s the government subsidized the installation of small driers (30 tons per day) for farmer groups and large driers (60 to more than 100 tons per day) for cooperative millers. However, only 10 percent of the farmer-operated driers were used, and mechanical drying is now largely undertaken by the rice mills (Thepent and Chamsing 2009).

Sugarcane harvesters have begun to be imported but were used by only 82,000 holdings ( 1 percent) in 2013 , almost all ( 96 percent) operated by contractors. Harvesting of cassava is still done largely by hand, using locally developed digging tools. According to Thepent (2015), a maize combine harvester has been available since 1995. From 2005 to 2007 the AERI modified the locally produced rice combine harvester to be suitable for maize (Chiaranaikul n.d.). Two models were developed, one with minor modifications, capable of harvesting $0.3-0.6$ ha per hour and one, with a four-row cob-snapping unit and modified threshing system, capable of harvesting $0.8-1.0$ ha per hour. Both models are now in commercial production and are increasingly used by maize farmers on a contract basis.

\section{TRANSPORTATION}

Though part of a broader trend, the harnessing of mechanical power for transportation, coupled with public investment in roads and infrastructure, has also had a profound effect on agricultural development. As mentioned above, one of the attractions of 2WTs in the 1960s and 1970s was the capacity to hitch them to a cart to make a multipurpose transport vehicle. The so-called pedestrian tractor thus became a means to haul people and produce 
much more easily than with a buffalo- or ox-drawn cart. Imported 4WTs also became a means of transportation for those who could afford them.

Meanwhile, the highly successful Thai automotive industry, a key component of the growth of the manufacturing sector, focused on the production of commercial vehicles, particularly pick-up trucks, which were highly suitable for conditions in rural areas (Natsuda and Thoburn 2011). Business or excise taxes had been set at lower rates than on passenger vehicles since the 1960s, adding to their attraction. The industry produced more than a million commercial vehicles in 2010. Many of these have been purchased by better-off farmers and rural dwellers, who use them to transport inputs, machinery, and produce for themselves and as a hired service to other farmers.

\section{Conclusion}

Agricultural mechanization in Thailand has a long and multistranded history, illustrating the importance of context in assessing alternative models of agricultural development. The demand for mechanization came from millions of small-scale farming households seeking to employ new technologies to intensify and expand their production of rice and commercial field crops in response to domestic and global markets, while faced with a growing shortage and increasing cost of farm labor due to rapid economic and demographic change. The supply of suitable machinery and tools came initially from small-scale workshops that were responsive to farmers' needs and were willing and able to borrow ideas and experiment with piecing together available parts (especially single-cylinder engines) to make new and better-adapted machines.

The sequence of mechanization in Thailand conforms well to the generalizations advanced by Binswanger (1986) and Pingali (2007). The first wave of mechanization involved the use of small-scale, power-intensive multipurpose machines, notably low-lift axial flow pumps and 2WTs. This was particularly the case for rice cultivation, whereas opening up dryland for sugarcane, maize, and cassava made greater use of 4WT-drawn implements. Later waves of mechanization involved larger-scale, control-intensive, specific-purpose machines, notably threshers, combine harvesters, and most recently, rice transplanters. Although most farmers could afford to purchase the small-scale machines, the larger, more costly machines (including 4WTs) were made widely available by the emergence of contract services provided by a class of better-off entrepreneurial farm households. Early mechanization copied, adapted, and substituted for imported machinery. Subsequently, the 
agricultural machinery industry became integrated into the wider regional economy, with rapid growth in both imports and exports.

The experience in Thailand supports Binswanger's generalization that "the rate and pattern of mechanization are governed substantially by an economy's land and labor endowments, by the nonagricultural demand for labor, and by demand for agricultural products" (1986, 27; see also Pingali 2007). The path of mechanization in Thailand was clearly induced by the increasing scarcity and cost of labor relative to land, partly driven by rapid growth in nonagricultural demand for labor, in the context of elastic (export) demand for rice and the major field crops. However, in this case, there was very little influence of public-sector researchers, nor of organized farmer associations-both seen as essential elements in the induced innovation hypothesis as first formulated by Hayami and Ruttan (1971). Rather, direct and informal links between smallholders and small-scale local manufacturers (the private sector) provided the impetus for the adaptation and development of machinery that was initially "good enough" for local needs.

As for policy recommendations for African countries, Thai experiences suggest that the role of government has been important but secondary, and has been more effective in keeping the private informal sector active. The government played roles in research and sharing of designs with private manufacturers, at times providing incentives and trade protection for the emerging domestic industry. It had also focused on rural electrification; subsidizing energy costs, especially diesel fuel; and providing affordable and widely available farm credit. More generally, the government has adopted a light-handed approach, supporting agricultural mechanization as a positive contribution to rural development but allowing the private sector-manufacturers, dealers, contractors, and farmers-to innovate in response to changing technology and markets. Its experiences also show that tractors can be widely used not only for crops like rice and wheat, but also for crops like sugarcane and maize, as well as root crops like cassava, even though in Africa, where these crops are widely grown, applications of tractors have conventionally been thought difficult. The Thailand case thus shows that, despite widespread neglect of engineering technologies relative to biological technologies in international policy debates and research, mechanization can play a significant role in broad-based agricultural and rural development. In particular, mechanization is compatible with smallholder-led development, through both small-scale, multipurpose machines owned by farmers and large-scale, specialized machines made accessible through private contract services. It is also compatible with (indeed, partly induced by) intensification via the utilization of conventional Green 
Revolution (seed-fertilizer-irrigation) technologies, especially in rice-based farming systems.

\section{References}

ADB (Asian Development Bank). 2015. Fossil Fuel Subsidies in Thailand: Trends, Impacts, and Reforms. Manila.

Anchan, T. 1983. Farm Mechanization Policy in Thailand. Working Paper No. 104, Consequences of Small Farm Mechanization Project. Bangkok: Kasetsart University.

Animaw, A. T., J. A. M. Nkanya, J. M. Nyakiba, and T. H. Woldemariam. 2016. Agricultural Mechanization and South-South Knowledge Exchange: What Can Ethiopian and Kenyan Policymakers Learn from Bangladesh's Experience? Ethiopia Strategy Support Program Research Note 47. Washington, DC: International Food Policy Research Institute.

Australian National University. 2019. CartoGIS. Accessed 4 April. http://asiapacific.anu.edu.au/ cartogis/.

BAC (Business Analytic Center). 2011. Farm Machinery Market in Thailand: Business Report 2011. Bangkok.

Biggs, D. 2012. "Small Machines in the Garden: Everyday Technology and Revolution in the Mekong Delta." Modern Asian Studies 46: 47-70.

Biggs, S., and S. Justice. 2015. Rural and Agricultural Mechanization: A History of the Spread of Small Engines in Selected Asian Countries. IFPRI Discussion Paper 01443. Washington, DC: International Food Policy Research Institute.

Binswanger, H. 1986. “Agricultural Mechanization: A Comparative Historical Perspective.” World Bank Research Observer 1:27-56.

Chakkaphak, C., and B. Cochran. 1986. "Development of Four-Wheel Tractors and Implements in Thailand." In Proceedings of the International Conference on Small Farm Equipment for Developing Countries, 151-159. Los Baños, Philippines: International Rice Research Center.

Chamsing, A. 2013. Agricultural Mechanization Technologies for Production and Processing of Cassava in Thailand. Bangkok: Agricultural Engineering Research Institute, Ministry of Agriculture and Cooperatives, Thailand.

Chamsing, A., and G. Singh. 2000. "Rice Mechanization and Processing in Thailand." Agricultural Mechanization in Asia, Africa and Latin America 33: 21-30.

Chancellor, W. J. 1983. The Sustainability of Mechanization in Thailand. Working Paper No. 98, Consequences of Small Farm Mechanization Project. Bangkok: Asian Institute of Technology. 
Chapman, E. C. 1978. "Shifting Cultivation and Economic Development in the Lowlands of Northern Thailand." In Farmers in the Forest: Economic Development and Marginal Agriculture in Northern Thailand, edited by P. Kunstadter, E. C. Chapman, and S. Sabhasri, 222-235. Honolulu: East-West Center.

Chiaranaikul, K. n.d. “Thai Rice Combine Harvesting.” PowerPoint presentation, Agricultural Engineering Research Institute, Thailand Ministry of Agriculture and Cooperatives, Bangkok.

Chinsuwan, W., and B. J. Cochran. 1986. “The Axial Flow Low Lift Pump in Thailand.” In Proceedings of the International Conference on Small Farm Equipment for Developing Countries, 195-203. Los Baños, Philippines: International Rice Research Center.

Coxhead, I., and J. Plangpraphan. 1998. Thailand's Economic Boom and Agricultural Bust: Some Economic Questions and Policy Puzzles. Staff Paper Series No. 419. Madison: Department of Agricultural and Applied Economics, University of Wisconsin.

Cramb, R. A. 2015. "Introduction." In Trajectories of Rice-Based Farming Systems in Mainland Southeast Asia. ACIAR Monograph No. 177, edited by R. A. Cramb, 1-16. Canberra: Australian Center for International Agricultural Research.

Cramb, R. A., and J. C. Newby. 2015. "Trajectories of Rice-Farming Households in Mainland Southeast Asia." In Trajectories of Rice-Based Farming Systems in Mainland Southeast Asia. ACIAR Monograph No. 177, edited by R. A. Cramb, 35-72. Canberra: Australian Center for International Agricultural Research.

Curran, S. R., and A. M. Cooke. 2008. "Unexpected Outcomes of Thai Cassava Trade: A Case of Global Complexity and Local Unsustainability." Globalizations 5: 111-127.

De Koninck, R., and J. Rousseau. 2012. Gambling with the Land: The Contemporary Evolution of Southeast Asian Agriculture. Singapore: NUS Press.

Ding, Q. S., B. Tangwongkit, and R. Tangwongkit. 2004. "Manual Sugarcane Harvesting System vs. Mechanical Harvesting System in Thailand." Agricultural Mechanization in Asia, Africa and Latin America 35: 33-36.

Donovan, G., H. Binswanger, and P. Pingali. 1986. "Farm Mechanization Issues and Policies." In Proceedings of the International Conference on Small Farm Equipment for Developing Countries, 23-34. Los Baños, Philippines: International Rice Research Center.

Ekasingh, B., P. Gypmantasiri, K. Thong-ngam, and P. Grudloyma. 2004. Maize in Thailand: Production Systems, Constraints, and Research Priorities. Mexico City: International Maize and Wheat Improvement Center (CIMMYT).

Ekasingh, B., C. Sungkapitux, J. Kitchaicharoen, and P. Suebpongsang. 2007. Competitive Commercial Agriculture in the Northeast of Thailand. Department of Agricultural Economics and Multiple Cropping Center, Faculty of Agriculture, Chiang Mai University, Thailand. 
FAO (Food and Agricultural Organization of the United Nations). 2017. FAOSTAT database. Accessed 18 November. http://faostat.fao.org.

Fujimoto, A., K. Adulavidhaya, and T. Matsuda, eds. 1990. Thai Rice Farming in Transition. Tokyo: World Planning.

Grandstaff, T. B., S. Grandstaff, V. Limpinuntana, and N. Suphanchaimat. 2008. "Rainfed Revolution in Northeast Thailand." Southeast Asian Studies 46: 289-376.

Hayami, Y., and V. Ruttan. 1971. Agricultural Development: An International Perspective. Baltimore: Johns Hopkins University Press.

Howeler, R., and T. M. Aye. 2014. Sustainable Management of Cassava in Asia: From Research to Practice. Cali, Colombia: International Center for Tropical Agriculture.

Jongsuwat, N. 1980. Productivity Growth and Farm Machinery Adoption in Thai Agriculture. Master's thesis, Faculty of Economics, Thammasat University, Bangkok.

Ken Research. 2016. Thailand Agricultural Machinery Market Outlook to 2020. Haryana, India. Accessed January 25, 2017. www.kenresearch.com/agriculture-and-animal-care/agriculture -equipment/thailand-farm-equipment-implements-market/25252-104.html.

Klyuev, V. 2015. Structural Transformation: How Does Thailand Compare? IMF Working Paper 15/51. Washington, DC: International Monetary Fund.

Konchan, S., and Y. Kono. 1996. "Spread of Direct Seeded Lowland Rice in Northeast Thailand: Farmers' Adaptation to Economic Growth.” Southeast Asian Studies 33: 523-546.

Kupkanchanakul, T. 2000. "Bridging the Rice Yield Gap in Thailand.” In Bridging the Rice Yield Gap in the Asia-Pacific Region, edited by M. K. Papademetriou, F. J. Dent, and E. M. Herath, 146-156. Bangkok: Food and Agriculture Organization of the United Nations Regional Office for Asia and the Pacific.

Leturque, H., and S. Wiggins. 2011. Thailand's Progress in Agriculture: Transition and Sustained Productivity Growth. London: Overseas Development Institute.

Molle, F., T. Shah, and R. Barker. 2003. "The Groundswell of Pumps: Multilevel Impacts of a Silent Revolution." Paper prepared for International Commission on Irrigation and Drainage, Asia Meeting, Taiwan, November.

Mongkoltanatas, J. 1986. “Axial-Flow Paddy Threshers in Thailand.” In Proceedings of the International Conference on Small Farm Equipment for Developing Countries, 389-398. Los Baños, Philippines: International Rice Research Center.

Natsuda, K., and J. Thoburn. 2011. Industrial Policy and the Development of the Automotive Industry in Thailand. Ritsumeikan Center for Asia Pacific Studies Working Paper No. 11-5. Beppu, Oita, Japan: Ritsumeikan Asia Pacific University. 
Ouyyanont, P. 2016. Rural Thailand: Change and Continuity. Trends in Southeast Asia No. 8. Singapore: Institute for Southeast Asian Studies.

Pingali, P. 2007. "Agricultural Mechanization: Adoption Patterns and Economic Impact." In Handbook of Agricultural Economics. Vol. 3, edited by R. Evenson and P. Pingali , 2779-2805. Amsterdam: Elsevier.

Poapongsakorn, N. 2006. “The Decline and Recovery of Thai Agriculture." In Rapid Growth of Selected Asian Economies: Lessons and Implications for Agriculture and Food Security, Part 2. Bangkok: Regional Office for Asia and the Pacific, Food and Agriculture Organization of the United Nations.

Poungchompu, S., and S. Chantanop. 2016. "Economic Aspects of Rice Combine Harvesting Service for Farmers in Northeast Thailand." Asian Social Science 12: 210-211.

Qiuqiong, H., S. Rozelle, and D. Hu. 2007. "Pump-Set Clusters in China: Explaining the Organization of the Industry That Revolutionized Asian Agriculture." Asia-Pacific Development Journal 14 (2): 75-105.

Ramsay, A. 1985. "Population Pressure, Mechanization, and Landlessness in Central Thailand." Journal of Developing Areas 19: 351-368.

Rerkasem, B. 2015. “The Agroecosystem of Thai Rice: A Review." CMU Journal of Natural Science 14: $1-21$.

Rigg, J. 2012. Unplanned Development: Tracking Change in South-East Asia. London: Zed Books.

Rijk, A. G. 1986. "The Role of Farm Mechanization in Developing Countries: Experience in Asian Countries." In Proceedings of the International Conference on Small Farm Equipment for Developing Countries, 3-21. Los Baños, Philippines: International Rice Research Center.

— 1989. Agricultural Mechanization Policy and Strategy: The Case of Thailand. Tokyo: Asian Productivity Organization.

Singhapreecha, C. 2014. "Economy and Agriculture in Thailand." Agricultural Policy Platform, Food and Fertilizer Technology Center for the Asia Pacific Region. Accessed December 7, 2016. http://ap.fftc.agnet.org/ap_db.php?id=246.

SME Development Bank. 2017. “Small and Medium Enterprise Development Bank of Thailand.” Accessed January 27. www.smebank.co.th/en/about.php.

Soni, P. 2016. "Agricultural Mechanization in Thailand: Current Status and Future Outlook." Agricultural Mechanization in Asia, Africa and Latin America 47: 58-66.

Srijantr, T. 2003. "Agrarian Transformations in the Chao Phraya Delta: A Case Study in Tambon Thung Luk Nok." In Thailand's Rice Bowl: Perspectives on Agricultural and Social Change in the Chao Phraya Delta, edited by F. Molle and T. Srijantr, 125-150. Bangkok: White Lotus Press. 
Sukharomana, S. 1983. The Farm Power Strategy of Thailand. Working Paper No. 75,

Consequences of Small Farm Mechanization Project. Bangkok: Kasetsart University.

Thailand, BOI (Board of Investment). 2016. Thailand's Machinery Industry. Bangkok.

Thailand, NSO (National Statistical Office). 2013. 2013 Agricultural Census. Bangkok.

Thepent, V. 2000. Agricultural Machinery and Mechanization Situation in Thailand. Country

Report. Bangkok: Agricultural Engineering Research Institute, Thailand.

_ 2014. "Country Presentation Paper: Thailand." Presented at Regional Roundtable of

National Agricultural Machinery Associations in Asia and the Pacific, Wuhan, China,

October 28-30. http://un-csam.org/ppta/201410wuhan/9TH.pdf.

-2015. Agricultural Mechanization in Thailand. Centre for Sustainable Agricultural

Mechanization Policy Brief No. 6. Bangkok: UN Economic and Social Commission for Asia and the Pacific.

Thepent, V., and A. Chamsing. 2009. Agricultural Mechanization Development in Thailand.

Paper presented at fifth session of Technical Committee of Asian and Pacific Centre for Agricultural Engineering and Machinery, Los Baños, Philippines, October 14-16.

Tijaja, J. 2010. “The Impact of China’s Demand on Domestic Value Chains: Lessons from the Cassava Value Chains in Thailand." Paper presented at annual conference of the Chinese Economic Association (UK and Europe), Oxford, UK, July 12-13.

Tomich, T., P. Kilby, and B. F. Johnston. 1995. Transforming Agrarian Economies: Opportunities Seized, Opportunities Missed. Ithaca, NY: Cornell University Press.

USAID (US Agency for International Development). 2011. "Property Rights and Resource

Governance: Thailand-Country Profile." Accessed December 20, 2016. www.land-links .org/country-profile/1548/.

USDA (US Department of Agriculture). 2016. Thailand Biofuels Annual 2016. Global

Agricultural Information Network Report No. TH6075. Washington, DC: USDA Foreign Agricultural Service.

Vorasayan, J., and S. Pathumnakul. 2014. "Optimal Logistics System for Sugarcane Mechanical Harvesting in Thailand." Journal of Applied Science and Agriculture 9: 28-35.

Warr, P. 2007. “Long-Term Economic Performance in Thailand.” ASEAN Economic Bulletin 24: $138-163$.

- 2014. "Agricultural Liberalization, Poverty, and Inequality: Indonesia and Thailand." Journal of Asian Economics 35: 92-106.

Weerathaworn, P. 2015. “Sugar Industry in Thailand.” Presentation at Agri Benchmark Cash Crop Conference, Goiania, Brazil, July. 
World Bank. 2016. Thailand: Getting Back on Track, Reviving Growth and Securing Prosperity for All. Bangkok.

— 2017. World Bank Open Data database. Accessed March 28. https://data.worldbank.org /about/get-started.

Zhang, X., J. Yang, and T. Reardon. 2015. Mechanization Outsourcing Clusters and Division of Labor in Chinese Agriculture. IFPRI Discussion Paper 01415. Washington, DC: International Food Policy Research Institute. 



\title{
EVOLUTION OF AGRICULTURAL MECHANIZATION IN VIET NAM
}

\section{Hiroyuki Takeshima, Yanyan Liu, Nguyen Van Cuong, and Ian Masias}

\begin{abstract}
Despite the reportedly rapid growth of mechanization, as well as its unique history in economic and social systems, information on the patterns of agricultural mechanization growth in Viet Nam has been limited. Through an extensive review of existing literature and several rounds of nationally representative household survey data, we document the evolution of mechanization (particularly with tractors and combine harvesters) in Viet Nam, including the heterogeneity across regions and farm sizes, and the emerging roles of the private sector in the supply of machinery and hiring services. The historical growth pattern of mechanization in Viet Nam had been nonlinear, characterized by somewhat high tractor use prior to 1975 , followed by a decline in the 1980s before a resurgence in the 1990s, with considerable variations in adoption patterns across regions. Since the economic and social reform in the late 1980s, the private sector has rapidly emerged as the major player in meeting the demand for greater farm power uses, including the domestic manufacturing of power tillers, the introduction of larger combine harvesters, and the emergence of individual machine owners as the primary suppliers of hiring services. Although machinery use has gradually spread from larger farms to smaller farms, there are some signs that the comparative advantage has been shifting toward larger farms.
\end{abstract}

\section{Introduction}

Viet Nam has reportedly experienced rapid growth in agricultural mechanization lately, particularly in the use of tractors and combine harvesters (Pingali 2007; Reardon et al. 2014). The recent growth in mechanization has been similar to that of other developing countries in Asia. However, in the long term, the historical growth of agricultural mechanization has been unique due to the considerable changes in the political and economic systems in Viet Nam, which few other countries in Southeast Asia or South Asia have experienced. 
Documentation of the key agricultural mechanization patterns in Viet Nam is limited and large knowledge gaps exist. There has been little information on the actual extent of mechanization prior to 1975, in particular the use of tractors in Viet Nam. Understanding such historical patterns is important in assessing how the early exposures to tractors might have contributed to their spread in later decades. There is also little information available regarding the subnational variations in machine adoption, including that of tractors and combine harvesters. Last, little documentation exists on how the supply of machines and hiring services is emerging in Viet Nam. Understanding such supply-side development is important in assessing how the public-sector policies and the private sector have contributed to mechanization growth.

This chapter fills such knowledge gaps and documents the evolution of the growth of mechanization in Viet Nam based on an extensive review of the existing literature and several rounds of a nationally representative household survey. The available evidence suggests that the level of tractor use in Viet Nam had been relatively high in the 1970s and the early 1980s, but declined through the late 1980s before it started taking off again in the 1990s. The relatively high level of tractor use up to the early 1980 s was partly for political and military reasons, because both the West and the Soviet Union gave the country substantial support in providing heavy machinery, including tractors. We also find that the mechanization growth pattern has been heterogeneous within the country, with distinctions between the relatively smallholder-dominated deltas and the land-abundant central coast regions. Based on the literature review, we also find that the private sector-led hiring services have been increasingly overtaking the public and cooperative-based service providers, consistent with the patterns elsewhere in Asia, including countries like China with relatively stronger socialist structures of the economy (Zhang, Yang, and Reardon 2017).

This chapter contributes to the literature on agricultural mechanization by providing a focused, in-depth description of the evolutionary pattern of agricultural mechanization in Viet Nam and its subregions. It builds on the past and emerging literature that focuses on providing holistic perspectives on the spread of agricultural mechanization and the development of relevant sectors, rather than an analysis of specific causal mechanisms (IRRI 1978, 1983, 1986; Kienzle, Ashburner, and Sims 2013; Mandal, Biggs, and Justice 2017). The chapter also provides important historical perspectives and contexts for studies that focus on the more recent agricultural mechanization issues in Viet Nam (for example, Liu, Violette, and Barrett 2016).

The evolution of agricultural mechanization in Viet Nam has not been linear. The significant changes in the levels of mechanization, particularly in the 
use of tractors and combine harvesters, are partially associated with key historical events that changed the political and economic systems in the country over the last half-century. Table 6.1 shows a back-of-the-envelope approach to estimating the levels of mechanization based on a detailed review of existing studies that have not been widely chronicled in the existing mechanization literature. It also summarizes rough indicators of the economy and agricultural transformation. Viet Nam's recent history of agricultural mechanization can be roughly grouped into four phases: (1) until around 1975 (before reunification); (2) around 1975 to approximately the 1980s: collectivized production; (3) around 1990 to around 2010: liberalization and expansion of power tiller and medium-size 20-35 hp tractor use; (4) around 2010 and after: deepened mechanization growth through large tractors and combine harvesters.

The chapter is structured in the following way. The next section provides a qualitative analysis of the factors driving the spread of mechanization and the variations across the regions within the country. After that, the chapter briefly describes the emerging patterns in the supply of machinery and mechanization services. The last section provides concluding messages. ${ }^{1}$

\section{Descriptive Analysis of the Growth Pattern of Mechanization}

This section provides detailed descriptive evidence of the growth pattern of mechanization in Viet Nam between recent periods, using several rounds of the Vietnamese Living Standard Survey (VLSS), which was later renamed Vietnamese Household Living Standard Survey (VHLSS), since 2002 (GSOV 2016). Hereafter, we refer to both VLSS and VHLSS as "VHLSS." For a detailed description of the VHLSS, see Liu, Violette, and Barrett (2016).

\section{Subnational Variations in Machine Rental and Ownership}

The recent machinery use patterns in Viet Nam have been consistent with the hypothesis that mechanization growth tends to be faster in areas with favorable agricultural environments (for example, lowland areas such as deltas). Table 6.2 reports proportions of farm households that rented machinery by region and their changes between 1992 and $2008 .^{2}$ The Mekong and

1 This chapter is a shortened version of Takeshima and others (2018), which also contains more detailed descriptions of the historical evolution of mechanization in the country.

2 Although the VHLSS does not report detailed descriptions of how machines were used by households, tractors in Viet Nam have typically been used for land preparation and transportation.

For example, tractors are used for land preparation on rice plots in the following way. For the 


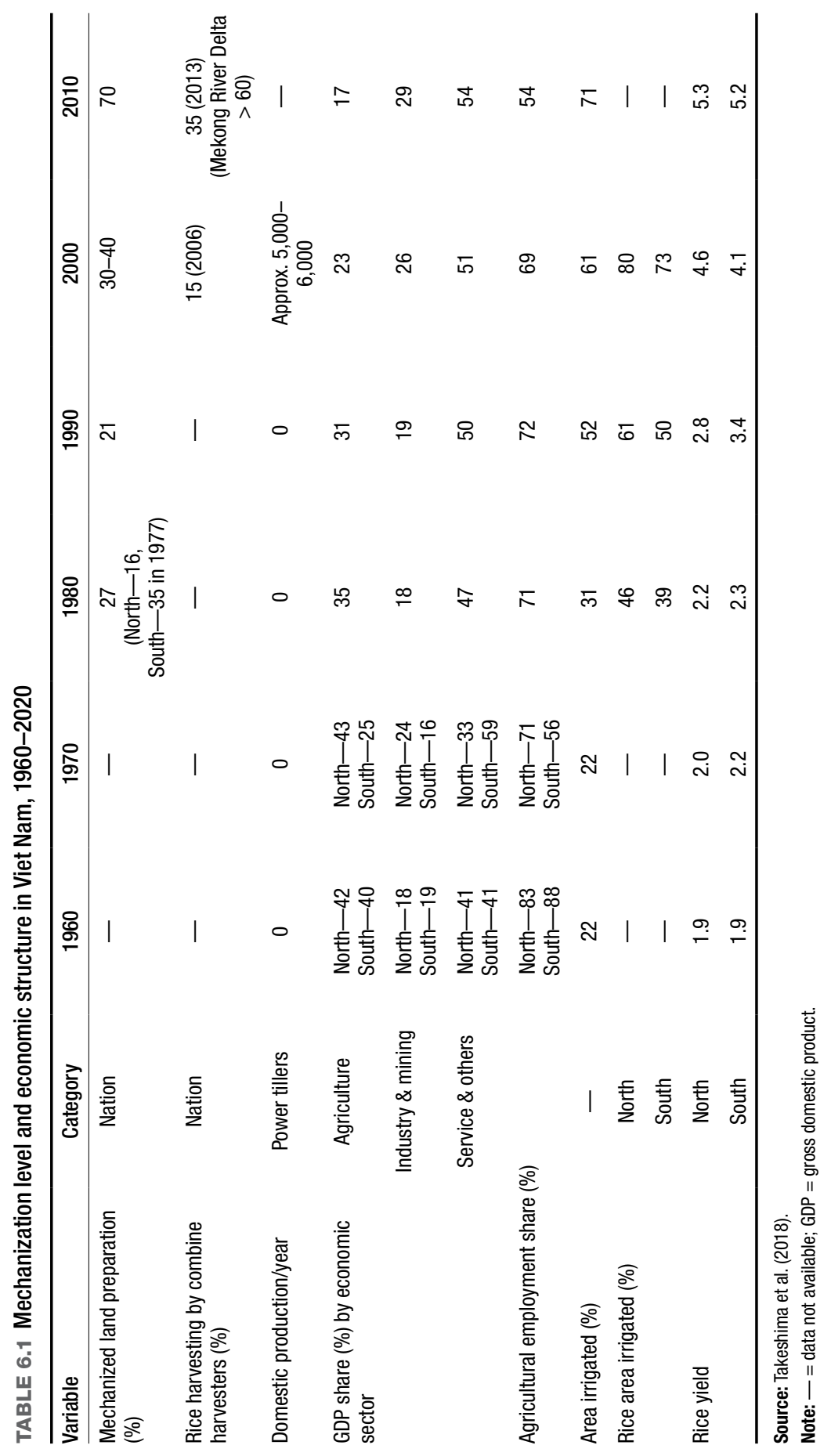


Red River Deltas are the main regions of rice production and the most populated areas in Viet Nam. The Mekong River Delta had the highest machinery rental rate (49 percent) in 1992 and has remained one of the most mechanized areas since. However, the Red River Delta became the most prevalent machinery rental region from 2004 to 2008 (with 80-85 percent of total rentals). Machinery rental has also grown substantially in the Central Highlands, increasing to 55 percent in 2008 (Table 6.2). This region has the lowest population density and is the main production area for cash crops (Table 6.3). The pattern in the Central Highlands has been consistent with the hypothesis that mechanization helps the growth of larger farms in relatively landabundant areas where market access is good. Unsurprisingly, the mountainous Northwest region had the lowest rate, at 27 percent in 2008.

Table 6.4 reports the proportion of households that owned tractors by region from 1992 to 2008. Tractor ownership was consistently low except for the Central Highlands, where about 13 percent of households owned tractors in 2008. In other regions, tractor-owning households accounted for less than 2 percent of households in 2008. There are also slight variations in the major types of tractors across regions (Table 6.5). Whereas the majority of tractors owned in 2007 in all regions were 2WTs with less than $12 \mathrm{hp}$, the South Central Coast, Central Highland, and Mekong Delta were relatively more populated with $4 \mathrm{WTs}$ of greater than $12 \mathrm{hp}$. In particular, 7.5 out of 1,000 farm households in the Mekong Delta owned larger 4WTs with horsepower greater than 35 . This was substantially higher than the national average of 1.7 out of 1,000 farm households.

Table 6.2 and Table 6.4 together indicate that a significant share of tractor adoptions have been achieved through rentals rather than ownership. This has applied not only to the expensive 4WTs but also the relatively cheaper 2WTs.

first rice crop, before sowing the germinated seeds, farmers muddy and level the land because the soil is wet after the flooding season. For the second rice crop, if only two rice crops are being planted in that year, they plow, muddy, and level the land. However, if they are planting three annual rice crops, they may not plow the land and may instead burn the rice straw left in the field because time for land preparation is very short in this rice season. Then, if there is a third rice crop, they again plow, muddy, and level the land (Tuyến 2013).

For transportation, four-wheel tractors (4WTs) and two-wheel tractors (2WTs) are typically used in the following way. In Viet Nam, tractors used for transportation are often called xe cay for a 4WT and công nong for a 2WT. Fitted with trailers, 2WTs (côngnong) are often used to ship around 2 tons of goods per trip to trading hubs at the commune center that are as far as $10 \mathrm{~km}$ away, although for a distance of more than $500 \mathrm{~m}$, farmers may use motorbikes or animal traction (horses, buffalo) rather than 2WTs (Lançon, Sautier, and Anh 2014). Many village collectors reportedly own 2WTs with such a 2 ton-capacity trailer (Lançon, Sautier, and Anh 2014). Transport costs in districts such as Krông Nô are generally around 10 Vietnamese dong (VND)/ $\mathrm{kg} / \mathrm{km}$ (about $0.04 \mathrm{US}$ cents), although some farmers in the more remote areas pay around 40 $\mathrm{VND} / \mathrm{kg} / \mathrm{km}$ (Lançon, Sautier, and Anh 2014). 
TABLE 6.2 Proportion of machine rental by region, Viet Nam, 1992-2008

\begin{tabular}{lcccccc}
\hline Region & 1992 & 1998 & 2002 & 2004 & 2006 & 2008 \\
\hline Red River Delta & 0.130 & 0.577 & 0.705 & 0.803 & 0.816 & 0.853 \\
Northeast & 0.005 & 0.269 & 0.210 & 0.305 & 0.383 & 0.421 \\
Northwest & 0.110 & 0.168 & 0.190 & 0.230 & 0.288 & 0.272 \\
North Central Coast & 0.260 & 0.300 & 0.585 & 0.659 & 0.679 & 0.727 \\
South Central Coast & 0.114 & 0.457 & 0.629 & 0.675 & 0.702 & 0.761 \\
Central Highlands & 0.033 & 0.380 & 0.376 & 0.588 & 0.535 & 0.546 \\
Southeast & 0.063 & 0.489 & 0.431 & 0.507 & 0.444 & 0.459 \\
Mekong River Delta & 0.491 & 0.699 & 0.713 & 0.742 & 0.690 & 0.668 \\
\hline
\end{tabular}

Source: Authors' estimations based on Vietnamese Household Living Standard Survey.

TABLE 6.3 Median total land cultivated per household (in square meters) by region, Viet Nam, 1992-2008

\begin{tabular}{lrrrrrr}
\hline Region & $\mathbf{1 9 9 2}$ & $\mathbf{1 9 9 8}$ & $\mathbf{2 0 0 2}$ & $\mathbf{2 0 0 4}$ & $\mathbf{2 0 0 6}$ & \multicolumn{1}{c}{$\mathbf{2 0 0 8}$} \\
\hline Red River Delta & 2,442 & 2,376 & 2,160 & 2,052 & 1,980 & 1,946 \\
Northeast & 3,700 & 3,395 & 3,600 & 3,310 & 3,314 & 3,240 \\
Northwest & 8,899 & 7,400 & 7,840 & 7,352 & 9,000 & 8,200 \\
North Central Coast & 2,701 & 2,559 & 2,800 & 2,773 & 2,825 & 2,545 \\
South Central Coast & 2,565 & 2,847 & 2,500 & 2,474 & 2,500 & 2,500 \\
Central Highlands & 8,500 & 9,700 & 10,000 & 10,000 & 10,200 & 10,350 \\
Southeast & 7,000 & 7,775 & 7,100 & 8,000 & 8,000 & 7,000 \\
Mekong River Delta & 7,800 & 7,400 & 6,400 & 6,435 & 6,000 & 6,000 \\
\hline
\end{tabular}

Source: Authors' calculations based on Vietnamese Household Living Standard Survey.

The growth of machine rentals has been observed across many regions, including northern Viet Nam, where the use of rented 2WTs was less common than in southern Viet Nam in the 1990s (Minot and Goletti 2000, 14).

Importantly, the growth in tractor use in Viet Nam since the 1990s is likely to have been the result of rising demand for overall farm power use, rather than substitution for manual farm power. Figure 6.1 plots the proportion of households that owned tractors, rented machinery, or hired labor from 1992 to 2008. Although we do not see much change in tractor ownership, the percentage of cultivating households that rented machines more than tripled, from 19 percent in 1992 to 63 percent in 2008. The percentage of households that hired labor also increased sharply, from 32 percent in 1992 to 55 percent in 2008 . 
TABLE 6.4 Tractor ownership by region, Viet Nam, 1992-2008

\begin{tabular}{lcccccc}
\hline Region & 1992 & 1998 & 2002 & 2004 & 2006 & 2008 \\
\hline Red River Delta & 0.001 & 0.002 & 0.008 & 0.010 & 0.006 & 0.008 \\
Northeast & 0.003 & 0.004 & 0.009 & 0.012 & 0.011 & 0.012 \\
Northwest & 0.000 & 0.000 & 0.006 & 0.000 & 0.003 & 0.000 \\
North Central Coast & 0.002 & 0.002 & 0.010 & 0.006 & 0.009 & 0.002 \\
South Central Coast & 0.003 & 0.012 & 0.007 & 0.010 & 0.010 & 0.009 \\
Central Highlands & 0.099 & 0.212 & 0.099 & 0.116 & 0.125 & 0.128 \\
Southeast & 0.014 & 0.069 & 0.025 & 0.025 & 0.025 & 0.020 \\
Mekong River Delta & 0.016 & 0.028 & 0.014 & 0.021 & 0.018 & 0.020 \\
\hline
\end{tabular}

Source: Authors' estimations based on Vietnamese Household Living Standard Survey.

TABLE 6.5 Tractors per 1,000 farm households, by region, Viet Nam, 2007

\begin{tabular}{lccc}
\hline Region & $<12 \mathrm{hp}$ & $12-35 \mathrm{hp}$ & $>35 \mathrm{hp}$ \\
\hline Red River Delta & 14.9 & 3.1 & 0.3 \\
Northeast & 28.3 & 3.3 & 0.3 \\
Northwest & 9.0 & 1.1 & 0.4 \\
North Central Coast & 12.3 & 3.4 & 0.9 \\
South Central Coast & 9.2 & 4.6 & 4.0 \\
Central Highland & 97.8 & 56.8 & 5.8 \\
Southeast & 23.2 & 10.6 & 3.5 \\
Mekong River Delta & 21.8 & 7.5 & 7.5 \\
Total & 24.3 & 8.8 & 1.7 \\
\hline
\end{tabular}

Source: Tsukada (2012, Table 3).

\section{Farm Size and Machinery Use}

Another important pattern of mechanization is the considerable spread among smallholders. Such patterns have been reported for other Asian countries, but not for Viet Nam.

Based on rice planting area, we categorize farmers into two equal groups: "smaller-holders," cultivating less than 5,760 square meters of rice area, and "larger-holders," cultivating more than 5,760 square meters of rice area. Figure 6.2 plots tractor ownership and machine rental from 1992 to 2008 for these two groups. Larger-holders and smaller-holders have similarly low levels of machine ownership, compared with the levels of machine use through rentals, indicating that not only smaller-holders but also most larger-holders in Viet Nam have relied on rented machines rather than owned machines. 
FIGURE 6.1 Trend of tractor ownership, machine renting, and labor hiring for all farming operations in Viet Nam, 1992-2008

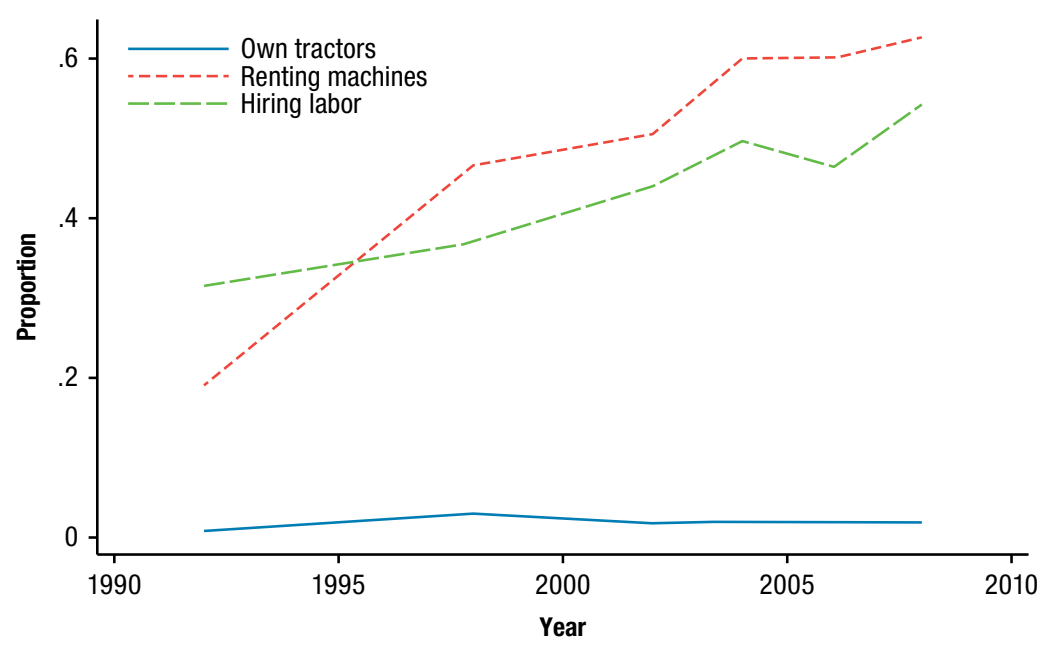

Source: Authors' calculations based on Vietnamese Household Living Standard Survey.

Note: Proportion is in terms of households, and not weighted by areas.

Whereas larger-holders have had a higher propensity to rent machines throughout the period, the difference between the two groups has decreased over time, especially in the late 2000s, indicating that smaller-holders have also been able to benefit from machine rentals.

Figure 6.3 shows the relationship between tractor ownership and rice planting area for 1992 and 2008, estimated through a nonparametric regression. The dotted lines show the 95 percent confidence intervals around the point estimates. In 1992, tractor ownership had been mostly concentrated among very large farms cultivating more than 20,000 square meters (approximately 10 in the natural $\log$ ), although the large confidence intervals suggest the estimation was not precise. In 2008, whereas large farms still exhibited a slightly higher rate of tractor ownership than small farms, the tractor ownership seemed to spread relatively more evenly across farms of different sizes. Although tractor ownership remained low, as mentioned above, Figure 6.3 suggests it has relatively increased among small farms lately. 
FIGURE 6.2 Tractor ownership and machine rental for larger- and smaller-holders, based on rice planting area, Viet Nam, 1992-2008

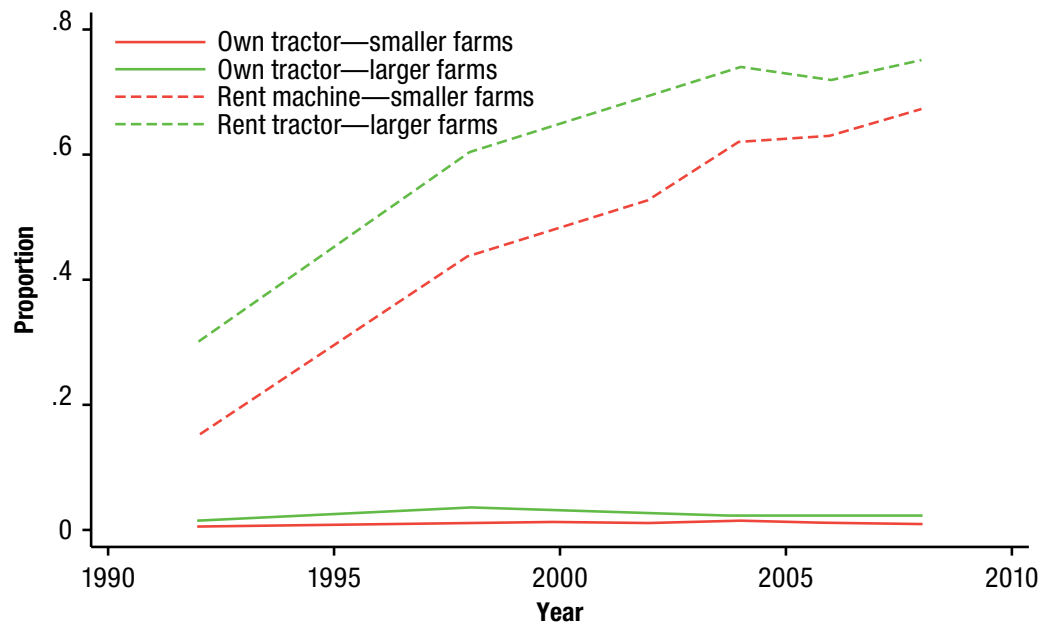

Source: Authors' calculations based on Vietnamese Household Living Standard Survey.

FIGURE 6.3 Relationship between tractor ownership and rice planting area, Viet Nam, 1992 and 2008

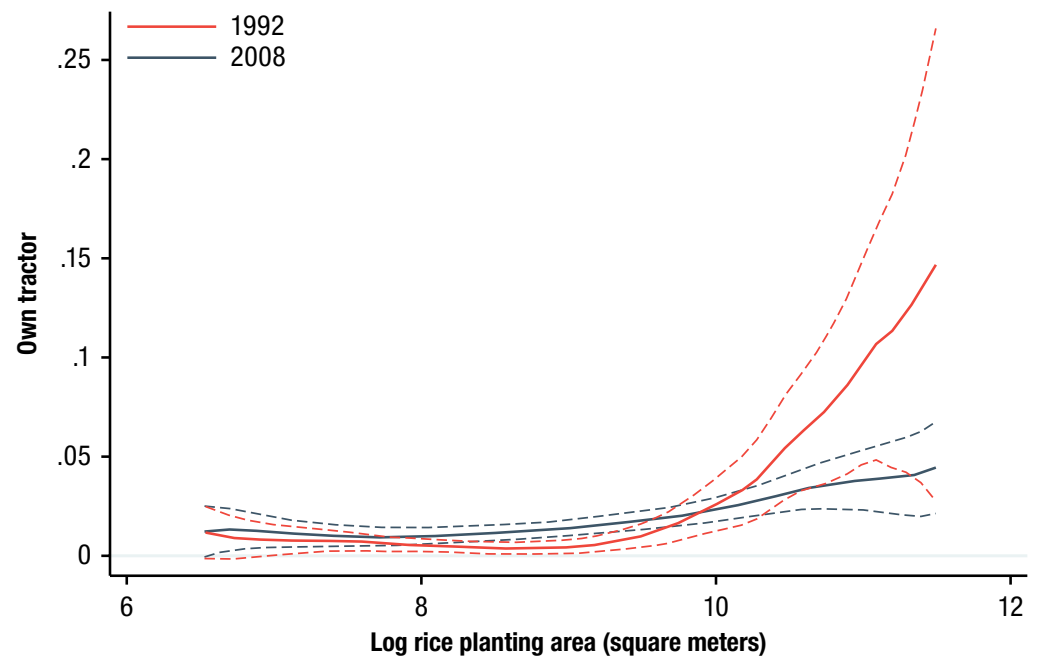

Source: Authors' calculations based on Vietnamese Household Living Standard Survey.

Note: Red dashed lines represent 95\% confidence intervals for 1992 line. Green dashed lines represent 95\% confidence intervals for 2008 line. 
Figure 6.4 illustrates a similar trend as Figure 6.3, but in the case of machine rentals. ${ }^{3}$ Machine rentals are significantly positively associated with farm size in both 1992 and 2008. This indicates that the complementarity between land and machines has remained important. However, the slope of the curve for 2008 is flatter than the slope of the curve for 1992, suggesting that machine rental has increased more among small farms.

It is important to note that the complementarity between land size and use of machines remains potentially influential. This is because, during 1992 and 2008, when tractor use grew considerably, the production intensity of rice, which is often the most mechanized crop among smallholders in Asia, also rose more, relative to the production of other crops.

Figure 6.5 depicts the mean and median of the total land cultivated per household and the total annual cropland cultivated per household from 1992 to 2008. Although the mean of landholdings was relatively stable over time, the median fell slightly at a steady pace over this period, suggesting a change in the landholding distribution. Figure 6.6 and Figure 6.7 depict the distribution of total cultivated land and annual cropland for 1992 and 2008. Both figures show similar patterns of distributional change from 1992 to 2008: the percentage of medium-sized farms fell, and there was a slight increase in percentage for both small farms and large ones. In contrast, the total rice planting area increased for all farm size percentiles over this period, showing a pattern different from that of total cultivated area across all crops (Figure 6.8). This difference may be attributed to increased intensification in rice production. Indeed, the proportion of irrigated annual land increased from 57 percent in 1992 to 81 percent in 2008, allowing for rice to be planted in more cropping seasons within a year. Similarly, in one of the most mechanized regions, the average farm size among the VLSS and VHLSS sample households increased from 1.0 ha in 1996 to 1.4 ha in 2009 in the Mekong River Delta.

Relatedly, Liu, Violette, and Barrett (2016) showed that although rice yield was significantly negatively associated with farm size (with an inverse relationship of farm size and land productivity) in the early 1990s, that relationship had largely disappeared by 2008 , indicating that the complementarity between landholdings and machine use has started becoming more effective. This finding is consistent with the patterns in many other Asian countries

3 Machine rental is proxied by whether the household incurred expenses for rental of assets, machinery, equipment, or means of transport. The VHLSS do not provide information on machine rental by type of machine or farming activity. 
FIGURE 6.4 Relationship between machine rental and rice planting area, Viet Nam, 1992 and 2008

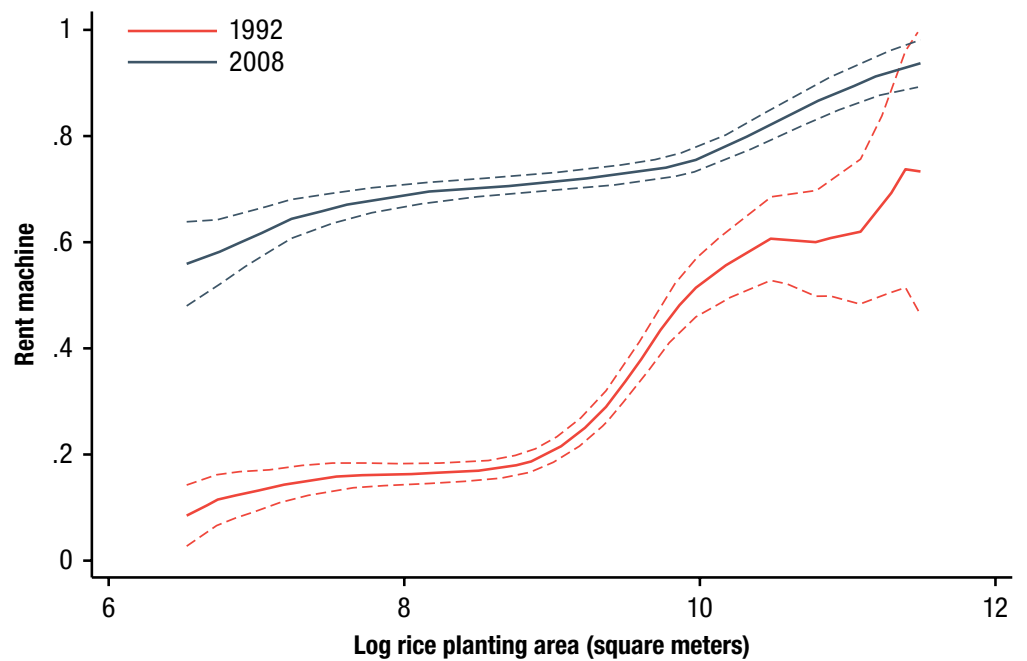

Source: Authors' calculations based on Vietnamese Household Living Standard Survey.

Note: Red dashed lines represent 95\% confidence intervals for 1992 line. Green dashed lines represent 95\% confidence intervals for 2008 line.

FIGURE 6.5 Trend of total land cultivated per household and total annual cropland cultivated per household, Viet Nam, 1992-2008

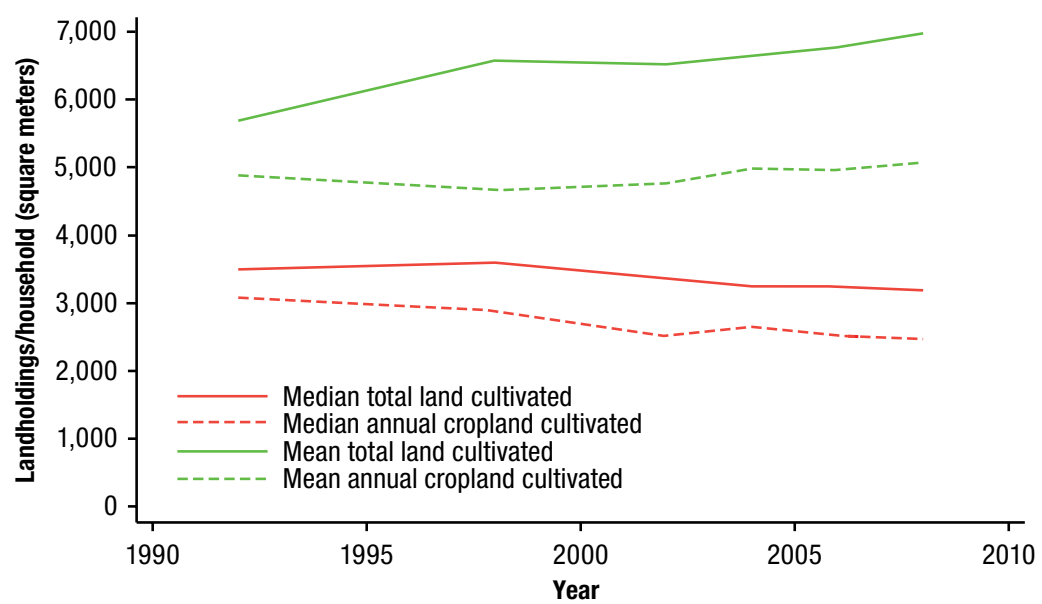

Source: Authors' calculations based on Vietnamese Household Living Standard Survey. 
FIGURE 6.6 Kernel density of total cultivated area, Viet Nam, 1992 and 2008

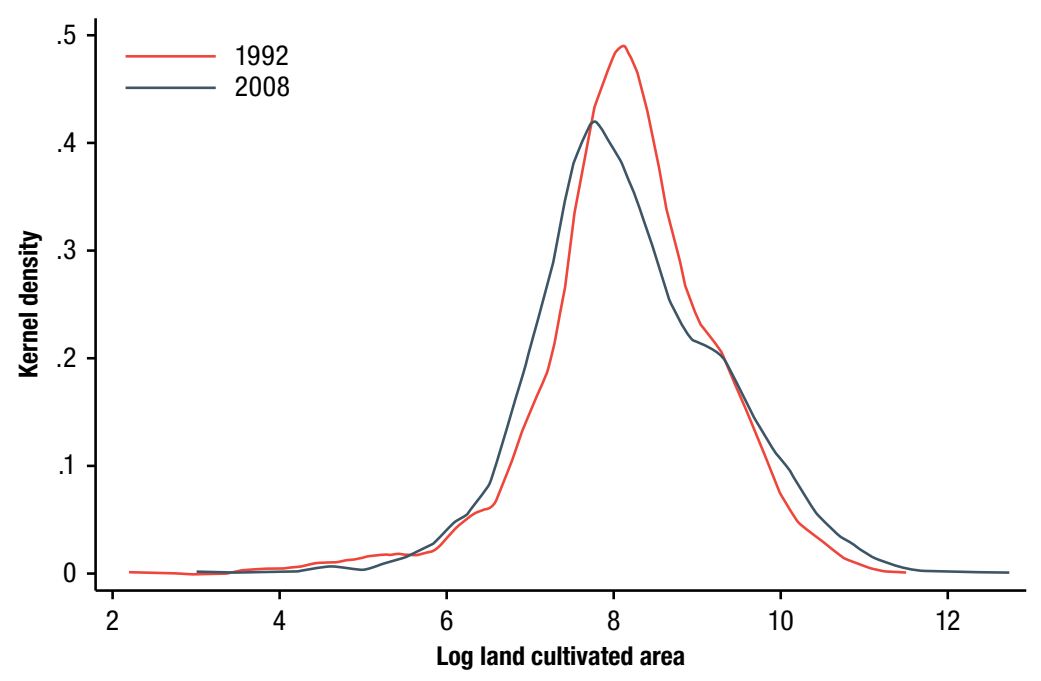

Source: Authors' calculations based on Vietnamese Household Living Standard Survey.

FIGURE 6.7 Kernel density of total annual cropland, Viet Nam, 1992 and 2008

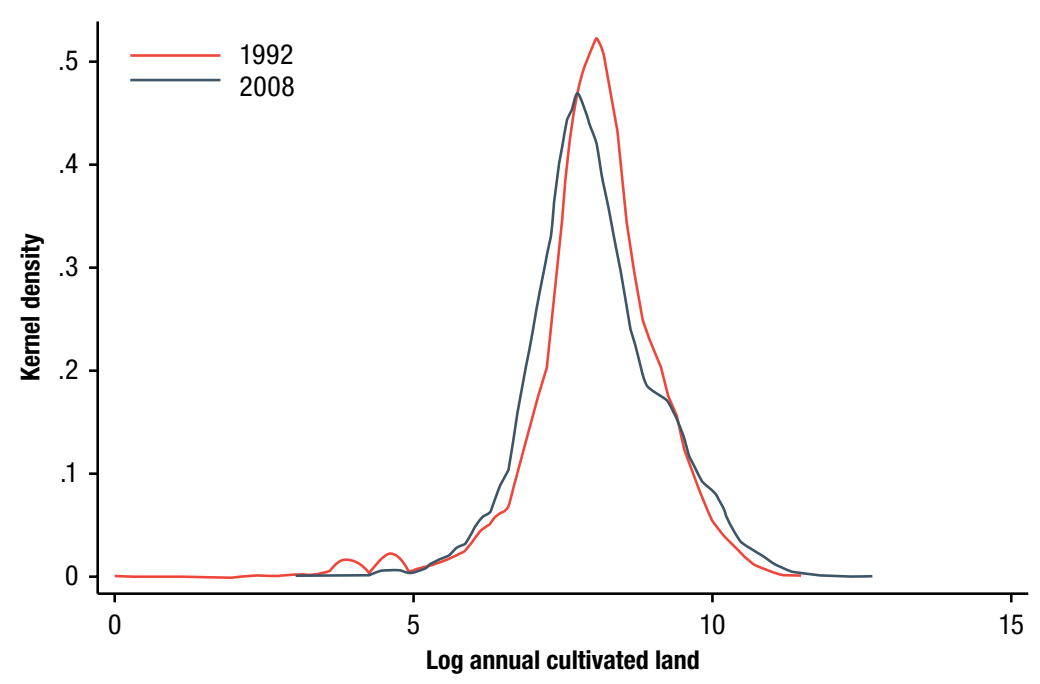

Source: Authors' calculations based on Vietnamese Household Living Standard Survey. 


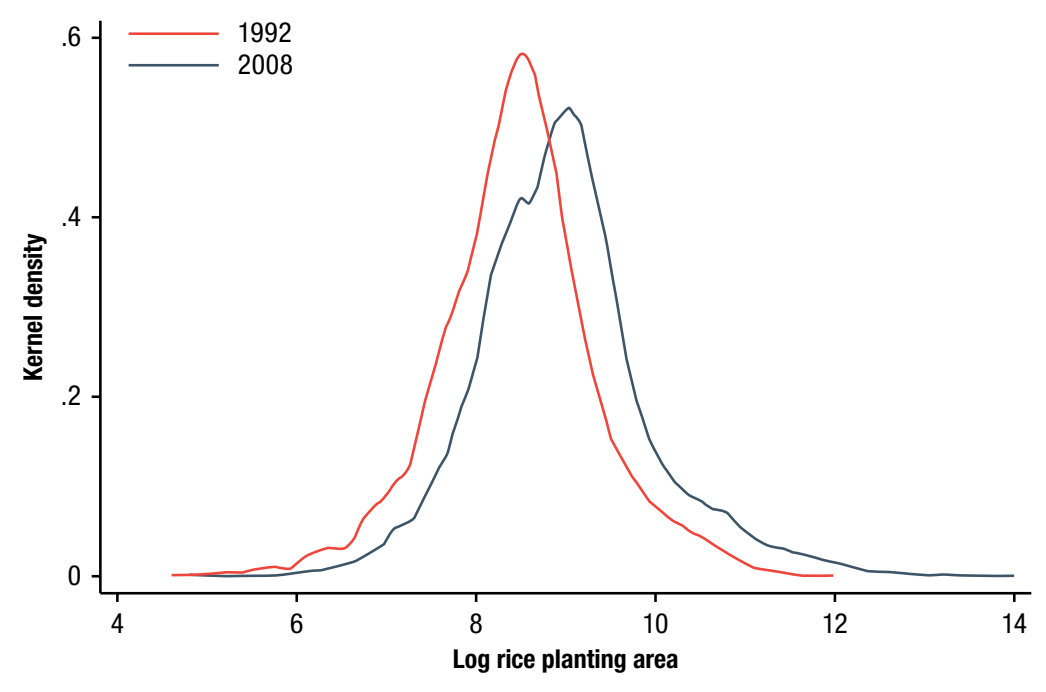

Source: Authors' calculations based on Vietnamese Household Living Standard Survey.

(Foster and Rosenzweig 2011; Yamauchi 2016). Although the spread of tractor use has benefited smallholders as much as larger farmers, further intensification of mechanization may gradually shift the comparative advantages to larger farmers and have serious implications on the future of smallholders in Viet Nam.

\section{Wages and Mechanization Growth}

As mentioned above, increased machinery use in Viet Nam is likely to have been the result of increased overall demand for farm power, as is indicated by the positive associations between the share of farm households using machines and those hiring labor (Figure 6.1). Nevertheless, it is important to note that rising wages have also been important drivers of the growth of mechanization.

Figure 6.9 plots the median female and male real agricultural wages from 1992 to 2008 . Real wages increased significantly from 1992 to $1998^{4}$ and lev-

4 This period in Viet Nam also saw an increasing rural-urban wage gap, explained by the returns on skills (Nguyen et al. 2007), and also marked the beginning of the decline in the agricultural share of employment (Table 6.1). 
FIGURE 6.9 Median daily real male and female agricultural wage, Viet Nam, 1992-2008

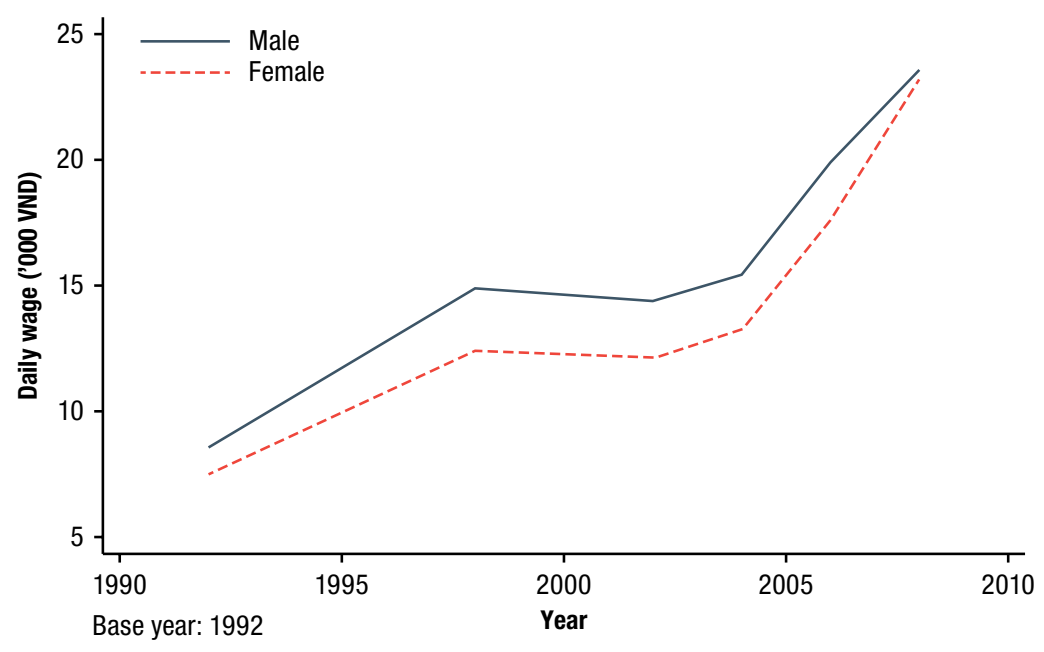

Source: Authors' calculations based on Vietnamese Household Living Standard Survey. Note: VND = Vietnamese dong.

eled off from 1998 to 2004, probably reflecting the lagged effects of the Asian financial crisis of $1997 / 1998$. From 2004 to 2008 , the real wage again picked up rapidly, at a rate even faster than that seen during 1992-1998. Table 6.6 reports the median male real wage by region from 1992 to 2008, using VHLSS commune survey data. Although real wages were consistently lower in the northern regions than in the southern regions, regional wage differences narrowed considerably by 2008 . This indicates an increasingly spatially integrated national labor market and fast transmissions of wage increases in certain regions based on increases in the cost of labor in other regions.

\section{Factors Associated with Use of Machines}

The descriptive analysis above provides several indicators that the growth of mechanization between 1992 and 2008 had been driven by multiple factors. More formal analysis of the factors associated with machine use are presented in Table 6.7 (see appendix for the estimation method). In column (1), for years 1992-1998, we do not detect significant association between farm size and machinery adoption, likely due to low adoption rate overall. In the other two columns, representing later years, farmers with larger holdings are more likely to use machines, consistent with scale economies of machinery adoption. Machine use does not respond to real agricultural wage in columns (1) and (2). 
TABLE 6.6 Real median daily wage of male agricultural labor, Viet Nam, 1992-2008 ('000 VND)

\begin{tabular}{lrrrrrr}
\hline Region & 1992 & 1998 & 2002 & 2004 & 2006 & 2008 \\
\hline Red River Delta & 7.49 & 14.41 & 13.59 & 15.28 & 19.90 & 28.06 \\
Northeast & 5.16 & 11.17 & 11.00 & 13.00 & 15.78 & 22.22 \\
Northwest & 6.96 & 9.05 & 9.28 & 9.38 & 14.48 & 18.66 \\
North Central Coast & 7.67 & 12.12 & 12.96 & 13.22 & 19.95 & 23.58 \\
South Central Coast & 7.34 & 15.56 & 14.39 & 16.17 & 17.60 & 23.51 \\
Central Highlands & 9.21 & 13.40 & 13.38 & 13.89 & 18.46 & 26.53 \\
Southeast & 11.44 & 15.70 & 17.26 & 17.14 & 21.60 & 25.63 \\
Mekong River Delta & 15.01 & 18.69 & 17.51 & 19.04 & 22.41 & 25.53 \\
\hline
\end{tabular}

Source: Authors' calculations based on Vietnamese Household Living Standard Survey. Note: VND = Vietnamese dong.

In contrast, machine use significantly increases the real wage in column (3), suggesting efficiency improvements in rural factor markets.

\section{Market Institutions in Mechanization Service Provision}

This section briefly summarizes the evolving modes of machinery suppliers and mechanization service providers in Viet Nam. Overall, recent patterns suggest that the private sector has been transforming both markets.

\section{Agricultural Machinery Manufacturing}

As was mentioned above, the growth of the supply of power tillers in the domestic market during the 1990s had been led by the growth in domestic manufacturing, although some power tillers had also been imported. By the end of the 1990s, 5,000-6,000 power tillers were already being domestically manufactured annually by major manufacturers such as Vikyno and Vinapro (JICA 2000), which were leading manufacturing of diesel engines and other machinery (Hien, Khanh, and Quick 2007). Some power tillers were domestically manufactured using a diesel engine fitted into a scrap chassis (Starkey et al. 2002, 57). ${ }^{5}$ By 2001, Viet Nam had started exporting tractors (mostly power tillers) (FAO 2018).

5 In Viet Nam, the use of the small engine for multiple types of small machinery was started indigenously by domestic engineers who saw the potential of changing the use of the equipment for power boats and axial flow pumps in the 1960s (Sansom 1969; Stewart 1974; Biggs and Justice 2015), and later on power tillers. 
TABLE 6.7 Regression results on machine use

\begin{tabular}{lccc}
\hline & $(1)$ & $(2)$ & $(3)$ \\
Variable & Sample years & Sample years $=$ & Sample years $=$ \\
\hline Log total area of rice (all varieties) & 0.00234 & $0.0968^{\star \star \star}$ & $0.0540^{\star \star}$ \\
Log male real ag. wage (VND in 1992) & $(0.0258)$ & $(0.0317)$ & $(0.0235)$ \\
& -0.0729 & 0.0730 & $0.103^{\star \star}$ \\
Male household head (yes = 1) & $(0.101)$ & $(0.0513)$ & $(0.0436)$ \\
& -0.0675 & -0.0308 & -0.0221 \\
Age of household head & $(0.0447)$ & $(0.0776)$ & $(0.0197)$ \\
& -0.000305 & -0.000135 & -0.000412 \\
Highest education of household members & $(0.00110)$ & $(0.00205)$ & $(0.000565)$ \\
& -0.0000498 & 0.00359 & -0.00202 \\
Number of male members & $(0.00749)$ & $(0.00851)$ & $(0.00637)$ \\
& $0.0403^{\star}$ & -0.0114 & 0.00208 \\
Household size & $(0.0215)$ & $(0.0286)$ & $(0.00824)$ \\
Year dummy & $-0.0282^{\star \star}$ & 0.00489 & 0.00609 \\
Observations & $(0.0138)$ & $(0.0190)$ & $(0.0103)$ \\
\hline
\end{tabular}

Source: Authors' calculations based on Vietnamese Household Living Standard Survey.

Note: Asterisks indicate the statistical significance: ${ }^{\star \star \star} 1 \%,{ }^{\star \star} 5 \%,{ }^{\star} 10 \%$. Standard errors in parentheses. VND $=$ Vietnamese dong.

Although there is no direct evidence, the importation of power tillers in the 1980s may have resulted in local adaptations and eventual manufacturing. For example, in the late 1980s, Daedong Industry Co. in the Republic of Korea started exporting power tillers and farm engines to Viet Nam via barter trade-gaining a foothold in communist countries (Lee 2007). Similarly, Tongyang Moolsan Co. supplied power tillers and farm engines to Viet Nam and was recognized by the Vietnamese government for its technology (Lee 2007).

Domestic manufacturing also accounted for 30 percent of combine harvesters (Viet Nam, MIT 2015), which are mostly the domestic production of Kubota combines by Kubota Viet Nam Ltd. (the rest were often manufactured in China and exported to Viet Nam). Direct evidence on how industrial policy in Viet Nam has led to growth in the domestic manufacturing of combines is scarce, but anecdotal evidence suggests that domestic manufacturing 
of harvesters and reapers originally promoted by the Vietnamese government has gradually declined. ${ }^{6}$

Rice milling machines are mainly manufactured in the country by companies such as Bui Van Ngo, Lamico, and so on, with rice processing lines that have a capacity of 4-40 tons ${ }^{7}$ per hour, and grain dryer arrays of 30-200 tons per batch. Bui Van Ngo's product quality is world-class (comparable to Japanese Satake, which is one of the major suppliers of modern rice milling machines globally and in the Asia region), and Bui Van Ngo has exported rice equipment to about 20 countries in Asia, the Americas, and Africa.

Manufacturing of engines in Viet Nam has also grown. Today, diesel engines from 5 to $30 \mathrm{hp}$ can be produced domestically, with an annual production capacity of 40,000 units, approximately 30 percent of domestic market share. In addition, about 2,000 provincial medium-size or small mechanical workshops deal with fabrication, trial, sale, and repair of machines. The leading manufacturer, Viet Nam Engine and Agricultural Machinery Corporation (VEAM), has also exported engines. VEAM is a large state-owned company with reported assets around $\$ 600$ million $^{8}$ in 2014 and was recently converted into a joint stock entity in 2016. VEAM has seven large factories throughout Viet Nam and has set up a national network of dealers for its $2 \mathrm{WTs}$, engines, and other machinery. It inherits the old-time support for heavy industries and has some advantages over private companies in terms of loans and investment. However, to be competitive in the manufacturing of machines, the company should have a solid basis in modern metallurgy, which is severely lacking in Viet Nam. Thus, even with a large inventory of machine tools and production capacity, VEAM has just played a modest role in supplying machinery for agriculture.

\section{Machinery Supply}

In Viet Nam today, tractors are largely marketed by the private sector, which supplies both new and used machines, provides repair and maintenance

6 Before the growth of combine harvesters in the 2010s, manufacturing of reapers and minicombines had grown temporarily (Hien, Khanh, and Quick 2007). Reaper manufacturing in Viet Nam peaked in 1988 with about 15 manufacturers, which had gradually declined to 3 by 2000, producing 100-200 units per year each (Hien, Khanh, and Quick 2007). Mini-combine harvesters that could harvest around 1 ha per day had been developed in a public-private partnership between the Philippine Rice Research Institute and Briggs \& Stratton. Around 700 machines were produced by Vinapro in Viet Nam through 2009 (Pandey et al. 2010, 338). Most of these mini-combines were bought by private farmer-contractors with their own money. "Tons" refers to metric tons throughout the chapter.

8 Dollar amounts are in US dollars throughout the chapter. 
services as well as some extension and training, and offers credit services for prospective machine owners. Vietnamese-manufactured power tillers (Vikyno, Vinapro, and so on) have been substituting for imported power tillers since the 1990s. Domestic manufacturers have been expanding their supply networks and likely providing spare parts. The Japanese company Kubota has been making inroads into the Vietnamese market for 4WTs and combine harvesters. In fact, new Kubota 4 WTs are competing against old Kubota tractors (Kubota Corporation 2011). Kubota tractors sold in Viet Nam are, however, modified to be much stronger and more durable than those used in Japan. This is because although there is only one production season per year in Japan, Viet Nam typically has two or three production seasons per year, and tractors are used extensively throughout the year.

The private sector has also largely been supplying combine harvesters. Although harvesters originally promoted in Viet Nam generally did not spread quickly, Chinese combines have been increasingly adopted, particularly between 2006 and 2009, because these Chinese companies also provided after-sales services and spare parts. Gradually, the Japanese Kubota combine, with a generally smaller harvest loss rate, ${ }^{9}$ has overtaken the Chinese combines. By 2013, Kubota's share in the Vietnamese combine harvester market had reached 75 percent. Concurrently, the number of Vietnamese manufacturers fell from 15 to 3, with 15 percent market share (Gummert et al. 2013). Kubota's dealers and network have grown to supply machines, after-sales services, and repair and maintenance services.

\section{Custom Hiring Service Provision}

Historically, three major types of tractor/combine harvester owner and service provider arrangements have existed in Viet Nam: (1) individual ownership, (2) government-run systems, and (3) cooperatives-run systems.

(1) INDIVIDUAL OWNERSHIP

In southern Vietnam, individual ownership and service provision was the most common form of ownership before 1975. In the 1960s, larger farmers who had received increased income from using water pumps and new varieties were then able to invest in further labor-saving technical innovations, such as rototillers and tractors (Wiegersma 1988).

9 Currently, three types of Kubota combine harvesters with the typical cutting width of about 1.5-2.0 $\mathrm{m}$ are popular (MIT 2015): the DC-35 (35 hp), which harvests about $0.1-0.3$ ha per hour, and the DC-60 (60 hp) or DC-70 (70 hp), which harvest about $0.3-0.7$ ha per hour. 
In the late 1970s, after the reunification of the country, individual ownership of tractors, tillers, threshers, pumps, and draft animals was abolished, and these were sold to the provinces at values below market prices (Pingali and Xuan 1992), with the intent of making the local governments and cooperatives the major providers of services.

However, such measures were relatively incomplete, and many individual owners remained in business in southern Viet Nam. The diffusion of cooperatives in southern Viet Nam was generally limited; only 6 percent of farmers in the Mekong River Delta belonged to cooperatives in 1986, compared with more than 90 percent in northern Viet Nam (Pingali and Xuan 1992). Despite the law, villagers still owned substantial stocks of nonland capital, such as water pumps or small tractors, and provided services to lower-middleincome and poor peasant cultivators, or to the agricultural cooperatives, on a contractual basis (Van Luong and Unger 1988; Gorman 2014).

After Resolution No. 10 was instituted in 1988, initiating the process of decollectivization, ${ }^{10}$ tractor plowing services were privatized, although in some cases the services remained the responsibility of the collectives (Kirk and Tuan 2009). Individual ownership began growing again in southern Viet $\mathrm{Nam}$, as well as in northern Viet Nam. Initially, tractors were purchased from the cooperatives that used to own them. The new individual tractor owners often had diverse backgrounds. For example, individuals in Quang Binh province purchased tractors from cooperatives, using the private savings accumulated through various activities such as a duck-raising business (Quan 2009). Households studied by Quan (2009) in Quang Binh had invested 21 million Vietnamese dong (or VND; about \$1,400) from their own savings on a small tractor in 2004, which was primarily used for moving the mobile saw used for wood processing. Other studies indicate that in some cases, manure collectors also purchased tractors and gradually replaced human and buffalo carts (Peters et al. 2004).

By 1999 , tractors were predominantly owned by individual farming households -88 percent for large tractors, 97 percent for power tillers, and 98 percent for diesel engines (JICA 2000), and this prevalence of individual owners had further deepened by 2007-94 percent of tractors greater than $35 \mathrm{hp}, 98.5$ percent of those 12-35 hp, and 99.7 percent of those less than 12 hp (Viet 2014). In Viet Nam today, 2WTs are widely used and account for the majority of tractors. The low cost of 2WTs suggests that ownership is not

10 Resolution 10 obliged the agricultural cooperatives to contract land to peasant households for 15 years for annual crops and 40 years for perennial crops (Kirk and Tuan 2009). 
solely restricted to wealthy households, but they are also affordable to middleincome households. As a result, the roles of cooperatives that allow joint ownership of tractors may be less significant. There has also been a significant decrease in the price of land preparation services after small tractors (12 hp) were introduced and replaced big tractors $(50 \mathrm{hp}$ ).

Figure 6.10 plots the probability that a farm household provides tractor rental services, conditional on rice planting area, among 789 tractor owners, aggregated from three rounds (2004, 2006, and 2008) of the VHLSS. Larger rice farmers are more likely to provide rental services. This is primarily because larger farmers are generally still more likely to own tractors (albeit with relative growth of tractor ownership among smaller farms, as illustrated in Figure 6.3) for use on their own farms, but also for earning profits from hiring out to neighboring farms.

\section{(2) GOVERNMENT-RUN SYSTEM}

Government-run agricultural machine stations were set up under the Communist Party in the 1980s, with the aim of providing affordable mechanization services to farmers and cooperatives. By 1983, agricultural machine stations were set up in 200 districts throughout the country, which could potentially handle 30 percent or more of the tilling of the arable lands in the country (US Department of Commerce 1983), slightly more than the actual area tilled by tractors in 1980 (27 percent). Additionally, 120 stations for minor repairs of tractors and 45 maintenance workshops were created throughout the country with Soviet assistance. By May 1983, 200 "machine collectives" and 100 "machine cooperatives" had been set up in southern Viet Nam, with a fleet of 3,200 tractors (Marr and White 1988, 167). In 1984, at the Sixth Plenum of the Central Committee (Fifth Congress), a plan was developed to transfer control of agricultural support stations and agencies dealing with tractor operations, irrigation, farm implement factories, and so on from the provinces to the districts (Vasavakul 2015). By 1985, there were about 300 district-level agricultural machine stations (previously called tractor stations) with a fleet of approximately 20,000 tractors of various sizes and more than 20,000 tractor operators-primarily tasked with providing tilling services for agricultural cooperatives (US CIA 1985).

In the early 1980s, some cooperatives still found it cheaper to hire draft animals from contractors rather than hire tractors from a district hiring station (White 1982). The incentive structures for station workers, as prescribed in government directives in 1982, had not been properly implemented, and workers were poorly incentivized, insufficiently compensated, and not 
FIGURE 6.10 Proportions of samples providing tractor rental services, conditional on rice planting area, among tractor owners, Viet Nam, 2004-2008

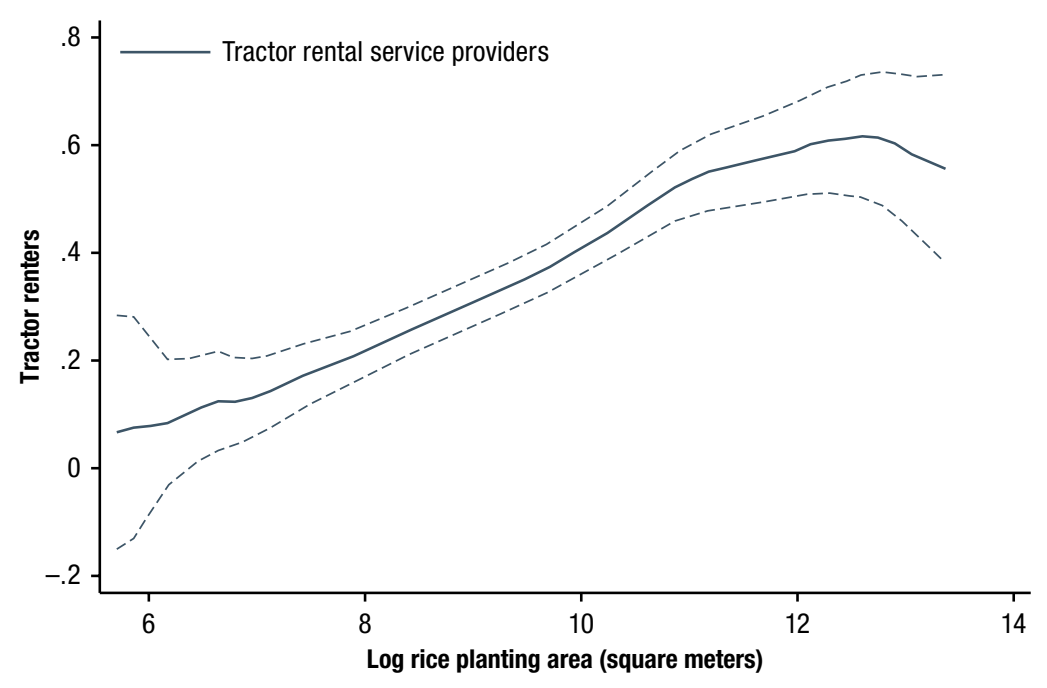

Source: Authors' calculations based on Vietnamese Household Living Standard Survey.

Note: Dashed lines are 95\% confidence intervals.

provided with adequate protective equipment (US CIA 1985). The efficacy of these government-run systems was evident in the resulting closure of all the district tractor stations in Viet Nam by 1990 after the market reforms of the late 1980s (Tan 2011).

\section{(3) COLLECTIVES AND COOPERATIVES}

After the decollectivization that started in 1988, collectives gradually transferred the ownership of tractors to individuals (though some cooperatives still owned tractors), but these cooperatives still played important roles in coordinating land preparation. In the early 1990 s, cooperatives in northern Viet Nam often used riding tractors to provide primary plowing and harrowing services to groups of villagers, who would then apply secondary plowing using private animals or tractors from individual contractors (Kono and Doan 1995).

Under the new cooperative law, many former "agricultural production collectives" had been converted to "service cooperatives" (Scott 2008). This process was mostly complete by 2005 (Quan 2009). The main services of new cooperatives included the management of the irrigation systems and the 
electricity-generating facilities, the supply of farm inputs, field preparation, extension, and the marketing of outputs (Wolz 2000; Quan 2009).

These newly converted cooperatives provided hiring services through their own tractors or acted as an intermediary between farmers and individual tractor owners (often called contractors) (Takahashi 2015). Contractors were usually a local group serving households within their commune with members contributing capital to buy their own tractors and some receiving government support to purchase tractors. ${ }^{11}$ When contracting with individual tractor or buffalo owners, cooperatives often relied on competitive bidding, with a ceiling price for the land preparation service predetermined by the representatives of the members of the cooperatives (Quan 2009). In other cooperatives, several board members jointly invested in tractors and received dividends from the profit earned through hiring (Takahashi 2015).

\section{COMBINE HARVESTER SERVICE PROVIDERS}

Information on combine harvester ownership and service provision is generally limited. However, anecdotal evidence suggests that the individual farmerto-farmer model is quite common in Mekong River Delta, where 75 percent of combine harvesters in Viet Nam were located as of 2014 (Viet 2014), the most common being the Japanese Kubota. Many Kubota combine owners are wealthy large farmers, cultivating 20-100 ha annually. In Mekong River Delta, 20 percent of Kubota combine owners cultivated more than 100 ha in 2011 (Kubota Corporation 2011). These combine owners hire out their services, earning several hundred million Vietnamese dong ( $\$ 10,000$ or more) per year after deducting costs (Kubota Corporation 2011).

\section{Relatively Weak Government Involvement during Mechanization Growth Phase since the 1990s}

In Viet Nam, as in some other Asian countries, the government's direct policies toward mechanization followed the growth rather than led it for the period up to the 1990s, when mechanization substantially took off. For example, information on subsidies in Viet Nam up to the period of the 2000s is limited, suggesting that subsidies were not widely provided. Only in 2009 did the government take a proactive policy on mechanization through Resolution

11 Communes are the lowest governmental administrative units in Viet Nam. A commune is usually a homogeneous community in terms of topography and livelihood activities. The concept of a modern commune relates more to the term "community" than to the idea of collective ownership. Typically, there are between 15 and 35 communes in a district, and within a commune there are typically 5 to 10 villages or "hamlets" (Quan 2009). 
48/NQ-CP, which aimed at reducing rice postharvest losses from the current 11-13 percent loss down to a 5-6 percent loss by 2020 (Nguyen and Hien 2014). Decision 68/2013/QD-TTg ${ }^{12}$ in 2013 and Decision 08/2014/ TT-BNNPTNT in 2014 addressed credit policies to reduce postharvest losses and to improve mechanization in postharvest operations, aiming for providing subsidies on interest rates for selected machines and equipment, provided to cooperatives, farmers' groups, households, and individuals (listed in that priority order).

Other policies had been implemented in the past, but had relatively limited effects on the growth of mechanization. For example, the National Center for Testing of Agricultural Machinery issued permits for locally mass-produced or imported equipment. However, after 1990, this agency became self-financed with a reduced role and scope (no longer in charge of southern provinces) and was renamed Center for Evaluation of Machines and Equipment. The agency liberalized the applications of diverse machinery in agriculture, but it also allowed for more low-quality imported secondhand machines that were unsuitable for production and resulted in losses to farmers using these machines.

\section{Conclusions}

Viet Nam has reportedly experienced rapid growth in agricultural mechanization lately. However, available information about the historical growth patterns of mechanization in the country has been rather vague. Significant knowledge gaps exist regarding the actual extent of mechanization, the heterogeneity of adoption patterns across regions and farm sizes, and the characteristics of emerging suppliers of machines and hiring services.

As far as tractors are concerned, available evidence indicates that tractor adoption rates in Viet Nam had reached moderately high levels by 1980 (close to 30 percent of the entire country and even higher in Southern Viet Nam), albeit under a very different sociopolitical system than today. Future studies must investigate how such exposures might have contributed to the resurgence of tractors in the 1990s.

Substantial public investments including those in agricultural research and development and in irrigation infrastructure, as well as the acceleration of the economic transformation in the country, are likely to have stimulated the

12 Government documents may be downloaded from http://vanban.chinhphu.vn/portal/page /portal/chinhphu/hethongvanban?class_id=18mode=detail\&document_id=170904. 
demand for increased farm power use after the economic and social reforms in the late 1980s. The mechanization patterns have been highly divergent across regions, characterized by growth in the smallholder-dominated deltas and the land-abundant regions of the central coast. Machine use has been largely enabled by rentals rather than ownership. Whereas machinery use and tractor ownership have been originally concentrated among larger farmers, they have gradually spread to smaller farms, enabling many smallholders to stay competitive in the face of rising farm wages. However, the past few decades have also seen an increase in the areas cultivated annually for crops such as rice through increased production frequency enabled by the expansion of irrigation infrastructure. Mechanization growth is likely to shift the comparative advantage of farming toward larger farms, where land market development may become increasingly important.

Since the economic and social reform in the late 1980s, the private sector has rapidly emerged as the major player in meeting the demand for greater farm power use in Viet Nam. The fast pace of growth of the power tiller manufacturing industry during the 1990s and the shift from smaller combines to larger combine harvesters in the last several years are largely consistent with the predictions in earlier literature (for example, Binswanger 1986) that the supply side is generally not a major constraint for mechanization growth in developing countries, compared with the demand-side constraints, even in transition countries such as Viet Nam.

As for policy recommendations to Africa, Vietnamese experiences offer the following lessons. First, as described above, significant investments in public goods, including complementary seed technologies and irrigation infrastructure that were partly expanded during the socialist regimes, played important roles in stimulating demand for tractor plowing. Second, the significant involvement of government in tractor hiring services intensified during the 1980s through collectivization, and generally did not lead to significant tractor use growth. Similar attempts in African countries, in which the government selects the potential hiring service providers, are likely to face similar challenges. Instead, the growth of hiring service providers should be left to the market. Third, once the demand for mechanization had risen, partly through the aforementioned investments in the development of complementary technologies and irrigation and road infrastructure, the liberalization of the economy in the 1990s led to considerable growth in mechanization use and domestic manufacturing of 2WTs. It is likely to be important for African countries to follow such dynamics in the sequence of public goods investments and market promotion in order to stimulate mechanization adoption growth. 


\section{References}

Biggs, S., and S. Justice. 2015. Rural and Agricultural Mechanization: A History of the Spread of Small Engines in Selected Asian Countries. IFPRI Discussion Paper 01443. Washington, DC: International Food Policy Research Institute.

Binswanger, H. 1986. “Agricultural Mechanization: A Comparative Historical Perspective.” World Bank Research Observer 1 (1): 27-56.

FAO (Food and Agriculture Organization of the United Nations). 2018. FAOSTAT database. Accessed April 27. http://faostat.fao.org.

Foster, A. D., and M. R. Rosenzweig. 2011. Are Indian Farms Too Small? Mechanization, Agency Costs, and Farm Efficiency. New Haven, CT, US: Economic Growth Center, Yale University.

Gorman, T. 2014. "Moral Economy and the Upper Peasant: The Dynamics of Land Privatization in the Mekong Delta." Journal of Agrarian Change 14 (4): 501-521.

GSOV (General Statistics Office of Vietnam). 2016. Vietnamese Living Standard Survey and Vietnamese Household Living Standard Survey. Hanoi, Vietnam.

Gummert, M., P. H. Hien, T. V. Khanh, and M. A. Kyaw. 2013. Combine Harvesting in South and Southeast Asia: Current Status and Trends. Los Baños, Philippines: International Rice Research Institute.

Hien, P. H., T. V. Khanh, and G. R. Quick. 2007. "Development of Rice Combines in Viet Nam.” Electronic-only proceedings of the International Conference on Crop Harvesting and Processing, Louisville, KY, US, February 11-14. http://opensourceecology.org/wiki /Combine_Research_Paper\#Development_of_rice_combines_in_Viet_Nam.

IRRI (International Rice Research Institute). 1978. Proceedings of the International Agricultural Machinery Workshop. Los Baños, Philippines.

- 1983. Consequences of Small-Farm Mechanization. Los Baños, Philippines.

— 1986. Small Farm Equipment for Developing Countries. IRRI. Los Baños, Philippines.

JICA (Japan International Cooperation Agency). 2000. Vietnam: Report by Agricultural Development Survey Team (Nogyo-Kaihatsu Kiso Chosa-dan Hokokushu). Report submitted to JICA. Tokyo.

Kienzle, J., J. E. Ashburner, and B. G. Sims. 2013. Mechanization for Rural Development: A Review of Patterns and Progress from Around the World. Rome: Food and Agriculture Organization of the United Nations.

Kirk, M., and N. D. A. Tuan. 2009. Land-Tenure Policy Reforms: Decollectivization and the Doi Moi System in Vietnam. IFPRI Discussion Paper 927. Washington, DC: International Food Policy Research Institute. 
Kono, Y., and D. T. Doan. 1995. "Effect of Water Control on Rice Cultivation in the Red River Delta, Vietnam: A Case Study in the Nhue River Irrigation System." Southeast Asian Studies 32 (4): 425-445.

Kubota Corporation. 2011. "The Bountiful Mekong Delta: Vietnam Catches the Wave of Mechanized Farming." Global Index, 7-18. www.kubota.com/globalindex/backnumber /pdf2011_en/gi-e-3.pdf.

Lançon, F., D. Sautier, and D. T. Anh. 2014. Vietnam: Rural Connectivity and Agriculture Logistics in Domestic Market Supply Chains_Synthesis Report. Washington, DC: World Bank.

Lee, Y. H. 2007. “Trade of Agricultural Machinery in Korea.” Mimeo.

Liu, Y., W. Violette, and C. Barrett. 2016. Structural Transformation and Intertemporal Evolution of Real Wages, Machine Use, and Farm Size-Productivity Relationships in Vietnam. IFPRI Discussion Paper 01525. Washington, DC: International Food Policy Research Institute.

Mandal, S., S. Biggs, and S. Justice. 2017. Rural Mechanization: A Driver in Agricultural Change and Rural Development. Dhaka, Bangladesh: Institute for Inclusive Finance and Development.

Marr, D. G., and C. P. White. 1988. Postwar Vietnam: Dilemmas in Socialist Development. Ithaca, NY, US: Southeast Asia Program, Cornell University.

Minot, N., and F. Goletti. 2000. Rice Market Liberalization and Poverty in Vietnam. IFPRI Research Report 114. Washington, DC: International Food Policy Research Institute.

Nguyen, B. T., J. W. Albrecht, S. B. Brogman, and D. M. Westbrook. 2007. “A Quantile Regression Decomposition of Urban-Rural Inequality in Vietnam.” Journal of Development Economics 83: 466-490.

Nguyen, L. H., and P. H. Hien, eds. 2014. Rice Post-Harvest Technology in Viet Nam. English Translation and Update. Hanoi: Agricultural Publishing House.

Pandey, S., D. Byerlee, D. Dawe, A. Dobermann, S. Mohanty, S. Rozelle, and B. Hardy. 2010. Rice in the Global Economy: Strategic Research and Policy Issues for Food Security. Los Baños, Philippines: International Rice Research Institute.

Peters, D., N. T. Son, N. B. Mui, and P. N. Thach. 2004. "Piglet Enterprise Assessment and Improvement in Cat Que Commune, Vietnam." Livestock Research for Rural Development 16 (2): $1-19$.

Pingali, P. 2007. “Agricultural Mechanization: Adoption Patterns and Economic Impact." In Handbook of Agricultural Economics, edited by R. Evenson and P. Pingali, 2779-2805. Amsterdam: Elsevier.

Pingali, P. L., and V. T. Xuan. 1992. "Vietnam: Decollectivization and Rice Productivity Growth." Economic Development and Cultural Change 40 (4): 697-718. 
Quan, T. 2009. “Transition from Subsistence Farming to Commercial Agriculture in Quang Binh Province, Vietnam." Doctoral dissertation, Lincoln University, Jefferson City, MO, US.

Reardon, T., K. Chen, B. Minten, L. Adriano, T. Dao, J. Wang, and S. Gupta. 2014. “The Quiet Revolution in Asia's Rice Value Chains." Annals of the New York Academy of Sciences 1331: 106-118.

Sansom, R. L. 1969. “The Motor Pump: A Case Study of Innovation and Development." Oxford Economic Papers 21 (1): 109-121.

Scott, S. 2008. "Agrarian Transformations in Vietnam." In The Political Economy of Rural Livelihoods in Transition Economies: Land, Peasants and Rural Poverty in Transition, edited by M. Spoor, 175-199. Abingdon, Oxfordshire, UK: Routledge.

Starkey, P., S. Ellis, J. Hine, and A. Ternell. 2002. Improving Rural Mobility Options for Developing Motorized and Nonmotorized Transport in Rural Areas. Technical Paper 525. Washington, DC: World Bank.

Stewart, F. 1974. “Technology and Employment in LDCs." World Development 2 (3): 17-46.

Takahashi, F. 2015. "Business Activities of 'Transformed' Agricultural Cooperatives and Their Role in Supporting Local Agriculture in Northern Vietnam." International Journal of Environmental and Rural Development 6 (2): 87-93.

Takeshima, H., Y. Liu, N. V. Cuong, and I. Masias. 2018. Evolutions of Agricultural Mechanization in Vietnam: Insights from the Literature Review and Multi-Rounds of Farm Household Survey Data. IFPRI Discussion Paper 01724. Washington, DC: International Food Policy Research Institute.

Tan, P. V. 2011. "Agricultural Machinery in Logistics and Supply Chain of Rice Production: A Challenge for Vietnam.” Unpublished slides, Southern Institute of Agricultural Engineering and Post-Harvest Technology, Ho Chi Minh City, Viet Nam. http://slideplayer.com/slide /2382011/.

Tsukada, K. 2012. "Mechanization of Rice Farming in Mekong Delta." In Rural Development in Vietnam - Transformation of Rural Economy under the Fast Economic Growth, edited by S. Sakata. Chiba, Japan: Institute of Developing Economies.

Tuyến, N. Q. 2013. “Outcomes of Vietnam’s Agrarian Policies after 'Doi Moi': A Case Study of Attempted Agricultural Intensification and Diversification in a Village in Vietnam's Mekong Delta." Global Journal of Human Social Science Arts and Humanities 13 (6): 37-47.

US CIA (Central Intelligence Agency). 1985. Southeast Asia Report. Springfield, VA, US: Foreign Broadcast Information Service.

US Department of Commerce. 1983. Southeast Asia Report. No. 1372. Springfield, VA. 
Van Luong, H., and J. Unger. 1998. "Wealth, Power, and Poverty in the Transition to Market Economies: The Process of Socio-Economic Differentiation in Rural China and Northern Vietnam." The China Journal 40: 61-93.

Vasavakul, T. 2015. "Vietnam: Sectors, Classes, and the Transformation of a Leninist State." In Driven by Growth: Political Change in the Asia-Pacific Region, edited by J. W. Morley, 59-82. Abingdon, Oxfordshire, UK: Routledge.

Viet, N. Q. 2014. “Status of Custom Hiring in Vietnam.” In 2nd Regional Forum on Sustainable Agricultural Mechanization in Asia and the Pacific: Enabling Environment for Custom Hiring of Agricultural Machinery. Beijing: Centre for Sustainable Agricultural Mechanization, United Nations Economic and Social Commission for Asia and the Pacific.

Viet Nam, MIT (Ministry of Industry and Trade). 2015. Vietnam Manufacturing Supporting Industry Yearbook 2014-2015. Hanoi.

White, C. P. 1982. "Socialist Transformation of Agriculture and Gender Relations: The Vietnamese Case.” IDS Bulletin 13 (4): 44-51.

Wiegersma, N. 1988. Vietnam: Peasant Land, Peasant Revolution: Patriarchy and Collectivity in the Rural Economy. New York: St. Martin's Press.

Wolz, A. 2000. "The Development of Agricultural Co-Operatives in Vietnam Since Transformation." Issue 72 of Discussion Paper. Research Centre for International Agrarian \& Economic Development. Heidelberg, Germany.

Yamauchi, F. 2016. "Rising Real Wages, Mechanization and Growing Advantage of Large Farms: Evidence from Indonesia." Food Policy 58: 62-69.

Zhang, X., J. Yang, and T. Reardon. 2017. "Mechanization Outsourcing Clusters and Division of Labor in Chinese Agriculture." China Economic Review 43: 184-195.

\section{Appendix 6A: Empirical Model}

Results in Table 6.7 are estimated through the following fixed-effects panel equation:

$$
d_{m i t}=\delta_{0, m i}+\delta_{1} \ln \mathrm{w}_{m t}+\delta_{2} \ln a_{m i t}+\delta_{4} \mathrm{z}_{m i t}+\delta_{5} D_{t} \times R_{i}+\epsilon_{m i t},
$$

where $d_{m i t}$ is a dummy variable indicating machine use for household $i$ in commune $m$ and year $t$. It takes a value of 1 if the household owned any tractors or spent on machine rentals and 0 otherwise. $\ln \mathrm{w}_{m t}$ is $\log$ male agricultural wage (in real terms); $\ln a_{m i t}$ is $\log$ rice planting area; $\delta_{0, m i}$ is a household fixed effect that captures time-invariant household and location-specific effects such as 
land quality and weather; $z_{m i t}$ is a vector of household-specific time-varying characteristics; $D_{t}$ is a year dummy; and $R_{i}$ is a vector of regional dummies. We include the region-year fixed effects to capture region-specific time-variant effects (such as interest rates, output and input prices, and public policies, which are assumed uniformly across communes within one region for year $t) ; \epsilon_{m i t}$ is the error term. We cluster standard errors at the commune level. Equation (1) is estimated using the 1992-1998 panel, 2002-2004 panel, and 2006-2008 panel of the VHLSS separately. 



\section{PART 3}

\section{Late-Adopter Asian Countries}



Chapter 7

\title{
EVOLUTION OF AGRICULTURAL MECHANIZATION IN BANGLADESH: THE CASE OF TRACTORS FOR LAND PREPARATION
}

\author{
Mansur Ahmed and Hiroyuki Takeshima
}

\begin{abstract}
In Bangladesh, mechanization-particularly tractor use for land preparation-has grown, despite the country's having one of the smallest average farm sizes in the region and a historically large rural labor force. The early period of this growth, up to the mid-2000s, was led by technological factors that significantly raised the demand for intensive farm power for land preparation. Economic transformation, including rising real wages, played a greater role in the expansion of mechanization following the mid-2000s. Recently, mechanization has become increasingly associated with growth of nonfarm income-earning activities, and household survey data show that it is increasingly substituted for labor. A considerable part of the growth of tractor use for land preparation during the last three decades has been led by the private sector, whereas the government has engaged in relatively few direct interventions in mechanization. These patterns of mechanization growth in Bangladesh have important implications for other countries that have yet to go through this process.
\end{abstract}

\section{Introduction}

In recent decades, agriculture in Bangladesh has undergone a remarkable transformation. Smallholder households in the country have adopted agricultural machinery, especially for land preparation, at an unprecedented level. Intensification of production systems along with the tightening of the rural labor market have created power bottlenecks in agricultural production, particularly in land preparation, harvesting, and threshing operations. These bottlenecks are alleviated with the adoption of labor-saving agricultural technology, which in turn raises agricultural productivity and reduces the perunit cost of crop production (Pingali 2007). Mandal (2002) estimated that in

This chapter was written prior to Mansur Ahmed's World Bank employment. 
Bangladesh around 150,000 power tillers have been imported annually since liberalized import policies were implemented in the mid-1990s.

The increase in market-based hiring of agricultural technology in Bangladesh brings the benefit of modern technology within reach of subsistence smallholder households. For example, in 2008 about 89 percent of farm households used tractor or power tillage for land preparation in agricultural production, yet only 4 percent of farm households owned a tractor, a power tiller, or both (Ahmed and Goodwin 2016). Smallholder households are also increasingly engaging in nonfarm economic activities, both to diversify the risks of farm income volatility from price shocks and production loss, and to smooth consumption during the lean season. This phenomenon encourages smallholder households to increasingly adopt agricultural mechanization in their farm practices.

This chapter explores the factors that play direct or indirect roles in the agricultural mechanization of smallholder farm households through the development of the custom hiring service (CHS) market for agricultural machinery in Bangladesh. The chapter examines the factors that affect the uptake of power tillers and tractors in Bangladesh. Because agricultural mechanization has evolved much more quickly for land preparation than for other farm activities, this chapter also explores and identifies constraints contributing to the slower pace of mechanization in weeding, harvesting, and threshing. Insights from the Bangladesh example of agricultural mechanization through $\mathrm{CHS}$ can provide insights for many developing countries in Asia, Africa, and elsewhere that are seeking sustainable ways to promote agricultural mechanization.

For the analysis of this chapter, we will rely on multiple rounds of the Household Income and Expenditure Survey (HIES), a nationally representative cross-sectional survey conducted by the Bangladesh Bureau of Statistics. We will use the three latest rounds of the HIES (2000, 2005, and 2010) to analyze the drivers of smallholder mechanization in rural Bangladesh. In addition to the use of these and other primary data, this chapter also uses secondary data from various sources to understand the evolution of smallholder agricultural mechanization in Bangladesh.

\section{Evolution of Agricultural Mechanization and Supporting Policies in Bangladesh}

The early wave of agricultural mechanization in Bangladesh occurred because of policies and programs that began in the 1970s in support of the Green 
Revolution, including the release of successful high-yielding varieties (HYVs) and the spread of deep and shallow tube wells for irrigation. In countries like Bangladesh with extremely small average farm sizes, the major driver of demand for farm power comes from demand for increased intensity or frequency of tillage per plot of land, induced by the introduction of HYVs that would respond more to such intensive tillage.

Between 1972 and 1989, Bangladesh's domestic plant breeding institutes made 217 crosses of new rice varieties per year (Witcombe et al. 2013), from which approximately 1 out of 200 elite varieties were eventually selected and released. Few African countries with significant rice areas have invested in plant breeding at such intensity, even up until today. ${ }^{1}$ By the late $1990 \mathrm{~s}$ most of the popular rice varieties adopted by farmers had originated from these domestically crossed varieties, and by 1998 Bangladesh had spent $\$ 3.4$ million $^{2}$ on rice breeding activities alone (Hossain et al. 2003). Rice breeding has also focused on rainfed areas (Orr 2012), so the demand for intensive tillage rose considerably even in nonirrigated systems. By the early 1990 s, right before power tillers began to be substituted for draft animals, the intensity of animal traction use had reached a substantial level—typically as high as 90 head-days per farming household per year (Mandal and Parker 1995), which is substantially higher than the intensity in African countries. For example, the average is just 6-9 head-days per farming household per year in Nigeria, as shown in the Nigeria chapter of this book. In the 1980s, though the share of rice area cultivated with tractors was still small, 98 percent of areas had been prepared by draft animals (IRRI 1986). The demand for intensive farm power for land preparation had thus risen significantly by the 1980s, and already far exceeded the levels in African countries today.

The surge of power tiller imports from China in the early 1990s is often attributed to the liberalization of import policies (Mottaleb, Krupnik, and Erenstein 2016; Mandal, Biggs, and Justice 2017). However, liberalization alone would not have caused this, if the demand for intensive farm power use had not risen following the improvements in varieties. Such technologyled growth in demand for farm power in the late 1980s and the 1990s is also consistent with the fact that mechanization grew in the 1990s and most of the 2000s despite flat agricultural real wages (Figure 7.1). By the time the real wage started rising in the late 2000 s, 80 percent of land preparation was

1 For example, from 1961 to 2010, Nigeria, the largest rice producer in Africa, made only 10 crosses per year, 1/20 the number in Bangladesh (Takeshima and Maji 2016).

2 Dollar figures are US dollars throughout the chapter. 
FIGURE 7.1 Agricultural labor, cattle/buffalo, machinery, and real wages, Bangladesh, 1992-2013

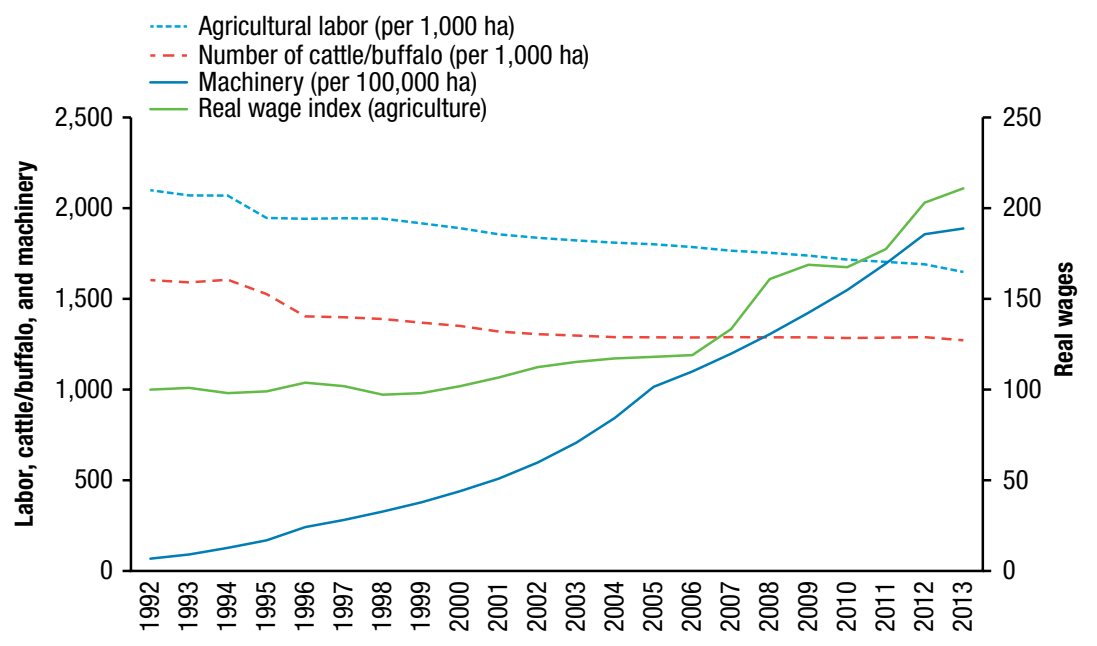

Source: Authors' own calculation using data from USDA (2018).

already done by tractors (Table 7.1). Wage increases since the late 2000s, and the declining use of draft animals and agricultural labor (Figure 7.1; Zhang et al. 2014), are likely to have induced further expansion of mechanization. The imported, fairly inexpensive power tillers - priced at around $\$ 800-\$ 1,000$ (Mottaleb et al. 2017) - have accounted for the majority of tractor power provided, although recently four-wheel tractors (4WTs) have started to account for an increasing share of tractor use. In 2010, 4WTs contributed 40 percent to the total 95 percent of rice area that was plowed by tractors (Table 7.1).

Mechanization of other operations in Bangladesh has remained low. The number of combine harvesters in the country is minimal; the total was just 30 in 2008, 100 in 2011 (Biggs and Justice 2013), and 160 in 2012 (CSAM 2014). Similarly, the number of transplanters was just 200 in $2011 .^{3}$ Mechanization of these operations is likely to grow in the coming decades.

Although Bangladesh's agricultural mechanization lagged behind that of neighboring South Asian countries in the 1980s and 1990s, mechanization growth in the last decade has been outstanding, and the country has quickly outpaced its neighbors in terms of the intensity of agricultural machinery per 1,000 ha of agricultural land (Figure 7.2). Given the fact that average farm

3 Presentation at the Bangladesh Agricultural Research Institute on November 4, 2015. 
TABLE 7.1 Evolution of economic and employment structure and mechanization in Bangladesh, 1980s-2010s

\begin{tabular}{|c|c|c|c|c|}
\hline Variable & $1980 \mathrm{~s}$ & 1990s & $2000 s$ & 2010s \\
\hline \multicolumn{5}{|l|}{ Sector share of GDPa } \\
\hline Agriculture & 31 & 27 & 20 & 18 \\
\hline Manufacturing/industry & 21 & 23 & 25 & 27 \\
\hline Service & 46 & 50 & 55 & 56 \\
\hline \multicolumn{5}{|l|}{ Employment share (\%) } \\
\hline Agriculture & - & 60 & 51 & 44 \\
\hline Manufacturing/industry & - & 11 & 13 & 18 \\
\hline Service & - & 21 & 32 & 35 \\
\hline $\begin{array}{l}\text { Share (\%) of rice area } \\
\text { plowed by tractors }\end{array}$ & $<2(1986)^{b}$ & $28(1996)^{c}$ & $\begin{array}{c}80(2008)^{d} \\
\text { Wheat: } 75(2002) \\
\text { by } 2 \text { WTe }\end{array}$ & $\begin{array}{c}95^{\mathrm{b}} \\
(55-2 \mathrm{WT}, \\
40-4 \mathrm{WT})\end{array}$ \\
\hline $\begin{array}{l}\text { Share (\%) of area plowed } \\
\text { by animals }\end{array}$ & $98(1986)^{b}$ & - & - & $30(2013)^{f}$ \\
\hline $\begin{array}{l}\text { Share (\%) of spare parts } \\
\text { produced locallyg }\end{array}$ & - & - & $2(2004 / 2005)$ & 77 (2011) \\
\hline $\begin{array}{l}\text { Share of arable land irrigat- } \\
\text { ed }(\%)^{\mathrm{h}}\end{array}$ & Approx. 20 & Approx. 40 & Approx. 60 & - \\
\hline
\end{tabular}

Source: a World Bank (2018). b IRRI (1986). ${ }^{\mathrm{c}}$ Ahmed (2001). ${ }^{\mathrm{d}}$ Roy and Singh (2008); author's conversation with The Metal Ltd. ${ }^{\mathrm{e}}$ Meisner et al. (2003). ${ }^{\mathrm{f}}$ Ahmed (2013). ${ }^{9}$ Alam and Khan (2017). ${ }^{\mathrm{h}}$ FAO (2018).

Note: - = data not available; $2 \mathrm{WT}=$ two-wheel tractors; 4WT = four-wheel tractors; GDP = gross domestic product.

size in Bangladesh is the smallest in the region, the major cause of the spread of agricultural mechanization is the CHS market. This is true even though the dominant machine, the power tiller, is relatively affordable when compared with 4 WTs. In 2013, a nationally representative survey showed that 72 percent of farmers used power tillers, but only 2 percent of farmers actually owned them. This suggests that on average, each power tiller-owning farmer served 36 other farmers (Ahmed 2013).

The private sector in Bangladesh played a key role in the overall agricultural mechanization process. Agricultural machinery importers and suppliers in Bangladesh have extensive service and sales networks, and often provide credit support and free servicing offers to support the sale of agricultural machines. Since the mid-2000s, about 100 importers in the country have been responsible for the total of approximately 50,000 power tillers imported per year, which mostly come from China (Mottaleb et al. 2017). Over time, the numbers of tractor dealers and retailers in the country have increased to 500 and 2,000-2,500, respectively (Bhattarai et al. 2017). It is important to note that the power tiller import market is still quite concentrated; for example, 


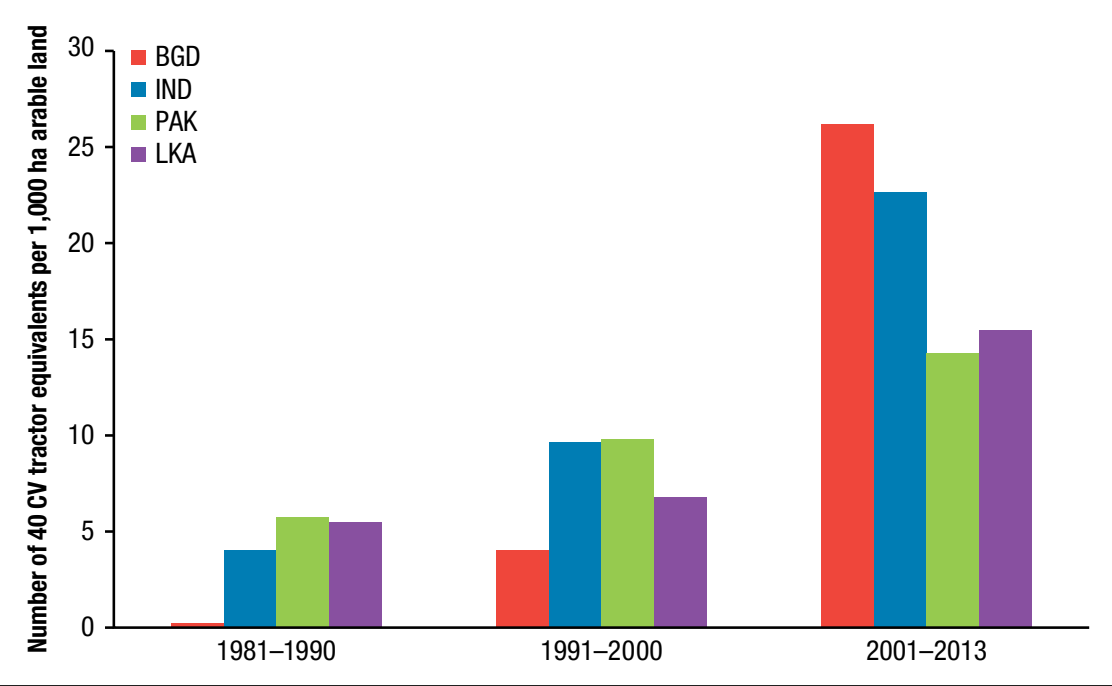

Source: Authors' own calculation using data from USDA (2018).

Note: The total stock of farm machinery in " $40 \mathrm{CV}$ tractor equivalents" aggregates the number of two-wheel tractors (2WTs), four-wheel tractors (4WTs), and combine harvesters. For weights, we assume 2WTs average $12 \mathrm{CV}$; 4WTs, $40 \mathrm{CV}$; and combine harvesters, $20 \mathrm{CV}$. Data for each category are from the Food and Agriculture Organization of the United Nations, except for the data for 2WT, which were compiled from national sources. BGD = Bangladesh; $\mathrm{CV}=$ cheveaux vapeur, or metric horsepower; IND = India; LKA = Sri Lanka; PAK = Pakistan.

in 2014 the largest importer accounted for 80 percent of the 60,000 units imported that year. ${ }^{4}$

Along with the continuous increase in agricultural machine imports, local manufacturing of small-scale agricultural machines and spare parts has also grown. During the 2000s and onward, substantial growth occurred in local manufacturing of agricultural machinery, attachments, and spare parts. As the overall market for spare parts for power tillers, diesel engines, and centrifugal pumps grew from $\$ 89.2$ million in $2004 / 2005$ to $\$ 309.3$ million in 2011, the share of locally manufactured products increased from about 2 percent in 2004/2005 ( $\$ 1.78$ million) to 77 percent in 2011 ( $\$ 237.9$ million) (Alam 2005; Alam and Khan 2017). Much of this growth has been spatially concentrated; in 2011, 80 percent of the local spare parts were produced in Bogra district, with Dhaka and Jessore districts accounting for the remaining 20 percent (Alam and Khan 2017). Such high spatial concentration may reflect the role of clusters in the growth of the manufacturing industry, as well

4 Furthermore, Bhattarai and others (2017) have suggested that the number of importers with substantial import quantities could be as low as $8-10$. 
as high spatial mobility of spare parts. Aside from spare parts for centrifugal pumps, the manufacturing of centrifugal pumps themselves also grew; by 2010 , about 560,000 units of centrifugal pumps had been supplied for shallow tube wells and low-lift pumps in the country, almost all of which were produced locally (Alam and Khan 2017). Again, Bogra district accounted for 90 percent of centrifugal pumps produced in Bangladesh. In the mid-2010s, meetings with agricultural machinery firms revealed that local manufacturing of small power tillers had begun for the first time in the country, produced by Alim Industries Ltd. in Sylhet district (Animaw et al. 2016). This local manufacturing has been enabled by the spread of local workshops and artisans; by 2012 , there were 550 agrimachinery manufacturing workshops, 250 spare parts manufacturing workshops, 10,000 repair and maintenance workshops, and 100,000 village artisans (CSAM 2014).

Though the government in Bangladesh has not been directly involved in the importation and supply of agricultural machinery, it has provided key supports through the tariff liberalization of agricultural equipment imports, and subsidies and tax exemptions to local producers of agricultural machinery and private businesses importing, manufacturing, and selling agricultural machines and tools. These supporting policies may have driven the development of the agricultural machinery hiring service market in Bangladesh. Generally, over the last two decades, successive governments have adopted agricultural policies that were conducive to agricultural mechanization.

Several government agencies worked together to achieve the goal of increased agricultural mechanization. The major agencies include the Bangladesh Agricultural Development Corporation, the Bangladesh Rural Development Board, the Department of Agricultural Extension, the Bangladesh Rice Research Institute, the Bangladesh Agricultural Research Institute, and the Bangladesh Agricultural Research Council. Furthermore, the Department of Agricultural Extension has 26,000 staff across the country, amounting to a high ratio of extension staff to farmers and creating a strong extension system in the country.

\section{Demand-Side and Supply-Side Factors in the Growth of CHS: Descriptive Evidence}

There are many factors that affect agricultural mechanization directly and indirectly through CHS. This section explores why smallholders are accessing mechanization through CHS, instead of through individual ownership of machines. The use of longitudinal data that track the behavioral changes 
of the smallholder farm households in rural Bangladesh may be the best strategy to identify the major factors behind smallholders' adoption of mechanized processes in land preparation, harvesting, and threshing. For the analysis in this chapter, we will rely on multiple rounds of a nationally representative cross-sectional survey, the HIES. The Bangladesh Bureau of Statistics, a wing of the Ministry of Planning of the government of Bangladesh, has conducted this survey periodically since $1973 / 1974$, and it has undergone many transformations in terms of methodology and coverage over the decades. We will use the three latest rounds of the HIES (2000, 2005, and 2010) for analyzing the drivers of smallholder mechanization in rural Bangladesh. This chapter also complements the HIES analysis with some results from three rounds of a unique panel survey (Ahmed and Goodwin 2016). ${ }^{5}$

The HIES collects detailed information about households' farm production practices, such as land preparation, weeding, harvesting, and threshing. In addition to farm production practices, the survey asks for information related to households' socioeconomic status as well as constraints such as access to finance and markets. We sketch profiles for both mechanized and nonmechanized households using descriptive analysis from the survey data for the last decade, and identify the potential correlates that may drive rural smallholder farm households to adopt mechanization in their farm production practices. We also sketch a profile of the mechanized service providers to identify their role in farm mechanization and to identify the factors behind the development of this service market in rural Bangladesh.

The rural module of the HIES included 3,005 farm households in 2000 and 4,798 farm households in 2010. Although the survey does not allow us to track adoption of all kinds of agricultural machinery through the hire market, we are able to identify the adoption practices within the hire market for tractors/power tillers. The evidence shows a consistent increase in the adoption rate of tractors/power tillers over last decade, with use of tractors/power tillers increasing from 56 percent in 2000 to 67 percent in 2010 (Table 7.2). ${ }^{6}$ The HIES survey also elicits information about ownership of agricultural machinery; resuts show that the rate of agricultural machinery ownership has grown over time. For example, the number of threshers per 1,000 farmers increased

5 The first round of this panel survey took place in 1988 , and the repeat rounds were conducted in $2000,2004,2008$, and 2013. We could access the data for 2000, 2004, and 2008 only.

6 The panel survey of rural households conducted by Mahaboob Hossain showed that the adoption of tractors/power tillers for land preparation was 87 percent in 2008 (cited in Ahmed and Goodwin 2016). 
TABLE 7.2 Profile of farm machines of farm households, Bangladesh, 2000-2010

\begin{tabular}{lrrr}
\hline Category & 2000 & 2005 & 2010 \\
\hline Farmers & 3,005 & 3,824 & 4,798 \\
Adoption of tractors/power tillers (\%) & 56 & 62 & 67 \\
Cost of tractor rental per ha (in 2010 BDT) & 1,848 & 2,066 & 3,481 \\
Tractors (per thousand farmers) & 6 & 4 & 6 \\
Power tillers (per thousand farmers) & 12 & 17 & 17 \\
Threshers (per thousand farmers) & 22 & 35 & 28 \\
Power pumps (per thousand farmers) & 17 & 12 & 25 \\
Deep tube wells (per thousand farmers) & 14 & 10 & 14 \\
Shallow tube wells (per thousand farmers) & 61 & 66 & 84 \\
Sprayers (per thousand farmers) & 22 & 17 & 45 \\
Husking machines (per thousand farmers) & 9 & 4 & 8 \\
Ginning machines (per thousand farmers) & 2 & 0 & 3 \\
\hline
\end{tabular}

Source: Authors' own calculation using data from Household Income and Expenditure Surveys for 2000-2010. Note: $\mathrm{BDT}=$ Bangladeshi taka.

from 22 in 2000 to 28 in 2010. Similarly, the number of mechanized sprayers per 1,000 farmers has doubled in the last decade.

The kernel density of operating land distribution reveals a clear distinction between the households that use agricultural machines and those that own them. More than 80 percent of using, or "adopter," households are marginal or small-scale farmers operating less than 1 ha, whereas less than 40 percent of machine-owning households are marginal or small-scale farmers (Figure 7.3). The 2008 agricultural census reported that 84 percent of rural farm holdings were actually small farm holdings - that is, less than 2.5 acres (BBS 2010) and ownership of agricultural machinery is often beyond these farmers' reach. The high adoption rate of agricultural machinery among smallholder households is therefore an outcome of the presence of the CHS market. Evidence suggests that the majority of agricultural machinery owners are large-scale farmers who hire out their tools to non-owner farmers (who are mostly smallholders) through the CHS market (Figure 7.4).

Figure 7.5 shows that the share of agricultural machinery-owning households that hire out their machines through the CHS market has declined from 90 percent in 2000 to 65 percent in 2010. This suggests that an increasing number of farm households have purchased agricultural machinery for their own use only, most of whom are large- or medium-scale farmers. Figure 7.4 also shows that the medium-scale farmers are increasingly buying 
FIGURE 7.3 Kernel density of land distribution among adopters and owners of machinery, Bangladesh, 2000-2010
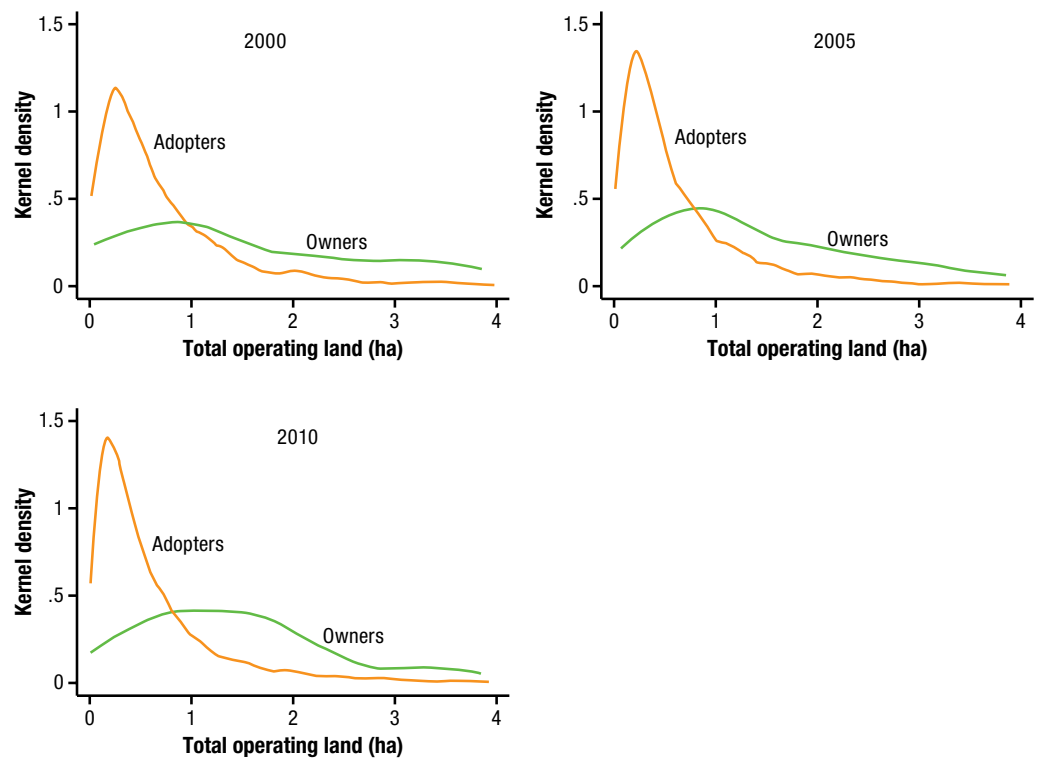

Source: Authors' own calculation using data from Household Income and Expenditure Surveys for 2000-2010.

FIGURE 7.4 Landownership and adoption of agricultural machinery, Bangladesh, 2000-2010

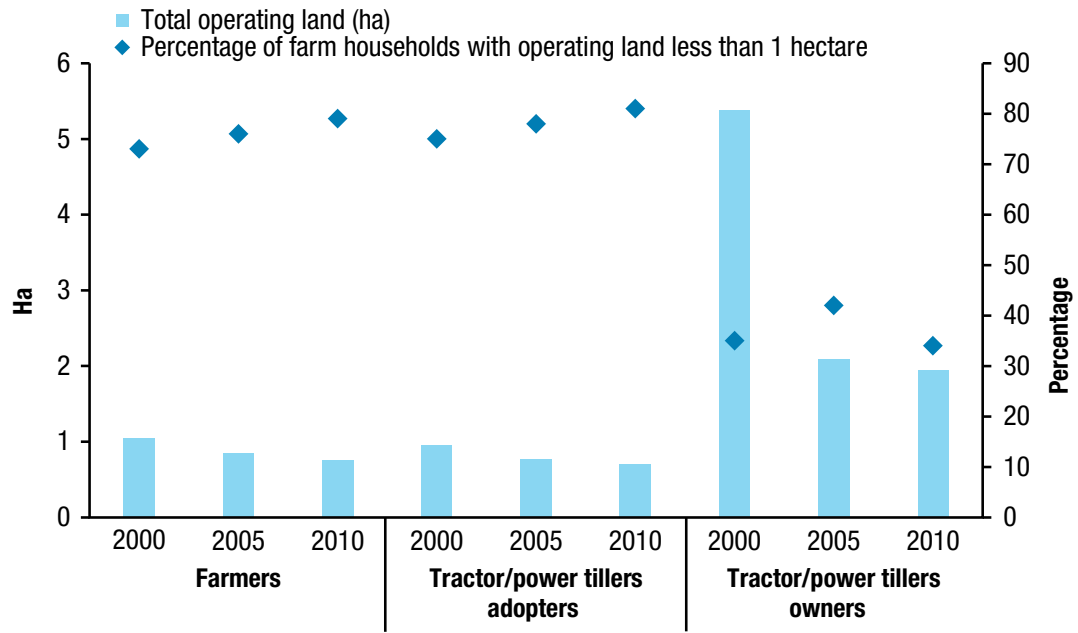

Source: Authors' own calculation using data from Household Income and Expenditure Surveys for 2000-2010. 
FIGURE 7.5 Percentage of owners hiring out their tractors/power tillers, Bangladesh, 2000-2010

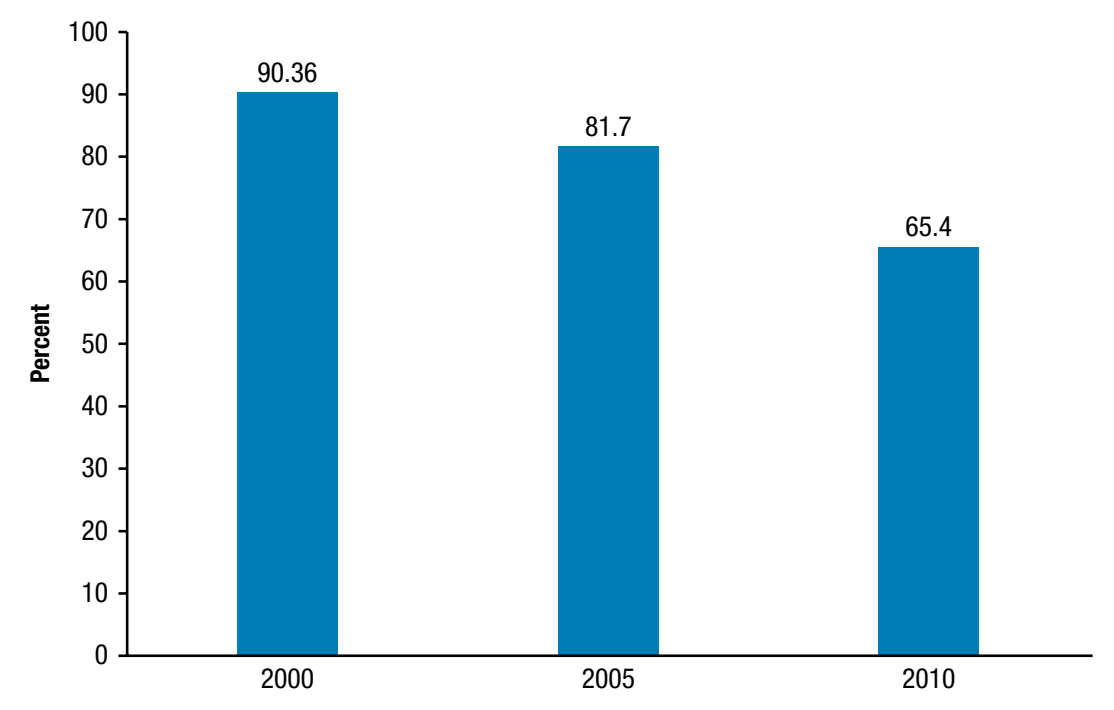

Source: Authors' own calculation using data from Household Income and Expenditure Surveys for 2000-2010.

agricultural machines and thus the average amount of operating land of the owning households has declined from more than 5 ha in 2000 to less than 2 ha in 2010 .

\section{Agroecological Conditions and Agricultural Mechanization}

The literature on farm mechanization often suggests that adoption of agricultural machinery is significantly related to the agroecological conditions and cropping patterns in a country. Despite minimal variation in agroecological conditions and cropping patterns across Bangladesh, we observe significant variation in adoption behaviors across the agroecological distribution of farm households. Although the longitudinal data show that mechanical adoption is increasing across agroclimatic conditions, these data also show that the share of adopter households is comparatively low in coastal regions, especially in the saline coast region. ${ }^{7}$ For example, in 2008 the adoption rate of tractors/ power tillers for land preparation in the saline coast was 76 percent, whereas

7 Mahaboob Hossain, the principal investigator of the survey, categorized sample villages into five different groups based on their agroclimatic conditions. The five agroclimatic conditions are flood-prone, drought-prone, saline coast, non-saline coast, and favorable (cited in Ahmed and Goodwin 2016). 
it was 89 percent in favorable and flood-prone regions (Figure 7.6). Farmers in drought-prone and non-saline coast regions are catching up quickly in terms of agricultural machinery adoption, with the shares of adopter farm households increasing much faster in these regions from 2000 to 2008 than in other regions. For example, the share of agricultural households that used tractors/ power tillers for land preparation in drought-prone zones increased from 51 percent in 2000 to 84 percent in 2008 . We see some variation in the adoption rates across administrative divisions, with rates ranging from 83 percent to 91 percent in 2008 (Figure 7.7). Sylhet division, especially, lagged in terms of adoption in early 2000 but caught up quickly with the rest of the country and increased its adoption rate from 43 percent in 2004 to 91 percent in 2008.

Table 7.3 reveals various characteristics of adopter (non-owner), owner, and non-adopter farm households across rural Bangladesh. The rate of adoption of agricultural machinery for land preparation increased consistently over the 2000s, from 56 percent in 2000 to 67 percent in 2010. The intensity of ownership also increased from 1.6 percent in 2000 to 2 percent in 2010 . The adoption rate of 67 percent, with the ownership rate of 2 percent, suggests a large role for the CHS market in the spread of agricultural mechanization in Bangladesh. More than 95 percent of farm households, most of which are smallholders, rely on CHS to get the necessary services for their farm production process.

The variation in demographic characteristics between adopter households and non-adopter households is also evident. The average age of adopter household heads is slightly lower compared with the non-adopter household heads, implying a tendency for agricultural machinery adoption to be higher among younger farmers. The adoption rate is lower among female-headed households, and access to the CHS market may be a constraining factor for these households. There is systematic variation in household sizes between the adopter and non-adopter households. Finally, non-Muslim farm households were initially slow to adopt agricultural machinery, but they caught up quickly.

Labor-land ratios have important implications for the growth of agricultural mechanization. Table 7.3 also reveals that labor shortage is, in fact, a key factor for agricultural mechanization in Bangladesh. The shortage highlights the need for agricultural mechanization and explains why smallholders rely on the CHS markets for the services of agricultural machines. Average labor endowment is much lower among adopter households compared with non-adopter households. For example, in 2010, adopter households had about 14,000 labor hours per hectare available, whereas non-adopter households had more than 31,000. Average labor endowment is even lower among owner 


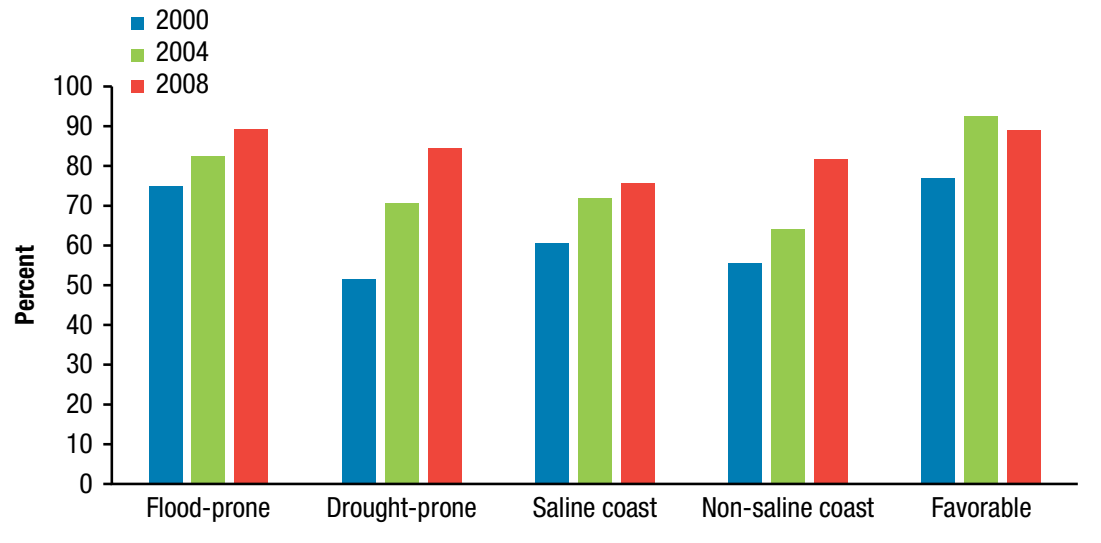

Source: Authors' own calculation using data from Ahmed and Goodwin (2016).

FIGURE 7.7 Mean adoption rate of tractors/power tillers by division, Bangladesh, 2000-2008

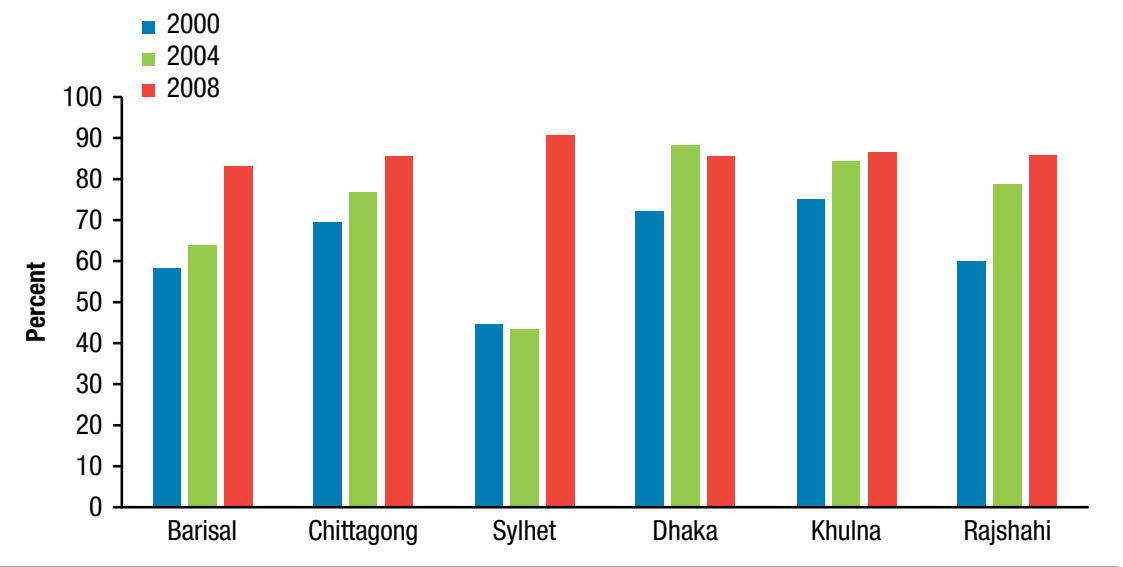

Source: Authors' own calculation using data from Ahmed and Goodwin (2016).

households, and these severe labor shortages may have driven them to own agricultural machines. This is consistent with the hypothesis that low labor endowment is one of the key factors that can explain the rise in smallholder mechanization demand.

There is no variation in terms of literacy among the heads of adopter and non-adopter households. Also, there is minimal variation in enterprise ownership, electricity access, and mobile phone use. The agricultural machinery 
TABLE 7.3 Characteristics of tractor/power tiller adopter and owner households, Bangladesh, 2000-2010

\begin{tabular}{|c|c|c|c|c|c|c|c|c|c|}
\hline \multirow[b]{2}{*}{ Variable } & \multicolumn{3}{|c|}{ HIES 2000} & \multicolumn{3}{|c|}{ HIES 2005} & \multicolumn{3}{|c|}{ HIES 2010} \\
\hline & $\begin{array}{l}\text { Non- } \\
\text { adopter } A\end{array}$ & Adopter & Owner & $\begin{array}{l}\text { Non- } \\
\text { adopter }\end{array}$ & r Adopter & Owner & $\begin{array}{l}\text { Non- } \\
\text { adopter }\end{array}$ & Adopter & Owner \\
\hline Percentage of households & 44.43 & 55.57 & 1.57 & 38.02 & 61.98 & 1.97 & 32.76 & 67.24 & 2.04 \\
\hline Age of head & 47 & 45 & 50.51 & 48 & 47 & 53.52 & 49 & 47 & 50.01 \\
\hline Female head (yes $=1$ ) & 0.06 & 0.03 & 0.02 & 0.14 & 0.05 & 0.01 & 0.20 & 0.07 & 0.04 \\
\hline Household size & 5.65 & 5.43 & 7.98 & 4.43 & 4.69 & 6.11 & 4.49 & 4.85 & 5.50 \\
\hline Religion (non-Muslim = 1) & 0.11 & 0.06 & 0.04 & 0.13 & 0.12 & 0.08 & 0.13 & 0.12 & 0.07 \\
\hline Employed workers per ha & 14.75 & 4.72 & 2.06 & 14.26 & 5.43 & 2.12 & 12.46 & 5.91 & 3.11 \\
\hline Ag. labor per ha & 6.59 & 1.92 & 0.17 & 3.76 & 1.86 & 0.11 & 2.94 & 1.94 & 0.54 \\
\hline Ag. farmers per ha & 11.14 & 3.63 & 1.61 & 1.39 & 2.48 & 1.68 & 1.50 & 2.55 & 2.50 \\
\hline Non-ag. labor per ha & 4.69 & 1.21 & 0.22 & 4.44 & 0.88 & 0.08 & 3.95 & 1.19 & 0.10 \\
\hline Annual work hours per ha & 39,687 & 11,888 & 4,985 & 35,293 & 12,535 & 3,972 & 31,382 & 13,694 & 6,675 \\
\hline Literacy of head (yes = 1) & 0.42 & 0.42 & 0.63 & 0.48 & 0.42 & 0.59 & 0.52 & 0.43 & 0.55 \\
\hline Enterprise (yes $=1$ ) & 0.22 & 0.26 & 0.28 & 0.23 & 0.22 & 0.31 & 0.24 & 0.24 & 0.26 \\
\hline Electricity (yes $=1$ ) & 0.19 & 0.20 & 0.26 & 0.36 & 0.34 & 0.45 & 0.50 & 0.44 & 0.57 \\
\hline Mobile phone (yes = 1) & 0.00 & 0.00 & 0.00 & 0.10 & 0.06 & 0.15 & 0.66 & 0.62 & 0.90 \\
\hline Aus (yes $=1$ ) & 0.21 & 0.22 & 0.19 & 0.13 & 0.17 & 0.28 & 0.09 & 0.15 & 0.22 \\
\hline Aman $($ yes $=1)$ & 0.50 & 0.68 & 0.83 & 0.32 & 0.63 & 0.68 & 0.20 & 0.64 & 0.73 \\
\hline Boro (yes = 1) & 0.48 & 0.78 & 0.74 & 0.32 & 0.80 & 0.81 & 0.20 & 0.79 & 0.79 \\
\hline Wheat (yes = 1) & 0.15 & 0.17 & 0.33 & 0.05 & 0.10 & 0.26 & 0.04 & 0.11 & 0.20 \\
\hline Jute (yes $=1$ ) & 0.09 & 0.16 & 0.20 & 0.07 & 0.18 & 0.28 & 0.06 & 0.23 & 0.38 \\
\hline Other (yes $=1$ ) & 0.54 & 0.59 & 0.79 & 0.35 & 0.52 & 0.76 & 0.50 & 0.94 & 0.93 \\
\hline Forest (yes = 1) & 0.70 & 0.69 & 0.78 & 0.23 & 0.37 & 0.47 & 0.42 & 0.52 & 0.72 \\
\hline Fish $($ yes $=1)$ & 0.23 & 0.22 & 0.45 & 0.11 & 0.22 & 0.25 & 0.17 & 0.24 & 0.28 \\
\hline Livestock (yes = 1) & 0.88 & 0.87 & 0.98 & 0.25 & 0.43 & 0.46 & 0.75 & 0.90 & 0.93 \\
\hline Cattle/buffalo per ha & 5.49 & 2.92 & 1.54 & 4.81 & 3.91 & 2.61 & 4.58 & 4.76 & 5.97 \\
\hline $\begin{array}{l}\text { Own cultivated land (dec- } \\
\text { imals) }\end{array}$ & 153 & 132 & 740 & 129 & 123 & 410 & 109 & 105 & 345 \\
\hline $\begin{array}{l}\text { Total operating land (dec- } \\
\text { imals) }\end{array}$ & 288 & 237 & 1,384 & 234 & 192 & 535 & 213 & 171 & 501 \\
\hline
\end{tabular}

Source: Authors' own calculation using data from Household Income and Expenditure Surveys for 2000-2010.

Note: HIES = Household Income and Expenditure Survey. 
adoption rate is generally very high among boro (spring rice) and aman (rainy-season rice) producers, but quite low among aus (dry-season rice) producers; adoption of agricultural machines is also low among the farm households that produce wheat and jute. The farm households that are involved in forestry, fisheries, and livestock are more likely to adopt agricultural machinery in their farm production processes. Cattle and buffalo are generally used for traditional cultivation processes, and Table 7.3 reveals that, especially in 2000 and 2005, the farm households that adopt agricultural machinery own fewer of these animals than the farm households that do not adopt agricultural machinery.

In this section, we have seen that farm households hiring agricultural machinery own and operate a smaller area of cultivable land than the machine-owning households. Table 7.3 also shows that machinery-using farm households own or operate less land than the non-adopter farm households, implying a fast rate of adoption among smallholders.

\section{Drivers of Mechanization Adoption}

This section discusses the empirical evidence on the factors playing an important role in agricultural mechanization growth in Bangladesh (Appendix 7A describes the econometric models used).

Table 7.4 presents the results on the adoption and ownership of tractors, power tillers, or both, using equation (1) in the appendix. The first six columns present results on adoption decisions from each of three rounds (HIES 2000,2005 , and 2010), and the last six columns present results on ownership decisions of farm households from the same three rounds. In general, youths are more inclined to adopt new technologies than their elder counterparts, and the age of household heads is negatively correlated with adoption in 2000 and 2010. However, age is generally not an important factor in explaining the ownership of agricultural technologies. Among other demographic variables, household size is an important determinant of adoption and ownership of agricultural machinery. A large household often implies a joint family with large land and financial endowments, which make such a family more likely to own and adopt agricultural technologies, compared with singlefamily farm households. Gender also plays an important role in the adoption of agricultural technologies. Female-headed households are less likely to adopt agricultural machinery, which may be due to a lack of gender-friendly social norms-especially toward female workers in agricultural activities-and a lack of management skills. 


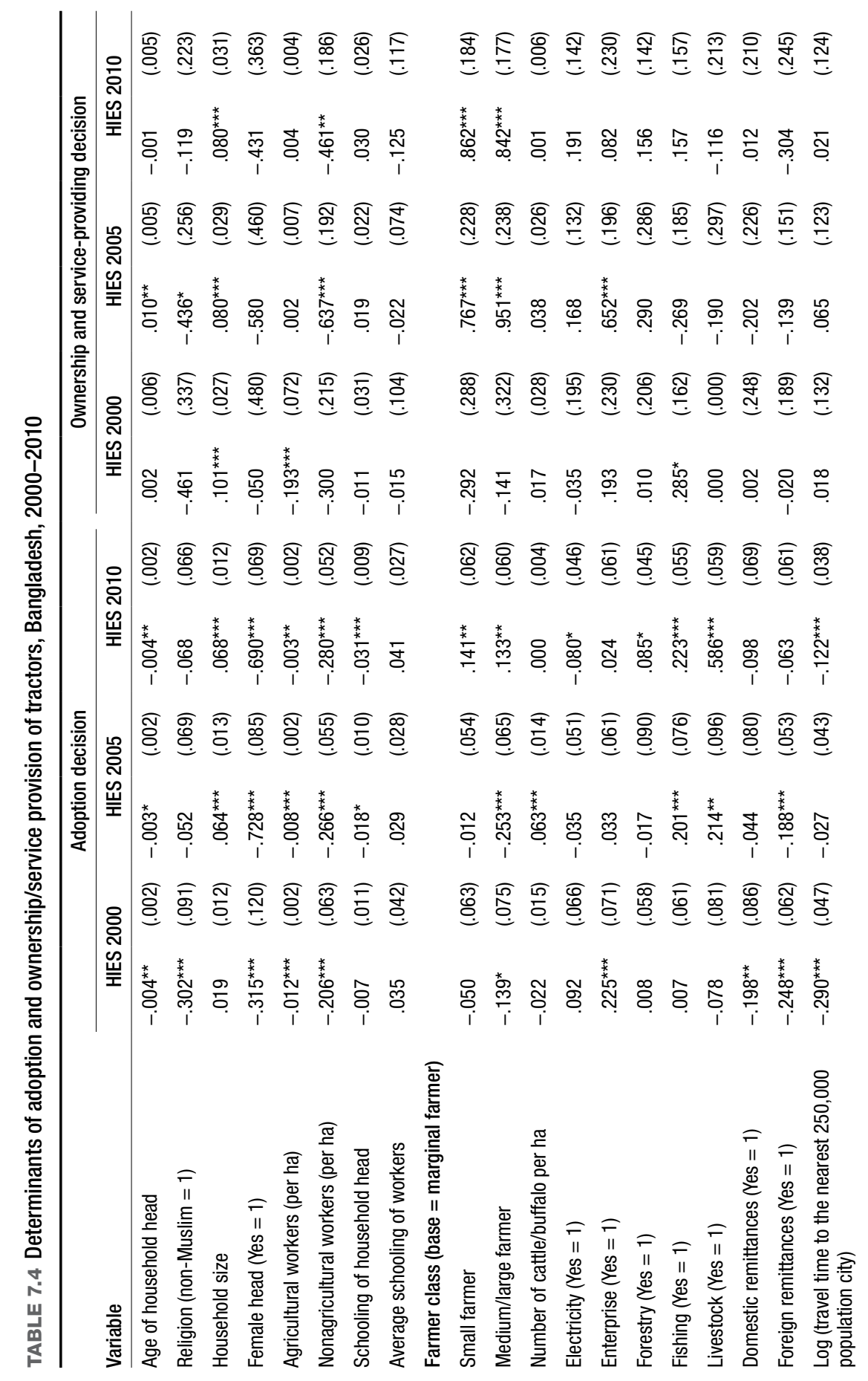




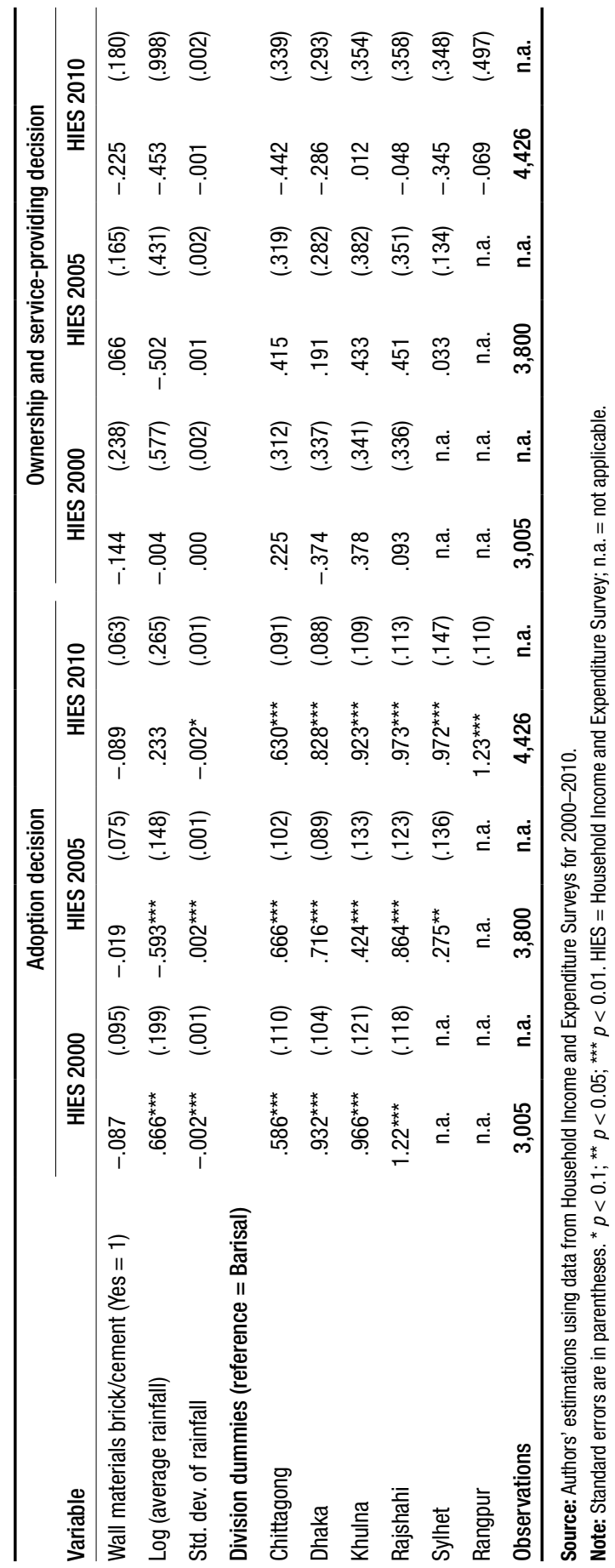


Households with high labor endowments of both farm and nonfarm workers are less likely to adopt and own agricultural machinery. Agricultural machines in Bangladesh are generally labor-saving technologies, and thus households with an excess labor endowment do not have a strong need to adopt mechanized agricultural processes unless there are high opportunity costs from engaging labor in farm activities. The results suggest that schooling, especially overall education levels of all household workers, plays a limited role in the adoption of agricultural machinery. Supporting this result, Ahmed and Goodwin (2016) found that the education of working household members was not an important driver of technology adoption in rural farm households.

Effects of farm size on adoption are somewhat ambiguous, reflecting the possibility that some smallholders may be more productive than larger farmers, if returns on machine use intensity per unit of land are sufficiently high. Households with large farms are still more likely to be the owners of farming machinery, compared with smallholder households, and it is the CHS market that brings the services of agricultural machinery to the doorsteps of smallholder farm households. The role of households' orientation toward high-value crop production (for example, livestock or fisheries) in the adoption of agricultural machinery has also become more significant over time. The receipt of remittances, both foreign and domestic, has not come out as an important driver of either adoption or ownership of agricultural machinery, even in later years; indeed, in earlier years the effects were negative. This might indicate that liquidity constraints were not binding on machine adoption, and remittances would even substitute for higher agricultural incomes from intensification. The role of rainfall and its variability has changed over the years, possibly because, over the years, the frontier of machine-use adoption moved from favorable areas to more marginal areas with very different hydrological conditions and thus farming systems.

The clear demarcation between the advanced urban economy and the rural farm economy has been disappearing rapidly due to infrastructure development in recent decades. Therefore, the overall business climate in rural areas has improved significantly. Improved connectivity has been an important driver of the adoption of agricultural machinery in rural areas. The results indicate that distance (measured by travel time) to a big city (with a population of 250,000 or more) is negatively associated with the rate of machine adoption. Across regions, our regression results show minimal variation in machinery ownership but significant variation in overall machinery adoption. Barisal division has the lowest rate of agricultural machinery adoption, 
whereas the adoption rate is quite high in the Rajshahi, Rangpur, and Sylhet divisions.

Table 7.5 shows the results from equation (2) in the appendix. Most of the results from the panel survey regressions are in line with our findings from the HIES data. Higher dependency ratios among the rural households induce households to adopt agricultural machinery. Education (particularly higher levels), as in the earlier results, does not stand out as an important driver of agricultural machinery use. High intensity of nonagricultural workers among rural households induces them to adopt labor-saving agricultural technologies. Agricultural mechanization is also strongly positively associated with the share of irrigated land of rural farm households. Crop diversification generally supports agricultural mechanization among rural farm households. The results also confirm that connectivity, measured as distance from Dhaka in kilometers, and access to electricity are important for the rural farm households in their machine adoption decisions.

The panel regressions provide some new insights because of new determinants available in the data. Soil type and village ecological conditions come out as important factors in the adoption of agricultural machinery among rural farm households. Adoption rates are high among households with a higher amount of clay loam, loam, and sandy loam land; farm households with sandy land are less likely to adopt agricultural machinery. Farm households in flood-prone areas are most likely to adopt labor-saving agricultural technologies, followed by the farm households in favorable zones and droughtprone zones. The adoption rate is much lower in both saline and non-saline coastal zones.

\section{Impact of Agricultural Mechanization on Nonfarm Labor Supply and Agricultural Productivity}

Policymakers and development economists have long been cautious about promoting agricultural mechanization in densely populated countries with surplus labor, due to its potential displacement of labor and tenant farmers. However, existing evidence suggests minimal labor displacement effects occur from power-intensive agricultural operations such as tillage, water lifting, and milling (Pingali 2007). Therefore, agricultural mechanization has been a focus in many densely populated countries such as Bangladesh and India.

Agricultural mechanization can enhance agricultural productivity in three ways: (1) improvement in crop yields, (2) cultivation area expansion, and (3) agricultural labor savings. Early literature on agricultural mechanization 
TABLE 7.5 Determinants of adoption of tractors and/or power tillers, Bangladesh, 2000-2008

\begin{tabular}{lcccc}
\hline Variable & \multicolumn{2}{c}{ Unbalanced panel } & \multicolumn{2}{c}{ Balanced panel } \\
\hline Head is female (Yes $=1)$ & -.054 & $(.323)$ & -.167 & $(.412)$ \\
Log (head age) & .203 & $(.227)$ & -.203 & $(.300)$ \\
Log (dependency ratio) & $.196^{\star \star \star}$ & $(.061)$ & $.209^{\star \star \star}$ & $(.078)$ \\
Dummy of head with primary education & -.061 & $(.063)$ & $-.167^{\star \star}$ & $(.080)$ \\
Dummy of head with secondary education & .020 & $(.128)$ & -.128 & $(.148)$ \\
Dummy of head with SSC and above education & .099 & $(.210)$ & -.111 & $(.244)$ \\
Any female worker in the HH? & -.210 & $(.215)$ & -.325 & $(.267)$ \\
Share of nonagricultural workers in the HH & $.178^{\star \star}$ & $(.073)$ & $.240^{\star \star}$ & $(.098)$ \\
Proportion of irrigated land & $.749^{\star \star \star}$ & $(.074)$ & $.704^{\star \star \star}$ & $(.104)$ \\
Proportion of rented/sharecropped land & $.367^{\star}$ & $(.192)$ & .254 & $(.240)$ \\
Crop diversification index & $.457^{\star \star \star}$ & $(.125)$ & $.372^{\star \star}$ & $(.161)$ \\
Fragmentation index & .032 & $(.174)$ & .272 & $(.217)$ \\
Proportion of high land in total cultivated land & .021 & $(.142)$ & .033 & $(.175)$ \\
Proportion of medium land in total cultivated land & $-.207^{\star \star}$ & $(.105)$ & -.202 & $(.138)$ \\
Proportion of low land in total cultivated land & -.189 & $(.153)$ & -.180 & $(.188)$ \\
Proportion of loamy land in total cultivated land & $.568^{\star \star *}$ & $(.162)$ & $.513^{\star \star}$ & $(.205)$ \\
Proportion of sandy loam land in total cultivated land & $.439^{\star \star *}$ & $(.158)$ & $.410^{\star \star}$ & $(.201)$ \\
Proportion of clay loam land in total cultivated land & $.869^{\star \star *}$ & $(.165)$ & $.795^{\star \star *}$ & $(.208)$
\end{tabular}

found no evidence of yield differences between draft animal power and power tillage (Binswanger 1978; Herdt 1983). However, agricultural mechanization does help to improve the technical efficiency of farmers (Hormozi, Asoodar, and Abdeshahi 2012). Area expansion, substitution for labor shortages, and labor savings are other motivations for power-intensive operations in agricultural production. However, in a densely populated country like Bangladesh, the potential for cultivable land expansion is extremely limited because the amount of arable land per agricultural worker is tiny; for example, there was just 0.26 ha per worker from 2006 to 2011 in Bangladesh.

The empirical literature on the productivity effects of agricultural mechanization indicates that labor savings are the primary source of productivity gains from power-intensive agricultural operations (Pingali, Bigot, and Binswanger 1987). Given the limited scope of area expansion, labor savings or labor shortages are likely the primary factors motivating power-intensive agricultural operations in Bangladesh. Ahmed and Goodwin (2016) found that rural farm households that adopted labor-saving technology participated more 


\begin{tabular}{lcccc} 
Variable & \multicolumn{2}{c}{ Unbalanced panel } & \multicolumn{2}{c}{ Balanced panel } \\
\hline CV of rainfall in last 10 years & -.003 & $(.006)$ & -.003 & $(.008)$ \\
Log (distance from Dhaka in km) & $-.217^{\star \star}$ & $(.098)$ & -.208 & $(.132)$ \\
Access to electricity (Yes = 1) & $.231^{\star \star \star}$ & $(.061)$ & $.201^{\star \star}$ & $(.079)$ \\
Village ecology (base = flood-prone) & & & & \\
Drought-prone & $-.576^{\star \star \star}$ & $(.120)$ & $-.715^{\star \star \star}$ & $(.166)$ \\
Saline coast & $-.957^{\star \star \star}$ & $(.146)$ & $-.923^{\star \star \star}$ & $(.202)$ \\
Non-saline coast & $-.895^{\star \star \star}$ & $(.169)$ & $-.860^{\star \star \star}$ & $(.227)$ \\
Favorable & -.134 & $(.100)$ & $-.253^{\star}$ & $(.135)$ \\
Year dummy (base $=2000)$ & & & & \\
2004 & $.425^{\star \star \star}$ & $(.065)$ & $.418^{\star \star \star}$ & $(.084)$ \\
2008 & $.594^{\star \star *}$ & $(.085)$ & $.723^{\star \star \star}$ & $(.113)$ \\
Landownership (base $=$ marginal farmer, & & & & \\
less than 0.40 ha) & & & & \\
Small farmer, 0.41-1.00 ha & -.046 & $(.072)$ & .003 & $(.092)$ \\
Medium or large farmer, 1.00+ ha & -.060 & $(.093)$ & -.030 & $(.116)$ \\
Observations & 3,308 & n.a. & 2,070 & n.a. \\
Log-likelihood & & & & \\
\hline
\end{tabular}

Source: Authors' estimations using data from Ahmed and Goodwin (2016).

Note: Standard errors are in parentheses. ${ }^{\star} p<0.1,{ }^{\star \star} p<0.05,{ }^{\star \star \star} p<0.01 . \mathrm{CV}=$ coefficient of variation; HH $=$ household; n.a. $=$ not applicable; $S S C=$ secondary school certificate.

in and supplied more labor to the nonfarm sector, when compared with farm households that did not use agricultural machinery.

Ahmed and Goodwin (2016) studied the nonfarm labor supply behavior of farm households in rural Bangladesh using a unique longitudinal dataset. Table 7.6 presents the results from Ahmed and Goodwin (2016); the first two columns present marginal effects from a probit model that examined the nonfarm labor market participation of farm households due to agricultural mechanization, and the last two columns present results from a linear regression model that examined the changes in levels of nonfarm labor supply due to agricultural mechanization. Both regressions controlled for a range of other relevant covariates such as demographics, schooling, and land. The results from the probit model suggest that, when controlling for other relevant factors, rural farm households that have adopted agricultural mechanization are 25 percent more likely to participate in the nonfarm labor market than are non-adopter farm households. Similarly, the results from the linear regression show that mechanized farm households supply, on average, 24 labor-days 
TABLE 7.6 Probit model and linear regression models (including correlated random effects variables)

\begin{tabular}{|c|c|c|c|c|}
\hline \multirow[b]{2}{*}{ Variable } & \multicolumn{2}{|c|}{ Probit model } & \multicolumn{2}{|c|}{$\begin{array}{c}\text { Nonfarm labor supply } \\
\text { equation }\end{array}$} \\
\hline & Mar. eff. & Std. err. & Coeff. & Std. err. \\
\hline Mechanized (yes = 1) & $0.255^{\star \star \star}$ & $(0.083)$ & $23.790^{\star \star}$ & $(9.260)$ \\
\hline Age of household head & -0.004 & $(0.006)$ & -0.298 & $(0.799)$ \\
\hline Household size & $0.062^{\star \star \star}$ & $(0.023)$ & 3.750 & (2.918) \\
\hline \multicolumn{5}{|l|}{$\begin{array}{l}\text { Labor endowment dummies (ref: single } \\
\text { working member) }\end{array}$} \\
\hline Two adult workers & $0.217^{\star \star}$ & $(0.103)$ & $37.128^{\star \star \star}$ & $(12.723)$ \\
\hline Three adult workers & $0.342^{\star \star}$ & $(0.167)$ & $87.527^{\star \star \star}$ & $(21.861)$ \\
\hline Female participation in labor force (yes $=1$ ) & $0.240^{\star}$ & $(0.141)$ & 22.229 & $(18.830)$ \\
\hline Log (total schooling years of workers) & 0.028 & $(0.020)$ & $3.661^{*}$ & (1.937) \\
\hline \multicolumn{5}{|l|}{$\begin{array}{l}\text { Land endowment dummies (ref: marginal } \\
\text { landowner, }<0.4 \text { ha) }\end{array}$} \\
\hline Small landowner ( $\geq 0.4$ ha and $<1.0$ ha) & -0.013 & $(0.099)$ & 0.415 & (11.922) \\
\hline Medium landowner ( $\geq 1.0$ ha and $<2.0 \mathrm{ha}$ ) & 0.059 & $(0.129)$ & -4.837 & $(15.814)$ \\
\hline Large landowner ( $\geq 2.0 \mathrm{ha})$ & $0.347^{\star}$ & $(0.184)$ & 28.082 & (24.283) \\
\hline NG0 membership (yes = 1) & $0.340^{\star \star \star}$ & $(0.074)$ & $32.485^{\star \star \star}$ & (8.493) \\
\hline Log (gross margin of farming in 2008 BDT) & 0.009 & $(0.038)$ & -0.071 & $(4.750)$ \\
\hline Fragmentation index & -0.224 & $(0.213)$ & $-59.365^{\star \star}$ & (23.835) \\
\hline Cropping intensity & 0.061 & $(0.117)$ & -0.186 & $(12.787)$ \\
\hline
\end{tabular}

more to the nonfarm labor market than do nonmechanized farm households. Generally, labor productivity is higher in nonfarm activities, and thus agricultural mechanization leads to increased incomes for the farm households through their increased participation in nonfarm-sector activities. The continuous tightening of rural labor markets in Bangladesh is likely to further support the nonfarm wage income effect on agricultural mechanization.

\section{Conclusions}

Mechanization in Bangladesh, particularly the spread of tractor use for land preparation, has grown in the last several decades. This is despite Bangladesh's having one of the smallest average farm sizes in the region and an abundant rural labor force. Several key lessons from the Bangladesh experience may be applicable to African countries. 


\begin{tabular}{|c|c|c|c|c|}
\hline \multirow[b]{2}{*}{ Variable } & \multicolumn{2}{|c|}{ Probit model } & \multicolumn{2}{|c|}{$\begin{array}{l}\text { Nonfarm labor supply } \\
\text { equation }\end{array}$} \\
\hline & Mar. eff. & Std. err. & Coeff. & Std. err. \\
\hline Year dummy $(2008=1)$ & $-0.223^{\star \star \star}$ & $(0.077)$ & -1.448 & $(8.891)$ \\
\hline \multicolumn{5}{|l|}{$\begin{array}{l}\text { Correlated effects variables (group means of } \\
\text { the variables) }\end{array}$} \\
\hline Age of household head & -0.002 & $(0.007)$ & 0.292 & $(0.963)$ \\
\hline Household size & -0.225 & $(0.160)$ & -2.680 & $(18.425)$ \\
\hline Total adult workers & $0.139^{\star}$ & $(0.081)$ & 10.235 & $(10.416)$ \\
\hline Log (total schooling years of workers) & 0.035 & $(0.022)$ & $6.116^{\star \star \star}$ & (2.294) \\
\hline Log (total landownership) & $-0.085^{\star \star}$ & $(0.041)$ & -4.836 & $(4.801)$ \\
\hline Log (gross margin of farming in 2008 BDT) & $-0.092^{*}$ & $(0.054)$ & -7.904 & $(6.677)$ \\
\hline Fragmentation index & -0.180 & $(0.252)$ & -22.662 & $(30.109)$ \\
\hline Cropping intensity & 0.122 & $(0.135)$ & 22.831 & $(16.224)$ \\
\hline Constant & 0.080 & $(0.281)$ & $87.174^{\star \star \star}$ & $(31.932)$ \\
\hline Wald chi²(21) / F(21, 1,669) & $206.7^{\star \star \star}$ & $\begin{array}{c}12.62 \\
(p-v a l= \\
0.000)\end{array}$ & & \\
\hline R-squared/pseudo R-squared & 0.084 & 0.15 & & \\
\hline Observations & 1,691 & & & \\
\hline
\end{tabular}

Source: Authors' estimations using data from Ahmed and Goodwin (2016).

Note: The results came from pooled regressions using a correlated random effects approach, which allows for fixed-effects estimates of variables that vary across households and over time. BDT = Bangladeshi taka; $\mathrm{NGO}=$ nongovernmental organization.

First, early spread of tractor use for land preparation was primarily led by technological factors, at least up until the mid-2000s. Since the 1970s, significant investments in agricultural research and development, including plant breeding, have led to higher demand for intensive farm power for land preparation, even on small plots of land. This effect was so strong that by the early 1990s, the intensity of draft animal power use had already far exceeded the levels in Africa today. Such an increase in demand was a critical precondition for the subsequent spread of tractor use from the late 1990s onward. The liberalization of power tiller imports in the early 1990s successfully led to increased power tiller use, but had the demand for power not reached a sufficient level at that time, we may not have seen the same effect.

The effects of wages on mechanization were relatively limited during this early takeoff stage. However, in the 2000s, as economic transformation continued and real wages rose, mechanization spread even further. At this stage, 
mechanization was associated with farm households' increasing participation in nonfarm income-earning activities. As is indicated by the empirical results, it was at this point that mechanization became labor-substituting.

Given the fact that Bangladesh's small farm sizes prevented machinery ownership from being profitable for most farms, it is clear that the CHS market played a critical role in the spread of agricultural mechanization. The CHS market helped increase both adoption and ownership of agricultural machinery by decoupling farm size from use and ownership of machinery. Though the government has not been directly involved in the importation and supply of agricultural machinery, it has provided important support through the liberalization of tariffs on agricultural equipment imports. It has also granted subsidies and tax exemptions to local producers of agricultural machinery and to private businesses importing and selling agricultural machines and tools, as well as those engaging in fabrication, adaption, or manufacturing of spare parts, attachments, and power tillers.

The results and discussions in this chapter have important implications for further agricultural mechanization in Bangladesh. Favorable policy supports along with skills training could help to spread agricultural mechanization to other agricultural activities such as weeding, harvesting, and threshing. The $\mathrm{CHS}$ model can be further promoted through policies supporting the use of high-cost farm machinery such as combine harvesters, thereby making them viable options.

\section{References}

Ahmed, A. 2013. "Farm Mechanization in Bangladesh: Evidence from IFPRI National Household Survey." Presentation at workshop Rural Mechanization: Policy and Technology Lessons from Bangladesh and Other Asian Countries, Dhaka, March 7-8.

Ahmed, M., and B. Goodwin. 2016. "The Agricultural Mechanization and Nonfarm Labor Supply Behavior of Farm Households in Bangladesh.” Paper presented at 2016 annual conference of Agricultural and Applied Economics Association, Boston, July 31-August 2.

Ahmed, R. 2001. Recent Developments in Mechanized Cultivation: Emerging Issues in the Agriculture of Bangladesh. FMRSP Working Paper No. 33. Dhaka: Bangladesh Food Management and Research Support Project, Ministry of Food, Government of the People's Republic of Bangladesh.

Alam, M. M. 2005. Identification of SMEs and BDS Providers and Analysis of Supply and Value Chain in Agri-Machinery Sub-Sector of Bangladesh. Dhaka: South Asia Enterprise Development Facility. 
Alam, M. M., and I. N. Khan. 2017. "Status of Agricultural Machinery Manufacturing in Bangladesh." In Rural Mechanization: A Driver in Agricultural Change and Rural Development, edited by S. Mandal, S. Biggs, and S. Justice. Dhaka: Institute for Inclusive Finance and Development.

Animaw, A. T., J. A. M. Nkanya, J. M. Nyakiba, T. H. Woldemariam, and H. Takeshima. 2016. Agricultural Mechanization and South-South Knowledge Exchange: What Can Ethiopian and Kenyan Policymakers Learn from Bangladesh's Experience? Ethiopia Strategy Support Program Policy Note 47. Washington, DC: International Food Policy Research Institute.

BBS (Bangladesh Bureau of Statistics). 2010. Reports on Household Income and Expenditure Survey (HIES) for 2000, 2005 and 2010. Dhaka.

Bhattarai, M., Md. Saidur Rahman, P. K. Joshi, and H. Takeshima. 2017. Custom Hiring Services of Farm Machines in Bangladesh: Business Model Analysis. Unpublished report, International Food Policy Research Institute, Washington, DC.

Biggs, S., and S. Justice. 2013. "Rural and Agricultural Mechanization in Bangladesh and Nepal: Status, Processes and Outcomes." In Mechanization for Rural Development: Integrated Crop Management - A Review of Patterns and Progress from Around the World, edited by J. Kienzle, J. Ashburner, and B. Sims. Rome: Food and Agriculture Organization of the United Nations.

Binswanger, H. P. 1978. The Economics of Tractors in South Asia. New York: Agricultural Development Council; Hyderabad, India: International Crops Research Institute for the Semi-Arid Tropics.

Chamberlain, G. 1984. "Panel Data." In Handbook of Econometrics. Vol. 2, edited by Z. Grilliches and M. D. Intriligator, 1247-1318. Amsterdam: North-Holland.

CSAM (Centre for Sustainable Agricultural Mechanization). 2014. "Country Pages.” Accessed July 2. http://un-csam.org/cp_index.htm.

FAO (Food and Agriculture Organization of the United Nations). 2018. AQUASTAT database. Rome. www.fao.org/land-water/databases-and-software/aquastat/en/.

Herdt, R. 1983. "Mechanization of Rice Production in Developing Asian Countries: Perspective, Evidence and Issues." In Consequences of Small-Farm Mechanization. Los Baños, Philippines: International Rice Research Institute.

Hormozi, M. A., M. A. Asoodar, and A. Abdeshahi. 2012. "The Impact of Mechanization on Technical Efficiency: A Case Study of Rice Farmers in Iran." Procedia Economics and Finance 1: 176-185. 
Hossain, M., D. Gollin, V. Camanilla, E. Cabrera, N. Johnson, G. S. Kush, and G. McLaren. 2003. "International Research and Genetic Improvement in Rice: Evidence from Asia and Latin America." In Crop Variety Improvement and Its Effect on Productivity: The Impact of International Agricultural Research, edited by R. Evenson and D. Gollin. Wallingford, UK: Centre for Agriculture and Bioscience International.

IRRI (International Rice Research Institute). 1986. Small Farm Equipment for Developing Countries. Los Baños, Philippines.

Mandal, M. A. S. 2002. "Agricultural Machinery Manufacturing and Farm Mechanization: A Case of Rural Nonfarm Economic Development in Bangladesh." Paper presented at international workshop Fostering Rural Economic Development through Agriculture-Based Enterprises and Services, Berlin, November 19-22.

Mandal, M. A. S., S. Biggs, and S. Justice. 2017. "Rural Mechanization: A Driver in Agricultural Change and Rural Development." Dhaka, Bangladesh: Institute for Inclusive Finance and Development.

Mandal, M. A. S., and D. E. Parker. 1995. The Evolution and Implications of Decreased Public Involvement in Minor Irrigation Management in Bangladesh. IWMI Report 16921. Colombo, Sri Lanka: International Water Management Institute.

Meisner, C. A., A. Sufian, E. Baksh, M. Smith O’Donoghue, M. A. Razzaque, and N. K. Shaha. 2003. "Whole Family Training and Adoption of Innovations in Wheat-Producing Households in Bangladesh." Journal of Agriculture Education and Extension 9: 165-176.

Mottaleb, K. A., T. J. Krupnik, and O. Erenstein. 2016. "Factors Associated with Small-Scale Agricultural Machinery Adoption in Bangladesh: Census Findings.” Journal of Rural Studies 46: $155-168$.

Mottaleb, K. A., D. B. Rahut, A. Ali, B. Gérard, and O. Erenstein. 2017. “Enhancing Smallholder Access to Agricultural Machinery Services: Lessons from Bangladesh." Journal of Development Studies 53 (9): 1502-1517.

Orr, A. 2012. "Why Were So Many Social Scientists Wrong about the Green Revolution? Learning from Bangladesh.” Journal of Development Studies 48 (11): 1565-1586.

Pingali, P. 2007. “Agricultural Mechanization: Adoption Patterns and Economic Impact.” In Handbook of Agricultural Economics. Vol. 3, edited by R. Evenson and P. Pingali, 2779-2805. Amsterdam: Elsevier.

Pingali, P. L., Y. Bigot, and H. Binswanger 1987. Agricultural Mechanization and the Evolution of Farming Systems in Sub-Saharan Africa. Washington, DC: World Bank.

Roy, K. C., and G. Singh. 2008. “Agricultural Mechanization in Bangladesh.” Agricultural Mechanization in Asia, Africa and Latin America 39 (2): 83-93. 
Takeshima, H., and A. Maji. 2016. Varietal Development and the Effectiveness of Seed Sector Policies: The Case of Rice in Nigeria. IFPRI Nigeria Strategy Support Program Working Paper 34. Washington, DC: International Food Policy Research Institute.

USDA (United States Department of Agriculture). 2018. Economic Research Service Agricultural Productivity Project. Washington, DC.

Witcombe, J., S. Gyawali, M. Subedi, D. S. Virk, and K. D. Joshi. 2013. "Plant Breeding Can Be Made More Efficient by Having Fewer, Better Crosses." BMC Plant Biology 13: 1-12.

World Bank. 2018. World Development Indicators. Washington, DC.

Zhang, X., S. Rashid, K. Ahmad, and A. Ahmed. 2014. "Escalation of Real Wages in Bangladesh: Is It the Beginning of Structural Transformation?” World Development 64: 273-285.

\section{Appendix 7A: Empirical Models on Mechanization Adoption}

The econometric model is guided by the descriptive analysis in the previous sections and uses the HIES cross-sectional data in the following probit specification:

$$
P_{i}=\alpha+\beta X_{i}+\varepsilon_{i},
$$

where $P_{i}$ is the adoption or the ownership and service provision of tractors, power tillers, or both by the $i$ th household, $X_{i}$ is a vector of household and worker characteristics, and $\varepsilon_{i}$ is the error term.

We complement (1) with another model using a unique panel dataset available for 2000, 2004, and 2008 (Ahmed and Goodwin 2016). The panel survey observes rural households from 62 villages to study their poverty, income, and productivity dynamics. Only farm households are considered in the regressions. Here, we use adoption of tractors, power tillers, or both in land preparation for agricultural production as a proxy for the adoption of overall agricultural machinery. Specifically, we estimate

$$
P_{i t}=\alpha+\beta X_{i t}+\rho_{t}+\varepsilon_{i t}
$$

where $P_{i t}$ denotes the adoption of agricultural machinery by the $i$ th household in year $t . X_{i t}$ is a vector of household and worker characteristics, year-specific effects are represented by $\rho_{t}$, and $\varepsilon_{i t}$ represents the idiosyncratic normally distributed error terms.

Importantly, the agent simultaneously makes decisions on other relevant aspects, such as landownership, taking of credit or loans, whether to own 
other agricultural equipment (such as threshing machines, motor pumps, deep or shallow tube wells, sprayers, husking machines, and ginning machines), and whether to use other modern inputs such as improved varieties. Estimating (1) and (2) as part of the system of equations that simultaneously estimate the determinants of these outcomes often leads to less biased and more consistent and efficient estimations of the determinants of mechanization-related outcomes, which are our primary interests. We therefore estimate (1) and (2) as multivariate probit models. In particular, (2) is estimated by combining multivariate probit with a Chamberlain (1984)-type correlated random effects model, in which we insert the time average of various exogenous variables as additional variables to approximate unobserved household fixed effects. However, due to the space limitations, we show only the results on mechanization-related outcomes. 


\title{
MYANMAR'S RAPID AGRICULTURAL MECHANIZATION: DEMAND AND SUPPLY EVIDENCE
}

Myat Thida Win, Ben Belton, and Xiaobo Zhang

\begin{abstract}
This chapter analyzes recent patterns of agricultural mechanization in Myanmar from the demand side (farms) and the supply side (machinery dealerships). On the demand side, we analyze the historical and current use of machinery in agriculture, based on a survey of rural households conducted in 2016 in the Ayeyarwady delta close to Myanmar's largest city, Yangon. On the supply side, we draw evidence from a survey of agricultural machinery supply businesses. Myanmar's agriculture sector has encountered labor shortages and rising wages since 2011 as workers have begun to move to urban industrial and service sectors. Farmers have responded by rapidly substituting machinery for manual labor. In surveyed areas of Ayeyarwady, draft animals used for land preparation have almost disappeared. Of paddy-farming households, 94 percent used machines for land preparation, and only 12 percent still used draft animals. Widespread mechanization of harvesting has also occurred. Half of all sampled paddy-farming households used combine harvesters (up from almost none in 2013), and 38 percent used mechanical threshers. Access to machines is virtually scale neutral due to vibrant private machine hiring markets. On the supply side, agricultural machinery dealerships have proliferated and spread from Myanmar's core agricultural zones to more intermediate and peripheral areas. Explosive growth of machine sales has been facilitated by a lack of restrictions and duties on machinery imports, liberalization of the banking sector that has allowed private banks to offer hire-purchase loans to customers of machinery dealerships, and changes to the law that allow land use certificates to be used as loan collateral.
\end{abstract}

\section{Introduction}

Myanmar's economy stagnated for almost five decades prior to the start of political reforms in 2011. Since that time the country has experienced rapid growth and is the fastest-growing major economy in the region (ADB 2016). Growth has been accompanied by nascent structural transformation. Rural 
laborers have begun moving out of agriculture in large numbers to take up better-remunerated jobs in the more productive and rapidly expanding urban industrial and service sectors. Meanwhile, some parts of the country have seen massive out-migration of young people to richer neighboring countries such as Thailand.

Consequently, Myanmar's agricultural sector is increasingly faced with labor shortages that have caused real wages to spike in many rural areas, particularly during peak seasons. The trend is particularly acute in locations close to major cities such as Yangon. Rising labor costs have reshaped the structure of agricultural production, driving farmers to substitute capital, in the form of labor-saving agricultural machinery, for labor.

The pace of change has been dramatic. For example, a survey conducted by the World Bank in late 2013 and early 2014 in the country's main agricultural zones found extremely limited ownership and use of agricultural machinery. Only 0.5 percent of paddy farmers surveyed owned a combine harvester, and just 1 percent of farmers made use of one (World Bank 2016). Our own survey data, reported in this article, show that just two years later most paddy lands accessible by road in the country's "rice bowl," the Ayeyarwady delta, were harvested using combines. The scale and extent of this transformation are all the more spectacular given that it took decades for mechanization to unfold in many other Asian countries. Another remarkable feature of mechanization in Myanmar is that it has taken place so rapidly, largely in the absence of active government policies, which have been a prominent feature of mechanization in East Asian countries. ${ }^{1}$

Based on primary surveys, this chapter unravels the process of mechanization in Myanmar. The extremely rapid pace of mechanization in Myanmar makes it an advantageous place to study the mechanization process. Unlike in countries where mechanization has occurred over a much longer time frame, survey respondents retain excellent recall of their experiences with agricultural machinery. This enables us to provide a much more detailed and historically accurate analysis of the process than is usually possible.

A unique feature of our study is the use of primary survey data from both the demand side and the supply side. Previous literature on mechanization has mainly focused separately on either the demand side (farm households-for example, Kienzle, Ashburner, and Sims 2013) or the supply side (machinery suppliers or rental service providers—-for example, Yang et al. 2013). On the

1 For example, China provided subsidies for machinery purchase (Zhang, Yang, and Reardon 2017). 
demand side, we analyze the historical and present use of machinery in agricultural production, based on a survey of rural households in the Ayeyarwady and Yangon regions. On the supply side, we gather evidence from an enterprise survey of 49 agricultural machinery supply businesses in Yangon and a scoping assessment of machine supply businesses and rental service providers conducted in Ayeyarwady, Yangon, Mandalay, and Magway regions.

The chapter is organized as follows. The following section provides details on the survey methodologies adopted. The section after that sets out the demand-side story of mechanization in Myanmar, providing details on rates, current levels, and characteristics of mechanization. The next section presents the supply-side story, with discussion of agricultural machinery imports, domestic manufacturing, sales volumes, financing arrangements, and the changing geographical distribution of machine suppliers over time. Following that, we analyze the policy context in which the changes described in the preceding sections have occurred. The final section concludes, exploring the implications of the Myanmar case for countries where mechanization is still in the early stages.

\section{Methodology}

Results presented here draw on two surveys conducted in Myanmar: a household survey of agricultural machinery users and an enterprise survey of machinery supply businesses. Details are provided below.

\section{Myanmar Aquaculture-Agriculture Survey}

The Myanmar Aquaculture-Agriculture Survey (MAAS) was implemented in May 2016. The survey was designed to fulfill several requirements. These included generating a baseline of information on crop and fish farm yields, farm size, land tenure status, crop management practices and profitability, patterns of migration, and access to agricultural credit. The survey included modules on the ownership and use of agricultural machinery, and on purchase prices and dates. A separate recall module included questions on the use of machinery for land preparation and harvesting during the survey year, and 5 and 10 years previously. Data collected from these modules provide the basis for the demand-side analysis presented later. Data on migration rates and wages are drawn from other modules of the MAAS.

The MAAS adopted a two-stage sampling strategy. For the first stage, 40 village tracts from four townships-Kayan, Twantay, Maubin, and Nyaungdon-falling within approximately a $60 \mathrm{~km}$ radius of the city of 
Yangon (Myanmar's largest commercial center, with a population of approximately 5 million) were selected purposively based on an assessment of the cropping systems present in each. For the second stage, enumeration areas (EAs) were selected from these village tracts by probability proportional to size, using the national population census of 2014 as the sampling frame. The locations of the surveyed village tracts are illustrated in Figure 8.1.

This procedure yielded a sample of 78 EAs. A census of households was conducted in every selected EA to serve as the final sampling frame for randomized selection of respondent households. Eight farm and seven nonfarm households were selected for interview in each EA. Respondents from 1,120 households, representing a total population of 37,390 households, were interviewed. The total number of crop-farming households interviewed was $329 .^{2}$ Here, we would like to add a cautionary note. Our sample may overestimate the degree of mechanization because labor shortage is more acute in the Yangon region than elsewhere. In addition, infrastructure in Yangon is generally in better condition than elsewhere.

\section{Supply Side: Machinery Supplier Cluster Survey}

The supply-side section of the chapter draws on data from an enterprise survey of agricultural machinery dealerships, conducted by the authors in July 2016 at Mingalar Than Myint compound in Yangon. The compound is located in a commercial area and is close to the main road and river routes leading to the Ayeyarwady delta-Myanmar's main rice-growing zone. Scoping interviews conducted prior to the survey indicated that most of the machinery supply dealerships in Yangon are located within the compound, which therefore constitutes by far the largest cluster of such businesses in Myanmar. Most of the largest machinery supply businesses in Myanmar operate branches in this cluster. The survey was thus able to capture information on a large share of national agricultural machinery sales.

A census of businesses in the cluster was conducted prior to the survey, identifying 30 businesses selling agricultural machinery and 27 shops selling spare parts for agricultural machines. All agricultural machinery suppliers and spare parts shops listed in the census were selected for the survey. Of these, 3 machinery suppliers and 5 spare parts shops declined to participate, giving a total sample size of 49 businesses. The survey instrument was developed based

2 Other interviewees were from landless households (549) and households engaged in fish farming (242). 
FIGURE 8.1 Location of village tracts surveyed, Myanmar, 2016

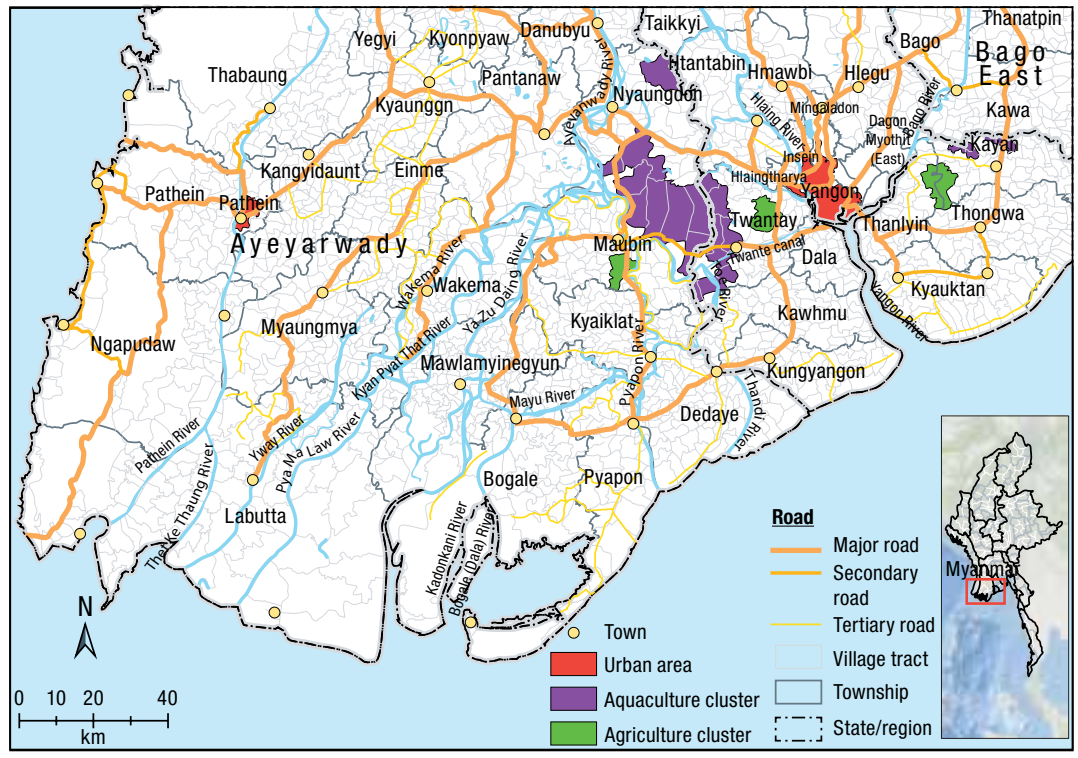

Source: Authors' own survey (2016).

on scoping interviews, and pretested with similar businesses located outside the cluster prior to implementation. This chapter presents survey findings from the agricultural machinery supply businesses.

\section{Demand-Side Evidence of Agricultural Mechanization}

\section{Mechanization as a Labor-Saving Technology}

The process of mechanization is already so advanced that machinery has almost replaced the use of draft animals (the traditional form of traction) in agriculture in the areas surveyed. The share of farm households using agricultural machinery and draft animals to perform activities related to paddy cultivation during the 2015 monsoon and 2016 dry seasons is presented in Figure 8.2. Use of machinery was most common in land preparation, for which almost all paddy-farming households (94 percent) used machines, with only 12 percent reporting still using draft animals. The share of households 
FIGURE 8.2 Machinery and draft animal use in paddy cultivation, Myanmar, 2015/2016

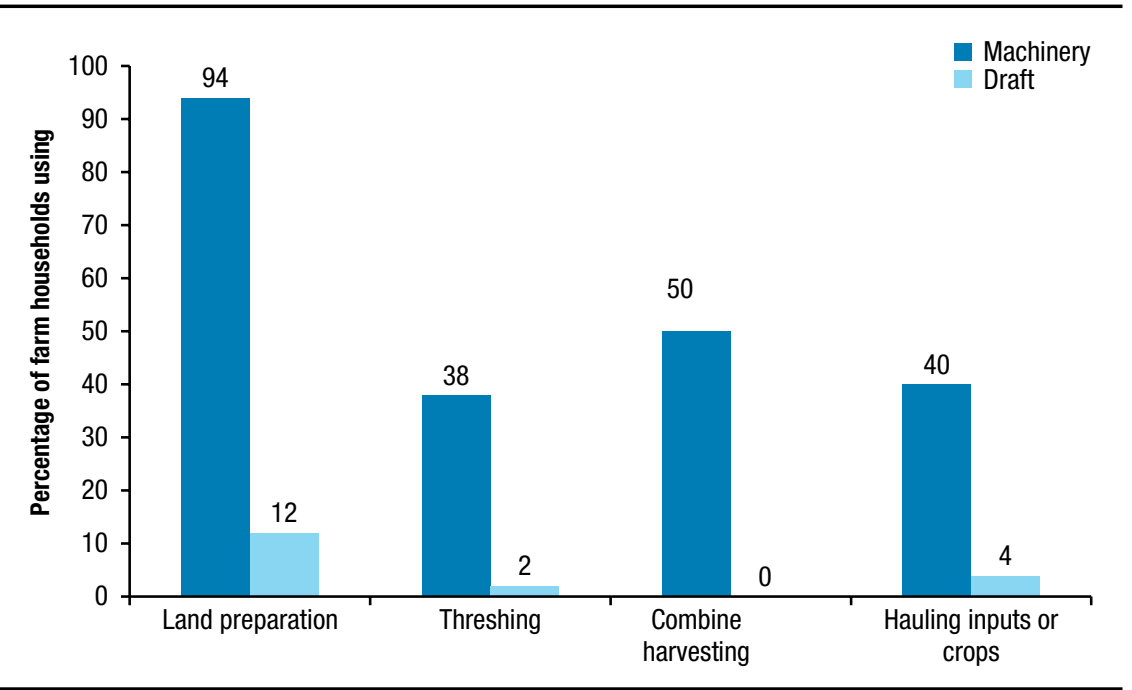

Source: Authors' own survey (2016).

using draft animals for other activities was even smaller. Widespread mechanization of harvesting has also taken place. Half of all sampled paddy-farming households used large-scale machinery (combine harvesters) for this purpose, and 38 percent used small-scale machines (threshers).

This transformation is closely linked to a tightening labor market. Analysis of MAAS data revealed accelerating rural-to-urban migration taking place in study areas close to Yangon city, resulting in rural labor shortages and rising wage rates. Of the households surveyed, 16 percent reported having a household member who was a long-term migrant. Of these, 92 percent were domestic (migrating within Myanmar), and 90 percent worked in urban areas (Htoo and $\mathrm{Zu} 2016)$. Migration is a very recent phenomenon. More than 80 percent of all long-term migrants migrated from 2010 onward, corresponding with the period when Myanmar's political system and economy began to open. These outflows have accelerated over time, with one-third of all migrants having left home in 2015 alone. In addition to long-term migrants, 44 percent of all workers in regular salaried employment commuted, residing at home but working in nearby, mainly urban areas (Htoo and $\mathrm{Zu} 2016$ ).

Simultaneous increases in reported agricultural wage rates are consistent with the occurrence of structural transformation. The real agricultural daily wage rate in surveyed villages increased by 8 percent between 2011 and 2013, 
from 2,600 Myanmar kyats (MMK) to MMK 2,800, and it jumped by a further 32 percent, to MMK 3,700, in 2016, corresponding to the movement of labor out of agriculture. ${ }^{3}$

The timing of these wage increases corresponds to the rapid rise of mechanization, suggesting that migration, labor shortages, and mechanization are closely connected. Table 8.1 illustrates changes in the share of agricultural households using machinery for land preparation and for harvesting over the period 2006-2016. The percentage of households using some type of machinery for land preparation rose steadily, from 36 percent in 2006 to 72 percent in 2011, to reach 97 percent in 2016. The share of households using any type of machinery for harvesting doubled, from 5 percent in 2006 to 10 percent in 2011, and then jumped sharply in the subsequent five years, reaching 57 percent in 2016. This latter trend appears closely related to the increasing costs of labor employed in paddy harvesting.

\section{The Sequential Nature of Mechanization}

Ownership of agricultural machinery increased slowly until 2008 but grew exponentially thereafter, accelerating particularly quickly after 2010 (Figure 8.3). In most countries, the process of agricultural mechanization follows a sequential pattern. Stationary, power-intensive operations such as pumping water and threshing are mechanized first, followed by mobile, control-intensive operations such as harvesting (Pingali 2007). A similar pattern is also apparent in Myanmar. Figure 8.3 summarizes the cumulative number of purchases of machines of different types made by households in the surveyed village tracts in each year from 1990 to 2015. Consistent with the sequence reported by Pingali (2007), limited adoption of surface-water pumps and two-wheel tractors (2WTs) began in the early 1990s, followed by mechanical threshers and four-wheel tractors (4WTs) post-2000, almost a decade later. Adoption of combine harvesters is a very recent phenomenon, occurring only from 2013 onward.

This sequence is also reflected in Table 8.2, which depicts the total annual value (at constant 2015 prices) of purchases of machinery made by households in the areas surveyed during the period 2000-2015. Two-wheel tractors (2WTs) and water pumps together accounted for most of the value of machine sales during the first half of this period, with threshers and four-wheel tractors (4WTs) contributing a growing share thereafter.

31 US dollar = MMK 1,200 in early 2016. 
TABLE 8.1 Share of farm households using machinery for land preparation and harvesting, Myanmar, 2006-2016 (percentages)

\begin{tabular}{lccc}
\hline Machine use & $\mathbf{2 0 0 6}$ & $\mathbf{2 0 1 1}$ & $\mathbf{2 0 1 6}$ \\
\hline Land preparation & 36 & 72 & 97 \\
Harvesting & 5 & 10 & 57 \\
\hline
\end{tabular}

Source: Authors' own survey (2016).

FIGURE 8.3 Cumulative purchases of selected machinery, Myanmar, 1990-2015

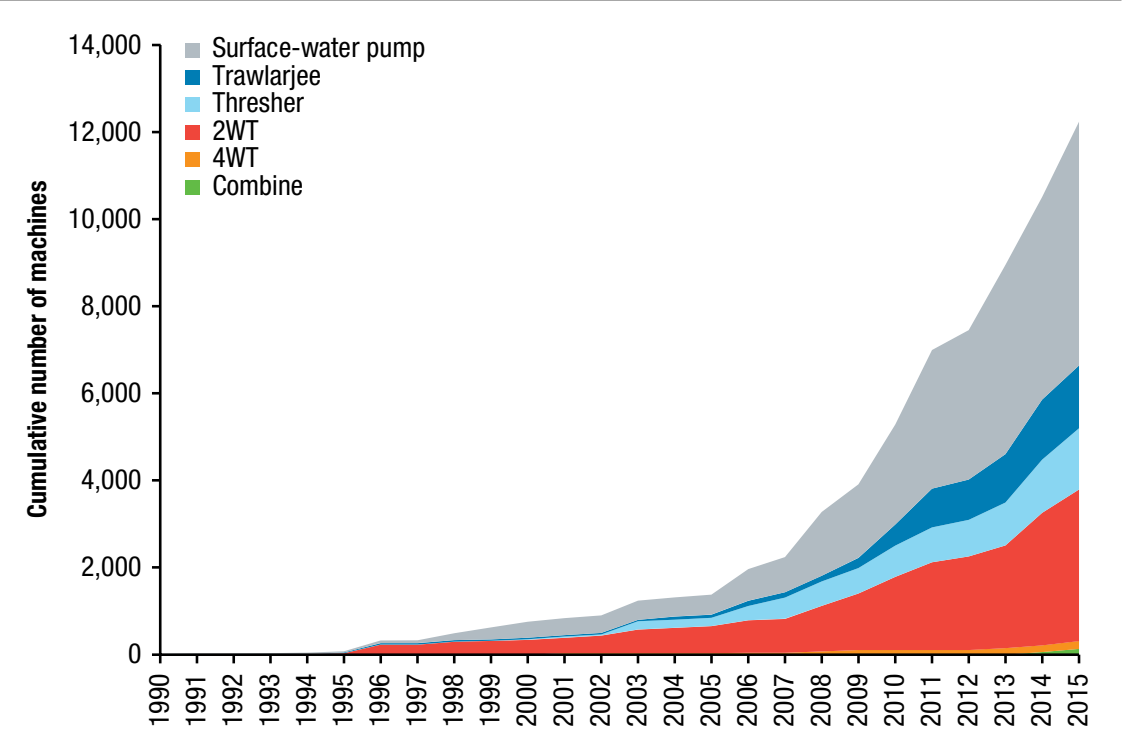

Source: Authors' own survey (2016).

Note: A trawlarjee is a rudimentary motorized vehicle consisting usually of a tractor engine mounted onto a cart or trolley. 2WT = two-wheel tractor; 4WT = four-wheel tractor.

The total value of machinery purchases began to increase significantly after 2009, and accelerated extremely rapidly from 2013 onward, more than tripling in just two years, from 2013 to 2015. Combine harvesters (of which there were no purchases reported prior to 2014) and 4WTs contributed about half of the total value of machinery sales in 2015. The contribution of $4 \mathrm{WTs}$ to the total value of purchased machinery was low prior to 2013. The number of 4WT units purchased changed little before and after 2013, suggesting that more expensive high-performance machines were increasingly adopted after 2013. 
TABLE 8.2 Real purchase value of selected machinery and average annual growth rate, Myanmar, 2000-2015

\begin{tabular}{lcc}
\hline Year & $\begin{array}{c}\text { Purchase value } \\
\text { (million MMK) }\end{array}$ & $\begin{array}{c}\text { Annual growth rate } \\
(\%)\end{array}$ \\
\hline Prior to 2010 & 5,126 & 10 \\
$2011-2013$ & 6,759 & 2 \\
$2013-2015$ & 18,209 & 64 \\
\hline
\end{tabular}

Source: Authors' own survey (2016).

Note: Purchase values are in constant 2015 prices. MMK = Myanmar kyats.

\section{Small-Scale versus Large-Scale Mechanization}

Agricultural machinery can be categorized as small-scale (for example, 2WTs and threshers) or large-scale (for example, $4 \mathrm{WTs}$ and combine harvesters). In Myanmar during the time covered by our survey, large-scale mechanization was most advanced in the case of harvesting, with more than 40 percent of all agricultural households in our sample using combine harvesters for harvesting. A similar percentage of households used threshers. A large majority of households (68 percent) used 2WTs for land preparation, whereas 17 percent used large $4 \mathrm{WT}$. The comparatively low rate of $4 \mathrm{WT}$ use in the areas surveyed reflects the fact that these heavy machines are not well suited for preparing soft or waterlogged soils for paddy cultivation in the delta. Their adoption is more widespread in Myanmar's central dry zone, where conditions are more arid, nonpaddy crops are more widely grown, and soils are drier.

\section{Mechanization and Farm Size}

In the locations where the survey was implemented, farm size and the adoption of agricultural machinery were weakly correlated at best, indicating that such machinery is a scale-neutral technology. Capital constraints and the indivisible nature of agricultural machinery mean that large farms are generally assumed to be more likely to mechanize than smallholders. However, as illustrated by Figure 8.4, there is very little variation by farm size in the share of households using 2WTs and 4WTs. Use of combine harvesters varies more with farm size, but the difference is still small, ranging from 50 percent on farms with area less than 5 acres to 61 percent on farms with area greater than 10 acres. This finding has important implications. First, it means that small farms can benefit from the cost and time savings of machinery use, and will not find themselves at a relative disadvantage, as they might if only large farms 
FIGURE 8.4 Share of households using machinery for land preparation and harvesting, by farm size group, Myanmar, 2015/2016

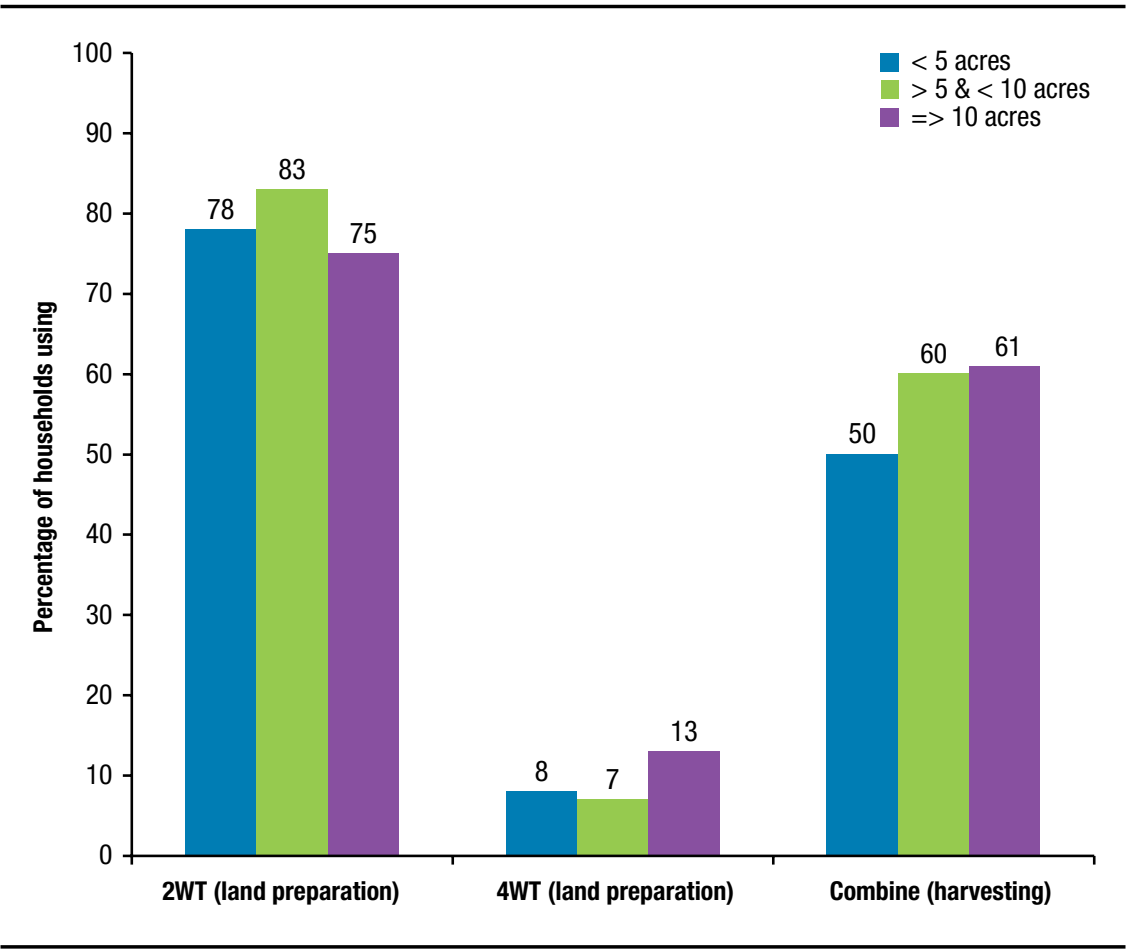

Source: Authors' own survey (2016).

Note: $2 \mathrm{WT}$ = two-wheel tractor; 4WT = four-wheel tractor.

adopted. Second, it means that the consolidation of fragmented landholdings is not a prerequisite for mechanization, as some accounts suggest (for example, Pingali 2007).

\section{Hiring Services}

Observed scale neutrality is accounted for by the rapid growth of an active hiring services market for agricultural machinery. This is illustrated in Figure 8.5, which presents data on the share of households owning versus renting machinery for land preparation (left-hand panel) and for harvesting (right-hand panel) in 2006, 2011, and 2016. Use of machinery for harvesting jumped dramatically from 2011 to 2016, mirroring the growth of combine harvester sales after 2013. The vast majority of machines used for harvesting were accessed by hiring. The emergence of the hiring services market has also driven combine harvester sales, because hiring out machinery provides 
FIGURE 8.5 Use of owned or rented machinery for land preparation and for harvesting in paddy cultivation, Myanmar, 2006-2016

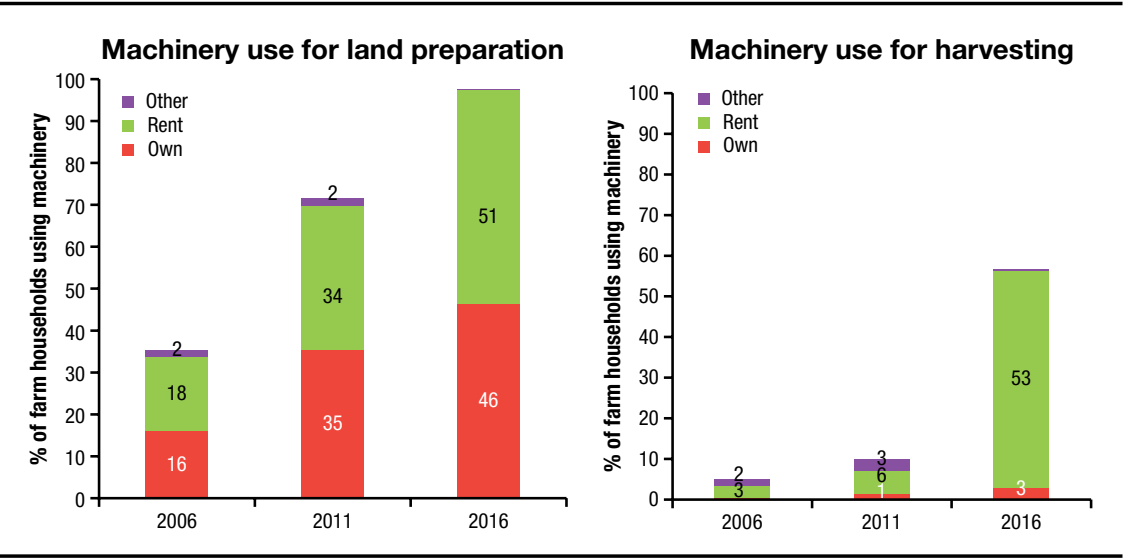

Source: Authors' own survey (2016).

revenue that enables owners to pay off outstanding hire-purchase loans and quickly recoup their investments. Among households using machines for land preparation, approximately equal shares of respondents owned and hired the machines used (predominantly $2 \mathrm{WTs}$ ) in all three years. Although the country's Agricultural Mechanization Department (AMD) offers some machine hiring services, the market is dominated by a vibrant private sector; none of the households in the surveyed village tracts reported making use of machinery offered by the AMD.

As expected, ownership of agricultural machinery is most common among farmers with large landholdings, whereas smaller farmers are more likely to access machinery through hiring services. Use of hiring services is most common for expensive machinery (for example, combine harvesters). The hiring market for combine harvesters is dominated by larger farmers who buy machines to hire out to other farmers as a business, in addition to using them on their own farms. More than 95 percent of farms with area under 5 acres that made use of combine harvesters hired these services in 2015/2016, as compared with 74 percent of those operating more than 10 acres of land (Table 8.3).

\section{Regional Variations}

The use of machinery in agricultural production is subject to regional variations that reflect geographical differences in labor costs. Our scoping work in both the delta and the dry zone points to differences in the severity of labor shortages and their impacts on both farm wages and the adoption of 
TABLE 8.3 Share of households using owned versus rented machinery for land preparation and combine harvesting, by farm size category, Myanmar, 2015/2016 (percentages)

\begin{tabular}{lcccccccc}
\hline & \multicolumn{2}{c}{ Farms $<5$ acres } & & \multicolumn{2}{c}{ Farms $5-10$ acres } & & \multicolumn{2}{c}{ Farms $>10$ acres } \\
\cline { 2 - 3 } Equipment use & 0wned & Rented & & Owned & Rented & & Owned & Rented \\
\hline Land preparation & 31 & 69 & & 54 & 46 & & 87 & 13 \\
Combine harvesting & 4 & 96 & & 8 & 92 & & 26 & 74 \\
\hline
\end{tabular}

Source: Authors' own survey (2016).

labor-saving machinery, with effects in delta townships close to Yangon being the most extreme.

However, the characteristics of machine use also vary by region according to agroecological conditions and crops farmed. Combine harvesters are used only to harvest rice. Commonly farmed pulse varieties are not sufficiently erect to allow combine harvesting. Locally manufactured threshers have been adopted widely for paddy, and are occasionally modified for threshing pulses such as green gram. $4 \mathrm{WT}$ are increasingly used for land preparation, particularly in the dry zone, but use of draft animals remains widespread in the dry zone, in part because using machinery during the later stages of land preparation for oilseeds and pulses causes excessive soil compaction. In contrast, in the main rice-growing areas of the Ayeyarwady delta, 2WTs have already almost completely replaced animal traction.

\section{Supply-Side Evidence of Mechanization}

\section{Key Players in the Mechanization Supply Chain}

The agricultural machinery supply chain in Myanmar is rather simple, and the market for agricultural machinery is highly concentrated. Most of the 26 agricultural machinery dealerships surveyed in the Yangon mechanization cluster specialize exclusively in machinery sales. The 3 largest dealerships surveyed accounted for 58 percent of the estimated value of sales made during the first six months in 2016, and the 8 largest dealerships together accounted for 91 percent of the total value of sales. Similarly, whereas 70 percent of machine supply businesses (19 enterprises) had 3 or fewer branches, the largest single business operated 23 branches nationwide.

More than half of these businesses market their products with assistance from rural sales agents (distributors). Distributors stock small numbers of machines consigned by dealerships, on which they can earn sales commissions, 
or seek out and refer potential customers to dealerships after vetting their reputation and creditworthiness.

There is some diversification in the activities and services of machinery suppliers, particularly among larger enterprises, but the capacity to manufacture agricultural machinery is still limited. Domestic manufacturing is presently limited to production of simple welded parts, mainly trawlarjee frames and metal wheels for $2 \mathrm{WTs}{ }^{4}$ Several local companies also manufacture threshers, and most farmers use these locally made threshers instead of imported ones, but such manufacturers mainly operate independently of the machinery supply businesses surveyed.

A few machinery dealerships subcontract out the manufacture of small machines to companies located in China. Manufacturing started as early as 1990, whereas subcontracting began after 2005. One-third of dealerships assemble imported machine parts in Myanmar to reduce import costs. Assembly of 2WTs and trawlarjees was first initiated in 1995. Companies producing trawlarjee frames and wheels for $2 \mathrm{WTs}$ combine these with complex imported parts such as engines. Four dealerships have recently begun to assemble $4 \mathrm{WT}$ and combines.

The vast majority of agricultural machinery sold in Myanmar is imported from neighboring China and Thailand. Of all small machines (one-wheel tractors and 2WTs, engines, dynamos, water pumps, and roller boats) sold by dealers in 2016, 87 percent originated from China. Of $4 \mathrm{WTs}$ and combines, 57 percent originated from Thailand, reflecting a strong preference among buyers for the Kubota brand machines manufactured there. Imports of machines from other countries were limited. The majority of machine imports are via overland border trade; 65 percent of dynamos and water pumps, and 58 percent of combines were imported in this way.

Real prices of small machines sold in Myanmar fell significantly from 2006 to 2016 (as reported by MAAS respondents), providing additional incentives to mechanize. The purchase price of $2 \mathrm{WT}$ s fell at an average rate of 5.8 percent per year over this period, and that of surface-water pumps declined by 5.1 percent per year. China's low-cost manufacturing capacity appears to be a main driver of lower prices for these types of machinery. Access to imports of small, low-cost Chinese machines such as $2 \mathrm{WTs}$ and water pumps is also known to have stimulated rapid mechanization in other countries in the region, including Bangladesh (Biggs, Justice, and Lewis 2011).

4 A trawlarjee is a rudimentary motorized vehicle consisting usually of a tractor engine mounted onto a cart or trolley. 


\section{Machine Sales}

Mirroring the results of the demand-side survey, numbers of dealerships selling almost all categories of agricultural machinery grew swiftly from 2012 to 2016 (Table 8.4). The number of units sold annually (all machine types) increased by a massive 535 percent over this period, rising from 21,223 to $134,7000^{5}$

Sales have been dominated by small machines in terms of numbers, but sales of 4WTs and combine harvesters grew particularly rapidly after 2014 . Combine harvesters grew nearly 6,000 percent in four years, up from 40 units in 2013 to 2,372 in 2016; 90 percent of this growth took place in 2015/2016 alone. Annual sales of $4 \mathrm{WTs}$ increased by almost 1,100 percent between 2012 and 2016, rising from 275 units to 3,200 (Table 8.5).

Large machines already appear to have begun to replace smaller ones. Annual sales of threshers dwindled by 79 percent, from a high of 220 units in 2014 to 46 in 2016. Annual increases in sales of reapers peaked in 2015, after three years of brisk growth, and fell by 8 percent thereafter. $4 \mathrm{WT}$ s also appear to have eaten into sales of 2WTs, which plateaued in 2014/2015 (Table 8.5). The average number of sales staff working for dealerships in the cluster grew by 43 percent between 2013 and 2016, corresponding to increasing volumes of sales.

\section{Geographical Expansion}

As the volume and value of machinery sales made by branches within the Yangon cluster has skyrocketed, so too has the number of machinery supply business outlets outside the cluster, spreading beyond initial core markets, which have become increasingly competitive.

The establishment of machine supply shops in Yangon occurred earlier than in most other areas of the country. Five machinery supply businesses surveyed in the Mingalar Than Myint compound were already established in 1990. Numbers grew gradually until 2004 and then doubled in the six years leading up to 2010 (from 11 to 23), before increasing more slowly to reach 27 in 2016 . Establishment of new branches outside the cluster by businesses located within it occurred far more rapidly than establishment of new businesses inside the cluster, particularly after 2010 .

5 This figure excludes sales made by branches outside the Mingalar Than Myint compound. Sales volumes for 2016 are extrapolated, based on sales made during the first six months of 2016. Key informants confirmed that sales during the first and second half of the year are similar. 
TABLE 8.4 Cumulative number of agricultural machinery dealers selling different types of machine, Myanmar, 1995-2016

\begin{tabular}{lrrrrrc}
\hline & \multicolumn{5}{c}{ Number of dealers selling } \\
\cline { 2 - 7 } Year & All & 2WTs & 4WTs & Combines & Water pumps & Reapers \\
\hline 1995 & 7 & 2 & 0 & 0 & 1 & 0 \\
2000 & 11 & 4 & 0 & 0 & 3 & 1 \\
2005 & 13 & 5 & 0 & 0 & 6 & 1 \\
2010 & 23 & 8 & 4 & 0 & 11 & 5 \\
2015 & 26 & 12 & 10 & 8 & 13 & 10 \\
2016 & 27 & 13 & 12 & 11 & 13 & 10 \\
\hline
\end{tabular}

Source: Authors' own survey (2016).

Note: $2 \mathrm{WT}=$ two-wheel tractor; $4 \mathrm{WT}$ = four-wheel tractor.

TABLE 8.5 Annual sales of selected machinery by dealerships in Mingalar Than Myint compound, Myanmar, 2012-2016

\begin{tabular}{|c|c|c|c|c|c|c|c|c|c|}
\hline \multirow[b]{2}{*}{ Machine type } & \multicolumn{5}{|c|}{$\begin{array}{l}\text { Annual sales } \\
\text { by year }\end{array}$} & \multicolumn{4}{|c|}{$\begin{array}{l}\text { Year-over-year change } \\
\text { in sales (\%) }\end{array}$} \\
\hline & 2012 & 2013 & 2014 & 2015 & 2016 & $\begin{array}{c}2012- \\
2013\end{array}$ & $\begin{array}{c}2013- \\
2014\end{array}$ & $\begin{array}{c}2014- \\
2015\end{array}$ & $\begin{array}{c}2015- \\
2016\end{array}$ \\
\hline 2WTs \& accessories & 9,598 & 11,715 & 14,912 & 14,872 & 20,684 & 22 & 27 & -0.3 & 39 \\
\hline Engines/dynamos/water pumps & 8,105 & 11,547 & 62,806 & 59,103 & 99,026 & 42 & 444 & -6 & 67 \\
\hline 4WTs & 275 & 420 & 870 & 1,662 & 3,200 & 53 & 107 & 91 & 92 \\
\hline Combine harvesters & 0 & 40 & 237 & 955 & 2,372 & n.a. & 493 & 303 & 148 \\
\hline Reapers & 305 & 335 & 860 & 1,351 & 1,244 & 10 & 157 & 57 & -8 \\
\hline Threshers & 0 & 30 & 220 & 167 & 46 & n.a. & 663 & -24 & -72 \\
\hline
\end{tabular}

Source: Authors' own survey (2016).

Note: 2 WT = two-wheel tractor; 4 WT = four-wheel tractor; n.a. $=$ not applicable.

The pattern of spatial development observed suggests that labor shortages and wage rate increases (the main drivers of mechanization) occurred first in the agricultural zone surrounding Yangon, and began to be transmitted to more remote and less dynamic areas only after 2013. On the supply side, it also suggests that businesses have sought to extend their customer base by opening new branches in more peripheral hinterland areas, as the oldest markets in the country's agricultural heartland have matured.

Before 2011, branches linked to businesses in the cluster were highly concentrated in Yangon, Mandalay, Bago, and Ayeyarwady (Figure 8.6). Together these regions form a "core" agricultural corridor running down the center 
FIGURE 8.6 Number and location of machinery suppliers, Myanmar, 2010, 2013, and 2016

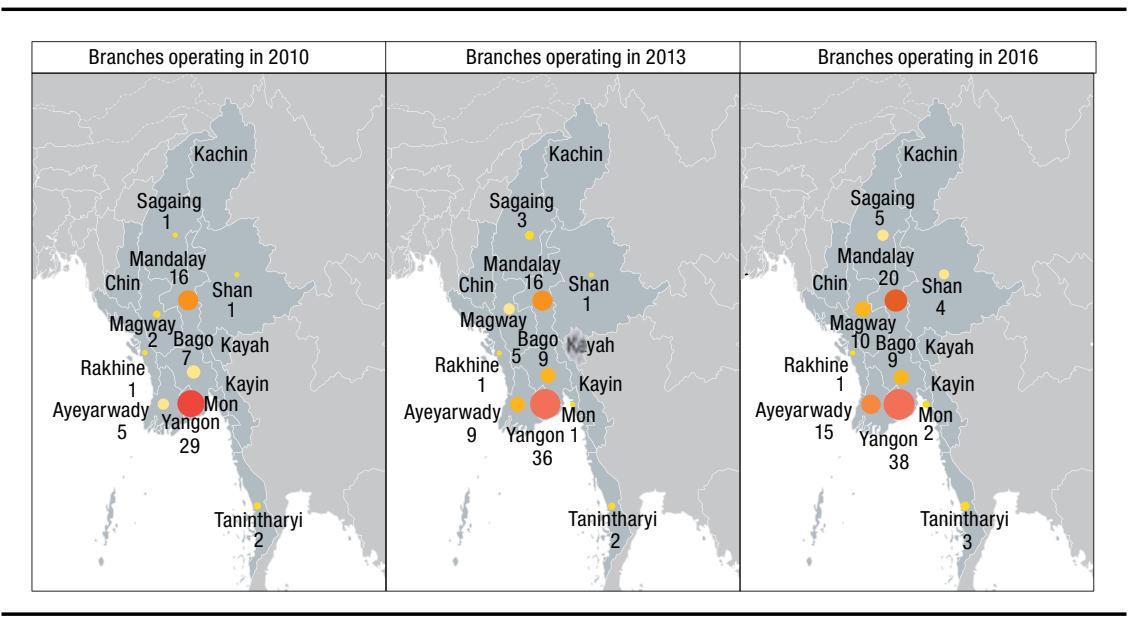

Source: Authors' own survey (2016).

Note: The dots are scaled to the number of businesses in each region and the number of businesses is labeled.

of the country, following the course of the Ayeyarwady River and including Myanmar's two largest commercial centers (the cities of Yangon and Mandalay). Businesses in the cluster operated a total of 57 branches in 2010, of which 89 percent were located in these four core regions.

Most growth from 2011 to 2013 occurred in the southern part of the core zone, close to Yangon. The number of branches operated by businesses in the cluster grew by 30 percent during this period, to reach 70 . Branch numbers increased by a further 29 percent from 2014 to 2016 . Growth in the delta continued during this period but was also accompanied by increasing numbers of newly established branches in the northern part of the core corridor (the Mandalay region); in the intermediate regions of Magway and Sagaing; and in the peripheral states of Shan, Mon, and Tanintharyi. Geographic concentration decreased as a result, and 23 percent of branches are now located outside of the four original core regions.

\section{Hire-Purchase Arrangements}

Customer finance has played a critical role in catalyzing the adoption of agricultural machinery. Two forms of customer finance are available: (1) hirepurchase financing offered by machinery dealerships using their own working capital and (2) hire-purchase financing provided by banks and other commercial financial institutions. 
For both types of hire-purchase arrangement, customers make an initial down payment on the item they intend to buy (usually 30 percent of its value). If financing is provided directly by the dealership, the customer repays the loan balance to the dealership in installments (usually two) over a fixed period (usually 12 months), with interest. The repayment system for hire-purchase arrangements made through banks is similar, except that the bank transfers the balance of the loan to the machinery dealership upon commencement of the agreement and the customer repays the outstanding amount to the bank. In either case, the agreement is guaranteed using the loan recipient's agricultural land use certificate (called Form 7) as collateral. ${ }^{6}$

Half of the agricultural machinery dealerships surveyed, including all those stocking large machines, offered at least one type of financing arrangement. Specifically, three dealers (11 percent of the total) provided direct hire-purchase financing, five dealers (18 percent) provided hire-purchase financing in partnership with banks, and seven dealers ( 26 percent) offered both services. Around six banks, all commercial, provided hire-purchase loans for agricultural machinery in partnership with machine suppliers. Interest rates were capped at 13 percent per year, in line with national banking regulations.

The boom in machinery sales detailed above could not have occurred in the absence of bank-financed hire-purchase agreements; this is particularly apparent for $4 \mathrm{WTs}$ and combine harvesters, the average cost of which ranges from $\$ 13,000$ to $\$ 31,000$, depending on country of origin. ${ }^{7}$ Banking regulations do not allow machinery suppliers (or other types of business) to borrow more than the value of their assets. If bank financing for purchases of large machinery had not become available, the capital constraints faced by machinery dealerships would have caused sales to grow far more slowly. This is confirmed by Table 8.6, which shows that in 2016 hire-purchase agreements through banks accounted for a large majority of purchases of combine harvesters (77 percent) and 4WTs (68 percent). This is all the more remarkable given that banks only began to offer hire-purchase financing in 2013, following the passing of the Farmland Law of 2012, which made agricultural land use rights transferable and enabled Form 7 to be used as collateral against formal loans.

\footnotetext{
6 One bank, Yoma, does not require collateral for its hire-purchase loans, accepts a lower down payment, and offers repayment schedules of two to three years.

7 Dollar figures are US dollars throughout the chapter.
} 
TABLE 8.6 Share of 2016 sales of selected machinery, by type of finance, Myanmar

\begin{tabular}{lccc}
\hline Type of machine & $\begin{array}{c}\text { Hire-purchase } \\
\text { arrangement } \\
\text { with bank } \\
\text { (\% of sales) }\end{array}$ & $\begin{array}{c}\text { Hire-purchase } \\
\text { arrangement with } \\
\text { machinery supplier } \\
\text { (\% of sales) }\end{array}$ & $\begin{array}{c}\text { Up-front cash } \\
\text { payment by } \\
\text { customer } \\
\text { (\% of sales) }\end{array}$ \\
\hline Two-wheel tractor & 35 & 17 & 48 \\
Trawlarjee & 46 & 28 & 26 \\
Four-wheel tractor & 68 & 5 & 27 \\
Combine harvester & 77 & 2 & 22 \\
\hline
\end{tabular}

Source: Authors' own survey (2016).

\section{Policy Environment}

Agricultural mechanization has long been a policy priority for Myanmar. The AMD and the Department of Cooperatives (both under the Ministry of Agriculture, Livestock, and Irrigation) provide, respectively, agricultural machinery hiring services and machinery sales through hire-purchase finance arrangements. However, despite their activities, the market share of agricultural machinery hiring services and sales provided by government-led programs was extremely limited at the time of the survey, because the private sector has proven highly responsive and efficient in meeting demand.

Private machinery suppliers tend to stock machinery brands demanded by farmers, for which repair services and spare parts are widely available. In contrast, government departments have often made their purchasing decisions based on the availability of equipment provided through bilateral agreements and loans from other governments. For example, several respondents interviewed during the scoping exercise reported that Myanmar had received a loan facility from the Republic of Korea's government aimed at supporting mechanization and offered on the condition that loans would be used to buy a particular brand of Korean combine harvesters and $4 \mathrm{WTs}$. The Myanmar government sold these machines that it received with a preferential four-year hire-purchase term (four times longer than that usually offered commercially). However, the manufacturer reportedly failed to provide spare parts or aftersale repair services, and the equipment was said to be poorly suited for use under local conditions. The result was that demand for the machines was limited despite the attractive financing.

The AMD has provided machinery hiring services to farmers since long before the emergence of the private hire market. However, demand for these services remains low. This is in part because much of the fleet of machinery available for hire by the government is obsolete or does not include brands 
preferred by farmers. In addition, accessing these services is often more complicated and time-consuming than accessing the mechanization services offered by private providers.

Although government attempts to support mechanization directly have proven largely ineffective, Myanmar's mechanization policy has been successful in supporting the rapid emergence of a market-led, supply and demanddriven model of mechanization service provision, which came about in response to the incentives created by economic structural change. This success is largely because government policies have had few distortionary effects. In particular, there are no restrictions on imports of agricultural machinery that might hamper the sector's development, and agricultural machinery is not subject to any import duty.

Several other policies implemented after 2011 have played important complementary roles in supporting the growth of agricultural mechanization. Until 2012, private banks were not allowed to extend credit to farmers, on the basis that this facility was already provided by the state-owned Myanmar Agricultural Development Bank (OECD 2014). Various other restrictions placed on the banking sector have also been partially relaxed, although these reforms still have a long way to run.

Since 2012, this development has been complemented by the issuance of formal, transferable land use rights to agricultural land, through the provision of the Form 7 title document that enables farmland to be used as collateral to access credit from banks and machinery dealerships for the purchase of machinery.

\section{Conclusions}

Agricultural mechanization is already well advanced in the areas of Myanmar surveyed by the MAAS, almost completely replacing the use of draft cattle. Economic reforms and the growth in the nonfarm sector since 2011 have stimulated the onset of a process of structural transformation, as labor moves from agriculture to the more productive urban industrial and service sectors. Resultant rural labor shortages and increases in real wage rates have been major drivers of rural mechanization, particularly from 2013 onward. The declining real price of some types of machinery has contributed to the acceleration of this process.

Results from our supply-side survey of agricultural machinery dealerships in Myanmar's largest cluster of these businesses mirror those from our demand-side survey of machinery users in townships close to the city. 
Adoption of machinery began with small, relatively low-cost machines such as engines, dynamos, water pumps, and 2WTs. The adoption of combine harvesters and $4 \mathrm{WTs}$ is a more recent phenomenon, having accelerated particularly rapidly from 2013 onward. Combine harvesters have already begun to replace smaller, single-purpose machines (threshers and reapers) for harvesting. Demand for 2WTs for land preparation remains high, but $4 \mathrm{WT}$ s have begun to eat into this market somewhat.

The spectacular growth in the volume and value of sales made by businesses surveyed in the Yangon cluster, combined with the rapid geographic spread of their branches, confirms the demand-side growth reported from the delta. Sales by machinery dealership branches located in the cluster increased by more than 500 percent from 2012 to 2016 alone, and particularly after 2013, there has been geographic expansion of dealership branches beyond core agricultural regions in the delta and lower dry zone to more peripheral states and regions. This suggests both that the core market is maturing and driving suppliers to seek to open up new markets, and that agricultural wage rates-a key driver of mechanization-are beginning to rise in areas distant from the country's main urban centers.

These findings have resonance beyond Myanmar. Smallholders account for the majority of famers in most developing countries, including those in Africa south of the Sahara. The persistent concern that mechanization is not applicable to smallholder farmers has led to calls for the establishment of large commercial farms in Africa south of the Sahara (Collier and Dercon 2014). However, as Pingali found, the limited spread of mechanization in Africa reflects the predominance of low-yielding subsistence production systems, itself the result of "relatively inelastic demand conditions due to low population densities or poor market infrastructure," with the result that mechanization is not cost effective (2007, 2781).

Myanmar's experience of rapid, scale-neutral mechanization provides a counterpoint to the position of Collier and Dercon (2014), and thus makes a contribution to the debate as to whether, and under what conditions, mechanization is likely to prove viable for smallholder farmers in Africa. The rather limited role of direct policy intervention in agricultural mechanization in Myanmar (except through laissiez-faire policies) and the evident importance of broader structural conditions and policies that favor an enabling environment also provide support for Pingali’s (2007) observation, by suggesting that efforts to promote mechanization are unlikely to succeed until the fundamentals are in place. 
As for recommendations for Africa, the recent experiences in Myanmar offer useful insights. First, in Myanmar, improvements in access to financial services following post-2011 reforms have also accelerated the adoption of agricultural machinery, particularly from 2013 onward. The sale of machinery via hire-purchase financing, under which buyers can pay for machinery in installments after entering a contract with a machinery supplier, has been a key innovation in this regard, particularly in the case of expensive machines such as $4 \mathrm{WT}$ and combines. Hire-purchase arrangements financed by banks have played a pivotal role in supporting the boom in sales of agricultural machinery on the supply side, by partially overcoming capital constraints that prevented dealerships from providing direct financing to their customers at sufficient levels. The issuance since 2012 of transferable land use rights that can be used as loan collateral, along with partial relaxation of restrictions on the banking sector, has made this possible. For African countries, land policy reforms that enable increased use of land use rights as collateral may lead to greater use of bank credit for tractor purchase. Second, although banks extend credit mainly to better-resourced farmers who use land as collateral, in Myanmar there is a trickle-down effect for smallholder farmers, who are able to hire mechanization services at competitive rates. The rise of private hiring markets has dramatically improved access to these machines among farmers with small and large landholdings alike, rendering the technologies effectively scale neutral. Third, less distortion in import policies after the economic reform led to a significant inflow of cheaper, "good enough" machines such as power tillers from manufacturers in neighboring countries such as China.

\section{References}

ADB (Asian Development Bank). 2016. Asian Development Outlook 2016: Asia’s Potential Growth. Manila.

Biggs, S., S. Justice, and D. Lewis. 2011. "Patterns of Rural Mechanization, Energy and Employment in South Asia: Reopening the Debate." Economic and Political Weekly 46 (9): $78-82$.

Collier, P., and S. Dercon. 2014. "African Agriculture in 50 Years: Smallholders in a Rapidly Changing World?" World Development 63: 92-101.

Htoo, K., and A. M. Zu. 2016. Rural-Urban Migration Around Yangon City, Myanmar. Food Security Policy Project Research Highlights No. 5. East Lansing, MI, US: Michigan State University. 
Kienzle, J., J. E. Ashburner, and B. G. Sims, eds. 2013. Mechanization for Rural Development: A Review of Patterns and Progress from Around the World. Rome: Plant Production and Protection Division, Food and Agriculture Organization of the United Nations.

OECD (Organisation for Economic Co-Operation and Development). 2014. OECD Investment Policy Reviews: Myanmar 2014. OECD Publishing. http://dx.doi.org/10.1787 19789264206441-en.

Pingali, P. 2007. "Agricultural Mechanization: Adoption Patterns and Economic Impact." In Handbook of Agricultural Economics. Vol. 3, edited by R. Evenson and P. Pingali, 2779-2805. Amsterdam: Elsevier.

World Bank. 2016. Myanmar: Analysis of Farm Production Economics. Washington, DC.

Yang, J., Z. Huang, X. Zhang, and T. Reardon. 2013. “The Rapid Rise of Cross-Regional Agricultural Mechanization Services in China." American Journal of Agricultural Economics 95 (5): $1245-1251$.

Zhang, X., J. Yang, and T. Reardon. 2017. "Mechanization Outsourcing Clusters and Division of Labor in Chinese Agriculture." China Economic Review 43: 184-195. 


\title{
EVOLUTION OF AGRICULTURAL MECHANIZATION IN NEPAL
}

Hiroyuki Takeshima and Scott E. Justice

\begin{abstract}
Mechanization levels in Nepal, a largely agricultural country, were relatively low until a few decades ago. However, significant mechanization growth, including the adoption of tractors, has occurred since the 1990s, against a backdrop of rising rural wages, particularly for plowing, combined with growing emigration, growth in key staple crop yields, overall broad agricultural production growth, and improved market access and participation. This growth in mechanization has taken place despite the general absence of direct government support or promotion. The growth of tractor use in the plains of the Terai zone has transformed agricultural production rather than inducing labor movement out of agriculture. Thus it has raised overall returns to scale in intensification and enabled the cultivation of greater areas by medium smallholders than by resource-poor smallholders. Tractors have also facilitated the intensification of crop production per unit of land among very small farmers, enabling mechanization growth despite the continued decline in farm size, although these farmers may not have benefited as much as medium smallholders. Potential future research areas with policy relevance include mitigating accessibility constraints on tractor custom hiring services, identifying appropriate regulatory policies for mechanization, and providing complementary support to some smallholders who may not fully benefit from tractor adoption alone.
\end{abstract}

\section{Historical Background of Mechanization Evolution in Nepal}

The mechanization level in Nepal, a largely agricultural country, was relatively low until a few decades ago. Significant mechanization growth, including the adoption of tractors, has occurred since the 1990s. The growth patterns have varied considerably across the country's diverse agroecological environments

This chapter is a shortened version of Takeshima (2017b), which contains more detailed description of the historical evolution of mechanization in the country. 


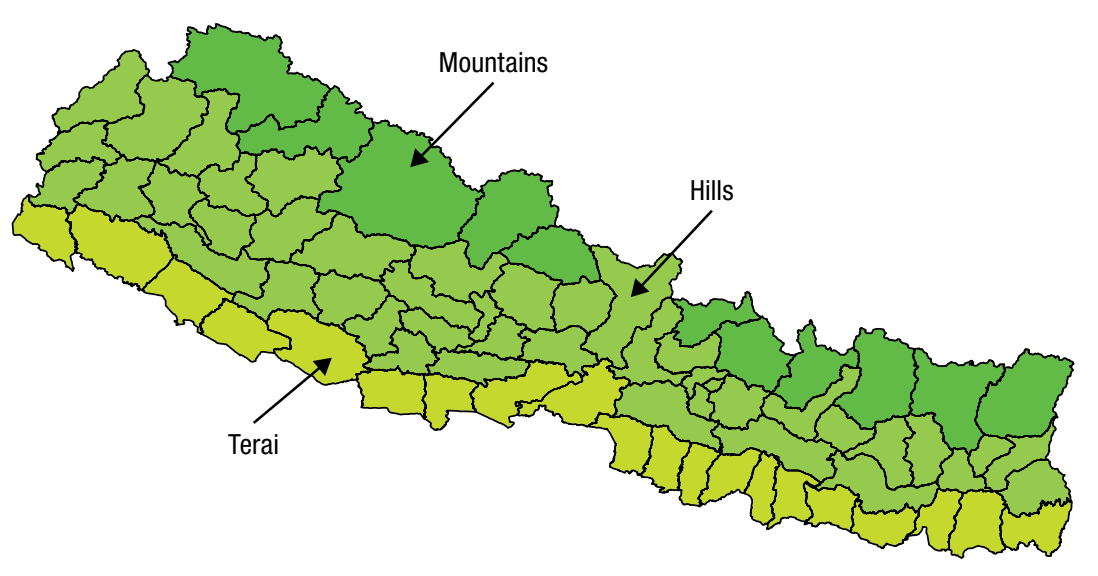

Source: Authors.

(Figure 9.1). Table 9.1 summarizes the key mechanization growth trends, as well as the relevant background economic structure of the country in the past several decades. As far as mechanization is concerned, the recent era can be categorized into roughly three periods: (1) pre-1990s, (2) 1990s-2006: takeoff of tractor adoption rates in the Terai, and (3) 2006 and after: widespread growth of tractor adoption throughout the Terai, takeoff of motorized pumps in the Terai, and takeoff of power tillers and mini-tillers in the Hills.

\section{Demand-Side Analysis}

\section{Use and/or Ownership of Tractors and Combine Harvesters}

Nepal has diverse agroecological environments (Table 9.2) that cut across its five development regions, (from east to west) Eastern, Central, Western, Midwestern, and Far Western. Most notably, whereas the Terai is characterized by more lowland and flatter terrain, the Hills region is characterized by greater endowments of upland and more rugged terrain, as well as more pastures and draft animals.

\section{TRACTORS}

Growth in tractor use in Nepal has occurred mostly in the Terai, whereas growth has been slower in the Hills, based on data from the Nepal Living Standards Survey, or NLSS (Nepal, CBS 1996, 2004, 2011); however, there 
TABLE 9.1 Evolution of different scales of mechanization in Nepal, 1970-2016

\begin{tabular}{|c|c|c|c|c|c|c|c|c|c|}
\hline Variable & $\begin{array}{c}1970- \\
1974\end{array}$ & $\begin{array}{c}1975- \\
1979\end{array}$ & $\begin{array}{c}1980- \\
1984\end{array}$ & $\begin{array}{c}1985- \\
1989\end{array}$ & $\begin{array}{c}1990- \\
1994\end{array}$ & $\begin{array}{l}1995- \\
1999\end{array}$ & $\begin{array}{l}2000- \\
2004\end{array}$ & $\begin{array}{c}2005- \\
2009\end{array}$ & $\begin{array}{c}2010- \\
2016\end{array}$ \\
\hline \multicolumn{10}{|c|}{ Percentage of farm power availability from different sources } \\
\hline Mechanical & - & - & 8 & - & 15 & - & 32 & - & - \\
\hline Animal & - & - & 43 & - & 39 & - & 28 & - & - \\
\hline Labor & - & - & 49 & - & 46 & - & 40 & - & - \\
\hline \multicolumn{10}{|c|}{ Approximate number of tractors estimated from various sources } \\
\hline All tractors & - & 2,000 & - & 5,000 & 8,500 & 16,300 & 25,000 & 30,000 & 47,000 \\
\hline 4-wheel tractors & - & 1,700 & - & 4,000 & 7,200 & - & - & - & 30,000 \\
\hline 2-wheel tractors & - & 300 & 750 & 1,000 & 1,300 & - & - & - & 12,000 \\
\hline Mini-tillers & - & - & - & - & - & - & - & 500 & 5,000 \\
\hline \multicolumn{10}{|c|}{ Farmers adopting tractors (\%) } \\
\hline Nepal & - & - & - & - & 1 & 5 & 16 & - & 23 \\
\hline Terai zone & - & - & - & - & - & 8 & 29 & - & 46 \\
\hline \multicolumn{10}{|c|}{ Rice and wheat areas harvested by combine harvesters (\%) } \\
\hline $\begin{array}{l}\text { Western Terai (Kapil- } \\
\text { bastu, Rupendhai, and } \\
\text { Nawalparasi) }\end{array}$ & - & - & - & - & - & - & 1 & 2 & 10 \\
\hline \multicolumn{10}{|l|}{ GDP share (\%) } \\
\hline Agriculture & 68 & 66 & 61 & 51 & 46 & 41 & 38 & 34 & 35 \\
\hline Industry & 10 & 10 & 12 & 16 & 19 & 22 & 19 & 17 & 16 \\
\hline Service & 22 & 24 & 27 & 33 & 35 & 37 & 43 & 49 & 49 \\
\hline $\begin{array}{l}\text { Labor force in agricul- } \\
\text { tural sector }(\%)\end{array}$ & - & - & - & - & $\begin{array}{r}83 \\
(1991)\end{array}$ & $\begin{array}{r}76 \\
(1999)\end{array}$ & - & $\begin{array}{r}74 \\
(2008)\end{array}$ & $\begin{array}{r}67 \\
(2013)\end{array}$ \\
\hline Male (\%) & - & - & - & - & 75 & 67 & - & 62 & - \\
\hline Female (\%) & - & - & - & - & 91 & 85 & - & 84 & - \\
\hline
\end{tabular}

Source: Takeshima (2017b).

Note: $-=$ data not available; GDP $=$ gross domestic product.

are some indications that use has been growing faster since 2010 (the most recent round of the NLSS), particularly in the Central development region, thanks to growth in the use of power tillers and mini-tillers. Within the Terai, the Central and Western development regions led the diffusion of tractor use, but the Eastern, Midwestern, and Far Western development regions have caught up (Table 9.3).

Although NLSS data do not report which crops tractors are actually used for, the correlation of crops grown by the households and their tractor use offers certain insights. Table 9.4 summarizes the share (percentage) of farmers 
TABLE 9.2 Land-to-labor ratio, terrain ruggedness, and draft animal holdings, Nepal, 2010

\begin{tabular}{|c|c|c|c|c|c|c|c|c|c|c|}
\hline \multirow{2}{*}{$\begin{array}{l}\text { Development } \\
\text { region }\end{array}$} & \multicolumn{2}{|c|}{$\begin{array}{c}\text { Agricultural } \\
\text { area per capita } \\
\text { (cropped area + } \\
\text { pasture) (ha) }\end{array}$} & \multicolumn{2}{|c|}{$\begin{array}{l}\text { Average owned } \\
\text { farm size } \\
\text { (lowland) (ha) }\end{array}$} & \multicolumn{2}{|c|}{$\begin{array}{l}\text { Average owned } \\
\text { farm size } \\
\text { (upland) (ha) }\end{array}$} & \multicolumn{2}{|c|}{$\begin{array}{c}\text { Terrain } \\
\text { ruggedness } \\
\text { index }\end{array}$} & \multicolumn{2}{|c|}{$\begin{array}{c}\text { Draft animals } \\
\text { per farm } \\
\text { household } \\
\text { (bullocks/cows/ } \\
\text { buffalo) }\end{array}$} \\
\hline & Terai & Hills & Terai & Hills & Terai & Hills & Terai & Hills & Terai & Hills \\
\hline All & 0.12 & 0.22 & 0.59 & 0.19 & 0.09 & 0.39 & 43 & 478 & 2.2 & 3.0 \\
\hline Eastern & 0.13 & 0.25 & 0.59 & 0.26 & 0.09 & 0.54 & 38 & 463 & 2.4 & 3.5 \\
\hline Central & 0.09 & 0.16 & 0.60 & 0.21 & 0.10 & 0.28 & 22 & 405 & 1.7 & 2.4 \\
\hline Western & 0.13 & 0.19 & 0.69 & 0.17 & 0.03 & 0.35 & 36 & 489 & 2.0 & 2.6 \\
\hline $\begin{array}{l}\text { Midwestern and } \\
\text { Far Western }\end{array}$ & 0.12 & 0.29 & 0.48 & 0.13 & 0.11 & 0.43 & 90 & 554 & 2.7 & 3.8 \\
\hline
\end{tabular}

Source: Takeshima, Adhikari, et al. (2015).

TABLE 9.3 Share (percentage) of farm households using tractors, by year and agroecological belt, Nepal, 1995-2010

\begin{tabular}{|c|c|c|c|c|c|c|c|c|c|}
\hline \multirow{2}{*}{$\begin{array}{l}\text { Development } \\
\text { region }\end{array}$} & \multicolumn{3}{|c|}{ Terai } & \multicolumn{3}{|c|}{ Hills } & \multicolumn{3}{|c|}{ Mountains } \\
\hline & 1995 & 2003 & 2010 & 1995 & 2003 & 2010 & 1995 & 2003 & 2010 \\
\hline All & 8 & 29 & 46 & 3 & 5 & 8 & 1 & 0 & 2 \\
\hline Eastern & 2 & 13 & 33 & 0 & 0 & 2 & 1 & 0 & 0 \\
\hline Central & 11 & 39 & 56 & 5 & 9 & 20 & 0 & 0 & 5 \\
\hline Western & 15 & 56 & 72 & 1 & 4 & 5 & 0 & 0 & 0 \\
\hline $\begin{array}{l}\text { Midwestern and } \\
\text { Far Western }\end{array}$ & 5 & 15 & 29 & 1 & 0 & 1 & 1 & 0 & 0 \\
\hline
\end{tabular}

Source: Takeshima, Adhikari, et al. (2015).

growing each of the major crops, differentiated by their tractor use status, in the Nepal Terai and Hills in 2010.

One of the dominant staple-crop production systems in the Nepal Terai is the well-known rice-wheat systems that are common in the Indo-Gangetic Plain, in which rice is grown during the rainy season and wheat is produced during the dry season. In 2010,70 percent and 50 percent of tractor-using farm households and nonusing farm households, respectively, practiced this system in the Nepal Terai (Table 9.4). Although other crops such as maize, lentils, potatoes, and vegetables are also commonly grown, tractors are most commonly used for tillage for rice and wheat (Ladha et al. 2003). In this system, water leveling and wet tillage (puddling) are common forms of tillage for rice, and intensive deep tillage is practiced for wheat at the beginning of the dry season to reduce the soil compaction developed from rainy-season rice 
TABLE 9.4 Mechanization and cropping patterns (percentage of farmers growing each crop), Nepal, 2010

\begin{tabular}{|c|c|c|c|c|c|c|c|c|c|c|c|c|}
\hline \multirow[b]{3}{*}{ Crop } & \multicolumn{6}{|c|}{ Terai } & \multicolumn{6}{|c|}{ Hills } \\
\hline & \multicolumn{2}{|c|}{$\begin{array}{l}2010 \\
\text { season }\end{array}$} & \multicolumn{2}{|c|}{$\begin{array}{l}2010 \text { rainy } \\
\text { season }\end{array}$} & \multicolumn{2}{|c|}{$\begin{array}{l}2010 \text { dry } \\
\text { season }\end{array}$} & \multicolumn{2}{|c|}{$\begin{array}{l}2010 \\
\text { season }\end{array}$} & \multicolumn{2}{|c|}{$\begin{array}{l}2010 \text { rainy } \\
\text { season }\end{array}$} & \multicolumn{2}{|c|}{$\begin{array}{l}2010 \text { dry } \\
\text { season }\end{array}$} \\
\hline & $\begin{array}{l}\text { Tractor } \\
\text { users }\end{array}$ & $\begin{array}{l}\text { Non- } \\
\text { users }\end{array}$ & $\begin{array}{l}\text { Tractor } \\
\text { users }\end{array}$ & $\begin{array}{l}\text { Non- } \\
\text { users }\end{array}$ & $\begin{array}{l}\text { Tractor } \\
\text { users }\end{array}$ & $\begin{array}{l}\text { Non- } \\
\text { users }\end{array}$ & $\begin{array}{l}\text { Tractor } \\
\text { users }\end{array}$ & $\begin{array}{l}\text { Non- } \\
\text { users }\end{array}$ & $\begin{array}{c}\text { Tractor } \\
\text { users }\end{array}$ & $\begin{array}{l}\text { Non- } \\
\text { users }\end{array}$ & $\begin{array}{l}\text { Tractor } \\
\text { users }\end{array}$ & $\begin{array}{l}\text { Non- } \\
\text { users }\end{array}$ \\
\hline Rice & 95 & 74 & 93 & 72 & 2 & 2 & 90 & 64 & 89 & 63 & 17 & 3 \\
\hline Wheat & 69 & 50 & 0 & 0 & 69 & 50 & 47 & 49 & 0 & 0 & 47 & 48 \\
\hline Maize & 38 & 44 & 22 & 34 & 15 & 11 & 73 & 95 & 67 & 91 & 17 & 9 \\
\hline Winter maize & 16 & 10 & 1 & 0 & 15 & 11 & 17 & 9 & 0 & 1 & 17 & 9 \\
\hline Summer maize & 21 & 36 & 22 & 34 & 0 & 0 & 67 & 90 & 67 & 90 & 0 & 0 \\
\hline Lentils & 58 & 41 & 0 & 0 & 57 & 41 & 5 & 15 & 0 & 0 & 5 & 15 \\
\hline Winter potatoes & 57 & 53 & 0 & 0 & 52 & 47 & 57 & 46 & 0 & 0 & 57 & 46 \\
\hline Mustard & 48 & 35 & 0 & 1 & 46 & 33 & 31 & 38 & 1 & 1 & 30 & 36 \\
\hline Onions & 37 & 37 & 1 & 1 & 27 & 29 & 20 & 24 & 2 & 1 & 18 & 23 \\
\hline Garlic & 42 & 40 & 1 & 1 & 28 & 30 & 27 & 28 & 0 & 2 & 27 & 26 \\
\hline Winter vegetables & 60 & 67 & 1 & 1 & 49 & 59 & 56 & 67 & 2 & 1 & 54 & 66 \\
\hline $\begin{array}{l}\text { Summer vege- } \\
\text { tables }\end{array}$ & 51 & 57 & 38 & 51 & 1 & 0 & 48 & 66 & 46 & 65 & 2 & 1 \\
\hline
\end{tabular}

Source: Authors' calculations based on data from the Nepal Living Standards Survey for 2010 (Nepal, CBS 2011).

production. Four-wheel tractors rather than two-wheel tractors have traditionally been more commonly used, because the soil is dry when deep tillage for wheat is practiced and requires fairly strong machine power. Relatedly, wet tillage for rice is often practiced by relying on monsoon rains (Sharma, Ladha, and Bhushan 2003) rather than thoroughly flooding by irrigation, for which four-wheel tractors can be used.

In the Hills, the association between tractors and wheat appears weaker. In addition, although maize (particularly summer maize) is more widely grown in the Hills than elsewhere, the share of maize growers is higher among nonusers of tractors. Therefore, in the Hills, tractors may be more strongly associated with rice.

\section{COMBINE HARVESTERS}

The extent of combine harvester use in Nepal is not well known, partly because neither the agricultural census nor the NLSS collects such information. Recent studies report that where harvesting services are provided, they are provided by private-sector actors, including large combine owners in India (Biggs, Justice, and Lewis 2011) or within the Terai (Pant 2013). Areas studied 
by Pant (2013) were populated by farmers with medium-size landholdings (2-3 ha), for whom rice was harvested at a rate of about 0.70 ha per hour and at a cost of about $\$ 50^{1}$ per hectare, a price that is approximately 25 percent lower than the cost of manual harvesting. A recent study in the Western development region of the Terai (Kapilvastu, Rupandehi, and Nawalparasi districts) suggests that the number of combine harvesters in these districts has increased from 1 in the year 2000 to 24 in 2010 and 150 in 2014, by which time 21 percent of wheat area and 8 percent of rice area in these districts might have been harvested by combine harvesters (Paudel et al. 2015).

\section{Key Characteristics of Terai Farm Households with Different Mechanization Statuses}

Takeshima (2017b, Table 2.4) summarized the key characteristics of Terai and Hills households, differentiated by farming status and further by mechanization status. Farm households generally consume less than nonfarm households do, as measured by real expenditure per capita. Within farm households, tractor-owning households enjoy higher consumption and own more assets than other farm households. In 2010, their expenditures and asset values were about 4 to 6 times higher than the levels of all farm households in the Terai, and more than 10 times higher than those of households in the Hills. Differences between tractor renters and users of only draft animals are smaller than those between tractor owners and users of draft animals. Tractor renters, however, enjoy consumption and assets that are typically 30-50 percent higher than those of draft-animal-only users in the Terai. In the Terai, nonmechanized households' incomes and assets are typically much lower than those of other farm households.

About 40-50 percent of farm households sell their crops, and 60 percent sell either crops or livestock products. These shares are higher among tractor owners, followed by tractor renters and draft-animal-only users. Nonmechanized farm households are primarily engaged in subsistence agriculture. Working-age members of tractor-owning households are better educated, having completed, on average, approximately seven years of schooling, substantially more than the average for other farm households (Takeshima 2017b).

Tractor renters also have generally better market access than draft-animalonly households and other nonmechanized households. This is particularly pronounced in the Hills. In the Terai, between 2003 and 2010, more tractor

1 Dollar figures are US dollars throughout the chapter. 
owners emerged in suburban areas or areas where access had improved (closer to various facilities than non-owners, unlike in 2003). Much growth in tractor ownership in the Terai between 2003 and 2010 occurred in relatively suburban areas instead of remote farm areas (Takeshima, Adhikari, et al. 2015).

In the Hills, wages vary more across household types, and tractor renters pay higher wages than do farmers not using tractors. Mechanization status is also positively associated with local land-to-labor ratios (measured in agricultural land endowment per capita, which combines cropped areas and pastures). Intuitively, farm households are in areas with greater agricultural land endowment than are nonfarm households. Among farm households, tractor owners or tractor users are in areas less endowed with agricultural land than are draft animal users, possibly because pastures are important sources of feed for animals.

Mechanization status is closely negatively associated with terrain ruggedness. Specifically, more tractors are used in flatter areas than in rugged areas, and tractor owners are located in especially flat areas. This applies to both the Terai and the Hills, even though the Hills zone has considerably more rugged terrain than the Terai overall.

\section{Farm Size Distribution and Tractor Use}

In the Nepal Terai, tractor use has grown while average farm size has declined over time due to growth in the absolute number of farm households and also due to land fragmentation (Takeshima, Adhikari, et al. 2015). However, tractor adoption is still positively associated with farm size (Takeshima 2017b, Table 2.4). Tractor-owning households tend to own more farmland than other farm households. Though the patterns are less clear in the Hills, tractor owners own the largest lowland areas (though their cultivated areas are not the largest). However, the extent of substitution of tractors for animal traction in the Terai between 2003 and 2010 was greater among larger farm households (Figure 9.2). Consequently, although in 2003 tractor adoption rates were relatively uncorrelated with farm size, by 2010 they were positively correlated with farm size.

\section{Evolution of Farm Household Characteristics}

Although Takeshima (2017b, Table 2.4) compared farm household characteristics across mechanization statuses in 2010, the evolution of overall farm household characteristics up to 2010 also provides a useful indication of the context in which tractor use has grown (Table 9.5). 
FIGURE 9.2 Share of Terai farm households renting tractors or using only draft animals, by farm size (left = tractor renters; right = draft animals only), Nepal, 2003 and 2010
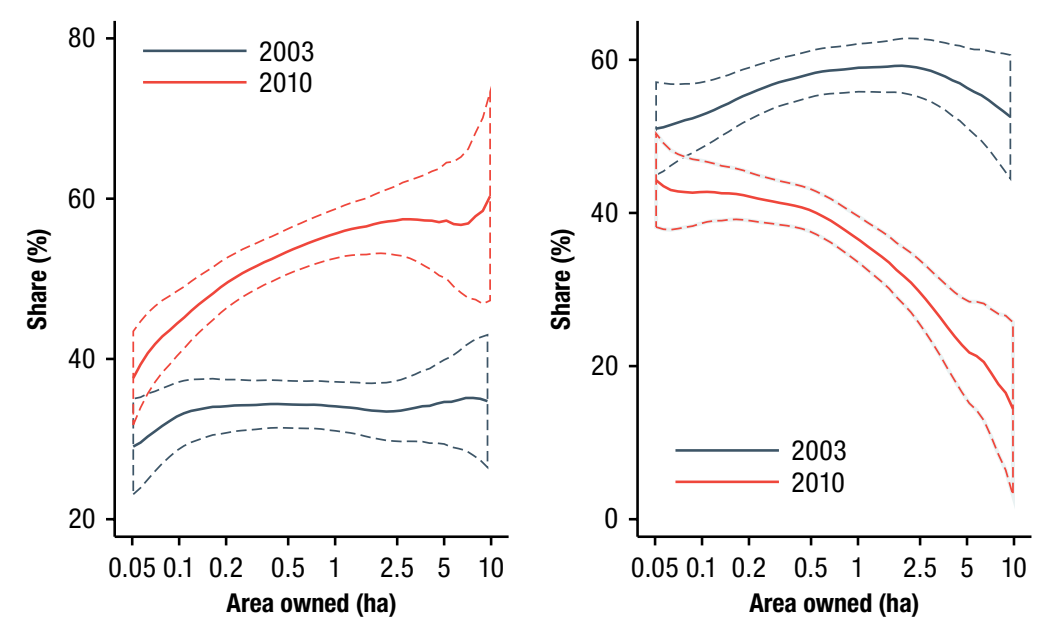

Source: Takeshima, Adhikari, et al. (2015).

Note: Dashed lines represent $95 \%$ confidence interval.

Between 1995 and 2010, for many farm households in the Terai, access to markets improved considerably, and at a relatively faster rate than in the Hills and Mountains. This access has been associated with increased market participation, which was also slightly higher in the Terai throughout this period. Better market access and adoption of tractors are often positively related because the former often induces more intensive land preparation, for which the substitution of tractor power for animal power has greater returns, and also because tractors may offer an important means of transporting harvests to market. During this period, the operational scale of farm households, in terms of production revenues, increased as well. The operational scale of farm households in the Terai was greater than that of households in the Hills or Mountains and grew relatively faster between 1995 and 2010.

This growth occurred despite the continued decline in average farm size due to fragmentation. The share of those cultivating less than 0.2 ha increased, whereas the share of those cultivating more than 3.0 ha a year decreased. The growth in tractor adoption in the Terai reduced the rate of this decline (this is the positive effect on area cultivated, presented in the later section of this chapter titled "Role of Mechanization in Agricultural Transformation"), but 
TABLE 9.5 Farm household characteristics, Nepal, 1995-2010

\begin{tabular}{|c|c|c|c|c|c|c|c|c|c|}
\hline \multirow[b]{2}{*}{ Variable } & \multicolumn{3}{|c|}{ Terai } & \multicolumn{3}{|c|}{ Hills } & \multicolumn{3}{|c|}{ Mountains } \\
\hline & 1995 & 2003 & 2010 & 1995 & 2003 & 2010 & 1995 & 2003 & 2010 \\
\hline Households in farming (\%) & 76 & 73 & 72 & 88 & 80 & 76 & 97 & 96 & 91 \\
\hline Selling crops $(\%)^{\mathrm{a}}$ & 52 & 86 & 77 & 38 & 59 & 57 & 41 & 57 & 53 \\
\hline Selling crops or livestock products (\%) ${ }^{\mathrm{a}}$ & 70 & 89 & 85 & 63 & 72 & 73 & 56 & 78 & 68 \\
\hline \multicolumn{10}{|l|}{ Area cultivated per year (ha) } \\
\hline Average (ha) & 2.4 & 2.0 & 1.4 & 1.5 & 1.3 & 1.0 & 2.1 & 1.6 & 1.3 \\
\hline \multicolumn{10}{|l|}{ Distribution (\%) } \\
\hline$<0.2$ ha & 8 & 9 & 15 & 11 & 9 & 12 & 7 & 6 & 5 \\
\hline $0.2-3.0$ ha & 67 & 72 & 74 & 81 & 83 & 84 & 75 & 84 & 88 \\
\hline$>3.0 \mathrm{ha}$ & 25 & 19 & 11 & 8 & 8 & 4 & 18 & 11 & 7 \\
\hline \multicolumn{10}{|c|}{ Annual agricultural revenue (crop + livestock) (equivalent to metric tons of cereal) } \\
\hline Average & 3.3 & 4.5 & 4.5 & 2.2 & 3.2 & 2.7 & 2.1 & 2.8 & 2.6 \\
\hline \multicolumn{10}{|l|}{ Distribution (\%) } \\
\hline$<1.0$ & 22 & 17 & 20 & 30 & 20 & 22 & 30 & 14 & 20 \\
\hline $1.0-3.0$ & 32 & 31 & 33 & 48 & 39 & 46 & 49 & 49 & 52 \\
\hline$>3.0-5.0$ & 21 & 20 & 19 & 15 & 23 & 20 & 14 & 27 & 20 \\
\hline$>5.0$ & 25 & 33 & 29 & 7 & 18 & 11 & 7 & 11 & 8 \\
\hline $\begin{array}{l}\text { Share }(\%) \text { of agricultural revenue in } \\
\text { total Household revenue (among farm } \\
\text { households) }\end{array}$ & 79 & 73 & 73 & 82 & 75 & 77 & 87 & 81 & 81 \\
\hline Rice, wheat, and maize & 57 & 51 & 45 & 42 & 35 & 31 & 42 & 40 & 31 \\
\hline Other crops & 28 & 33 & 36 & 35 & 38 & 43 & 40 & 37 & 47 \\
\hline Livestock products & 15 & 16 & 19 & 23 & 27 & 26 & 18 & 23 & 22 \\
\hline Time to nearest market center (minutes) & 120 & 60 & 30 & 150 & 180 & 120 & 180 & 180 & 120 \\
\hline
\end{tabular}

Source: Authors' calculations based on data from the Nepal Living Standards Survey for 1995, 2003, 2010 (Nepal, CBS 1996, 2004, 2011).

Note: a. Figures are weighted by the area cultivated by the household.

it has not caused a substantial turnaround in average farm size. The aforementioned growth in operational scale in terms of production value has therefore been achieved through substantial growth in production value per calculated area.

Importantly, the growth in the production scale in terms of value occurred without substantial changes in household revenue composition; the share of revenues from staple crops (rice, wheat, and maize) remained high and declined relatively slowly, and agricultural revenues remained the majority of 
overall household revenues. In the Terai, household economic growth was relatively neutral across activities, growing not only for nonagricultural activities but also for agricultural activities, including the production of key staple crops. It was in this context that the adoption of tractors grew rapidly among farm households in the Terai.

\section{Broader Economic Transformation and the Labor Market}

Although both agricultural and nonagricultural sectors have grown in Nepal, labor has gradually shifted to more labor-intensive nonagricultural sectors. Combined with the increase in average education levels between 1995 and 2010 —from 2.5 to 4.7 years of schooling for those 15 years of age or older (Takeshima, Adhikari, et al. 2015) — this shift in labor has raised farming wages. Takeshima (2017b, Table 2.6) summarized the breakdown of labor activities and the evolution among the working-age population (ages 15-59), which accounts for approximately 55 percent and 58 percent of males and females, respectively, in Nepal. In addition to the aggregate shares of labor force by sector, shown in Table 9.1, Takeshima (2017b, Table 2.6) provided further insights into the breakdown across agroecological belts, more disaggregated types/sectors of activities, and the effects of out-migration on the overall workforce, which are often not taken into account in a standard view of the employment share by sector. Importantly, because Takeshima (2017b, Table 2.6) also allocated shares to emigrants and those who were not working for various reasons, the shares he reported for both the agricultural sector and the nonagricultural sector were lower than the employment shares we report in Table 9.1.

Takeshima (2017b, Table 2.6) offered key insights. The share of emigrants (measured by the absent population) has grown, particularly among the working-age male population. By 2010, it accounted for approximately 15-20 percent of working-age males in Nepal. The greatest growth is observed in the Hills (from 11 percent in 1995 to 21 percent in 2010), where tractor use growth has been slower than in the Terai. However, some of the migrants from the Hills might have relocated to the Terai, as shown by the faster growth of the working-age population in the Terai than in the Hills. The shares of nonfarm work grew, particularly for males in the Terai (from 9 percent to 17 percent for nonagricultural self-employment, and from 7 percent to 19 percent for nonagricultural wage employment) and for females in the Hills (from 9 percent to 27 percent). Employment growth in the construction sector and the finance and business sector accounted for a substantial share of this growth. 
The share of the labor force in agricultural labor needs careful interpretation. The share declined overall between 1995 and 2010, which is consistent with the increase in agricultural wages we will see in the next section. This decline occurred across the agroecological belts, not only in the Terai. Although the share of agricultural wage work declined relatively more sharply in the Terai (from 22 percent to 10 percent for males, and from 21 percent to 14 percent for females), the share also remained higher in the Terai, indicating a greater reliance on hired labor in farming there. As we will see in the section "Role of Mechanization in Agricultural Transformation," tractor use growth has actually had a positive effect on hired labor use for complementary farming operations that have remained unmechanized despite the wage increases. The decline in agricultural wage work is unlikely to have been caused by the growth in tractor use. It is likely to have been caused largely by increasing labor absorption into the nonfarm sector (which would have happened even in the absence of growth in tractor use). This has, however, raised wages, which has induced substitution for labor in certain activities (such as plowing) by tractors.

Table 9.6 shows the changes in real daily wages for various farming operations, measured in terms of how many kilograms of milled rice a day of labor can buy, given the local milled rice price. In absolute terms, the increase in wages for plowing has been relatively greater than the increase in wages for all the other farming operations. Though an investigation of the causes of these differential wage growth rates is beyond the scope of this book, these figures may suggest that agricultural productivity in Nepal has become increasingly dependent on intensive plowing over time. However, although the plowing wage has increased across all agroecological belts, the adoption of tractors in the Hills and Mountains has been slower, due to other geographical features, as described above.

\section{Determinants of Tractor Adoption and Intensity of Use (Expenditures on Rented Tractors)}

Applying double-hurdle models to pooled cross-sectional samples of farm households in the NLSS, Takeshima, Adhikari, and Kumar (2016) estimated the determinants of tractor adoption and the intensity of tractor use (total expenditures on hiring services). Generally, both adoption and intensity of use are positively associated with a larger lowland area owned (but not upland area), a higher value of such land, greater holdings of livestock and farm equipment, having electricity as the main source of lighting in the house (which releases family labor), and a larger household—see Takeshima, Adhikari, and 
TABLE 9.6 Daily agricultural wages (in $\mathrm{kg}$ of milled rice a day of labor purchases), Nepal, 1995 and 2010

\begin{tabular}{lccccc}
\hline Activity and year & All-male & Terai & Hills & Mountains & All-female \\
\hline Plowing-1995 & 3.6 & 4.0 & 3.2 & 2.7 & 2.4 \\
Plowing-2010 & 6.7 & 7.1 & 6.3 & 5.3 & 7.1 \\
Planting-1995 & 2.8 & 3.1 & 2.4 & 2.1 & 2.5 \\
Planting-2010 & 4.2 & 4.6 & 4.0 & 3.4 & 4.2 \\
Weeding-1995 & 2.6 & 2.9 & 2.3 & 2.0 & 2.5 \\
Weeding-2010 & 4.9 & 5.3 & 4.7 & 3.9 & 4.3 \\
Harvesting-1995 & 2.8 & 3.1 & 2.5 & 2.1 & 2.5 \\
Harvesting-2010 & 5.3 & 5.7 & 5.0 & 4.2 & 4.4 \\
\hline
\end{tabular}

Source: Authors' calculations based on data from the Nepal Living Standards Survey for 1995 and 2010 (Nepal, CBS 1996, 2011).

Note: The milled rice purchase price is the average of the prices of fine, coarse, and beaten/flattened rice, which are appropriately replaced by district, regional, and rural/urban medians when missing.

Kumar (2016) for the interpretations. In addition, adoption of hired tractors is positively associated with flatter terrain, lower elevations, and better access to the nearest market center and a paved road. The intensity of tractor use upon adoption is positively associated with higher real wages and higher chemical fertilizer prices, which are typically substitutes for tractor use. ${ }^{2}$ Intensity of use is also positively associated with greater rainfall and less rainfall variability.

Findings in Takeshima, Adhikari, and Kumar (2016) also provide modest evidence that access to custom hiring services may be still limited. A greater share of tractor owners within the village development committee (VDC) ${ }^{3}$ is associated with both greater adoption of and greater expenditures on hired tractors in the Hills and Mountains. Even marginal adoption of tractors led to a significant increase in income in the Terai, consistent with the accessibility constraints. This finding is also consistent with the limited spatial mobility of tractors and the geographic coverage of tractor hiring services observed in Nigeria, where four-wheel tractors also provide most tractor services through custom hiring (Takeshima, Edeh, et al. 2015).

2 However, as noted in the section titled "Role of Mechanization in Agricultural Transformation," the use of tractors may lead to an overall increase in some labor or chemical fertilizer use if the income effects or scale effects from using tractors outweigh the substitution effects.

3 VDCs are administrative units below the district level in Nepal. Approximately 3,000 VDCs exist in Nepal, though their numbers change over time. 


\section{Summary: Demand for Mechanization}

In most of the Terai and the lowland areas of the Hills, demand among smallholders for tractors for land preparation has grown sufficiently, generating large enough markets for custom hiring services. Demand for mechanized harvesting is more difficult to assess due to the lack of information. However, in parts of the Terai, such as the Western development region, the demand is likely to have grown sufficiently, as witnessed by growth in the mechanically harvested shares of wheat and rice. The demand for conventional machines in relatively more rugged areas, particularly in the Hills and Mountains, may remain lower. However, demand for mini-tillers, which are suitable for use in these environments, may be rising to a sufficient scale.

The share of farm households mechanizing harvesting has remained lower than the share of those using tractors (mostly likely for land preparation). These growth patterns, reflecting sequential adoption, are consistent with past theories.

A number of factors seem to affect growth in the demand for tractor use in Nepal. Growth in tractor use in the Terai is correlated particularly with rising wages for plowing, consistent with the hypothesis that tractors substitute for the labor used for plowing. Plowing wages have also increased faster than wages for other farming operations, which may partially explain why overall labor use may not decrease as a result of tractor adoption (see further discussion in "Role of Mechanization in Agricultural Transformation").

Plowing wages have risen both in the Terai and in the Hills, though they have remained slightly lower in the latter. Geographic factors, however, seem to explain the slower growth in tractor use in the Hills. Slower growth in tractor use is correlated with rugged terrain, general remoteness from the nearest market center, and the relatively lower endowment of lowland in the Hills. Most farm households in the Hills are also located in areas with lower population density with respect to agricultural land, including pastures, conditions that may be more favorable for keeping draft animals.

\section{Supply-Side Analysis}

There was no integrated agricultural mechanization policy in Nepal until 2014, when the Agricultural Mechanization Promotion Policy was promulgated (Takeshima et al. 2016). The government of Nepal, however, has implemented various policies relevant to agricultural mechanization. 


\section{Machinery Purchase and Import Policies}

TRADE AND IMPORT POLICIES (TARIFFS, DIRECT RESTRICTIONS, AND OTHER INTERVENTIONS)

In Nepal, tractor importation was relatively limited until the 1960s (FAO 2016), though between 1965/1966 and 1969/1970, some 794 tractors and 1,280 pump sets were imported by the Land Reform Savings Corporation, the National Trading Corporation, the Agricultural Supply Corporation, Birgunj Sugar Factory, and private dealers (Hjort 1973). A vehicle tax introduced in 1972/1973 applied to all types of vehicles, presumably including tractors (Khadka 1991). In the 1970s, the import tax on farm equipment was reduced to 1 percent of the CIF (cost, insurance, and freight) or FOB (free on board) price of imported equipment (Shrestha 1978).

Throughout the tax reforms in Nepal, tractors were exempted from taxes. In 1990, the Wealth Tax Act exempted agricultural machinery, including tractors, from taxes. Although tractors for other purposes had generally been subject to value-added tax (VAT) (Jenkins and Kuo 2000), the 1996 VAT Act granted tax exemption to selected agricultural products, including agricultural machinery (NARMA Consultancy Pvt. Ltd. 2016). Since then, tractors used for agricultural purposes have been exempt from VAT, but tractors for transporting nonagricultural goods have been subject to VAT (Sharma and Sarker 2015), which was 5 percent as of 2014 (World Bank 2016). There are ad valorem tariffs of 5 percent for nonagricultural tractors as well (World Bank 2016). This differential VAT has, however, not been easily implemented because suppliers of tractors do not always know for which purposes their tractors will be used (Sharma and Sarker 2015).

Generally, 15 percent tariffs have been imposed on general parts that can be used for tractors (World Bank 2016). However, under the India-Nepal Transit Treaty and the bilateral Treaty of Trade, also with India, a preferential tariff applies, which is currently generally 7.25 percent (Sharma 2015; World Bank 2016). Anecdotal evidence suggests that such high tariffs were placed to curb the growing congestion and worsening road conditions across the country.

No concessional loans or other bilateral agreements have been specifically applied to tractor imports to Nepal, though Nepal has various bilateral agreements with India, its largest trade partner and largest foreign aid donor since as early as $1970 .^{4}$

4 In 1970/1971, India accounted for 45 percent of foreign aid to Nepal, with the United States and China accounting for 22 percent and 17 percent, respectively (Hjort 1973). 


\section{PROMOTION POLICIES (SUBSIDIES AND OTHER POLICIES)}

The government's efforts to promote agricultural mechanization began in Nepal in the 1960s with the introduction of four-wheel tractors, sometimes through donor-supported policies (Joshi, Conroy, and Witcombe 2012). In 1964, 64 tractors and 30 pump sets were introduced into the country (CSAM 2014). In the 1970s, the Agricultural Development Bank of Nepal provided loans at 14 percent interest per year (Shrestha 1978). Similarly, agricultural credit projects financed by the Asian Development Bank (ADB) started importing tractors and distributing them to farmers, but the initiative was discontinued in the early 1980s (Pariyar and Singh 1995). There were concerns that the demand for mechanization was still too low (Roumasset and Thapa 1983) and that subsidizing it could displace workers. Similarly, over the period 1980-1985, ADB Nepal discouraged financing tractors and other agricultural machines (CSAM 2014).

Since then, subsidies for tractors or other mechanization tools have been rare in Nepal, except for irrigation-related machinery such as pumps (Biggs et al. 2002). Generally, financial support for tractors or power tillers, other than through tax exemptions, as mentioned above, has been discouraged for fear of increased traffic congestion (Joshi, Conroy, and Witcombe 2012).

It is only recently that more direct support for and promotion of machinery such as tractors and power tillers has been expanded. Under the Agriculture Perspective Plan (1995-2015) and National Agriculture Policy 2004, the Directorate of Agricultural Engineering, which was established in 2004 within the Department of Agriculture, has been implementing promotional extension and training programs for agricultural machinery and providing related services (Nepal, MoAD 2014; Takeshima et al. 2017). Sometimes, financial support for machine investments has been provided through poverty reduction programs. For example, in 2004, the Poverty Alleviation Fund in Nepal was prepared to refinance loans for two-wheel tractors and other smaller-scale equipment to poorer rural households (Biggs and Justice 2015). In 2014, the Ministry of Agriculture and Livestock Development approved the Agricultural Mechanization Subsidy Mobilization Directives for distributing subsidies through the Directorate of Agricultural Engineering (NARMA Consultancy Pvt. Ltd. 2016).

\section{LICENSING AND REGULATION}

Nepal's regulatory infrastructure related to agricultural machinery is generally underdeveloped. Since 1991, development and testing of agricultural machinery has been conducted at the Agricultural Engineering Division of the Nepal 
Agricultural Research Council (Takeshima et al. 2016). However, among the countries studied by the World Bank's Enabling the Business of Agriculture Project, Nepal is one of the countries with the weakest regulatory systems (weaker than those of some of the African countries, including Ethiopia, Ghana, and Tanzania), in terms of "legal requirements with regard to suitability, testing of agricultural tractors, specific licensing required to operate a tractor, as well as warranties and post-sale services that must be provided at the retail level" (World Bank 2016, 88). Although a separate license, issued by the Department of Transport Management under the Ministry of Labour and Transport Management, is required to drive a tractor or power tiller, currently no license is required either to import tractors or to become a tractor dealer. ${ }^{5}$

Imported tractors and combine harvesters are required to be registered with the Zonal Transportation Division and to obtain a Nepal vehicle number plate under the Vehicle and Transport Management Act (1992) and the Vehicle and Transport Management Rule of Nepal (1997) (Paudel et al. 2015; Gyawali 2014). In Nepal, however, the cost to register an imported tractor, when measured as a percentage of per capita income, is higher than that in Ethiopia or Ghana (World Bank 2016), and it is unclear what percentage of tractors or combine harvesters are officially registered. There is also a fiveyear restriction on change of ownership of two-wheel tractors, the removal of which has been under consideration (ADB 2013).

\section{OWNERSHIP AND MARKET INSTITUTIONS OF MECHANIZATION SERVICE PROVISION}

The provision of tractors, power tillers, and mini-tillers has been led by the growing number of private-sector importers and dealers. Indian tractor manufacturers (HMT, Mahindra, and Sonalika), Eicher, and Ford, as well as Bhajuratna Agency, Bhudev Trading Ford Tractor Division, and Bajra Enterprises, operate in Nepal, selling their respective brands of tractors, as well as Chinese power tillers (Adhikary 2004). The number of power tiller importers had reached 6 or 7 by 2002, with each selling about 100 per year without subsidies (Biggs et al. 2002). The number of mini-tiller importers had reached 10 by 2015 (Biggs and Justice 2015).

\section{CUSTOM HIRING SERVICE PROVIDERS}

Tractors and combine harvesters are owned by various types of entities-individual owners, cooperatives, and specialized enterprises-for the purpose of providing hiring services. Although information on custom hiring service providers is limited, a recent International Food Policy Research Institute

5 Personal communication with Ministry of Agriculture and Livestock Development staff. 
(IFPRI) survey of service providers provides useful insights (IFPRI 2016). Various types of service providers were interviewed (Table 9.7). Because the samples of each type are small, we do not intend to obtain a differential picture of the nature of service provision across different types; rather, we focus on farmer-to-farmer/private service providers and on collective insights for all types combined.

Out of 150 service providers, a majority owned tractors with $35-54 \mathrm{hp}$. About half of farmer-to-farmer/private service providers had obtained tractors or power tillers at second hand, indicating an active market for secondhand tractors. The providers typically owned a farm of approximately 1.9 ha, with an annual operational size of approximately $3 \mathrm{ha}$ (Table 9.8). Their land was predominantly lowland (irrigated) plots. The farmer-to-farmer/private service providers owned 3.3 ha on average, which is somewhat larger than the landholdings of other types of service providers.

Table 9.9 summarizes the extent of operations (number of days used per year) by different types of tractors and tillers owned, and the breakdown between own-farm use, hiring out in other farms, and nonfarm work. Tractors are generally used approximately $170-200$ days per year. Tractors are used more for nonfarm work than for farm work (although we do not have information on total revenues earned from each of these activities). Tractors are typically used 133-190 days a year for nonfarm work, which is far more than the approximately 40 days used for farming. For farming activities, tractors are used predominantly for hiring out; whereas they are typically used for only 2-4 days for farming operations on the owner's farm, they are used about 25-40 days for farming on other farms. It is therefore likely that hiring out is an important source of the benefits derived from tractor ownership. Furthermore, unlike in some African countries, such as Nigeria, the use of tractors for nonfarm work (such as transportation) is much more common in Nepal and can be the primary benefit of tractor ownership. This pattern generally holds true for farmer-to-farmer/private service providers. Importantly, whereas in some countries, such as Bangladesh, higher-horsepower four-wheel tractors are used more in farming and lower-horsepower four-wheel tractors (less than $35 \mathrm{hp}$ ) are used more for nonfarm work (such as transportation) (Animaw et al. 2016), patterns of tractor use across farming and nonfarm activities in Nepal do not seem to exhibit differences based on horsepower.

Power tillers and mini-tillers are used less than four-wheel tractors (around 20-40 days per year), especially for nonfarm work, for which a majority are not used at all. Their use for hiring out on other farms is still common. Power tillers are used 15 days for hiring out, as opposed to 5 days on the owner's 
TABLE 9.7 Types of hiring service providers interviewed, Nepal, 2016

\begin{tabular}{lc}
\hline Type & Sample of interviewed service providers \\
\hline Farmer-to-farmer/private & 39 \\
Nongovernmental organization-led & 32 \\
Conventional extension model & 28 \\
Cooperative & 21 \\
Government-led (Directorate of Agricultural Engineering) & 30 \\
Total & 150 \\
\hline
\end{tabular}

Source: IFPRI (2016).

TABLE 9.8 Size of landholdings by interviewed tractor service providers, Nepal, 2016

\begin{tabular}{|c|c|c|c|c|c|c|c|}
\hline Variable & $\mathrm{N}$ & $\begin{array}{l}\text { Total } \\
\text { (ha) }\end{array}$ & Upland & $\begin{array}{l}\text { Lowland } \\
\text { (irrigated) }\end{array}$ & $\begin{array}{c}\text { Lowland } \\
\text { (nonirrigated) }\end{array}$ & $\begin{array}{c}\text { Grazing/ } \\
\text { barren } \\
\text { land }\end{array}$ & $\begin{array}{l}\text { Public } \\
\text { land }\end{array}$ \\
\hline Own four-wheel tractor, $35-54 \mathrm{hp}$ & 104 & 1.9 & 0.1 & 1.7 & 0.1 & 0.0 & 0.0 \\
\hline Farmer-to-farmer/private & 27 & 3.3 & 0.1 & 3.0 & 0.2 & 0.0 & 0.1 \\
\hline Other types & 77 & 1.5 & 0.1 & 1.3 & 0.0 & 0.0 & 0.0 \\
\hline Own power tiller & 44 & 1.8 & 0.1 & 1.7 & 0.0 & 0.0 & 0.0 \\
\hline
\end{tabular}

Source: Author's calculations based on data from IFPRI (2016).

farm. Mini-tillers are used about 30 days for hiring out, similar to four-wheel tractors. Hiring out for farming operations is therefore likely to be the primary source of revenue from power tillers and mini-tillers.

\section{SOURCES OF FINANCING}

The tractors and power tillers owned by the interviewees were largely financed by personal savings, remittance incomes, and other informal sources, which together accounted for 60-70 percent of the purchasers' total financial requirements (Table 9.10). Although about 30 percent of tractors were also partly financed through loans from commercial banks or agricultural cooperative banks, these loans met only about 20-25 percent of the total financial requirements. The heavy reliance on personal savings and other informal sources to finance tractor purchases is consistent with the findings in other countries (for example, Nigeria).

Table 9.11 summarizes the breakdown of operating costs and depreciation per year per tractor (or power tiller), for farmer-to-farmer/private service providers, and for others. Cost breakdowns are generally similar for both tractors and power tillers and for different types of service providers. Operating costs account for 30-40 percent of expenses for tractors, and close to half for power 
TABLE 9.9 Extent of custom hiring service operations, in number of days used per year, ${ }^{\mathrm{a}}$ Nepal, 2016

\begin{tabular}{lrrccr}
\hline Type of tractor/tiller & Sample & \multicolumn{1}{c}{ Total } & $\begin{array}{c}\text { Number of } \\
\text { days used } \\
\text { on own farm }\end{array}$ & $\begin{array}{c}\text { Number of } \\
\text { days used on } \\
\text { other farms }\end{array}$ & $\begin{array}{c}\text { Number of } \\
\text { days used for } \\
\text { nonfarm work }\end{array}$ \\
\hline Tractor $(\geq 55 \mathrm{hp})$ & 10 & $170(178)$ & $2(2)$ & $39(39)$ & $146(133)$ \\
Tractor $(35-54 \mathrm{hp})$ & 98 & $177(196)$ & $4(2)$ & $40(35)$ & $133(150)$ \\
Tractor $(\leq 34 \mathrm{hp})$ & 4 & $203(215)$ & $3(3)$ & $35(25)$ & $165(190)$ \\
Power tiller & 40 & $32(20)$ & $5(4)$ & $15(13)$ & $12(0)$ \\
Mini-tiller & 8 & $38(32)$ & $5(4)$ & $33(30)$ & $0(0)$ \\
$\begin{array}{l}\text { Tractors owned by } \\
\text { farmer-to-farmer/private }\end{array}$ & 33 & $171(170)$ & $4(3)$ & $46(40)$ & $121(131)$ \\
service providers & & & & & \\
\hline
\end{tabular}

Source: IFPRI (2016).

Note: ${ }^{a}$ Figures are sample averages, and figures in parentheses are sample medians.

TABLE 9.10 Sources of financing for tractors and power tillers

\begin{tabular}{|c|c|c|c|c|c|c|}
\hline \multirow[b]{3}{*}{ Source } & \multicolumn{3}{|c|}{$\%$ share of finance } & \multicolumn{3}{|c|}{$\begin{array}{l}\% \text { of service providers using } \\
\text { each source to partly finance } \\
\text { each machine }\end{array}$} \\
\hline & \multicolumn{2}{|c|}{ Four-wheel tractors } & \multirow[b]{2}{*}{$\begin{array}{l}\text { Power } \\
\text { tillers }\end{array}$} & \multicolumn{2}{|c|}{ Four-wheel tractors } & \multirow[b]{2}{*}{$\begin{array}{l}\text { Power } \\
\text { tillers }\end{array}$} \\
\hline & $\begin{array}{l}\text { Farmer- } \\
\text { to-farmer/ } \\
\text { private }\end{array}$ & $\begin{array}{l}\text { Other (govern- } \\
\text { ment, extension, } \\
\text { cooperatives, } \\
\text { NGOs) }\end{array}$ & & $\begin{array}{l}\text { Farmer- } \\
\text { to-farmer/ } \\
\text { private }\end{array}$ & $\begin{array}{c}\text { Other (govern- } \\
\text { ment, extension, } \\
\text { cooperatives, } \\
\text { NGOs) }\end{array}$ & \\
\hline Personal savings & 61 & 53 & 60 & 88 & 76 & 63 \\
\hline Remittance income & 13 & 5 & 1 & 19 & 8 & 2 \\
\hline Other family members & 1 & 1 & 2 & 3 & 1 & 2 \\
\hline \multicolumn{7}{|l|}{ Loan } \\
\hline Money lender & 3 & 2 & 2 & 6 & 7 & 2 \\
\hline Other informal sources & 2 & 6 & 5 & 3 & 12 & 7 \\
\hline Commercial bank & 16 & 18 & 4 & 25 & 29 & 4 \\
\hline $\begin{array}{l}\text { Agricultural cooperative } \\
\text { bank }\end{array}$ & 4 & 5 & 9 & 6 & 9 & 9 \\
\hline Government scheme & 0 & 0 & 0 & 0 & 0 & 0 \\
\hline Other sources & 0 & 6 & 6 & 0 & 11 & 6 \\
\hline
\end{tabular}

Source: IFPRI (2016).

Note: $\mathrm{NGO}=$ nongovernmental organization. 
TABLE 9.11 Breakdown of key cost components for four-wheel tractors and power tiller operations (US dollars ${ }^{\mathrm{a}}$ per year per machine), excluding costs for attachments, Nepal, 2016

\begin{tabular}{lrrr}
\hline & \multicolumn{2}{c}{ Four-wheel tractors } & \\
\cline { 2 - 3 } Component & $\begin{array}{c}\text { Farmer-to-farmer/ } \\
\text { private }\end{array}$ & $\begin{array}{c}\text { Other (government, } \\
\text { extension, } \\
\text { cooperatives, NG0s) }\end{array}$ & $\begin{array}{c}\text { Power } \\
\text { tillers }\end{array}$ \\
\hline Sample size & 32 & 76 & \multicolumn{1}{c}{46} \\
\hline Operators (self-assessed if owner-operated) & $1,060(1,200)$ & $1,270(1,420)$ & $635(400)$ \\
Fuels/lubricants & $240(225)$ & $263(250)$ & $127(35)$ \\
Repair/maintenance & $431(300)$ & $420(360)$ & $199(95)$ \\
Spare parts & $347(235)$ & $302(200)$ & $139(55)$ \\
Labor & $72(50)$ & $83(50)$ & $37(18)$ \\
Depreciation ${ }^{\text {b }}$ & $865(870)$ & $997(947)$ & $350(234)$ \\
Total costs related to tractors/power tillers, & $3,016(3,013)$ & $3,337(3,215)$ & $1,472(878)$ \\
excluding costs related to attachments & & & \\
\hline
\end{tabular}

Source: IFPRI (2016).

Note: ${ }^{\text {a }}$ Figures are calculated using the exchange rate of US $\$ 1=100$ Nepalese rupees. Figures are sample averages, and figures in parentheses are sample medians. ${ }^{b}$ Calculated by dividing the expected service life of machine by the original (unsubsidized) value of the machine, deflated by the consumer price index (World Bank 2016). NG0 = nongovernmental organization.

tillers; maintenance, repairs, and spare parts account for 25-35 percent; fuels and lubricants account for less than 10 percent; and depreciation costs account for the remaining $25-30$ percent.

Importantly, farmer-to-farmer/private service providers who are receiving relatively less support (such as subsidies) appear at least as efficient as and may be incurring lower costs than the other types of service providers (spending on average $\$ 3,000$ per tractor, as opposed to the $\$ 3,337$ spent by other service providers). These figures suggest that continued research is important in better understanding the nature of service provision by such private-sector farmer-to-farmer service providers.

\section{Medium-Scale Farms as Major Suppliers of Hiring Services}

In some countries, evidence suggests that farmer-to-farmer service providers tend to be owners of medium-scale farms rather than large farms (Houssou et al. 2015). In Nepal, approximately half of tractor owners participating in the NLSS said they provide hiring-out services. Although statistically significant differences cannot be detected due to the extremely small sample size of tractor owners in NLSS data, the median size of the owned and annually cultivated farm is consistent with the hypothesis that medium-scale farms rather than large-scale farms are the major suppliers of tractor renting-out services (Table 9.12). 
TABLE 9.12 Median owned and annually cultivated farm size (ha) of tractor owners, differentiated by hiring-out status, Nepal Terai, 2003 and 2010

\begin{tabular}{lcccccc}
\hline & \multicolumn{2}{c}{ Owned land } & & \multicolumn{2}{c}{ Annually cultivated land } \\
\cline { 2 - 3 } \cline { 5 - 6 } Type of tractor owner & 2003 & 2010 & & 2003 & 2010 \\
\hline Those with hiring-out revenue & 1.2 & 1.7 & & 3.0 & 3.2 \\
Those without hiring-out revenue & 2.0 & 2.7 & & 4.0 & 4.3 \\
\hline
\end{tabular}

Source: Authors' calculations based on data from the Nepal Living Standards Survey for 2003 and 2010 (Nepal, CBS 2004, 2011).

\section{COMBINE HARVESTER SERVICE PROVIDERS}

The number of farmer-to-farmer combine harvester service providers has also been growing. The IFPRI (2016) survey did not interview a sufficiently large number of combine harvester service providers. However, Paudel and colleagues (2015), based on a survey of 150 service providers in the three districts in Western Terai (Kapilavastu, Rupandehi, and Nawalparasi), found that the share of area harvested by combine harvesters increased from 1 percent in 2000 to 8 percent and 20 percent for rice and wheat, respectively, in 2014 . The 150 combine harvester owners operate approximately 200 ha per year on average, though this rate has declined from about 500 ha in the early 2000s. It appears most operate within their home districts.

The emergence in Nepal of private-sector providers of tractors, power tillers, and combine harvesters for hire has likely contributed to the recent growth in the use of these mechanization technologies. In addition, as is mentioned in the next section, in the neighboring Bihar state of India, privatesector service providers of zero-till machines have also been emerging (Keil, D'Souza, and McDonald 2016), and some may operate in the Terai zone of Nepal. Many of these private service providers have grown with essentially no government support, acquiring machines and financing from the private sector and achieving a cost-efficiency that is comparable to or even better than that of other service providers. As is shown in the next section, however, there remain some signs that farmers are constrained by the lack of access to these services at competitive market prices, and continued research is needed to identify how the government can support these service providers to address unmet demands.

\section{Role of Mechanization in Agricultural Transformation}

This section provides empirical evidence of various effects of the adoption of tractors on agricultural productivity, intensification, and farm 
household welfare, using NLSS data. These effects are estimated using the propensity score-based inverse probability weighting (IPW) method (more detailed descriptions of model specifications are provided in Appendix 9A). Specifically, the section highlights the (1) effects on farm size dynamics and exit from agriculture; (2) effects on land productivity; (3) effects on other aspects such as gender, feminization, and the environment. Although most farmers in Nepal are smallholders, we differentiate resource-poor smallholders (owning a lowland farm of not more than 1 acre) and medium smallholders (owning a lowland farm larger than 1 acre), in the Terai where appropriate, to highlight the differential effects of tractor adoption on their outcomes. Because these outcomes are potentially correlated with each other, IPW is estimated using IPW-SUR (seemingly unrelated regressions) methods.

\section{Effects on Farm Size and Farm Size Dynamics}

The effects of tractor ownership on farm size dynamics are more difficult to assess due to the small number of tractor owners in the data. However, available evidence suggests that tractor ownership may not have strong effects on farm size dynamics in the short term. All nine tractor owners in the NLSS panel sample decreased the size of their owned farm and operational scale, by typically around 20-30 percent, and only two out of the nine tractor owners in the panel sample saw increases in farmland cultivated before the next round of the NLSS (Table 9.13).

\section{Can Mechanization Help Smallholders Survive and Become More Productive?}

Tractor adoption seems to have helped some smallholders survive in the agricultural sector and become more productive. For example, tractor adoption has led to an approximately 14 percent increase in agricultural income and a 12.5 percent increase in per capita household income for resource-poor smallholders (Table 9.14), indicating improvement in the overall profitability of their production systems. In contrast, the effects for medium smallholders are weaker and statistically insignificant. Similarly, in the Hills, the effects are positive on agricultural income but insignificant on overall household income. Tractor adoption may help smallholders in the Terai to survive in farming more than it helps those in the Hills. These results are consistent with the hypothesis that tractors are complementary to flatter topography. 
TABLE 9.13 Change in owned farm size and operational size, by tractor owners and nonowners (panel samples), Nepal, 1995, 2003, 2010

\begin{tabular}{llcccc}
\hline & & $\begin{array}{c}\text { Change in } \\
\text { Initial size } \\
\text { of farmland } \\
\text { owned (ha) }\end{array}$ & $\begin{array}{c}\text { change in } \\
\text { farmland owned } \\
\text { between rounds } \\
\text { of NLSS (ha) }\end{array}$ & $\begin{array}{c}\text { Initial size } \\
\text { of farmland } \\
\text { cultivated } \\
\text { per year (ha) }\end{array}$ & $\begin{array}{c}\text { charmland } \\
\text { cultivated per year } \\
\text { between rounds of } \\
\text { NLSS (ha) }\end{array}$ \\
\hline Tractor ownership & Mean & 3.1 & -0.9 & 6.7 & -2.5 \\
Non-owners $(N=1,400)$ & Median & 3.3 & -0.9 & 8.1 & -1.7 \\
& Mean & 1.0 & -0.2 & 1.9 & -0.4 \\
& Median & 0.6 & -0.0 & 1.2 & -0.1 \\
\hline
\end{tabular}

Source: Authors' calculations based on data from the Nepal Living Standards Survey for 1995, 2003, 2010 (Nepal, CBS 1996, 2004, 2011).

TABLE 9.14 Effects of adopting tractors on household income (total income and agricultural income), Nepal, 1995, 2003, 2010

\begin{tabular}{lccc}
\hline Outcome & Small & Medium & Hills \\
\hline $\begin{array}{l}\text { Real per capita household income } \\
\text { (kg of cereals) }\end{array}$ & $77.399(166.531)$ & $112.244(210.136)$ & $106.011(351.600)$ \\
$\begin{array}{l}\text { Growth rate of real per capita } \\
\text { household income (natural log) }\end{array}$ & $.125^{\star \star \star}(.050)$ & $.039(.054)$ & $.085(.062)$ \\
$\begin{array}{l}\text { Per capita agricultural income } \\
\text { (kg of cereals) }\end{array}$ & $101.161^{\star}(59.332)$ & $117.965^{\star \star}(50.870)$ & $196.137^{\star \star \star}(58.900)$ \\
$\begin{array}{l}\text { Growth rate of per capita agricultur- } \\
\text { al income (natural log) }\end{array}$ & $.140^{\star}(.084)$ & $.070(.068)$ & $.326^{\star \star \star}(.106)$ \\
\hline
\end{tabular}

Source: Authors' calculations based on data from the Nepal Living Standards Survey for 1995, 2003, 2010 (Nepal, CBS 1996, 2004, 2011); results for Hills are from Takeshima and Bhattarai (2019).

Note: Figures are estimated effects. Figures in parentheses are standard errors of the estimated effects. Asterisks indicate the statistical significance: ${ }^{\star \star *} 1 \%,{ }^{\star *} 5 \%,{ }^{*} 10 \%$.

\section{POSSIBLE CAUSAL EFFECTS ON SMALLHOLDER EXIT FROM FARMING}

Will mechanization allow some smallholders to scale up while allowing others to exit farming, with the development of other nonfarm economic opportunities? The available data do not allow a thorough assessment of the causal effects of tractor diffusion on smallholders' exit from farming. However, a rough diagnosis suggests that the linkages are relatively weak. Figure 9.3 illustrates how, at the VDC level, the share of households engaged in farming is associated with the share of farm households using tractors. If tractor diffusion induces a significant rate of exit from farming by smallholders, we would expect negatively sloping lines in Figure 9.3. However, the share of households engaged in farming among all households in the VDC is generally unrelated to the level of diffusion of tractor use in the VDC. This also holds if we limit 
FIGURE 9.3 Correlation between village development committee-level share (percentage) of tractor-using farm households and share of households engaged in farming, Nepal, 1995-2010
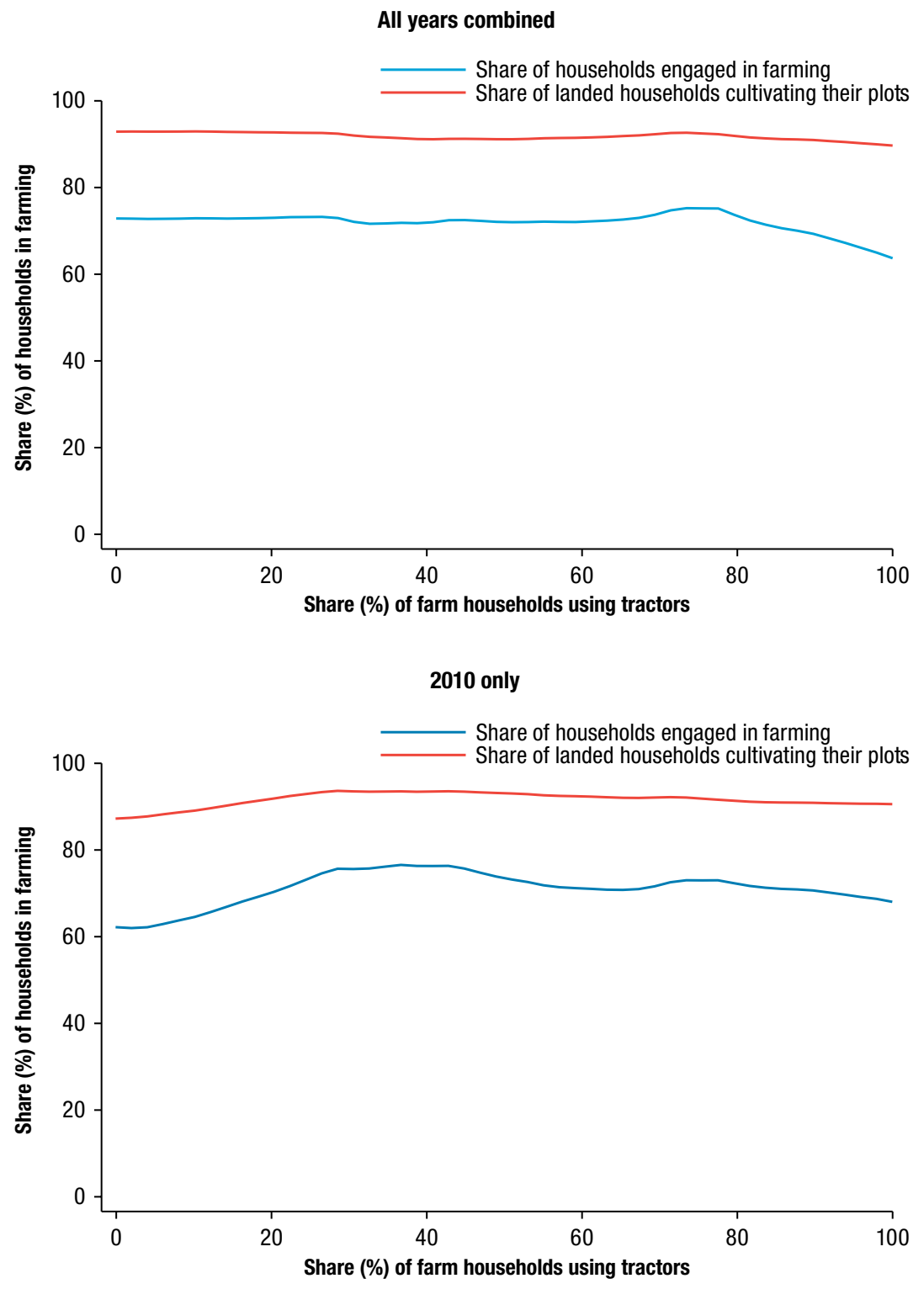

Source: Authors' calculations based on data from the Nepal Living Standards Survey for 1995, 2003, and 2010 (Nepal, CBS 1996, 2004, 2011). 
our sample to households that own farmland (landed households) and to figures at the district level. Therefore, the evidence is generally weak for tractorinduced exit from farming by smallholders. ${ }^{6}$

Similarly, tractor rentals in 2003 did not seem to have a significant effect on farming exit. This is based on a separate propensity score matching method using the panel samples that constitute a fraction of the NLSS, in which we assessed the effect of tractor use in 2003 on whether the same households were still farming in 2010. Results are not shown due to the small sample size, but they at least suggest that the linkage between the use of tractors and future exit from farming is generally weak.

These effects also differ between resource-poor smallholders and medium smallholders (Table 9.15). Although using tractors often leads to reduced land rental revenues, these effects are clearer among medium smallholders. Similarly, tractor adoption also lowers off-farm income more among resourcepoor smallholders than among medium smallholders. Off-farm income decreases for resource-poor smallholders due to tractor adoption, partly as a result of the reduced time spent by adult female household members in offfarm activities (Table 9.16). These conditions suggest that tractor adoption does not induce farm exit, and resource-poor smallholders may actually shift more resources to farming when they use tractors.

\section{EFFECTS ON LAND PRODUCTIVITY AND ADOPTION OF OTHER MODERN TECHNOLOGIES}

Tractor adoption has different effects on the farming practices of resourcepoor smallholders and medium smallholders in the Terai, versus those in the Hills (Table 9.17). For resource-poor smallholders in the Terai, tractor adoption generally has greater land productivity-enhancing effects through more intensive use of nonland inputs, such as chemical fertilizer and irrigation, as well as expansion of the cultivated area. These effects are somewhat weaker among medium smallholders in the Terai and farmers in the Hills.

Importantly, tractor adoption often increases rather than decreases the overall use of labor, particularly labor by adult female household members and/or hired labor (only child labor use by resource-poor smallholders in the Terai is reduced). This is possibly because in the Nepal Terai, although tractor use has been increasingly adopted for certain activities, other farming operations (planting, fertilizer application, weeding, bird scaring, harvesting)

6 Of course, we cannot extract from these figures longer-term trends or more general equilibrium patterns at more aggregated regional levels, or the effects of more advanced mechanization patterns beyond tractor use. The evidence here, however, at least suggests that growth in tractor use has largely preserved smallholders in Nepal instead of inducing their exit from farming. 
TABLE 9.15 Effects of tractor use on livestock revenue, land rental revenue, and off-farm income, Nepal Terai and Hills, 1995, 2003, 2010

\begin{tabular}{|c|c|c|c|}
\hline \multirow[b]{2}{*}{ Variable } & \multicolumn{2}{|c|}{ Terai } & \multirow[b]{2}{*}{ Hills } \\
\hline & Small & Medium & \\
\hline $\begin{array}{l}\text { Real per capita livestock } \\
\text { revenue (kg of cereal) }\end{array}$ & $72.672(48.643)$ & $54.930^{\star \star}(25.985)$ & $110.625^{\star \star}(42.427)$ \\
\hline $\begin{array}{l}\text { Real per capita land rental } \\
\text { revenue (kg of cereal) }\end{array}$ & $-9.363(7.845)$ & $-48.225^{\star \star}(20.274)$ & $-9.467(7.568)$ \\
\hline $\begin{array}{l}\text { Real per capita land rental } \\
\text { revenue (kg of cereal)- } \\
\text { rainy season }\end{array}$ & $-8.433(7.118)$ & $-27.833^{\star}(16.046)$ & $-11.986^{\star \star}(4.915)$ \\
\hline $\begin{array}{l}\text { Real per capita land rental } \\
\text { revenue (kg of cereal)—- } \\
\text { dry season }\end{array}$ & $-.905(1.193)$ & $-16.685^{\star}(8.561)$ & $.461(4.438)$ \\
\hline $\begin{array}{l}\text { Real per capita land rental } \\
\text { payment (kg of cereal) }\end{array}$ & $-.155(.220)$ & $-.457(.291)$ & $.045(.087)$ \\
\hline $\begin{array}{l}\text { Real per capita off-farm } \\
\text { income (kg of cereal) }\end{array}$ & $-323.972^{\star}(173.072)$ & $-111.731(266.625)$ & $-626.314^{\star \star \star}(210.504)$ \\
\hline
\end{tabular}

Source: Authors' calculations based on data from the Nepal Living Standards Survey for 1995, 2003, 2010 (Nepal, CBS 1996, 2004, and 2011).

Note: Figures in parentheses are standard errors of the estimated effects. Asterisks indicate the statistical significance:

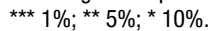

TABLE 9.16 Effects of tractor use on off-farm income-earning activities (person-hours within 12 months), Nepal Terai and Hills, 1995, 2003, 2010

\begin{tabular}{|c|c|c|c|}
\hline \multirow[b]{2}{*}{ Variable } & \multicolumn{2}{|c|}{ Terai } & \multirow[b]{2}{*}{ Hills } \\
\hline & Small & Medium & \\
\hline $\begin{array}{l}\text { Male family member (hours } \\
\text { per year) }\end{array}$ & $-181.506(119.734)$ & $-253.592^{\star \star}(116.907)$ & $140.680(135.114)$ \\
\hline $\begin{array}{l}\text { Male family member per } \\
\text { capita (hours per year) }\end{array}$ & $-127.228^{\star}(70.311)$ & $-189.902^{\star \star \star}(66.515)$ & $105.653(87.294)$ \\
\hline $\begin{array}{l}\text { Female family member } \\
\text { (hours per year) }\end{array}$ & $-164.931^{\star \star \star}(53.729)$ & $-96.195(57.381)$ & 74.070 (86.619) \\
\hline $\begin{array}{l}\text { Female family member per } \\
\text { capita (hours per year) }\end{array}$ & $-118.865^{\star \star \star}(41.493)$ & $-11.061(34.994)$ & $78.202(55.237)$ \\
\hline
\end{tabular}

Source: Authors' calculations based on data from the Nepal Living Standards Survey for 1995, 2003, 2010 (Nepal, CBS 1996, 2004, and 2011).

Note: Figures in parentheses are standard errors of the estimated effects. Asterisks indicate the statistical significance:

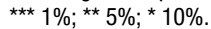


TABLE 9.17 Effects of mechanization on agricultural input use (land, fertilizer, labor), Nepal Terai and Hills, 1995, 2003, 2010

\begin{tabular}{|c|c|c|c|}
\hline \multirow[b]{2}{*}{ Outcome } & \multicolumn{2}{|c|}{ Terai } & \multirow[b]{2}{*}{ Hills } \\
\hline & $\begin{array}{l}\text { Resource-poor } \\
\text { smallholders }\end{array}$ & $\begin{array}{l}\text { Medium } \\
\text { smallholders }\end{array}$ & \\
\hline Area cultivated per year (ha) & $.257^{\star \star \star}(.078)$ & $.151(.129)$ & $-.005(.080)$ \\
\hline $\begin{array}{l}\text { Own area cultivated in dry } \\
\text { season (ha) }\end{array}$ & $.041^{\star \star}(.021)$ & $.090(.058)$ & $.021(.038)$ \\
\hline $\begin{array}{l}\text { Own area cultivated in rainy } \\
\text { season (ha) }\end{array}$ & $.048^{\star \star}(.023)$ & $.138^{\star \star}(.057)$ & $.029(.040)$ \\
\hline Net area sharecropped in (ha) & $.080^{\star \star}(.033)$ & $.213^{\star \star \star}(.063)$ & $.038(.028)$ \\
\hline Net area rented in (ha) & $.005(.012)$ & $-.014(.029)$ & $-.016(.012)$ \\
\hline $\begin{array}{l}\text { Chemical fertilizer use per ha } \\
\text { (kg of nutrients/ha) }\end{array}$ & $11.016^{\star \star \star}(3.645)$ & $-2.435(4.612)$ & $-9.372(10.659)$ \\
\hline Irrigation in dry season (\%) & $9.056^{\star \star \star}(3.447)$ & $2.940(3.163)$ & $11.634^{\star \star \star}(3.855)$ \\
\hline Irrigation in wet season (\%) & $10.989^{\star \star \star}(3.426)$ & $6.303^{\star \star}(3.117)$ & $21.068^{\star \star \star}(3.561)$ \\
\hline $\begin{array}{l}\text { Family labor use-male (hours } \\
\text { per year) }\end{array}$ & 69.703 (71.019) & $14.961(101.170)$ & $-90.606(71.869)$ \\
\hline $\begin{array}{l}\text { Family labor use-male per } \\
\text { capita (hours per year) }\end{array}$ & 32.341 (43.945) & $49.657(56.864)$ & $-32.305(49.755)$ \\
\hline $\begin{array}{l}\text { Family labor use-female } \\
\text { (hours per year) }\end{array}$ & $233.178^{\star \star \star}(67.669)$ & $176.655^{\star}(106.665)$ & $99.382(87.648)$ \\
\hline $\begin{array}{l}\text { Family labor use-female per } \\
\text { capita (hours per year) }\end{array}$ & $181.401^{\star \star \star}(41.420)$ & $109.870^{\star \star}(51.484)$ & $156.866^{\star \star}(62.623)$ \\
\hline $\begin{array}{l}\text { Family labor use—child (hours } \\
\text { per year) }\end{array}$ & $-179.180^{\star \star \star}(49.150)$ & $1.946(69.557)$ & $-72.732^{\star}(42.401)$ \\
\hline $\begin{array}{l}\text { Hired labor male (days per } \\
\text { year) }\end{array}$ & $.391(.554)$ & $7.506^{\star \star \star}(2.038)$ & $.832(1.075)$ \\
\hline $\begin{array}{l}\text { Hired labor female (days per } \\
\text { year) }\end{array}$ & $2.854^{\star \star \star}(1.120)$ & $7.645^{\star \star}(3.679)$ & $5.074^{\star \star \star}(1.805)$ \\
\hline
\end{tabular}

Source: Authors' calculations based on data from the Nepal Living Standards Survey for 1995, 2003, 2010 (Nepal, CBS 1996, 2004, 2011). Results for Hills are from Takeshima and Bhattarai (2019).

Note: Figures in parentheses are standard errors of the estimated effects. Asterisks indicate the statistical significance: $* \star \star$ $1 \% ;{ }^{* \star} 5 \% ;{ }^{*} 10 \%$. 
remain largely unmechanized. Although tractor adoption substitutes for labor in land preparation, the resulting intensification, expansion of operational size, and growth in harvest may raise the demand for labor, leading to net increases in labor use. Effects on labor source differ as well; for resourcepoor smallholders, adult female family members' labor accounts for much of the increase in overall labor use, whereas for medium smallholders, hired labor accounts for an important share of labor use increases. These differences in the effects on labor type may relate to the aforementioned differences between land productivity-enhancing behaviors and land-expansion behaviors. ${ }^{7}$

The patterns in the Hills are slightly different from those in the Terai. Whereas the effects of mechanization on labor use by farmers in the Hills are similar to those on labor use by resource-poor smallholders in the Terai, the effects on use of certain inputs, such as chemical fertilizer, are relatively small. This is partly because of the potentially lower returns on use of chemical fertilizer in the hilly environment than in the flatter Terai zone (Takeshima et al. 2017).

Although detailed agronomic information is not available in the NLSS, the patterns among resource-poor farmers in the Terai are consistent with the hypothesis that in land-constrained environments, tractor use can allow deeper tillage that may improve the soil quality and raise fertilizer absorption efficiency or irrigation efficiency (through improved drainage, for example).

These differences are also reflected in the effects on real crop revenue per hectare, an indicator of yield (Table 9.18). Although the effects of tractor adoption on real crop revenue per hectare are significantly negative for medium smallholders in the Terai, they are relatively insignificant for resource-poor smallholders in the Terai and those in the Hills.

\section{TRACTOR ADOPTION AND RETURNS TO SCALE IN FARMING}

Not only is input use affected by tractor adoption, but a recent study also suggests that renting in tractors through custom hiring services affects the shape of the production function itself by increasing the returns to scale in agricultural production, including livestock (Takeshima 2017a) (Table 9.19). The study shows a direct causal effect of tractor use on returns to scale, unlike earlier studies that only assume the association between mechanization and returns to scale. The study addresses the two sources of endogeneity (tractor

7 In Asian countries, more hired labor is typically used for activities for which efforts are easily visible (such as transplanted areas, harvested quantities), whereas family labor is used for watering, pest control, fertilizer application, seedbed preparation-tasks that require care and judgment without immediately visible outcomes (Kikuchi and Hayami 1999). 
TABLE 9.18 Effects of mechanization on real revenue per hectare, Nepal Terai and Hills, 1995, 2003, 2010

\begin{tabular}{lccc}
\hline & \multicolumn{2}{c}{ Terai } & \\
\cline { 2 - 3 } Variable & Small & Medium & Hills \\
\hline Growth rate of real crop revenue & $-.012(.056)$ & $-.150^{\star \star}(.065)$ & $.085(.073)$ \\
per ha of cultivated area & & & \\
\hline
\end{tabular}

Source: Authors' calculations based on data from the Nepal Living Standards Survey for 1995, 2003, 2010 (Nepal, CBS 1996, 2004, 2011).

Note: Figures in parentheses are standard errors of the estimated effects. Asterisks indicate the statistical significance: ** $5 \%$.

TABLE 9.19 Effects of tractor custom hiring service on agricultural returns to scale in Nepal Terai, 2010

\begin{tabular}{|c|c|c|}
\hline \multirow[b]{2}{*}{ Variable } & \multicolumn{2}{|c|}{$\begin{array}{l}\text { Estimated Cobb-Douglas production function coefficients } \\
\text { with and without hired tractors }\end{array}$} \\
\hline & Tractor custom hiring service hirers & Nonhirers \\
\hline Fertilizer nutrients & $.002(.027)$ & $-.016(.016)$ \\
\hline Adult male family labor & $-.003(.005)$ & $.003(.009)$ \\
\hline Adult female family labor & $-.015(.013)$ & $.060^{\star \star \star}(.007)$ \\
\hline Child family labor & $.019^{\star \star \star}(.006)$ & $.019^{\star \star \star}(.006)$ \\
\hline Hired labor & $-.010(.009)$ & $-.015^{\star}(.009)$ \\
\hline Area cultivated & $.529^{\star \star \star}(.058)$ & $.397^{\star \star \star}(.061)$ \\
\hline Irrigation & $.009(.008)$ & $.016(.012)$ \\
\hline Agricultural capital & $.291^{\star \star \star}(.055)$ & $.161^{\star \star}(.064)$ \\
\hline Other cash expenditures & $.092(.064)$ & $.084^{\star \star \star}(.024)$ \\
\hline Returns to scale & $.914^{\star \star \star}(.056)$ & $.709^{\star \star \star}(.061)$ \\
\hline
\end{tabular}

Source: Takeshima (2017a).

Note: Figures in parentheses are standard errors of the estimated effects. Asterisks indicate the statistical significance: ${ }^{\star \star \star} 1 \%$; ${ }^{\star \star} 5 \%$; ${ }^{\star} 10 \%$.

adoption and use of other inputs) through an IPW generalized method of moments estimator (see Takeshima 2017a for detail). In addition, it shows that this transformational effect is realized through tractor custom hiring services instead of tractor ownership. Although the external validity of the evidence requires further research, it shows that in certain areas in Nepal, tractors are not simply complementing or substituting for other inputs but also substantially transforming production technology.

\section{EFFECTS ON GENDER AND FEMINIZATION OF FARMING}

The adoption of tractors in the Nepal Terai seems to lead to a slight feminization of farming, but through increased overall use of female labor rather than 
a substantial decrease in male labor. This effect may be different from the feminization that occurs after more comprehensive mechanization, in which a further decrease in male labor use becomes more pronounced.

Increased use of female labor as a result of tractor adoption can also explain the recent findings on the effect of tractor use on women's fertility, which is often interpreted as the result of labor substitution. For example, Bhandari and Ghimire (2013) showed that tractor adoption reduces the subsequent fertility of women in the Western Chitwan Valley of Nepal. Although Bhandari and Ghimire (2013) associated the findings with the reduced demand for children as a result of substitution of tractors for labor, it is also possible that this decline is actually a result of increased demand for female labor in farming for activities that are not easily mechanized even after a tractor is introduced (such as planting, weeding, and harvesting), which is consistent with the findings above. ${ }^{8}$

\section{KEY ENVIRONMENTAL EFFECTS}

Various studies have suggested that tractor use in Nepal, which is part of the Indo-Gangetic Plain, will have certain environmental effects, though their extent has not been identified based on representative data from the Nepal Terai. Some of the effects with global implications are increased emissions of carbon dioxide to the atmosphere as a result of biological decomposition of soil organic matter, and increased emissions through machinery fuel usage (Grace et al. 2003). However, one of the key effects with more direct local implications is the impact on the physical characteristics of soils and on the productivity of the dominant production system in the region, the rice-wheat system. In particular, wet tillage (puddling), for which tractors are commonly used in the Nepal Terai (see "Demand-Side Analysis," above), often has negative effects on postrice wheat production during the dry season (Sharma, Ladha, and Bhushan 2003). These effects are caused by loss of soil organic matter, destruction of soil structure that leads to higher bulk density, higher soil penetration resistance, enhanced surface cracking, low porosity, and low water permeability. These conditions cause waterlogging, poor soil aeration, restricted root growth, and decreased availability of soil nutrients to the wheat plants (Sharma, Ladha, and Bhushan 2003). Soil compaction is one of the key outcomes, causing the development of subsurface hardpan (often to a depth of $10-45 \mathrm{~cm}$ below the puddled layer). Though subsurface hardpan develops due to various

8 See Do, Levchenko, and Raddatz (2016) for the negative effect of increased female labor demand on fertility. 
factors-including animal and human processes during tillage, transplanting, weeding, and other activities, as well as chemical precipitation of certain minerals in the subsoil layers-it is also caused by the use of heavy machinery such as tractors (Sharma, Ladha, and Bhushan 2003). Soil compaction is partly caused on purpose, because moderate soil compaction is ideal for rice cultivation. However, it necessitates intensive tillage during the land preparation for dry-season wheat production, often further raising demand for intensive tillage for wheat under the conventional tillage system (Ladha et al. 2003).

In the rice-wheat systems in regions like the Indo-Gangetic Plain across India, Pakistan, and the Nepal Terai, where tillage intensity per hectare has reached quite a high level, the demand for an alternative farming system that reduces tillage intensity is gradually on the rise as a solution to reduce the aforementioned effects on the soil, including soil compaction, and raise overall productivity. Out of 13 million ha of rice-wheat systems spreading over the Indo-Gangetic Plain (Chauhan et al. 2012), some 5 million ha are under production systems involving no tillage for dry-season wheat, although the adoption of no tillage for rainy-season rice is still minimal (Hobbs, Sayre, and Gupta 2008). Nepal accounts for 600,000 ha of this rice-wheat system (Chauhan et al. 2012). In the Indian state of Bihar, situated adjacent to the Nepal Terai, private sector-led zero-till custom hiring service providers have emerged over time, whereby tractors continue to be used but with zero-till implements (Keil, D'Souza, and McDonald 2016). This procedure has been adopted for land preparation for wheat after rice is harvested. Some of these service providers may travel to the Nepal Terai if there is demand. Although information is currently scarce, some zero-till service providers may actually be located inside the Nepal Terai.

\section{Conclusions}

Given the country's small average landholdings and heavy reliance on agriculture, the recent growth of tractor use in Nepal has been impressive, particularly in the Terai. The growth has occurred against a background of rising rural wages, particularly for plowing, combined with growing emigration, increases in the yields of key staple crops, and overall broad agricultural production growth, as well as improved market access and participationfactors that have all potentially raised the demand for machine power, including tractors.

In the Terai zone, increasing tractor use has played a role in agricultural transformation mostly through the effect on agricultural production, rather 
than by inducing smallholder farm households to exit agriculture or laborers to shift out of agriculture. Tractors have helped resource-poor smallholders intensify crop production per unit of land while also helping medium smallholders expand their cultivated area. This has enabled growth in tractor use despite the continued decline in average farm sizes caused primarily by fragmentation, and despite the continuing high share of households engaged in farming. Tractor adoption has also transformed overall agricultural production technologies by directly causing the shift from diminishing returns to scale to constant returns to scale in the production function, which has been an important process experienced by agricultural sectors in developed countries.

This growing demand for tractors has been met by various types of custom hiring service providers, including private-sector farmer-to-farmer service providers who have emerged with essentially no direct government support, acquiring machines and financial resources from the market and informal sources. The growth in combine harvester service providers also suggests the potential of the private sector to meet the demand by smallholders.

In the Hills and Mountains regions of Nepal, the contrast with the Terai zone offers useful insights that could be relevant to future growth in mechanization in similarly hilly or mountainous regions in Africa. Certain factors in the Hills are similar to those in the Terai; for example, the labor market in the Hills has seen increases in wages, caused in part by rising education levels, the growth of the nonfarm sector, and extensive emigration from the area by working-age males. The unique agroecological characteristics of the Hills, such as the rugged terrain and relative scarcity of lowland, however, seem to have remained key obstacles to the growth in tractor use there, despite its substantial growth in the neighboring Terai zone. However, even in the Hills and Mountains regions, induced innovations often enable improvements in land quality (Templeton and Scherr 1999). These areas too are expected eventually to develop their own mechanization systems in the future. The recent growth (albeit from a low base) in the use of Chinese-made mini-tillers on sloped upland plots in the Hills may be an example of such a system.

Nepalese experiences offer various useful policy recommendations for African countries. First, whereas tractor use has grown considerably in the Terai, access to custom hiring services may still be somewhat constraining. This is similar to the situation in some of the African countries, where the majority of tractors are four-wheel tractors, for which indivisibility of technologies is still relevant because of limited mobility and seasonal fluctuations in 
demand. These experiences suggest that in locations where conditions indicate that four-wheel tractors are more suitable and common, the overall spread of tractor use requires market developments that support a substantial increase in tractor populations as well as efficiency improvements in custom hiring service markets.

Second, tractor use has grown in the Terai even though the area has one of the weakest regulatory policies for tractors in terms of machine quality controls. Once adoption has reached a sufficient scale, designing and implementing appropriate regulatory policies becomes more relevant to the sector. African countries can also first focus on liberalizing machine imports to allow the inflow of various types of tractors and machines, and then start investing in regulatory capacity once adoption reaches certain levels.

Third, recent evidence suggests that the investments in complementary technologies, such as high-yielding improved varieties, have also been partly responsible for increased tractor use among smallholders (though these effects dissipate as farms get larger) (Takeshima and Liu 2018). Such patterns suggest that similar investments in complementary technologies are likely to be important to raise the uptake of mechanization in Africa, especially among smallholders who would otherwise not benefit from mechanization due to the lack of scale economy.

\section{References}

ADB (Asian Development Bank). 2013. ADB 7762-NEP Final Report. Technical Assistance for the Preparation of the Agricultural Development Strategy. Manila, Philippines.

Adhikary, S. K. 2004. “Nepal Country Paper." Paper presented at the Technical Advisory Committee and Governing Board Meeting of Asian and Pacific Centre for Agricultural Engineering and Machinery, Hanoi, December 13-16.

Animaw, A. T., J. A. M. Nkanya, J. M. Nyakiba, T. H. Woldemariam, and H. Takeshima. 2016. Agricultural Mechanization and South-South Knowledge Exchange: What Can Ethiopian and Kenyan Policymakers Learn from Bangladesh's Experience? Ethiopia Strategy Support Program Policy Note 47. Washington, DC: International Food Policy Research Institute.

Bhandari, P., and D. Ghimire. 2013. "Rural Agricultural Change and Fertility Transition in Nepal.” Rural Sociology 78 (2): 229-252.

Biggs, S., and S. Justice. 2015. Rural and Agricultural Mechanization: A History of the Spread of Small Engines in Selected Asian Countries. IFPRI Discussion Paper 01443. Washington, DC: International Food Policy Research Institute. 
Biggs, S., S. Justice, C. Gurung, J. Tripathi, and G. Sah. 2002. "The Changing Power Tiller Innovation System in Nepal: An Actor-Oriented Analysis." Paper presented at the workshop Agricultural and Rural Mechanization, Bangladesh Agricultural University, Mymensingh, Bangladesh, November 2.

Biggs, S., S. Justice, and D. Lewis. 2011. "Patterns of Rural Mechanization, Energy and Employment in South Asia: Reopening the Debate." Economic and Political Weekly 46 (9): 78-82.

Chauhan, B. S., G. Mahajan, V. Sardana, J. Timsina, and M. L. Jat. 2012. "Productivity and Sustainability of the Rice-Wheat Cropping System in the Indo-Gangetic Plains of the Indian Subcontinent: Problems, Opportunities, and Strategies." Advances in Agronomy 117 (1): $315-369$.

CSAM (Centre for Sustainable Agricultural Mechanization). 2014. "Country Pages.” Accessed July 2. http://un-csam.org/cp_index.htm.

Do, Q. T., A. A. Levchenko, and C. Raddatz. 2016. "Comparative Advantage, International Trade, and Fertility." Journal of Development Economics 119: 48-66.

FAO (Food and Agriculture Organization of the United Nations). 2016. FAOSTAT database. Accessed December 1. http://faostat.fao.org.

Grace, P. R., L. Harrington, M. C. Jain, and G. P. Robertson. 2003. “Long-Term Sustainability of the Tropical and Subtropical Rice-Wheat System: An Environmental Perspective." In Improving the Productivity and Sustainability of Rice-Wheat Systems: Issues and Impacts, edited by J. K. Ladha, J. E. Hill, J. M. Duxbury, R. K. Gupta, and R. J. Buresh. Madison, WI, US: American Society of Agronomy.

Gyawali, P. K. 2014. "A Final Year Project Report on Vehicle Over Speed Detection and Recognition.” Doctoral dissertation, Tribhuvan University, Kirtipur, Nepal.

Hjort, H. W. 1973. Assisting Agricultural Development in Nepal. Washington, DC: Foreign Development Division, Economic Research Service, US Department of Agriculture, cooperating with US Agency for International Development.

Hobbs, P. R., K. Sayre, and R. Gupta. 2008. "The Role of Conservation Agriculture in Sustainable Agriculture." Philosophical Transactions of the Royal Society B: Biological Sciences 363 (1491): $543-555$.

Houssou, N., C. Asante-Addo, X. Diao, and S. Kolavalli. 2015. Big Tractors, but Small Farms: Tractor Hiring Services as a Farmer-Owner's Response to an Under-Developed Agricultural Machinery Market. IFPRI Ghana Strategy Support Program Working Paper 39. Washington, DC: International Food Policy Research Institute.

IFPRI (International Food Policy Research Institute). 2016. Custom Hiring Services of Agricultural Machinery Survey. Kathmandu, Nepal. 
Jenkins, G. P., and C. Y. Kuo. 2000. "A VAT Revenue Simulation Model for Tax Reform in Developing Countries." World Development 28 (4): 763-774.

Joshi, K. D., C. Conroy, and J. R. Witcombe. 2012. Agriculture, Seed, and Innovation in Nepal: Industry and Policy Issues for the Future. Washington, DC: International Food Policy Research Institute.

Keil, A., A. D’Souza, and A. McDonald. 2016. “Growing the Service Economy for Sustainable Wheat Intensification in the Eastern Indo-Gangetic Plains: Lessons from Custom Hiring Services for Zero-Tillage." Food Security 8 (5): 1011-1028.

Khadka, R. B. 1991. Evolution, Current Problems, and Possibilities for Reform of the Nepalese Tax System (I). Tokyo: Seijo University.

Kikuchi, M., and Y. Hayami. 1999. "Technology, Market, and Community in Contract Choice: Rice Harvesting in the Philippines." Economic Development and Cultural Change 47 (2): 371-386.

Ladha, J. K., J. E. Hill, J. M. Duxbury, R. K. Gupta, and R. J. Buresh. 2003. Improving the Productivity and Sustainability of Rice-Wheat Systems: Issues and Impacts. Madison, WI, US: American Society of Agronomy.

NARMA Consultancy Pvt. Ltd. (Centre for Natural Resources Management, Analysis, Training and Policy Research). 2016. Agri-Mechanization Promotion Strategy Implementation Plan and Budgeting. Report prepared for the Government of Nepal. Kathmandu, Nepal: Ministry of Agricultural Development.

Nepal, CBS (Central Bureau of Statistics). 1996. Nepal Living Standards Survey Report 1996: Main Findings. Vol. 1. Kathmandu.

_. 2004. Nepal Living Standards Survey II (2003/04): Survey Design and Implementation. Kathmandu.

_. 2011. Nepal Living Standards Survey 2010/11: Statistical Report. Vol. 1. Kathmandu.

Nepal, MoAD (Ministry of Agricultural Development). 2014. Agriculture Mechanization Promotion Policy. Kathmandu.

Pant, K. P. 2013. Monetary Incentives to Reduce Open-Field Rice-Straw Burning in the Plains of Nepal. SANDEE Working Paper 81. Kathmandu, Nepal: South Asian Network for Development and Environmental Economics.

Pariyar, M. P., and G. Singh. 1995. "Farm Mechanization in Nepal." Agricultural Mechanization in Asia, Africa and Latin America 26: 55-61. 
Paudel, G., A. McDonald, S. Justice, S. Adhikari, M. Devkota, and D. Sherchan. 2015.

"Conservation Agriculture: A Resilient Way to Exterminate Trade-Offs in Combine Harvesters Use and Residue Burning in Rice-Wheat Systems of Nepal.” Paper presented at International Conference on Open Burning of Agricultural Residue in the Himalayas Region, Kathmandu, February 20-21.

Roumasset, J., and G. Thapa. 1983. “Explaining Tractorization in Nepal: An Alternative to the 'Consequences Approach.” Journal of Development Economics 12 (3): 377-395.

Sharma, D. R., and T. Sarker. 2015. Weaknesses of VAT in Nepal. Amsterdam: International Bureau of Fiscal Documentation.

Sharma, K. 2015. "Trade Policymaking in a Land-Locked Developing Country: The WTO Review of Nepal." World Economy 38 (9): 1335-1349.

Sharma, K., J. Ladha, and L. Bhushan. 2003. "Soil Physical Effects of Puddling in Rice-Wheat Cropping Systems." In Improving the Productivity and Sustainability of Rice-Wheat Systems: Issues and Impacts, edited by J. K. Ladha, J. E. Hill, J. M. Duxbury, R. K. Gupta, and R. J. Buresh, 97-114. Madison, WI, US: American Society of Agronomy.

Shrestha, B. K. 1978. "Status of Agricultural Mechanization in Nepal." In Proceedings of the International Agricultural Machinery Workshop. Los Baños, Philippines: International Rice Research Institute.

Takeshima, H. 2017a. "Custom-Hired Tractor Services and Returns to Scale in Smallholder Agriculture: A Production Function Approach.” Agricultural Economics 48 (3): 363-372.

Takeshima, H. 2017b. Overview of the Evolution of Agricultural Mechanization in Nepal, with a Particular Focus on Tractors and Combine Harvesters. IFPRI Discussion Paper 01662. Washington, DC: International Food Policy Research Institute.

Takeshima, H., R. Adhikari, and A. Kumar. 2016. Is Access to Tractor Service a Binding Constraint for Nepali Terai Farmers? IFPRI Discussion Paper 01508. Washington, DC: International Food Policy Research Institute.

Takeshima, H., R. Adhikari, M. N. Poudel, and A. Kumar. 2015. Farm Household Typologies and Mechanization Patterns in Nepal Terai. IFPRI Discussion Paper 01488. Washington, DC: International Food Policy Research Institute.

Takeshima, H., R. Adhikari, S. Shivakoti, B. D. Kaphle, and A. Kumar. 2017. “Heterogeneous Returns to Chemical Fertilizer at the Intensive Margins: Insights from Nepal." Food Policy 69: 97-109.

Takeshima, H., and M. Bhattarai. 2019. "Agricultural Mechanization in Nepal-Patterns, Impacts and Enabling Strategies for Promotion.” In Agricultural Transformation in Nepal: Trends, Prospects, and Policy Options, edited by G. Thapa, A. Kumar, and P. K. Joshi. Singapore: Springer. 
Takeshima, H., E. Edeh, A. Lawal, and M. Isiaka. 2015. "Characteristics of Private-Sector Tractor Service Provisions: Insights from Nigeria." Developing Economies 53 (3): 188-217.

Takeshima, H., and Y. Liu. 2018. The Role of Plant-Breeding R\&D in Tractor Adoption among Smallholders in Asia: Insights from Nepal Terai. IFPRI Discussion Paper 01719. Washington, DC: International Food Policy Research Institute.

Takeshima, H., R. B. Shrestha, B. D. Kaphle, M. Karkee, S. Pokhrel, and A. Kumar. 2016. Effects of Agricultural Mechanization on Smallholders and Their Self-Selection into Farming: An Insight from the Nepal Terai. IFPRI Discussion Paper 01583. Washington, DC: International Food Policy Research Institute.

Templeton, S. R., and S. J. Scherr. 1999. "Effects of Demographic and Related Microeconomic Change on Land Quality in Hills and Mountains of Developing Countries." World Development 27 (6): 903-918.

World Bank. 2016. World Integrated Trade Solution. Washington, DC: World Bank.

\section{Appendix 9A: Estimation of the Impacts of Tractor Adoption (Tables 9.14-9.19)}

\section{Tables 9.14-9.18}

We focus our analyses on specific regions with relatively favorable environments for intensifying tractor adoption. As was seen in the section titled "Demand-Side Analysis," the extent and depth of the adoption of tractors vary considerably across agroecological belts (the Terai and the Hills), as well as within the Terai zone. Comparing adopters and non-adopters of tractors in very different environments often biases the estimates of tractor adoption.

Specifically, in Tables 9.15 through 9.18, we focus on farm households in the Terai zone and in the VDCs in which at least one tractor adopter and one or more non-adopters are included in the samples in each round of the NLSS. Furthermore, we separately assess the impacts for small-farm households (those owning less than 0.4 ha of lowland farmland) and medium-farm households (those owning $0.4-5.0$ ha of lowland farmland). Table 9A.1 summarizes the set of variables used for estimating the probability of adopting tractors for each subgroup of samples, which are then used to construct the inverse of the weights in an IPW regression. These variables are selected to capture diverse aspects of household characteristics that are likely to be directly or indirectly associated with tractor adoption decisions, including agroecological 
conditions, household demographics, access to infrastructure and institutions, human capital and other wealth, and market conditions for complementary inputs. As is shown, when considering the IPW-adjusted results, no variable exhibits statistically different means between tractor adopters and non-adopters. Furthermore, Figure 9A.1 shows that the estimated probability, using the variables above, shows sufficient balancing properties. Using these diverse sets of variables to construct the probability weights minimizes the risk that we might incorrectly attribute the observed differences in outcomes to tractor adoption, when in fact the differences are due to differences in other household characteristics.

\section{Table 9.19}

Table 9.19 is based on similar IPW regressions, but with extensions through a combination of regression adjustments and instrumental variable regressions (detailed descriptions are available in Takeshima 2017a). In short, the effect of tractor adoption on returns to scale is estimated by simultaneously addressing the endogeneity of input variables in standard Cobb-Douglas production functions using instrumental variables (typically price variables of these inputs) and addressing the endogeneity of tractor adoption variables through IPW. As is shown in Takeshima (2017a), the model satisfies various properties, including the validity of instrumental variables used and the balancing properties of IPW. 
TABLE 9A.1 Significance ( $p$-values) of differences in averages between tractor adopters and non-adopters for each variable used in inverse probability-weighted regression

\begin{tabular}{|c|c|c|c|c|c|c|}
\hline \multirow[b]{3}{*}{ Variable } & \multicolumn{6}{|c|}{ Sample } \\
\hline & \multicolumn{2}{|c|}{ Terai (small) } & \multicolumn{2}{|c|}{ Terai (medium) } & \multicolumn{2}{|c|}{ Hills } \\
\hline & $\begin{array}{c}\text { Raw } \\
\text { sample }\end{array}$ & $\begin{array}{c}\text { IPW } \\
\text { sample }\end{array}$ & $\begin{array}{l}\text { Raw } \\
\text { sample }\end{array}$ & $\begin{array}{c}\text { IPW } \\
\text { sample }\end{array}$ & $\begin{array}{l}\text { Raw } \\
\text { sample }\end{array}$ & $\begin{array}{l}\text { IPW } \\
\text { sample }\end{array}$ \\
\hline $\begin{array}{l}\text { Obtained credit in the previous year } \\
\text { (yes = 1) }\end{array}$ & .161 & .611 & .206 & .898 & .351 & .734 \\
\hline $\begin{array}{l}\text { Obtained formal-sector credit in the } \\
\text { previous year (yes = 1) }\end{array}$ & .072 & .757 & .725 & .960 & .503 & .778 \\
\hline Land area owned (lowland) & .000 & .547 & .008 & .826 & .239 & .767 \\
\hline Land area owned (upland) & .694 & .268 & .498 & .582 & .007 & .512 \\
\hline $\begin{array}{l}\text { Gender of household head } \\
(\text { male }=1 ; \text { female }=0)\end{array}$ & .815 & .902 & .738 & .782 & .651 & .719 \\
\hline $\begin{array}{l}\text { Real household asset value-- } \\
\text { excluding farmland, livestock, } \\
\text { equipment }\end{array}$ & .087 & .865 & .985 & .876 & .888 & .801 \\
\hline $\begin{array}{l}\text { Real household asset value-live- } \\
\text { stock }\end{array}$ & .149 & .424 & .142 & .579 & .041 & .839 \\
\hline $\begin{array}{l}\text { Real household asset value- } \\
\text { equipment }\end{array}$ & .121 & .935 & .378 & .655 & .078 & .957 \\
\hline $\begin{array}{l}\text { Literacy of household head } \\
\text { (literate = 1) }\end{array}$ & .000 & .907 & .005 & .788 & .006 & .044 \\
\hline $\begin{array}{l}\text { Whether owning nonproductive land } \\
\text { (yes = 1) }\end{array}$ & .009 & .970 & .000 & .330 & .164 & .562 \\
\hline $\begin{array}{l}\text { Whether owning enterprise asset } \\
\text { (yes = 1) }\end{array}$ & .038 & .796 & .815 & .516 & .237 & .597 \\
\hline $\begin{array}{l}\text { Average education levels of } \\
\text { working-age household } \\
\text { members }\end{array}$ & .000 & .805 & .003 & .888 & .009 & .477 \\
\hline Number of plots owned & .199 & .876 & .000 & .790 & .219 & .905 \\
\hline $\begin{array}{l}\text { Ownership of draft animals } \\
\text { (yes = 1) }\end{array}$ & .638 & .233 & .698 & .938 & .696 & .894 \\
\hline Age of household head & .062 & .920 & .780 & .814 & .653 & .643 \\
\hline Rainfall (average) & .000 & .970 & .000 & .900 & .000 & .800 \\
\hline Rainfall (standard deviation) & .000 & .992 & .000 & .654 & .004 & .639 \\
\hline Solar radiation index & .374 & .727 & .002 & .568 & .001 & .667 \\
\hline $\begin{array}{l}\text { Piped water as drinking water } \\
\text { source }(1=\text { yes })\end{array}$ & .720 & .677 & .188 & .654 & .165 & .921 \\
\hline $\begin{array}{l}\text { Electricity the main source of light } \\
(1=\text { yes })\end{array}$ & .000 & .872 & .000 & .888 & .000 & .825 \\
\hline $\begin{array}{l}\text { Wood the main source of cooking } \\
\text { fuel (yes = 1) }\end{array}$ & .056 & .782 & .000 & .673 & .000 & .453 \\
\hline
\end{tabular}


TABLE 9A.1 Continued

\begin{tabular}{|c|c|c|c|c|c|c|}
\hline \multirow[b]{3}{*}{ Variable } & \multicolumn{6}{|c|}{ Sample } \\
\hline & \multicolumn{2}{|c|}{ Terai (small) } & \multicolumn{2}{|c|}{ Terai (medium) } & \multicolumn{2}{|c|}{ Hills } \\
\hline & $\begin{array}{l}\text { Raw } \\
\text { sample }\end{array}$ & $\begin{array}{l}\text { IPW } \\
\text { sample }\end{array}$ & $\begin{array}{l}\text { Raw } \\
\text { sample }\end{array}$ & $\begin{array}{c}\text { IPW } \\
\text { sample }\end{array}$ & $\begin{array}{l}\text { Raw } \\
\text { sample }\end{array}$ & $\begin{array}{l}\text { IPW } \\
\text { sample }\end{array}$ \\
\hline $\begin{array}{l}\text { Whether the community has gar- } \\
\text { bage disposal service (yes = } 1 \text { ) }\end{array}$ & .201 & .862 & .926 & .891 & .777 & .774 \\
\hline Use garbage for fertilizer (yes = 1) & .364 & .538 & .203 & .327 & .086 & .997 \\
\hline Household size (adult males) & .615 & .908 & .619 & .629 & .423 & .962 \\
\hline Household size (adult females) & .059 & .838 & .492 & .696 & .205 & .532 \\
\hline Household size (children) & .406 & .799 & .091 & .992 & .013 & .148 \\
\hline VDC sample share of irrigators & .314 & .511 & .672 & .688 & .726 & .383 \\
\hline Per capita agricultural area & .006 & .923 & .410 & .678 & .002 & .850 \\
\hline Terrain ruggedness index & .044 & .979 & .000 & .607 & .000 & .773 \\
\hline Elevation & .002 & .779 & .000 & .981 & .001 & .939 \\
\hline $\begin{array}{l}\text { Share of samples with advanced } \\
\text { caste in VDC }\end{array}$ & .000 & .627 & .000 & .571 & .000 & .591 \\
\hline $\begin{array}{l}\text { Share of nonindigenous population } \\
\text { in VDC }\end{array}$ & .828 & .899 & .008 & .563 & .604 & .895 \\
\hline Price of chemical fertilizer (urea) & .790 & .661 & .022 & .862 & .973 & .855 \\
\hline Price of chemical fertilizer (DAP) & .217 & .769 & .000 & .903 & .587 & .771 \\
\hline Farm wage & .001 & .714 & .003 & .811 & .000 & .913 \\
\hline Tractor rental service price & .717 & .526 & .506 & .826 & .000 & .519 \\
\hline Distance to the nearest major river & .667 & .361 & .004 & .989 & .000 & .465 \\
\hline $\begin{array}{l}\text { Distance to the nearest agricultural } \\
\text { R\&D institute }\end{array}$ & .000 & .888 & .000 & .966 & .000 & .391 \\
\hline Distance to Indian border & .116 & .788 & .001 & .925 & .006 & .640 \\
\hline Time of travel to the nearest bank & .007 & .444 & .336 & .927 & .000 & .761 \\
\hline Time of travel to the nearest bus & .001 & .326 & .617 & .391 & .000 & .757 \\
\hline $\begin{array}{l}\text { Time of travel to the nearest } \\
\text { cooperative }\end{array}$ & .485 & .890 & .046 & .560 & .000 & .781 \\
\hline $\begin{array}{l}\text { Time of travel to the nearest } \\
\text { market center }\end{array}$ & .076 & .369 & .003 & .962 & .000 & .769 \\
\hline Time of travel to the nearest shop & .312 & .792 & .909 & .954 & .001 & .764 \\
\hline Year dummy (2010) & .382 & .563 & .000 & .745 & .006 & .608 \\
\hline Year dummy (2003) & .382 & .563 & .000 & .752 & .077 & .996 \\
\hline Urban area dummy & .235 & .770 & .588 & .965 & .970 & .822 \\
\hline Region dummy (Central) & .000 & .895 & .002 & .869 & .000 & .654 \\
\hline Region dummy (Western) & .000 & .965 & .000 & .680 & .124 & .288 \\
\hline
\end{tabular}




\begin{tabular}{|c|c|c|c|c|c|c|}
\hline \multirow[b]{3}{*}{ Variable } & \multicolumn{6}{|c|}{ Sample } \\
\hline & \multicolumn{2}{|c|}{ Terai (small) } & \multicolumn{2}{|c|}{ Terai (medium) } & \multicolumn{2}{|c|}{ Hills } \\
\hline & $\begin{array}{l}\text { Raw } \\
\text { sample }\end{array}$ & $\begin{array}{l}\text { IPW } \\
\text { sample }\end{array}$ & $\begin{array}{l}\text { Raw } \\
\text { sample }\end{array}$ & $\begin{array}{c}\text { IPW } \\
\text { sample }\end{array}$ & $\begin{array}{l}\text { Raw } \\
\text { sample }\end{array}$ & $\begin{array}{c}\text { IPW } \\
\text { sample }\end{array}$ \\
\hline Region dummy (Midwestern) & .002 & .734 & .000 & .966 & .000 & .593 \\
\hline Region dummy (Far Western) & .000 & .700 & .000 & .978 & .003 & .734 \\
\hline $\begin{array}{l}\text { VDC sample share renting out } \\
\text { tractors }\end{array}$ & .161 & .861 & .356 & .850 & .351 & .910 \\
\hline Number of observations & \multicolumn{2}{|c|}{852} & \multicolumn{2}{|c|}{731} & \multicolumn{2}{|c|}{644} \\
\hline
\end{tabular}

Source: Authors' calculations based on data from the Nepal Living Standards Survey for 1995, 2003, 2010 (Nepal, CBS 1996, 2004, 2011).

Note: $\mathrm{DAP}=$ diammonium phosphate; IPW = inverse probability-weighted; R\&D = research and development; $\mathrm{VDC}=$ village development committee.

FIGURE 9A.1 Balancing properties of inverse probability-weighted regressions

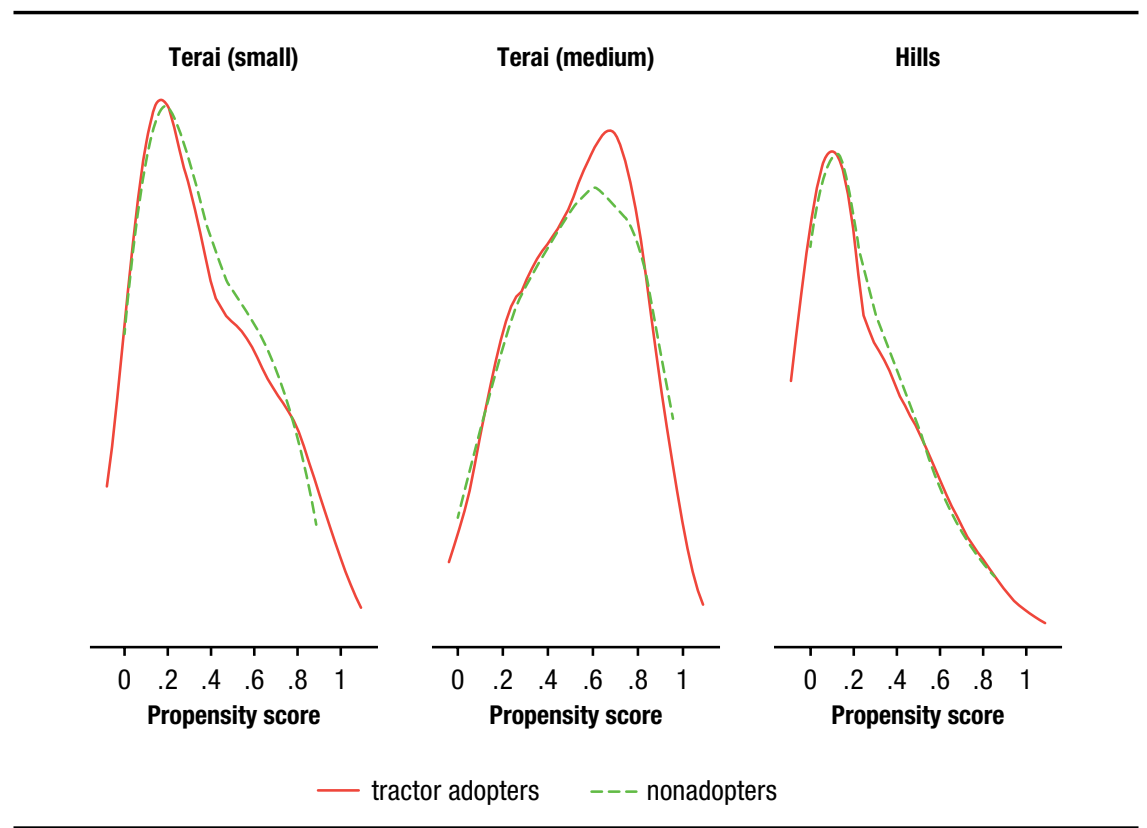

Source: Authors based on Nepal Living Standards Survey for 1995, 2003, 2010 (Nepal, CBS 1996, 2004, 2011). 



\section{PART 4}

\section{African Countries}





\title{
THE RAPID - BUT FROM A LOW BASE-UPTAKE OF AGRICULTURAL MECHANIZATION IN ETHIOPIA: PATTERNS, IMPLICATIONS, AND CHALLENGES
}

\author{
Guush Berhane, Mekdim Dereje, Bart Minten, and Seneshaw Tamru
}

\begin{abstract}
The uptake of agricultural mechanization in Ethiopia is low, with less than 1 percent of agricultural plots plowed with a tractor. However, in recent years the uptake of agricultural machinery has accelerated. We note an impressive increase in imports of combine harvesters and of tractors, seemingly associated with the increasing costs of agricultural labor and animal traction, for which agricultural mechanization can substitute. We estimate that a quarter of the area in Ethiopia planted with wheat-the fourth most important cereal in the country-is currently harvested by combine harvesters, and they are widely used in the major wheat-growing zones in the southeast of the country in particular. Private mechanization service providers have rapidly emerged. Smallholders in these wheat-growing zones rely heavily on agricultural machinery rental services for plowing, harrowing, and harvesting. We find that mechanization is associated with significantly lower labor use, and that the adoption of combine harvesters_-but not tractors—is significantly associated with higher yields, seemingly due to lower postharvest losses. Although further expansion of mechanization in the country is desired given the environmental and financial costs of holding oxen, and the higher yields linked with some forms of mechanization, it appears to be hampered by farm structures, particularly small farm sizes and consequent limits in scale; fragmented plots; crop diversity; physical constraints, such as the presence of stones, steep fields, and certain soil types; and economic and financial constraints, including limited access to foreign exchange and credit, and the still relatively low wages in less commercialized zones.
\end{abstract}

\section{Introduction}

Ethiopia's economy is quickly transforming, with double-digit average growth rates noted in the last decade. Specifically, Ethiopia's agricultural sector is transforming rapidly, and it has been an important contributor to the overall economic growth process as well as to significant poverty reduction in the 
country (World Bank 2015b). Over the last decade, this sector has modernized, as shown by large increases - more than a doubling-in modern input use, such as chemical fertilizers and improved seeds, which explain part of the growth. ${ }^{1}$ Evidence shows that this agricultural growth has been associated with significant increases in real rural wages over this same period-real rural wages have risen by 54 percent in the last decade, albeit from a low base (Bachewe et al. 2016) - as well as rises in costs of animal traction. As agricultural economies grow and as relative factor costs change, because of changes in wages and costs of animal traction, a typical pattern toward greater use of machinery in agriculture is observed internationally (Pingali, Bigot, and Binswanger 1987). Empirical evidence documenting these emerging trends in the mechanization of agriculture in Ethiopia is, however, scarce.

On the policy side, we see an increasing interest in the country in stimulating agricultural mechanization. This interest is seemingly driven by two reasons. First, a large portion of agricultural work in Ethiopia is done with the help of livestock. However, livestock are an important contributor to global warming. To make the economy more climate resilient, there are plans to restructure the livestock sector to rely on fewer (but more productive) livestock that are used less in land preparation and threshing activities (Ethiopia, MoA and MoEF 2011). Second, successful changes have occurred in Ethiopia's rural and agricultural economy in the last decade, and there is an increasing push toward further agricultural transformation and modernization of the sector (Bachewe et al. 2015). Mechanization is seen as an integral part of this transformation. This is reflected in the development of a new comprehensive mechanization strategy by the Agricultural Transformation Agency (ATA) and the Ministry of Agriculture and Natural Resources (MoANR), as well as by the setting of ambitious targets on mechanization in the country's Growth and Transformation Plan for the period 2016-2020. It is planned that agricultural mechanization levels will be raised from about $0.1 \mathrm{~kW} / \mathrm{ha}$ in 2014 to $1 \mathrm{~kW} /$ ha by 2025 (Ethiopia, ATA 2014). Such targets fit well within the objectives of the country's industrialization strategy and its plans for the greening of its economy (Ethiopia, MoA and MoEF 2011).

This emphasis on mechanization as a means to achieve a better-performing agricultural sector is not new to Ethiopia. During the Emperor's era, there was a significant effort to increase agricultural mechanization in the country, albeit

1 Bachewe and others (2015) showed that the expansion in modern input use appears to have been driven by high government expenditures on the agricultural sector, including agricultural extension, but also by an improved road network, higher rural education levels, and favorable international and local price incentives. 
mostly focused on large commercial farms. During the Derg period, from 1974 to 1991, most of these large farms were nationalized and attention to agricultural mechanization focused on these large state farms. However, cooperatives in the cereal-based system were also targeted (FACASI Project 2016). The focus of the current government has been on improving smallholder production through adoption of improved technologies in which mechanization, until recently, played a relatively minor role (Ethiopia, ATA 2014). Although there have been some recent efforts in Ethiopia to promote small-scale mechanization, such as two-wheel tractors (Baudron et al. 2015), the focus has largely been on large-scale mechanization, such as large-horsepower tractors.

In the research presented in this chapter, we analyze patterns in agricultural mechanization in Ethiopia based on unique primary and secondary data. We demonstrate that the use of agricultural mechanization has been rapidly increasing in Ethiopia, although it is still mostly limited to specialized wheat-growing areas. This low level of adoption is partly linked to adverse economic conditions for increased mechanization in farming, such as low rural wages, problematic access to foreign exchange, and limited access to credit. Mechanization is, however, also hampered by technical constraints due to smallholder agriculture and its small and fragmented plots, Ethiopia's rugged topography, and the widespread presence of stones in fields, which complicate mechanized plowing. Moreover, the diversification in Ethiopian crop agriculture farming systems makes it difficult for a single machine to take off, because different crops might need different harvesting equipment.

Nonetheless, recently we have seen significant dynamics in the use of mechanization in farming, noting a fast increase in the number of tractors and combine harvesters in the country, though starting from a low base. The number of imported tractors has increased fivefold over the last 5 years, and the annual import value of combine harvesters is now more than tenfold what it was 15 years ago. Although a large share of the functional tractors is being used by larger commercial farmers and state farms, we also see increasing uptake of mechanization by smallholders, especially in the wheat sector. Commercial mechanization service providers are rapidly emerging, providing plowing, harrowing, and harvesting services for a fee. This change is seemingly associated with rapidly increasing costs of farm labor and animal traction, for which these machines substitute. However, demand for mechanization might still be an issue in these settings, as there appears now to be an oversupply of tractors in the country.

The objectives of the chapter are fivefold. We first illustrate mechanization patterns in the country, and particularly focus on smallholder 
mechanization. We limit our discussion to the most common forms of mechanization in the country, namely, tractors and combine harvesters. Second, we illustrate changing trends in demand conditions. Third, we look at mechanization service provisions and related policies. Fourth, we focus on analyzing the associated effects of mechanization on modern input adoption, labor productivity, and yields. We perform these analyses through a combination of quantitative and qualitative methods. Finally, we finish with a discussion of the implications and challenges for further scaling up agricultural mechanization in Ethiopia.

\section{Data and Methodology}

To gather the required information for this study, we conducted two types of activities. First, interviews were held with key informants in mid- and late 2016. These informants included representatives of the Ethiopian Institute of Agricultural Research, the MoANR, private importers, the Metals and Engineering Corporation (METEC), the ATA, cooperative unions, operators of tractors and combine harvesters, brokers, the Mechanization Service Provider Association, and farmer focus groups.

Second, we relied on three sources of quantitative data:

1. Import data for the last decade from the UN Comtrade database (United Nations 2017). These data include information on quantities, country of consignment, values, and prices of imported agricultural machinery.

2. Household data from a survey conducted between June and July 2013 on the zone of influence (ZOI) of the US government's Feed the Future $(\mathrm{FtF})$ Program in Ethiopia. ${ }^{2}$ These data are representative of the $\mathrm{ZOI}$ within which the FtF program operates but are not regionally or nationally representative. However, the sample is large-nearly 7,000 households - and widespread, the survey having been administered in 252 villages in 84 of Ethiopia's 670 rural districts (woredas). Together the treatment and the control groups represent more than 25 million people residing in more than 6 million households.

2 The main purpose of the FtF survey was to obtain pre- and postintervention information in localities that received investments to improve agricultural production and nutrition under the $\mathrm{FtF}$ program, or in localities that were to act as comparison sites for the evaluation of FtF. 
3. Household data from the Ethiopia Socioeconomic Survey (ESS). The ESS 2013/2014 was implemented in 433 enumeration areas and covers 5,262 households. Small rural towns (with populations of less than 10,000 people) and urban areas (more than 10,000 people) were sampled to allow representative population estimates for six regional strata as well as national-level estimates.

This chapter focuses on agricultural mechanization and the use of associated implements, which we define in one of two ways in this chapter. We will follow the distinction made by the ATA (Ethiopia, ATA 2014) of high- and intermediate-mechanization implements (HIMIs)_including tractors, combine harvesters, and threshers-versus low-mechanization implements (LMIs) - implements such as traditional plows, sickles, and so on. Manufacture of LMIs is mostly done by local blacksmiths, in contrast to HIMIs, which are mostly imported. Although we present some statistics on the ownership of LMIs, in this chapter we mainly focus on patterns in use of, demand for, and supply of HIMIs, particularly tractors and combine harvesters.

\section{Agricultural Growth and Structural Transformation in Ethiopia}

Ethiopia is among the poorest countries in the world, but it has registered remarkable economic growth and poverty reduction over the last decade (World Bank 2015b). Real gross domestic product (GDP) grew annually by an average 10.7 percent over the period 2005 to 2014 . The agricultural sector also grew rapidly, at an average annual rate of 7.6 percent. The sector accounted for 47 percent of real GDP on average over the last decade, and it was the largest contributor to GDP until the services sector superseded it in 2010/2011.

We can point to several reasons for the growth in the agricultural sector. First, it is partially explained by increasing adoption of modern inputs, such as chemical fertilizer. Bachewe and others (2016) showed that chemical fertilizer use increased by 144 percent over the period 2005 to 2014, and 76 percent of the cereal farmers in the country had adopted chemical fertilizer by 2014, up from 46 percent in 2004 . We also see important changes in the agricultural economy related to employment and wages, livestock prices, and connectivity and market access, as well as small changes in farm sizes. Because these changes might impact the agricultural mechanization process, they are discussed consecutively. 
Second, despite the important overall economic growth that has been observed recently, we see little structural transformation in terms of employment through labor movement from the agricultural sector to the service and manufacturing sectors. ${ }^{3}$ On the other hand, we see a significant increase in the level of rural wages paid, as seen in Figure 10.1 (left panel). Real wages of unskilled labor in rural areas increased by more than 50 percent over the period 2000 to 2016 . However, although there has been growth in wages in rural areas, these wages notably are still significantly lower than those in other comparable countries. Rural wage data from other countries are shown on the right panel of Figure 10.1. We find that wages in Ethiopia in 2012 were significantly lower than those in Asian countries for which data are presented. It is estimated that average unskilled labor (daily) wages in Nepal, Bangladesh, and Myanmar in about 2012 were $\$ 0.95,51.59$, and about $\$ 1.00$ higher, respectively, than average daily wages in Ethiopia. Agricultural wages in Ethiopia were only 57, 44, and 56 percent of the average agricultural wages paid in these respective countries. Compared with two East African countries (Tanzania and Kenya) for which we have data, wages in Ethiopia were significantly lower as well.

Third, agricultural growth over the last decade has been achieved partly through an increase in the area of land cultivated, but mostly through yield increases. Using the nationally representative dataset of Ethiopia's Central Statistical Agency (CSA), Bachewe and others (2015) found that cultivated land increased by 27 percent over the last decade. This increase has led to increasing pressure on land use for other purposes-such as forests and communal lands-and to subsequent scarcity of grazing areas for livestock. In turn, the lack of grazing areas led to growth in the commercial feed sector, as demonstrated by the rapid emergence of commercial feed mills (Mekasha et al. 2014). This trend seems to have contributed to relatively higher costs of holding cattle, which has impacted the cost of animal traction, illustrated in Figure 10.2. The average oxen price in the country almost doubled in real terms over the period 2001 to 2016.

3 Most of Ethiopia's population remains in rural areas, deriving their living mainly from agriculture, and the nonfarm sector remains small when compared with that of other countries (Bachewe et al. 2016). For example, Schmidt and Bekele (2016) find that the growth of the nonfarm sector only contributed to a small drop in the share of people making a living in the agricultural sector, that is, 3 percent between 2005 and 2013, a drop from 80 to 77 percent.

4 Unfortunately, because wage data are not widely available, these data provide only an indication of wages paid in a limited number of Asian and African countries.

5 Dollar figures are US dollars throughout the chapter. 
FIGURE 10.1 Real daily wages of unskilled laborers in rural areas of Ethiopia, 2003 to 2016 (left panel), and rural wage data from other developing countries (right panel)
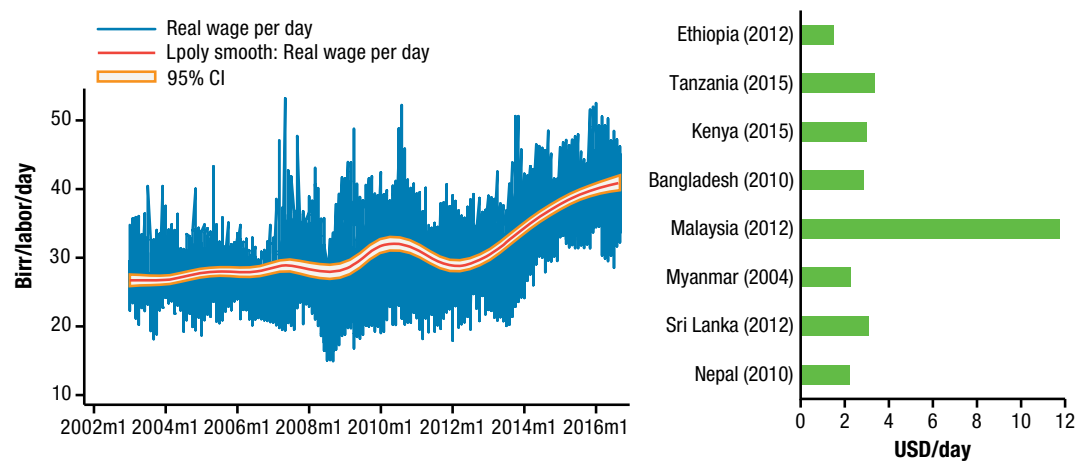

Source: Authors' calculations based on Ethiopia, CSA's price database; Bachewe et al. (2016); and Bymolt and Zaal (2015). Note: $\mathrm{Cl}=$ confidence interval; USD $=$ US dollars. $\mathrm{m} 1$ = month 1 .

\section{FIGURE 10.2 Real prices of oxen in Ethiopia, 2004-2016}

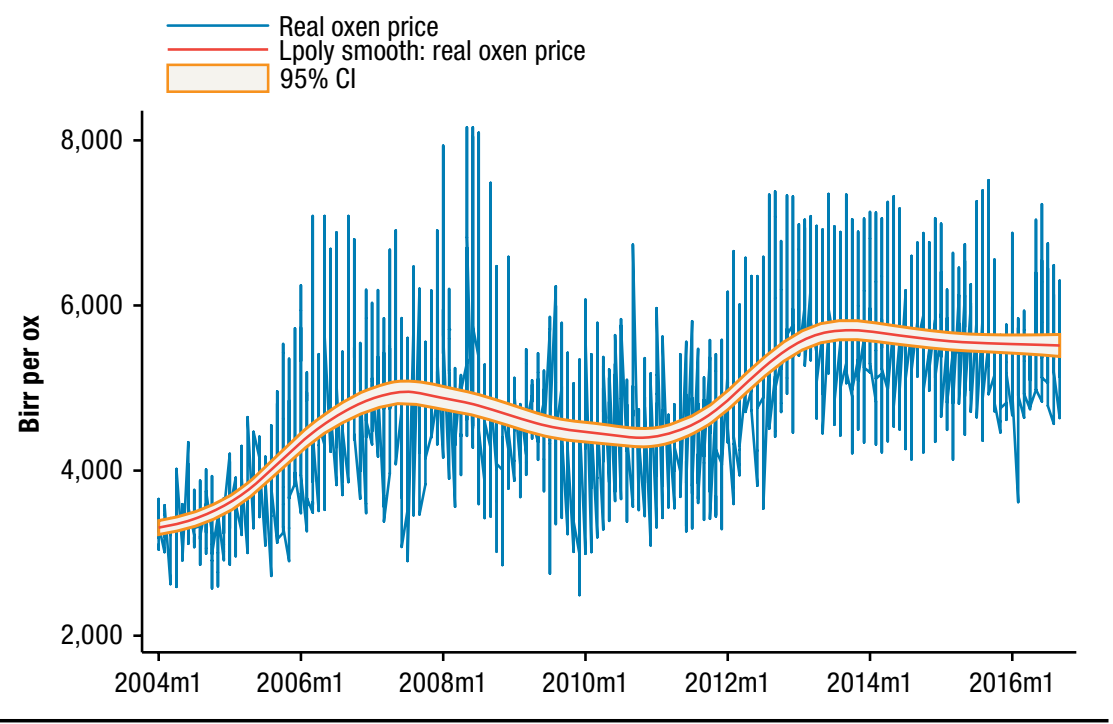

Source: Authors' calculations based on Ethiopia Central Statistical Agency price data.

Note: $\mathrm{Cl}=$ confidence interval. $\mathrm{m} 1$ = month 1 . 
Fourth, the functioning of agricultural markets has improved significantly over the last decade (Minten, Tamiru, and Stifel 2014). Two major factors have contributed to better connecting rural farmers to demand centers. For one thing, urbanization in Ethiopia is among the lowest in the world, with only 17 percent of the population estimated to live in cities in 2012 (World Bank 2015a). However, rapid growth of cities has occurred in the last decade and even faster changes are expected in the future. Schmidt and Kedir (2009) estimated that, based on an agglomeration index approach and using the last three national censuses (1984, 1994, and 2007), urbanization rates increased from 3.7 to 14.0 percent over the period studied, almost quadrupling the urban share of the national population (Ethiopia, Population Census Commission 2008). In addition, driven by complementary rapid road infrastructure development, the total length of all-weather surfaced roads tripled in less than 15 years, from an estimated 32,900 km in 2000 to $99,500 \mathrm{~km}$ in 2013 (NBE 2014). Kedir, Schmidt, and Tilahun (2015) further estimated that only 15 percent of the population was located within three hours of a city with a population of at least 50,000 in $1997 / 1998$, but by $2010 / 2011$, this number had changed to 47 percent of the population. ${ }^{6}$ These developments in markets and connectivity are important factors in providing necessary incentives for increasing investments in agriculture, including in capital-intensive agricultural mechanization.

Fifth, Ethiopia is largely characterized by smallholder agriculture. Smallholder farmers dominate agricultural land use in Ethiopia, making up 94 percent of total cultivated land in 2014/2015, with this share having changed little over the last decade. ${ }^{7}$ Figure 10.3 illustrates how the mean and the median farm size of these smallholders has evolved over the last 10 years. Farm sizes were small at the beginning of the decade-long period, with a mean and median of 1.10 and 0.77 ha per farm, respectively. These figures had declined slightly by 2015 , to 1.08 and 0.72 ha per farm, respectively. This pattern of small farm sizes adversely affects mechanization because smaller farms are generally less capitalized and rely less on mechanization, as we will see later.

6 The World Bank (2015a) expects that urban populations will continue to grow rapidly in Ethiopia, projecting an annual growth rate of 5.4 percent over the coming decades, which would lead to a tripling of the urban population, from 15.2 million in 2012 to 42.3 million in 2034 . By 2028,30 percent of the population of Ethiopia is expected to be living in urban areas.

7 Smallholders cultivated 14.22 million ha (Ethiopia, CSA 2015a) in the main (meher) season in 2014/2015. This compares with 0.98 million ha for commercial farmers (Ethiopia, CSA 2015b). 
FIGURE 10.3 Evolution of farm sizes of smallholders (less than 25 ha), Ethiopia, 2004-2015

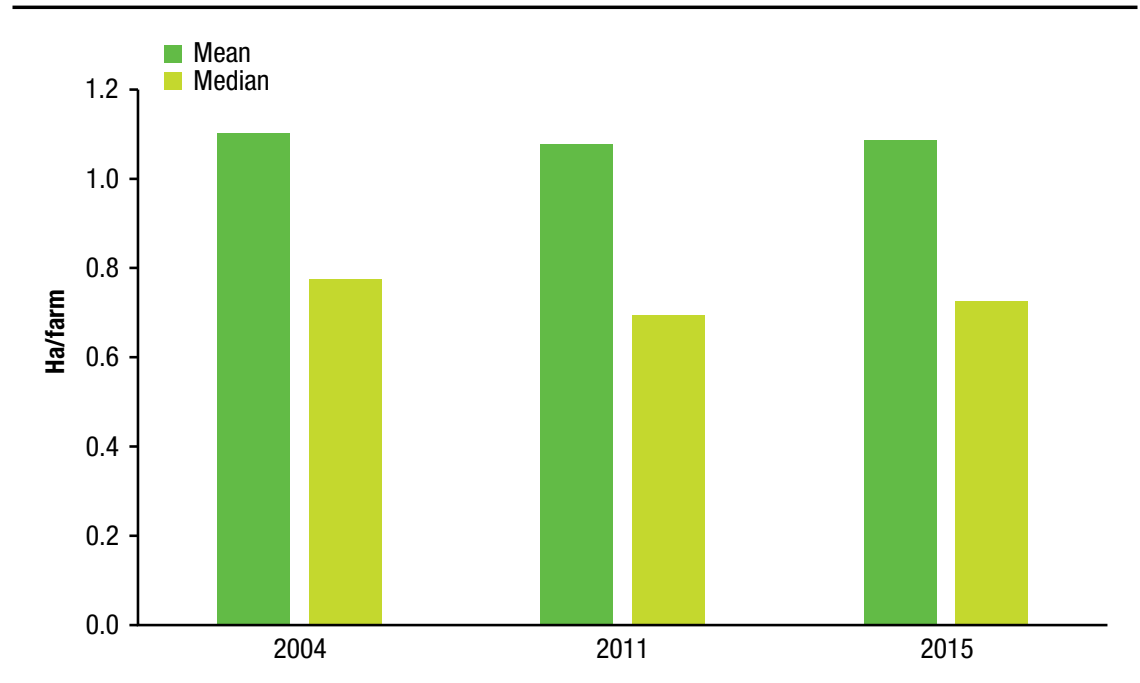

Source: Authors' calculations based on Ethiopia, CSA (2015a).

Although the importance of smallholders in Ethiopian agriculture is large, the relative importance of commercial farmers-defined by the CSA as those that have more than 25.2 ha-is increasing over time, although starting from a relatively low base. The area cultivated by commercial farms increased from 0.46 million ha in 2007/2008 to almost 1.0 million ha in 2014/2015 (Ethiopia, CSA 2015b). Moreover, these commercial farms are spatially concentrated and are focused on specific crops (Figure 10.4). The major crops grown by commercial farms are sesame, cotton, sorghum, maize, and wheat. Several of these crops are spatially clustered-commercial farms producing sesame are mostly located in the northwest; maize, mostly in the west; and wheat in the south and southeast of the country (cotton and sorghum are more scattered across Ethiopia).

Finally, to understand the demand for mechanization, two defining characteristics of Ethiopian agriculture are important to highlight. First, Ethiopia is characterized by a rugged topography with strong differences in altitude over short distances. When considering agricultural production environments, a distinction is made between the highlands (higher than 2,500 meters above sea level, or MASL), the midlands (about 1,600-2,500 MASL), and the lowlands (less than 1,600 MASL). Second, there are distinctive rainfall patterns in the country. Rainfall is unimodal in the west and north of the country, with one main harvest (meher), whereas it is bimodal in the east 
FIGURE 10.4 Commercial farms in Ethiopia, 2014/2015: Crops grown by percentage (left panel) and area under commercial farms by zone, '000 ha (right panel)
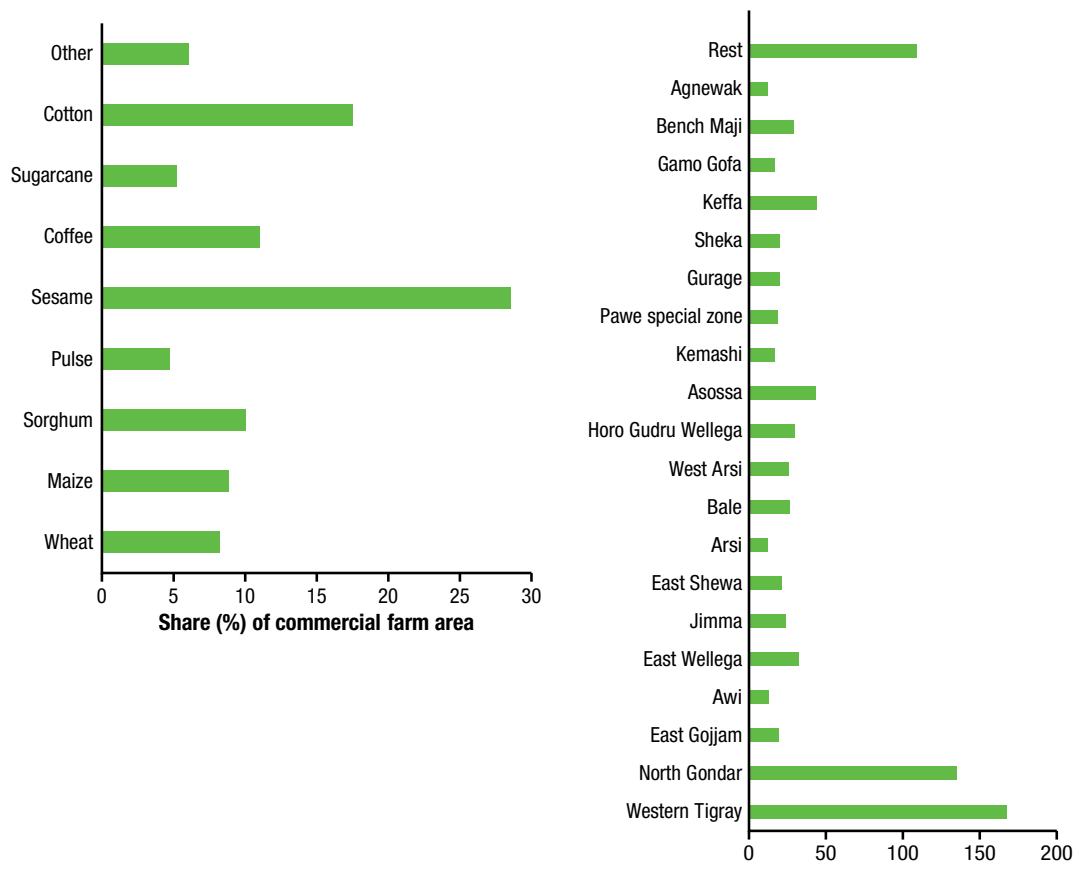

Source: Authors' calculations based on Ethiopia, CSA (2015b).

and southeast of the country, giving rise to a second season (belg) in those areas (Figure 10.5). Moreover, rainfall is more reliable in the west and southeast of the country, compared with other parts. Based on these characteristics, Chamberlin and Schmidt (2012) divided the country into five development domains: moisture-reliable highlands, moisture-reliable lowlands, droughtprone highlands, drought-prone lowlands, and pastoralist areas.

\section{Demand-Side Analysis}

\section{Current Machinery Use and Ownership}

Using data from the $2013 \mathrm{FtF}$ survey, Table 10.1 illustrates ownership of different types of machinery by farm size, divided into quintiles. The median size of the farms in the dataset varies between 0.3 ha for the smallest quintile up to 3.4 ha for the largest quintile. The median for the whole sample is 1.1 


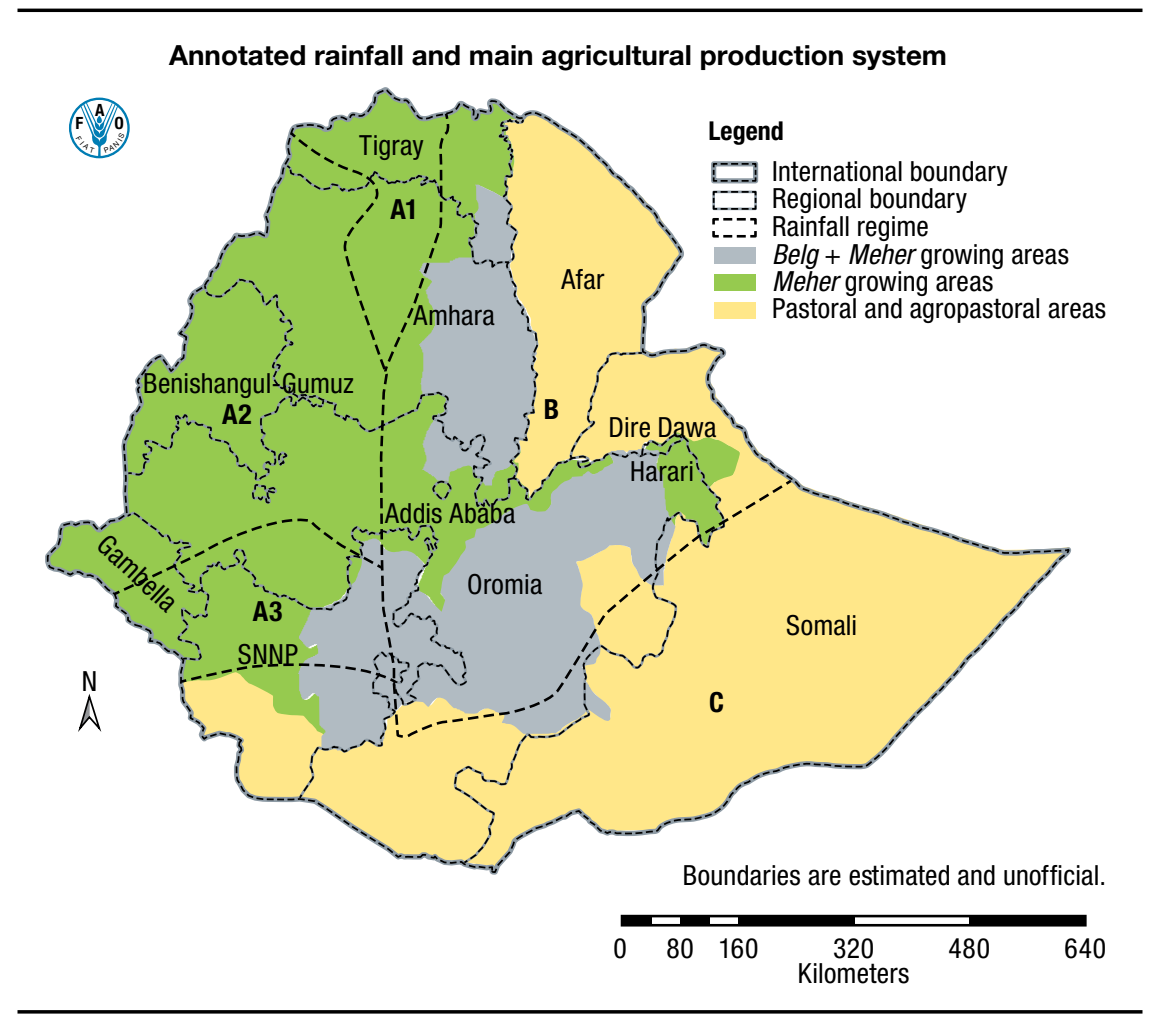

Source: Food and Agriculture Organization of the United Nations.

Note: SNNPR = Southern Nations, Nationalities, and Peoples' Region.

ha, close to the average for the country. ${ }^{8}$ Ownership of HIMIs is shown overall to be low in the country-0.1, 0.3 , and 0.1 percent of households reported owning a motorized water pump, a small tractor, and a hand-held motorized tiller, respectively. The mean value of HIMIs for these households is 144 birr (or about \$7). The median value is 0 birr. As expected, we see a strong association of farm size with ownership of HIMIs. In the case of small tractors, 0.5 percent of the largest farms reported owning a small tractor, but this declines to 0.0 percent for the smallest farms.

Table 10.1 also presents statistics on the ownership of LMIs. The average value of LMI assets amounts to 521 birr (or \$27), still low but significantly higher than the value of HIMIs owned. We see a strong association

8 It is to be noted that the commercial farms larger than 25 ha are not part of this survey. 
TABLE 10.1 Ownership of machinery, Ethiopia, 2013

\begin{tabular}{|c|c|c|c|c|c|c|c|}
\hline \multirow[b]{2}{*}{ Equipment type } & \multirow[b]{2}{*}{ Unit } & \multirow[b]{2}{*}{ All } & \multicolumn{5}{|c|}{ Farm size (by quintile) } \\
\hline & & & Q1 & Q2 & Q3 & Q4 & Q5 \\
\hline \multicolumn{8}{|l|}{ FtF areas } \\
\hline \multirow[t]{2}{*}{ Average size of farm } & Mean ha & 1.6 & 0.3 & 0.7 & 1.2 & 1.8 & 4.2 \\
\hline & Median ha & 1.1 & 0.3 & 0.8 & 1.1 & 1.8 & 3.4 \\
\hline \multicolumn{8}{|c|}{ High- and intermediate-mechanization implements (HIMls) } \\
\hline Motorized water pump (diesel) & $\%$ of households & 0.1 & 0.0 & 0.0 & 0.0 & 0.0 & 0.3 \\
\hline Small tractor & $\%$ of households & 0.3 & 0.0 & 0.3 & 0.1 & 0.7 & 0.5 \\
\hline Hand-held motorized tiller & $\%$ of households & 0.1 & 0.0 & 0.0 & 0.0 & 0.1 & 0.2 \\
\hline \multirow[t]{2}{*}{ Total value HIMls } & Mean $\mathrm{Br}$ & 144 & 0 & 10 & 6 & 19 & 685 \\
\hline & Median $\mathrm{Br}$ & 0 & 0 & 0 & 0 & 0 & 0 \\
\hline \multicolumn{8}{|l|}{ Low-mechanization implements (LMls) } \\
\hline Plow yoke & $\%$ of households & 64.3 & 30.6 & 56.4 & 69.6 & 79.3 & 86.0 \\
\hline Plow beam & $\%$ of households & 64.1 & 30.8 & 55.3 & 70.2 & 78.9 & 85.5 \\
\hline Plow lever & $\%$ of households & 63.3 & 30.6 & 54.7 & 68.6 & 78.1 & 84.8 \\
\hline Plow blade & $\%$ of households & 63.6 & 30.4 & 55.1 & 68.8 & 78.6 & 85.3 \\
\hline Leather tie for plow (miran) & $\%$ of households & 61.6 & 29.0 & 52.3 & 67.5 & 75.7 & 83.7 \\
\hline Plow metal support (wegel) & $\%$ of households & 63.7 & 30.0 & 56.1 & 69.1 & 78.9 & 85.0 \\
\hline Oxen-pulled plow, metal (maresha) & $\%$ of households & 65.1 & 31.4 & 57.4 & 71.0 & 79.8 & 86.0 \\
\hline Sickle & $\%$ of households & 79.9 & 60.3 & 76.9 & 84.0 & 87.4 & 90.9 \\
\hline Pickax (doma) & $\%$ of households & 38.1 & 27.3 & 36.7 & 38.4 & 41.7 & 46.7 \\
\hline
\end{tabular}

between farm size and ownership of LMIs, with the reported value of LMIs for the highest farm size quintile being almost four times higher than that of the lowest quintile. The median shows an even higher gradient. Within the LMI category, household ownership of mareshas (oxen-pulled plows) stands at 65 percent, sickles at 80 percent, and axes at 71 percent. Few farmers own more modern LMIs, such as a chemical sprayer (1 percent) or a mechanical water pump (4 percent). The ESS results, presented at the bottom of Table 10.1, illustrate a pattern similar to that of the LMI ownership results in the FtF survey (however, no data on HIMI ownership were available in the ESS dataset).

Table 10.2 illustrates the use of machinery by farm size for different agricultural operations. In the $\mathrm{FtF}$ survey, information was collected on land preparation, harvesting, and threshing activities. In the ESS survey, only 


\begin{tabular}{llrrrrrr} 
& & \multicolumn{5}{c}{ Farm size (by quintile) } \\
\cline { 4 - 8 } Equipment type & Unit & All & \multicolumn{1}{c}{ Q1 } & \multicolumn{1}{c}{ Q2 } & Q3 & Q4 & \multicolumn{1}{c}{ Q5 } \\
\hline Ax (metrebia) & \% of households & 71.1 & 51.9 & 64.8 & 75.7 & 79.3 & 84.1 \\
Pruning/cutting shears (megrezia) & \% of households & 9.1 & 8.9 & 6.9 & 7.2 & 11.5 & 11.1 \\
Hoe, wood/metal (gesso) & \% of households & 19.1 & 17.3 & 14.7 & 18.0 & 16.4 & 28.9 \\
Scythe, wood/metal (mencha) & \% of households & 4.8 & 3.0 & 4.1 & 4.8 & 4.6 & 7.3 \\
Hoe (mekotkocha) & \% of households & 53.9 & 47.5 & 50.9 & 58.7 & 60.1 & 52.5 \\
Spade or shovel (akefa) & \% of households & 38.8 & 25.0 & 30.3 & 37.5 & 42.9 & 58.5 \\
Backpack chemical sprayer & \% of households & 1.0 & 0.8 & 1.9 & 3.1 & 4.4 & 8.6 \\
Mechanical water pump (hand, foot) & \% of households & 3.8 & 0.0 & 0.1 & 0.5 & 0.4 & 0.5 \\
Broad bed maker (oxen-pulled) & \% of households & 0.3 & 0.0 & 0.1 & 0.2 & 0.4 & 0.9 \\
Total value LMls & Mean Br & 521 & 229 & 416 & 516 & 619 & 829 \\
& Median Br & 425 & 130 & 347 & 465 & 535 & 660 \\
National level (ESS) (LMls) & & & & & & & \\
Sickle & \% of households & 80.5 & 78.2 & 82.2 & 86.4 & 89.5 & 85.8 \\
Ax (metrebia) & \% of households & 42.8 & 49.7 & 43.3 & 42.8 & 42.3 & 43.7 \\
Pickax (doma) & \% of households & 51.1 & 57.4 & 52.4 & 52.2 & 53.2 & 50.8 \\
Plow/maresha (traditional) & \% of households & 69.7 & 63.4 & 69.6 & 75.6 & 83.2 & 76.6 \\
Plow/maresha (modern) & \% of households & 2.2 & 2.1 & 2.3 & 1.9 & 2.3 & 2.9 \\
Water pump & \% of households & 3.5 & 3.6 & 1.6 & 1.1 & 0.8 & 4.5 \\
\hline
\end{tabular}

Source: Authors' calculations based on household data from 2013 Feed the Future survey and Ethiopia Socioeconomic Survey 2013/2014.

Note: $\mathrm{Br}=$ Ethiopian birr; ESS = Ethiopia Socioeconomic Survey 2013/2014; FtF = Feed the Future.

information on plowing was requested. The latter survey shows that in only 1 percent of plots was a tractor used for plowing. The most prevalent means of tilling was through animal traction or by hoe. The results of the survey also show strong links between the size of the farm and the use of tractors. The adoption of tractors for the farms in the largest farm size quintile is at 3 percent, three times as high as for the average farmer (at 1 percent). When we look at data from the FtF survey, similar trends are noted. Land preparation is mostly done through animal traction (79 percent of the plots) and by hoe (20 percent). Machines were reported to have been used on only 0.7 percent of plots. Other agricultural operations also illustrate the low level of use of machines: only 1.2 percent and 2.3 percent of the harvesting and threshing operations, respectively, were done using machines or mechanical equipment. 
TABLE 10.2 Use of machinery, percentage of plots, Ethiopia, 2013

\begin{tabular}{|c|c|c|c|c|c|c|}
\hline \multirow[b]{2}{*}{ Variable } & \multirow[b]{2}{*}{ All } & \multicolumn{5}{|c|}{ Farm size (by quintile) } \\
\hline & & Q1 & Q2 & Q3 & Q4 & Q5 \\
\hline \multicolumn{7}{|l|}{ FtF area } \\
\hline \multicolumn{7}{|l|}{ Land preparation } \\
\hline Hoe only ${ }^{\mathrm{a}}$ & 20.5 & 33.2 & 19.5 & 15.6 & 16.5 & 16.7 \\
\hline Animals ${ }^{b}$ & 78.8 & 66.4 & 79.8 & 83.9 & 82.9 & 81.9 \\
\hline Machine $^{c}$ & 0.7 & 0.4 & 0.6 & 0.6 & 0.6 & 1.5 \\
\hline Observations & 28,966 & 6,244 & 5,389 & 5,420 & 5,944 & 5,969 \\
\hline \multicolumn{7}{|l|}{ Harvesting } \\
\hline Manual & 98.80 & 98.90 & 99.00 & 99.20 & 98.90 & 98.00 \\
\hline Machine & 1.20 & 1.10 & 1.00 & 0.80 & 1.10 & 2.00 \\
\hline Observations & 30,800 & 6,609 & 5,705 & 5,636 & 6,301 & 6,549 \\
\hline \multicolumn{7}{|l|}{ Threshing } \\
\hline Manual & 49.8 & 59.6 & 47 & 41.4 & 47.1 & 54.3 \\
\hline Sheller & 1.5 & 1.6 & 1.2 & 0.7 & 1 & 3 \\
\hline Animals & 47.9 & 38.2 & 51.1 & 57.4 & 51.4 & 41.2 \\
\hline Mechanical & 0.8 & 0.7 & 0.7 & 0.5 & 0.5 & 1.5 \\
\hline Observations & 24,930 & 4,793 & 4,583 & 4,818 & 5,266 & 5,470 \\
\hline \multicolumn{7}{|c|}{ National level (ESS survey) } \\
\hline \multicolumn{7}{|l|}{ Plowing } \\
\hline Tractor & 0.9 & 0.4 & 0.6 & 0.5 & 0.8 & 2.8 \\
\hline Livestock & 32.6 & 10.0 & 23.1 & 39.9 & 56.3 & 48.6 \\
\hline Hoe & 25.3 & 54.8 & 28.7 & 21.2 & 12.8 & 9.6 \\
\hline Other & 41.1 & 34.8 & 47.7 & 38.5 & 30.1 & 39.0 \\
\hline
\end{tabular}

Source: Authors' calculations based on the household data from 2013 Feed the Future survey and Ethiopia Socioeconomic Survey 2013/2014.

Note: ESS = Ethiopia Socioeconomic Survey 2013/2014; FtF = Feed the Future. ${ }^{\text {a }}$ plots that were prepared using only hoe; ${ }^{b}$ plots that were prepared with some involvement of animals; ${ }^{c}$ plots where machines were used somehow (solely or together with hoe and animals).

We further try to understand to what extent differences in the use of mechanization might exist between crop types. We present the results for both cereals and noncereals in Table 10.3. In the case of cereals, according to data from the FtF survey, machines were used for land preparation, harvesting, and threshing on 1.1, 1.6, and 2.2 percent of the plots, respectively. We note that mechanization is most prevalent for the wheat crop, where 6.5 and 6.6 percent of the farmers reported to have relied on machines for harvesting 
TABLE 10.3 Use of machinery by crop, percentage of plots, Ethiopia, 2013

\begin{tabular}{|c|c|c|c|c|c|c|c|c|c|c|c|c|}
\hline Variable & 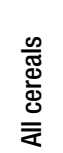 & $\stackrel{\sqrt{\sigma}}{\varrho}$ & 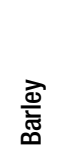 & $\begin{array}{l}\mathbb{\Xi} \\
\stackrel{\mathbb{\Phi}}{3}\end{array}$ & $\stackrel{\stackrel{N}{N}}{\stackrel{N}{\tilde{N}}}$ & $\begin{array}{l}\text { 豆 } \\
\text { 言 } \\
\text { 心 }\end{array}$ & 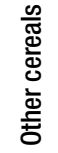 & 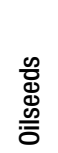 & $\frac{\mathscr{\mathscr { d }}}{\mathrm{\mathscr {O }}}$ & \begin{tabular}{l} 
응 \\
잉 \\
\multirow{2}{0}{} \\
$\stackrel{0}{x}$
\end{tabular} & 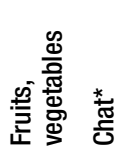 & 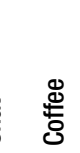 \\
\hline
\end{tabular}

FtF areas

Land preparation

$\begin{array}{lrrrrrrrrrrrrr}\text { Hoe only } & 5.9 & 2.0 & 8.0 & 2.2 & 10.8 & 5.8 & 1.0 & 2.9 & 9.0 & 31.3 & 84.3 & 89.9 & 92.8 \\ \text { Animals } & 93.0 & 97.8 & 91.6 & 96.7 & 87.9 & 90.5 & 98.5 & 93.7 & 90.9 & 68.6 & 15.6 & 9.8 & 7.1 \\ \text { Machine } & 1.1 & 0.2 & 0.4 & 1.1 & 1.4 & 3.7 & 0.4 & 3.3 & 0.2 & 0.1 & 0.1 & 0.3 & 0.1 \\ \text { Observations } & 17,039 & 3,830 & 2,152 & 2,635 & 5,649 & 1,517 & 1,256 & 616 & 4,190 & 2,131 & 1,344 & 328 & 769\end{array}$

Harvesting

$\begin{array}{llllllllllllll}\text { Manual } & 98.4 & 99.2 & 98.9 & 93.5 & 99.6 & 99.5 & 98.4 & 99.5 & 99.5 & 99.0 & 99.5 & 99.0 & 99.6\end{array}$

$\begin{array}{llllllllllllll}\text { Machine } & 1.6 & 0.8 & 1.1 & 6.5 & 0.4 & 0.5 & 1.6 & 0.5 & 0.5 & 1.0 & 0.5 & 1.0 & 0.4\end{array}$

$\begin{array}{llllllllllllll}\text { Observations } & 16,799 & 3,788 & 2,132 & 2,594 & 5,520 & 1,523 & 1,242 & 617 & 4,157 & 2,100 & 1,942 & 452 & 1,477\end{array}$

Threshing

\begin{tabular}{|c|c|c|c|c|c|c|c|c|c|c|c|c|c|}
\hline Manual & 42.4 & 23.2 & 20.0 & 17.0 & 86.1 & 35.2 & 23.8 & 73.2 & 44.3 & n.a. & n.a. & n.a. & n.a. \\
\hline Sheller & 1.0 & 0.6 & 0.3 & 0.7 & 1.9 & 0.5 & 0.5 & 1.3 & 0.4 & n.a. & n.a. & n.a. & a. \\
\hline Animals & 55.4 & 75.5 & 79.3 & 76.4 & 11.8 & 64.1 & 75.5 & 25.6 & 55.2 & n.a. & n.a. & n.a. & l.a. \\
\hline Mecha & 1.2 & 0.6 & 0.3 & 5.9 & 0.2 & 0.2 & 0.2 & 0.0 & 0.0 & n.a. & n.a. & n.a. & n.a. \\
\hline Observations & 16,541 & 3,784 & 2,123 & 2,580 & 5,296 & 1,518 & 1,240 & 607 & 4,081 & n.a. & n.a. & n.a. & n.a. \\
\hline \multicolumn{14}{|c|}{ National level (ESS survey) } \\
\hline \multicolumn{14}{|l|}{ lowing } \\
\hline Tractor & 0.9 & 0.8 & 0.5 & 0.7 & 1.7 & 5.5 & 0.3 & 2.5 & 1.0 & 0.8 & 0.7 & 1.0 & 0.0 \\
\hline Livestock & 32.6 & 84.5 & 72.6 & 83.0 & 61.5 & 55.2 & 84.3 & 79.7 & 68.1 & 27.4 & 14.7 & 6.5 & 0.0 \\
\hline Hoe & 25.3 & 3.6 & 13.2 & 5.1 & 24.4 & 24.9 & 1.6 & 8.9 & 18.3 & 66.6 & 77.3 & 82.4 & 0.0 \\
\hline Other & 41.1 & 11.2 & 13.7 & 11.1 & 12.3 & 14.5 & 13.8 & 8.9 & 12.6 & 5.2 & 7.3 & 10.1 & 0.0 \\
\hline
\end{tabular}

Source: Authors' calculations based on the household data from 2013 Feed the Future survey and Ethiopia Socioeconomic Survey 2013/2014.

Note: n.a. $=$ not applicable; ESS $=$ Ethiopia Socioeconomic Survey 2013/2014; FtF = Feed the Future. * Chat, also known elsewhere in the world as qat or khat, is a shrub whose leaves are chewed.

and threshing, respectively. In the case of sorghum, we see a relatively high use of machines for land preparation (3.7 percent). The ESS survey shows overall similar results. For noncereals, oilseeds show the highest use of machines for land preparation.

In focus group interviews conducted during the $\mathrm{FtF}$ survey, questions were asked about the use of different types of mechanization in the community in which the focus group interviews were held. We present these results by zone. 
TABLE 10.4 Share of households that use machines, by zone, as reported by focus groups, Ethiopia, 2013

\begin{tabular}{lccccccc}
\hline Zone & Tractor & $\begin{array}{c}\text { Combine } \\
\text { harvester }\end{array}$ & Planter & Thresher & weeder & $\begin{array}{c}\text { Water } \\
\text { pump }\end{array}$ & 0thers \\
\hline Central Tigray & 0.1 & - & - & - & - & 2.5 & - \\
East Tigray & 3.1 & - & - & - & - & 0.8 & - \\
Southern Tigray & 1.5 & - & - & - & 0.0 & 0.4 & - \\
Western Tigray & 23.6 & - & 0.3 & 33.3 & - & 1.6 & - \\
North Gondar & 1.1 & - & - & 0.2 & - & 0.1 & - \\
South Gondar & 8.3 & - & - & - & - & 0.3 & - \\
North Shewa & 2.4 & - & - & - & - & 0.7 & 4.4 \\
East Gojjam & 1.0 & 0.8 & - & - & - & 0.4 & 0.0 \\
West Gojjam & 7.4 & - & - & - & - & 0.4 & 0.0 \\
Wag Himra & 0.3 & - & - & - & - & 0.1 & - \\
Awi & 0.5 & - & - & - & - & 16.0 & - \\
West Wellega & - & - & - & - & - & 1.0 & - \\
llu Aba Bora & 0.4 & - & - & - & 23.9 & 2.6 & - \\
Jimma & 0.0 & - & - & - & 1.2 & 1.1 & 0.4 \\
West Shewa & 0.6 & - & - & - & - & - & - \\
North Shewa & 2.4 & - & - & - & - & 6.1 & - \\
East Shewa & 8.7 & 0.9 & - & 0.7 & - & 10.4 & - \\
& & & & & & & -
\end{tabular}

Although caution is warranted in interpretation because the results are not representative at the zonal level, we believe that they provide a good indication of the type of machines in vogue, as well their spatial spread (Table 10.4). The results confirm the overall low use of machines in farming in the country. Tractors ( 4.1 percent), combine harvesters ( 3 percent), and water pumps (2.5 percent) are the most used. We further note the higher uptake of tractors and combine harvesters in specific parts of the country. More than 5 percent of the households used tractors in Western Tigray, South Gondar, West Gojjam, East Shewa, Arsi/Bale, and parts of the Somali region (Jijiga/Liben). The data further show that combine harvesters are seemingly most widely used in the southeast (Arsi, Bale, and West Arsi) and in the Somali region (the Jijiga zone).

The data from these surveys therefore indicate the low level of ownership and use of machines for agricultural activities by smallholders in the country. However, we note important patterns by crop and over space. Mechanization is more prevalent in the case of wheat, where we see mechanized plowing and 


\begin{tabular}{lccccccc} 
Zone & Tractor & $\begin{array}{c}\text { Combine } \\
\text { harvester }\end{array}$ & Planter & Thresher & $\begin{array}{c}\text { Mechanical } \\
\text { weeder }\end{array}$ & $\begin{array}{c}\text { Water } \\
\text { pump }\end{array}$ & 0thers \\
\hline Arsi & 6.8 & 14.5 & - & - & - & - & - \\
Bale & 8.5 & 30.9 & 5.1 & - & - & - & - \\
Borena & 1.9 & - & - & 0.9 & - & 9.4 & 2.2 \\
West Arsi & 5.6 & 14.0 & - & 19.7 & - & 0.3 & 0.3 \\
Qeleme Wellega & - & - & - & - & - & 4.7 & - \\
Horo Gudru Wellega & 0.2 & - & - & 1.0 & - & 5.5 & - \\
Jijiga & 37.6 & 33.3 & - & - & - & - & - \\
Liben & 8.3 & - & - & - & - & 8.0 & - \\
Gurage & 7.1 & - & - & - & - & - & - \\
Kembata Timbaro & - & - & - & - & - & 5.8 & - \\
Sidama & 0.0 & - & - & - & - & 2.0 & 2.7 \\
Gedeo & - & - & - & - & - & 0.1 & - \\
Wolayita & 2.5 & - & - & - & - & 6.1 & - \\
Sheka & 1.5 & - & - & - & - & 3.2 & - \\
Kefa & 1.1 & - & - & - & - & 0.1 & - \\
Konta & 0.2 & - & - & - & - & 0.4 & - \\
Siliti & 0.4 & - & - & - & - & 2.4 & 0.2 \\
Total & 4.1 & 3.0 & 0.1 & 1.5 & 0.6 & 2.5 & 0.4 \\
\hline
\end{tabular}

Source: Authors' calculations based on the household data from 2013 Feed the Future survey. Note: $-=$ no data.

harvesting for 5 percent of plots. We also note more uptake in the northwest, south, and southeast of the country, as well as in the Somali region. Furthermore, these FtF and ESS surveys do not cover commercial farms in the country. Although these farmers cultivate significantly less land than smallholders, they are, however, relatively more important for mechanization. Moreover, whereas levels of use of mechanization are low, important dynamics are noted. This is covered in the next section, where alternative datasets are considered.

\section{Changes over Time}

We rely on trade data from Comtrade (United Nations 2017) to look at changes over time in large machine imports. Because there are no local manufacturers of tractors and combine harvesters, these trade data allow us to assess levels and dynamics in their ownership and use. Figure 10.6 (left panel) shows how the value of imports of main agricultural machinery, including four-wheel tractors, combine harvesters, two-wheel tractors, and threshers, has changed 
FIGURE 10.6 Imports of agricultural machines into Ethiopia, three-year moving averagesvalue of main agricultural machines, 2001-2014 (left panel); number of four-wheel tractors, 2005-2014 (right panel)
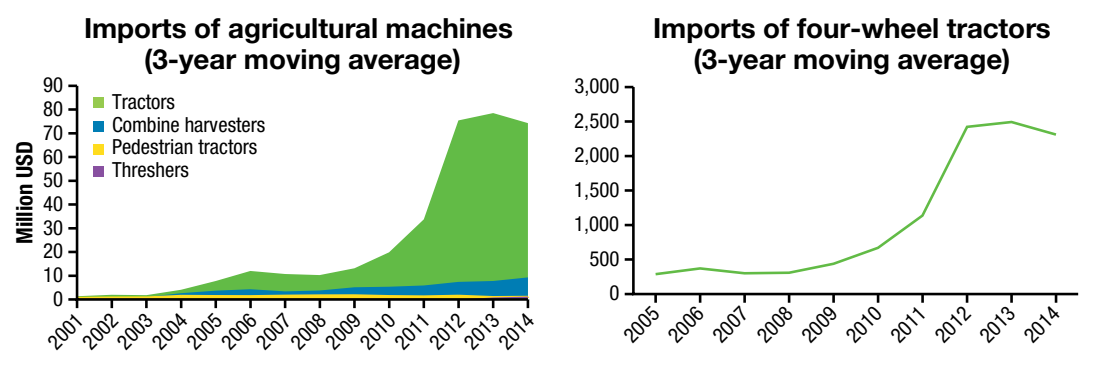

Source: Authors' calculations based on Comtrade data (United Nations 2017).

Note: USD = US dollars.

over the period 2000 to 2014 . To make the trends in imports clearer, we rely on three-year moving averages. Although the value of imports of agricultural machinery was around $\$ 10$ million in 2005/2006, this number had increased to over $\$ 70$ million by $2013 / 2014$. The major contributor to that change has been the large increase in imports of four-wheel tractors. More than $\$ 60$ million was spent on the import of these tractors in 2014. The secondlargest category is combine harvesters. The import value of two-wheel tractors and of threshers was relatively much less important. The graph on the right in Figure 10.6 shows the moving average of the number of four-wheel tractors imported into the country over the period 2005 to 2014 . Although fewer than 500 tractors were imported in 2005 , this number increased to almost 2,500 in 2013/2014. Over the period 2005 to $2014,12,128$ tractors were reported imported in total. These import data indicate overall that large changes have occurred in the last decade, and especially so in the last five years.

One important new player in the tractor market in Ethiopia is Adama Agricultural Machinery Industry (AAMI), from which we obtained detailed sales data for the period 2012/2013 up to 2015/2016. Although five main companies dominated the imports of tractors up to 2011 (World Bank 2012), this all changed when METEC became more aggressively involved in the assembly of tractors in the country. Established as the Nazareth Tractor Assembly Plant in 1984 through a technical and economic cooperation agreement between Ethiopia and the USSR, the company was renamed AAMI in 1992 with the start of the new government. It was then transferred to METEC in 2010. Before the transfer to METEC, it had assembled about 6,000 tractors over a 20 -year period, or about 300 tractors per year on 
average. Its mode of operations, however, changed drastically when it became part of METEC, given the additional resources and technical know-how of METEC.?

The sales data on tractors presented in Figure 10.7 show that AAMI sold more than 2,500 tractors in 2012/2013 - at the beginning of its association with METEC. However, after that, sales have been dropping off quicklysales in 2015/2016 were only a quarter of those in 2012/2013. ${ }^{10}$ Because AAMI apparently has continued assembly of tractors over time (as seen in the import data), these data indicate that the firm has a significant number of unsold tractors in stock. Comparing numbers in Figures 10.6 and 10.7 shows that in 2014, about 850 tractors were sold by AAMI, whereas total imports stood at 2,300 that year. Though imports by private dealers have increased, they did not show enough of an increase-as reported by them-to close the import gap. These data therefore indicate that there is an oversupply of tractors in the country.

The data from AAMI also provide an idea about the type of tractors in demand or sold. Almost half of the tractors sold by AAMI were between 40 and $80 \mathrm{hp}$ (Figure 10.7). Two-wheel (or walking) tractors were relatively less important, at 23 percent of sales. In the last four years, 1,350 of such twowheel tractors were sold by AAMI. Large tractors of $90 \mathrm{hp}$ and greater made up almost 20 percent of the number of tractors sold. Figure 10.7 further illustrates the increasing share of larger tractors in AAMI sales. Whereas twowheel tractors and small tractors (of between 18 and $30 \mathrm{hp}$ ) represented a quarter of the sales in 2012/2013, this fell to 12 percent in 2015/2016. For the business operations of AAMI, these smaller tractors are far less important, because the sales price of a $90 \mathrm{hp}$ tractor is 40 times higher than the price of a two-wheel tractor. ${ }^{11}$ During an interview, personnel from AAMI described the types of clients that purchased different types of tractors. They noted that about 50 percent of the tractors were bought by "medium" (or commercial)

9 See www.METEC.gov.et. METEC operates 15 “industries," of which AAMI is one. AAMI operates four factories: (1) a tractor factory, (2) an implement factory (in collaboration with Adama University), (3) a pumps factory, and (4) an irrigation material factory. In total, AAMI employs 800 permanent and temporary workers.

10 The reasons are not very clear. It might be due to the supply of spare parts. Because AAMI has regularly changed the makes of tractors that it assembles, complaints have been logged about the availability of spare parts for them.

11 Reported prices by AAMI at the time of interview (mid-2016) were as follows: walking tractor, $\mathrm{Br}$ 26,000; $15 \mathrm{hp}$ tractor, $\mathrm{Br} 40,000 ; 40 \mathrm{hp}$ tractor (plus harrow and plow), Br 388,000; and 90 hp tractor, Br 945,000. 
FIGURE 10.7 Tractor sales by Adama Agricultural Machinery Industry (part of Metals and Engineering Corporation), Ethiopia, 2012/2013-2015/2016

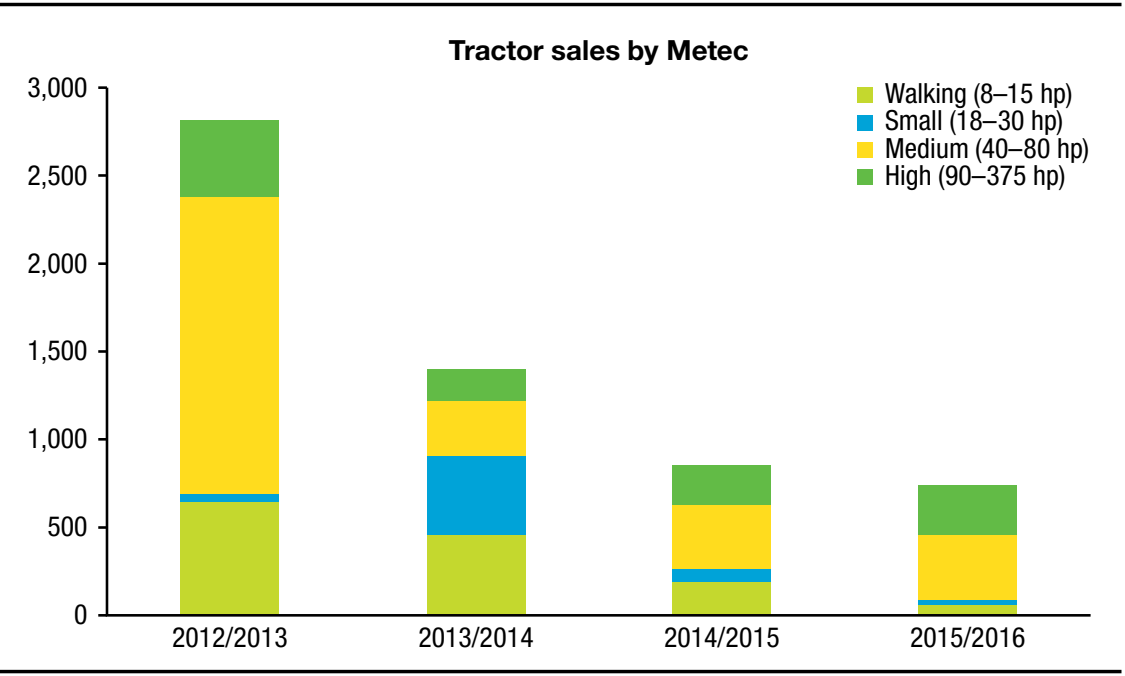

Source: Authors' calculations based on Adama Agricultural Machinery Industry sales data provided to authors in mid-2016. Note: $\mathrm{hp}=$ horsepower.

farmers, 20 percent by "small-scale" farmers, and 30 percent by "large-scale" farmers or state-run farms. ${ }^{12}$

In the last decade, there has also been a rapid increase in the number of combine harvesters imported. Figure 10.8 (left-hand panel) shows that the real value of combine harvester imports to the country in the beginning of the 2000s was around $\$ 1$ million. This had increased in 2014 to almost $\$ 10$ million, a tenfold increase. The average value of a combine harvester imported was just over $\$ 100,000$ over the period 2006-2015. The graph on the right in Figure 10.8 shows the changes in the number of combine harvesters imported into Ethiopia over the last decade. The number increased from around 40 in 2007 to almost 80 in 2014. Total imports of combine harvesters in the last 10 years amounted to 600 , an estimate similar to one mentioned in key informant interviews on current functional combine harvesters in the country. ${ }^{13}$ To assess the importance of combine harvesters in the country,

12 Large-scale farmers include especially state-run farms. For example, the Oromia Seed Enterprise (one of the biggest state farms), which cultivates almost 25,000 ha in the Oromia region, reportedly owns 150 tractors and almost 40 combine harvesters. Also, sugar farms, in which the government is increasingly investing, are important in this category (World Bank 2015b).

13 Claas, the biggest importer of combine harvesters, reported that it had imported $800 \mathrm{com}$ bine harvesters in the country since the start of its operations in the beginning of the 1990s. It estimated that 500 of its combine harvesters were still functional. It was further estimated 
FIGURE 10.8 Imports of combine harvesters into Ethiopia, three-year moving averages, by value, 2001-2014 (left panel); by number, 2007-2014 (right panel)

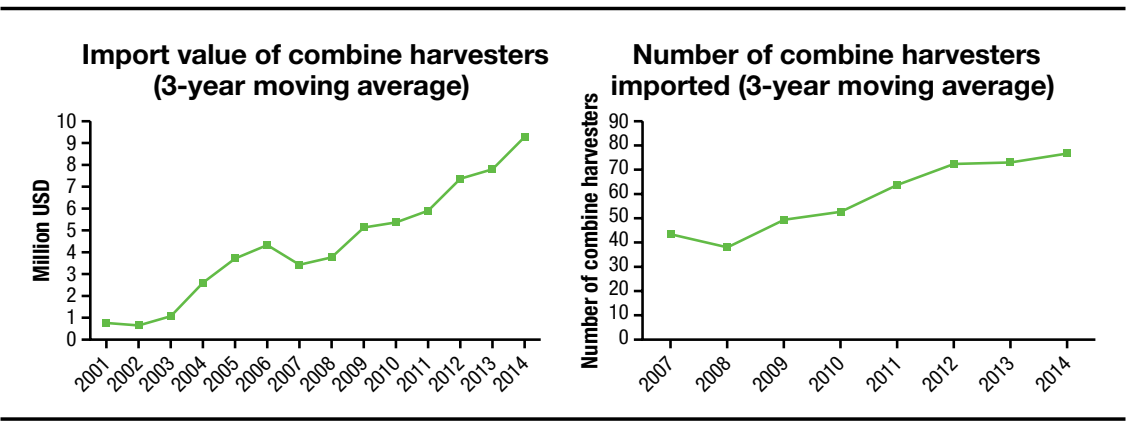

Source: Authors' calculations based on Comtrade data (United Nations 2017).

Note: USD = US dollars.

along with the area harvested, we rely on back-of-the-envelope calculations. ${ }^{14}$ Using such an approach, we estimate that a quarter of the cultivated wheat area was harvested by combine harvesters in 2014/2015. ${ }^{15}$

Our survey data and focus group interviews indicate strong spatial differences in the use of mechanization. These data indicate that mechanized services of tractors and combine harvesters have especially been taken up in major wheat-growing areas in the southeast of the country (the zones of Arsi, West Arsi, and Bale, in particular). That area seems to be unique for a combination of reasons:

- First, commercial farms and smallholders coexist, and the smallholder population is relatively large compared with that of the rest of the country (Figure 10.9).

- Second, there has been a history of interventions by projects to stimulate mechanization uptake, and farmers have been exposed to mechanized

that New Holland was servicing about 50 to 100 of its own brand of tractors per year. John Deere reported that it had 75 functional combine harvesters in the country. There were further reported imports by Massey Ferguson (100 over the last 10 years), Deutz (10) and Sambo (10).

14 Using wheat area cultivated by smallholders ( 1.6 million ha) and commercial farms ( 0.08 million ha) in 2014/2015, there was nationally about 1.7 million ha of wheat planted (exactly 1,774,420 ha). Relying on statements of key informants and assuming that combine harvesters harvest 8 ha a day and are functional for 120 days per year (our stakeholders mentioned that some were active for 150 days), and that there were 500 functional combine harvesters, this would imply an area harvested by combine harvesters of 480,000 ha.

15 We get lower numbers from our survey because commercial farmers are not included, the major Arsi-West Arsi-Bale area is underrepresented, and a random sample of farmers was used (not focusing on area cultivated). 


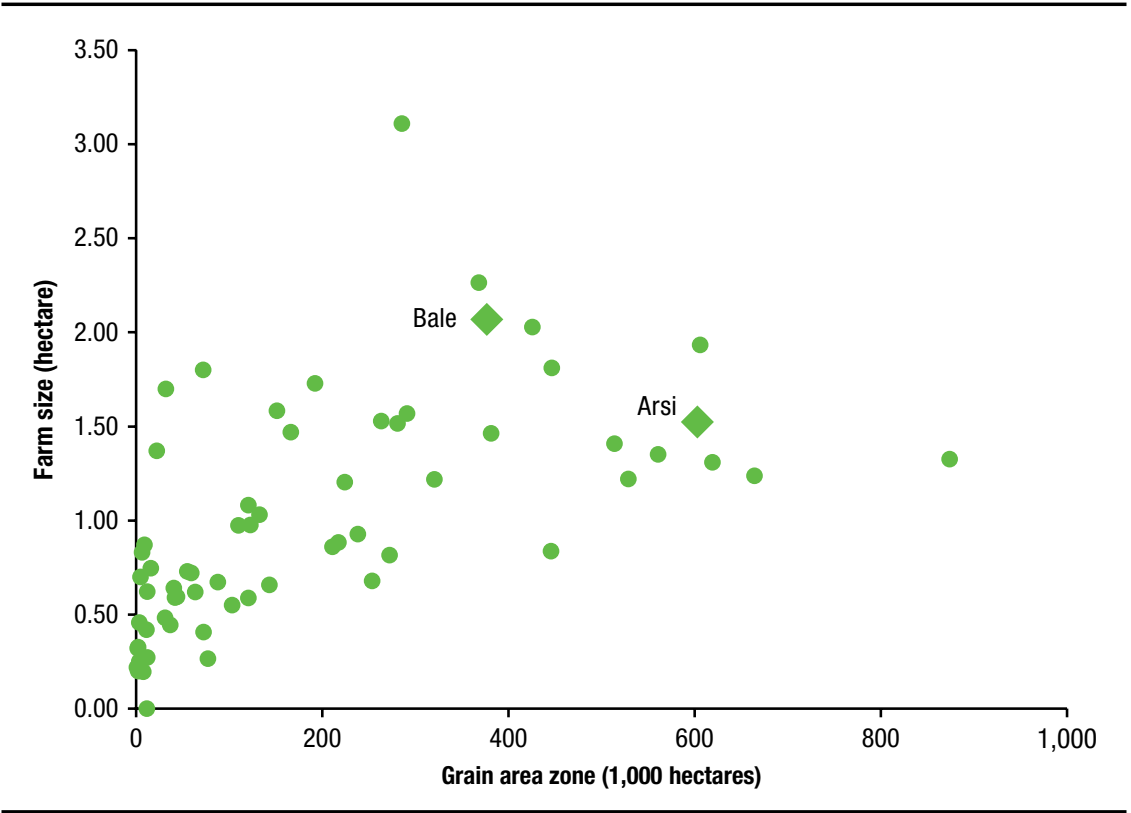

Source: Authors' calculations based on Ethiopia, CSA (2015b).

services for a longer period, seemingly facilitating their adoption by smallholders at a larger scale. ${ }^{16}$

- Third, in those zones where mechanization is taking off, we find terrain that is contiguous and relatively flat and stone-free, and plots are larger, with more fertile soils, making the adoption of mechanization easier (Table 10.5).

- Fourth, rural wages are on the higher side in these areas. This matters because mechanization is a substitute for agricultural labor. For example, Berhane, Hirvonen, and Minten (2016) showed the strong linkage of wages with use of mechanization in the Ethiopian context (Figure 10.10).

- Fifth, in some of these highland areas within these zones, there are two harvests-rather rare in Ethiopia-and there is significant time pressure between harvesting and threshing the output of the meher season,

16 The Arsi zone was exposed early on to agricultural mechanization technologies due to priorities set in the Arsi Rural Development Unit and the Chilalo Agricultural Development Union, financed by the Swedish International Development Agency. 
TABLE 10.5 Comparison of some characteristics of mechanization-intensive zones with other zones, Ethiopia, 2013

\begin{tabular}{|c|c|c|c|c|c|c|c|c|}
\hline \multirow[b]{2}{*}{ Zone } & \multicolumn{2}{|c|}{ Avg. plot size, ha } & \multicolumn{3}{|c|}{ Soil fertility, \% } & \multicolumn{3}{|c|}{ Slope of the plot, \% } \\
\hline & Mean & Median & Fertile & $\begin{array}{l}\text { Semi- } \\
\text { fertile }\end{array}$ & Infertile & Plain & Hilly & Valley \\
\hline \multicolumn{9}{|c|}{ Mechanization-intensive zones } \\
\hline Arsi & 0.39 & 0.25 & 73 & 24 & 3 & 76 & 23 & 1 \\
\hline Bale & 0.51 & 0.41 & 71 & 24 & 6 & 79 & 21 & 0 \\
\hline West Arsi & 0.38 & 0.25 & 73 & 25 & 3 & 79 & 19 & 1 \\
\hline Jijiga & 0.57 & 0.33 & 62 & 29 & 10 & 97 & 3 & 0 \\
\hline West Tigray & 0.75 & 0.38 & 89 & 8 & 2 & 90 & 9 & 1 \\
\hline \multicolumn{9}{|l|}{ Other zones } \\
\hline All other FtF zones & 0.25 & 0.15 & 64 & 30 & 6 & 71 & 28 & 2 \\
\hline Total & 0.28 & 0.19 & 65 & 29 & 6 & 72 & 27 & 2 \\
\hline
\end{tabular}

Source: Authors' calculations based on the household data from 2013 Feed the Future survey. Note: FtF = Feed the Future.

FIGURE 10.10 Mechanization and daily wage rates, Ethiopian birr/day, 2015

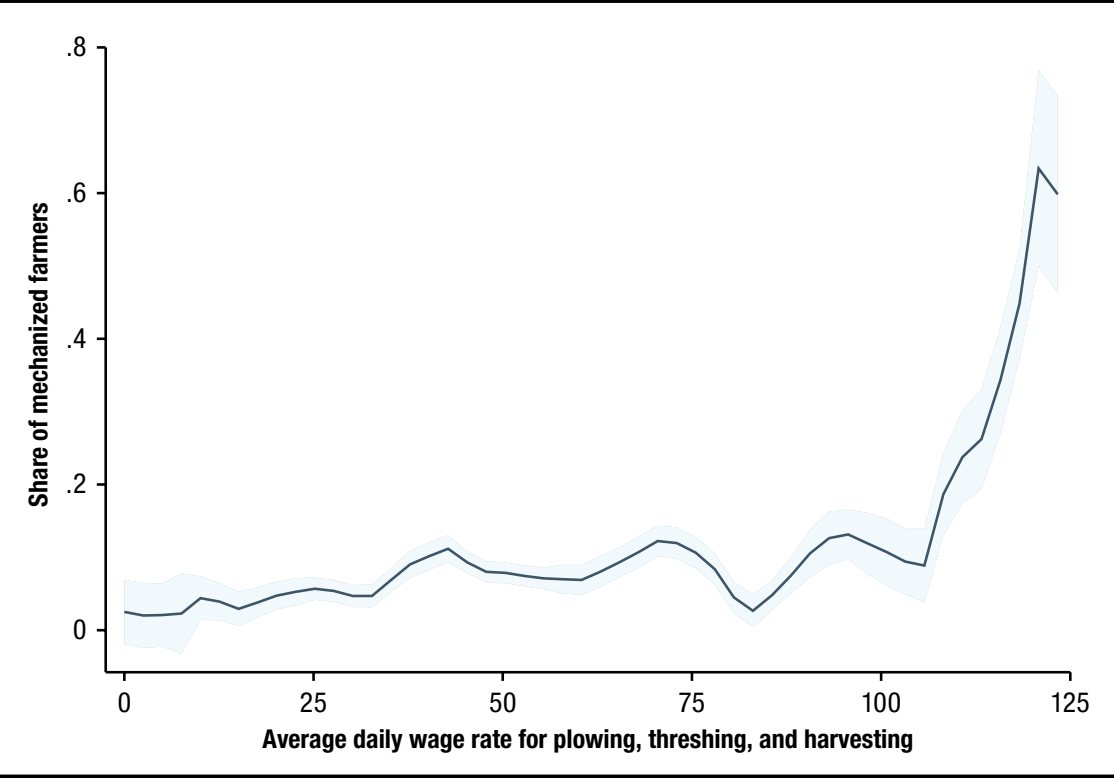

Source: Berhane, Hirvonen, and Minten (2016).

Note: Light blue is the $95 \%$ confidence interval. 
and the subsequent plowing of the fields for the upcoming belg season. Mechanization's reduction of the time needed to complete these agricultural processes might have contributed to further successful adoption.

It is, however, important to highlight that although all these factors might have contributed to the success of mechanization in that part of the country, it is hard to pinpoint one specific driving force from the feedback provided by several key informants.

In brief, the results indicate that the demand for mechanization in land preparation and in harvesting in the case of wheat has grown to a level whereby there is a large enough demand from smallholders to warrant a hiring market. We estimate that a quarter of the smallholder farming area under wheat in Ethiopia is harvested by combine harvesters. We also find that there is a strong spatial component to agricultural mechanization.

\section{Supply-Side Analysis}

There are no manufacturers of tractors or combine harvesters in Ethiopia; all of these machines are imported from abroad. For taxation purposes, agricultural machinery is treated similar to other investment goods, and therefore, it is exempt from taxes and excise duties (World Bank 2012). Spare parts have similar privileges if they are imported at the same time as the machinery. If they are imported separately, the import duty is between 10 and 25 percent, and value-added tax (VAT) is charged at 15 percent (World Bank 2012). Although the taxation of agricultural machinery is relatively lower than for other commercial imports, an important hurdle to scale has been access to foreign exchange for dealers to import machinery. This clearly has lowered the availability of agricultural machinery and, therefore, its use. For example, this hurdle resulted in situations where people had the resources to pay for agricultural machinery, yet had to wait for months - or even years-before the foreign exchange could be obtained and the final hurdle preventing importation of agricultural machinery could be resolved. However, this constraint has been (partly) alleviated recently because agricultural mechanization has been declared a priority area with preferential access to foreign exchange. Also, AAMI enjoys a special institutional status and so suffers less from such import constraints.

Different types of payment facilities have been established to assist in the acquisition of agricultural machinery. First, AAMI offers credit facilities. Tractors of $30 \mathrm{hp}$ or less can be bought with only a 30 percent down payment, 
and tractors of $40 \mathrm{hp}$ or higher require a 50 percent down payment. The rest of the payment can be made over a two-year period. This access to credit was reported by several focus groups to be among the main attractions for purchasing tractors from AAMI. Second, the Oromia International Bank provides loans for agricultural machinery purchases from private dealers. Interest rates, however, have been relatively high-current annual nominal interest rates are 16 percent, having increased from 8 percent three years ago. In the case of commercial banks, a 50 percent down payment is often the norm, and loans have to be paid back in two to three years.

Although there are no local manufacturers of tractors and combine harvesters, there are local assembly plants for tractors. In particular, AAMI is engaged in assembling machinery, but other dealers are planning to do likewise. ${ }^{17}$ AAMI mostly imports tractor parts from Poland, China, and Belarus in "knocked-down" (KD), "completely knocked-down" (CKD), and "semiknocked-down" (SKD) form. Other importers deal with "completely built-up" (CBU) units. The most important private dealers include Gedeb, ADEP, AMNIO, Caleb, and Ries Engineering. It is estimated that, combined, they import 100 to 200 tractors a year (World Bank 2012). The tractors they provide are more expensive than those provided by AAMI, but they are also reported to be of a higher quality. ${ }^{18}$ This higher quality means that for the same horsepower in a tractor, AAMI-assembled tractors reportedly took more time to repair than similar tractors from other dealers. However, at farm level, no distinction was made in the pricing of service provision between AAMI tractors and tractors from other dealers. Most of the private companies also have good post-sales service provision, whereas AAMI is reported to fall short in service provision due largely to the frequency with which it makes changes in the brands of tractors it imports. ${ }^{19}$

In the case of tractors, ownership appears to lie more in the hands of commercial farmers and state farmers than those of service providers. One importing company estimated that 60 percent of tractors are owned by farmers and 40 percent by service providers. However, in the case of combine harvesters, ownership is mostly by mechanized service providers. The chairman of the

17 The advantage of doing local assembly is that it makes it cheaper to bring tractors into the country. Whereas one can fit three complete large tractors in a shipping container, the components for up to eight unassembled tractors can fit in a single container.

18 For example, one informed stakeholder put the current price of a $120 \mathrm{hp} \mathrm{John} \mathrm{Deere} \mathrm{tractor} \mathrm{at}$ Br 1.8 million. This compares with $\mathrm{Br} 1.2$ million for a similarly powered tractor from AAMI.

19 However, AAMI provides 10-day training courses in the use of its tractors to buyers and provides repair and maintenance services for tractors in the field. 
Mechanized Service Provider Association estimated that about 50 of the 700 functional combine harvesters in the country are owned by commercial farmers and parastatals (such as the Oromia Seed Enterprise and the Agricultural Equipment and Technical Services Share Company), and the rest are operated by commercial providers of mechanized services. It is estimated that there are 200 such private service providers nationally, implying that each provider owns, on average, three combine harvesters. ${ }^{20}$ Providers of these services typically live in areas where mechanized services are widely used. ${ }^{21}$ Most service providers are often involved in other businesses, such as cereal trade, consumer shops, or flour factories. The provision of mechanized services is a largely seasonal activity, and other activities are required to fill the slack period in their business. However, there is limited integration of their other economic activities with their mechanization service provision—for example, few reported also buying harvested wheat as part of their trade activities.

Table 10.6 shows to what extent farmers in the FtF survey said they use machine rental services for land preparation, harvesting, and threshing. As discussed earlier, machine use in agriculture is low, and the majority of farmers employing agricultural machinery in their farming rely on such rental services - very few farmers use their own tractor, combine harvester, or thresher. Own machines make up only 19 percent of machines used for land preparation, 22 percent for harvesting, and 2 percent for threshing. Results from the ESS survey show higher own tractor use than in the FtF survey. Nonetheless, the ESS survey estimates that almost 70 percent of farmers rely on rental agreements to assure the plowing of their fields, again illustrating the importance of the provision of rental services for mechanized farm operations for these smallholder farmers.

Rental arrangements and prices of mechanized services depend on the kind of activity undertaken and the location. ${ }^{22}$ Tractor service rates in the southeast of the country, in Bale and Arsi, in 2016 were typically fixed at 1,200 birr $(\$ 60)$ per hectare for plowing. These rates are higher than for harrowing and

20 The largest provider was reported to own 14 combine harvesters. Bigger service providers existed earlier, but they have divested out of harvesting.

21 The chairman of the Association of Mechanized Service Providers estimated that 5 percent of service providers were based in Addis Ababa, 17 percent in Bale, 16 percent in Dodola, 12 percent in Assosa, 5 percent in Shashemene, 5 percent in Arsi Negele, 20 percent in NazarethAssela, 5 percent in Jijiga, and the rest scattered in rural towns.

22 The increasing emphasis on tax collection by the government has had an important impact on charges made to farmers. Whereas a number of these activities previously, for example three years ago, were done informally, this is not the case anymore. Service providers usually pay 15 percent VAT on services provided. Service providers also pay a 35 percent profit tax. 
TABLE 10.6 Importance of machine rental services, by farm size, Ethiopia, 2013

\begin{tabular}{|c|c|c|c|c|c|c|}
\hline \multirow[b]{2}{*}{ Variable } & \multirow[b]{2}{*}{ All } & \multicolumn{5}{|c|}{ Farm size (by quintile) } \\
\hline & & Q1 & Q2 & Q3 & Q4 & Q5 \\
\hline \multicolumn{7}{|c|}{ FtF area, percentage of households } \\
\hline Land preparation by machine & 1.79 & 0.56 & 1.49 & 1.68 & 1.45 & 3.76 \\
\hline $\begin{array}{l}\text { Of these, } \\
\text { Owned }\end{array}$ & 19.5 & 0.0 & 42.3 & 23.6 & 12.0 & 14.0 \\
\hline Rented & 71.9 & 88.1 & 50.2 & 68.8 & 73.6 & 79.1 \\
\hline Share-owned & 0.7 & 0.0 & 0.0 & 0.0 & 4.6 & 0.0 \\
\hline Government-owned & 7.9 & 11.9 & 7.5 & 7.5 & 9.9 & 6.9 \\
\hline Observations & 162 & 16 & 28 & 25 & 25 & 68 \\
\hline Harvesting by machine & 3.69 & 2.24 & 3.09 & 3.6 & 2.86 & 6.71 \\
\hline $\begin{array}{l}\text { Of these, } \\
\text { Owned }\end{array}$ & 21.6 & 9.8 & 23.8 & 12.5 & 26.9 & 27.1 \\
\hline Rented & 58.7 & 52.5 & 54.8 & 66.5 & 47.9 & 63.1 \\
\hline Share-owned & 5.0 & 11.0 & 2.5 & 8.4 & 8.3 & 1.2 \\
\hline Government-owned & 14.6 & 26.6 & 18.9 & 12.7 & 17.0 & 8.6 \\
\hline Observations & 253 & 33 & 45 & 45 & 35 & 95 \\
\hline Threshing by machine & 2.13 & 1.22 & 1.88 & 1.88 & 1.66 & 4.03 \\
\hline $\begin{array}{l}\text { Of these, } \\
\text { Owned }\end{array}$ & 2.0 & 0.0 & 0.0 & 0.0 & 4.5 & 3.5 \\
\hline Rented & 95.9 & 100 & 96.2 & 100 & 90.6 & 94.8 \\
\hline Share-owned & 0.8 & 0.0 & 0.0 & 0.0 & 4.9 & 0.0 \\
\hline Government-owned & 1.4 & 0.0 & 3.8 & 0.0 & 0.0 & 1.7 \\
\hline Observations & 161 & 19 & 31 & 28 & 23 & 60 \\
\hline \multicolumn{7}{|c|}{ National level (ESS survey), percentage of plots } \\
\hline Plowing with tractor & 0.9 & 0.4 & 0.6 & 0.5 & 0.8 & 2.8 \\
\hline $\begin{array}{l}\text { Of these, } \\
\text { Owned }\end{array}$ & 31.4 & 69.0 & 54.1 & 44.8 & 40.0 & 16.1 \\
\hline Rented & 68.6 & 31.0 & 45.9 & 55.2 & 60.0 & 83.9 \\
\hline
\end{tabular}

Source: Authors' calculations based on the household data from 2013 Feed the Future survey and Ethiopia Socioeconomic Survey 2013/2014.

Note: ESS = Ethiopia Socioeconomic Survey 2013/2014; FtF = Feed the Future. 
for covering up of seed, for which 650 birr and 500 birr, respectively, per hectare was typically charged. In some Vertisol soil areas in Arsi, farmers reported that a second plowing would be required by tractor operators just before sowing. The costs of the second plowing would be lower, at about 900 birr per hectare. ${ }^{23}$ The differential costs reflect the effort entailed, because plowing a hectare would take about 2 to 2.5 hours during the first plow, compared with 30 minutes for the second plow. In areas where the soil is more difficult to plow, this is also reflected in costs. For example, plowing in the Ginir area-located in the lowlands-could cost between 1,800 birr and 2,000 birr per hectare because soils are harder and more difficult to till than in the Bale area, for example. Plowing costs are also higher after fallow periods, given the greater effort and longer time required for this operation. Moreover, distance to major towns is an important determinant of prices, because tractors must travel farther and extra costs, therefore, are incurred. Focus groups in Bale estimated that, depending on distance traveled, prices for plowing could range from 2,000 birr to 3,000 birr per hectare.

In the case of combine harvesting, the price is commonly fixed per quintal harvested. ${ }^{24}$ Strong differences are noted in price setting over space and time, depending on several factors:

- The type of soil influences the time needed for harvest. In sandy soils, machines have greater difficulty maneuvering, and harvesting therefore takes longer. Hence, charges for harvesting in these conditions are higher.

- Yields from specific areas are strongly related to the prices charged. In areas where yields are typically low—such as lowlands, where yields are often significantly lower than elsewhere-it takes farmers operating combine harvesters more time to achieve specific quantities of harvest. Prices charged in these areas reflect these lower yields. ${ }^{25}$

- The dominant religion of an area matters because this can influence the working days of the operator of the combine harvester. Whereas workers operating machines in Muslim areas face no particular taboos on days

23 A second plowing might also be needed following abundant rain, when there is not enough rain (and soil is hard), or when fields are cultivated after being left fallow.

24 On top of harvesting costs, providers typically offer transport services from the field to the farm at an additional cost. An extra charge of $\mathrm{Br} 5$ to $\mathrm{Br} 10$ per quintal is usual for this extra service. Service providers typically rent trucks for this purpose-the amount paid varied in 2015 between $\mathrm{Br}$ 35,000 and $\mathrm{Br}$ 40,000 per month.

25 In some of these low-yield areas, a pricing system per hectare might be used, instead of perquintal prices. 
worked, the situation is very different in areas dominated by Orthodox Christianity, which is practiced more widely in the north of the country. In such areas, there are usually several specific days a month that fields cannot be worked. There are also fields that are close to churches that cannot be cultivated on days that the saint of that church is celebrated. These taboo days result in a higher number of days that combine harvesters are not used. This in turn drives up prices. ${ }^{26}$

- The temperature in some regions, especially in the lowland Somali region, is prohibitively high during parts of the day. Combine harvesters therefore typically operate only during the morning. Because machines and operators are not fully used, this also raises the price.

- The location of the farms matters. The farther away the farms are from towns and from a road, the more expensive it becomes to fuel the combine harvesters. If the farms are really far away, combine harvesters are partly disassembled and the machine is transported on trucks. This further increases the cost.

- Harvesting costs are higher on sloped land than on flat areas because there is a higher risk of overturning a combine harvester.

These different factors lead to a wide range of charges for harvesting of wheat. Indicative charges - as reported by focus group interviews and by key informants for the year 2015/2016 - are shown in Figure 10.11. ${ }^{27}$

26 It was estimated that a combine harvester could work for only 15 days per month, on average, in the Gojjam area. There have been negotiations in the last year between church leaders and representatives of MoANR. As a result, the number of workable days has now increased in that area to between 20 and 22 days per month. In the Bale-Arsi area, combine harvesters typically operate all days of the month.

27 Several focus group interviews were held to explore the economics of mechanization. The following costs and benefits associated with the use of combine harvesters as against traditional methods of harvesting and threshing were reported in a village near Assela in the Arsi-Bale area. In the case of traditional methods of harvesting and threshing, for a quarter hectare of wheat, five person-days of labor would be required for harvesting. The costs of these workers would be $\mathrm{Br} 80$ per day per person, for a total of $\mathrm{Br} 400$. In addition, the costs of food and drink for the harvest workers would amount to $\mathrm{Br} 220$. The total labor costs for harvesting are $\mathrm{Br}$ 620. Ten oxen would be required for threshing. These would be rented at a total cost of $\mathrm{Br} 300$. Threshing labor would require four persons at $\mathrm{Br} 50 /$ day, for a total cost of $\mathrm{Br} 200$, but food and drink would also need to be provided for the threshers, at a cost of $\mathrm{Br} 150$. The total costs for threshing the harvest from a quarter hectare of wheat are $\mathrm{Br} 650$. The total cost of traditional harvesting and threshing is therefore about $\mathrm{Br} 1,270$ per quarter hectare. In contrast, the costs for using combine harvesters are about $\mathrm{Br} 50$ per quintal times 15 quintals that are typically harvested off a quarter-hectare plot, or $\mathrm{Br} 750$ per quarter hectare. 
FIGURE 10.11 Seasonal changes in use of combine harvesters (left panel) and in harvesting charges (right panel), Ethiopia, 2015/2016
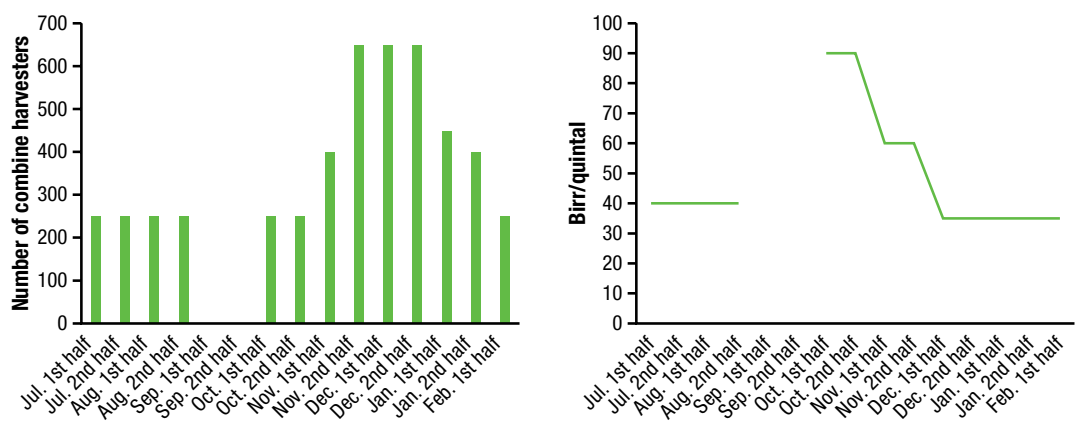

Source: Authors' calculations based on key informant interviews.

The possibility of two harvests as well as spatial differences in timing of land preparation lead to variation in the timing of service provision. Figure 10.12 illustrates the movement of tractors that perform plowing and harrowing services in the main wheat areas in Bale and Arsi. Between March and May, tractors are used to prepare fields for the belg period. In July and August, 200 tractors might be used in that area-especially in Bale-in preparation for the meher season. Many tractors are used in Arsi between May and September in preparation, first, for the belg harvest and, second, for the meher harvest. During September and October, some tractors move to Borena and others might be transported to Harari until December. In January and February, all tractors are idle and are serviced during that period. Tractor owners are mostly based in local areas, and it is especially the larger, more expensive tractors that travel around. Tractors are typically less influenced by seasonal movements than are combine harvesters. This is for two reasons. First, tractors perform more tasks than combine harvesters-plowing, second plowing, harrowing, covering of seeds, and sometimes sowing_and are, therefore, needed longer in the same place. ${ }^{28}$ Second, tractors cost less than combine harvesters. Relatively richer farmers can afford them, in contrast to combine harvesters.

We also see regional movements of combine harvesters that reflect spatial differences in harvesting periods. The two maps in Figure 10.13(a) and 10.13 (b) illustrate this pattern of movement of combine harvesters during the

28 For example, one stakeholder indicated that tractors that are not characterized by seasonal movement could stay active for five months for all these different activities. 
FIGURE 10.12 Seasonal movement of tractors between the Arsi, Bale, Borena, and Harari zones, Ethiopia, 2015/2016

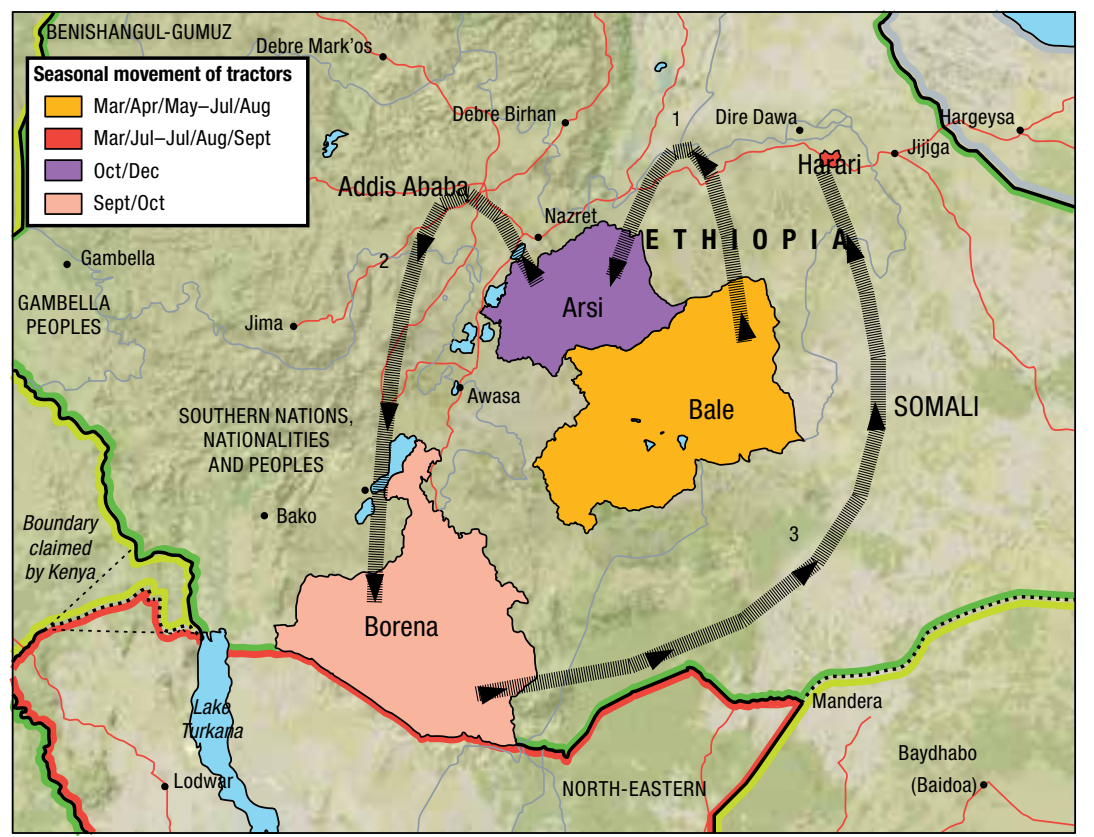

Source: Authors' calculations based on key informant interviews.

meher harvest season, as explained by different key informants. Two main routes are taken by these combine harvesters. The first is along the southwestern part of the wheat production belt, shown in Figure 10.13(a), the second along the southeastern part, shown in Figure 10.13(b). In each of the routes, the service providers begin their service in areas where the wheat harvest comes in early, due mainly to the semi-arid (or humid) agroecology-typically at the beginning of November. Providers along the first route begin their activities in woredas on the Rift Valley floor around Lake Ziway and Silite. Only a limited number of combine harvesters are active (75 approximately), mainly due to the relatively lower level of wheat production in these lowland areas. Starting from mid-November, when the harvest of the relatively lower parts of the Eteya, Arsi Negele, and Asassa woredas comes in, the number of active combine harvesters rises. In addition to the combine harvesters from the Lake Zeway and Silite areas that move to these areas, new (previously idle) combine harvesters enter these areas. Depending on altitude, the harvests in these areas continue until the end of November. 
FIGURE 10.13(a) Seasonal movement of combine harvesters in Arsi, Bale, and neighboring areas, Ethiopia, November 2015 to February 2016-Route 1

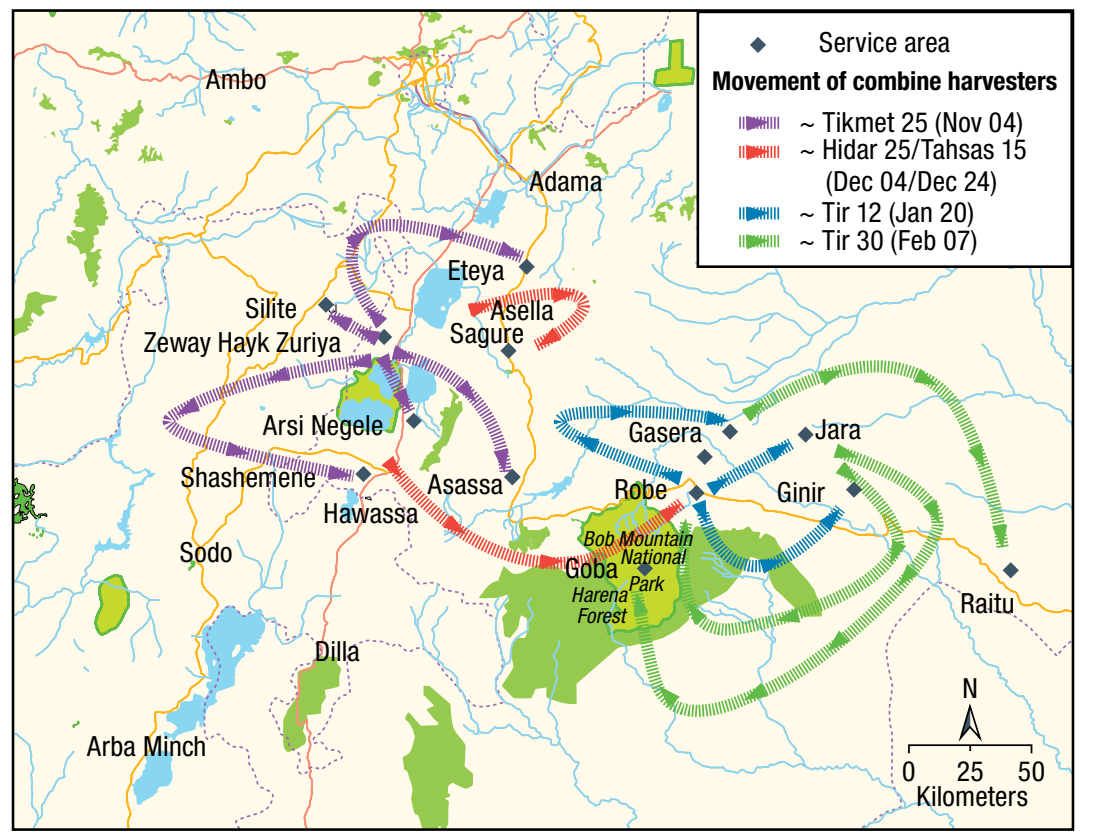

Source: Authors' calculations based on key informant interviews

Combine harvesters on the second route begin providing their service in the Lole and Kanchare areas, where wheat is harvested in early November. At the end of November, providers along the second route gradually move to the productive lowlands of Sagure and Eteya. In December the combine harvesters from the two routes head to the high wheat-producing areas. These areas include Asella, Sagure, Arsi Negele (the upper part), Asassa, and Shashemene. According to the chairman of the Mechanized Service Provider Association, given the high production, yield, and large area, between 400 and $500 \mathrm{com}-$ bine harvesters are estimated to be active there until the end of December.

From late December until the end of February, the combine harvesters from the first route spread out over different areas. Some stay behind and work in the relatively higher highlands of Asella, Sagure, Arsi Negele, and Asassa, where the harvest comes in later. These combine harvesters stay in these areas until the last week of January and afterward head to other wheat-producing areas. A significant number of combine harvesters also move to the other high wheat-producing woredas of Gasera and the upper parts of 
FIGURE 10.13(b) Seasonal movement of combine harvesters in Arsi, Bale, and neighboring areas, Ethiopia, November and December 2015-Route 2

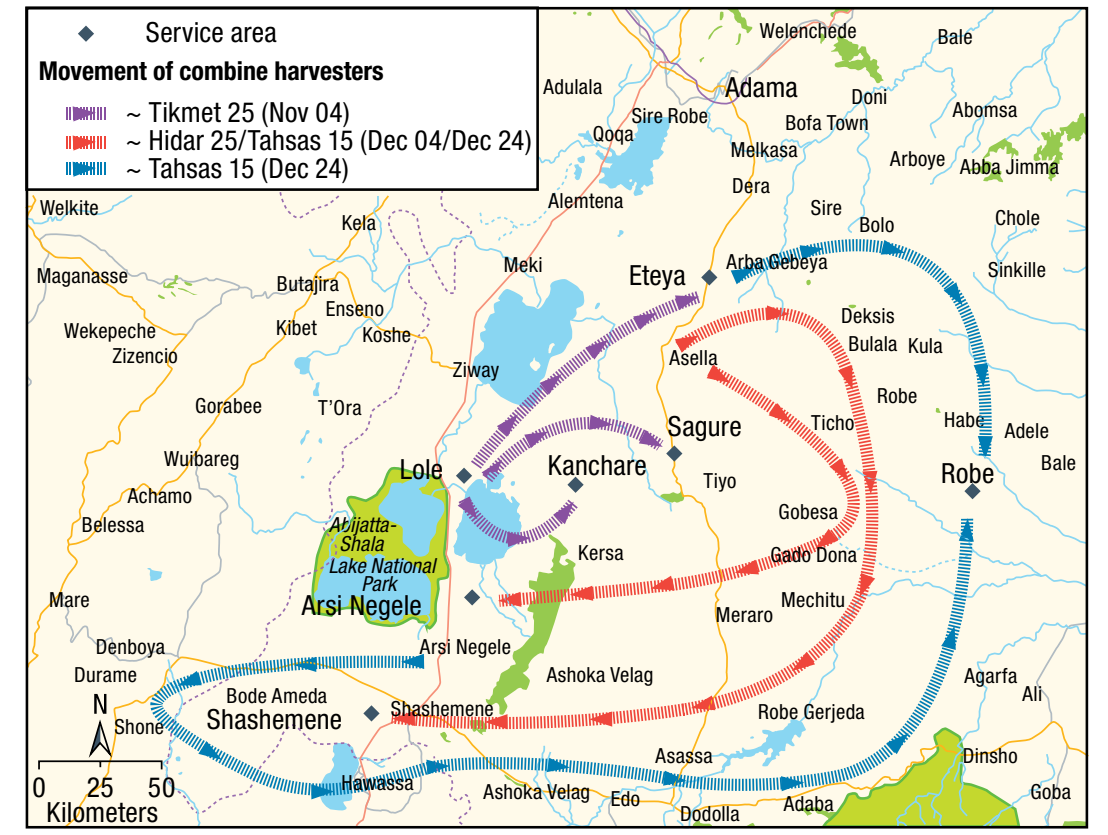

Source: Authors' calculations based on key informant interviews.

Jara and Robe. They typically work there until the first week of February. Including some that arrive late from other areas, about 300 combine harvesters are estimated to be active in these areas. Then, combine harvesters from the two areas join and move to the lower parts of Robe, Jara, Goba, and Ginir areas, where they are deployed until the end of February. In contrast, immediately after the last week of December, almost all the combine harvesters from the second route directly head to the eastern side of Robe and its surrounding woredas. The machines, depending on demand, could stay in these areas until the end of February. After these harvests and until the belg season, the combine harvesters remain idle for about six months. When the belg harvest of the Bale area comes in, 500 combine harvesters might be in use during that period. On top of the southeast areas (especially Bale), it is estimated that 75 extra combine harvesters might be needed in the Jijiga area. Additionally, 200 combine harvesters might be sent to the Borena area as well.

Two harvest periods during which combine harvesters can be used, combined with differences in harvesting periods between the warmer lowland and 
the colder highland regions, contribute to a smoothing of the seasonal harvest labor peak that is typical of other crops in Ethiopia. This has contributed to the successful takeoff of combine harvesters in this area.

The coordination of journeys required for moving combine harvesters (and to a lesser extent tractors) is usually done by local brokers, unless owners of combine harvesters live in the area. Brokers can oversee several kebeles, and they typically coordinate with different farmers in a village to assess whether there is enough work for a combine harvester for at least a day (about 15 and 10 ha in flat and sloped areas, respectively). Brokers commonly assess quantities of harvest and the time when areas are ready to be harvested, and then coordinate with mechanized service providers. These brokers charged about 2 birr per quintal in 2016 for this service. Because they might have a stake in assuring good harvests, some of the brokers were reported also to advise farmers on improved crop management practices before harvest.

Finally, the maintenance of combine harvesters and tractors is crucial. AAMI, as well as private dealers, normally provides warranties for its machines for up to 1,000 hours of operation. Moreover, two types of maintenance services are additionally offered in the field. First, AAMI and private dealers often have teams that travel to specific areas where many tractors are present. For example, Claas has mobile workshops with two mechanics each that service combine harvesters during these harvest periods. The company also has branches in different areas where agricultural machines are being used, such as Shashemene. Second, maintenance is provided by independent mechanics. They service different types of machines and travel to areas where tractors and combine harvesters are functional. In the Bale-Arsi area, there are currently two such mechanics for combine harvesters. Notably, the mechanics from companies are mostly used during the warranty period of the machines, but there is commonly a switch to independent mechanics afterward. This switch is seemingly driven by a price difference between these two types of maintenance service providers.

\section{Role of Mechanization in Agricultural Transformation}

Mechanization can play an important transformative role in agriculture (Binswanger 1986). Important impacts of mechanization include increasing labor productivity and land productivity, which are desired objectives for development and poverty alleviation. Relying on $\mathrm{FtF}$ data from the highly mechanized zones of the country, we test to what extent farmers that use 
tractors and combine harvesters obtain higher labor and land productivity. The advantage of limiting the sample to those areas is that we have farmers that are rather similar in climatic and agroecological conditions and we have a reasonable number of adopters and nonadopters of mechanization in our sample.

Figure 10.14 and Table 10.7 show that wheat farmers from southeast Ethiopia who rely on combine harvesters use only 55 percent of the labor applied by farmers who do not use combine harvesters. Moreover, we also note differences in yield, indicating that land productivity is higher in the case of farmers using combine harvesters, although it is not significant at conventional statistical levels, as measured by a $t$-test.

We also compare to what extent the farmers that use combine harvesters are adopting different technologies and factor markets (Table 10.7). First, we look at the association with modern inputs. We note that there are no strong differences between farmers adopting mechanized versus nonmechanized practices. Furthermore, the adoption of chemical fertilizers, agrochemicals, and improved seeds are at similar levels between both types of farmers. Second, we also look at the extent to which farmers using mechanized practices rely on land rental markets. One might hypothesize that when farmers have excess labor at their disposal, this would allow them to rent in and cultivate more land. However, we do not see such an association in the use of combine harvesters with the share of rented-in or sharecropped-in land in these settings. This lack of association of mechanization with land rental markets might be linked to regulations that might inhibit the development of active and efficient rental markets, as shown by other authors (for example, Ghebru and Holden 2016).

To better understand associations between mechanization and productivity, we run simple regressions of combine harvester use on wheat yield, controlling for several household- and plot-level characteristics, as well as input use and location differences. Table 10.8 presents the results for five different specifications, iteratively controlling for input use and demographic characteristics. We find a strong positive association between yield levels and use of machines for harvesting and threshing (mostly with combine harvesters). Given that the traditional methods of harvesting and threshing in Ethiopia use rudimentary technology, this may be attributed to reductions in yield losses during and after harvesting and threshing using such traditional methods. This is also consistent with our findings from interviews with key informants, in which they reported that combine harvesters reduce expected losses. These losses include those due to crop consumption by livestock during 
FIGURE 10.14 Density functions on association of combine harvesters with labor productivity (left) and with crop yields (right), Ethiopia, 2013

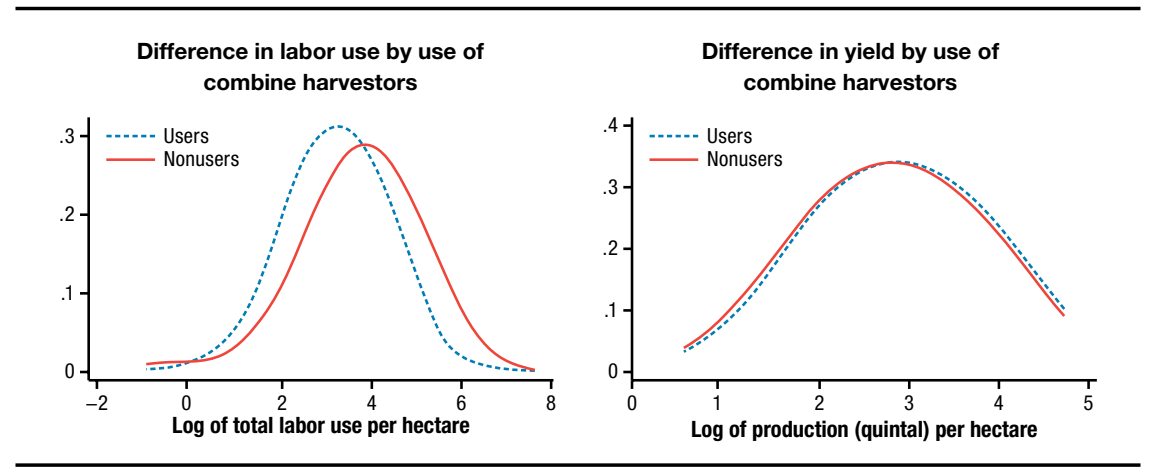

Source: Authors' calculations based on the household data from 2013 Feed the Future survey.

TABLE 10.7 Labor and land productivity in the wheat cluster in southeast Ethiopia, 2013

\begin{tabular}{|c|c|c|c|c|}
\hline \multirow[b]{2}{*}{ Variable } & \multicolumn{2}{|c|}{$\begin{array}{l}\text { Adoption of combine } \\
\text { harvester }\end{array}$} & \multicolumn{2}{|c|}{$t$-test } \\
\hline & Yes & No & $t$-value & Sig. \\
\hline \multicolumn{5}{|l|}{ Labor use, days/ha } \\
\hline Mean & 50.1 & 78.0 & 3.63 & 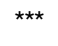 \\
\hline Median & 32.2 & 56.0 & n.a. & n.a. \\
\hline \multicolumn{5}{|l|}{ Land productivity, quintals/ha } \\
\hline Mean & 20.1 & 18.5 & -1.61 & n.a. \\
\hline Median & 20.0 & 16.0 & n.a. & n.a. \\
\hline \multicolumn{5}{|l|}{ Modern input use } \\
\hline Diammonium phosphate (DAP), $\mathrm{kg} / \mathrm{ha}$ & 99.1 & 97.3 & -0.22 & n.a. \\
\hline Urea, kg/ha & 20.6 & 29.4 & 1.60 & n.a. \\
\hline Herbicide, L/ha & 1.5 & 1.1 & -1.61 & n.a. \\
\hline Fungicide, L/ha & 0.3 & 0.7 & 0.61 & n.a. \\
\hline Pesticide, L/ha & 0.0 & 0.2 & 2.39 & ** \\
\hline Other chemicals, L/ha & 0.11 & 0.04 & -1.00 & n.a. \\
\hline Improved seeds, $\mathrm{kg} / \mathrm{ha}$ & 103.0 & 76.3 & -1.59 & n.a. \\
\hline Improved seeds, $\%$ of plots & 41 & 47 & 1.32 & n.a. \\
\hline \multicolumn{5}{|l|}{ Land rental } \\
\hline Rented in, \% & 3.9 & 2.9 & -0.64 & n.a. \\
\hline Sharecropped in, \% & 1.5 & 4.7 & 2.20 & ** \\
\hline Observations & 221 & 298 & n.a. & n.a. \\
\hline
\end{tabular}

Source: Authors' calculations based on the household data from 2013 Feed the Future survey. Note: ${ }^{\star \star \star} p<0.01,{ }^{\star \star} p<0.05,{ }^{\star} p<0.1$. n.a. $=$ not applicable. 
TABLE 10.8 Regressions to examine the association of the use of machines for harvesting and threshing on wheat yield in southeast Ethiopia, 2013, quintals/ha

\begin{tabular}{|c|c|c|c|c|c|}
\hline Variable & Model 1 & Model 2 & Model 3 & Model 4 & Model 5 \\
\hline \multirow{2}{*}{$\begin{array}{l}\text { Use of machines for harvesting and } \\
\text { threshing (yes = 1) }\end{array}$} & $0.204^{\star \star \star}$ & $0.234^{\star \star \star}$ & $0.212^{\star \star \star}$ & $0.186^{\star \star \star}$ & $0.202^{\star \star \star}$ \\
\hline & (3.361) & $(3.845)$ & $(3.581)$ & (3.092) & (3.303) \\
\hline \multirow[t]{2}{*}{ Log (plot area) } & n.a. & $-0.548^{\star \star \star}$ & $-0.488^{\star \star \star}$ & $-0.473^{\star \star \star}$ & $-0.478^{\star \star \star}$ \\
\hline & n.a. & $(-3.914)$ & $(-3.595)$ & $(-3.490)$ & $(-3.407)$ \\
\hline \multirow[t]{2}{*}{ Log (number of plots) } & n.a. & 0.002 & -0.004 & -0.031 & -0.036 \\
\hline & n.a. & $(0.024)$ & $(-0.051)$ & $(-0.371)$ & $(-0.436)$ \\
\hline \multirow[t]{2}{*}{ Log (total household land size) } & n.a. & 0.033 & 0.045 & 0.061 & 0.110 \\
\hline & n.a. & $(0.348)$ & $(0.495)$ & $(0.667)$ & (1.103) \\
\hline \multirow[t]{2}{*}{ Log (plot distance from home) } & n.a. & 0.016 & 0.022 & 0.021 & 0.018 \\
\hline & n.a. & $(0.621)$ & $(0.886)$ & $(0.854)$ & $(0.720)$ \\
\hline \multirow[t]{2}{*}{ Semi-fertile soil (yes $=1$ ) } & n.a. & 0.207 & $0.307^{\star}$ & $0.319^{\star \star}$ & $0.343^{\star *}$ \\
\hline & n.a. & $(1.177)$ & $(1.827)$ & $(1.968)$ & $(2.103)$ \\
\hline \multirow[t]{2}{*}{ Fertile soil (yes $=1$ ) } & n.a. & 0.256 & $0.362^{\star \star}$ & $0.374^{\star \star}$ & $0.414^{\star *}$ \\
\hline & n.a. & $(1.465)$ & $(2.156)$ & $(2.322)$ & $(2.533)$ \\
\hline \multirow[t]{2}{*}{ Flat plot (yes = 1) } & n.a. & 0.087 & 0.073 & 0.051 & 0.037 \\
\hline & n.a. & $(0.999)$ & $(0.828)$ & $(0.593)$ & $(0.429)$ \\
\hline Modern input use & no & no & yes & yes & yes \\
\hline Distance from nearest town & no & no & no & yes & yes \\
\hline Demographic characteristics & no & no & no & no & yes \\
\hline Zonal dummies & yes & yes & yes & yes & yes \\
\hline \multirow[t]{2}{*}{ Constant } & $2.876^{\star \star \star}$ & $2.688^{\star \star \star}$ & $2.296^{\star \star \star}$ & $2.539^{\star \star \star}$ & $3.084^{\star \star \star}$ \\
\hline & $(66.64)$ & $(12.63)$ & (10.55) & $(10.87)$ & $(6.943)$ \\
\hline Observations & 482 & 481 & 480 & 480 & 480 \\
\hline$R$-squared & 0.033 & 0.093 & 0.141 & 0.147 & 0.160 \\
\hline
\end{tabular}

Source: Authors' calculations based on the household data from 2013 Feed the Future survey.

Note: Robust $t$-statistics in parentheses. ${ }^{\star \star \star} p<0.01,{ }^{\star \star} p<0.05,{ }^{\star} p<0.1$. n.a. $=$ not applicable.

threshing using animals, to wind when winnowing by hand, during transportation from the field to the farm or from the field to the threshing floor, to crop damage because of untimely rain during harvesting, and to theft while storing unthreshed crops in the field.

We perform a similar exercise in the case of tractor use. In Table 10.9, we present simple comparisons of wheat yields in mechanization-intensive zones (West Tigray, Jijiga, West Arsi, Arsi, and Bale) for those farmers that used 
TABLE 10.9 Labor and land productivity by tractor use in mechanization-intensive zones, Ethiopia, 2013

\begin{tabular}{|c|c|c|c|c|c|c|}
\hline \multirow[b]{2}{*}{ Variable } & \multirow[b]{2}{*}{ Observations } & \multirow{2}{*}{$\begin{array}{l}\% \text { using } \\
\text { tractors }\end{array}$} & \multicolumn{2}{|c|}{ Tractor use? } & \multicolumn{2}{|c|}{$t$-test } \\
\hline & & & Yes & No & $t$-value & Significance \\
\hline \multicolumn{7}{|l|}{ Labor use, days/ha } \\
\hline Mean & 1,894 & 13 & 45.8 & 97.0 & 4.65 & 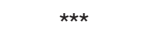 \\
\hline Median & 1,894 & 13 & 32.0 & 56.0 & n.a. & n.a. \\
\hline \multicolumn{7}{|l|}{ Land productivity, quintals/ha } \\
\hline \multicolumn{7}{|l|}{ All } \\
\hline Mean & 1,926 & 13 & 8.3 & 15.5 & 10.64 & 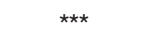 \\
\hline Median & 1,926 & 13 & 5.9 & 13.5 & n.a. & n.a. \\
\hline \multicolumn{7}{|l|}{ By crop } \\
\hline Barley & 458 & 4 & 11.7 & 15.4 & 1.86 & * \\
\hline Wheat & 506 & 9 & 14.0 & 19.3 & 3.29 & $\star * *$ \\
\hline Maize & 634 & 14 & 6.1 & 16.2 & 8.38 & 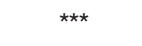 \\
\hline Sorghum & 224 & 36 & 8.4 & 7.3 & -1.44 & n.a. \\
\hline Sesame & 104 & 25 & 2.2 & 2.7 & 1.37 & n.a. \\
\hline \multicolumn{7}{|l|}{ Modern input use } \\
\hline $\begin{array}{l}\text { Diammonium phosphate (DAP), } \\
\mathrm{kg} / \mathrm{ha}\end{array}$ & 2,162 & 14 & 7.1 & 58.4 & 10.51 & $* \star \star$ \\
\hline Urea, kg/ha & 2,162 & 14 & 1.0 & 15.8 & 4.76 & $\star * \star$ \\
\hline Herbicide, L/ha & 2,162 & 14 & 0.1 & 3.9 & 0.98 & n.a. \\
\hline Fungicide, L/ha & 2,162 & 14 & 0.0 & 0.3 & 1.19 & n.a. \\
\hline Pesticide, L/ha & 2,162 & 14 & 0.0 & 0.1 & 2.15 & ** \\
\hline Other chemicals, L/ha & 2,162 & 14 & n.a. & 0.0 & 1.32 & n.a. \\
\hline Improved seeds, $\mathrm{kg} / \mathrm{ha}$ & 2,162 & 14 & 14.7 & 42.3 & 3.47 & $* \star \star$ \\
\hline Improved seeds, $\%$ of plots & 2,162 & 14 & 13.4 & 32.4 & 6.82 & 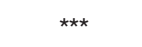 \\
\hline \multicolumn{7}{|l|}{ Land rental } \\
\hline Rented in, \% & 2,162 & 14 & 1.2 & 2.8 & 1.85 & * \\
\hline Sharecropped in, \% & 2,162 & 14 & 1.0 & 2.1 & 1.43 & n.a. \\
\hline
\end{tabular}

Source: Authors' calculations based on the household data from 2013 Feed the Future survey. Note: ${ }^{\star \star \star} p<0.01,{ }^{\star \star} p<0.05,{ }^{\star} p<0.1$. n.a. $=$ not applicable.

tractors with those that did not. As in the case of combine harvesters, we find strong effects on labor of the use of tractors. Farmers that rely on tractors use half of the labor that nonusers of tractors use (also shown in Figure 10.15). In contrast with combine harvesters, we do not find an effect on yield in a simple $t$-test. If anything, we find higher yields for nonadopting farmers in the 
FIGURE 10.15 Density functions on the association of tractor use and labor productivity, Ethiopia, 2013

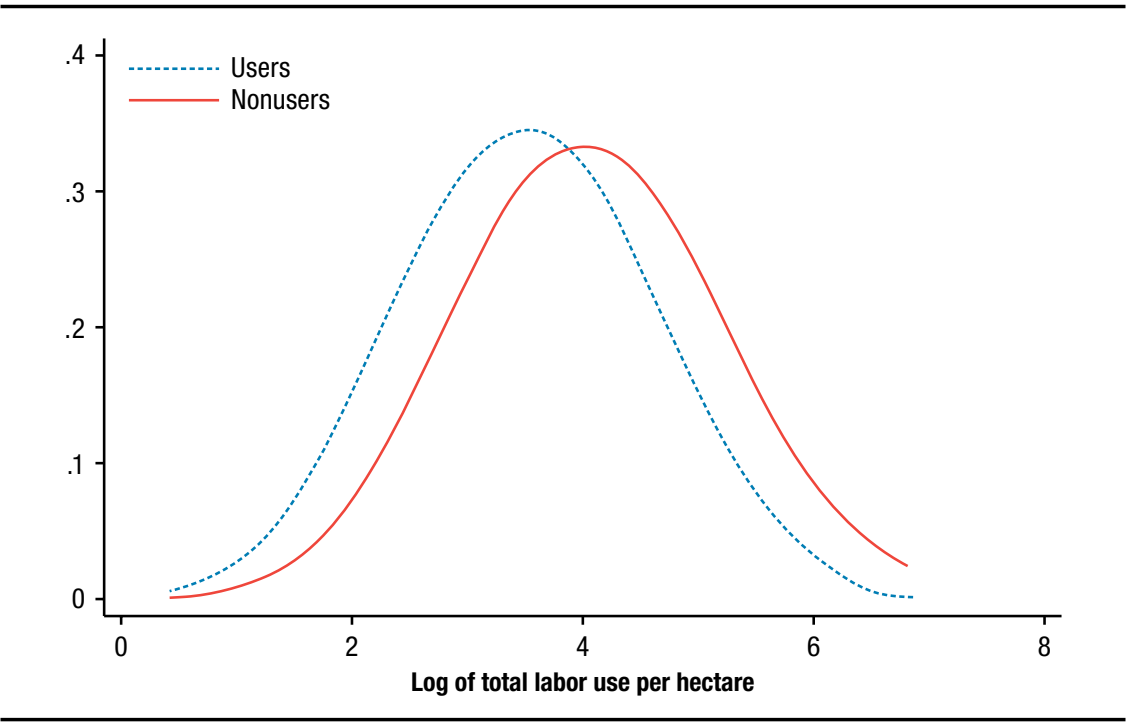

Source: Authors' analyses based on the household data from 2013 Feed the Future survey.

case of wheat and maize. When we control for other factors (Table 10.10), we do not find a significant association between tractor use and yield levels. This is a finding consistent with other studies from other parts of the world (Pingali, Bigot, and Binswanger 1987), as well as with evidence from our key informant discussions in these areas. Finally, when we compare modern input use between farmers that use tractors and those that do not, we do not see an increase in modern input use for those that adopt tractors. In fact, often the opposite is seen.

Because Ethiopia is still at an early stage of agricultural mechanization uptake, widespread effects of mechanization are not yet obvious. However, one could speculate what further impacts might be achieved from higher adoption levels.

- Tilling and harvesting activities are more frequently undertaken by men than by women, whereas women have a relatively larger role in weeding (Hailu, Weersink, and Minten 2016). More mechanization would therefore seemingly imply that women would become relatively more important in the agricultural production process. 
TABLE 10.10 Regressions to examine the association of the use of tractors on wheat yield in mechanization-intensive zones, quintals/ha, Ethiopia, 2013

\begin{tabular}{|c|c|c|c|c|c|}
\hline Variable & Model 1 & Model 2 & Model 3 & Model 4 & Model 5 \\
\hline \multirow[t]{2}{*}{ Use of tractor (yes $=1$ ) } & $-0.150^{\star \star \star}$ & -0.045 & -0.031 & -0.029 & -0.015 \\
\hline & $(-2.792)$ & $(-0.927)$ & $(-0.632)$ & $(-0.574)$ & $(-0.302)$ \\
\hline \multirow[t]{2}{*}{ Log (plot area) } & n.a. & $-0.667^{\star \star \star}$ & $-0.663^{\star \star \star}$ & $-0.664^{\star \star \star}$ & $-0.665^{\star \star \star}$ \\
\hline & n.a. & $(-10.520)$ & $(-10.400)$ & $(-10.360)$ & $(-10.420)$ \\
\hline \multirow[t]{2}{*}{ Log (total household land size) } & n.a. & $0.073^{\star \star}$ & $0.073^{\star \star}$ & $0.073^{\star \star}$ & $0.076^{\star \star}$ \\
\hline & n.a. & $(2.044)$ & (2.062) & $(2.074)$ & $(2.052)$ \\
\hline \multirow[t]{2}{*}{ Log (number of plots) } & n.a. & $-0.080^{\star}$ & $-0.096^{\star \star}$ & $-0.095^{\star \star}$ & $-0.107^{\star \star}$ \\
\hline & n.a. & $(-1.868)$ & $(-2.233)$ & $(-2.204)$ & $(-2.449)$ \\
\hline \multirow[t]{2}{*}{ Log (plot distance from home) } & n.a. & $0.050^{\star \star \star}$ & $0.044^{\star \star \star}$ & $0.044^{\star \star \star}$ & $0.042^{\star \star \star}$ \\
\hline & n.a. & $(4.458)$ & $(4.005)$ & $(4.004)$ & $(3.814)$ \\
\hline \multirow[t]{2}{*}{ Semi-fertile soil (yes $=1$ ) } & n.a. & 0.053 & 0.087 & 0.087 & 0.092 \\
\hline & n.a. & $(0.759)$ & $(1.251)$ & $(1.259)$ & $(1.314)$ \\
\hline \multirow[t]{2}{*}{ Fertile soil (yes $=1$ ) } & n.a. & $0.258^{\star \star \star}$ & $0.288^{\star \star \star}$ & $0.289^{\star \star \star}$ & $0.291^{\star \star \star}$ \\
\hline & n.a. & $(3.749)$ & $(4.264)$ & $(4.272)$ & $(4.263)$ \\
\hline \multirow[t]{2}{*}{ Flat plot (yes = 1) } & n.a. & $0.077^{\star \star}$ & 0.054 & 0.056 & 0.052 \\
\hline & n.a. & (2.049) & $(1.411)$ & $(1.436)$ & $(1.339)$ \\
\hline \multicolumn{6}{|l|}{ Crops (barley = base) } \\
\hline \multirow[t]{2}{*}{ Wheat } & $0.199^{\star \star \star}$ & $0.214^{\star \star \star}$ & $0.165^{\star \star \star}$ & $0.166^{\star \star \star}$ & $0.160^{\star \star \star}$ \\
\hline & $(5.134)$ & $(5.683)$ & $(4.379)$ & $(4.392)$ & $(4.253)$ \\
\hline \multirow[t]{2}{*}{ Maize } & 0.013 & 0.051 & $0.104^{\star \star}$ & $0.103^{\star \star}$ & $0.106^{\star \star}$ \\
\hline & $(0.280)$ & $(1.109)$ & $(2.179)$ & (2.148) & $(2.213)$ \\
\hline \multirow[t]{2}{*}{ Sorghum } & $-0.300^{\star \star \star}$ & $-0.196^{\star \star \star}$ & $-0.149^{\star \star}$ & $-0.150^{\star \star}$ & $-0.146^{\star \star}$ \\
\hline & $(-4.886)$ & $(-3.354)$ & $(-2.520)$ & $(-2.551)$ & $(-2.485)$ \\
\hline \multirow[t]{2}{*}{ Sesame } & $-1.131^{\star \star \star}$ & $-0.836^{\star \star \star}$ & $-0.760^{\star \star \star}$ & $-0.761^{\star \star \star}$ & $-0.773^{\star \star \star}$ \\
\hline & $(-14.21)$ & $(-10.49)$ & $(-9.196)$ & $(-9.178)$ & $(-9.360)$ \\
\hline Modern input use & no & no & yes & yes & yes \\
\hline Distance from nearest town & no & no & no & yes & yes \\
\hline Demographic characteristics & no & no & no & no & yes \\
\hline Zonal dummies & yes & yes & yes & yes & yes \\
\hline \multirow[t]{2}{*}{ Constant } & $2.322^{\star \star \star}$ & $2.124^{\star \star \star}$ & $2.047^{\star \star \star}$ & $2.018^{\star \star \star}$ & $2.106^{\star \star \star}$ \\
\hline & $(27.83)$ & (14.62) & (14.05) & (11.27) & (8.048) \\
\hline Observations & 1,926 & 1,914 & 1,913 & 1,913 & 1,913 \\
\hline$R$-squared & 0.340 & 0.410 & 0.423 & 0.423 & 0.428 \\
\hline
\end{tabular}

Source: Authors' calculations based on the household data from 2013 Feed the Future survey Note: Robust t-statistics in parentheses. ${ }^{\star \star \star} p<0.01,{ }^{\star \star} p<0.05,{ }^{\star} p<0.1$. n.a. $=$ not applicable. 
- Land rental markets might become more active with better access to mechanization in the country, which would allow more area cultivation by single owners. Although rental markets are still relatively little used in Ethiopia, a more active market that allows allocation of land to the most efficient cultivators - possibly those with access to mechanization - might possibly contribute to further transformation of the agricultural sector in the country.

- Labor demands are significantly higher during the harvesting period, and wages show a slightly upward trend during that period. We use CSA wage data over the last 10 years to check the extent of seasonality in rural wages, likely driven by seasonal changes in demand (Figure 10.16). We find that wages are indeed slightly higher at the end and the beginning of the year, around the harvest period of the main agricultural season in Ethiopia (meher), and lower in the middle of the year, usually referred to as the slack season. However, the differences are not very large (an amplitude of 5 percent), and they are not significant at conventional statistical levels. The release of labor during that period might therefore lead to downward pressure on wages during that period. This is also the period when there is a significant demand for hired labor, and increasing mechanization might lead to lower demand for such labor. That labor could possibly be used more efficiently in the off-farm sector, although opportunities in that area are still limited in Ethiopia (Bachewe et al. 2016).

\section{Conclusions and Implications}

The use of agricultural mechanization is low in Ethiopia. However, the number of tractors imported in the country was five times higher in 2014 than 5 years earlier, and the annual import value of combine harvesters is now more than tenfold the value of 15 years ago, with currently about 700 combine harvesters active in the country. A significant number of tractors are being used by larger commercial farmers and state farms. However, we also observe increasing uptake of mechanization by smallholders, especially so in the wheat sector, with many making use of growing numbers of commercial agricultural mechanization service providers for plowing, harrowing, and harvesting. We estimate that a quarter of the area under wheat, the fourth most important cereal in the country, is currently harvested by combine harvesters.

Mechanization, especially using combine harvesters, has been rapidly adopted in wheat-growing areas in the southeast of the country. Several 
FIGURE 10.16 Seasonal movements in real rural wages in Ethiopia, July 2004-June 2014, monthly wage index (average yearly wage is 1.00 )

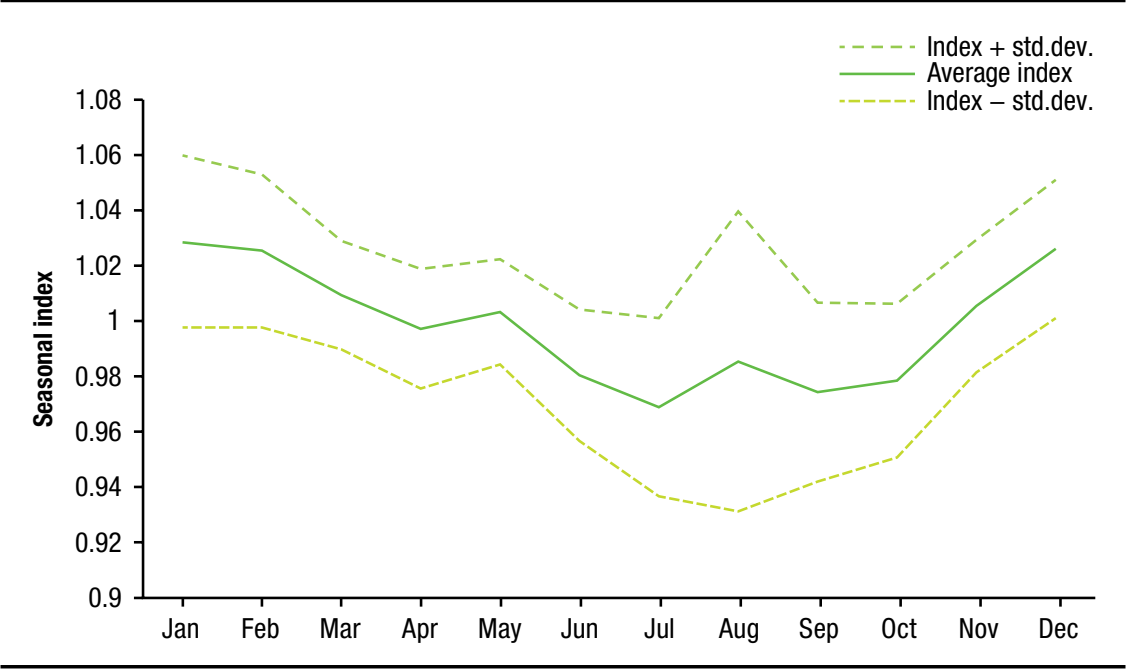

Source: Authors' computation using Ethiopia, CSA's price database.

factors have contributed to the rapid uptake of agricultural mechanization in this area:

- Many commercial farms are in the southeast, which has encouraged machine rental markets to develop, because these larger farms often had excess capacity for the machines that they owned. However, nonfarmer commercial service providers have rapidly emerged as well, especially for combine harvesters.

- There are large clusters of farms growing wheat in those areas, which are suited for mechanization, given the economies of scale that could be achieved.

- The area is relatively flat, a rather exceptional situation in Ethiopia.

- Most of the southeast receives a bimodal rainfall pattern, with two harvests in the year. This results in higher rates of return on investments in tractors and combine harvesters.

- Soils are not as sandy as in other parts of the country, allowing faster plowing and harvesting. 
These special conditions in the southwestern wheat-producing areas of Ethiopia should be taken into consideration when planning for scaling-up of agricultural mechanization in other farming zones of the country. The case of wheat in the southeast of the country shows that mechanization uptake and appropriate institutions that offer rental services can rapidly develop when conditions are right.

Several challenges face efforts to scale up mechanization in other parts of the country, as well as with other crops than wheat. First, not all plots are well adapted to mechanized plowing in Ethiopia. Physical constraints might be linked to the type of soils; that is, soils with too much moisture or that are too sandy are considered prohibitive for mechanization. Stony fields are also not suited for mechanized plowing because stones might damage plows. Sloped and steep fields also are often an important deterrent to mechanization in Ethiopia. Second, given the preference for large machines, because smaller machines might not have the required power, land fragmentation and the small farm plots in many parts of Ethiopia further complicate the use of agricultural machines. Most Ethiopian farmers have plots smaller than the minimum plot size in which combine harvesters seemingly can operate effectively. This implies that policies that promote consolidation of land-such as through land rental markets, for example-would be needed to mitigate this issue.

Several interventions could be implemented to stimulate further agricultural mechanization uptake in the country. These include the following:

- Improved access to foreign exchange for commercial dealers to import agricultural machinery. This problem has lowered the availability and, therefore, the use of agricultural machinery. However, this now may be less of an issue since AAMI recently came into the market. AAMI has ready access to foreign exchange because of its special status. Moreover, the agricultural mechanization sector has been declared a priority sector with consequent priority access to foreign exchange. Further efforts to reduce import restrictions are crucial in increasing the availability of machinesin terms of both quantity and diversity—in several Asian countries, as described in the Asian chapters.

- Interventions in the financial markets. For example, a policy whereby repayment periods for machines could be extended should be explored, given that the risks to investments in machinery are usually larger than 
those in other investment domains and returns on investment are slower. ${ }^{29}$ For example, the drought in 2015 reduced the harvest and led to some machines being underused. Moreover, because most banks require collateral on loans of about 50 percent, seeking ways to possibly reduce this amount might encourage greater uptake of agricultural machines. Further stimulation of an active leasing market might also encourage more entrants.

- Improved knowledge by extension agents on possible benefits of and challenges with innovation in the use of agricultural machinery on farms might allow for more rapid and more widespread take-up. The agricultural extension system is not yet geared toward farm mechanization, with extension agents receiving no training on the topic.

- Access to spare parts and maintenance for tractors. The lack of timely maintenance services and the lack of spare parts remain key bottlenecks to mechanization. Although the entry of AAMI in the market has made the acquisition of tractors more accessible because of the lower prices and the credit facilities they offer, these tractors are perceived to be less sturdy than the more expensive tractors from private dealers; they break down more often, and complaints about access to spare parts because of regular changes in models and makes are common. Ready access to repair services and spare parts is required to further enable sustainable use of the AAMI machines. As is described in the Asian chapters, local manufacturing of spare parts and attachments have emerged in Asia through less restrictive import policies that stimulated importation of a large number of machines and machine parts, which local fabricators could study and adapt, and through public research and development that further provided designs and prototypes to the private sector.

- Access to investment licenses. Importing machines is allowed only for commercial farmers that can present investment licenses. These licenses permit access to duty-free machines imported by privileged dealers. Without such licenses, smallholders can purchase only imported machines at higher prices, set by dealers, or else are restricted to locally assembled

29 For trucks, which operate full-time, investors can repay any purchase credit in a period of three to four years. However, combine harvesters are active only for three to four months during a year. Therefore, payback within a period of three to four years may be challenging for investors in combine harvesters. 
machines—seemingly not the first preference for most farmers. Given Ethiopia's focus on smallholders, such a restrictive import policy undermines progress in smallholder mechanization.

- Using more adapted technologies. Although the use of combine harvesters in crops other than wheat (maize, barley, and teff) is currently under experimentation, the profitability of use of combine harvesters is higher in the case of wheat, compared with maize, for example. The risks associated with the use of combine harvesters on maize are perceived to be much higher than for wheat, and the life of combine harvesters with the technologies that are currently available is seen to be lower when used on maize than on wheat. The use of technologies more adapted for such other crops should therefore be further explored. Moreover, it is not well understood what the constraints are to uptake of cheaper two-wheel tractors-which are widespread in Asia. More studies are needed to better understand these constraints.

\section{References}

Bachewe, F., G. Berhane, B. Minten, and A. S. Taffesse. 2015. Agricultural Growth in Ethiopia (2004-2014): Evidence and Drivers. IFPRI Ethiopia Strategy Support Program Working Paper 81. Addis Ababa: International Food Policy Research Institute.

- 2016. Non-Farm Income and Rural Labor Markets in Ethiopia. IFPRI Ethiopia Strategy Support Program Working Paper 90. Addis Ababa: International Food Policy Research Institute.

Baudron, F., B. Sims, S. Justice, D. G. Kahan, R. Rose, S. Mkomwa, P. Kaumbutho, J. Sariah, R. Nazare, G. Moges, and B. Gérard. 2015. "Re-Examining Appropriate Mechanization in Eastern and Southern Africa: Two-Wheel Tractors, Conservation Agriculture, and Private Sector Involvement." Food Security 7 (4): 889-904.

Berhane, G., K. Hirvonen, and B. Minten. 2016. Synopsis, Agricultural Mechanization in Ethiopia: Evidence from the 2015 Feed the Future Survey. IFPRI Ethiopia Strategy Support Program Research Note 48. Addis Ababa: International Food Policy Research Institute.

Binswanger, H. 1986. “Agricultural Mechanization: A Comparative Historical Perspective.” World Bank Research Observer 1 (1): 27-56.

Bymolt, R., and F. Zaal. 2015. Moving to Mechanization: Mechanization in Maize Farming Systems in Kenya, Tanzania and Ethiopia. Amsterdam: Royal Tropical Institute (KIT). 
Chamberlin, J., and E. Schmidt. 2012. "Ethiopian Agriculture: A Dynamic Geographic Perspective." In Food and Agriculture in Ethiopia: Progress and Policy Challenges, edited by P. Dorosh and S. Rashid, 21-52. Philadelphia: University of Pennsylvania Press.

Ethiopia, ATA (Agricultural Transformation Agency). 2014. "Ethiopian National Agricultural Mechanization Strategy: Vision, Systemic Challenges and Strategic Interventions.” Unpublished, Addis Ababa.

Ethiopia, CSA (Central Statistical Agency). 2015a. Agricultural Sample Survey 2014/15. Vol. I, Report on Area and Production of Crops, Private Peasant Holdings, Meher Season. Addis Ababa.

- 2015b. Large and Medium Scale Commercial Farms Sample Survey 2014/15. Vol. 8, Area and Production of Crops and Farm Management Practices. Addis Ababa.

Ethiopia, MoA (Ministry of Agriculture) and MoEF (Ministry of Environment and Forest). 2011. "Climate-Resilient Green Economy: Green-Economy Strategy." Unpublished, Addis Ababa. Ethiopia, Population Census Commission. 2008. Summary and Statistical Report of the 2007 Population and Housing Census: Population Size by Age and Sex. Addis Ababa.

FACASI (Farm Mechanization and Conservation Agriculture for Sustainable Intensification) Project. 2016. "Development of Agricultural Mechanization in Ethiopia and the Role of National Policies." Unpublished, International Maize and Wheat Improvement Center (CIMMYT), Mexico City.

Ghebru, H., and S. Holden. 2016. "Land Access, Land Rental Markets and Rural Poverty Dynamics in Ethiopia: Panel Data Evidence Using Survival Models.” Paper presented at 2016 World Bank Conference on Land and Poverty, Washington, DC, March 14-18.

Hailu, G., A. Weersink, and B. Minten. 2016. “Farm Practices and Productivity.” Unpublished, Ethiopia Strategy Support Program, International Food Policy Research Institute, Addis Ababa.

Kedir, M., E. Schmidt, and H. Tilahun. 2015. "Production Patterns and Fertilizer Use." Unpublished, Ethiopia Strategy Support Program, International Food Policy Research Institute, Addis Ababa.

Mekasha, A., B. Gerard, K. Tesfaye, L. Nigatu, and A. J. Duncan. 2014. "Inter-Connection between Land Use/Land Cover Change and Herders'/Farmers' Livestock Feed Resource Management Strategies: A Case Study from Three Ethiopian Eco-Environments." Agriculture, Ecosystems \& Environment 188: 150-162.

Minten, B., S. Tamiru, and D. Stifel. 2014. "Structural Transformation in Cereal Markets in Ethiopia." Journal of Development Studies 50 (5): 611-629.

NBE (National Bank of Ethiopia). 2014. Annual Report 2013-2014. Addis Ababa. 
Pingali, P., Y. Bigot, and H. P. Binswanger. 1987. Agricultural Mechanization and the Evolution of Farming Systems in Sub-Saharan Africa. Washington, DC: World Bank; Baltimore: Johns Hopkins University Press.

Schmidt, E., and F. Bekele. 2016. Rural Youth and Employment in Ethiopia. IFPRI Ethiopia Strategy Support Program Working Paper 98. Addis Ababa: International Food Policy Research Institute.

Schmidt, E., and M. Kedir. 2009. Urbanization and Spatial Connectivity in Ethiopia: Urban Growth Analysis Using GIS. IFPRI Ethiopia Strategy Support Program Working Paper 3. Addis Ababa: International Food Policy Research Institute.

United Nations. 2017. UN Comtrade database. Accessed February 1, 2017. http://comtrade.un .org/.

World Bank. 2012. Agribusiness Indicators: Ethiopia. Report no. 68237-ET. Washington, DC.

—.2015a. Ethiopia Urbanization Review: Urban Institutions for a Middle-Income Ethiopia. Washington, DC.

- 2015b. Ethiopia's Great Run: The Growth Acceleration and How to Pace It. Report no. 99399-ET. Washington, DC. 



\title{
AGRICULTURAL MECHANIZATION IN GHANA: ALTERNATIVE SUPPLY MODELS FOR TRACTOR HIRING SERVICES
}

\author{
Xinshen Diao and Hiroyuki Takeshima
}

\begin{abstract}
As in most countries in Africa, agricultural mechanization in Ghana was slow to develop until the 1990s; however, this has changed markedly since the early 2000s. According to the nationally representative Labor Force Survey conducted in 2015/2016, about one third of Ghana's crop-growing farmers, including smallholders, reported using some form of machinery, mostly tractors for land preparation. Still, policymakers are concerned that mechanization should be proceeding at a faster rate and worry that supply-side issues may be constraining its uptake, especially among smallholders. With this in mind, the government recently started to directly re-engage the promotion of mechanization, devoting public resources to directly subsidize machinery imports and to establish a network of subsidized agricultural mechanization service centers around the country (Diao et al. 2014). Parallel with these government programs is the rapid development of private-sector supply systems, through which an increased number of secondhand tractors were imported and purchased by relatively largescale farmers. In turn, these farmers provide hiring services to smaller-scale farmers for use mainly in land preparation, harvesting, and threshing. In this chapter, we review recent developments in the uptake of agricultural mechanization in Ghana and the factors driving the growth in farmers' demand. We then discuss alternative supply models in the country, comparing them with recent government interventions. This leads to our conclusions about appropriate mechanization policies for the future.
\end{abstract}

\section{A Historical Overview of Mechanization in Ghana}

Ghana is a relatively land-abundant country, but agriculture, which was the mainstay of the economy until the late 1990s, is still dominated by small firms. Mechanized agriculture has existed since before independence among a few large-scale farmers; however, even though land was available for farm 
expansion in many places, overall mechanization levels have been low until recently.

Like the country's early industrialization strategy, state-led direct interventions characterized agricultural policies in the 1960-1970s. Under such policies, the government promoted large-scale mechanized farming through a series of intervention programs such as the famous Operation Feed Yourself (OFY) program (Girdner et al. 1980), the Upper Regional Agricultural Development Project, and the Volta Regional Agricultural Development Project (Okolie 2003). In combination with protectionist policies in trade and markets, including rice import controls and local rice price support policies (Abdulai and Huffman 2000), the large-scale agriculture promotion policies led to the establishment of largely mechanized large estate farms, particularly in rice production areas in northern Ghana (Amanor 2011). Tractors that were imported for these large farms were implicitly subsidized by the significantly overvalued exchange rate. In the meantime, the government of Ghana, similarly to governments in many other African countries including Nigeria, Zambia, and Tanzania, sought to promote tractorization of subsistence farmers through the establishment of tractor hiring services (THS) schemes operated by the government (Akinola 1987). According to Seager and Fieldson (1984), the Ministry of Agriculture in the 1960s owned and operated 1,500 tractors in its 32 district mechanization stations in the savannah zone. The low service charges paid by farmers for the service provision of land clearing, tillage, and harvesting were estimated to be about 3-74 percent of actual costs, depending on the service rendered (Stryker et al. 1990). With the focus shifting to rice-growing areas in the 1970s, the heavily subsidized mechanization model was further expanded in the north, where rice was grown. Of a total of 239 heavy farm machines operated by the Ministry of Agriculture in the 1970s, about 40 percent were in the Northern and Upper regions and mainly used for rice production. Similarly, about 60 combine harvesters were operated by the Ministry of Agriculture in the northern rice-growing zones (Akoto 1987).

As expected, low efficiency arose as result of the heavily subsidized and state-run THS schemes. It was estimated that only about 40 percent of the government tractors were serviceable and each of these plowed an average of only 12-18 ha annually. In contrast, the private tractor owners could plow up to 240 ha per tractor per year (Stryker et al. 1990 p. 116).

Facing a series of economic and political crises that had pushed the country's economy to the edge of a total collapse, the Government of Ghana started the Structural Adjustment Program (SAP) in 1983, earlier than most other 
African countries that underwent similar IMF- and World Bank-guided reform processes. The significant cuts in the government's overall budget and support to state interventions, including various agricultural subsidy programs, led to the eventual discontinuation of the government-supported THS schemes. With the huge devaluation of domestic currency, prices for imported capital goods, including tractors, became considerably high in terms of local currency and few large farmers could afford to buy such imported capital goods. These two factors led to a fall in the level of agricultural mechanization following the SAP in the 1980-1990s (Aryeetey and Baah-Boateng 2007). This is similar to what occurred in many African countries, including Nigeria as described in this book. The decline in mechanization in the 1980-1990s was a correction from the unsustainable level of mechanization in the 19601970 s created by the government's direct interventions and other distortionary policies. While the 1970 s were characterized by substantially higher levels of public expenditure in agriculture, including spending on mechanization, most direct interventions were expensive and had limited effects on overall agricultural performance (Akoto 1987). This suggests that the early mechanization push in the 1960-1970s was a failure.

\section{The Emergence of High Demand for Mechanization in Ghana}

The failure in the early push for tractorization by African governments has led agricultural economists to emphasize the importance of demand-side factors in mechanization. In the 1980s the lag in mechanization was attributed mainly to the slow progression of agricultural intensification from long fallow to permanent agriculture. By examining the existing farming systems in Africa carefully, Pingali, Bigot, and Binswanger (1987) provided a formal analysis on the main reasons for the slow progress of agricultural mechanization in Africa. The authors argue that the slow transition from hand hoes to mechanized plowing can be explained by the lack of evolution in farming systems. In long- and medium-fallow systems, tree stumps are present in the fields because they have not had time to rot away. Therefore, the plow cannot be used in these systems until they have progressed to the stage of short fallow or permanent agriculture. When the systems move from long or medium fallow to short fallow or permanent agriculture, one reason for the switch in technology is that as fallows get shorter, grassy weeds and hardened soils become harder to overcome with hand hoeing, making animal or tractor plowing more attractive. 
One theory, developed based on Hans Ruthenburg's (1980) historical analysis of the evolution of tropical farming systems, predicts that farming communities will only adopt draft animals or tractors for land preparation once their land use intensity reaches a critical threshold. Ruthenburg measured land use intensity as the ratio of the harvested area to the total agricultural area (cropland plus fallow land). He called this the R-value and concluded that it must exceed 33 before mechanization of land preparation would take hold. This is equivalent to when the average fallow period has been shortened to less than two years for each year of cultivation.

Diao et al. (2014) calculate annual R-values for Ghana over the period 1961 to 2011 (Figure 11.1). While still relatively land-abundant, land use intensity has increased since the late 1990s in Ghana. Until the late 1990s, Ghana had low R-values, during which time there was little evidence of demand for tractor mechanization. From the late 1990s onward, however, the R-values have permanently risen above the threshold of 33, reaching 40 to 43 in the late 2000s. While this highly aggregated data fails to capture important regional variations, it does suggest that farming systems and land use intensity have changed significantly in Ghana since the late 1990s, permitting more mechanization.

However, Binswanger and Savastano (2016) notice that while rising population density and improved market access have transformed a large share of African agriculture to permanent cropping-for example, in Ethiopia, Kenya, and the Savannah zones of West Africa-only in a few of these areas has mechanical tilling been adopted, either via animal draft or via tractors. Therefore, Binswanger-Mkhize (2017) argues that the farming systems explanation no longer seems to be a sufficient explanation for the slow progress of mechanization in some African countries.

Indeed, Ruthenburg's R-value as a measure of land use intensity seems to be only a necessary but not sufficient condition for assessing the demand for mechanization. Another relevant theory from the literature is the induced innovation theory, which essentially predicts that mechanization being a labor-saving technology means that demand will develop once labor becomes sufficiently costly relative to capital and other purchased inputs (Hayami and Ruttan 1970, 1985; Binswanger and Ruttan 1978; Pingali, Bigot, and Binswanger 1987). This typically happens after a country has reached a point in its economic transformation where the number or the share of workers remaining in agriculture begins to decline and the land-labor ratio increases. For field crops, this usually leads to farms getting bigger and as there is greater scarcity of labor relative to land, farmers have an incentive to adopt laborsaving technologies like mechanization. 
FIGURE 11.1 R-value measure of farming system evolution in Ghana, 1961-2014

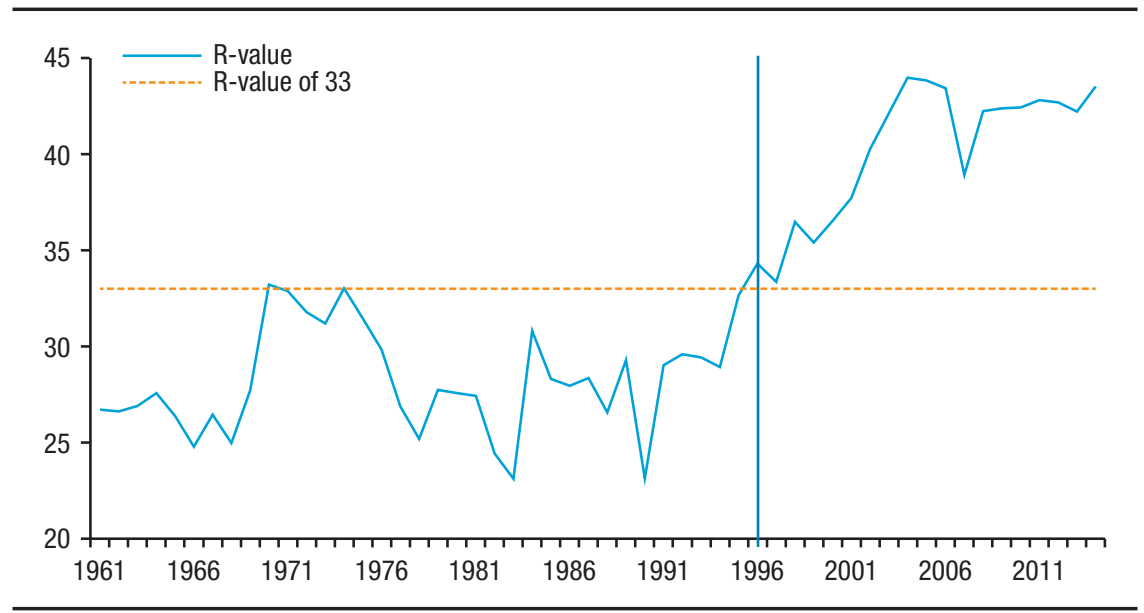

Source: Compiled from FAO data.

\section{Land-Labor Ratio}

Unlike many African countries, Ghana is still a relatively land-abundant country; as shown in Table 11.1, the average cropped area per rural person actually increased by 11.8 percent between 2000-2010. This happened despite continued population growth, because rapid urbanization has pulled many workers out of agriculture on a full- or part-time basis, and changing marketable opportunities have simultaneously led farmers to increase their cultivated areas. However, Table 11.1 shows that there are important regional differences in these changes. Looking across regions, there is an inverse relationship between increases in the cropped area per rural person over 2000-2010 and population density. For example, Brong Ahafo region experienced the largest percentage increase in its cropped area per rural person (52.5 percent) and was also among the regions with the lowest population density in 2010. At the other extreme, the Greater Accra region experienced a 38.8 percent decline in its cropped area per rural worker and had the highest population density after Central region in 2010. Moreover, the regions that experienced the largest increases in their land-labor ratios are the most important regions in terms of national food crop production (Table 11.1).

\section{Farm Size}

One consequence of an increasing land-labor ratio has been that farms have grown larger where land is relatively abundant. The expansion of farm size 
TABLE 11.1 Crop area per rural person, by region, 2000 and 2010

\begin{tabular}{lccccc}
\hline & $\begin{array}{c}2010 \\
\text { Region }\end{array}$ & $\begin{array}{c}\text { Rural population density } \\
\text { (persons/(km²) }\end{array}$ & $\begin{array}{c}\text { 2010 share in } \\
\text { national food crop } \\
\text { area (percent) }\end{array}$ & \multicolumn{2}{c}{ Crop area per rural person (ha) } \\
\cline { 5 - 6 } & 57 & 6.7 & 2000 & 2010 & Percent change \\
\hline Western & 118 & 7.0 & 0.20 & 0.18 & -6.7 \\
Central & 117 & 0.3 & 0.06 & 0.23 & 12.3 \\
Greater Accra & 77 & 14.1 & 0.34 & 0.35 & -38.8 \\
Eastern & 68 & 5.9 & 0.14 & 0.16 & 4.0 \\
Volta & 77 & 12.8 & 0.24 & 0.26 & 7.7 \\
Ashanti & 32 & 18.5 & 0.35 & 0.54 & 52.5 \\
Brong Ahafo & 25 & 16.1 & 0.33 & 0.35 & 7.0 \\
Northern & 32 & 10.6 & 0.58 & 0.68 & 16.8 \\
Upper West & 94 & 8.0 & 0.41 & 0.36 & -12.6 \\
Upper East & 51 & 100.0 & 0.28 & 0.31 & 11.8 \\
National & & & &
\end{tabular}

Source: Diao et al (2014).

is one of the most important ways for farmers in Ghana to respond to the increased market demand for food crops from urbanization and growth in household income, and recent improvements in market access have made it possible for many farmers to switch to more market-oriented production.

Nationally, there has been an increase in the share of medium-sized (2-20 ha) farms at the expense of small (less than $2 \mathrm{ha}$ ) farms, and medium-sized farms now account for half of all farms (Table 11.2). This change masks important differences at regional levels. In the northern regions (comprising the savannah and transition zones), medium-sized farms have surged ahead and now account for 60 percent of all farms. However, there has been a reverse trend in the south (comprising the forest and coastal zones), where the share of medium-sized farms has actually declined (from 44.7 percent to 41.1 percent) and the share of small farms has increased.

Generally, for medium-sized farmers to further expand their farm size, they depend on mechanization for land preparation. Moreover, while they are more likely to become owners of tractors, they cannot fully utilize the capacity of the tractors on their own farms. Thus, the increasing farm sizes and tractor ownership seem to reinforce each other from both demand and supply sides of mechanization. That is, owning a tractor might encourage the farmers to cultivate a larger piece of farmland, which is a demand-side factor from mediumsized farmers for mechanization. At the same time, cultivating a large land size 
TABLE 11.2 Changes in the farm size distribution, 2005/2006 and $2012 / 2013$

\begin{tabular}{lccc}
\hline $\begin{array}{l}\text { Region/year } \\
\text { National: }\end{array}$ & $\begin{array}{c}\text { Small } \\
(<2 \text { ha })\end{array}$ & $\begin{array}{c}\text { Medium } \\
(2-20 \text { ha })\end{array}$ & $\begin{array}{c}\text { Large } \\
(>20 \text { ha })\end{array}$ \\
2005/2006 & & & \\
2012/2013 & 53.3 & 44.7 & 1.9 \\
North: & 49.3 & 49.8 & 0.9 \\
2005/2006 & & & \\
2012/2013 & 44.3 & 52.5 & 3.2 \\
South: & 38.6 & 60.0 & 1.4 \\
2005/2006 & & & \\
2012/2013 & 53.3 & 44.7 & 1.9 \\
\hline
\end{tabular}

Source: Authors' calculations using GSS (2014).

Note: South $=$ Coastal + Forest zones; North $=$ Savannah + Transition zone .

might also encourage these farmers to procure a tractor and participate in the THS, thereby increasing the supply of mechanization.

\section{Urbanization}

Urbanization is an important factor driving increased demand for mechanization because growing market demand for agricultural products is often a key driver of intensification. In Ghana, intensification as a whole, and mechanization in particular, appears to be fairly correlated with market access, measured by travel time to large towns and proximity to roads (Cossar 2015). Changes in dietary structure associated with urbanization lead to increased demand for cereals, which generally have higher labor requirements than roots and tubers and are more conducive to mechanization (Nin-Pratt and McBride 2014).

Ghana has rapidly urbanized in the past two decades and since 2010 more than half of the total population lives in urban areas. There has been substantial migration of workers from rural to urban areas alongside considerable employment growth in the rural nonfarm economy, which have together led to a decline in the share of workers remaining in agriculture to about 40 percent of total employment in recent years. However, national statistics mask considerable spatial heterogeneity within Ghana. Until recently, a majority of its labor force was still working in agriculture, particularly in northern Ghana. However, because of low population density in the north, farm sizes 
tend to be larger there than in the south (Table 11.2). Moreover, because the north corresponds closely to the savannah and transition agroecological zones, its agriculture is dominated by field crops (particularly cereals) that are suitable for tractor land preparation, instead of permanent tree crops grown in the forest zone in the south that are not suitable for tractor operation. Indeed, in recent years, northern Ghana has increasingly become a food basket, providing maize and rice to urban markets throughout the whole country.

\section{Rising Rural Wages}

Urbanization also creates nonfarm jobs in both urban and rural areas, putting an upward pressure on rural real wage rates and hence creating demand for labor-saving technologies like mechanization. Mechanized plowing significantly reduces the labor required for land preparation and, to a lesser extent, reduces the labor required for weeding and harvesting (Pingali, Bigot, and Binswanger 1987). When hired labor is a major source of agricultural labor in certain farming activities - for example, in land preparation and harvestthe bottleneck effect of seasonal labor shortages increasingly becomes a factor prompting farmers to switch to mechanized services where they are available. The demand for mechanized service is further boosted when rural hired labor represents a relatively large share of production costs and becomes more expensive. Under such circumstances, even small farmers begin to demand mechanization technology. Recent economic structural changes have increased job opportunities in the rural nonfarm economy, and many family members of smallholder rural households are participating in nonfarm economic activities (Diao et al. 2014), which puts an upward pressure on rural wages.

Rising rural labor costs in both the north and south are one of the most important emerging factors in recent years to explain the accelerated demand for mechanization in Ghana. Table 11.3 provides agricultural wages for different types of farming activities at the national level and annual average rates across regions from 1991 to 2012. At the national level, agricultural real wages have grown by almost 7 percent per year over the period. At the regional level, agricultural wages have grown at a similar pace across regions in both the north and south. There are some exceptions to this; for example, male wages for land clearing in the Eastern region grew at about half the national rate.

While mechanization for land preparation is not necessarily a productivity-enhancing technology (Pingali, Bigot, and Binswanger 1987), reducing the dependency on hired labor improves farmers' control over the timing of agricultural operations. In semi-arid areas of Ghana with few days of rainfall, or in areas with bimodal rainfall that practice multiple seasons 
TABLE 11.3 Agricultural wages and annual average growth rate in Ghana, 1991-2012, by type of work

\begin{tabular}{lccc}
\hline Year/region & Men clearing & Women harvesting & Men harvesting \\
\hline \multicolumn{2}{l}{ Level of national average agricultural real wage (new Cedis, deflated by CPI) } \\
1991 & 1.18 & 0.94 & 1.11 \\
1998 & 1.39 & 1.03 & 1.35 \\
2005 & 2.30 & 1.84 & 2.38 \\
2012 & 4.55 & 3.60 & 4.24 \\
Average annual growth rate (1991-2012) & & \\
Western & 10.82 & 7.69 & 6.56 \\
Central & 6.10 & 6.80 & 6.66 \\
Volta & 7.52 & 7.42 & 7.31 \\
Eastern & 3.22 & 5.73 & 5.27 \\
Ashanti & 6.29 & 7.79 & 7.93 \\
Brong Ahafo & 5.41 & 4.87 & 6.78 \\
Northern & 5.26 & 4.66 & 3.25 \\
Upper East & 6.80 & 6.19 & 6.47 \\
Upper West & 6.46 & 5.00 & 3.55 \\
National & 6.62 & 6.57 & 6.60 \\
\hline
\end{tabular}

Source: Authors' calculation using multiple rounds of household surveys (GSS 2014). Note: $\mathrm{CPI}=$ consumer price index.

of cropping, seasonal labor bottlenecks can have impacts on productivity. In Northern Ghana a two-week delay in planting can lead to a 30-55 percent loss of yield (Houssou, Diao, and Kolavalli 2014a).

Putting together the agroecological factors and dynamics of recent economic transformation, it is reasonable to believe that demand for mechanization is rising and is no longer a constraint for the development of mechanization in Ghana. However, because agricultural production is largely influenced by agroecological conditions, both potential demand and adoption of mechanization often exhibit substantial spatial variation within a country. Existing demand for mechanization is often first concentrated in certain areas, such as those where farm size is relatively larger than the national average (for example, Northern Ghana) or those that are highly urbanized with small farm sizes (for example, Greater Accra areas). The recent Labor Force Survey conducted in 2015/2016 in Ghana shows that while just one third of crop-growing households practice mechanized agriculture using farm machinery (primarily for plowing), the adoption rate is as high as 88.5 percent in the 
Upper West region and 76.9 percent in the Greater Accra region (GSS 2016). On the other hand, there is relatively low demand for mechanization in the parts of the southern forest zone that have dominant permanent tree crops and tree stump issues. The adoption rate of mechanization is in the range of 2-10 percent in these forest zone regions (GSS 2016). In Ghana's Upper East region, the adoption rate of mechanized agriculture is also low at 18 percent (GSS 2016), mainly because of a tradition of using animal traction (Houssou et al. 2013b) and the predominance of smaller farms. It should also be emphasized that mechanization adoption varies significantly not only across regions in Ghana but also within regions across districts (Houssou et al. 2015). In Brong Ahafo region, for example, mechanization has been widely adopted in the maize-dominant grassland areas, but it is not the case in tree cropdominant places or in the forest areas (Cossar 2015). Clearly, a nationwide push for mechanization by the government should be avoided given such heterogeneity in the demand for and suitability of mechanization across areas.

Observations from field visits of IFPRI researchers in the savannah zone of Ghana in 2012-2013 also confirm the emerging high demand for mechanization, including from small famers. During their field visits, many small and relatively large farmers were interviewed, as well as tractor owners and users of hiring services. Everywhere they went, the researchers heard complaints from farmers about the lack of tractor services to meet their demand, and there was no single case in which a tractor owner complained of a lack of adequate demand for his or her services. Farmers who hired tractor services reported that they often had to approach more than one tractor owner before securing services to plow their field. Farmers who hired out their tractor services reported that they never have any concern for lack of consumers, and during land preparation season, they are often inundated with requests for services. With evidence that tractor ownership has increased in recent years, farmers hiring tractor services reported that it is becoming easier in some locations to secure plowing and maize threshing services, as compared with the past (Diao et al. 2014).

\section{The Supply of Agricultural Mechanization in Ghana}

The supply of mechanization includes manufacturing and importation of machines, mechanized service provision to farmers, fabrication and distribution of attachments and spare parts, and machinery repair and maintenance services. In Ghana, there are currently two parallel supply channels for 
agricultural mechanization services: the private sector's supply system characterized by farmer-to-farmer hiring out services, and a government-sponsored Agricultural Mechanization Services Enterprise Center (AMSEC) program. We consider each in the two subsections that follow.

\section{Private Sector-Led Mechanization}

The private-sector supply chain is well-developed and combines machinery importers, mechanized service providers (mostly medium-scale farmers), and repair and maintenance shops. The private sector has operated in Ghana's mechanization business for more than two decades, and it has scaled up in the last decade. Other than benefiting from an import tariff exemption that applies to all agricultural machinery imports, the private sector supply chain receives no other support from the government. The scale of the private sector is significant; while the government imported about 3,000 new tractors and 300 power tillers over 10 years, a similar (and possibly greater) number of used tractors were imported by private importers in the same period (CEPS 2012). The share of used tractors in total imports has increased substantially since 2010 (Figure 11.2), suggesting considerable and growing demand for affordable tractors in the private sector.

Private importers are predominantly small-scale businesspeople who have well-developed import channels in Europe for secondhand tractors, and tractor importation is typically only part of their business. This diversification enables them to spread their risks and to smooth out the seasonal nature of the demand for tractors. Their clients are mostly medium- and large-scale farmers, who want to buy imported secondhand tractors (USAID/ACDI-VOCA 2013). As in the automobile market, used tractors have a price advantage over new tractors of the same brand and are typically even less costly than the subsidized new machines imported for the government.

Secondhand tractors are attractive to farmers not only because they are more affordable, but because they can obtain tractor brands of their own choice. Moreover, since the private sector has operated in the tractor import business for many years, the spare parts for the brands they import are available in most locations at reasonable prices. By contrast, the brands of new tractors imported by the government keep changing, and spare parts for them are harder to obtain.

Medium- and large-scale farmers are the main buyers of secondhand tractors from private importers, and they are also the main providers of mechanized services to other farmers. For most of them, hiring out tractor services after they have plowed their own land is an important way to justify the 
FIGURE 11.2 Tractor imports in Ghana, 2003 to 2012

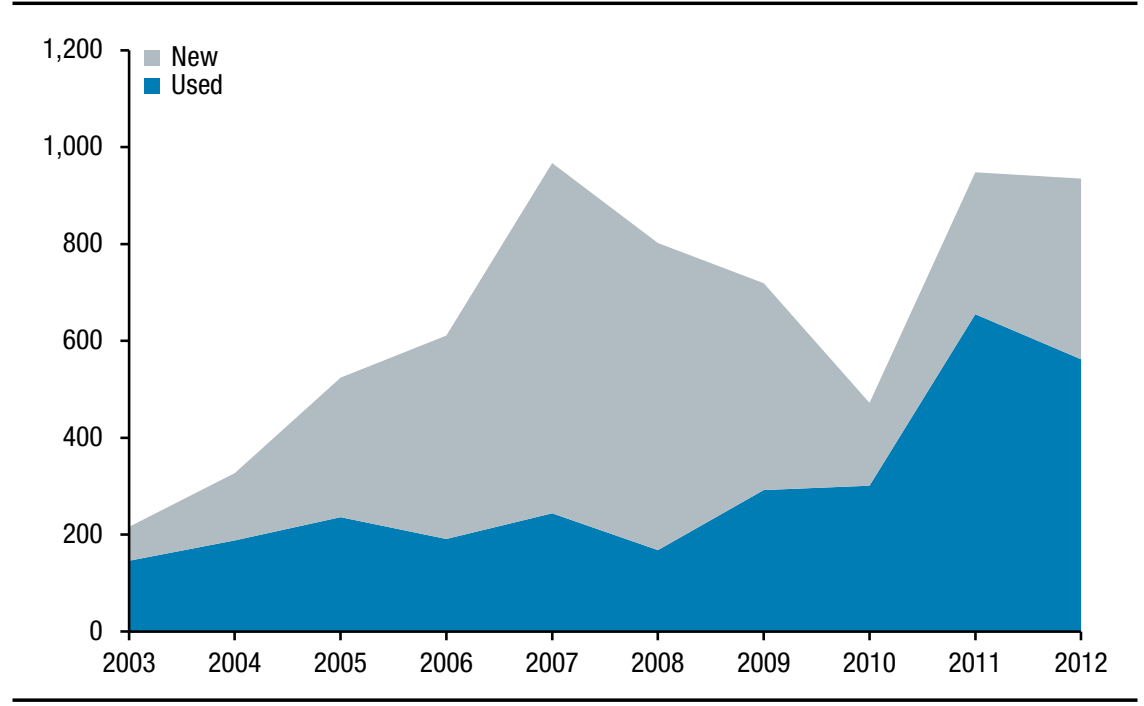

Source: CEPS (2012).

substantial lump sum investment cost involved (Houssou, Diao, and Kolavalli 2014a). The 2013 IFPRI/SARI survey found that for tractor owners the ratio of their numbers as service providers to the number of service users is 1 to 100-120 in 2012; on average, a medium-scale farmer who owns a tractor provided hiring services to $100-120$ other farmers, of which almost half are small-scale farmers with land area less than 2 ha (Houssou, Diao, and Kolavalli 2014a). On the other hand, almost half of the surveyed smallscale farmers hire tractor services for plowing; nearly all of these services were sourced locally and most were provided by other farmers (Benin 2013). Because of the dominant role of medium- and large-scale farmers in providing tractor services, the market for land preparation services is competitive. One outcome is that farmers in different locations are paying similar prices for plowing services (Benin 2013).

\section{Market Failures in Agricultural Machinery Investment}

Tractors are expensive, and like other indivisible lump sum investments, owning a tractor has an investment risk associated with the uncertainty about the returns to investment. While demand for mechanization appears to be growing among farmers in Ghana, such demand does not necessarily lead to adequate supply responses. Market failures could slow down the private sector's supply response to the increased demand for hiring services for mechanization. 
While the private sector has operated in Ghana's mechanization business for more than two decades, up until the early 2000s few farmers in Ghana owned tractors and most of those who did were large-scale. The farmer-tofarmer hiring services are a rather new business in many areas of the country. Like an infant industry, the market for such hiring services is in its early development stage, and the uncertainty in such markets for potential tractor owners is whether local demand for hiring services is large enough to make their investment profitable. The 2013 IFPRI/SARI survey found that 85 percent of tractor owners were the consumers of hiring services for about 10 years on average before they decided to purchase their own tractors; this exposure to the service market gave them a better understanding of the market (Houssou, Diao, and Kolavalli 2014b).

Migratory service provision is rare in Ghana. While there are different agricultural seasons in the north and south, only about one fifth of surveyed tractor owners migrate between the two regions and most of these owners are clustered in one district (Chapoto et al. 2014). While it is unclear why more owners do not take advantage of the different seasons, possible explanations include uncertainty over demand, information asymmetries in other areas, and lack of transport infrastructure. Risk and uncertainty will likely decrease as the hiring services market becomes more established and more private owners participate, but currently the supply response is expected to lag behind demand as individuals providing hiring services require a period of learningby-doing. In China however, county-level governments have facilitated the process for migratory service provision by helping machine owners overcome the risks caused by coordination failures and information asymmetries (Yang et al. 2013).

Market failure caused by the uncertainty in the service hiring market is magnified by the lack of accessible credit in the financial market for such investments. In Ghana, tractor owners depend on their own savings for machinery investment. Only 3.4 percent of surveyed medium-scale farmers who owned tractors obtained any loan for their purchases (Chapoto et al. 2014). Accumulation of the large amount of money needed to purchase tractors takes time. Land tenure traditions also contribute to this problem. In Ghana, land has historically been communally owned. Such traditional land tenure systems help the country avoid land concentration in the hands of a small number of large owners, but also mean that individual farmers cannot use land as a personal business asset with which to secure loans to purchase agricultural machinery. Interest rates for existing commercial loans are also too high to attract borrowers for agricultural machinery investment. 
Consequently, the supply of hiring services tends to be concentrated in the areas where there are large- and medium-scale farmers who can afford the investment in machines, and the supply response in other areas is slow to meet the rapidly growing demand for mechanization.

Investment risk is also associated with the cost of a tractor. Besides the low-cost, relatively affordable secondhand tractors, there is almost no available small agricultural machinery that is both affordable and suitable for local conditions. This is an important constraint to investing in a tractor for many farmers. In developing countries in Asia, on the other hand, tractors come in a wide range of sizes, horsepower, and prices. Power tillers and low-horsepower, small four-wheel tractors have been manufactured in China, India, and some other Asian countries. Prices for these smaller machines are affordable for many small- and medium-scale farmers in Asia (Diao et al. 2014). Farmers in Ghana commonly favor large and powerful tractors; the average horsepower of tractors in Ghana ranges from 60-80, while smaller tractors popular in Asian countries fall in the range of $20-40 \mathrm{hp}$ (World Bank 2014).

In Ghana, like in other African countries, the availability of smaller agricultural machinery-including small tractors that are relatively affordable for small-scale farmers and suitable for African soil conditions-is limited. Power tillers are used in irrigated paddy rice fields for plowing in the Kpong irrigation scheme in Eastern region (Takeshima et al. 2013). But with a low level of irrigation in the country, the potential for adoption of power tillers is low. Without affordable and suitable smaller tractors, the market alone is unlikely to create enough incentive for would-be suppliers of mechanization services to meet demand. While further research is needed to fully understand why smaller tractors have not been widely adopted in Ghana, here we explore a few reasons for the market failures in mechanization.

\section{LIMITED KNOWLEDGE AND INFORMATION ABOUT SMALL MACHINERY}

The early push for mechanization through state-run mechanization service centers in the 1960-1970s exposed Ghanaian farmers mainly to large tractors; in fact, many large tractors imported during that period are still operated and owned by large-scale farmers today. There is little knowledge among farmers and would-be-suppliers of mechanization services about different types of mechanized technologies, such as the returns to tractors of different amounts of horsepower, the merits of small machinery such as hand tillers, or the appropriate use and handling of different machines. Similarly, would-be importers need to be aware of various engine and equipment sizes and their potential uses in order to assess potential demand and business opportunities 
related to smaller mechanized equipment. Secondhand tractors imported from Europe by private traders are all large, and the existing supply chains for spare parts often cater to the few brands of large tractors already popular in the country. While knowledge about smaller machine availability and performance will increase as information and evidence spreads, until then importers, farmers, and potential tractor owners will be unlikely to change their preference for larger machinery.

\section{LACK OF SMALLER ENGINES FOR AGRICULTURAL MACHINERY SUITABLE FOR AFRICAN CONDITIONS}

It is not clear whether smaller engines for agricultural machinery that have been widely adopted in Asian countries are suitable for African conditions. In most areas of Africa that are dependent on rainfall for crop production, the tropical soils are heavy and highly compacted. In many areas of Ghana, we were frequently told that current small-scale tractor engines are not suitable for local conditions because they are not powerful enough for land preparation if soils are very dry before the rains. Additional research and development $(\mathrm{R} \& \mathrm{D})$ investment in designing smaller engines for locally-appropriate equipment appears necessary. For such investments, the social returns are often larger than the private returns to firms, when the technology can be easily copied by other firms. The existence of this potential positive externality may require incentivizing private investment.

\section{LIMITED OPTIONS FOR MULTIPURPOSE TRACTORS}

Plowing is a seasonal activity and while tractor use for plowing reduces the risk associated with delays in land preparation and crop planting, investment in a tractor is unlikely to be profitable for small-scale farmers without using the tractor for other purposes. In fact, the use of tractors can be extended to many functions beyond land preparation, such as using the tractor's engine to power threshing machines or water pumps. This multifunctionality is often an important condition for achieving profitable utilization rates for tractors. The hiring services that can be widely disseminated among many farmers in Asian developing countries are strongly associated with the multifunctionality of tractor use, especially in the early stage of mechanization (Diao et al. 2014). In Bangladesh, for example, it was the removal of import restrictions on small, cheap, diesel engines from China that first led to the rapid development of mechanized small-scale irrigation. When the restrictions on Chinese-made power tillers were lifted later, they were immediately used to power shallow tubewells for irrigation. Researchers argue that the synergy between power 
tillers and irrigation led to the rapid mechanization in Bangladesh (Biggs and Justice 2015).

However, in many parts of Ghana irrigation options are limited by lack of suitable and affordable small-scale irrigation technology and limited knowledge of how to utilize available water resources such as ponds, creeks, and shallow water resources for irrigation. This lack of technology and information significantly restricts opportunities for utilizing a tractor's power. Another common use of tractors is transportation. When Asian countries started to adopt power tillers for land preparation, the machinery was also the lowestcost transport equipment available in rural areas. While farmers in Ghana have started to use tractors as engines for maize threshing machines and occasionally for carting crops from the field, motorized tricycles (both imported and locally assembled) are currently much more popular for transporting goods and people; they also cost less and use less energy than most large tractors. As a result, tractor use is largely limited to plowing. The survey shows that 90 percent of the revenues generated from tractor service provision in Ghana are from plowing services (Houssou et al. 2013). In addition, lack of knowledge of good practices for land preparation in areas without a tradition of animal traction further limits tractor use. Ghanaian farmers often prefer a one-time plowing and are reluctant to pay additional fees for a second plowing or for leveling and harrowing, which are common practices in East African areas with animal traction. The survey shows that only a fraction of tractors was used for second plowing or for harrowing, although the attachments for harrowing are imported by the government at subsidized prices.

\section{Ghana's Agricultural Mechanization Services Enterprise Center (AMSEC) Program}

The existence of market failures leads to the government's concern that supply-side issues may be constraining mechanization uptake, especially among smaller farms. With this in mind, in 2007 the government started to directly engage in the importation and subsidization of tractors and has established about 90 Agricultural Mechanization Services Enterprise Centers (AMSECs) around the country (Diao et al. 2014). While the intention of such a government program is to address market failures, the analysis below indicates that the AMSEC model has not overcome the market failures discussed above; in fact, such state-supported professional hiring services make less efficient use of tractors than do nonsubsidized farmer-to-farmer hiring services (Oluka 2000; Kienzle, Ashburner, and Sims 2013; Takeshima et al. 2015). 


\section{STATE-INFLUENCED TRACTOR IMPORTS}

The main source of funding for AMSEC is through concessional loans received by the government, primarily from various emerging economies such as Brazil, China, and India. Such concessional loan agreements require that Ghana imports tractors from the lending country. Therefore, different loan agreements have brought in different brands of tractors from different countries. In theory, the government does not directly import any tractors, but uses private agents to act on its behalf. However, the government selects the private agents and they have no say over the type of machinery to be imported or ability to negotiate prices, both of which are determined as part of the loan agreements. The import of Farmtrac tractors is a good example of this process and its problems. After receiving a concessional loan for tractor imports in 2007 and 2008 from the Export-Import Bank of India, the government selected a local company as its import agent. The company imported 500 Farmtrac tractors from India in 2007 and 2008, but had no say in the selection of the Farmtrac brand, the tractor models chosen, or the import prices. Expecting their business to continue with the government, the company constructed a large warehouse and built up stocks of spare parts with its own money. However, in 2009 the government entered into a new concessional loan arrangement with the Indian government to import John Deere machinery manufactured in India and a new local company was selected as the government's importing agent. This undercut the company importing Farmtrac tractors; not only could they no longer import subsidized tractors from India, but their own investment in building up a stock of spare parts was devalued. Similar one-time arrangements have been made recently for importing Mahindra tractors from India and other brands from China, Brazil, and other countries.

In discussing the market failures that lead to the lack of small-scale engines for agricultural machinery suitable for African conditions in the previous subsection, we pointed out that additional R\&D investment in designing smaller engines for locally-appropriate equipment appears necessary. The manufacturers in tractor-exporting countries have the best capacity for such R\&D and may be able to develop smaller products and new technology suitable for Ghana. However, such investment will not be attractive if the current brands and models can be easily sold to Ghana through the concessional loan agreements between Ghanaian and donor country governments. In fact, instead of mitigating this market failure, importation under the current concessional loan agreement discourages the incentives for the private sector in donor 
countries to conduct $\mathrm{R} \& \mathrm{D}$ investment, which is necessary for developing affordable and suitable small tractors for Ghana and other countries in Africa.

\section{GOVERNMENT-SELECTED “PRIVATE” ENTITIES AS AMSECS}

In order to avoid direct government management of mechanization services, private agents are selected by the government to own and operate the machinery services centers. The first group of 12 AMSECs was established between 2007-2008 and each center was given a package of seven tractors with basic attachments by the government. The centers paid only 20 percent of the already-subsidized price of the tractors, with the outstanding amount to be paid off over four years without interest. A further 77 AMSECs were established in 2009-2010 through a similar process and under the same financing arrangement. Given that the subsidized tractor prices are well below market prices to begin with, the generous financial arrangements seemingly make AMSECs a lucrative and attractive business and the government has not had any difficulties in attracting applicants. In fact, there have been so many applicants that the government has had to turn most down; however, the criteria for selection are not given. This raises concerns about possible rent-seeking behavior. Obviously, the establishment of the AMSECs through this less than transparent process is not only unlikely to overcome the market failures discussed above, but also risks creating a government failure and distorting the mechanization services market.

\section{DIFFICULTIES WITH THE SPECIALIZED TRACTOR SERVICES}

The AMSECs were designed to provide specialized tractor services to the local market without adequate consideration of whether this is would be profitable. Unfortunately, it turned out that many AMSECs were not profitable and have defaulted on their debt repayments, leaving the government responsible for the repayment of concessional loans.

Houssou et al. (2013a) have demonstrated why tractor hiring alone is not profitable for many AMSECs. Based on subsidized tractor prices, actual operational costs in Ghana, and an assumed 10 percent capital depreciation rate, they calculate that a minimum of 287 ha must be plowed per tractor in order for the net profit from plowing services to be comparable to the interest earnings from a similarly-sized savings deposit in a bank account-a necessary condition for tractor renting to break even. Using survey data, Houssou et al. (2013a) show that few AMSECs plow sufficient acreages to be profitable. An important reason is that the plowing season is too short to enable tractors to plow larger acreages within the localities that each AMSEC serves. The plowing season is as short for the farmers as it is for tractor owners. The low price 
of secondhand tractors owned by farmers is just one reason that they make a potentially profitable investment, but for a medium-scale farmer the total returns to investment include not only preparing their own land, but also revenues earned from providing hiring services.

One way to increase the utilization of tractors is through seasonal migration to different regions with complementary plowing seasons. South Ghana, for example, has two cropping seasons while the north has one; this difference could in theory be exploited by mobile tractor service providers to increase the number of operational days per tractor (Houssou et al. 2013a). In practice, there is little evidence of any of the AMSECs attempting to be regionally mobile, although there is evidence that some private tractor owners are doing so.

Another possible way to make AMSECs more profitable would be for them to diversify beyond plowing and offer a wider range of mechanization services. As discussed above, limited options for using tractors for multiple purposes is also a constraint for the private sector's investment in tractors. The survey by Benin et al. (2012) showed that AMSECs did not do better. In 2010, only 38 of 136 surveyed machinery services firms provided services other than plowing, and even these firms still got 80-90 percent of their revenue from plowing. As discussed, the lack of knowledge of good land preparation practices in areas without a tradition of animal traction limits tractor use. So far there has not been much demand for additional services in Ghana; farmers often prefer one-time plowing and are reluctant to pay additional fees for a second plowing or for leveling and harrowing, which are a common practice in areas of East Africa with animal traction. There is a role for the government to play in addressing this knowledge gap, but AMSECs do not currently seem to have better capacity to do this than individual farmers providing hiring services or private importers, both of whom have more experience in this business. Furthermore, experience in some other countries has shown that demand for mechanized services other than plowing typically develops in parallel with innovation in the design and adaptation of other kinds of tractor implements and machines tailored to the niche needs of specific groups of farmers or localities (Diao et al.2014). This kind of innovation is much more likely to arise in the private sector than with the government-sponsored AMSECs.

\section{Conclusions}

Ghana's farming systems have undergone significant changes in the last 30 years, which have led to a growing demand for mechanization. So far, the 
demand has been primarily for tractor plowing and this need is being met by parallel supply systems: the heavily subsidized, state-interventionist AMSEC program; and a well-developed, private-sector supply chain of importers, machinery service contractors (mostly farmers), and repair and maintenance shops. There are market failures that have led to inadequate supply responses to the demand of small farmers for mechanization. The AMSEC model recently promoted by the government has not overcome such market failures, and does not seem to be viable in its present form. Continuation of the AMSEC program in its present form will only add to the financial burden on the government and possibly foster rent-seeking behavior among government-selected agents who import tractors or run the AMSECs. Rethinking the role of government in facilitating the supply response of mechanization leads to the following policy recommendations:

- Instead of promoting the government-sponsored AMSEC model in Ghana, attention should switch to the private sector-led supply chain, and in this regard, the farmer-to-farmer tractor hiring services merit more assessments to better understand the broad support needed from government for their further development. These recommendations are in line with experiences described in many of the Asian chapters, in which informal-sector, farmer-to-farmer tractor hiring services have been the driving force, rather than government-designed schemes.

- Research and development focusing on affordable and smaller agricultural machinery suitable for Africa's local conditions should be an important component of agricultural technological innovation programs for the government and development partners. The R\&D activities that aim to generate knowledge of the benefits of different types of mechanized technologies can be jointly conducted with researchers from other countries. Regulatory policies in testing, certification, and licensing of different types of machinery need to be revisited to effectively mitigate information asymmetries without substantially raising the costs of machinery.

- Agreements with donor-country governments' concessional loan arrangements should pay more attention to the suitability and affordability of different types of agricultural machinery. Both the Ghanaian government and donor countries' governments can facilitate technological development and knowledge transfer under such agreements and promote smaller-scale engines of agricultural machinery suitable for local conditions. This can be done through collaboration and partnership between technicians, 
engineers, and other experts from donor countries with counterparts in Ghana, including tractor users and importers.

- Reform subsidies by avoiding arbitrary selection of recipients and types of subsidized machinery and increasing transparency to eliminate rentseeking behavior. Several of the Asian chapters described how subsidies have often been less distorting if they are applied to a wide range of equipment regardless of brands, while simultaneously reducing the rates of subsidies has avoided fiscal burden. The effectiveness (or lack thereof) of different modalities of temporary subsidies, including direct subsidies to farmers and interest rates rather than price subsidies, should be thoroughly analyzed.

- Encourage private financial institutions' agricultural machinery lending. Also, within the current land tenure system, experiment with formal land use rights that would allow land to be used as collateral for loans, as described in the Myanmar chapter. Through broad engagements with the private sector on both the demand and supply sides of private financing, explore any practical approach, with necessary government support, and promote the financial market development in agricultural machinery investment.

- Experiment with conservation farming with minimum tillage requirements tailored to local conditions. While there are opportunities for technological leapfrogging in some areas of Ghana, substantial R\&D is needed, from data collection and analysis of detailed soil maps to location-specific recommendations for proper practices.

- Government should encourage engineering departments in universities and polytechnics to provide technical support for design or adaption of more simple machinery suitable for local conditions, as has been done in several Asian countries including India, Sri Lanka, and Thailand. While local fabrication exists in Ghana for simple machines, like other small businesses in the country, these small firms operate on their own without financial or technical support from the government. Government can facilitate collaboration with experts on small agricultural machinery from other developing and developed countries and encourage them to engage in knowledge and suitable technological transfers from abroad to Ghana.

- Low-cost outreach courses for mechanics and tractor owners in rural areas to improve their knowledge of tractors and other machinery and 
repair skills could be considered as part of training programs supported by donors and provided by local or international technical institutes.

\section{References}

Abdulai, A., and W. Huffman. 2000. "Structural Adjustment and Economic Efficiency of Rice Rarmers in Northern Ghana." Economic Development and Cultural Change 48 (3): 503-520.

Akinola, A. 1987. "Government Tractor Hire Service Scheme as a Tractorization Policy in Africa: The Nigerian Experience." Agricultural Administration and Extension 25 (2): 63-71.

Akoto, O. A. 1987. “Agricultural Development Policy in Ghana." Food Policy 12 (3): 243-254.

Alam, M., and M. Khan. 2008. "Manufacturing of Agricultural Machinery in Bangladesh: Opportunities and Constraints." In Proceedings of the Regional Workshop on Farm Mechanization for Small Holder Agriculture in SAARC Countries. Bhopal, India: South Asian Association for Regional Cooperation.

Amanor, K. S. 2011. "From Farmer Participation to Pro-Poor Seed Markets: The Political Economy of Commercial Cereal Seed Networks in Ghana." IDS Bulletin 42 (4): 48-58.

Aryeetey, E., and W. Baah-Boateng. 2007. Growth, Investment and Employment in Ghana. Working Paper 80. Geneva: Policy Integration Department, International Labor Office.

Benin, S. 2013. Impact of Ghana's Agricultural Mechanization Services Center Program. IFPRI Discussion Paper 01330. Washington, DC: International Food Policy Research Institute.

Benin, S., M. Johnson, K. Jimah, J. Taabazuing, A. Tenga, E. Abokyi, G. Nasser, G. Ahorbo, and V. Owuusu. 2012. "Evaluation of Four Special Initiatives of the Ministry of Food and Agriculture." Draft Report. Washington, DC: International Food Policy Research Institute.

Biggs, S., and S. Justice. 2015. Rural and Agricultural Mechanization: A History of the Spread of Small Engines in Selected Asian Countries. IFPRI Discussion Paper 01443.

Binswanger, H. P. 2017. “Agricultural Mechanization in Sub-Saharan Africa: A Review.” Draft Paper for Accelerating African Poverty Reduction. Mimeo.

Binswanger, H. P., and G. Donovan. 1987. Agricultural Mechanization: Issues and Options. Washington, DC: World Bank.

Binswanger, H. P., and V. W. Ruttan. 1978. Induced Innovations. Baltimore and London: Johns Hopkins University Press.

CEPS. 2012. Ghana Import Data. Accra, Ghana: Customs, Excise and Preventive Services. 
Chapoto, A., N. Houssou, A. Mabiso, and F. Cossar. 2014. Medium and Large-Scale Farmers and Agricultural Mechanization in Ghana: Survey Results. Accra, Ghana: Ghana Strategy Support Program of the International Food Policy Research Institute and Savanna Agricultural Research Institute.

Cossar, F. 2015. Are Boserupian Explanations of Mechanization Use Adequate to Explain the Local Concentration of Agricultural Mechanization in Ghana? Washington, DC: International Food Policy Research Institute.

Diao, X., F. Cossar, N. Houssou, and S. Kolavalli. 2014. "Mechanization in Ghana: Emerging Demand and the Search for Alternative Supply Models." Food Policy 48: 168-181.

Girdner, J., V. Olorunsola, M. Froning, and E. Hansen. 1980. “Ghana’s Agricultural Food Policy: Operation Feed Yourself." Food Policy 5(1): 14-25.

GSS. 2014. Ghana Living Standards Survey Data (Rounds 2-6). Ghana Statistical Service, Accra, Ghana.

_. 2016. 2015 Labor Force Survey Report. Accra, Ghana: Ghana Statistical Service.

Hayami, Y., and V. Ruttan. 1970. "Factor Prices and Technical Change in Agricultural

Development: The United States and Japan.” Journal of Political Economy 78(5): 1115-1141.

— 1985. Agricultural Development: An International Perspective. Baltimore: Johns Hopkins University Press.

Houssou, N., C. Asante-Addo, X. Diao, and S. Kolavalli. 2015. Big Tractors but Small Farms: Tractor Hiring Services as a Farmer-Owner's Response to an Under-Developed Agricultural Machinery Market. Ghana Strategy Support Program Working Paper 39. Washington, DC: International Food Policy Research Institute.

Houssou, N., X. Diao, F. Cossar, S. Kolavalli, K. Jimah, and P. Aboagye. 2013a. “Agricultural Mechanization in Ghana: Is Specialization in Agricultural Mechanization a Viable Business Model?" American Journal of Agricultural Economics 95 (5): 1237-1244.

Houssou, N., X. Diao, and S. Kolavalli. 2014a. Economics of Tractor Ownership under Rainfed Agriculture with Applications in Ghana. IFPRI Discussion Paper 01387. Washington, DC: International Food Policy Research Institute.

-2014b. Can the Private Sector Lead Agricultural Mechanization in Ghana? Ghana Strategy Support Program Policy Note 4. Washington, DC: International Food Policy Research Institute.

Houssou, N., S. Kolavalli, E. Bobobee, and V. Owusu. 2013b. Animal Traction in Ghana. Ghana Strategy Support Program Working Paper 34. Washington, DC: International Food Policy Research Institute. 
Jayne, T. S., J. Chamberlin, L. Traub, N. Sitko, M. Muyanga, F. Yeboah, W. Anseeuw, A. Chapoto, A. Wineman, C. Nkonde, and R. Kachule. 2016. “Africa’s Changing Farm Size Distribution Patterns: The Rise of Medium-Scale Farms." Agricultural Economics 47 (S1): 197-214.

Kienzle, J., J. E. Ashburner, and B. G. Sims. 2013. Mechanization for Rural Development: A Review of Patterns Progress from around the World. Rome: Food and Agriculture Organization of the United Nations.

Nin-Pratt, A., and L. McBride. 2014. "Agricultural Intensification in Ghana: Evaluating the Optimist's Case for a Green Revolution.” Food Policy 48: 153-167.

Okolie, A. C. 2003. "Development Hegemony and the Development Crisis in Africa: The Importance of Indigenous Knowledges and Practices in the Making of Food Policy." The Journal of African American History 88 (4): 429-448.

Oluka, S. 2000. "Costs of Tractor Ownership under Different Management Systems in Nigeria." Nigerian Journal of Technology 19: 15-28.

Pingali, P., Y. Bigot, and H. Binswanger. 1987. Agricultural Mechanization and the Evolution of Farming Systems in Sub-Saharan Africa. Baltimore: Johns Hopkins University Press.

Ruthenburg, H. 1980. Farming Systems in the Tropics. Oxford, UK: Oxford University Press.

Seager, P., and R. Fieldson. 1984. Public Tractor Hire and Equipment Hire Schemes in Developing Countries (with Special Emphasis on Africa). Research Unit Report No. ARU 30. Washington, DC: Agriculture and Rural Development Department, World Bank.

Stryker, J. D., E. Dumeau, J. Wohl, P. Haymond, A. Cook, and K. Coon. 1990. Trade, Exchange Rate, and Agricultural Pricing Policies in Ghana. Washington, DC: World Bank.

Takeshima, H., H. Edeh, A. Lawal, and M. Isiaka. 2015. Characteristics of Private-Sector Tractor Service Provisions: Insights from Nigeria. Developing Economies 53 (3): 188-217.

Takeshima, H., K. Jimah, S. Kolavalli, X. Diao, and R. L. Funk. 2013. Dynamics of Transformation: Insights from an Exploratory Review of Rice Farming in the Kpong Irrigation Project. IFPRI Discussion Paper 01272. Washington, DC: International Food Policy Research Institute.

USAID/ACDI-VOCA. 2013. ADVANCE Tractor Census of Northern Ghana.

World Bank. 2014. Agribusiness Indicators: Synthesis Report. Agriculture Global Practice Discussion Paper 01. Washington, DC: World Bank Group.

Yang, J., Z. Huang, X. Zhang, and T. Reardon. 2013. “The Rapid Rise of Cross-Regional Agricultural Mechanization Services in China." American Journal of Agricultural Economics 95(5): 1245-1251. 


\title{
EVOLUTION OF AGRICULTURAL MECHANIZATION IN KENYA
}

Hugo De Groote, Cliff Marangu, and Zachary M. Gitonga

\begin{abstract}
Agricultural intensification is key to feed the rapidly increasing African population. Although the use of improved varieties has increased substantially over the last 20 years, the use of land- and labor-saving technologies, such as mechanization, has lagged behind. This study reviews existing literature and uses four household surveys conducted between 1992 and 2012 to analyze the evolution of agricultural mechanization in Kenya. The results show persistently low levels of mechanization in Kenya; in 2012, most farm households still used only hand tools. More than a quarter of farmers ( 28 percent) had a plow, but very few (2 percent) had a tractor. From 1992 to 2012, the percentage of farmers with oxen increased from 17 percent to 33 percent, but those with tractors decreased from 5 percent to 2 percent. Tractors were most important in the highlands, whereas animal traction was most important in the dry areas and moist mid-altitude zone. Adoption of tractors increased with income, acreage, and age. Adoption of animal traction increased with absentee husbands, age, sales of maize, livestock, family size, and access to extension; it decreased with land, fertilizer use, and income. Mechanization in Kenya is likely to continue to depend on animal traction, which is not linked to farm size, complements labor, helps to reduce fertilizer use, increases commercial maize production, and has room to growparticularly in the highlands. Agricultural extension, development projects, and research should consider the opportunities in animal traction and provide training and research on appropriate technologies in areas with sufficient land area.
\end{abstract}

\section{Introduction}

Despite recent economic growth in Africa, poverty levels in the continent remain alarmingly high, especially in rural areas. Most people still live and depend on rural land, while the population, along with demand for food and fuel, is increasing fast. To feed this rapidly growing population and avoid deforestation and land degradation from the new pressures on land, agricultural intensification is urgently needed. 
Other continents have experienced a Green Revolution of dramatic increases in agricultural production and reduction in food prices (Evenson and Gollin 2003), driven by technology and structural transformation; but this has not happened in Africa. Whereas the use of improved varieties has increased substantially, the use of other land-saving technologies (such as fertilizers and irrigation) and labor-saving technologies (mechanization) remains limited. Development and agricultural economists are struggling to explain what is restraining the Green Revolution in Africa. It is therefore important to study the processes of agricultural intensification in Africa. Although many studies have covered the adoption of improved varieties and fertilizer (Doss 2006; Jayne et al. 2003; Smale and Jayne 2003), recent studies on agricultural mechanization in Africa are lacking.

The topic of agricultural mechanization drew attention in the 1980 s, when several influential studies argued that African countries were not yet ready for widespread agricultural mechanization (Binswanger 1986; Pingali, Bigot, and Binswanger 1987). Since then, the topic has not received much interest, though animal traction in West Africa's cotton belt spread quickly during the $1980 \mathrm{~s}$ and 1990s (Tefft 2010). More recently, the Food and Agriculture Organization of the United Nations has been trying to revive interest in agricultural mechanization (FAO and UNIDO 2008). Recent studies in Ghana did not provide support for the classic government-run program of tractor services provision (Diao et al. 2014; Houssou et al. 2013). In Burkina Faso, however, animal traction was shown to increase both labor productivity and land productivity (Savadogo, Reardon, and Pietola 1998). As an alternative to expensive tractors, some have also argued for the use of small, multipurpose, inexpensive power sources such as two-wheel tractors (2WTs) (Baudron et al. 2015).

To add to the discussion on the role of agricultural mechanization in the intensification of agricultural production in Africa, this study provides a review of the relevant literature. This is followed by a quantitative analysis of the evolution of farm mechanization in Kenya over a recent 20-year period, based on four consecutive representative household surveys covering the major agricultural zones of the country.

\section{Background}

\section{History of Mechanization in Kenya}

The demand for farming system intensification, and potential demand for mechanization, started rising in Kenya in a few pockets of areas favorable for 
intensification. It has been argued that an increasing population and greater food demand motivate an increase in effective mechanization, in particular with regard to draft animals in areas where tractors are not appropriate or have failed (O'Neill and Kemp 1989). Migration to more favorable areas leads to more intensive production with a shorter fallow period. An example is Nyanza province, described as early as the 1940s (Humphrey 1947). Similarly, immigration occurred into the high altitudes, which had historically enjoyed a better climate and lower incidence of disease (including malaria and sleeping sickness), such as the North Kavirondo district (Wagner 1949) and the Kikuyu highlands (Humphrey 1945). Mechanization was more substantially stimulated by such farming intensification than by other factors. For example, the spread of the plow from settlers to smallholders had been a relatively minor channel of diffusion, because such transfers had often been inhibited by a number of discriminatory practices (Pingali, Bigot, and Binswanger 1987).

Infrastructure development also led to farming system intensification and increased use of more modern mechanization methods. Intensive production of maize in more fertile parts of Kenya was directly induced by the railways built by the colonial government, and commercial production of maize along the railways has been concentrated in the areas with high potential for production (Pingali, Bigot, and Binswanger 1987). Favorable areas with a good railway network, such as Nyanza province, started seeing the use of animal-drawn moldboard plows as early as the 1920s and the 1930s, for the production of maize and cotton (Pingali, Bigot, and Binswanger 1987). ${ }^{1}$

By the mid-1980s, the use of mechanization (motorized transport) had spread gradually for various transport operations in areas including most of the highlands, Embu and Machakos districts, and areas around Nairobi; it had also spread, though to a lesser extent, for plowing activities in areas including Embu and Machakos districts (Pingali, Bigot, and Binswanger 1987). In these areas, the use of animal-drawn plows had also started spreading by the mid1980s. Also by that time, private-sector contract-hire operations with tractors

1 The use of animal traction in Africa started around $6000 \mathrm{BCE}$, as shown in depictions of oxen and plows in Egyptian and early Mesopotamian civilizations, some of the earliest records in the world. In North Africa and Ethiopia, animal traction has been a core part of farming and transportation for over 2,000 years. In South Africa, European travelers observed the KhoiKhoi riding cattle and used them as pack animals in the 15th century (Joubert 1995). In West Africa, the use of horses, donkeys, and camels for riding and as pack animals has been popular for centuries, especially in sem-iarid areas (Starkey 2000). However, in many eastern and southern African regions, including many parts of Kenya, manual labor is still the main source of power in agriculture and draft animals are a relatively recent introduction (Lawrence and Pearson 2002). 
had also been observed in various locations within Kenya, including Nakuru and Narok districts (Pingali, Bigot, and Binswanger 1987).

Animal power has the potential to enhance a farmer's ability to adopt and use renewable practices such as animal manure, crop rotation, and ridging. It allows the cultivation of larger areas, increases household production and food security, and enhances the likelihood of a marketable surplus (BishopSambrook 2005). In the late 1990s, it was estimated that 65 percent of the cultivated area in Africa south of the Sahara (SSA) was prepared by hand, 25 percent by draft animals, and 10 percent by tractors (FAO and UNIDO 2008). In Kenya, the main draft animals are oxen and donkeys, which are well distributed throughout the country. The use of animal traction had also benefited from the breeding of larger cattle with greater tractive power. Kenya was one of the successful examples of such activities, where the use of breeding activities originally aimed at producing suitable beef and dairy cattle had been applied to breeding cattle for tractive purposes (Jaetzold and Schmidt 1982).

Tractors were introduced in Kenya shortly after World War II, and in the two decades following the nation's 1963 independence, the government promoted motorized mechanization to smallholders through state-sponsored tractor hiring and tractor credit schemes, with the aim of increasing the production of crops (Guthiga, Karugia, and Nyikal 2007). The adoption of tractors in SSA went through various phases between 1945 and 1981, each phase being significant in increasing the number of tractors in use (Pingali 2007). Kenya was among the first generation of tractor users in SSA, with the introduction of a substantial number of tractors in 1945-1955, and adoption spread from settler farmers to farms owned by native Africans. In early years, tractors were used in public irrigation schemes such as the Mwea Irrigation Settlement Scheme, where tractor hiring through leasing companies started in 1960 (Pingali, Bigot, and Binswanger 1987, Table 5.6).

In 1966/1967, government tractor hiring service was initiated in Kenya when 50 tractors were introduced to provide cultivation services, primarily for areas under the Masai Wheat Scheme (Pingali, Bigot, and Binswanger 1987). Although these 50 tractors achieved about 770 productive hours per machine in $1967 / 1968$, and remained relatively productive in early years, once the total number of tractors increased to 150 in 1980, the number of productive hours per tractor decreased substantially, to 167 a year in 1980 (Pingali, Bigot, and Binswanger 1987), which was considerably lower than the rate of about 1,000 hours recorded in the private sector in Kenya in 1981 (Seager and Fieldson 1984). Whereas such low performance of public-sector hiring services was similar to the experience of other African countries, in the case of Kenya, the 
public-sector hiring service operations were also restricted to their respective jurisdictions and not allowed to operate outside them. Similar to many other SSA countries, Kenya saw a decline in mechanization in the 1980s, especially in the use of tractors and tractor hiring services for farming (Pingali 2007). In Kenya, similar to other SSA countries, most farmers could not individually afford tractors, and the organization of cooperatives or farmer groups to access credit and obtain tractors was rare (Lamidi and Akande 2013).

Large-scale farming, in contrast to small-scale farming, has seen higher levels of mechanization at all stages of production. For example, irrigation schemes for sugarcane production in Kenya, similar to those in Sudan and Tanzania, have been highly mechanized. The major mechanized operations include land preparation, cane loading, and cane transport to the factory (Kienzle, Ashburner, and Sims 2013). Another example is large-scale wheat farming in Kenya, which uses tractors for cultivation and planting, spraying equipment, and combine harvesters; most of this machinery is owned rather than hired (Longmire and Lugogo 1989). However, these types of farmers have remained small in terms of share in Kenya.

After the collapse of tractor projects, attention was given to draft animal power as a more sustainable option. In Kenya, a program to support draft animal power was established in 1970, covering the selection and training of draft animals, the development of the collar harnesses and oxen yokes, farmer training, and development of specialized equipment (Onyango 1988). These efforts have produced mixed results. For maize production, the promotion of mechanization projects saw a relative success in Kenya, but to a limited extent compared with other countries in East Africa, such as Tanzania (Anthony 1988).

\section{Recommendations from the Literature}

This literature review indicates that both the government and the private sector have clear, but distinct, roles to play in sustainable mechanization. The role of government lies in education and training; in the creation, funding, and management of institutions responsible for the research; and in the distribution of information on agricultural mechanization. The government should also facilitate trade relationships with new suppliers of technology or equipment and help in maintaining standards (FAO and UNIDO 2008).

The private sector, on the other hand, is better equipped to look after the day-to-day provision of farm inputs, including farm machinery and the associated support services. In the developed world, once economic conditions produced effective demand for machinery, private firms were able to respond rapidly (Binswanger 1986). Decisions on the operations to be performed, 
prices to be charged, and so on, are better made by individual contractors, rather than by the government. The private sector has clear incentives for the mechanization of agriculture-more mechanization implies a higher demand for their services and higher revenues (Pingali, Bigot, and Binswanger 1987). Governments, as in Ghana, can impede this progress by crowding out or otherwise preventing private-sector importation of appropriate and affordable machinery for use in hiring services (Diao et al. 2014).

The economic costs of using tractors, animals, or human labor are determined by the relative costs of labor and capital, the interest rate, capacity utilization, farm size, the availability of fodder, the comparative maintenance costs of animals and tractors, and the difficulty of obtaining spare parts, fuel, and repair services for the tractors, or veterinary services for the animals (Pingali, Bigot, and Binswanger 1987). Therefore, the farmers must calculate and compare the costs and benefits of alternative options and find those best suited to their needs. However, draft animal power, tractor power, and human power should be taken as complementary sources of power for agriculture production and not as mutually exclusive. In Burkina Faso, for example, nonfarm income was a major factor that allowed farmers to invest in animal traction (Savadogo, Reardon, and Pietola 1998).

The development and modernization of Africa's agriculture will depend to a large extent on the transformation of agricultural policies. Agricultural mechanization policy ought to be seen within the context of an overall agricultural growth strategy (Pingali 2007). It is imperative for African leaders and policymakers to understand the importance of mechanization for Africa's future. There should be concerted efforts by all stakeholders to accelerate the rate of mechanization adoption by farmers in SSA, whether through draft animals or tractors. These efforts to accelerate mechanization will require substantial long-term political and financial commitments, which ought to address the critical problems in the agriculture sector and help to improve the prospects for African agriculture and farmers (Mrema, Baker, and Kahan 2008). In the meantime, it is important to look at available information to guide policies, as we do in the next section.

\section{Methods}

\section{Conceptual Framework}

Intensification of agriculture is generally driven by an increasing population, which requires communities to produce increasing amounts of food on a fixed 
land area (Boserup 1965). Technology development tends to follow the direction of the scarcest resources, a process called induced innovation (Ruttan and Hayami 1984). Mechanization, the replacement of human labor by machinery, therefore tends to occur where land is abundant or labor is scarce, as in many settler communities such as North America or in large-scale settler farms such as those in eastern and southern Africa in the first half of the 20th century. However, when the population grows rapidly, as is the current case in Africa, land becomes scarce and labor becomes abundant. These conditions are likely to remain until there is a structural transformation in the form of movement of large groups from rural to urban areas, driven by economic development and the creation of job opportunities in cities. Only when rural labor moves to the cities, and the economy is sufficiently strong to absorb them and pay increasing wages, will labor become scarce in rural areas.

Animal traction has some benefits other than replacing labor: draft animals provide manure to replace expensive mineral fertilizer, and they provide transport of inputs and produce within the farm as well as to and from local market centers. It reduces drudgery and offers an increase in agricultural production above family needs.

\section{Empirical Framework}

In this chapter, we take advantage of household survey data available from four surveys conducted over a recent 20-year period to analyze agricultural mechanization in Kenya. We first examine the use of farm implements by rural households in the most recent survey (2012) and the geographical distribution of the different technologies. Because different surveys used different questions and variables, it was not easy to pool the data. We therefore limit the analysis of the evolution of mechanization by charting the proportion of farmers who over the years have adopted tractors, plows, and oxen, and the distribution of adoption patterns over different agroecological zones. Finally, we use the most recent survey to run a logistic regression analyzing the factors that affect the adoption of these three factors. We hypothesize that characteristics of the household head (including age, education, and gender) and of the household itself (including available land, labor, and livestock), as well as access to the markets and rural services (including agricultural extension and microcredit) all play a role in adoption.

\section{Data Sources}

The data were collected during rural household surveys conducted in Kenya over a recent 20-year period-1992, 2002, 2010, and 2012 (De Groote, 
Marangu, and Gitonga 2018). The first three surveys were cross-sections, whereas for the last survey the households from the 2010 round were revisited, with a rotation of 20 percent of the sample. Each survey was representative of all major maize-growing areas of the country, where most rural households are located, and each used a stratified two-stage design, with agroecological zones as strata, sublocations as primary sampling units, and households as the second stage. Each survey covered more than 1,300 households (Figure 12.1, Table 12.1).

The first survey was conducted in 1992 by the International Maize and Wheat Improvement Center and the Kenya Agricultural Research Institute in the major agroecological zones of Kenya (Hassan, Lynam, and Okoth 1998). This study redefined these zones into six major agroecological zones for maize production (Figure 12.1). From the coast inland, we encounter the lowland tropics, followed by the dry mid-altitude and the dry transitional zones. These three zones are characterized by low yields, less than 1.5 tons $^{2}$ per hectare.

Although these zones cover 29 percent of Kenya's maize area, their maize production is just 11 percent of the country's total production. Central and western Kenya are dominated by the highland tropics, which are bordered at the west and east by the moist transitional zone that is transitional between the mid-altitude zone and the highlands. These zones have high yields (more than 2.5 tons per hectare) and produce 80 percent of Kenya's maize on 30 percent of Kenya's maize area.

The first survey was conducted in 1992 and covered 79 clusters, selected from the sampling frame of the Central Bureau of Statistics, and 1,407 farmers (Hassan, Lynam, and Okoth 1998). The second survey covered 185 sublocations, randomly selected from the 1999 census report (Kenya, CBS 2001), and 1,800 farmers (Table 12.1). The third survey was conducted in 2010; it covered 120 sublocations in the first stage, and 1,344 farmers in total. The fourth survey, conducted in 2012, revisited the same sublocations of the 2010 survey and visited the same households, except for a randomly selected replacement of 20 percent of the households. This survey therefore had the same number of sublocations (120) and the same number of households $(1,344)$ as the previous survey.

2 "Tons" refers to metric tons throughout the chapter. 
FIGURE 12.1 Map with primary sampling units of different surveys, Kenya, 1992-2012

$\square$ Survey sites 1992

- Survey sites 2001

$\triangle$ Survey sites 2010 and 2012

\section{Agroecological zones}

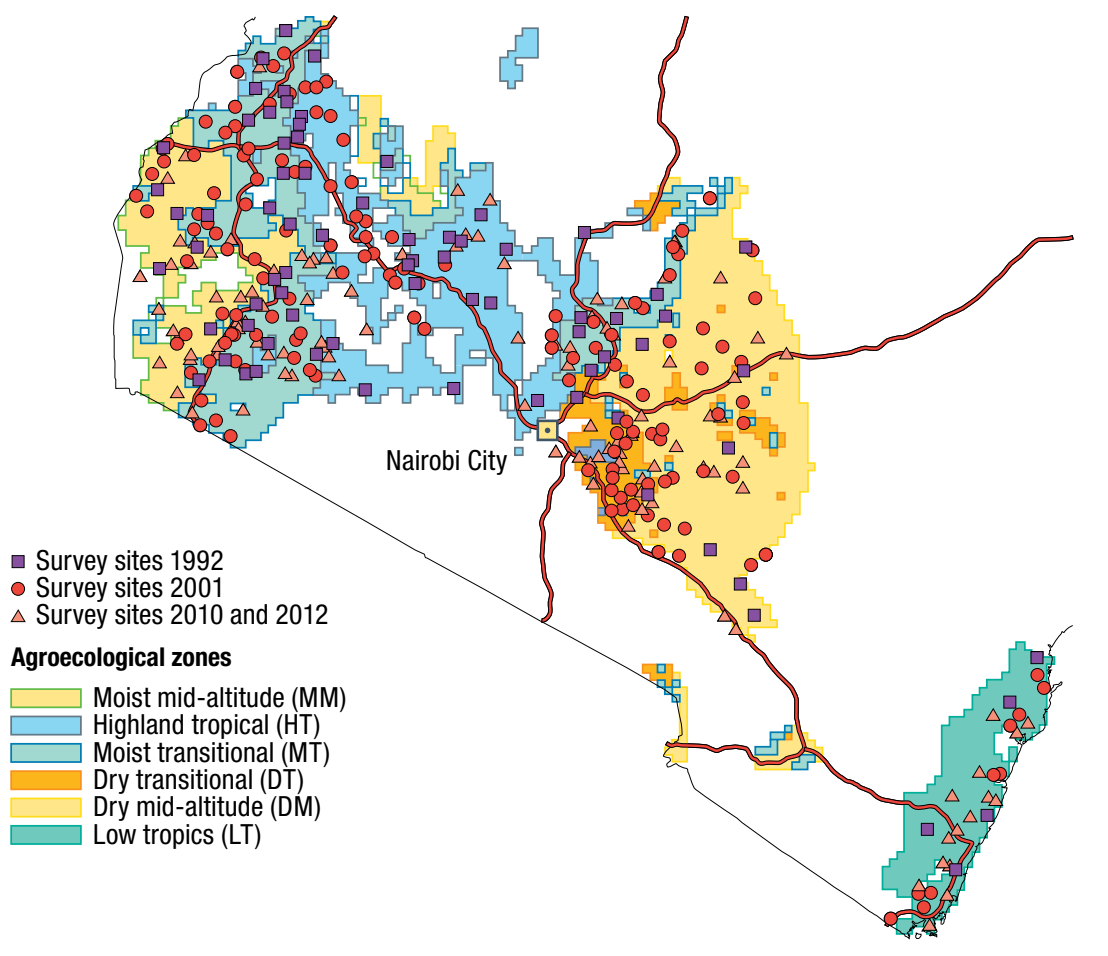

Source: De Groote, Marangu, and Gitonga (2018).

TABLE 12.1 Sampling design of the four surveys, Kenya, 1992-2012

\begin{tabular}{|c|c|c|c|c|c|c|c|c|c|c|c|c|}
\hline \multirow[b]{2}{*}{$\begin{array}{l}\text { Agroecological } \\
\text { zone }\end{array}$} & \multicolumn{3}{|c|}{1992} & \multicolumn{3}{|c|}{2002} & \multicolumn{3}{|c|}{2010} & \multicolumn{3}{|c|}{2012} \\
\hline & PSUs & $\begin{array}{l}\text { HHs } \\
\text { /PSU }\end{array}$ & HHs & PSUs & $\begin{array}{l}\text { HHs } \\
\text { /PSU }\end{array}$ & HHs & PSUs & $\begin{array}{l}\text { HHs } \\
\text { /PSU }\end{array}$ & $\mathrm{HHs}$ & PSUs & $\begin{array}{l}\text { HHs } \\
\text { /PSU }\end{array}$ & HHs \\
\hline Low tropics & 5 & 20 & 100 & 20 & 15 & 300 & 15 & 6 & 90 & 15 & 6 & 90 \\
\hline Dry mid-altitude & 10 & 18 & 181 & 25 & 8 & 200 & 18 & 12 & 217 & 18 & 12 & 216 \\
\hline Dry transitional & 4 & 20 & 80 & 20 & 5 & 100 & 17 & 12 & 203 & 17 & 12 & 204 \\
\hline Moist mid-altitude & 9 & 20 & 183 & 25 & 10 & 250 & 20 & 12 & 240 & 20 & 12 & 240 \\
\hline Moist transitional & 23 & 18 & 412 & 55 & 10 & 550 & 30 & 12 & 354 & 30 & 12 & 354 \\
\hline High tropics & 28 & 16 & 451 & 40 & 10 & 400 & 20 & 12 & 240 & 20 & 12 & 240 \\
\hline Total & 79 & n.a. & 1,407 & 185 & n.a. & 1,800 & 120 & n.a. & 1,344 & 120 & n.a. & 1,344 \\
\hline
\end{tabular}

Source: De Groote, Marangu, and Gitonga (2018).

Note: $\mathrm{HH}=$ number of households in the survey; n.a. = not applicable; PSU = primary sampling unit (clusters in 1992, sublocations in the other years). 


\section{Survey Results}

\section{Farm Implements Used}

The proportion of farmers who used different implements in 2012 reveals the very limited extent of agricultural mechanization in Kenya (Figure 12.2). The majority of farm implements used were hand tools, and most households owned at least some pangas (machetes), hoes, axes, spades, or shovels. More than half of the households owned a fork hoe or a slasher. The most popular mechanical device was the bicycle, owned by slightly less than half of the households ( 48 percent). The most popular modern farm implements were the backpack sprayer (owned by 46 percent of respondents) and the wheelbarrow ( 45 percent). As for mechanization, more than a quarter of farmers owned an ox plow (28 percent), but few had an oxen or donkey cart ( 8 percent), and even fewer had a push cart $(2$ percent). Tractors were rare, with only 2 percent of farmers in the survey owning them.

Devices to generate electricity were more popular than tractors-17 percent of respondents had solar panels and 6 percent had a generator. For transport, apart from the bicycle, only a few farmers owned vehicles and a few households had a motorbike (10 percent) or a car (5 percent).

\section{Evolution of Agricultural Mechanization}

Plotting the evolution of agricultural mechanization in Kenya over the last 20 years shows that levels of adoption have been consistently low (Figure 12.3). Oxen were introduced in the early 20th century by European and South African settlers, who switched to the use of tractors when these became available. After independence, the large settler farms and their equipment were purchased by African farmers and the upcoming elite. However, these farmers never had many tractors, and the proportion of farms with tractors is decreasing. In 1992, only 4 percent of respondents to the survey owned tractors, and in 2012 it was less than 2 percent.

During this same study period, however, there were many more farmers with plows than with tractors, indicating the relative importance of animal traction. The proportion of farmers who own plows steadily increased over the study period, from 12 percent to 28 percent. Similarly, the proportion of farmers owning oxen steadily increased, from 17 percent to 33 percent, over the 20 -year period. There was a dip in oxen ownership in the 2010 survey, likely because of a serious drought just before the year of the survey.

Plotting the results separately for each year and by zone shows the large differences in mechanization levels, both for tractors and animal traction, 
FIGURE 12.2 Farm implements used, by agroecological zone, farm households, Kenya, 2014

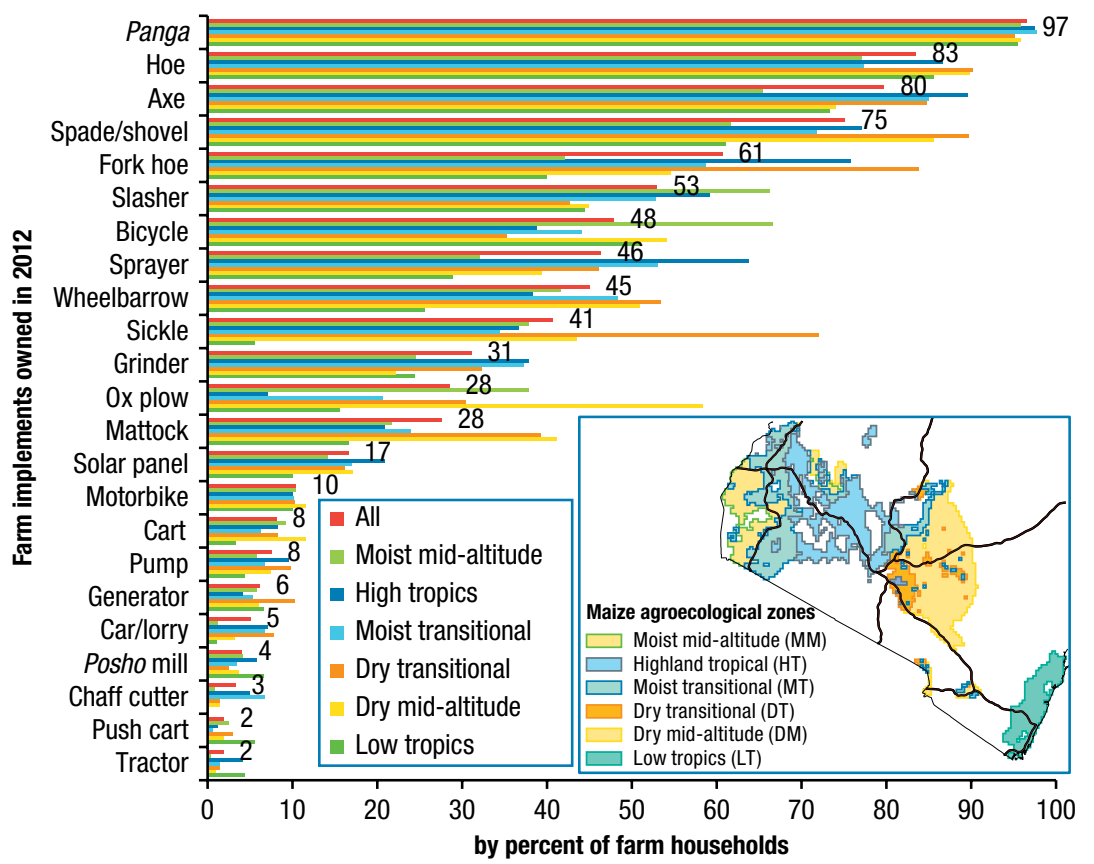

Source: De Groote, Marangu, and Gitonga (2018).

Note: A panga is a machete; posho is maize flour.

between the agroecological zones in Kenya (Figure 12.4). The results show that the relative importance of tractors and animal traction over the different zones has not changed over the years. Tractors have always been most important in the highlands, whereas oxen and oxen plows were most popular in the dry mid-altitude zones, followed by the moist mid-altitude zones. Most tractors were found in the highlands, with only a few in other zones. Only in the last survey did tractors show up in the coastal lowlands. Likely, the presence of tractors in the highlands is influenced by colonial history, which favored largescale, capital-intensive, commercial farming.

Ownership of plows is, understandably, strongly correlated with ownership of oxen. Especially in the dry zones, many farmers have oxen and plows. The popularity of oxen in the dry areas likely is affected by the lower population density, because farms have larger land areas for both farming and pasture, and they have more cattle from which to draw oxen. Similarly, farmers in the moist mid-altitude zones tend to have more cattle, a fact that has likely 
FIGURE 12.3 Evolution of farm mechanization in Kenya from 1992 to 2012

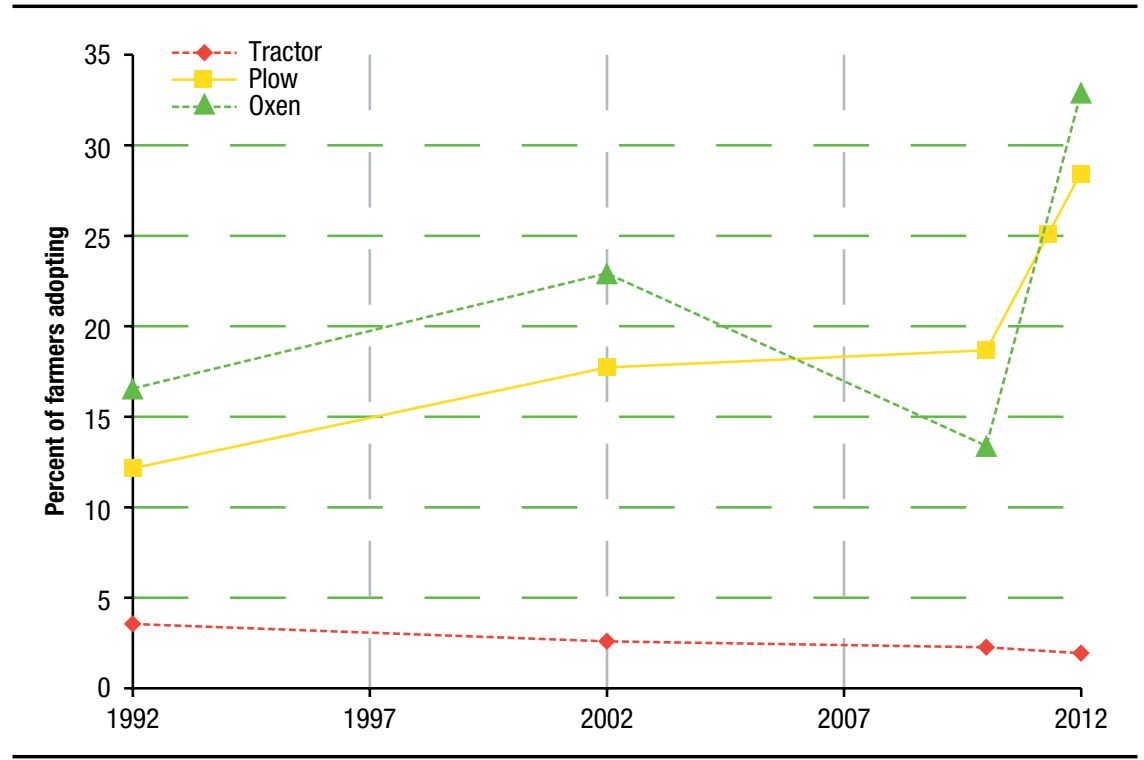

Source: De Groote, Marangu, and Gitonga (2018).

affected the adoption rates for animal traction. The high tropics, on the other hand, have the lowest levels of animal traction, despite the zone's high potential and large available land areas. This might be affected by the historic preference for tractors in the zone and the resulting presence of tractors for hire. The highlands tend to have only one long rainy season, so plowing is needed only once per year, as compared with the other zones, which tend to have two rainy seasons and therefore need to prepare land and plow twice per year.

The analysis further shows that few people have carts, either for donkeys or oxen-the rate of ownership is just 12 percent in the dry mid-altitude zones and less than 10 percent in all other zones. The proportion of farmers with carts does not seem to have increased much over the years.

Plotting the evolution of the use of different implements in each zone shows the similarity of the trajectories across the different zones (Figure 12.5). With few exceptions, the proportion of farmers who own tractors has been declining, whereas the number of oxen and plows is increasing. One exception is the coast, where several farmers obtained tractors between 2010 and 2012. Another exception is the reduction in the proportion of farmers with oxen or plows in the dry transitional zone; there was a strong increase in 2001, followed by a decrease in 2010, and then finally an increase leading up to 2012 . 
FIGURE 12.4 Evolution of farm mechanization in Kenya from 1992 to 2012, by agroecological zone and year
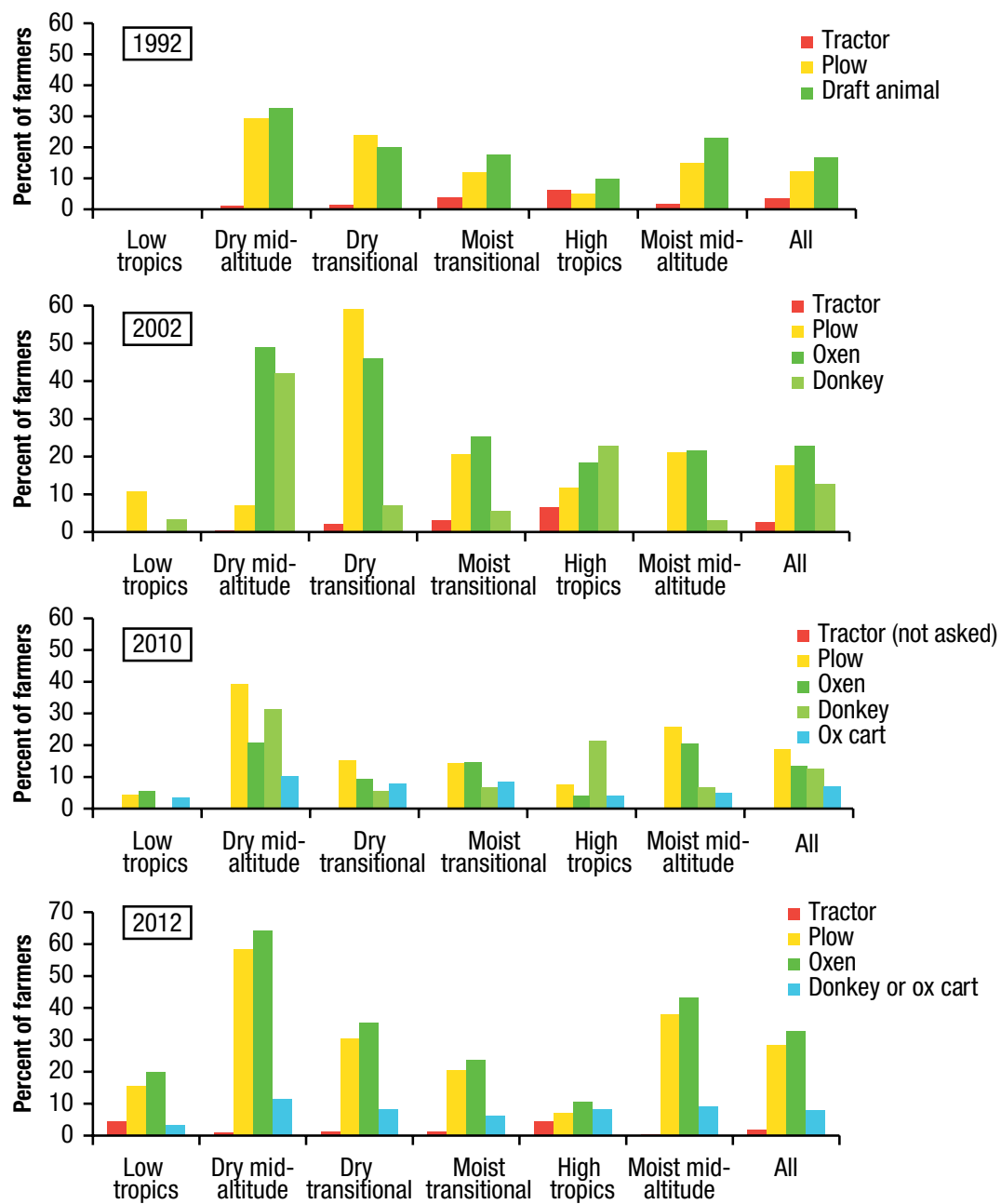

Source: De Groote, Marangu, and Gitonga (2018). 
FIGURE 12.5 Evolution of farm mechanization in Kenya from 1992 to 2012, by year and by agroecological zone

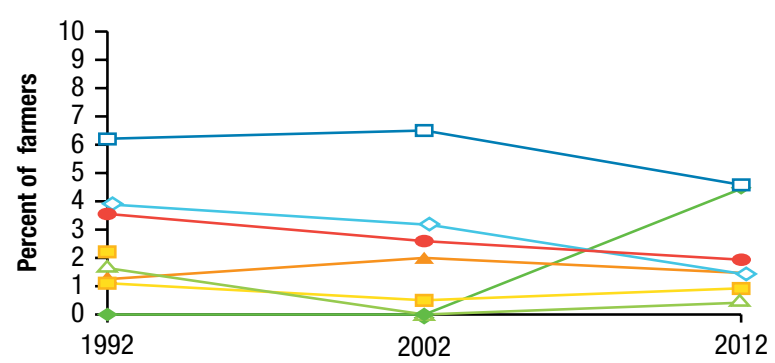

\section{Tractors}

$\rightarrow$ Low tropics

Dry mid-altitudes

Dry transitional

Moist transitional

$-\square-$ High tropics

$\triangle$ Moist mid-altitudes

- All

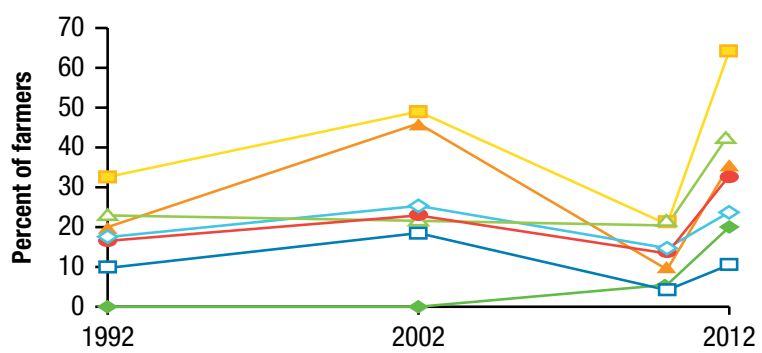

\section{Oxen}

$\checkmark$ Low tropics

- Dry mid-altitudes

- Dry transitional

$\prec$ Moist transitional

$-\square-$ High tropics

$\triangle-$ Moist mid-altitudes

$\because$ All

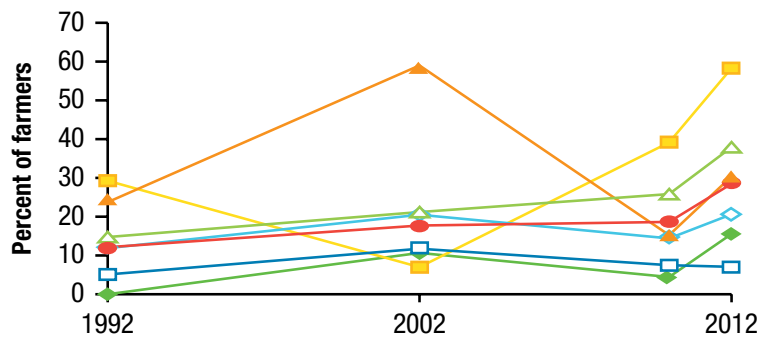

\section{Plows}

$\sim$ Low tropics

Dry mid-altitudes

Dry transitional

Moist transitional

High tropics

Moist mid-altitudes

All

Source: De Groote, Marangu, and Gitonga (2018).

\section{Factors Affecting the Adoption of Farm Mechanization}

A logistic model was estimated to analyze the factors affecting the adoption of agricultural mechanization. Three different dependent variables were used for the analysis - the adoption of tractors, of trained oxen, and of plows, all expressed as binary variables (yes $=1$, no $=0$ ).

Specifically, the following model is estimated:

$$
y_{i}=\left\{\begin{array}{l}
1 \text { with probability } \mathrm{P}_{i} \\
0 \text { with probability } 1-\mathrm{P}_{i}^{\prime}
\end{array}\right.
$$

in which $y_{i}$ denotes the three dependent binary variables described above and $P_{i}=P\left(Y_{i}=1 \mid x_{i}\right)$ is the probability that $y_{i}=1$ given the set of exogenous 
variables $x_{i}$. Under the assumption that $P_{i}$ can be approximated by the cumulative logistic distribution based on the linear prediction of the function of independent variable $x_{i}$ so that

$$
P_{i}=\frac{\exp \left(x_{i}^{\prime} \beta\right)}{1+\exp \left(x_{i}^{\prime} \beta\right)}=F\left(\mathrm{x}_{i}^{\prime} \beta\right),
$$

where $F(\cdot)$ denotes the cumulative logistic distribution function, coefficients $\beta$ can be estimated by maximizing the log maximum likelihood function

$$
\ln L=\sum_{\mathrm{i}=1}^{\mathrm{N}}\left[y_{i} \ln F\left(\mathrm{x}_{i}^{\prime} \beta\right)+\left(1-y_{i}\right) \ln \left(1-F\left(\mathrm{x}_{i}^{\prime} \beta\right)\right)\right]
$$

over the relevant samples $i=1, \ldots, N$.

The results, displayed in Table 12.2, show that the model parameters for tractors are very different from the other two, whereas the models for oxen and plows are more similar to each other. Only two factors significantly affect both the tractor and the oxen/plow models: age of the household head and household income are both positively associated with adoption of implements. Total available land per household affects the adoption of both tractors and oxen but in different ways-it increases the likelihood of adopting tractors but decreases ownership of trained oxen. Similarly, the agroecological zones matter: whereas the highlands have more tractors and fewer oxen, the dry and the moist transitional zones have more oxen and fewer tractors.

Clearly, the adoption of tractors and of oxen and plows follow different mechanisms. The adoption of tractors is affected by age, with older farmers more likely to have tractors. This is consistent with the observed decline in tractor ownership. Furthermore, tractor ownership increases with available land and capital, which is also understandable-tractors need sufficient land to justify their use, and they require a substantial amount of capital. After considering these factors, there are still regional differences: the high tropics, as well as the low tropics, have significantly higher proportions of farmers with tractors than the other zones. The higher adoption of tractors in the highlands clearly originates from the area's colonial history.

For the adoption of oxen, household composition matters. Households in which the husband is away are more likely to have oxen. This might be because of remittances from the husband or because the household is short of labor. However, neither argument is supported by the regression results; income actually decreases the probability of adopting oxen, and available labor increases the probability of adopting oxen. The latter indicates that oxen power complements labor rather than substitutes for it. A greater number of tropical livestock units in a household improves the probability of adopting oxen and plows. It most likely helps the household to have more cattle from 
TABLE 12.2 Factors affecting the adoption of farm mechanization, Kenya, farm household survey of 2012

\begin{tabular}{|c|c|c|c|c|c|c|c|c|c|c|}
\hline \multirow{2}{*}{\multicolumn{2}{|c|}{ Dependent variable }} & \multicolumn{3}{|c|}{ Tractor } & \multicolumn{3}{|c|}{ Trained oxen } & \multicolumn{3}{|c|}{ 0x plow } \\
\hline & & Coef. & SE & Sign. & Coef. & SE & Sign. & Coef. & SE & Sign. \\
\hline \multirow[t]{4}{*}{ Head } & Constant & -7.29 & 1.98 & $\star \star \star ~$ & -4.55 & 0.83 & $\star \star \star ~$ & -4.21 & 0.74 & 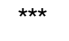 \\
\hline & $\begin{array}{l}\text { Age of household } \\
\text { head (years) }\end{array}$ & 0.04 & 0.02 & * & 0.00 & 0.01 & n.a. & 0.02 & 0.01 & $\star \star \star *$ \\
\hline & $\begin{array}{l}\text { Household head is } \\
\text { male }\end{array}$ & -0.37 & 1.05 & n.a. & 0.54 & 0.45 & n.a. & -0.25 & 0.39 & n.a. \\
\hline & $\begin{array}{l}\text { Head education } \\
\text { (years) }\end{array}$ & 0.04 & 0.04 & n.a. & 0.01 & 0.02 & n.a. & 0.03 & 0.02 & * \\
\hline \multirow[t]{3}{*}{ Marital status } & $\begin{array}{l}\text { Married but spouse } \\
\text { away }\end{array}$ & 0.59 & 0.91 & n.a. & 0.88 & 0.32 & $\star \star \star ~$ & 0.45 & 0.30 & n.a. \\
\hline & Divorced/separated & 0.00 & n.a. & n.a. & 0.18 & 0.80 & n.a. & -1.00 & 0.78 & n.a. \\
\hline & Widow/widower & 0.38 & 1.06 & n.a. & 0.50 & 0.46 & n.a. & -0.34 & 0.41 & n.a. \\
\hline \multirow[t]{6}{*}{ Household } & Adult equivalents & 0.14 & 0.090 & n.a. & 0.15 & 0.04 & $\star \star \star$ & 0.15 & 0.04 & $\star \star \star ~$ \\
\hline & $\begin{array}{l}\text { Tropical livestock } \\
\text { units }\end{array}$ & 0.00 & 0.018 & n.a. & 0.16 & 0.02 & $\star \star \star ~$ & 0.11 & 0.02 & $\star \star \star *$ \\
\hline & Total land (acres) & 0.03 & 0.014 & ** & -0.02 & 0.01 & $\star \star \star ~$ & 0.00 & 0.01 & n.a. \\
\hline & $\begin{array}{l}\text { Number of extension } \\
\text { contacts }\end{array}$ & 0.00 & 0.014 & n.a. & 0.01 & 0.00 & 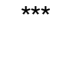 & 0.01 & 0.00 & 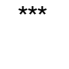 \\
\hline & Total income (KES) & 0.81 & 0.334 & ** & -2.18 & 0.48 & $\star \star \star \star ~$ & -1.41 & -2.18 & 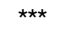 \\
\hline & $\begin{array}{l}\text { Percentage of land } \\
\text { owned }\end{array}$ & 0.56 & 1.012 & n.a. & 0.34 & 0.40 & n.a. & 0.53 & 0.35 & n.a. \\
\hline
\end{tabular}

which the oxen can be pulled. More land to cultivate, on the other hand, decreases the probability of having oxen but does not affect plows. This is counterintuitive; we would have expected larger farms to have more oxen.

The number of extension contacts is an important factor in the adoption of mechanization-an increase of 1 extension contact over the last year increases the probability of adopting oxen or plows by 1 percent.

Landownership (in terms of the percentage of land a household cultivates that it owns) does not seem to make a difference in mechanization. The use of fertilizer, for at least the top dressing, is negatively correlated with the adoption of animal traction-it is likely that when a household has oxen there is less need for fertilizer. Increased marketing of maize, on the other hand, increases the adoption of animal traction. Commercially oriented maize producers are more likely to invest in animal traction. After considering the above factors, agroecological zones are still important factors in the adoption of animal traction. Compared with the base (the low tropics), the dry areas and the 


\begin{tabular}{|c|c|c|c|c|c|c|c|c|c|c|}
\hline \multirow{2}{*}{\multicolumn{2}{|c|}{ Dependent variable }} & \multicolumn{3}{|c|}{ Tractor } & \multicolumn{3}{|c|}{ Trained oxen } & \multicolumn{3}{|c|}{ 0x plow } \\
\hline & & \multirow{2}{*}{$\begin{array}{c}\text { Coef. } \\
0.16\end{array}$} & \multirow{2}{*}{$\begin{array}{c}\text { SE } \\
0.731\end{array}$} & \multirow{2}{*}{$\begin{array}{c}\text { Sign. } \\
\text { n.a. }\end{array}$} & \multirow{2}{*}{$\begin{array}{c}\text { Coef. } \\
0.10\end{array}$} & \multirow{2}{*}{$\begin{array}{c}\text { SE } \\
0.25\end{array}$} & \multirow{2}{*}{$\begin{array}{c}\text { Sign. } \\
\text { n.a. }\end{array}$} & \multirow{2}{*}{$\begin{array}{c}\text { Coef. } \\
0.10\end{array}$} & \multirow{2}{*}{$\begin{array}{c}\text { SE } \\
0.22\end{array}$} & \multirow{2}{*}{$\begin{array}{c}\text { Sign } \\
\text { n.a. }\end{array}$} \\
\hline $\begin{array}{l}\text { Household } \\
\text { (continued) }\end{array}$ & $\begin{array}{l}\text { Basal fertilizer } \\
(1=\text { yes; } 0=\text { no })\end{array}$ & & & & & & & & & \\
\hline & $\begin{array}{l}\text { Top dressing } \\
(0=\text { no; } 1=\text { yes })\end{array}$ & 0.98 & 0.676 & n.a. & -0.70 & 0.24 & $* * \star$ & -0.56 & 0.21 & $* * *$ \\
\hline \multirow{5}{*}{$\begin{array}{l}\text { Agroecological } \\
\text { zone }\end{array}$} & Dry mid-altitude & -1.95 & 0.97 & ** & 1.58 & 0.46 & $* \star \star$ & 2.19 & 0.39 & $\star \star \star \star$ \\
\hline & Dry transitional & -2.25 & 1.01 & ** & 0.80 & 0.49 & n.a. & 1.11 & 0.41 & *** \\
\hline & Moist transitional & -2.51 & 0.89 & $\star \star \star ~$ & 0.34 & 0.47 & n.a. & 0.40 & 0.40 & n.a. \\
\hline & High tropics & -1.07 & 0.76 & n.a. & -1.69 & 0.58 & $* * \star$ & -1.75 & 0.51 & $* * *$ \\
\hline & Moist mid-altitudes & -2.54 & 1.17 & $\star \star$ & 1.07 & 0.46 & $\star \star$ & 0.90 & 0.39 & ** \\
\hline \multirow[t]{2}{*}{ Marketing } & $\begin{array}{l}\text { Distance to main } \\
\text { market }(\mathrm{km})\end{array}$ & 0.02 & 0.02 & n.a. & 0.00 & 0.01 & n.a. & -0.01 & 0.01 & n.a. \\
\hline & $\begin{array}{l}\text { Percentage of own } \\
\text { maize sold }\end{array}$ & 1.03 & 0.80 & n.a. & 1.64 & 0.32 & 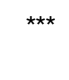 & 1.51 & 0.29 & *** \\
\hline \multirow[t]{3}{*}{ Model } & $\begin{array}{l}\text { Number of observa- } \\
\text { tions }\end{array}$ & 1,111 & n.a. & n.a. & 1,128 & n.a. & n.a. & 1,128 & n.a. & n.a. \\
\hline & Pseudo $R^{2}$ & 0.255 & n.a. & n.a. & 0.2576 & n.a. & n.a. & 0.24 & n.a. & n.a. \\
\hline & Log likelihood & -80.48 & n.a. & n.a. & -427.58 & n.a. & n.a. & -512.80 & n.a. & n.a. \\
\hline
\end{tabular}

Source: Authors' estimations based on data from De Groote, Marangu, and Gitonga (2018).

Note: $\mathrm{KES}=$ Kenya shillings; $\mathrm{SE}=$ standard error. n.a. $=$ not applicable. ${ }^{\star \star \star} \mathrm{p}<0.01,{ }^{\star \star} \mathrm{p}<0.05,{ }^{\star} \mathrm{p}<0.1$.

moist mid-altitude zones have higher levels of adoption, likely because they are affected by large amounts of cattle and low population densities. The high tropics have lower levels of animal traction, likely because they are affected by the historic use of tractors.

\section{Discussion}

This study examines the low adoption levels of agricultural mechanization in Kenya. In 2012, most farm households used only hand tools; slightly less than half owned a bicycle, a backpack sprayer, or a wheelbarrow. Slightly more than a quarter of farmers ( 28 percent) had a plow, whereas very few (2 percent) had a tractor. None of the interviewed farmers owned 2WTs. From 1992 to 2012, the proportion of farmers with trained oxen increased from 17 percent to 33 percent, whereas the proportion with tractors decreased from 5 percent to 2 percent. Tractors were most important in the highlands, and animal 
traction was most popular in the dry areas and moist mid-altitude zones (around Lake Victoria). Relative differences between zones have persisted over the years, although all zones have followed the same general trend of increased animal traction and decreased adoption of tractors. The factors that affect mechanization differ for tractors and animal traction. The adoption of tractors increases with household income, acreage, and age of the household head. The adoption of animal traction also increases with income and age of the household head but decreases with land area. Furthermore, adoption of animal traction is higher in households where the husband is away, and increases with sales of maize, ownership of livestock, family size, and access to extension services. Finally, adoption of animal traction is negatively correlated with the top dressing of fertilizer.

The four different household surveys over a 20 -year period offer good insights into the evolution of agricultural mechanization in the different zones of Kenya, despite the independent cross-sectional designs of the first three surveys. Another big issue was the fact that the different surveys did not use the same tools and definitions; however, this chapter shows how these shortcomings can be improved in future surveys. In particular, a distinction should be made between ownership of, access to, and use of (the latter two through ownership or hiring services) the different farm implements and draft animals involved in agricultural mechanization. Furthermore, within the different implements a distinction should be made between ox plows and tractor plows, and between different types of carts (oxen, donkey, or hand cart). Ownership and use of weeding implements - to be used with draft animalsand shelling equipment should also be included. Finally, a distinction should be made between oxen and trained oxen, and ownership of donkeys should be included.

Household surveys typically ask about implements and draft animals, but that leaves out other types of mechanization. For example, most households have moved from manual to mechanical milling, but mills are typically owned by small businesses in the towns and do not frequently show up in household surveys (just 4 percent of households reported using a mill in 2012). The presence of such services could be picked up by a community survey, and the use of those services could then be picked up in the household survey. Similarly ignored services include availability of electricity and irrigation.

Our results show that agricultural mechanization is slowly making progress in Kenya through animal traction rather than tractors, and this trend is likely to continue for many years. Promoting tractors does not seem welladvised, at least not for maize cultivation. Tractors are expensive (they were 
not developed for low-cost maize production in areas with low labor costs), and fuel prices are steadily increasing. Furthermore, the population in Kenya is growing rapidly and most are still living in rural areas, reducing the availability of agricultural land per person and therefore farm size, and suppressing rural wages. As a result, the proportion of farmers owning tractors is decreasing and is likely to decrease further. Whereas 2 WTs are substantially cheaper than larger tractors, the arguments against their efficacy are similar and the profitability of these implements needs to be carefully assessed against the potential of animal traction and manual labor.

These results from Kenya align with the conclusions of earlier studies (Pingali, Bigot, and Binswanger 1987) and suggest that the farming system in Africa has not yet reached the intensification levels suitable for investment in tractors. Similarly, they confirm the results from West Africa (Blench 2015) that African farming systems, or at least some of them, are more suited for animal traction than for tractors. Despite the increased interest from farmers, animal traction has been receiving little attention from rural development projects and extension agencies. In our analysis, animal traction has the following advantages: it is not linked to farm size; it does not reduce labor, and instead complements it; it helps reduce the use of chemical fertilizer; and it helps farmers to engage in commercial maize production. Moreover, there is still large potential for expanding animal traction, in particular in the highlands. Whereas tractors were popular in this zone, likely for historical reasons, animal traction should be given more attention because large land areas are still available for both crop production and pasture, population density is low, and commercial maize production is important. Contact with extension services increases the probability of technology adoption, so continued training of trainers, as well as research and dissemination of locally adapted implements, should be encouraged. Animal traction is not common, however, in areas with high population density, with low land area per household, and with low availability of pasture, which includes most of the moist transitional zone.

We conclude that, despite the seemingly more advanced nature and attractiveness of tractors for rural development, the short- to medium-term future of agricultural mechanization in Kenya lies in the promotion of animal traction in areas with sufficient land area.

Nevertheless, some recommendations laid out in the Asian chapters apply to Kenya. First, more research is needed to understand whether the limited substitution of animal traction with tractors reflects the low overall demand for mechanical power for land preparation (and thus less intensive tillage). Many Asian chapters suggest, for example, that the role of research and development 
in developing complementary technologies such as high-yielding varieties can be critical in raising the demand for greater farm power use beyond the level that animals alone can provide, so that the demand for stronger sources of power such as tractors starts to emerge. Second, as described in the introduction to this volume, Kenya's importation of tractors has been seemingly restrictive, and only four-wheel tractors of greater than $100 \mathrm{hp} \mathrm{have} \mathrm{commonly} \mathrm{been}$ imported. Reducing import restrictions, as was done in many Asian countries, could increase the importation of smaller tractors and power tillers, which could be more affordable and lead to increased adoption in certain areas.

\section{References}

Anthony, C. G. 1988. Mechanization and Maize: Agriculture and the Politics of Technology Transfer in East Africa. New York: Columbia University Press.

Baudron, F., B. Sims, S. Justice, D. Kahan, R. Rose, S. Mkomwa, P. Kaumbutho, J. Sariah, R. Nazare, G. Moges, and B. Gérard. 2015. "Re-Examining Appropriate Mechanization in Eastern and Southern Africa: Two-Wheel Tractors, Conservation Agriculture, and Private Sector Involvement." Food Security 7: 889-904.

Binswanger, H. 1986. “Agricultural Mechanization: A Comparative Historical Perspective." The World Bank Research Observer 1: 27-56.

Bishop-Sambrook, C. 2005. Contribution of Farm Power to Smallholder Livelihoods in Sub-Saharan Africa. Agricultural and Food Engineering Technical Report No. 2. Rome: Food and Agriculture Organization of the United Nations.

Blench, R. 2015. A History of Animal Traction in Africa: Origins and Modern Trends. Cambridge, UK: Kay Williamson Educational Foundation.

Boserup, E. 1965. The Conditions of Agricultural Growth: The Economics of Agrarian Change under Population Pressure. Piscataway, NJ, US: Transaction Publishers.

De Groote, H., C. Marangu, and Z. M. Gitonga. 2018. "Trends in Agricultural Mechanization in Kenya's Maize Production Areas from 1992-2012." Agricultural Mechanization in Asia, Africa and Latin America 49 (4): 20-32.

Diao, X., F. Cossar, N. Houssou, and S. Kolavalli. 2014. "Mechanization in Ghana: Emerging Demand, and the Search for Alternative Supply Models." Food Policy 48: 168-181.

Doss, C. R. 2006. “Analyzing Technology Adoption Using Microstudies: Limitations, Challenges, and Opportunities for Improvement." Agricultural Economics 34: 207-219.

Evenson, R. E., and D. Gollin. 2003. "Assessing the Impact of the Green Revolution, 1960 to 2000.” Science 300: 758-762. 
FAO (Food and Agriculture Organization of the United Nations) and UNIDO (United Nations Industrial Development Organization). 2008. Agricultural Mechanization in Africa ... Time for Action: Planning Investments for Enhanced Agricultural Productivity. Report of an Expert Group Meeting. Rome and Vienna.

Guthiga, P., J. Karugia, and R. Nyikal. 2007. "Does Use of Draft Animal Power Increase Economic Efficiency of Smallholder Farms in Kenya?" Renewable Agriculture and Food Systems 22: 290-296.

Hassan, R. M., J. Lynam, and P. Okoth. 1998. “The Spatial Sampling Frame and Design for Farmer and Village Surveys." In Maize Technology Development and Transfer: A GIS Application for Research Planning in Kenya, edited by R. M. Hassan. Oxfordshire, UK: Centre for Agriculture and Bioscience International.

Houssou, N., X. Diao, F. Cossar, S. Kolavalli, K. Jimah, and P. O. Aboagye. 2013. "Agricultural Mechanization in Ghana: Is Specialized Agricultural Mechanization Service Provision a Viable Business Model?” American Journal of Agricultural Economics 95: 1237-1244.

Humphrey, N. 1945. Thoughts on the Foundations of Future Prosperity in the Kikuyu Lands: Based on a Review of Some Factors Affecting Agriculture in the South Nyeri District. Nairobi: Colony and Protectorate of Kenya.

. 1947. The Liguru and the Land. Nairobi: Colony and Protectorate of Kenya.

Jaetzold, R., and H. Schmidt. 1982. Farm Management Handbook of Kenya. Vol. 2A. West Kenya. Nairobi: Government of Kenya, Ministry of Agriculture.

Jayne, T. S., J. Govereh, M. Wanzala, and M. Demeke. 2003. "Fertilizer Market Development: A Comparative Analysis of Ethiopia, Kenya, and Zambia." Food Policy 28: 293-316.

Joubert, B. 1995. “An Historical Perspective on Animal Power Use in South Africa." In Animal Power in South Africa: Empowering Rural Communities, edited by P. Starkey. Gauteng, South Africa: Development Bank of Southern Africa.

Kenya, CBS (Central Bureau of Statistics). 2001. 1999 Population and Housing Census, Volume 1. Population Distribution by Administrative Areas and Urban Centers. Nairobi: Ministry of Planning and National Development.

Kienzle, J., J. E. Ashburner, and B. Sims, eds. 2013. Mechanization for Rural Development: A Review of Patterns and Progress from Around the World. Rome: Food and Agriculture Organization of the United Nations.

Lamidi, W. A., and L. O. Akande. 2013. "A Study of Status, Challenges and Prospects of Agricultural Mechanization in Osun State, Nigeria." Journal of Education, Arts and Humanities 1 (1): 1-8.

Lawrence, P. R., and R. A. Pearson. 2002. "Use of Draft Animal Power on Small Mixed Farms in Asia." Agricultural Systems 71: 99-110. 
Longmire, J., and J. Lugogo. 1989. The Economics of Small-Scale Wheat Production Technologies for Kenya. Mexico City: International Maize and Wheat Improvement Center (CIMMYT).

Mrema, G. C., D. Baker, and D. Kahan. 2008. Agricultural Mechanization in Sub-Saharan Africa: Time for a New Look. Agricultural Management, Marketing and Finance Occasional Paper No. 22. Rome: Food and Agriculture Organization of the United Nations.

O’Neill, D. H., and D. C. Kemp. 1989. “A Comparison of Work Outputs of Draft Oxen.” Journal of Agricultural Engineering Research 43: 33-44.

Onyango, S. O. 1988. "Reducing Present Constraints to the Use of Animal Power in Kenya." In Animal Traction for Agricultural Development, edited by P. H. Starkey and A. Faye. Wageningen, Netherlands: Technical Center for Agricultural and Rural Cooperation.

Pingali, P. 2007. “Agricultural Mechanization: Adoption Patterns and Economic Impact." In Handbook of Agricultural Economics, edited by R. Evenson and P. Pingali, 2779-2805. Amsterdam: Elsevier.

Pingali, P., Y. Bigot, and H. P. Binswanger. 1987. Agricultural Mechanization and the Evolution of Farming Systems in Sub-Saharan Africa. Baltimore: Johns Hopkins University Press for World Bank.

Ruttan, V. W., and Y. Hayami. 1984. "Toward a Theory of Induced Institutional Innovation.” The Journal of Development Studies 20: 203-223.

Savadogo, K., T. Reardon, and K. Pietola. 1998. “Adoption of Improved Land Use Technologies to Increase Food Security in Burkina Faso: Relating Animal Traction, Productivity, and Non-Farm Income." Agricultural Systems 58: 441-464.

Seager, P. J., and R. S. Fieldson. 1984. Public Tractor Hire and Equipment Hire Schemes in Developing Countries (with Special Emphasis on Africa). Research Unit Report No. ARU 30. Washington, DC: Agriculture and Rural Development Department, World Bank.

Smale, M., and T. Jayne. 2003. Maize in Eastern and Southern Africa: "Seeds" of Success in Retrospect. Environment and Production Technology Division Discussion Paper No. 97. Washington, DC: International Food Policy Research Institute.

Starkey, P. 2000. "The History of Working Animals in Africa." In The Origins and Development of African Livestock: Archaeology, Genetics, Linguistics and Ethnography, edited by R. M. Blench and K. C. MacDonald. Oxfordshire, UK: Routledge.

Tefft, J. 2010. “Mali’s White Revolution: Smallholder Cotton from 1960 to 2006.” In Successes in African Agriculture: Lessons for the Future, edited by S. Haggblade and P. B. Hazell. Washington, DC: International Food Policy Research Institute.

Wagner, G. 1949. The Bantu of North Kavirondo. Vol. 1. London: Oxford University Press. 


\title{
EVOLUTION OF AGRICULTURAL MECHANIZATION IN NIGERIA
}

Hiroyuki Takeshima and Akeem Lawal

\begin{abstract}
Demand for mechanization in Nigeria is growing in a fairly consistent way, as predicted by economic theories. The farming system has intensified and the use of animal traction has grown at a substantial rate. Demand-side factors considerably explain the low adoption of tractors in Nigeria. Where demand is sufficient for tractors, the private sector has emerged over time as a more efficient provider of hiring services (particularly farmer-to-farmer services) than the public sector. Conditions are consistent with the hypothesis that, because of generally low support for the agricultural sector in Nigeria in the past few decades, agricultural mechanization (tractor use in particular) has remained low despite the declining share of the workforce engaged in the agricultural sector. Agricultural transformation in the form of a declining agricultural labor force has happened partly through the growth in the oil industry since the 1970s. Instead of inducing further exit from farming, tractor adoption in Nigeria might have helped those who have remained in farming to start expanding their production scale. A knowledge gap, however, remains regarding the dominance of large tractors and the potential effects of tractor adoption on smallholders who have yet to adopt them.
\end{abstract}

\section{Demand-Side Analysis}

Nigeria has a diverse production environment, including in its land-to-labor ratios and farm power use (Table 13.1). ${ }^{1}$ The North Central region (NC)

This chapter is a shortened version of Takeshima and Lawal (2018), which also discusses in more detail the historical evolution of mechanization in Nigeria.

1 The remaining sections of this chapter rely primarily on the first and second rounds of the Living Standards Measurement Study-Integrated Surveys on Agriculture (LSMS-ISA) for Nigeria, jointly collected by the National Bureau of Statistics of Nigeria and the World Bank, as well as on various spatial variables. The first and second rounds of the LSMS-ISA covered the main production seasons in 2010 and 2012, respectively. These two rounds of the LSMS surveys contain 10,000 observations in total, among which approximately 6,000 observations are farm households. 
TABLE 13.1 Farmland endowments, farm sizes, labor, and animal use by region, Nigeria, 2010 and 2012

\begin{tabular}{|c|c|c|c|c|c|c|}
\hline \multirow[b]{2}{*}{ Region } & \multicolumn{2}{|c|}{$\begin{array}{l}\text { Agricultural area } \\
\text { per capita } \\
\text { (ha per capita) }^{\mathrm{a}}\end{array}$} & \multicolumn{2}{|c|}{ Farm size (ha) } & \multicolumn{2}{|c|}{$\begin{array}{l}\text { Average manual farm } \\
\text { power use (days per farm } \\
\text { household per year) }\end{array}$} \\
\hline & $\begin{array}{c}\text { Area divided } \\
\text { by all } \\
\text { households }\end{array}$ & $\begin{array}{l}\text { Area divided } \\
\text { by farm } \\
\text { households }\end{array}$ & Average & Median & $\begin{array}{l}\text { Labor (family } \\
\quad+\text { hired) }\end{array}$ & $\begin{array}{l}\text { Animal } \\
\text { traction }\end{array}$ \\
\hline NW & 0.41 & 0.46 & 0.8 & 0.5 & 227 & 6 \\
\hline NE excluding Taraba & 0.68 & 0.74 & 2.0 & 1.2 & 302 & 9 \\
\hline $\mathrm{NC}+$ Taraba & 0.73 & 0.86 & 1.5 & 0.8 & 493 & 1 \\
\hline South & 0.14 & 0.21 & 1.0 & 0.2 & 380 & 0 \\
\hline
\end{tabular}

Source: Authors' calculations based on data from Living Standards Measurement Study-Integrated Surveys on Agriculture, Nigeria, 2010 and 2012; Ramankutty et al. (2008); and Nigeria, NPC (2010).

Note: $\mathrm{NC}=$ North Central; NE = North East; NW = North West. a. Agricultural area per capita is calculated using the sum of cropped area and pasture area (data from Ramankutty et al. 2008), with population data obtained from the Nigeria 2006 Population Census (Nigeria, NPC 2010).

plus Taraba state is the most endowed with agricultural area per capita (both cropped area and pasture area). The intensity of animal traction is higher in the North East (NE) excluding Taraba and North West (NW) regions than in other zones, although the land-to-labor ratio is lower in NW. The south zones are generally less endowed with farmland per capita, and the use of animal traction is almost nonexistent. As is shown below, these patterns are correlated with the adoption of tractors. However, the use of farm power, particularly animal traction, may be still relatively lower than in Asia. For example, in Japan, animal power use was often 150 hours/year/ha (30 days per farm household if it was used 5 hours/day) in the 1950s, immediately before the widespread substitution of power tillers for animal power (Takeshima and Lawal 2018).

\section{Machinery Use or Ownership by Farm Size}

In the 2010 and 2012 rainy seasons, 4 percent and 24 percent of farm households in Nigeria used tractors and animal traction, respectively (Table 13.2), covering 7 percent and 25 percent of the cultivated area (Table 13.3). For tractors, these shares were higher in the NC and NE regions, and moderate in the South West (SW) region. Animal traction was used by more than 50 percent of farm households in the NW and NE regions, but it was almost never used in the south of the country. The use of draft animals is limited in southern Nigeria largely due to trypanosomiasis carried by the tsetse flies that are prevalent (Alsan 2015). Southern Nigeria is also characterized by root crops and tree crops cultivated on relatively heavy soils and hilly upland, compared with 
TABLE 13.2 Percentage of farmers using tractors or animal traction in 2010 and 2012 rainy seasons in Nigeria

\begin{tabular}{lccccc}
\hline & \multicolumn{3}{c}{ Share (\%) of farm households using tractors or animal traction } \\
\cline { 2 - 5 } & & \multicolumn{3}{c}{ Animal traction } & $\begin{array}{c}\text { No tractor } \\
\text { or animal } \\
\text { traction }\end{array}$ \\
\cline { 2 - 5 } Region & Tractors & Total & $\begin{array}{c}\text { Owned } \\
\text { animal }\end{array}$ & $\begin{array}{c}\text { Rented } \\
\text { animal only }\end{array}$ & $\begin{array}{l}\text { animy } \\
\text { Total }\end{array}$ \\
North West & 4 & 24 & 14 & 10 & 72 \\
North East excluding Taraba & 2 & 55 & 30 & 25 & 44 \\
North Central + Taraba & 6 & 63 & 42 & 21 & 32 \\
South East & 10 & 7 & 4 & 3 & 84 \\
South South & 1 & 0 & 0 & 0 & 99 \\
South West & 0 & 0 & 0 & 0 & 100 \\
\hline
\end{tabular}

Source: Authors' calculations based on Living Standards Measurement Study-Integrated Surveys on Agriculture, 2010 and 2012.

Note: Because of rounding, figures may not always add up to 100 .

TABLE 13.3 Percentage of area using tractors or animal traction in 2010 and 2012 rainy seasons in Nigeria

\begin{tabular}{|c|c|c|c|c|c|}
\hline \multirow[b]{3}{*}{ Region } & \multicolumn{5}{|c|}{ Share $(\%)$ of cultivated area using tractors or animal traction } \\
\hline & \multirow[b]{2}{*}{ Tractors } & \multicolumn{3}{|c|}{ Animal traction } & \multirow{2}{*}{$\begin{array}{c}\text { No tractor } \\
\text { or animal } \\
\text { traction }\end{array}$} \\
\hline & & Total & Owned animal & $\begin{array}{c}\text { Rented } \\
\text { animal only }\end{array}$ & \\
\hline Total & 7 & 25 & 18 & 8 & 68 \\
\hline North West & 1 & 68 & 46 & 23 & 31 \\
\hline North East excluding Taraba & 5 & 61 & 44 & 17 & 36 \\
\hline North Central + Taraba & 19 & 9 & 6 & 3 & 72 \\
\hline South East & 1 & 0 & 0 & 0 & 99 \\
\hline South South & 0 & 0 & 0 & 0 & 100 \\
\hline South West & 4 & 0 & 0 & 0 & 96 \\
\hline
\end{tabular}

Source: Authors' calculations based on Living Standards Measurement Study-Integrated Surveys on Agriculture, 2010 and 2012.

Note: Because of rounding, figures may not always add up to 100 .

northern Nigeria, where more cereal crops are cultivated on relatively lighter soils and more flat land. This may partly explain the greater use of animal traction in northern Nigeria than in southern Nigeria.

Nigeria is largely dominated by smallholder farmers, with a median farm size of 0.5 ha and less than 10 percent of farm households cultivating 3 ha or more (Table 13.4). The adoption rates of tractors and animal traction 
TABLE 13.4 Farm size distribution in Nigeria and corresponding mechanization levels, 2010-2012

\begin{tabular}{lccc}
\hline Farm size (ha) & $\begin{array}{c}\text { \% of farm } \\
\text { households }\end{array}$ & $\begin{array}{c}\text { \% of farm households } \\
\text { using tractors }\end{array}$ & $\begin{array}{c}\text { \% of farm households } \\
\text { using animal traction }\end{array}$ \\
\hline $0-0.09$ & 16 & 1 & 8 \\
$0.1-0.49$ & 34 & 2 & 22 \\
$0.5-0.99$ & 21 & 4 & 39 \\
$1.0-1.49$ & 11 & 4 & 41 \\
$1.5-2.99$ & 11 & 9 & 43 \\
3.0 and more & 8 & 10 & 47 \\
\hline
\end{tabular}

Source: Authors, based on data from Living Standards Measurement Study-Integrated Surveys on Agriculture 2010 and 2012.

Note: Because of rounding, figures may not always add up to 100 .

are positively correlated with farm size, although the tractor adoption rates remain relatively low even among those cultivating 3 ha or more.

The information is limited regarding the farm size dynamics in Nigeria and whether farm expansion is an important motivation for mechanization. Although the share of population considered agricultural has declined over time, the absolute agricultural population has remained high (partly due to high population growth) and the average farm size has remained small in Nigeria. Therefore, a substantial farm expansion or shift in farm size distribution has not been observed in Nigeria.

There is no information, to the authors' knowledge, on all the types of tractors used in Nigeria. However, various sources of information suggest that most tractors used in the country are four-wheel tractors, with the horsepower ranging between 50 and 75, and the use of two-wheel tractors, or lowerhorsepower four-wheel tractors, is still limited (Takeshima et al. 2015; World Bank 2014).

\section{Agroecological Conditions, Cropping Systems, and Farm Household Typologies}

Tractor use is particularly correlated with rice, whereas tractor use on other crops is limited (Table 13.5). Tractors are used in as much as 30 percent of rice area in Nigeria, although the margins of error are large because of small samples. Importantly, most crops that are widely grown in Nigeria (maize,

2 There may be close to 500-1,000 functional power tillers in the country (Takeshima et al. 2014), considerably lower than the number of four-wheel tractors, which is around 30,000 (FAO 2016). 
TABLE 13.5 Estimated area and area shares of tractor use in Nigeria, 2010-2012

\begin{tabular}{lcc}
\hline Crop & $\begin{array}{c}\text { Tractor-cultivated area } \\
(1,000 \text { ha) }\end{array}$ & $\begin{array}{c}\text { Share (\%) of cropped area } \\
\text { with tractor use }\end{array}$ \\
\hline Rice & $410-790$ & $31[21,41]$ \\
Maize & $140-240$ & $6[4,8]$ \\
Sorghum & $70-190$ & $5[3,7]$ \\
Millet & $20-50$ & $2[1,3]$ \\
Cowpeas & $50-90$ & $4[3,5]$ \\
Groundnuts & $10-60$ & $3[1,5]$ \\
Cassava & $50-120$ & $3[2,4]$ \\
Yams & $10-70$ & $2[1,3]$ \\
Vegetables & $0-10$ & $1[0,2]$ \\
\hline
\end{tabular}

Source: Authors' calculations as the averages from Living Standards Measurement Study-Integrated Surveys on Agriculture (LSMS-ISA) 2010 and 2012.

Note: Due to the small sample size, we combine two waves of LSMS-ISA surveys and take the average from the two years. Lower- and upper-bounds of $95 \%$ confidence intervals are in square brackets.

sorghum, millet, and root crops) are "plow-negative," meaning that plow use on them is difficult (Alesina, Giuliano, and Nunn 2013). Rice is the only "plow-positive" crop—one for which the plow is beneficial—widely grown in Nigeria, because the production of the other major plow-positive crop, wheat, is minimal due to high temperatures.

\section{ASSOCIATIONS WITH FARM HOUSEHOLD TYPOLOGY}

Mechanization is closely related to distinct farming systems in both northern Nigeria and southern Nigeria (Takeshima, Nin Pratt, and Diao 2013a; Takeshima 2016) (Table 13.6). In the south of the country, a higher share of tractor use is found among medium-scale, input-intensive rice growers who are highly mechanized, have higher incomes and more assets, and operate in remote areas facing higher real wages for land preparation. In the north, a higher share of tractor use is found among mechanized cereal growers who have higher incomes and more assets, operate in remote areas facing higher real wages for land preparation, and use inputs more intensively.

Patterns of mechanization still differ somewhat between the north and the south in Nigeria. In the north, mechanization, including tractor use, seems to lead to intensive production without much effect on area expansion. Some tractor renters are located remotely from the market and grow staple crops, such as maize, sorghum, millet, and legumes, mostly for subsistence. Input intensity is driven rather by the use of irrigation for more commercial crops such as rice and vegetables. Correlation between tractor use and either crop 
TABLE 13.6 Major characteristics of each type of farm household in Nigeria, 2010

\begin{tabular}{|c|c|c|c|c|c|c|c|c|c|c|c|c|}
\hline \multirow{2}{*}{$\begin{array}{l}\text { Variable } \\
\text { Main crop }\end{array}$} & \multicolumn{6}{|c|}{ South } & \multicolumn{6}{|c|}{ North } \\
\hline & $c$ & mcy & $c$ & syc & $a$ & $r$ & $m s$ & $m s g$ & $s g l$ & $m$ & $s g l$ & $r v$ \\
\hline Real wage & 9 & 10 & 10 & 11 & 11 & 17 & 11 & 17 & 10 & 10 & 8 & 8 \\
\hline Population density & 366 & 473 & 315 & 105 & 335 & 44 & 92 & 91 & 114 & 129 & 155 & 173 \\
\hline$\%$ literate & 3 & 81 & 82 & 31 & 73 & 59 & 8 & 75 & 10 & 94 & 85 & 72 \\
\hline Household assets & 91 & 292 & 283 & 260 & 333 & 763 & 184 & 437 & 174 & 478 & 257 & 343 \\
\hline Expenditures & 46 & 85 & 69 & 42 & 118 & 112 & 35 & 53 & 32 & 53 & 36 & 57 \\
\hline$\%$ with nonfarm income & 33 & 58 & 52 & 25 & 84 & 90 & 51 & 52 & 44 & 66 & 71 & 90 \\
\hline$\%$ owning some plots & 10 & 12 & 14 & 8 & 37 & 48 & 36 & 41 & 20 & 25 & 23 & 3 \\
\hline$\%$ using irrigation & 0 & 1 & 1 & 2 & 10 & 41 & 9 & 0 & 3 & 5 & 3 & 86 \\
\hline Total area & 0.2 & 0.1 & 0.3 & 1.5 & 1.3 & 2.6 & 0.8 & 1.1 & 0.9 & 0.7 & 0.7 & 0.5 \\
\hline Fertilizer cost & 0 & 0 & 0 & 0 & 0 & 93 & 26 & 5 & 0 & 60 & 27 & 67 \\
\hline Seed, chemical cost & 0 & 4 & 0 & 33 & 34 & 87 & 14 & 26 & 4 & 27 & 11 & 39 \\
\hline$\%$ hiring harvesting labor & 23 & 15 & 16 & 34 & 57 & 79 & 50 & 14 & 48 & 79 & 68 & 93 \\
\hline$\%$ with crop sales & 70 & 80 & 56 & 95 & 100 & 90 & 62 & 75 & 59 & 68 & 56 & 62 \\
\hline$\%$ using animal traction & 0 & 0 & 0 & 0 & 0 & 0 & 58 & 4 & 56 & 69 & 74 & 48 \\
\hline$\%$ using tractors & 1 & 3 & 0 & 5 & 2 & 93 & 4 & 4 & 4 & 14 & 5 & 17 \\
\hline Number of observations & 274 & 275 & 233 & 61 & 63 & 29 & 157 & 79 & 362 & 148 & 347 & 29 \\
\hline
\end{tabular}

Source: Takeshima, Nin Pratt, and Diao (2013b).

Note: ${ }^{a}$ Main crops are those grown by more than $50 \%$ of households in each type: $a=$ cocoa; $c=$ cassava; $g=$ legumes; $I=$ millet; $m=$ maize; $r=$ rice; $s=$ sorghum; $v=$ vegetables; $y=$ yams.

sales or the intensity of inputs used is somewhat weaker in the north compared with the south. In northern Nigeria, it seems tractors are used mostly to replace labor rather than for intensification, and animal traction may be playing the role of an intermediate substitute for tractors.

In the south, due to the absence of animal traction, tractor use is more defining of the level of mechanization. In addition, farm size is generally smaller than in the north, and the farm size of tractor users appears relatively larger than that of nonusers. The intensity of input use among tractor-using farms also is more pronounced than in the north. Use of tractors is highly concentrated among the (irrigated) rice growers. In the south, the use of mechanization seems limited to area expansion for input-intensive production of certain crops, such as rice.

\section{AGRICULTURAL WAGES}

Reliable information on the trend of representative wages in Nigeria is scarce. Continued growth of the nonfarm sector and urbanization have been 
TABLE 13.7 Real male wages per day in Nigeria for land clearing and land preparation (in kilograms of local rice grain at local purchase price), 2010-2012

\begin{tabular}{lcc}
\hline & \multicolumn{2}{c}{ Sector } \\
\cline { 2 - 3 } Geopolitical zone & Urban & Rural \\
\hline NW & 4.0 & 3.5 \\
NE excluding Taraba & 4.5 & 4.0 \\
NC + Taraba & 6.5 & 3.5 \\
SE & 10.5 & 7.0 \\
SS & 9.0 & 7.0 \\
SW & 6.0 & 5.0 \\
\hline
\end{tabular}

Source: Authors' calculations as median values from Living Standards Measurement Study-Integrated Surveys on Agriculture, 2010 and 2012.

Note: $\mathrm{NC}=$ North Central; NE = North East; NW = North West; SE = South East; SS = South South; SW = South West.

considered factors that provide upward pressures on rural farm wages. The rural population growth rate has been relatively modest at 1 percent/year, considerably lower than the urban population growth rate of 4.4 percent/ year (World Bank 2016). Nominal farm wages, which often stand at around $\$ 4-\$ 6^{3}$ per day (Takeshima, Nin Pratt, and Diao 2013a) are higher than the nominal wages in Asia, where the daily agricultural wages were often $\$ 1-\$ 2$ per day (in 2010 dollars) before the 2000s (Barker, Herdt, and Rose 1985; Nepal chapter of this book), when tractor adoption started growing.

However, real rural wages in Nigeria, when measured based on the local purchase price of a kilogram of cereals, are equivalent to around $4 \mathrm{~kg}$ (of local rice grain at the local purchase price) in northern Nigeria, and $6 \mathrm{~kg}$ in southern Nigeria (Table 13.7). The figures in northern Nigeria, where most tractor use is found, are still lower than they were in Asia when the mechanization level started rising $-6 \mathrm{~kg}$ of rice in rural Bangladesh in 2001 (Zhang et al. 2014) and $8 \mathrm{~kg}$ in 1995 in Nepal (Takeshima 2017a). This is because of the generally high food price in Nigeria-for example, the farmgate price of rice in Nigeria is almost double that of Thailand (Gyimah-Brempong, Johnson, and Takeshima 2016). The current real farm wages in Nigeria, on average, may still be somewhat too low to induce wider-scale adoption of tractors. 
TABLE 13.8 Determinants of the area cultivated by tractors (pseudo-panel double hurdle model; marginal effects evaluated at the mean of observations), Nigeria, 2010-2012

\begin{tabular}{lcc}
\hline & \multicolumn{2}{c}{ Double hurdle model } \\
\cline { 2 - 3 } Dependent variable & $\begin{array}{c}\text { Probability of } \\
\text { using tractor }\end{array}$ & $\begin{array}{c}\text { Area cultivated by } \\
\text { tractors (ha) }\end{array}$ \\
\hline Model & Probit & $\begin{array}{c}\text { Truncated } \\
\text { regression }\end{array}$ \\
\hline In(cultivable land per capita) & $.007^{\star \star \star}$ & -.011 \\
Average area (ha) of owned or distributed land per plot & -.000 & $.153^{\star \star \star}$ \\
Number of owned or distributed plots & .002 & .012 \\
Household size & .001 & .024 \\
No. of working-age household members (no education, M) & $-.004^{\star}$ & -.078 \\
Primary education, M & .002 & .018 \\
Secondary education or above, M & -.001 & .021 \\
Koranic education, M & -.003 & -.162 \\
Any other education, M & -.019 & $.398^{\star}$ \\
No. of working-age household members (no education, F) & -.002 & -.041 \\
Primary education, F & .001 & -.088 \\
Secondary education or above, F & $.003^{\star \star}$ & $-.099^{\star \star}$ \\
Koranic education, F & .002 & .009 \\
Any other education, F & -.006 & -.350 \\
In(real district average farm wage) & .014 & -.129 \\
In(real asset value) & $.003^{\star \star *}$ & .023 \\
Own draft animals (yes = 1, no = 0) & .002 & -.246 \\
\end{tabular}

\section{Determinants of Tractor Use}

Table 13.8 summarizes the key determinants of the area cultivated by tractors in Nigeria (technical details are provided in Appendix 13A). The figures shown are marginal effects on the probability of using tractors, and the area cultivated by tractors, measured at the mean values of each variable.

Results are generally intuitive. Doubling of agricultural land per capita raises the likelihood of tractor adoption by 0.7 percentage points. A greater land endowment relative to labor induces the use of tractors. A greater number of noneducated male working-age household members reduces the likelihood of tractor service adoption. Conversely, a greater number of working-age female members with at least a secondary education raises the adoption of tractor services. These results are consistent with the hypothesis that human capital formation induces the substitution of machinery for land-preparation 


\begin{tabular}{lcc} 
& \multicolumn{2}{c}{ Double hurdle model } \\
\cline { 2 - 3 } Dependent variable & $\begin{array}{c}\text { Probability of } \\
\text { using tractor }\end{array}$ & $\begin{array}{c}\text { Area cultivated by } \\
\text { tractors (ha) }\end{array}$ \\
\hline Model & Probit & $\begin{array}{c}\text { Truncated } \\
\text { regression }\end{array}$ \\
\hline In(real values of draft animals) & -.000 & $.072^{\star}$ \\
Real price of 1 kg of fertilizer (average of urea and NPK) & .0007 & $-.007^{\star \star}$ \\
Soil with high workability $(1=$ workable, $0=$ otherwise) & $.014^{\star \star \star}$ & $.770^{\star \star}$ \\
Bulk density of the soil (tons per $\mathrm{m}^{3}$ of soil) & .041 & -1.115 \\
Clay contents of the soil (\% of clay $<2$ micrometers) & $-.001^{\star \star}$ & $-.022^{\star}$ \\
Distance to the nearest town with population of 20,000 (hours) & .001 & $-.094^{\star}$ \\
Euclidean distance to the nearest dam (geographical minutes) & $-.006^{\star}$ & $-.333^{\star \star}$ \\
Euclidean distance to the nearest river (geographical minutes) & -.183 & -3.832 \\
In(sample maximum owned and distributed land within district) (ha) & $.003^{\star \star}$ & n.a. \\
Time dummy (year 2012 $=1$ ) & Included & Included \\
Sector dummy (rural $=1$, urban $=0$ ) & Included & Included \\
Correlated random effects components & Included & Included \\
Zonal dummies & Included & Included \\
Constant & Included & Included \\
$\sigma$ & n.a. & $4.292^{\star \star *}$ \\
Number of observations & 5,241 & 223 \\
\hline
\end{tabular}

Source: Takeshima (2015a).

Note: Significance: ${ }^{\star \star \star} 1$ percent, ${ }^{\star \star} 5$ percent, ${ }^{*} 10$ percent. $\mathrm{F}=$ female; $\mathrm{M}=$ male; NPK $=$ nitrogen, phosphate, and potassium. n.a. $=$ not applicable.

labor. Once we control for human capital, farm labor wages in the area do not seem to affect tractor adoption, possibly indicating that it is the labor costs of household members that may induce substitution with tractors.

Doubling real asset values raises the adoption possibility by 0.2 percentage points, possibly because of the reduced risk aversion toward tractor services. Tractor service adoption is higher on more workable soil and soil with less clay content, possibly because of lower plowing costs. Adoption is also higher in areas closer to the nearest dam, possibly because of better access to formal irrigation facilities where intensive production, including mechanized plowing, can have high returns.

Upon the adoption of tractor services, the area cultivated by tractors depends largely on the average plot sizes and soil workability. A positive effect of the higher bulk density of soil may reflect the use of higher-horsepower 
tractors (as indicated in Takeshima et al. 2014) that are more appropriate for cultivating a larger area. A greater number of highly educated female workingage household members has negative effects on tractor use intensity, though it has positive effects on tractor adoption. This reflects the general orientation of such households to be engaged in farming to a lesser extent. However, an increased number of male working-age household members with any type of education has a positive effect, indicating somewhat complicated effects of human capital.

Greater draft animal assets positively affect tractor use intensity. A greater endowment of draft animal assets indicates possibly greater demand for such animals, for which tractors can substitute. An increase in real fertilizer price reduces the extent of tractor adoption, potentially indicating that tractor and fertilizer may be gross complements (possibly because of the synergy between deeper tillage and soil nutrient absorption). Soil workability, lower clay content, and proximity to a dam also induce greater tractor use intensity.

Importantly, doubling the size of the largest owned and distributed land within the local government area (LGA) in the sample raises the possibility of tractor service adoption by 0.2 percentage points. This indicates that the supply of tractor service is somewhat constrained by the scarcity of large farm households that are likely to have an incentive to invest in tractors and serve nearby farmers.

\section{Demand for Wider-Scale Adoption of Tractors in Nigeria}

Because tractor use growth in Nigeria has been stagnating for a few decades, it is generally difficult to identify its primary drivers. However, certain factors are associated with greater smallholder mechanization demand.

The demand for mechanization in land preparation has grown to a sufficient level in various pockets within Nigeria, potentially warranting the development of a hiring market with smallholders as customers. The demand for tractor adoption is higher in NC, NE, and SW than in other zones, higher in rice areas than in areas with other crops, and higher in areas where land is relatively more abundant than labor.

In northern Nigeria, relatively widespread use of animal traction suggests that a farming system that involves fairly intensive plowing has evolved. In such an environment, greater farm endowment relative to labor seems an important determinant of tractor adoption.

The use of animal traction may be another indicator of the use of farm power that is substitutable with tractors. This is also consistent with the 
correlation between more widespread animal traction use and tractor adoption in the north, particularly the NE region. However, the overall animal traction use intensity may still be lower compared with the use intensity in Asia. The average real wages are also still somewhat low. These factors may partly limit wider-scale adoption of tractors.

The prevalence of plow-negative crops (maize, millet, root crops) and the near absence of plow-positive crops such as wheat may limit the overall demand for tractor tillage in Nigeria. Although in the long run these crops are also likely to be mechanized, the cropping system may still limit the wider diffusion of tractor use in the short to medium term.

The demand for mechanized harvesting may be still generally low partly due to low overall yields and harvests, as well as low production intensity, with limited use of dry-season irrigation. The patterns in Nigeria, in which tractor tillage is observed to some extent (albeit in low intensity) and mechanized harvesting is still largely absent, are consistent with past sequential patterns, in which mechanization of land preparation has preceded the mechanization of harvesting.

\section{Supply-Side Analysis}

\section{Machinery Purchase, Import, and Financing Policies}

The Nigerian government has long intervened into domestic tractor markets, including subsidized tractor distribution. Until recently, subsidized tractor distribution had been similar to the nation's fertilizer subsidy program, in that both federal and state governments procured tractors and distributed them with subsidies. Subsidy rates have varied over time. Subsidies of 50-75 percent were common up to the early 1980s (Scherr 1989; World Bank 1985, 37). Sometimes the subsidies were provided to cooperatives or group farms. For example, a machinery ownership scheme launched in 1980 by the federal government provided half of the purchase cost of farm machinery to be owned and used by farming cooperatives or group farms (Manyong et al. 2005, 41). In the 2000s, the subsidy rates were slightly lower. For example, under the Obasanjo administration, the subsidy was typically 25 percent (Ladeinde et al. 2009). States often added subsidies, which vary from year to year. For example, the rate in Kaduna state was a 40 percent subsidy $(25$ percent by the federal government and 15 percent by the state government) in 2010 (Ajibola and Zalla 2011,3), but it rose to 50 percent (with the state government 
contribution increasing to 35 percent) in 2013. ${ }^{4}$ Takeshima and others (2014) also provided detailed descriptions of current state-level tractor distribution systems in Kaduna state in Nigeria, which seemed to continue in various states even as the federal government discontinued the subsidized distribution of tractors in 2012.

Government loans have also been made available, providing indirect subsidies in the form of interest rate subsidies. Details of government loan arrangements were not revealed to the authors and are expected to vary across states and over time. Informal interactions with the beneficiaries of subsidized tractors indicate that a recent common arrangement is an interest-free loan with a three-year payback period. Costs are, however, also often incurred due to delays in loan approval or through various transaction costs paid either by beneficiaries for subsidy applications or by the government for monitoring repayment (Takeshima et al. 2014).

The quantities distributed with subsidies were also determined ad hoc, often depending on the budget availability, and varied from year to year. The number of subsidized tractors distributed in the country was likely the highest from the late 1970s to the early 1980s. From 1975 to 1983, 22,000 (mostly imported) tractors were sold at subsidized prices to parastatal agencies, such as the River Basin Development Agencies, and to large-scale private companies (Jabbar 1995), as well as cooperative societies, group farmers, and retired tractor operators to run tractor hiring units, or THUs (Akinbamowo 2011). The federal government's expenditure on the tractorization program increased from 11 million Nigerian naira, or NGN (about \$16 million at the time, or $\$ 85$ million in 2010 dollars), during the first five-year plan (1970-1974) to NGN 54 million in 1975-1979 (about \$86 million then, or \$319 million in 2010 dollars), and NGN 240 million during the third plan, 1980-1985 (about $\$ 341$ million then, or $\$ 775$ million in 2010 dollars) (Jabbar 1995, 101). In the 2000 s, the number of tractors distributed by the federal government was often around 1,000 per year, but tractors were not distributed every year (Bello 2005).

\section{Trade, Import Policies (Tariffs, Direct Restrictions, and Other Interventions), and Parts}

In the early 1970s, import policies regarding tractors and agricultural equipment were generally liberalized (Manyong et al. 2005). During the 1970s, the

4 Personal communication with the Kaduna State Ministry of Agriculture (June 15, 2019).

5 Personal communication with Federal Ministry of Agriculture and Rural Development officials (June 16, 2019). 
import duty on raw materials used to manufacture pipes, electronics, metal fabrications, and kitchen utensils was abolished (Egwaikhide 1999). Although trade policies became generally more restrictive in the early 1980 s, the majority of importation of agricultural tractors was largely government-led between the late 1970s and the early 1980s, and was less dependent on trade policies.

After the Structural Adjustment Program (SAP) that started in the mid1980s, private-sector tractor importation was unregulated, except for the imposition of tariffs. However, tractor importation was still mostly led by the government, and the private sector's importations of four-wheel or two-wheel tractors remained small. This continued to be the case into the 2010s, when the government was importing approximately 900 tractors a year and the private sector brought in around 100 (World Bank 2014).

Import tariffs have been generally imposed on tractors and spare parts in Nigeria. Import duties (customs duties) have accounted for the bulk of import tariffs on agricultural tractors. Even after the introduction of value-added tax (VAT) in 1994, agricultural equipment, including tractors and spare parts, has often been exempt from VAT. Only recently, VAT has become imposed on certain types of agricultural tractors: 5 percent for fully built tractors imported, but still 0 percent for completely-knocked-down (CKD) and semiknocked-down (SKD) tractors imported, as of October 2016 (Takeshima \& Lawal 2018).

Import duties on component parts of commercial vehicles and tractors were reduced from 25 to 5 percent by 1989 (Busari and Udeaja 2007). Import duties for spare parts remained largely at 5 percent into the 2010s (World Bank 2014). Import duties for tractors have fluctuated but often remained less than 25 percent. Before 2005, import duties were often 0 percent for agricultural machinery (Manyong et al. 2005). More recently, some import duties have been imposed, which often differ between CKD, SKD, and fully built tractors (World Bank 2014). At times, including the latest tariff structure as of October 2016 (Takeshima \& Lawal 2018), all types of agricultural tractors have been exempted from import duties.

\section{CONCESSIONAL LOANS}

Whereas concessional loans are often used as part of South-South cooperation in several countries in Africa south of the Sahara, including Nigeria, the use of concessional loans for tractor imports seems to have been less common in Nigeria. This may be partly because in Nigeria, the 37 state governments often import tractors, and imports by the federal government have generally accounted for a small share of total imports. It is, however, not surprising if 
there are ongoing discussions between the state governments in Nigeria and foreign governments, which may later lead to the development of bilateral agreements.

Small tractors are generally less common in Nigeria, and importation of smaller Chinese tractors seems to have been minimal. This may be partly because China's concessional loans are not applied to tractor importations into Nigeria. In contrast, the shares of Indian four-wheel tractors seem to have been growing in Nigeria, including Mahindra and Sonalika brands, India's two major manufacturers. AGCO's Massey-Ferguson tractors are another new brand of tractor that is relatively commonly marketed. Both Mahindra and Sonalika set up tractor assembly lines in Nigeria in the late 2000s, to expand sales in both the Nigerian market and the rest of the West African region. Such growth seems to have been driven by the general growth of various private Indian companies' entries into Nigeria since its transition into a democratic regime in 1999 (Osondu-Oti 2015), rather than simply due to the Indian government's general interests in strengthening ties with Nigeria. Because Nigeria is the largest source of oil imported into India to meet its growing energy demand, this demand often motivates the use of concessional loans.

\section{Industrial Policy on Machinery Manufacturing}

Although Nigeria has attempted in the past to manufacture tractors domestically, it has largely failed. In the 1970s, two tractor assembly plants and the National Center for Agricultural Mechanization (NCAM) were established, with the aim of releasing 5,000 tractors per year (Jabbar 1995). Specifically, Nigeria Truck Manufacturers (NTM), assemblers of Fiat tractors as well as Fiat trucks, and Steyr Nigeria Ltd., assemblers of Steyr tractors and Steyr trucks, were both established in the 1970s. Similarly, Peugeot Automobile Nigeria Limited (PAN) and Volkswagen of Nigeria Limited (VWON) were established in Kaduna and Lagos, respectively, to assemble passenger cars from imported CKD parts and components, through joint ventures between the Nigerian government and the respective companies (Adubifa 1993, 43). However, both NTM and Steyr Nigeria Ltd. folded up within 10 years of their establishment, and PAN and VWON also closed within a short period of operations. Even while in operation, many of these companies complemented their sales with imported implements and equipment. Besides, government policy that production incorporate a minimum of 30 percent local content was never adhered to, because of the often low quality of locally produced raw materials such as steel (Adubifa 1993; Oni 2011). 
Attempts to raise the local manufacturing capacity have also been made. Mechanization units have been set up within the Agricultural Development Projects as well as the state and federal governments. These institutions and NCAM have been assigned a mandate to coordinate the local research and development $(\mathrm{R} \& \mathrm{D})$ conducted by 140 institutions, including universities, polytechnic institutes, research institutes, industrial development centers, incubation centers, and colleges of agriculture, and provide training for machine operators, mechanics, blacksmiths, and artisans at sites such as the Rural Artisan Training Support Unit in Ilorin (Ajibola and Zalla 2007). However, the extent of such activities, as well as the impact, is relatively unknown.

\section{Machine Ownership and Market Institutions for Mechanization Service Provision}

Currently, tractors in Nigeria are sold by both the large importers mentioned above and small and medium-size retailers. Several importers in Nigeria tend to meet the demand by institutional clients, such as state governments (for their tractor distribution programs), sugarcane estates, international groups, and Zimbabwean farmers in Kwara state (Ajibola and Zalla 2007; authors' fieldwork in 2014). These importers import either the finished product or equipment in CKD format, the latter of which is sold to distributors who assemble the machines. Some importers have specific clients and send technicians to provide services under contract (Ajibola and Zalla 2007). In addition, a number of tractor retailers, ranging from medium-scale retailers selling about 100 tractors per year to small-scale retailers selling 10-30 tractors per year (new, refurbished, or a combination of both), also operate in Nigeria. Small-scale retailers focus more on repair and maintenance; sales of tractors are often supplementary for them. These small retailers transact mostly with individual farmers. In Zaria, the second-largest city in Kaduna state, there are several small-scale retailers of this type. Small-scale retailers are likely to be the major source of secondhand tractors for individual buyers. Whereas some state governments still directly supply new tractors, these private-sector agents currently largely serve the tractor hiring service (THS) providers in Nigeria.

In Nigeria, there have been both THS providers run by the public sector and those run by the private sector. However, the public-sector THS has gradually been overtaken by that of the private sector. The Living Standards Measurement Study-Integrated Surveys on Agriculture (LSMS-ISA) survey indicates that a majority of THSs are provided by the private sector, as well as friends, neighbors, or relatives (Table 13.9). 
TABLE 13.9 Sources of tractor services in 2010 rainy season (percentages), Nigeria

\begin{tabular}{lc}
\hline Source & Share (\%) \\
\hline Private markets & 42 \\
Government & 28 \\
Friends/neighbors & 14 \\
Relatives & 10 \\
Others & 7 \\
\hline Source: Authors' calculations based on Living Standards Measurement Study- \\
Integrated Surveys on Agriculture, 2010. \\
Note: The percentages are calculated using sample weights. Because of rounding, \\
shares may not add up to 100.
\end{tabular}

\section{PUBLIC-SECTOR TRACTOR HIRING SERVICES}

In Nigeria, some of the first public-sector THUs were established in 1958 in the former Western region, which is now Oyo, Ondo, Ogun, and Bendel states (Makanjuola et al. 1990). The first National Development Plan (19621968) expanded THUs (Asoegwu and Asoegwu 2007). In the early 1970s, state governments were mostly in charge of the operation of government THUs (Manyong et al. 2005). Land clearing was also subsidized. Earlier THUs did not always provide services for farms. For example, at the Akure tractor station in southwestern Nigeria, 86 percent of the total work done in 1970 consisted of mowing school and police compounds (Kolawole 1972). Mechanics who could repair tractors were often few (Kolawole 1972). Publicsector THUs were expanded gradually after the 1970s. In 1983, more than 3,000 four-wheel and 300 single-axle tractors were in operation in more than 250 THUs distributed all over the country (Akinola 1987). In most cases, the government THUs were subsidized by 25-50 percent (Manyong et al. 2005), apart from the government's purchase of tractors and paying of wages and salaries (Akinbamowo 2011, 2).

By the mid-1980s, the government THUs were largely considered inefficient (Akinbamowo 2011); delays were frequent, forcing many farmers to travel distances of about $60 \mathrm{~km}$ or more about 10 to 15 times to visit the hire stations before being served (Akinola 1987, 66). By the mid-1980s, it was recommended that all government THUs be phased out within two years to be replaced by privately owned THUs (Akinbamowo 2011). For example, in Ondo state, THUs were commercialized by transferring 102 tractors and assorted equipment to the Ondo State Investment Holding Company (1989-1992) and later the Agricultural Inputs Supply Company (1992-1999) 
(Akinbamowo 2011). Other government THUs were also gradually transferred to the private sector.

Recently, the federal government of Nigeria shifted its focus from the direct distribution of subsidized tractors to the promotion of private-sector THSs. Currently, the Nigerian government is pursuing a mechanization implementation program (MIP), which focuses on establishing private sectormanaged tractor hiring enterprises called Agricultural Equipment Hiring Enterprises (AEHEs). The MIP also provides subsidies for small-scale farmers (those cultivating between $0.5 \mathrm{ha}$ and $4.0 \mathrm{ha}$ ) who use tractor services. As of 2016, about 80 AEHEs had been set up within key industrial clusters, each with five tractors plus implements, five two-wheel tractors, and a few other harvesters or threshers, operated by the private sector, including farmers, cooperatives, or investors. ${ }^{6}$

\section{PRIVATE-SECTOR TRACTOR HIRING SERVICES: FARMER-TO-FARMER SERVICE PROVISION}

By the mid-1980s, private-sector THUs were growing (Akinola 1987). Whereas various types of tractor ownership and service provision have been promoted, including cooperative, joint, or enterprise ownership, as briefly mentioned above, the most common type is the individual ownership of tractors by farmers, who provide farmer-to-farmer THSs.

Although nationally representative figures are, to the authors' knowledge, unavailable, a case study of 111 tractor owners in two Nigerian states, Kaduna and Nasarawa (Takeshima et al. 2014), provides useful insights into key characteristics of the tractor owners. The case study compared two types of tractor owners: (1) government-sourced (GS) tractor owners, who selected and obtained tractors from the government, and (2) market-sourced (MS) tractor owners, who obtained tractors from the market.

\section{BRANDS, SOURCES OF TRACTORS, AND FINANCING}

Tractors owned by sampled tractor owners varied in terms of brand, including Fiat, Ford, Massey Ferguson, Mahindra, New Holland, Steyr, and Tak tractors. Common brands and financing of tractors differed considerably between the MS owners and GS owners. Typically, MS owners had obtained secondhand tractors, which were mainly Steyr, Fiat, and Ford brands, whereas GS owners had obtained new tractors (New Holland, Massey Ferguson), although Massey Ferguson and Mahindra were owned extensively by both MS and GS owners. Relatively few tractors were registered, despite the requirements to do

6 Personal communications with Federal Ministry of Agriculture and Rural Development staff, February 28, 2018. 
so. This was particularly so among MS owners. For MS owners, 80 percent of tractor acquisition costs were financed by personal savings and informal loans. For GS owners, about 34 percent of the costs were financed by government loans, although 40 percent of the costs were still financed by private savings and informal loans.

\section{KEY CHARACTERISTICS OF SERVICE PROVISION}

Significant shares of tractor use are dedicated for the owners' own farms. Table 13.10 summarizes the typical area cultivated by each tractor per year, through hiring out and own-farm use. Typically, own-farm use accounts for 25-30 percent of the total area served by tractors. Tractor owners often value tractors for own-farm use more than for hiring out; in terms of perceived value, own-farm use accounts for 33-50 percent of total value extracted from tractor use (Takeshima et al. 2014). Such higher perceived value of own-farm use may reflect higher marginal returns than the competitive market prices owners can charge for hiring out. MS owners in the sample cultivated greater area per tractor per year (Table 13.10). On average, MS owners operated 169 ha at the mean and 133 ha at the median. These are statistically significantly higher than the mean and median among GS owners-103 and 70 ha, respectively (Table 13.10).

Tractors are used for a few activities. Table 13.11 summarizes how many hectares of different farming activities and how many hours of different nonfarm activities tractors are used for. Typically, harrowing, plowing/tilling, and ridge making account for a majority of farming use. For each of these, ownfarm use accounts for about a quarter of the total farming use of tractors. For nonfarm activities, transporting farm products or nonfarm goods accounts for the majority of tractor use. Own-farm use accounts for about 40 percent of total tractor use for nonfarm activities.

The extent of service provision is fairly seasonal, but MS owners are more active than GS owners throughout the year (Figure 13.1, left-hand panel). The asterisks in the figure indicate statistically significant differences between the two groups (at 10 percent statistical significance). In June, MS tractor owners operated close to 150 hours per tractor on average, whereas they operated for only 44 hours in September. The off-season hours operated by MS owners were still often greater than those operated by GS owners.

Figure 13.1, right hand-panel, illustrates the extent of travel by the service providers from home districts, measured in Euclidean distance, in each month. For example, on average, tractor owners stayed $6 \mathrm{~km}$ away from their home districts in January. This could mean either they spent the whole month 
TABLE 13.10 Area cultivated annually per tractor (hectares per year), Nigeria, 2013

\begin{tabular}{lccccc}
\hline & \multicolumn{2}{c}{ Government-sourced tractor owners } & & \multicolumn{2}{c}{ Market-sourced tractor owners } \\
\cline { 2 - 3 } \cline { 5 - 6 } Category & Mean & Median & & Mean & Median \\
\hline Total farming & 103 & 70 & & $169^{*}$ & $133^{\star}$ \\
Hired-out farming & 74 & 30 & & 128 & 88 \\
Own farming $^{\text {a }}$ & 29 & 16 & & 41 & 23 \\
\hline
\end{tabular}

Source: Takeshima et al. (2014).

Note: * $=10$ percent statistical significance. a. Counted multiple times if multiple operations (plowing, harrowing, ridge making) are applied to the same plots.

TABLE 13.11 Average annual tractor use by farming activity (all tractors combined), Nigeria, 2013

\begin{tabular}{|c|c|c|c|c|c|c|}
\hline \multirow[b]{2}{*}{ Type of activity } & \multicolumn{2}{|c|}{ Hiring } & \multicolumn{2}{|c|}{ Own farm } & \multicolumn{2}{|c|}{ Total } \\
\hline & Mean & Median & Mean & Median & Mean & Median \\
\hline \multicolumn{7}{|l|}{ Farming (ha) } \\
\hline Land clearing & 1 & 0 & 0 & 0 & 1 & 0 \\
\hline Harrowing & 74 & 33 & 21 & 11 & 94 & 60 \\
\hline Plowing, tilling & 49 & 11 & 16 & 8 & 64 & 45 \\
\hline Ridge making & 30 & 0 & 12 & 0 & 42 & 0 \\
\hline Rotovating & 2 & 0 & 1 & 0 & 3 & 0 \\
\hline Planting, weeding & 2 & 0 & 1 & 0 & 3 & 0 \\
\hline Harvesting & 1 & 0 & 0 & 0 & 1 & 0 \\
\hline Total farming ${ }^{\mathrm{a}}$ & 156 & 74 & 51 & 25 & 208 & 124 \\
\hline \multicolumn{7}{|l|}{ Nonfarm activities (hours) } \\
\hline Milling, threshing, processing & 2 & 0 & 7 & 0 & 9 & 0 \\
\hline Transporting farm products & 103 & 0 & 75 & 18 & 178 & 98 \\
\hline Transporting nonfarm goods & 44 & 0 & 22 & 0 & 67 & 0 \\
\hline Local transportation & 6 & 0 & 1 & 0 & 7 & 0 \\
\hline Fetching water & 8 & 0 & 3 & 0 & 10 & 0 \\
\hline Firewood transport & 13 & 0 & 5 & 0 & 17 & 0 \\
\hline Total nonfarm $^{\mathrm{a}}$ & 177 & 10 & 112 & 30 & 290 & 179 \\
\hline
\end{tabular}

Source: Takeshima et al. (2015).

Note: ${ }^{a}$ Figures may not add up to total due to rounding.

in a district that is $6 \mathrm{~km}$ from their home district, or they spent half the month in their home district ( $0 \mathrm{~km}$ away) and the rest of the month in a district that is $12 \mathrm{~km}$ away (so that the within-month average is $6 \mathrm{~km}$ ), regardless of the direction of travel. This is a crude, yet useful, indicator of how the extent of their travels varies across seasons. The extent of travel is generally 
FIGURE 13.1 Seasonality of tractor use, hours per month, by tractor owners (left panel); average distance between home district and where hiring services are provided (right panel); Nigeria, 2014
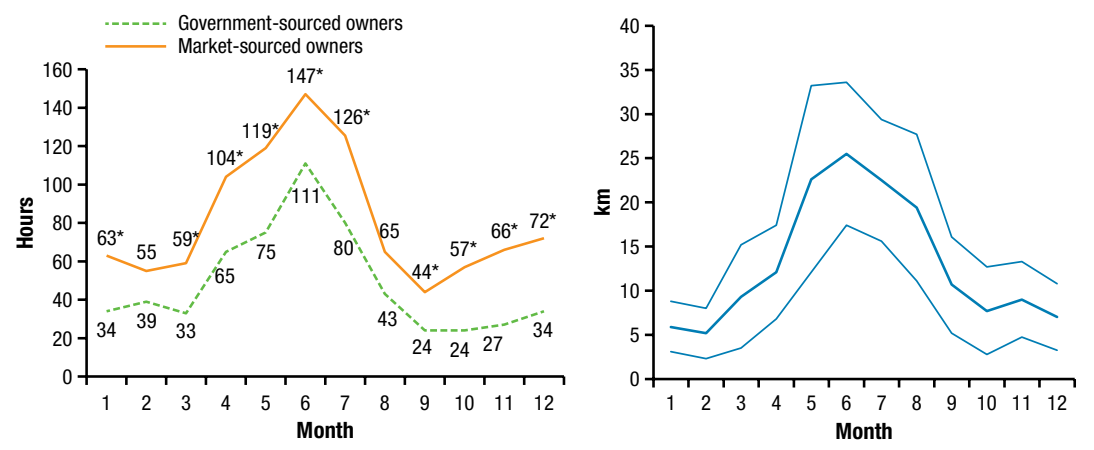

Source: Takeshima et al. (2014), based on 111 samples of tractor owners in Nasarawa and Kaduna states combined. Note: * Indicates the statistically significant difference from the figures for the government-sourced owners. In the right panel, the narrower lines indicate a $90 \%$ confidence interval around the average in each month.

low. On average, tractor owners stay only $10-15 \mathrm{~km}$ away from their home districts throughout the year. Distribution is also highly skewed, however, and the average is driven by a fraction of owners who spent time far away from their home districts. The operations are therefore generally confined to interviewees' home districts and to neighboring or adjacent districts, except for a few service providers who travel relatively long distances. Even during the peak season, service providers other than these long-distance travelers typically operate within a $25-30 \mathrm{~km}$ radius of their home districts. Typically, 75 percent of hiring services are provided within the LGA, and half of all hiring services are provided within the village. Moreover, a substantial share of operations is conducted on the tractor owners' own farms. Therefore, tractor owners typically conduct more than 80 percent of their operations within their own LGAs. MS owners are relatively more efficient than GS owners because, when they do travel, they tend to travel to areas with soils that are suitable for the horsepower of the tractors they own (Takeshima et al. 2015).

\section{PROFITABILITY}

Table 13.12 summarizes the revenues and costs of tractor use, by both GS owners and MS owners. MS owners earn annual revenues of $\$ 13,000$ at the mean and $\$ 11,000$ at the median (including the self-evaluated value of ownfarm use), which are statistically significantly higher than those of GS owners $(\$ 5,000$ at the median and $\$ 8,000$ at the mean). For both types of owners, 
TABLE 13.12 Profitability differences between types of tractor owner-operators (in US\$1,000s), Nigeria, 2013

\begin{tabular}{lcccccc}
\hline & \multicolumn{2}{c}{$\begin{array}{c}\text { Government-sourced } \\
\text { tractor owners }\end{array}$} & & & \multicolumn{2}{c}{$\begin{array}{c}\text { Market-sourced } \\
\text { tractor owners }\end{array}$} \\
\cline { 2 - 3 } \cline { 5 - 6 } Category & Mean & Median & & Mean & Median \\
\hline Total gross benefits per year & 8 & 5 & & $13^{*}$ & $11^{*}$ \\
Monetary value of own-farm use & 2 & 1 & & 4 & 3 \\
Farming activities & 2 & 1 & & 3 & 1 \\
Nonfarm activities & 0 & 0 & & 1 & 0 \\
Gross earnings from hiring out & 6 & 4 & & 9 & 6 \\
Farming activities & 5 & 3 & & 7 & 5 \\
Nonfarm activities & 1 & 0 & & 2 & 1 \\
Payment for operators and fuel & 3 & 1 & & 5 & 3 \\
Operators & 1 & 0 & & 2 & 1 \\
Fuel & 2 & 1 & & 3 & 2 \\
Maintenance and repair & 1 & 1 & & 1 & 1 \\
\hline
\end{tabular}

Source: Takeshima et al. (2014).

Note: ${ }^{*}=10$ percent statistical significance.

earnings from farming-related use account for 80-90 percent of total earnings. Earnings from hiring services account for 70 percent of total earnings. MS owners therefore use tractors to a greater extent than do GS owners for both own use and hiring, as well as for both farm and nonfarm activities. Differences of fuel and operator payments are small and statistically insignificant between MS owners and GS owners, as compared with the differences in the gross benefits. MS owners pay statistically significantly less for fuels, and sometimes for operators per unit for farming and nonfarm operations, than GS owners do (Takeshima et al. 2014). The maintenance and repair costs are not statistically significantly different between MS and GS owners.

In addition, in Nasarawa state, a significant share (23 percent) of sampled MS owners travel in a group. These group travelers earn more from hiring services than those who travel alone (Takeshima et al. 2014), indicating that forming a group is motivated by potentially greater returns.

Overall, there are private-sector THS providers in Nigeria who remain largely in the informal sector but have invested in tractors through personal savings and informal loans, and who provide more extensive services than those who are supported by the government. They do so despite the considerable seasonality in demand and generally limited mobility of tractors. 


\section{The Role of Mechanization in Agricultural Transformation}

This section provides empirical evidence of various effects of the adoption of tractors on agricultural productivity, intensification, and farm household welfare, using the LSMS-ISA 2010 and 2012, and narratives based on past studies. These effects are estimated using the propensity score matching (PSM) method (detailed technical issues are discussed in Appendix 13B). The estimates should be interpreted as the effects experienced by actual tractor adopters and cannot be generalized to include the effects for nonadopters. ${ }^{7}$ Because most adopters operate relatively larger farms (although many are still smallholders), the findings cannot be generalized as potential effects for smaller farms that have yet to adopt tractors. Due to the low level of tractor use growth, it is generally difficult to assess the role of mechanization in agricultural transformation. This is particularly so for mechanized harvesting. There are, however, some observed effects of mechanization on key economic behaviors and outcomes, which offer insights into how mechanization is related to the agricultural transformation that is unique in Nigeria.

\section{Substitution for Animal Traction}

The clearest effect of tractor adoption is found in its substitution for animal traction (Table 13.13). Generally, on average, adopting tractors leads to a 2-day reduction in the use of animal traction (using owned and rented animals combined) and a 1.4-day reduction in the use of animal traction by the farmer's own draft animals. In addition, adopting tractors reduces the probability of using animal traction by 20 percentage points. This effect is statistically significant at 5 percent and also robust against the violation of the unconfoundedness assumption in the PSM. These effects hold both at the national level and within the North West and North East zones, where the use of animal traction is particularly high.

\section{Significant Effects on Chemical Fertilizer Use and Area Cultivated}

Tractor adoption is also found to significantly increase both the area cultivated, by 0.4 ha on average, and the likelihood of the use of chemical fertilizer, by 13.7 percentage points (Table 13.14). Tractor use therefore seems to induce greater use of land and chemical fertilizer. Although not shown, the effects on

7 This is because we rely on average treatment effects "on the treated" (adopters), whose consistency requires fewer assumptions than average treatment effects for the entire population. 
TABLE 13.13 Effects of tractor adoption on animal traction use, Nigeria, 2010, 2012

\begin{tabular}{lccccc}
\hline & $\begin{array}{c}\text { Use of animal } \\
\text { traction } \\
\text { (days) }\end{array}$ & $\begin{array}{c}\text { Use of own } \\
\text { animal traction } \\
\text { (days) }\end{array}$ & $\begin{array}{c}\text { Use of rented } \\
\text { animal traction } \\
\text { (days) }\end{array}$ & $\begin{array}{c}\text { Whether using } \\
\text { animal traction } \\
\text { (yes }=1)\end{array}$ & $\begin{array}{c}\text { Whether using } \\
\text { own animal } \\
\text { traction } \\
\text { (yes }=1)\end{array}$ \\
\hline Whole sample & $-1.91^{\star \star}(.86)$ & $-1.36^{\star \star}(.67)$ & $-.55(.45)$ & $-.20^{\star \star *}(.05)$ & $-.11^{\star \star}(.04)$ \\
NW and NE & {$[2.73]$} & {$[2.98]$} & & {$[2.11]$} & {$[1.50]$} \\
& $-2.20^{\star \star}(1.08)$ & $-1.28^{\dagger}(.87)$ & $-.93^{\dagger}(.62)$ & $-.22^{\star \star *}(.07)$ & $-.11^{\star}(.06)$ \\
& {$[1.76]$} & & & {$[1.87]$} & {$[1.27]$} \\
\hline
\end{tabular}

Source: Living Standards Measurement Study-Integrated Surveys on Agriculture, 2010, 2012.

Note: Statistical significance: ${ }^{\star \star \star} 1 \%,{ }^{\star \star} 5 \%,{ }^{*} 10 \%, \dagger 15 \%$. NE = North East; NW = North West. Numbers in parentheses indicate the standard errors. Numbers in brackets indicate the Rosenbaum bounds of the robustness of results.

TABLE 13.14 Effects of tractor adoption on chemical fertilizer use, crop revenues, and household income, Nigeria, 2010, 2012

\begin{tabular}{ccccc}
\hline & $\begin{array}{c}\text { Use chemical } \\
\text { fertilizer } \\
(\text { yes }=1)\end{array}$ & $\begin{array}{c}\text { Real household } \\
\text { income } \\
\text { (PP period) }\end{array}$ & $\begin{array}{c}\text { Real household } \\
\text { income } \\
\text { (PH period) }\end{array}$ & $\begin{array}{c}\text { Real household } \\
\text { income (PP and PH } \\
\text { combined) }\end{array}$ \\
\hline $.410^{\star \star \star}(.144)$ & $.137^{\star \star}(.060)$ & $.148 \dagger(.097)$ & $.136(.098)$ & $.128 \dagger(.080)$ \\
{$[1.23]$} & {$[1.37]$} & {$[1.30]$} & {$[1.15]$} & {$[1.22]$} \\
\hline
\end{tabular}

Source: Living Standards Measurement Study-Integrated Surveys on Agriculture, 2010, 2012.

Note: Statistical significance: ${ }^{* \star} 1 \%,{ }^{* \star} 5 \%,{ }^{*} 10 \%, \dagger 15 \%$. PH = postharvesting; PP = postplanting. Numbers in parentheses indicate the standard errors. Numbers in brackets indicate the Rosenbaum bounds of the robustness of results.

cropping systems are found to be generally insignificant, indicating that such intensifications of land and chemical fertilizer use generally occur while preserving the current cropping systems.

Tractor use is also found to have slightly significant effects on household income (with less statistical significance). Specifically, it raises real household income during the postplanting period by 14.8 percent and in the postharvesting period to a lesser extent. Overall, tractor adoption seems to increase real household income by 13 percent. Although these effects are relatively less precise than those in Table 13.13, due to the small sample size, they still indicate the general directions of tractor adoption's impacts.

\section{Relatively Insignificant Effects on Labor Use}

In contrast to the substitution for animal traction use and the effects on land and chemical fertilizer use and real household income, the effects of tractor adoption on labor use are generally insignificant (Table 13.15). In addition, the effects are also insignificant on hired labor for harvesting. The effects on labor are insignificant for both the postplanting season and the postharvesting season, as well as for male, female, and child workers. The impacts on off-farm 
TABLE 13.15 Effects of tractor adoption on household labor use and off-farm income, Nigeria, 2010, 2012

\begin{tabular}{|c|c|c|c|c|c|c|c|}
\hline \multicolumn{3}{|c|}{$\begin{array}{l}\text { Farm labor use from postplanting } \\
\text { survey (person-days, 12-month } \\
\text { equivalent) }\end{array}$} & \multicolumn{3}{|c|}{$\begin{array}{c}\text { Farm labor use from postharvesting } \\
\text { survey (person-days, 12-month } \\
\text { equivalent) }\end{array}$} & \multicolumn{2}{|c|}{$\begin{array}{c}\text { Hired labor use for } \\
\text { harvesting (person-days) }\end{array}$} \\
\hline $\begin{array}{l}\text { Adult } \\
\text { males }\end{array}$ & $\begin{array}{c}\text { Adult } \\
\text { females }\end{array}$ & Children & $\begin{array}{l}\text { Adult } \\
\text { males }\end{array}$ & $\begin{array}{l}\text { Adult } \\
\text { females }\end{array}$ & Children & Males & Females \\
\hline $\begin{array}{c}10.037 \\
(12.123)\end{array}$ & $\begin{array}{c}4.457 \\
(12.134)\end{array}$ & $\begin{array}{c}17.844 \\
(22.019)\end{array}$ & $\begin{array}{c}23.417 \\
(22.549)\end{array}$ & $\begin{array}{l}-18.035 \\
(28.922)\end{array}$ & $\begin{array}{l}-1.844 \\
(30.792)\end{array}$ & $\begin{array}{l}3.655 \\
(4.029)\end{array}$ & $\begin{array}{l}-.367 \\
(2.227)\end{array}$ \\
\hline \multicolumn{3}{|c|}{$\begin{array}{l}\text { Off-farm labor use from postplanting } \\
\text { survey (person-days, 12-month } \\
\text { equivalent) }\end{array}$} & \multicolumn{3}{|c|}{$\begin{array}{l}\text { Off-farm labor use from } \\
\text { postharvesting survey (person-days, } \\
\text { 12-month equivalent) }\end{array}$} & \multirow{2}{*}{$\begin{array}{l}\text { Nonfarm } \\
\text { salary } \\
\text { (equivalent } \\
\text { to kg of } \\
\text { cereals) }\end{array}$} & \multirow{2}{*}{$\begin{array}{l}\text { Probability } \\
\text { of having } \\
\text { nonfarm } \\
\text { income (\%) }\end{array}$} \\
\hline $\begin{array}{l}\text { Adult } \\
\text { males }\end{array}$ & $\begin{array}{c}\text { Adult } \\
\text { females }\end{array}$ & Children & $\begin{array}{l}\text { Adult } \\
\text { males }\end{array}$ & $\begin{array}{l}\text { Adult } \\
\text { females }\end{array}$ & Children & & \\
\hline $\begin{array}{l}-3.474 \\
(13.967)\end{array}$ & $\begin{array}{c}-3.813 \\
(17.485)\end{array}$ & $\begin{array}{l}-18.845 \\
(13.579)\end{array}$ & $\begin{array}{c}12.151 \\
(24.987)\end{array}$ & $\begin{array}{c}2.480 \\
(30.923)\end{array}$ & $\begin{array}{c}4.298 \\
(25.879)\end{array}$ & $\begin{array}{c}-795.100 \\
(1009.661)\end{array}$ & $\begin{array}{c}7.2 \\
(5.8)\end{array}$ \\
\hline
\end{tabular}

Source: Living Standards Measurement Study-Integrated Surveys on Agriculture, 2010, 2012.

Note: Numbers in parentheses indicate the standard errors.

labor use, nonfarm salary, and the likelihood of having nonfarm income are also insignificant. Tractor adoption therefore may not be inducing significant transitions from farming to off-farm activities.

Overall, currently, the effect of mechanization on agricultural transformation in Nigeria is somewhat unique. Tractor adoption seems to be helping smallholders survive and become more productive, rather than inducing their exit from farming. This is partly consistent with the economic structures in Nigeria. The share of the labor force in the agricultural sector in Nigeria is already somewhat low given the level of mechanization; about 50 percent of the workforce has left farming even though the tractor adoption rate is only 8 percent (Takeshima 2015a). Those who are still in farming may be those who are less induced to exit farming due to various characteristics and household-specific constraints. Tractor adoption is used, rather, to help them become more productive.

In Nigeria, exit from farming has occurred without mechanization, possibly because of low agricultural support (such as R\&D) and labor absorption in the nonfarm sector (oil sector, financial industry, and so on). Tractors seem to be primarily substituting for animal traction, rather than for labor. Mechanization itself does not induce a further significant exit from farming or shift of labor into the nonfarm sector. However, tractor use helps those who 
have remained in farming to narrow their income gap with nonfarm households, partly by increasing area cultivated and the use of inputs such as chemical fertilizer.

\section{Tractor Use and Soil Compaction}

The effects of mechanization on soil compaction are known to be some of the key environmental consequences of applying greater weight on the plot. Whether these effects are particularly greater in Nigeria or not is still under investigation in the literature.

The heavy tractor weights are still one of the primary causes of soil compaction. In Nigeria, as was mentioned above, a majority of tractors imported are greater than $60 \mathrm{hp}$, with weights of more than 3.5 metric tons, which exceeds the limit set for soils resistant to compaction (Ahaneku and Asonibare 2014). Such a high average weight of tractors in Nigeria may be potentially damaging to the soils. Some soils are easily compacted; they include those that predominate in the fine sand and silt fractions in the Sahel, commonly found in northern Nigeria (Lal 1985). Similarly, for sandy loam soils in northern Nigeria, the dry bulk density of soils that changes due to tractor traffic before sowing does not get recovered during the production season (Mamman and Ohu 1997; Dauda and Samari 2002).

However, high-horsepower tractors do not necessarily cause more soil compaction than small tractors. This is because often soil compaction is aggravated by the greater number of passes, so that reducing the number of passes by using units that carry out several operations also generally reduces the soil degradation (Hamza and Anderson 2005). Sometimes stronger tractors are also needed to break up the compacted soils (Lal 1995). Sometimes yields respond to traction intensity in an inverted U-shaped curve-that is, they respond positively to the initial few tractor passes, and negatively afterward (Lal 1995). Similarly, animal traction can have a possibly significant effect on soil compaction (Soane and van Ouwerkerk 1994). Depending on its severity, switching from animal traction to tractors may not substantially aggravate soil compaction. Whereas the effects of soil compaction on Alfisols (Lixisols, Luvisols, and Nitisols) have been relatively commonly studied (Lal 1995), the effect on Fluvisols is generally understudied, even though Fluvisols are one of the major soil types in Nigeria on which tractors are used (Table 13.16). In addition, many earlier studies focused on crops other than rice (Lal 1995), although tractors are mostly used on rice in Nigeria. 
TABLE 13.16 Soil types and tractor use in Nigeria, 2010, 2012

\begin{tabular}{lcc}
\hline Soil type & $\begin{array}{c}\text { Share of tractor-using households, } \\
\text { by soil type (\%) }\end{array}$ & $\begin{array}{c}\text { Share of area cultivated by tractors, } \\
\text { by soil type (\%) }\end{array}$ \\
\hline Fluvisols & 26 & 34 \\
Lixisols & 5 & 29 \\
Luvisols & 19 & 14 \\
Nitisols & 2 & 9 \\
Arenosols & 4 & 6 \\
Leptosols & 7 & 5 \\
Plinthosols & 5 & 2 \\
Others & 32 & 1 \\
\hline
\end{tabular}

Source: Authors' calculations based on data from Living Standards Measurement Study-Integrated Surveys on Agriculture (2010 and 2012 combined) and FAO et al. (2012).

\section{Conclusions}

The adoption patterns suggest that demand for mechanization in Nigeria is growing in a fairly consistent way, as predicted by economic theory.

Substantial growth in the adoption of animal traction indicates that the demand for increased farm power is rising in Nigeria, consistent with the increase in overall population density. At the intensive margin, however, adoption of animal traction may still be low. Real farm wages may still be low in northern Nigeria. These factors are consistent with the low overall demand for tractor use in Nigeria. Where tractors are adopted, adoption seems induced by greater overall farmland endowment per population in the area, a larger size of tractor owners' farms, and cropping systems centered around plow-positive crops such as rice. When there is sufficient demand for tractors, the private sector has emerged over time as the source of more efficient service providers (particularly farmer-to-farmer service providers) than the public sector as far as meeting greater demand and overcoming the seasonality of demand and limited mobility. These patterns are consistent with the experiences described in the Asian chapters. These conditions suggest that demand factors considerably explain the low adoption of tractors in Nigeria. Conditions are consistent with the hypotheses that (1) because of generally low support for the agricultural sector in the past few decades in Nigeria, the growth in the nonagricultural sector increased the country's reliance on food importation, rather than domestic production intensity, and (2) agricultural mechanization (tractor use in particular) has remained low despite the declining share of the workforce engaged in the agricultural sector. This is in contrast to experiences 
in some Asian countries, such as Viet Nam (among others), where significant agricultural-sector investments in complementary technologies and agricultural infrastructure in the 1980s and 1990s partly led to the growth of mechanization in the 1990s and afterward.

Where tractors have been adopted, such adoption has generally helped smallholders to remain in farming, rather than inducing their exit from farming. This pattern is similar to experiences in some Asian countries, such as Nepal (as described in its chapter). Tractor adoption has not directly induced agricultural transformation in Nigeria. Agricultural transformation in the form of a declining agricultural labor force has happened partly through the growth of the oil industry since the 1970s. Tractor adoption might have, rather, helped those who remained in farming due to remoteness (and relative farmland abundance) to start expanding their scale of farming.

Last, there are still knowledge gaps, which need to be addressed in future studies. There are still signs of market imperfections (Takeshima 2015a). Accessibility of a custom hiring service may remain a constraint, possibly due to the dominance of expensive, high-horsepower tractors in Nigeria. It is unclear why small tractors are so few, relative to large tractors. Experiences in Asia suggest that technical support by the government through mechanization $\mathrm{R} \& \mathrm{D}$ on more diverse types of machines - rather than just large, high-horsepower tractors-may be needed to stimulate the private sector's importation and adaptation of smaller tractors. Furthermore, agricultural productivity growth and tractor use growth have been stagnant in Nigeria. Because of this, the linkages between agricultural productivity growth and tractor use growth remain largely unknown, even though several of the Asian chapters point toward significant productivity effects of mechanization for smallholders. Future studies will have to continue investigating how the increase in labor costs affects smallholder farmers, how tractor use growth may help smaller farmers who are yet to adopt tractors, and how wider-scale mechanization growth continues to affect the economic transformation in Nigeria.

\section{References}

Adubifa, A. 1993. "Technology Policy in National Development: A Comparative Study of the Automobile Industry in Nigeria and Brazil." Journal of Asian and African Studies 28 (1-2): $42-53$.

Ahaneku, I. E., and O. F. Asonibare. 2014. "Compaction Characteristics of Some Agricultural Soils in Niger State of Nigeria." Agricultural Engineering 4: 11-20. 
Ajibola, F., and T. Zalla. 2007. Value Chain Study of Small-Scale Agricultural Mechanization. DFID PrOpCom Monograph Series 9. London: United Kingdom Department for International Development.

Akinbamowo, R. 2011. "Trends and Challenges to Government Tractor Hiring Units in Ondo State, Nigeria." Journal of Agricultural Engineering and Technology 19 (2): 1-8.

Akinola, A. 1987. "Government Tractor Hire Service Scheme as a Tractorization Policy in Africa: The Nigerian Experience." Agricultural Administration \& Extension 25 (2): 63-71.

Alesina, A., P. Giuliano, and N. Nunn. 2013. "On the Origins of Gender Roles: Women and the Plough." Quarterly Journal of Economics 128 (2): 469-530.

Alsan, M. 2015. “The Effect of the Tsetse Fly on African Development." American Economic Review 105 (1): 382-410.

Asoegwu, S., and A. Asoegwu. 2007. "An Overview of Agricultural Mechanization and Its Environmental Management in Nigeria." Agricultural Engineering International: The CIGR eJournal 6 (9): 1-22.

Barker, R., R. W. Herdt, and B. Rose. 1985. The Rice Economy of Asia. Washington, DC: Resources for the Future.

Bello, A. 2005. Keynote address at commissioning of AFCOTT Mahindra Tractor Assembly Plant, Eleyele, Ibadan, Nigeria, September 15.

Busari, D., and E. Udeaja. 2007. "Tariff and Factor Allocation in a Small Open Economy: Nigeria." Economic and Financial Review 45 (2): 73-98.

Chamberlain, G. 1984. "Panel Data." In Handbook of Econometrics. Vol. 2, edited by Z. Grilliches and M. D. Intriligator, 1247-1318. Amsterdam: North-Holland.

Cochran, W., and D. Rubin. 1973. "Controlling Bias in Observational Studies: A Review." Sankhyā: The Indian Journal of Statistics, Series A 35 (4): 417-446.

Cragg, J. G. 1971. "Some Statistical Models for Limited Dependent Variables with Application to the Demand for Durable Goods." Econometrica 39 (5): 829-844.

Dauda, A., and A. Samari. 2002. "Cowpea Yield Response to Soil Compaction under Tractor Traffic on a Sandy Loam Soil in the Semi-Arid Region of Northern Nigeria." Soil Tillage Research 68: 17-22.

Egwaikhide, F. 1999. Determinants of Imports in Nigeria: A Dynamic Specification. African Economic Research Consortium Research Paper 91. Nairobi.

FAO (Food and Agriculture Organization of the United Nations). 2016. FAOSTAT database. Accessed August 31, 2016. http://faostat.fao.org. 
FAO, IIASA (International Institute for Applied Systems Analysis), ISRIC (International Soil Reference and Information Center), ISSCAS (Institute of Soil Science-Chinese Academy of Sciences), and JRC (Joint Research Center of the European Commission). 2012. Harmonized World Soil Database, vers. 1.2. Accessed August 1, 2012. www.fao.org/soils-portal/soil-survey /soil-maps-and-databases/harmonized-world-soil-database-v12/en/.

Gyimah-Brempong, K., M. Johnson, and H. Takeshima. 2016. The Nigerian Rice Economy: Policy Options for Transforming Production, Marketing, and Trade. Philadelphia: University of Pennsylvania Press.

Hamza, M., and W. Anderson. 2005. "Soil Compaction in Cropping Systems: A Review of the Nature, Causes and Possible Solutions.” Soil and Tillage Research 82 (2): 121-145.

Jabbar, M. 1995. "Energy and the Evolution of Farming Systems: The Potential for Mixed Farming in the Moist Savannas." In Moist Savannas of Africa: Potentials and Constraints for Crop Production: Proceedings of an IITA/FAO Workshop Held from 19-23 September 1994, Cotonou, Republic of Benin, edited by B. T. Kang, I. O. Akobundu, V. M. Manyong, R. J. Carsky, N. Sanginga, and E. A. Kueneman, 87-104. Ibadan, Nigeria: International Institute of Tropical Agriculture.

Kolawole, M. 1972. "Economic Aspects of Tractor Contracting Operations in Western Nigeria." Journal of Agricultural Engineering Research 17 (4): 289-294.

Ladeinde, M., E. Atanda, A. Ageh, S. Idowu, and S. Olayemi. 2009. “Agricultural Machinery Operators and Mechanics Training in Nigeria: An Overview of Contributions." Journal of Agricultural Engineering and Technology 17 (2): 11-18.

Lal, R. 1985. "A Soil Suitability Guide for Different Tillage Systems in the Tropics." Soil and Tillage Research 5 (2): 179-196.

1995. Tillage Systems in the Tropics: Management Options and Sustainability Implications. FAO Soils Bulletin 71. Rome: Food and Agriculture Organization of the United Nations.

Makanjuola, G. A. 1990. Agricultural Mechanization Policies and Strategies of Africa: A Case Study of Nigeria. Workshop on Agricultural Mechanization in Commonwealth Africa. Ahmadu Bello University, August 13-17.

Mamman, E., and J. Ohu. 1997. "Millet Yield as Affected by Tractor Traffic in a Sandy Loam Soil in Borno State, Nigeria." Soil Tillage Research 42: 133-140.

Manyong, V., A. Ikpi, J. Olayemi, S. Yusuf, B. Omonona, V. Okoruwa, and F. Idachaba. 2005. Agriculture in Nigeria: Identifying Opportunities for Increased Commercialization and Investment. Ibadan, Nigeria: International Institute of Tropical Agriculture.

Nigeria, NPC (National Population Commission). 2010. 2006 Population and Housing Census: Priority Tables, Volume III, Population Distribution by Sex, State, LGA \& Senatorial District. Abuja, Nigeria. 
Oni, K. C. 2011. Man, Machine and Food Insecurity. Inaugural Lecture Series 94. Ilorin, Nigeria: University of Ilorin.

Osondu-Oti, A. 2015. "An Appraisal of India-Nigeria Historical and Contemporary Relations." Alternation 15: 102-126.

Ramankutty, N., A. Evan, C. Monfreda, and J. Foley. 2008. "Farming the Planet: 1. Geographic Distribution of Global Agricultural Lands in the Year 2000.” Global Biogeochemical Cycles 22 (1): 1-19.

Rubin, D. 2001. “Using Propensity Scores to Help Design Observational Studies: Application to the Tobacco Litigation." Health Services and Outcomes Research Methodology 2 (3-4): 169-188.

Scherr, S. 1989. "Agriculture in an Export Boom Economy: A Comparative Analysis of Policy and Performance in Indonesia, Mexico and Nigeria." World Development 17 (4): 543-560.

Soane, B., and C. van Ouwerkerk. 1994. “Soil Compaction Problems in World Agriculture." In Soil Compaction in Crop Production. Vol. 11, edited by B. Soane and C. van Ouwerkerk, 1-26. Amsterdam: Elsevier.

Takeshima, H. 2015. Market Imperfections for Tractor Service Provision in Nigeria: International Perspectives and Empirical Evidence. IFPRI Discussion Paper 01424. Washington, DC: International Food Policy Research Institute.

Takeshima, H. 2016. “Understanding Irrigation System Diversity in Nigeria: A Modified Cluster-Analysis Approach." Irrigation and Drainage 65 (5): 601-612.

Takeshima, H. 2017. Overview of the Evolution of Agricultural Mechanization in Nepal, with a Particular Focus on Tractors and Combine Harvesters. IFPRI Discussion Paper 01662. Washington, DC: International Food Policy Research Institute.

Takeshima, H., H. Edeh, A. Lawal, and M. Isiaka. 2014. Tractor Owner Operators in Nigeria: Insights from a Small Survey in Kaduna and Nasarawa States. IFPRI Discussion Paper 01355. Washington, DC: International Food Policy Research Institute.

- 2015. "Characteristics of Private-Sector Tractor Service Provisions: Insights from Nigeria." Developing Economies 53 (3): 188-217.

Takeshima, H., and A. Lawal. 2018. Overview of the Evolution of Agricultural Mechanization in Nigeria. IFPRI Discussion Paper 01750. Washington, DC: International Food Policy Research Institute.

Takeshima, H., A. Nin Pratt, and X. Diao. 2013a. Agricultural Mechanization Patterns in Nigeria: Insights from Farm Household Typology and Agricultural Household Model Simulation. IFPRI Discussion Paper 01291. Washington, DC: International Food Policy Research Institute. 
- 2013b. "Mechanization and Agricultural Technology Evolution, Agricultural

Intensification in Sub-Saharan Africa: Typology of Agricultural Mechanization in Nigeria." American Journal of Agricultural Economics 95 (5): 1230-1236.

Takeshima, H., and E. Nkonya. 2014. “Government Fertilizer Subsidy and Commercial Sector Fertilizer Demands: Evidence from the Federal Market Stabilization Program (FMSP) in Nigeria." Food Policy 47: 1-12.

World Bank. 1985. Nigeria: Agricultural Sector Memorandum. Report No. 4723-UNI. Vols. I and

II. Washington, DC: World Bank.

- 2014. Agribusiness Indicators: Nigeria. Washington, DC: World Bank.

- 2016. World Development Indicators. Washington, DC: World Bank.

Zhang, X., S. Rashid, K. Ahmad, and A. Ahmed. 2014. "Escalation of Real Wages in Bangladesh: Is It the Beginning of Structural Transformation?" World Development 64: 273-285.

\section{Appendix 13A: Specifications for the Pseudo-Panel Double Hurdle Model (Table 13.8)}

Results for Table 13.8 were obtained through the following regressions. The adoption of tractors and its intensity (area cultivated) are in one way characterized as the variant of the hurdle model, in which there is a hurdle in accessing the tractor hiring market (which represents the majority of modes of tractor use among farmers in Nigeria). Following the transaction costs literature, this process is framed as follows:

$$
\begin{gathered}
d=f(X, Z), \\
T=g(X) \text { if } d=1,
\end{gathered}
$$

where $d^{1}=1$ if the farm household hires in tractor service ( $=0$ otherwise), and $T$ is the hiring intensity. $Z$ represents the specific factors that affect only the decision to hire tractors, $X$ represents the factors that affect both the decision to hire tractors and how much area on which to use tractors (such as agroecological conditions, households' farm sizes, farm wages, and access to general output and input markets other than a tractor hiring service), and $Y$ represents factors that affect both processes. The first equation can typically be estimated by a probit model in which the dependent variable $d$ is regressed on $X$ and $Z$. The second equation can be estimated using a truncated regression. Estimation of these two equations lead to Cragg's (1971) double-hurdle model. 
The specification also applies the idea of a correlated random-effects model as in Chamberlain (1984) and its pseudo-panel extension (Takeshima and Nkonya 2014) to control for some of the potentially unobserved cohortspecific effects. Specifically, we use LGAs as such cohorts. We assume that LGA sample averages of certain time-variant variables across two rounds of LSMS surveys are correlated with the unobserved LGA-specific effects. ${ }^{8}$ Inclusion of these cohort variables reduces the potential bias in the pooled cross-section method.

\section{Marginal Effects}

Marginal effects of the variable $k$ on the probability of using a tractor, evaluated at the mean of observations, are as follows:

$$
\left.\frac{\delta \operatorname{Prob}(d=1)}{\delta X_{k}}\right|_{X=\bar{X}}=\phi(\bar{X} \hat{\beta}) \hat{\beta}_{k},
$$

where $\phi(\cdot)$ is the standard normal density function and $\bar{X} \hat{\beta}$ is the linear prediction calculated with $\bar{X}$, a vector of sample mean values of each variable (among 5,241 observations), and $\hat{\beta}$, a vector of estimated coefficients from the probit regression. $\hat{\beta}_{k}$ is the estimated coefficient for variable $k$.

Marginal effects of variable $k$ on the area cultivated by tractors, conditional on using tractors, evaluated at the mean of observations, are:

$$
\left.\frac{\delta \mathrm{E}(T \mid T>0, X)}{\delta X_{k}}\right|_{X=\dot{X}}=\hat{\gamma}_{k}\left[1-\lambda\left(\frac{\dot{X} \hat{\gamma}}{\hat{\sigma}}\right)\left\{\frac{\dot{X} \hat{\gamma}}{\hat{\sigma}}+\lambda\left(\frac{\dot{X} \hat{\gamma}}{\hat{\sigma}}\right)\right\}\right],
$$

where

$$
\lambda(\cdot)=\frac{\phi(\cdot)}{\Phi(\cdot)},
$$

in which $\Phi($.$) is the standard normal distribution function. T$ is the dependent variable (area cultivated by tractors), and $\dot{X} \hat{\gamma}$ is the linear prediction calculated with $\dot{X}$, a vector of sample mean values of each variable (among 223 observations that actually use tractors), and $\hat{\gamma}$, a vector of estimated coefficients from the truncated normal regression. $\hat{\sigma}$ is the estimated standard deviation of the underlying truncated normal distribution. $\hat{\gamma}_{k}$ is the estimated coefficient for variable $k$.

8 We focused on LGA-level unobserved fixed effects (and thus pseudo-panel fixed effects), rather than household-level fixed effects, because the household characteristics exhibited considerable deviations between two rounds of LSMS and it was unclear whether households were actually panel households. However, their reported LGAs were likely to be correct in both rounds. 


\section{Appendix 13B: Balancing Properties of the Propensity Score Matching Analysis}

As was seen in the main text, the extent and depth of the adoption of tractors vary considerably across geopolitical zones within Nigeria. Comparing adopters and nonadopters of tractors in very different environments often biases the estimates of tractor adoption. We therefore focus on specific regions with relatively favorable environments for intensifying tractor adoption. Specifically, we focus on farm households in LGAs that have at least one tractor adopter and one nonadopter, and are included in the samples in LSMS-ISA 2010 and 2012. Furthermore, we exclude farm households cultivating more than 5 ha of land, which account for approximately 5 percent of samples, to improve the matching quality. The application of PSM shows that selected samples and estimated propensity scores satisfy requirements for sufficient balancing properties (Table 13B.1). Table 13B.2 shows the set of variables used and their effects on propensity scores. Note that, because we focus on specific subsamples for our analyses in PSM, the set of variables is somewhat different from those in Table 13.8.

TABLE 13B.1 Balancing properties of propensity score matching

\begin{tabular}{lc}
\hline Variable & Values \\
\hline Rubin's B & 0.35 \\
Rubin's R & 0.88 \\
$\%$ of variables with statistically significant differences (at 10\%) in means & 0 \\
Sample & \\
Control & 537 \\
Treated & 168 \\
Treated-on support & 147 \\
Total & 705 \\
\hline
\end{tabular}

Source: Living Standards Measurement Study-Integrated Surveys on Agriculture, 2010, 2012.

Note: In a well-balanced sample, Rubin's B should be less than 0.4 , Rubin's $R$ should be between 0.5 and 2.0 (Cochran and Rubin 1973; Rubin 2001), and few variables should have statistically significant differences in means between adopter and nonadopter samples. 
TABLE 13B.2 First-stage regression of propensity score matching method

\begin{tabular}{lc}
\hline Variable & Coefficient \\
\hline EA share (\%) of vegetable producers & -.002 \\
EA share (\%) of sorghum producers & -.001 \\
EA share (\%) of maize producers & -.0002 \\
EA share (\%) of rice producers & $.003^{\star \star \star}$ \\
EA share (\%) of cassava producers & .0004 \\
Annual precipitation (mm) & $-.0004^{\star}$ \\
Terrain roughness & .004 \\
Soil workability & -.142 \\
Drought index (0 = severe, 100 = no drought) & -.0003 \\
Household size & .003 \\
Gender of household head (female =1) & $.229^{\star \star}$ \\
Age of household head & -.002 \\
Share of noneducated working-age household members & $-.092^{\star \star}$ \\
Own farmland & $.087^{\star}$ \\
Area of own farmland (ha) & -.011 \\
Real value of household assets (natural log) & $.041^{\star \star \star}$ \\
Own draft animals & -.019 \\
Distance to the nearest town with population 20,000 & $.040^{\star \star}$ \\
Real price of chemical fertilizer & .057 \\
Number of farm plots & .020 \\
Agricultural land per capita & .026 \\
Euclidean distance to the nearest state governor-origin LGA & $.115^{\star \star}$ \\
Real agricultural wages & $-.044^{\star \star}$ \\
Soil bulk density & -.130 \\
Soil clay contents & $-.016^{\star \star \star}$ \\
Size of the largest farm area within EA (natural log) & -.020 \\
Geopolitical zones dummy & Included \\
Year dummy & Included \\
Urban/rural sector dummy & 705 \\
Sample size & .224 \\
\hline
\end{tabular}

Source: Living Standards Measurement Study-Integrated Surveys on Agriculture, 2010, 2012. Note: Asterisks indicate the statistical significance: ${ }^{\star \star \star} 1 \%,{ }^{\star \star} 5 \%,{ }^{\star} 10 \%$. EA = enumeration area; $\mathrm{LGA}=$ local government area. 


\title{
AGRICULTURAL MECHANIZATION IN TANZANIA
}

Geoffrey C. Mrema, David G. Kahan, and Andrew Agyei-Holmes

\begin{abstract}
Tanzania has seen a slow but steady growth in agricultural mechanization over the past few decades. The country's mechanization growth trend is fairly consistent with patterns elsewhere, with both agroecological and socioeconomic conditions as key determinants of increased mechanization. The private sector has often led the development of machinery markets and service providers to meet mechanization demand, including emerging medium- to large-scale farmers serving as self-financed owners of tractors providing custom hiring services. Despite such progress, several knowledge gaps exist regarding the roles of various factors in mechanization, including land tenure policy, and regarding identification of the roles of governments in effectively supporting the private sector toward further mechanization growth.
\end{abstract}

\section{Evolution of Agricultural Mechanization in Tanzania}

This chapter documents emerging mechanization patterns among smallholder farmers in Tanzania, including the changing trends in demand conditions, service provision, and related policies. It also uses case studies to provide narratives and insights into mechanization's effect on agricultural transformation and key socioeconomic and environmental outcomes.

\section{Evolution of Agricultural Mechanization in Tanzania from 1945 to 2015}

Emphasis and priorities within the interventions in agricultural mechanization in Tanzania have alternated from 1945 to 2015 between motorized power and draft animal power (DAP), depending on the thrust of the major agricultural development strategies and programs being implemented at any one time. As in many other African countries, the history of the evolution of agricultural mechanization in Tanzania can be roughly categorized into three periods. 


\section{UP TO THE MID-1980S (PRIOR TO THE STRUCTURAL ADJUSTMENT PROGRAM)}

The period preceding the mid-1980s was characterized by substantial publicsector promotion of agricultural mechanization, particularly through increased tractor supply and mechanization services. From 1945 to 1961, British colonial authorities sponsored various programs, such as the Great Groundnut Scheme (GGS) and subsidies for mechanization inputs provided to white settler farmers and a few African yeoman farmers. On the advice of the World Bank, between 1961 and 1970 the Tanzanian government implemented an agricultural transformation program anchored in highly mechanized village settlement schemes, modeled on the kibbutzim of Israel (World Bank 1961; De Wilde 1967; Ingle 1972; Maeda 1976; Hyden 1980). Between 1965 and 1985, the government and various cooperatives operated and managed tractor hiring services (THSs), providing land preparation services to small farms. Despite this public provision, more than 80 percent of the tractor fleet in Tanzania during this period was operated by the private sector (Collinson 1963; De Wilde 1967; Clayton 1972; Beeney 1975; TSAE 1974; Kinsey 1976).

From 1970 to 1990, socialist programs such as ujamaa (communal, or extended family) villages were implemented by the government. During the period, focus gradually shifted toward more appropriate technologies for small-scale and peasant subsistence farmers, though support remained for four-wheel tractors ( $4 \mathrm{WTs}$ ) used by large-scale farms that were managed by the state, communal entities such as village leadership, and the private sector (Nyerere 1967; Hall 1968; Clayton 1972; Raikes 1975; Mrema 1981; Kjærby 1983).

During this period, available government records suggest that the number of 4WTs in use in Tanzania increased from about 2,000 in 1950 to 2,580 in $1960,6,500$ in 1970, and 18,500 in 1985 (Figure 14.1). However, this growth was not sustainable. For example, the GGS largely failed due to factors such as the introduction of inappropriate mechanization practices, and it was abandoned by 1954. Furthermore, after Tanzania gained independence in 1961, many of the white settler farmers moved on to what they perceived as more politically safe territories, such as Kenya and then Northern and Southern Rhodesia, and many of the prior settlement programs were abandoned for being too costly (Mayne 1954, 1955, 1956; Lord 1963; Austen 1968). Therefore, whereas $4 \mathrm{WT}$ use spread quickly during this period, the growth in mechanization was due to substantial economic distortions and did not necessarily reflect an optimal allocation of resources. 


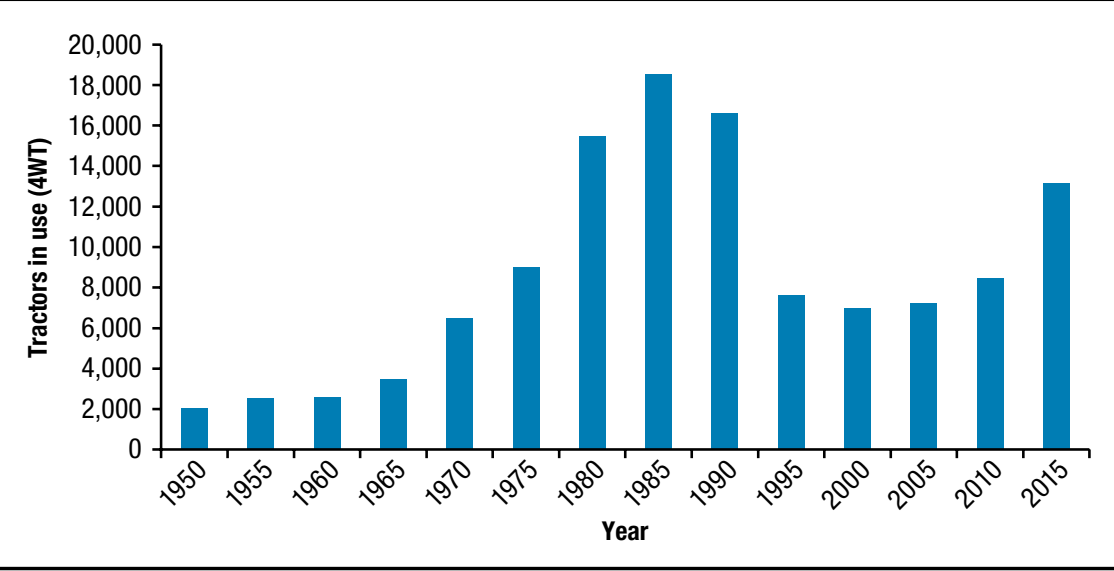

Source: Mrema (2017).

Note: 4WT = four-wheel tractors.

\section{BETWEEN THE 1980S AND MID-2000S}

During this period, the number of 4WTs in use fell from 18,500 in 1985 to 7,200 in 2005 (Figure 14.1). Loss of donor interest in mechanization and the government-implemented economic structural adjustment program (ESAP) from 1985 to 2005 created a period during which agricultural mechanization evolved without a clear strategy or vision. Although the political leadership remained highly supportive of agricultural mechanization, government ability to finance investments in the sector was constrained by the implementation of the ESAP (CCM 1988). Meanwhile, at the behest of Bretton Woods institutions, the economy was gradually opened to private-sector investment. Many of the public-sector THSs were privatized and the tractors sold to private operators. Due to financial austerity measures, the focus also shifted back to appropriate technologies such as DAP, which were disseminated through nongovernmental organizations funded by donor agencies and philanthropic organizations (Tanzania, MAFC 2006).

At the same time, overall demand for more intensive farming had risen in some parts of Tanzania. In eastern central Tanzania, between the mid-1990s and 2014, examinations through socioeconomic and remote-sensing data suggested that population growth drove a gradual transition from shifting cultivation to more intensive land preparation methods such as deep tillage (Kilawe et al. 2018), consistent with the evolution of the farming system and the role of that evolution in mechanization growth. 


\section{PERIOD SINCE THE MID-2000S}

The period since 2005 has seen a general reversal of the prior decline in mechanization. During this period, the number of operational $4 \mathrm{WT}$ has increased to reach 13,146 units in 2015. There has also been importation of secondhand tractors-mostly 4WTs from Europe and Japan (Agyei-Holmes 2014; Mmari and Mpanduji 2014; Tanzania, MAFC 2015; Mrema 2016; Shetto 2016). In addition, the number of two-wheel tractors (2WTs) started growing during this period, from fewer than 300 units in use in 2005 to more than 9,000 units in 2015. Part of the growth in 2WTs was induced by the severe drought in 2009 and 2010 that killed 50 percent of the cattle and oxen in the country (Kahan, Bymolt, and Zaal 2018). Tanzania, together with Madagascar and South Africa, had 70 percent of the 2WTs in Africa in 2018 (Mrema, Kienzle, and Mpagalile 2018). As of 2015, national data from the Ministry of Agriculture show that tractors and DAP were used for 14 percent and 24 percent of land preparation on cultivated land, respectively. The remaining 62 percent of land still relies entirely on manual labor with hand-tool technology (HTT). In some regions, however, land preparation with tractors is well above the national average and reaches up to 48 percent of cultivated land-for example, in the Arusha, Manyara, Mbeya, and Kilimanjaro regions (Tanzania, MALF 2016).

Several factors may have raised the demand for mechanization, albeit somewhat slowly, during this period. Over the past few decades, socioeconomic developments such as availability of social services (for example, universal primary education), migration to urban areas, aging rural populations, and new economic opportunities in rural areas have reduced the availability of labor for arduous field tasks, even at the very basic subsistence levels. For example, the urban population is growing at $4-5$ percent per year, and its population share is expected to grow from 30 percent today to 50 percent by 2030. Although Tanzania is still a relatively agricultural economy when compared with countries in West Africa, the share of the workforce employed in the nonfarm sector has been rising steadily, and recently exceeded 30 percent.

There has also been a shift in the government's mechanization policies. From 2005 to 2015, Tanzania implemented the first Agricultural Sector Development Program (ASDP1), and ASDP2 is expected to be implemented from 2016 to 2022. The Tanzania Agricultural Mechanization Strategy (TAMS) was developed and approved in 2006 as part of ASDP1 and was supposed to provide the framework for guiding interventions in the subsector, 
such as increased emphasis on private-sector provision of THS (Tanzania, MAFC 2015; Mrema 2016). Under the TAMS framework, incentive structures have been established to expand the provision of mechanization services (mainly farm equipment hiring services) to smallholder farmers in the rural community. This includes financial incentives to local institutes of technology to encourage design and development of appropriate farm tools and machinery suited for different categories of farmers and farming systems, and to build capacity for mechanization support services, especially for small-scale farms. Since 2009, subsequent investment initiatives have focused on the acquisition of mechanical power, especially $2 \mathrm{WTs}$, $4 \mathrm{WTs}$, and harvesting and postharvest processing equipment.

\section{Demand-Side Analysis}

Ergonomically, land preparation tasks are the most difficult and demand excessive power input from human muscles. These include basic tillage using the hand hoe, planting, and weeding. Land tillage by hand hoeing is ergonomically the most difficult task and requires $8-10 \mathrm{kcal}$ per minute in tropical environments such as Tanzania (Passmore and Durnin 1955; Stout 1979; Fluck and Baird 1979). Planting and weeding demand about 25-40 percent of the power required for hand hoeing. The significant effort required for these processes informs the Tanzanian ruling party's strategy to significantly reduce the area tilled by the hand hoe, currently at 60 percent, by 2035 (CCM 2015).

\section{The Agricultural Sector and the Demand for Farm Power}

Tanzania has a total area of $960,000 \mathrm{~km}^{2}$, about $886,040 \mathrm{~km}^{2}$ of which is land. Of that, there were approximately 45 million ha of arable land and 10 million ha under cultivation as of 2015. In the country, demand for farm power is informed by the dualistic nature of the large-scale farms (LSFs) and smallscale farms (SSFs) making up its agricultural sector. Medium-scale farms (MSFs) also operate in the country.

LSFs occupy 12-15 percent of the land currently under cultivation. In Tanzania, these farms are defined as those with area greater than 50 ha (Mrema 1991; TSAE 1974; Shetto 2016). Most range between 50 and 2,000 ha, with a few as large as 10,000 ha. The LSF subsector produces cash and food crops often linked to downstream agroprocessing value chains, including coffee, sisal, tobacco, pyrethrum, flowers and horticultural products, 
tea, maize, rice, wheat, dairy, beef, and sugarcane (Mayne 1955; World Bank 1961; Tanzania, MFEP 1988; BoT 2015). Around the time of Tanzania's independence, the LSF subsector was dominated by settler farmers and transnational corporations. During the 1970s and 1980s there was an increase in state-owned and -operated farms, though the private sector continued to dominate. After the ESAPs of the 1990s, most of the state farms were privatized.

Although MSFs and LSFs own most of the mechanically powered agricultural machinery in use in Tanzania, LSFs are particularly mechanized and have consistently owned more than 50 percent of the 4WTs in the country at any given time (Hall 1968; TSAE 1974; Fear 1976; Mrema 1981, 1991). Most LSFs have a fleet of $4 \mathrm{WTs}$ complete with different accessories and may also hire out specialized machinery such as combine harvesters. Some LSFs offer machinery hiring services to MSFs on a contract farming basis.

MSFs are defined as those with 10-50 ha of land. They typically own new 2WTs and sometimes new or used 4WTs, along with different accessories. For MSFs that do own $4 \mathrm{WTs}$, it is unlikely that they are fully used on the farm because they are often hired out to SSFs or used in nonfarm activities such as transportation. In instances where there are nearby THSs, MSFs may opt not to purchase such equipment and instead to rely on hiring services.

The SSF subsector is estimated to occupy up to 70 percent of the cultivated arable land in Tanzania and is split into two subgroups-peasant subsistence farms (PSFs) and small-scale commercial farms (SSCFs). PSFs produce largely for subsistence, whereas SSCFs produce for both subsistence and the market. It varies somewhat by region and population density, but generally PSFs are defined as cultivating 1-2 ha of land, whereas SSCFs operate on 4-10 ha. Improvements in infrastructure and market linkages are normally what help a PSF to grow into an SSCF.

When available, SSCFs typically use DAP or tractors for land preparation. However, some other tasks, such as planting maize, harvesting paddy, and shelling and threshing may also be mechanized. SSCFs either own or hire draft animals and 2WTs, and hire 4WTs. A few SSCFs may own 4WTs bought secondhand, in which case they likely offer THS to other SSCFs and to PSFs.

PSFs typically rely on family labor and HTT for all land preparation and crop husbandry tasks. This includes primary tillage and hoeing, planting, weeding, harvesting, and postharvest processing such as shelling or threshing. PSFs may hire DAP or tractors for land preparation to break the hardpan if they have nonfarm income and the hiring cost is affordable. 


\section{Regional Variations in Mechanization Patterns}

\section{DRAFT ANIMAL POWER AND TECHNOLOGIES}

DAP has been promoted in Tanzania for more than a century; however, its adoption has largely been confined to six drier regions in the northwest of the country: Shinyanga, Mara, Singida, Manyara, Tabora, and Mwanza. In 2005, these regions had about 83 percent of the 1.4 million draft animals in use, and the situation was largely unchanged as of 2015 (Figure 14.2) (Tanzania, MAFC 2006, 2015). These are also the regions where farmers have a tradition of both livestock and crop husbandry. Thus, the use of draft animals for tillage and transport services is especially important to those farmers who engage in both types of activities. Cultivation of cotton and tobacco, which as cash crops have greater market and institutional support, has also played a key role in advancing DAP in these regions.

The remaining 17 percent of DAP use is spread over the other 19 regions of mainland Tanzania. There are several factors limiting DAP use across the country. Unlike in the six drier regions mentioned above, tsetse flies are present throughout most of the country and as a result, a livestock husbandry tradition is relatively absent. Furthermore, the heavy soils found in many parts of the country make it necessary to use two or three pairs of oxen for tillage, increasing the investment and training costs of the process. Finally, where the window is short for using animal traction, feeding costs for draft animals (either purchased feed or biomass, which is equivalent to up to a few metric tons per year per farm) outweigh the benefits of owning them (Baudron et al. 2015). These factors may also explain why 2 WTs may be more widely used than DAP for tillage and puddling, even though these operations alone can be done more cheaply by DAP than 2WTs, as was witnessed in Mbarali district in Mbeya (Babu 2017).

In addition to these issues, there are factors that suggest DAP use will not gain prevalence even in the long term. Increasing demand for livestock products and the high costs of keeping livestock for draft purposes reduce its appeal (Tanzania, MAFC 2015; Mrema 2016). Also, because DAP is almost always employed at full capacity, families owning draft animals do not hire them out to others. Thus, DAP's role in the machinery hiring market is limited and likely to remain so. Finally, young Tanzanians tend to view DAP as an outdated technology that should not be used in the 21 st century. This idea is reinforced by the rapid pace of technological transformation that has been seen in other sectors, such as information and communication technology, and transportation. 


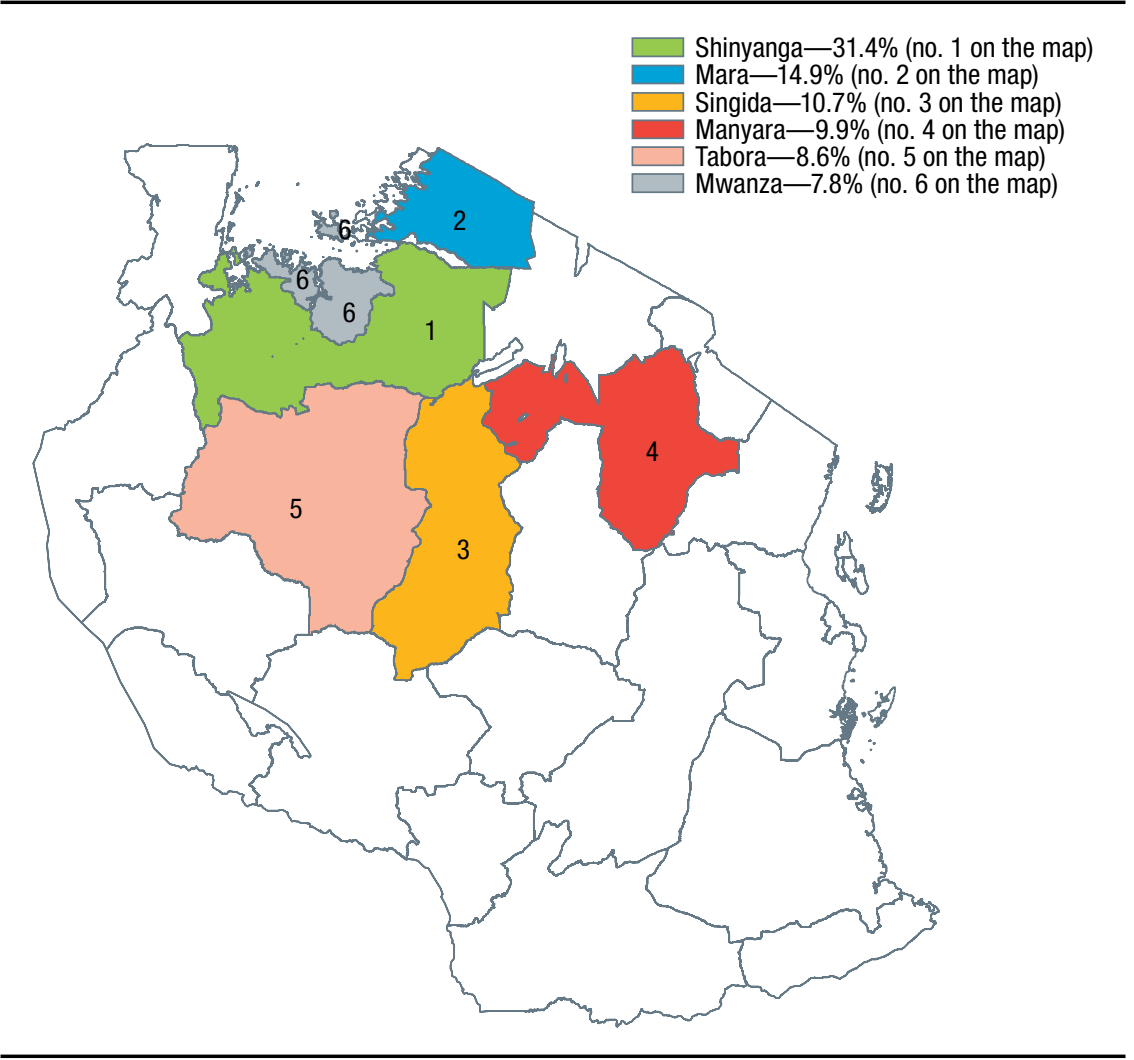

Source: Tanzania, MAFC (2006).

\section{MECHANICAL POWER}

Various types of mechanical technologies have been adopted in Tanzania, albeit with regional heterogeneity. These include tractors, motorized pumps and other water lifting devices, motorized harvesting and postharvest processing equipment such as combine harvesters and threshers, and grain milling equipment. The following section will discuss some of these technologies in more detail.

\section{Tractors}

The types of tractors in use in the country include traditional two-axle 4WTs in either the two-wheel drive or four-wheel drive version; low-horsepower 4WTs developed specifically for developing countries; and the power tiller, or 2WT. 
In the 1970s and 1980s, tractors designed specifically for agriculture in developing countries were brought into Tanzania. Most notable of these was the Swaziland-designed and -manufactured Tinkabi tractor, more than 500 of which were imported to Tanzania during the mid-1980s. However, these types of tractors were largely failures, and experimentation with them was stopped by the mid-1990s (Holtkamp 1989, 1991; Dihenga and Simalenga 1989).

The use of 4WTs and 2WTs has been growing through THSs, though adoption levels are still low. About 65 percent of 4WT ownership is concentrated in six regions-Morogoro, Arusha, Kilimanjaro, Manyara, Dodoma, and Shinyanga - and the remaining 35 percent is spread over the other 19 regions of the country (Figures 14.2 through 14.4). This regional distribution has not changed much from the years 2005-2015, though the actual number of 4WTs has increased significantly through imports from Asia. In 2005, there were an estimated 7,200 serviceable and operational 4WTs; this had grown to 13,000 by 2014 (Tanzania, MAFC 2016). The quality of the fleet is unclear, however, with a 2005 national survey finding that 73 percent of units were more than 15 years old, which is well beyond the design life of a $4 \mathrm{WT}$; 35 percent were more than 25 years old, and fewer than 10 percent were less than 10 years old.

Most 4WT ownership is not concentrated in the main grain surplusproducing regions of Tanzania. These regions-Songea, Iringa, Mbeya, and Rukwa-are in the south, whereas the majority of $4 \mathrm{WT}$ ownership tends toward northern regions. Anecdotal evidence suggests there is considerable interregional mobility of $4 \mathrm{WTs}$, which could lead to the development of a THS business model focused on specialized land preparation operations. Though detailed information on tractor use by non-owners is not available, THSs with 4WTs appear also to be concentrated in the regions that are well connected with roads, such as Arusha, Iringa, Manyara, Kilimanjaro, Dodoma, and Morogoro, and are linked to Dodoma's Kibaigwa International Grain Market as well as to cross-border food exports to Kenya. Most 4WTs in Tanzania are old. In 2005, 4WTs more than 15 years old accounted for 73 percent of all $4 \mathrm{WTs}$ in the country (Figure 14.5).

The use of 2WTs has also grown in recent years. Importation of 2WTs peaked in 2009, when the government supported the import of more than 2,000 units (Figure 14.6). These were distributed to district authorities throughout the country. The number of imported 2WTs has since declined, though new units continue to come into the country.

In 2015, 51 percent of 2WT ownership was concentrated in six regions: 27 percent of all 2WTs were in Mbeya, 7 percent in Morogoro, 7 percent 


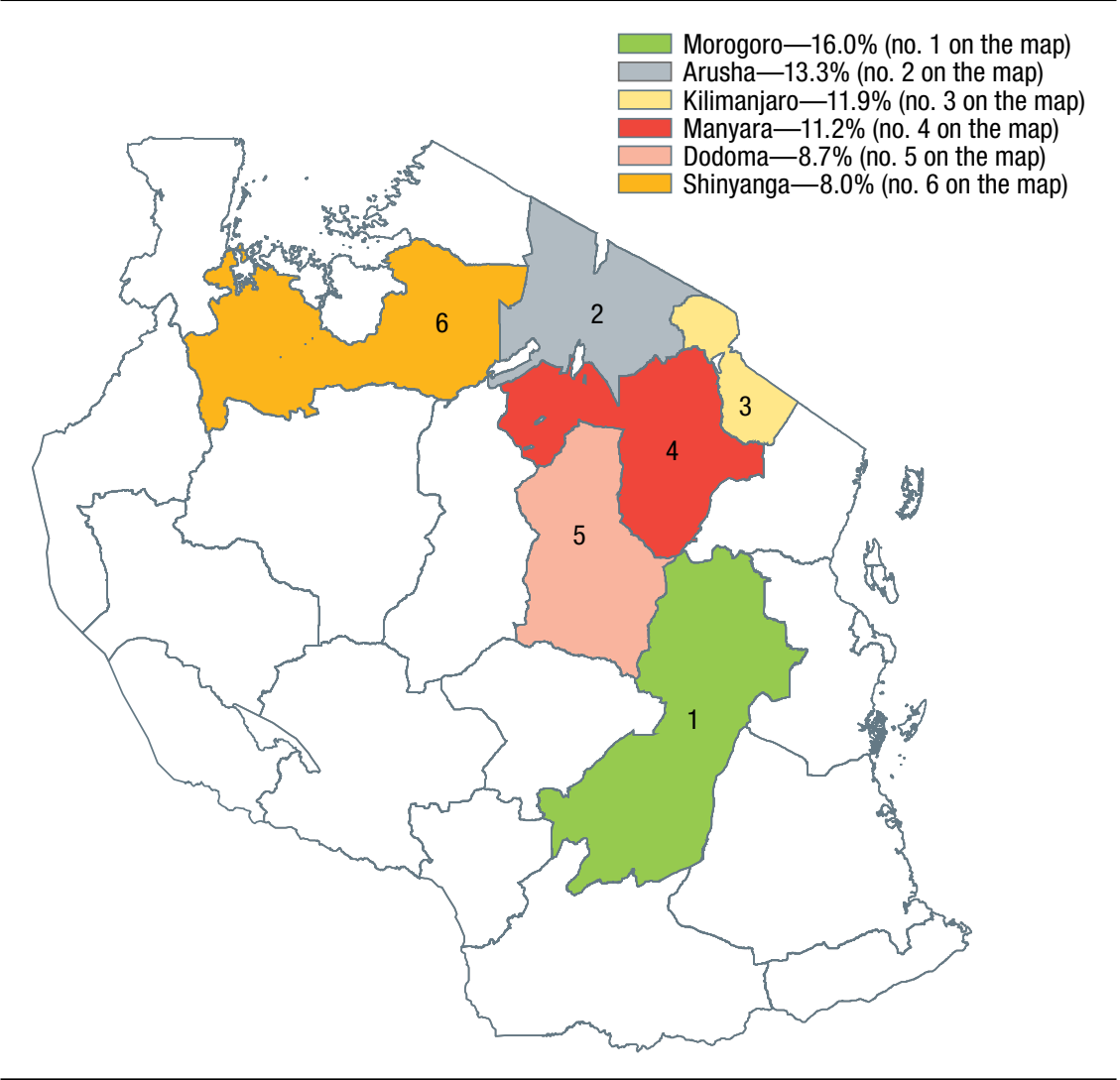

Source: Tanzania, MAFC (2006).

in Iringa, 6 percent in Ruvuma, 6 percent in Shinyanga, and 5 percent in Lindi. These regions are generally southern and at relatively high latitudes (Figure 14.7). The remaining 49 percent of $2 \mathrm{WTs}$ were spread over the rest of the country. Three of the six regions where most of the 2WTs were found (Mbeya, Iringa, Ruvuma) are also among the main regions of southern Tanzania that produce grain surpluses. Surveys undertaken in Mbeya showed that more than 80 percent of the 2WTs in the region were in a single district-Mbarali-where they were used in rice and maize production as well as in many nonfarm activities such as transportation (Lwesha 2015). The use of 2WTs for transportation has also been rising in other parts of the country as 


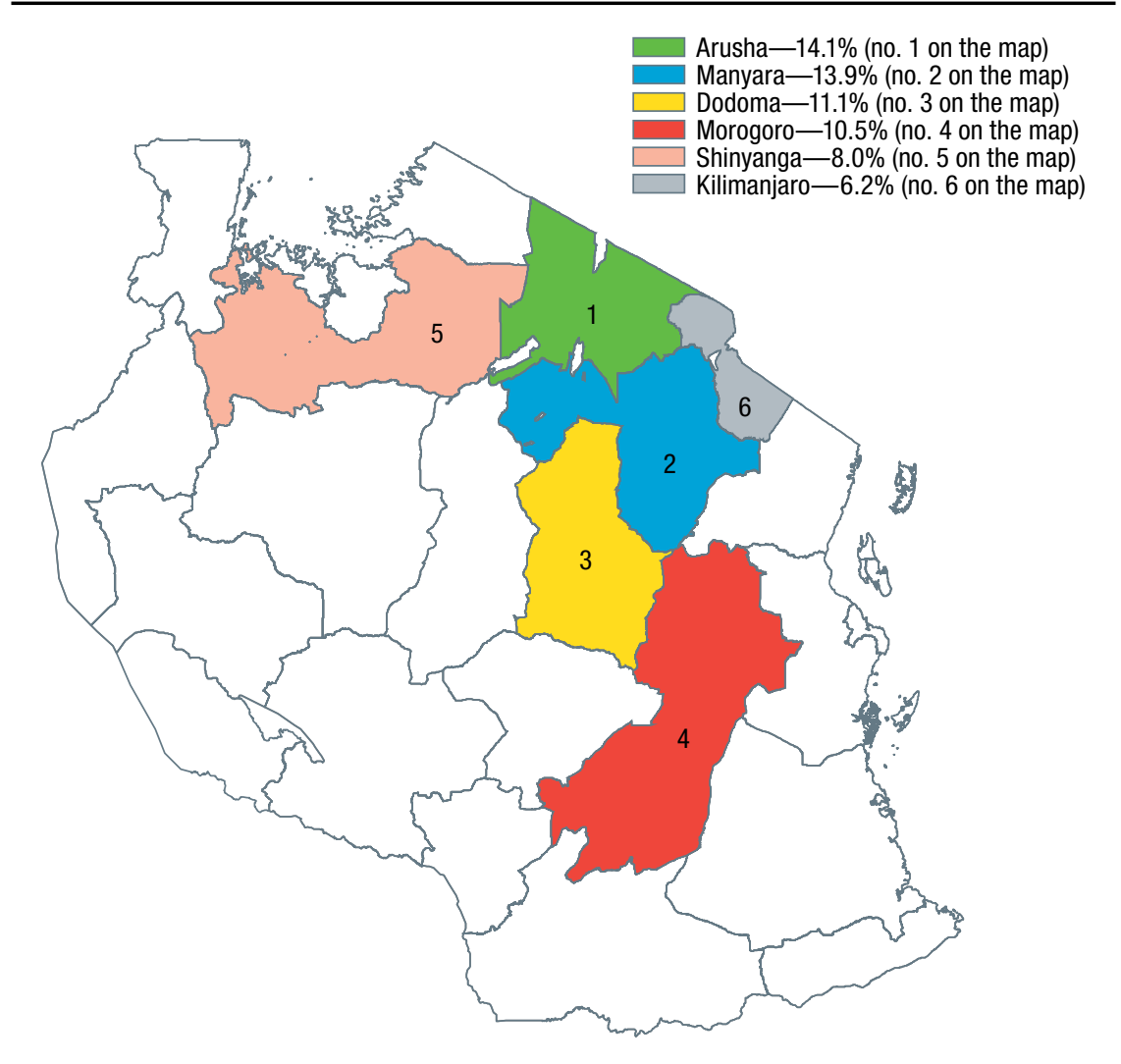

Source: Tanzania, MAFC (2016).

the demand for transport has grown, and as the capacity for repair of motorized vehicles and the availability of fuel and lubricants that can benefit 2WTs have increased (Baudron et al. 2015).

The data from Lwesha (2015) also suggest important cross-brand variations in power tiller utilization rates given machine prices (Table 14.1). Although Amec and Siam Kubota brand tractors were obtained at around the same time on average (2009), Amec brands were typically half the price of Siam Kubotas; nonetheless, their average utilization rates did not vary significantly in 2012/2013, indicating that Amec brand power tillers tended to be used more efficiently in economic terms. 
FIGURE 14.5 Age of four-wheel tractors in Tanzania, 2005

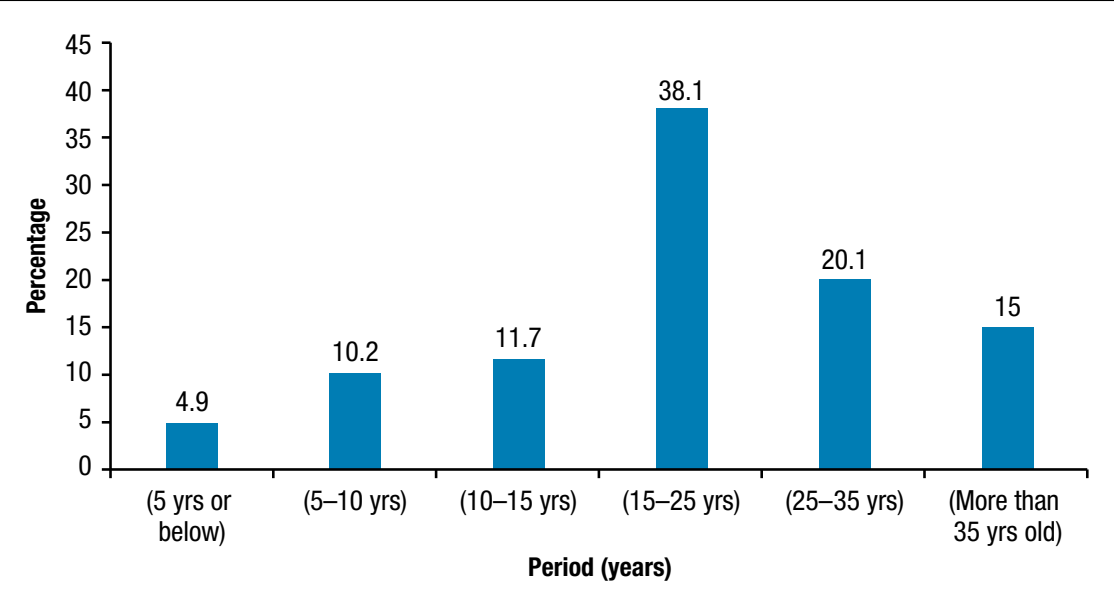

Source: Tanzania, MAFC (2006).

FIGURE 14.6 Number of two-wheel tractors imported by Tanzania, 2005-2014

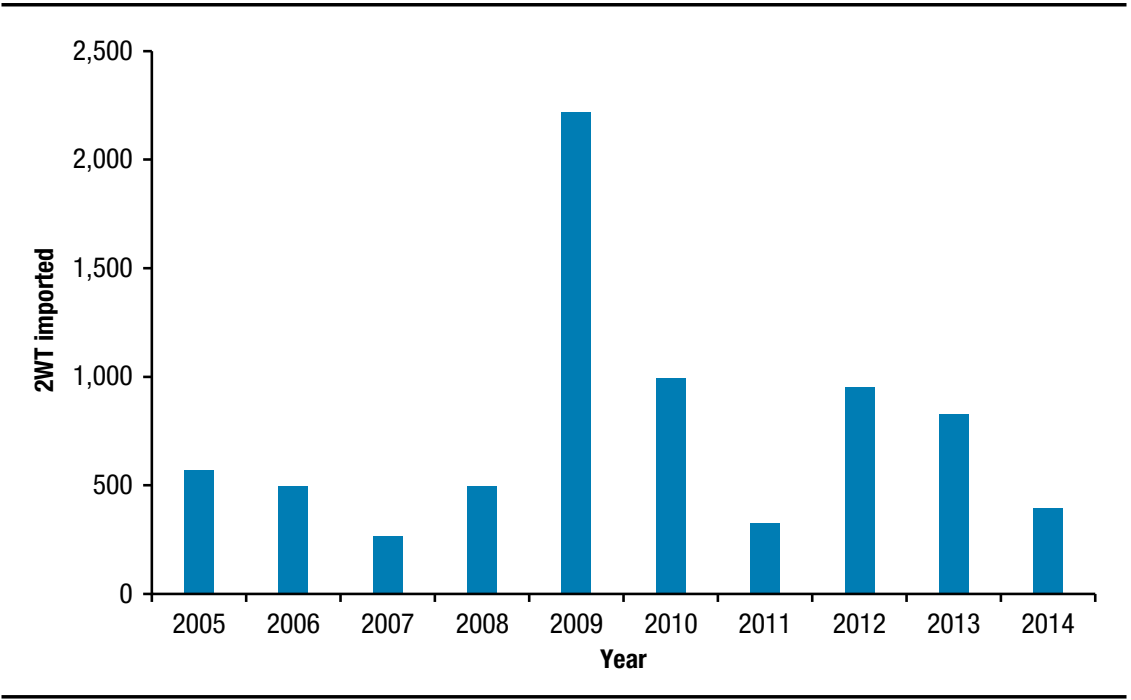

Source: Tanzania, MAFC (2016).

Note: 2 WT = two-wheel tractor. 


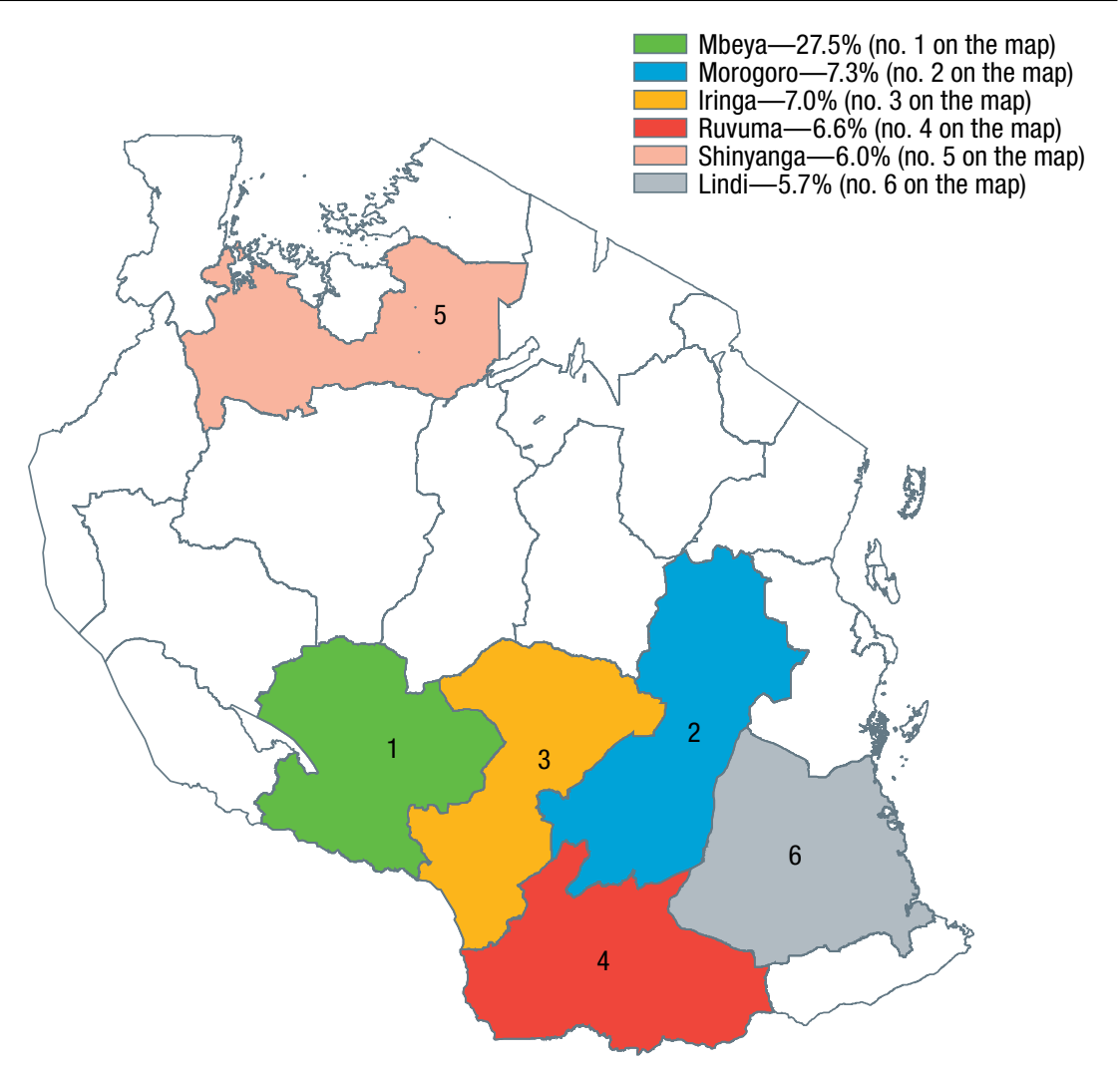

Source: Tanzania, MAFC (2016).

Note: 2 WT $=$ two-wheel tractor.

TABLE 14.1 Significant difference in utilization rates per price of machines between Siam Kubota and Amec power tillers in Mbarali district, Tanzania, 2012/2013

\begin{tabular}{|c|c|c|c|}
\hline Category & Siam Kubota & Amec & $\begin{array}{c}p \text {-value } \\
\text { (null hypothesis } \\
\text { of no differences } \\
\text { between brands) }\end{array}$ \\
\hline Average utilization rate (hours per year) & 633 & 636 & .959 \\
\hline Average year of purchase & 2009 & 2009 & .894 \\
\hline Average price (1,000 Tanzania shillings) & 8,365 & 3,705 & .000 \\
\hline
\end{tabular}

Source: Authors' analysis based on data in Lwesha (2015, appendix). 


\section{Combine harvesters}

Combine harvesters and other postharvest processing equipment (for example, threshers and shellers) are restricted to the large-scale commercial farms. There is, however, anecdotal evidence of increasing smallholder use of small combines and other equipment from Japan, China, and India. This has helped increase efficiency of harvesting and postharvest operations, and reduce postharvest losses. Unfortunately, there is a lack of information on the extent of use of these technologies in Tanzania, especially with regard to SSFs and farmers cultivating rice (Mrema 2016). Given the fact that the harvesting seasons change from the south to the north sequentially through the year, there is potential that entrepreneurs could invest in and offer commercially sustainable machinery hiring services to farmers, especially those cultivating rice.

\section{Supply-Side Analysis: Sourcing Machinery}

\section{Evolution of the Supply Chains for Agricultural Machinery and Implements}

Following the end of the Second World War, supply chains for agricultural machinery and implements were established through franchises of major global tractor manufacturers such as Ford, John Deere, Massey Ferguson, and Fiat. Although initially intended to supply agricultural machinery, implements, and equipment to the 1 million-acre GGS in southern and central Tanzania, they also supplied the emerging LSFs in the north of the country as well as the eastern and southern highlands regions (Mayne 1954, 1955, 1956; Lord 1963; Mrema 1981, 1991; Burch 1987). The farmers purchasing the equipment were largely European settlers and sisal plantation owners, as well as a few African and Asian yeoman farmers.

The franchises were all managed by private firms, some of which were Tanzanian-owned (such as KJ Motors, which sold John Deere tractors) and some of which were part of multinational corporations (MNCs). For example, Farm Machinery Distributors sold Massey Ferguson tractors and Riddoch Motors sold Ford tractors-both were owned by Lonrho. Other companies in the market included Incar, which managed Fiat tractors, and Gailey \& Roberts, which sold Caterpillar crawler tractors.

These companies dealt with agricultural machinery in addition to other equipment and vehicles, and were generally regarded as being quite efficient. Even as Tanzania gained independence and adopted socialist policies, 
these companies were not nationalized. However, in 1978 the two companies owned by Lonrho were nationalized, allegedly due to the MNC's actions against liberation efforts in southern Africa. The only state-owned company in the sector prior to this was Agricultural and Industrial Supplies Company, which sold International Harvester tractors (TSAE 1974). The supply chains that these companies created served individual farmers (MSFs and LSFs), state-owned farms, and other THS providers such as cooperatives and ujamaa villages.

In 1982, TRAMA (Tanzania Tractor Manufacturing Company) was established as a joint company that assembled Finnish-made Valmet tractors. By the mid-1980s, the Tanzanian economy was in a recession, and with the implementation of the ESAPs there was a decline in interest in mechanically powered mechanization and an increase in prioritization of appropriate technologies. The number of tractors being imported declined appreciably throughout the late 1980s and the 1990s, and this led to the collapse of the franchises that had been established in the 1960s (Tanzania, MAFC 2006; Mrema 2016). In 2005, when the government reactivated its programs in agricultural mechanization following the TAMS, new companies and players emerged that are now managing the supply chains for agricultural machinery and implements (Tanzania, MAFC 2006; Agyei-Holmes 2014; Mrema 2016).

\section{Import and Domestic Policies}

The TAMS, developed through Food and Agriculture Organization and United Nations Industrial Development Organization assistance, rekindled the government's interest in agricultural mechanization (Tanzania, MAFC 2005, 2006; Mrema 2016). Following the TAMS, major mechanization policies have included trade and import policies (tariffs, direct restriction), promotion policies (subsidies), concessional loans, licensing, subsidies on parts, and policies affecting financial support for machinery purchases and inputs. Manufacturing of agricultural machinery and implements in Tanzania is limited, and supply is largely sourced through imports. Import tariffs have therefore been waived by the government to reduce importer costs and increase affordability for farmers. Consequently, agricultural machinery and implements are exempt from import duties as well as value-added tax (VAT). Additionally, for imported farm machinery and implements, dealers are at liberty to import spare parts equivalent to 10 percent of the value of the good with no import duties or VAT imposed-duties and taxes apply only beyond this 10 percent. 


\section{Recent Government Support Initiatives}

Concessional loans and grants secured by the government have played a significant role in increasing imports of agricultural machinery and implements. Other initiatives have included the establishment of an agricultural window at the Tanzania Investment Bank to help farmers access loans for agricultural investments and subsidies for 2WTs under the Agricultural Sector Development Strategy, or ASDS (Tanzania, MAFC 2001), which make machinery affordable to both owners and those who hire the equipment. The subsidy initiatives are aimed at creating profitable markets for machinery dealers and distributors of farm machinery, especially within the $2 \mathrm{WT}$ subsector. The subsidies have also encouraged the establishment of farm machinery hiring services at the regional, district, and local levels. Similarly, the Japanesefunded $2 \mathrm{KR}$ program and the UK's Research Into Use program supported the development of $2 \mathrm{WT}$ mechanization through the provision of grant subsidies of up to 50 percent.

Between 2010 and 2011, a $\$ 40$ million $^{1}$ concessionary credit obtained from the Indian government was used to import and distribute 1,800 units of $4 \mathrm{WTs}$ to farmers. This was supervised by the state-operated National Service Corporation Sole Agri-Machinery Project (SUMA-JKT). Homegrown policies such as Kilimo Kwanza (Agriculture First), targeting agricultural growth and transformation, have also been critical for mechanization (Mgeni and Yustin 2014). One of the five initiatives under Kilimo Kwanza was the promotion of agricultural mechanization through the Ministry of Agriculture, Food Security, and Cooperatives, with public-private partnerships also expected to play a role. It covered activities that accommodated small-scale mechanization using $2 \mathrm{WTs}$ and $4 \mathrm{WTs}$ to facilitate commercial production. In response to the Kilimo Kwanza policy, the Agriculture Inputs Trust Fund (AGITF) redirected its efforts toward supporting the purchase of farm implements and tractors. Financed by the central government, the AGITF provides credit to farmers on concessionary terms to procure farm machinery (Agyei-Holmes 2014).

The creation of the Private Agricultural Sector Support Trust and the revamping of the AGITF, plus the establishment of the Tanzania Agricultural Development Bank in 2015, have also facilitated farmers' ability to acquire loans for machinery purchases by easing some bottlenecks of credit access,

1 Dollar figures are US dollars throughout the chapter. 
such as the inability of farmers to develop business plans and the unavailability of collateral.

\section{Public-Private Sector Collaboration}

Government and private-sector dealers are actively engaged in importing a wide range of farm machinery. The volume of imports by the government has at times been large, but supply has been erratic. On the other hand, imports through the private sector have been relatively small but constant over time (Agyei-Holmes 2014). Pre-2008, the number of units of 4WT imports through the private sector hovered at around 500 units per year. Total imports increased markedly, to 1,960 and 3,183 in 2010 and 2011, respectively, as a result of central government involvement. Although government participation can help to bridge supply gaps, it sometimes outcompetes the private sector; for example, the lower prices caused by subsidies can crowd out private firms (Lyimo 2011).

Trade liberalization policies have removed restrictions on the types of machines private businesses can import, provided they meet quality standards (Kazungu 2009). This has encouraged numerous private-sector actors to participate in the supply chain and led to a proliferation of the types and brands of tractors imported. As of 2012, there were 10-12 major and 30 minor companies engaged in the farm machinery import market. However, on an individual basis, each of these major companies imported fewer than 50 units per year (Mundial 2012). Limited volumes of imports result in high unit costs that tend to be passed on to the farmer. These cost challenges are exacerbated as import markets widen with new suppliers such as China and India entering the market (Agyei-Holmes 2016).

In the past, a greater proportion of farm machinery imports came from Europe, where quality standards were usually guaranteed. However, the cheaper imported tractors from China and India have captured a larger share of the market (Agyei-Holmes 2016). Also, private-sector dealers often fail to ensure that imports are accompanied by the necessary spare parts, which has dire consequences for the end user. This suggests the need for a stronger role of government in regulation in order to avoid negative externalities for the rest of the private sector (Mkubwa, Mtengwa, and Babiker 2014).

\section{Domestic Machinery Manufacturing, Standards, and Regulations}

Tractors are usually imported together with their accessories. Despite the dominance of imports in supplying these parts, the government continues to support domestic development of prototypes of machines and equipment 
through the Centre for Agricultural Mechanisation and Rural Technology (CAMARTEC). CAMARTEC has the responsibility to develop, redesign, and modify imported machinery to match local needs. Additionally, CAMARTEC has a regulatory function that makes it responsible for testing imported tractors and farm machinery implements to determine their suitability for local use.

In addition to CAMARTEC, there are also private local manufacturers that produce some of the less complex farm implements, such as rippers and subsoilers. Examples of these include Nandra Engineering Company Ltd., Seaz Agricultural Equipment Ltd., and InterMech Ltd. (Mkoga 2010). A recent phenomenon has been the expansion of private companies that are involved in the testing of prototypes and assembly of $2 \mathrm{WT}$ and $4 \mathrm{WTs}$. An example, albeit on a small scale, is a private firm in Mwanza region that assembles Victoria power tillers.

Collaboration with foreign firms through licensing agreements for the local assembling of tractors has also occurred in the past. In the 1980s a licensing agreement was reached between the government and the Finnish company Valmet Tractors, which resulted in the assembly of 2,300 tractor units (Simalenga 1989). However, by the end of the 1980s the assembly plant had difficulties competing with imports and eventually closed. More recently, negotiations have taken place with Iran Tractors and M\&M Tractors regarding the possibility of manufacturing tractors locally. In 2016, a contract was concluded between Ursus and SUMA-JKT, with the former company expected to supply 2,400 units of "semi-knocked-down" (that is, partially assembled) tractors to SUMA-JKT. This contract will involve some level of local assembling, though on a limited scale (Ursus 2016).

\section{Ownership and Mechanization Hiring Services}

Although the government intervened heavily in tractorization through THSs during the 1960 s to the mid-1970s, its role has gradually diminished since then. Since the early 2000s, THSs in Tanzania have been predominantly operated by the private sector, with the public sector-owned and -operated THSs controlling less than 20 percent of the tractor fleet. More than 90 percent of tractor-owning farmers now provide THSs.

LSFs normally procure new 4WTs and use them for 5-10 years before depreciating them for tax purposes and selling them to either MSFs or SSCFs, or to other freelance THS operators. In surveys of operators who offer THSs using $4 \mathrm{WTs}$, a significant proportion indicate that they procured their tractors secondhand either from public-sector THSs or from LSFs and MSFs that 
have sold them off. Furthermore, many of these operators have previously worked for the public-sector THS or the MSFs and LSFs. This suggests that the role of the public sector and the LSF and MSF sectors in building capacity and facilitating the procurement of secondhand machinery and implements to freelance operators, who then go on to offer machinery hiring services to smallholder farmers, has been underestimated (Lwesha 2015; Mrema 1991, 2016).

\section{TRACTOR HIRING SERVICES IN FOUR CASE STUDY DISTRICTS}

This section briefly describes key characteristics of agricultural machinery hiring services in Tanzania, based on case studies in four districts (Shetto 2016; Mrema 2016). Selected districts are Mbarali district in Mbeya region, Kiteto district in Manyara region, Kongwa district in Dodoma region, and Mvomero district in Morogoro region, which all represent different parts of the country. In Mbarali, irrigated paddy production is relatively common and 2WTs and 4WTs are commonly used. LSFs coexist with MSFs and SSCFs, and several cooperative and private-sector organizations have set up marketing and agroprocessing industries-for example, the Raphael Group, which won the 2015 European Marketing Research Center Africa Enterprise Award (EMRC 2016). Kiteto has a long tradition of mechanized agriculture due to the settlement schemes of the 1960s that led to several private and state-owned LSFs. It is anchored on a maize value chain linked to the Kibaigwa International Grain Market, Arusha City, and Kenya. Kongwa is also anchored on a maize value chain, linked through good roads and railways to the Kibaigwa International Grain Market, Dodoma Municipal Council, Dar es Salaam, and other major areas such as Mwanza and Morogoro. Finally, the sector in Mvomero is built around a combination of rice, fruit, and vegetable value chains and is linked to the large Dar es Salaam and Morogoro markets.

Table 14.2 shows the number of tractors and implements in 2015 in these four districts. There were a total of 1,630 $4 \mathrm{WTs}$ in these four districts, which accounted for about 12 percent of all functioning $4 \mathrm{WT}$ in the country at the time.

Three of these four districts were considerably more mechanized relative to the rest of Tanzania (Figure 14.8). The shares of the cultivated arable area in the districts prepared by tractors in 2015 were 78 percent in Kiteto, 65 percent in Mbarali, and 58 percent in Kongwa. Only in Mvomero was the share closer to national levels, at 16 percent (Tanzania, MAFC 2016; Shetto 2016).

Most tractor-owning farms surveyed in these four districts were MSFs or LSFs (Figure 14.9). Figure 14.10 shows the farm sizes of $2 \mathrm{WT}$ and $4 \mathrm{WT}$ 
TABLE 14.2 Number of tractors and implements in surveyed districts, Tanzania, 2015

\begin{tabular}{lcccccc}
\hline District & Tractors & Plows & Harrows & Trailers & Planters & $\begin{array}{c}\text { Combine } \\
\text { harvesters }\end{array}$ \\
\hline Kongwa & 735 & 650 & 32 & 490 & 3 & 0 \\
Kiteto & 357 & 342 & 20 & 252 & 6 & 0 \\
Mbarali & 310 & 300 & 130 & 278 & - & 57 \\
Mvomero & 228 & 115 & 92 & 105 & 26 & 13 \\
\hline
\end{tabular}

Source: Shetto (2016); Mrema (2016).

Note: $-=$ data not available.

FIGURE 14.8 Level of mechanization in the four case study districts, Tanzania, 2015

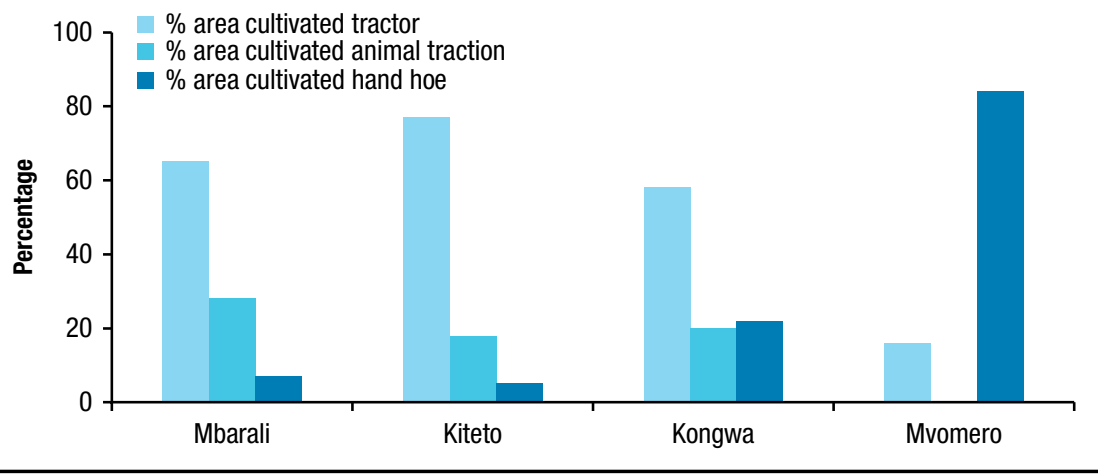

Source: Shetto (2016); Mrema (2016).

owners in Mbarali district, which had the most 2WTs in Tanzania. Typically, 2WT owners have farm sizes of 4-8 ha and rarely own more than 20 ha of land. Though 4WT owners in Mbarali district had relatively more variable farm sizes, most owned less than 40 ha and therefore fell under the MSF category.

Other key characteristics of the owners of 2WTs and 4WTs in Mbarali district suggest that $2 \mathrm{WT}$ owners were slightly younger than $4 \mathrm{WT}$ owners. A considerable share-about 40 percent-of $4 \mathrm{WT}$ owners had a university or vocational college education. Finally, most $2 \mathrm{WT}$ and $4 \mathrm{WT}$ owners were engaged in other income-earning activities, including artisanal and nonfarm business activities.

\section{HIRING SERVICE BUSINESS MODELS}

Three hiring service business models were identified through the survey: individual ownership, cooperative and joint ownership, and enterprise ownership. 
FIGURE 14.9 Size of farms operated by four-wheel tractor owners in the case study districts, Tanzania, 2015

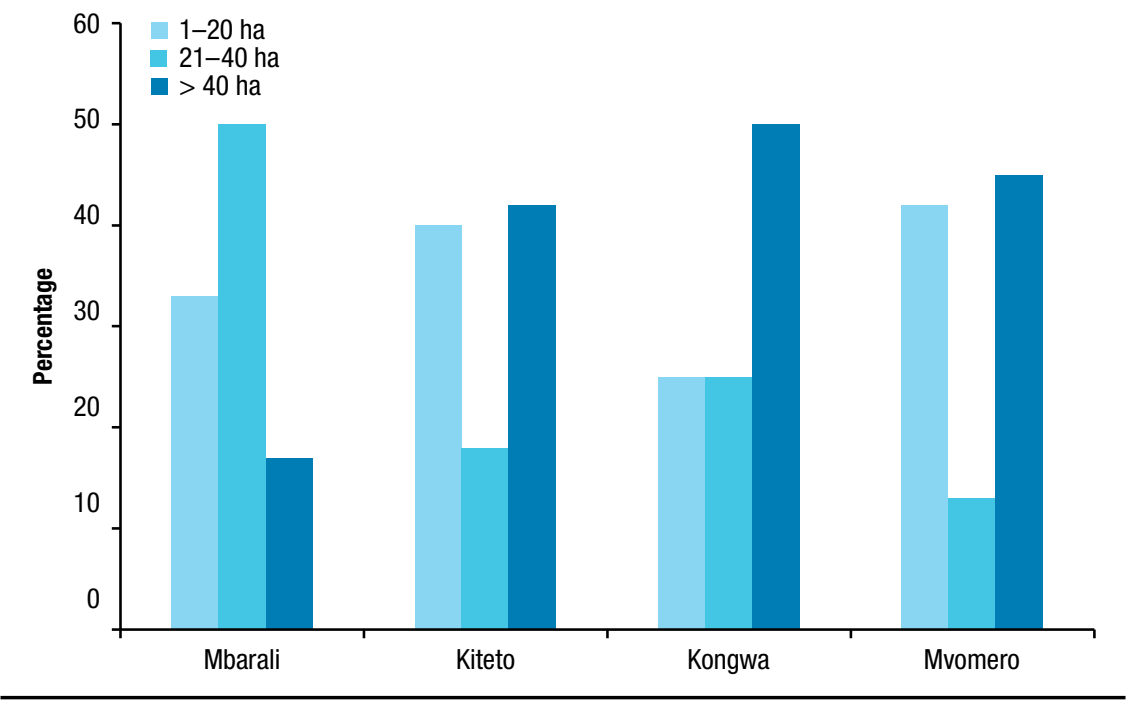

Source: Shetto (2016); Mrema (2016).

FIGURE 14.10 Size of farms in Mbarali district, Tanzania, farmed by tractor owners in 2013

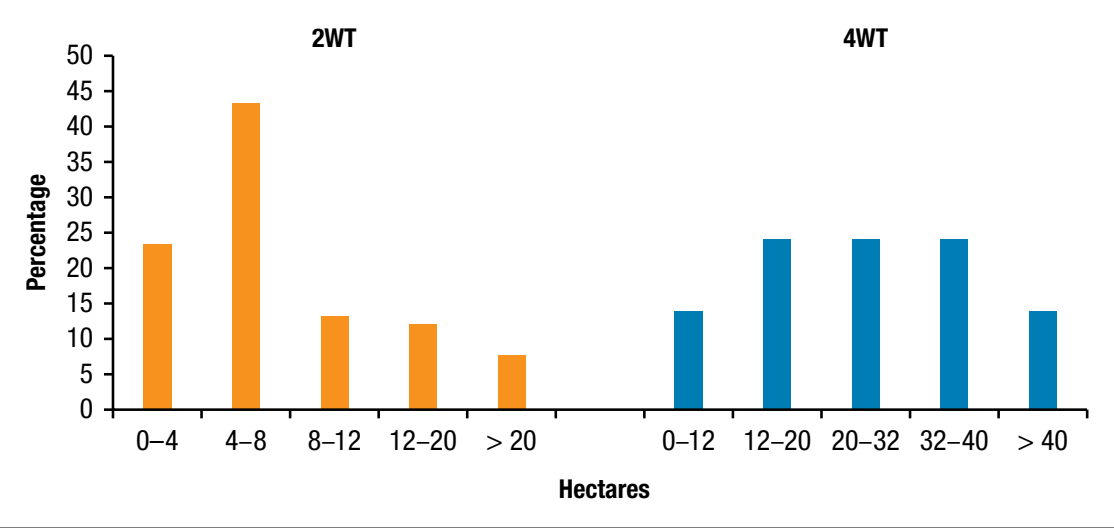

Source: Shetto (2016); Mrema (2016).

Note: 2 WT = two-wheel tractors; 4WT = four-wheel tractors. 
Individual ownership-Farmer-tractor-owner hiring service providers (4WT and 2WT)

The most commonly found business model is the farmer-tractor-owner custom hiring service. MSFs and LSFs that own $4 \mathrm{WT}$ s provide custom hiring services to other farmers in their locality and sometimes outside their districts. Data obtained from district offices show that about 92 percent of tractor owners provide THSs, ranging from 75 percent in Kongwa to 100 percent in Kiteto. Kongwa district has one of the largest concentrations of $4 \mathrm{WTs}$ in the country and a similarly high concentration of THS providers. However, some LSFs that own tractors in Kongwa use tractors more for the farm and less for THSs. Shares of tractor owners providing THSs are also high in districts without data from district offices, such as Mvomero, at 97 percent, and Mbarali, at 88 percent (Shetto 2016).

Shetto (2016) described the nature of farmers who were also THS providers, based on a survey of selected service providers. About half of $4 \mathrm{WT}$ were secondhand, and most had been bought outright; furthermore, about half of interviewed 4WT owners also owned trailers. Many tractor owners interviewed were involved in both farming and the provision of THSs to neighboring farmers (Shetto 2016). Typically, 4WTs were used for plowing and transportation, and about 62 percent of the owners hired out their tractors, mainly for transportation, ${ }^{2}$ and 38 percent used their trailers exclusively for their own farm activities. The size of the 4WTs generally varied from $20 \mathrm{hp}$ to 80 hp, with 61-80 hp being the most common sizes (Bymolt and Zaal 2015). Lower-horsepower 4WTs were preferred in areas where the soils are light, whereas larger 4WTs were preferred where heavy clay soils are dominant and where tractors are used for plowing paddy and sugarcane fields.

Almost 40 percent of the interviewed hiring service providers were found to serve clients more than $100 \mathrm{~km}$ away, and movement of combine harvesters was particularly extensive, with some owners traveling up to $600 \mathrm{~km}$. However, about 60 percent of respondents provided hiring services only to nearby villages and did not travel to other districts (Shetto 2016). There is an advantage to providing hiring services to multiple areas, because the variation in preparation and planting seasons that exists across the country helps

2 Some respondents indicated that there is high competition with other modes of transport such as ox carts, power tillers, and small trucks (of 3-5 tons). Ox carts and power tillers are preferred by some farmers with small farm sizes because the small harvested crop volume makes them more cost-effective and they can easily move around in areas with poor infrastructure, as compared with 4 WTs. Small trucks constitute increased competition in areas with improved infrastructure, especially for ferrying produce to markets over longer distances. 
overcome the fact that most seasons last only 30 days or less (Simalenga 1989; Simalenga and Have 1992).

The land preparation and planting seasons range from October/November in the most southern areas of the country (Mbeya and Songea regions) to March in the most northern districts (Arusha and Kilimanjaro). This creates a six-month period during which tractors can be fully engaged if they are moved around, and offers benefits to those farmers who provide services outside of their own district. From October through March, there are two distinct periods of 4WT movements. The most movement occurs from October through December, during which time $4 \mathrm{WT}$ are moved to Kiteto, Kongwa, Kilosa, Kilindi, Morogoro, Kilombero, Iringa, and Mbarali. From January through March, some 4WTs travel to Morogoro, Mvomero, Kilindi, and Handeni.

Ownership of a 4WT has benefits through both personal crop production and profits from providing THSs. For most tractor owners, revenues from crop sales are much greater than revenues from THSs (Shetto 2016). Therefore, in order to encourage continued private provision of THSs it is important that this service be profitable. The average cost of a $4 \mathrm{WT}$ plowing operation is $\$ 15$ per hour, with fixed costs accounting for 29 percent of the total operational costs. Variable costs comprise fuel ( 58 percent), labor (21 percent), and repairs and maintenance (20 percent). Farmers report that they rarely consider fixed costs when examining their operational costs, because fixed costs do not involve direct cash transactions. Shetto (2016) conducted a profitability analysis and a gross margin analysis that showed that 86 percent of surveyed THS providers were profitable, but the remaining 14 percent were not. About 30 percent had gross margins ranging from $\$ 238$ to $\$ 950$ per year, 36 percent had gross margins between $\$ 950$ to $\$ 2,300$, and 20 percent had gross margins greater than $\$ 2,300$ (Shetto 2016).

Anecdotal evidence and data from several studies has indicated that the profitability and sustainability of THSs are dependent on the farmer's ability to generate nonfarm work, especially during the off-season. Reports indicate that just 400 of the 1,000 recommended annual utilization hours for $4 \mathrm{WTs}$ can be obtained from land preparation, crop, and husbandry activities during the main cropping season. The remaining 600 hours come from nonfarm work, work in other parts of the crop production value chain (such as postharvest work in shelling, threshing, and transportation), or providing THSs in other parts of the country, where the cropping season is different (Simalenga and Hatibu 1994; Mpanduji 2000; Federico 1999; Lwesha 2015; Mrema 2016). 
Many farmers also provide THSs for 2WTs, which have been studied through the Farm Mechanization and Conservation Agriculture for Sustainable Intensification (FACASI) project. This project focused on 2WT hiring services in Arumeru, Mbulu, and Babati, all districts where farm households owning between 0.2 and 0.8 ha are engaged in maize- or legume-based farming systems. The FACASI survey identified around 117 2WT THS providers operating in these districts, typically using Chinesebrand 2WTs with 16-18 hp (Kahan and Titus, forthcoming). Around half of the 2WTs were bought by farmers through direct payment, and the other half relied on government loans provided on concessionary terms. The 2WTs in these districts were found to offer services for plowing on small, fragmented plots, as well as for shelling and transportation (Kahan and Titus, forthcoming).

Although 2WTs are used for plowing, their limited power means that this can be quite difficult, especially if soils are hard and dry. For this reason, government-promoted 2WT service centers have had relatively little success. Some 2WTs were originally introduced for minimum tillage operations with the combined ripper-seeder technology. However, most smallholders - even when exposed to conservation farming - prefer to plow their soils, which is often difficult with the limited power of 2WTs (Bymolt and Zaal 2015).

However, there may be more potential for increases in 2WT THSs for transport purposes. In Mvomero district, for example, both 4WTs and 2WTs are gradually replacing ox carts for transporting building brick and for gathering firewood. Cost-benefit analyses have been conducted that support this view. Agyei-Holmes (2014) found that among 225 sampled owners of power tillers and tractors across five regions, more than half used their machines to provide transportation services in order to bring in extra income.

The typical customers of 2WT hiring services are small farmers on landholdings of between 0.1 and 2.0 ha. Providers of $2 \mathrm{WT}$ services obtain the highest profits from shelling, followed by transportation, and then plowing operations. The typical annual number of customers for shelling is 200, but it is just 30 for plowing operations. These data are consistent with the hypothesis that the viability of the 2 WTs is enhanced by expanding $2 \mathrm{WT}$ use beyond time-bound and potentially difficult land preparation activities to include activities such as shelling and milling operations, and transport. There is also evidence to show that $2 \mathrm{WT}$ service providers earn higher levels of profit in maize-based systems. 
It is noteworthy that among some of the $2 \mathrm{WT}$ service providers there is a move to expand their fleet and purchase 4WTs. The provision of 2WT hiring services often represents an initial stage in motorized mechanization, giving service providers experience in machinery use and the hiring service business. The smaller $2 \mathrm{WT}$ s are more affordable than $4 \mathrm{WTs}$, but most $2 \mathrm{WT}$ THS providers aspire eventually to buy the larger machines (Shetto 2016; Kahan and Titus, forthcoming). Another study, in Babati district in Manyara region, also suggested the higher efficiency of individual-owner THSs for 2WTs, compared with group-owner THSs (Mbesa 2017).

\section{Cooperative/group farmer model}

Another THS business model is the cooperative/group farmer model. Many of the THSs provided by cooperatives that were promoted in the 1960s and 1970 s were not successful, including the World Bank-supported cooperativeowned THSs (Collinson 1963; De Wilde 1967; Adhola-Migot 1969; TSAE 1974; Alcober et al. 1983; Mrema 1991). However, there has recently been some recurrence of this type of provider, with two main types of cooperative and joint ownership models emerging. First, there are farmer groups that have been encouraged by the government to apply for tractor loans to ease the individual burden and encourage higher capacity utilization of tractors. Second, there are cases of two or three individuals coming together to procure a tractor for their own use and to hire it out to other farmers.

In the Dakawa Irrigation Scheme, a 2WT is owned by a group of about 20 farmers who share a communal plot of 8 ha in addition to their own individual farms. Land preparation with the $2 \mathrm{WT}$ is prioritized for the communal plot, after which farmers hire the mechanization services for their individual landholdings. Group members contribute to the running and maintenance costs of the tractor as well as fees for servicing the loan used to procure the machine. In another example, from Mbarali district, a group of farmers came together to create a partnership and raise funds to buy a tractor. They cultivate an area of 16 ha divided into four plots, with each plot owned by a different farmer. During the land preparation season, the tractor works on each of the four plots in turn. After work is completed on the group members' farms, they then hire the machine out to other farmers who want the service.

Despite positive anecdotal evidence, the management of shared property is sometimes difficult, especially when the size of the group increases and group members have significantly different farm sizes, and this may discourage cooperative ownership. 


\section{Enterprise ownership of the hiring service}

Finally, some THSs are provided through enterprise ownership business models. These include contract farming, commercial farming, and machinery dealer hiring services; however, compared with the other THS types, these enterprise models are generally less common.

Under the contract farming arrangement, private companies, commercial farms, and agroprocessors enter into contracts to provide guaranteed markets to producers and increase the accessibility of inputs and mechanization services on credit terms, in exchange for committing the harvested crops. For example, Arusha-based Quality Food Products Ltd. (QFP) operates contract farming on about 20,000 ha of maize, safflower, sunflower, and beans in several districts of Manyara and Singida regions. QFP provides machinery hiring services for planting with direct seeders, spraying, and harvesting, along with financing for inputs.

In areas where the land is very heavy and difficult to till with small tractors, some LSFs either have outgrower relations with smallholder farmers (especially in the sugar-growing areas) and provide mechanization services for their land preparation and harvesting, or they hire out portions of their land to small farmers and charge a fee for plowing, leveling, and the supply of irrigation water (Agyei-Holmes 2014).

A few agricultural machinery dealers have started providing machinery hiring services to targeted customers. The Tanzania Farmers Service Centre provides hiring services for combine harvesters to a few LSFs in Arusha and Kilimanjaro, and Tractors Ltd. and Agricom Ltd. provide services to specific customers. In another example, a company known as Unitrans has been contracted by Kilombero Sugar Company to provide machinery services at its sugar estate farms (Shetto 2016).

\section{Financing of tractors and the growth of spare parts and repair markets}

The majority (62 percent) of respondents to the survey acquired their tractors through cash financing from their own equity, 23 percent acquired them through machinery dealer agreements, about 13 percent obtained loans from the AGITF, and only 4 percent got loans from commercial banks. This is despite the government-led facilitation of low-interest loans for agricultural machinery through the AGITF, the Tanzania Investment Bank, and the Tanzania Agricultural Development Bank. As in other African countries, loans from commercial banks are rarely used for the purchase of agricultural machinery. The TAMS survey and other studies have shown that a significant 
FIGURE 14.11 Distances from home to shops selling spare parts, Mbarali district, Tanzania, 2013

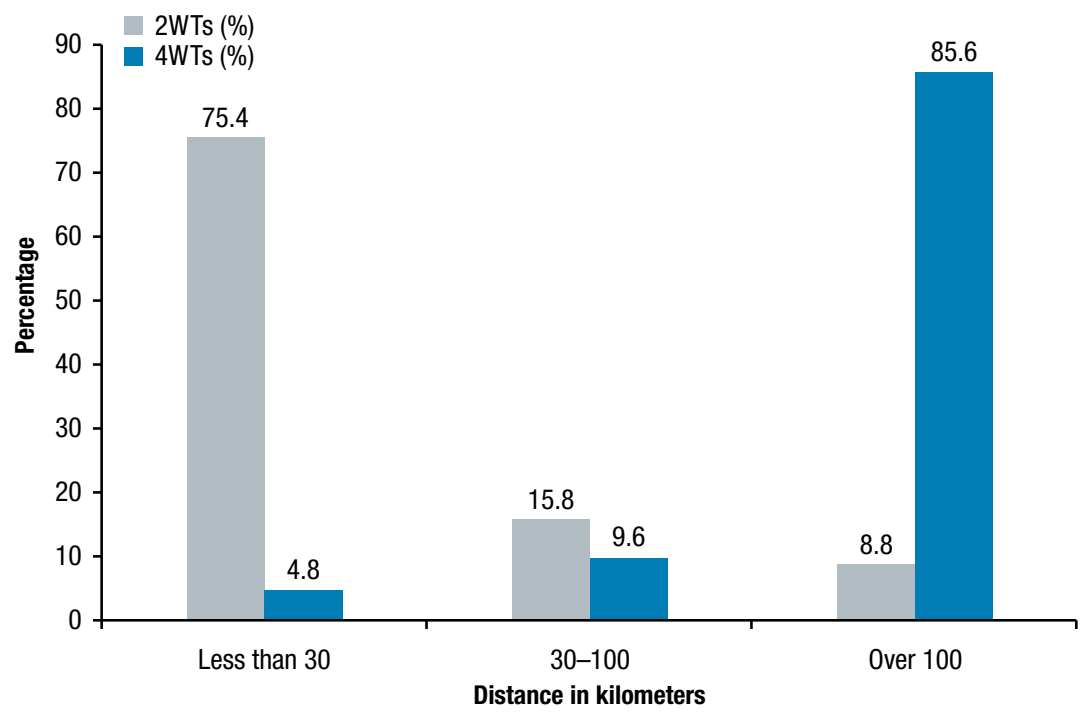

Source: Shetto (2016); Mrema (2016).

Note: 2 WTs = two-wheel tractors (power tillers); 4WTs = conventional four-wheel tractors.

proportion of the $4 \mathrm{WT}$ s owned by farmers and private operators were obtained from the public sector as secondhand units bought for cash, whereas only 3 percent of respondents purchased them through credit.

The accessibility of fuel, lubricants, and repair services was deemed satisfactory, with more than 85 percent of tractor owners reporting that they could source those inputs and services within $5 \mathrm{~km}$ of their location. Repair and maintenance services are mainly provided by mechanics in small garages found in various townships and village centers. Mobile mechanic services are also available when tractors are operating in places far from their homes. Spare parts are mainly sourced from machinery dealers (sometimes 50-300 $\mathrm{km}$ away), because spare parts traders usually have limited stocks. In districts where 2WTs are relatively common (such as Mbarali), 75 percent of 2WT owners travel less than $30 \mathrm{~km}$ to get spare parts because they can be obtained from dealers serving the large motorcycle transportation sector (Figure 14.11). In contrast, 85 percent of $4 \mathrm{WT}$ owners in Mbarali district travel more than $100 \mathrm{~km}$ to get spare parts, suggesting heterogeneity in the spare parts market for $2 \mathrm{WT}$ and $4 \mathrm{WTs}$. 


\section{Effects of Mechanization on Agricultural Transformation}

This section offers some insights into the effects of mechanization. A few of the key issues are its effects on agricultural transformation (farm size dynamics, productivity effects, and use of other modern inputs), labor markets, and to a lesser extent gender roles in farming and the environment.

In Tanzania, the ASDS has provided a long-term strategic framework for the development of the agricultural sector. The ASDS specifically stipulates that agricultural mechanization services will be provided largely by the private sector and should be one of the engines driving agricultural transformation. The evidence suggests that many farmers in rural areas, including the most vulnerable, have benefited substantially from THSs (Agyei-Holmes 2014).

\section{Effects on Farm Size}

In the four districts described in the previous section, accessibility of farm power was associated with a greater area cultivated by non-owners of tractors (1.6-2.0 ha, compared with $0.4-0.8 \mathrm{ha}$ ) (Shetto 2016). Those farmers who relied on draft oxen hiring only managed an area of between 0.4 and 0.8 ha. In Mbeya region, farmers who cultivated 2 ha of paddy rice before the introduction of 2WTs were found to cultivate around 8 ha after 2WTs became available (Agyei-Holmes 2014).

Similarly, a study in two districts (Kilombero district in Morogoro region and Mbarali district in Mbeya region) suggested that for a significant share of interviewed farmers, use of 2WTs was associated with greater area cultivated (Mmari and Mpanduji 2014). In particular, within the public irrigation schemes, some rice farmers increased their area from 1-2 ha to 2-5 ha. Farmers attributed this to the possession of power tillers and tillage implements such as plows and rotavators.

Generally, farmers expand their farm size once they acquire a tractor, but cannot fully utilize the capacity of the tractor on their own farms (Bymolt and Zaal 2015). For instance, in the Mbarali district 2WT owners use less than 30 percent of the capacity of their machines per year (Agyei-Holmes 2014). Thus, tractor owners have to extend their services to other farmers to enable the machines to work enough hectares to justify their cost. Tractor owners who work smaller areas on their own farms provide more THSs to other farmers, whereas those who work larger areas provide fewer THSs. Those farmers who invest in buying tractors and those who hire out their services have both been seen to benefit from increased incomes. Tractor owners realize benefits from increased crop production as a result of cultivated land area expansion, 
and they also benefit through direct income from the payments for services rendered.

Other case study evidence for the adoption of 2WTs in Babati district has suggested that land size influences the ownership decision. Farmers who own tracts of land greater than 6 ha are more likely to be willing to purchase a $2 \mathrm{WT}$ than those farmers who own less than 4 ha, because land can be used as collateral for credit accessibility (Mbesa 2017). This suggests that farm size and tractor ownership are bi-causal. In other words, owning a tractor might encourage the farmer to cultivate larger tracts of land, and at the same time, cultivating large tracts of land might also encourage the farmer to procure or hire a tractor for use.

\section{Effects on Productivity and on the Adoption of Other Modern Technologies}

Agriculture in Tanzania is primarily rainfed, with less than 4 percent of the cultivated land under irrigation (Kalinga 2001). However, rainfall seasons in many places are characterized as short. This means that the completion of key farming tasks such as plowing, planting, and weeding must be carried out in a short period of time. When using HTT to accomplish these tasks, only a small area of less than 1 ha can be cultivated. Therefore, increased mechanization can help to realize benefits from Tanzania's available arable land.

Studies based on the 2002/2003 and 2007/2008 Household Budget Surveys suggest that tractor use on farms has been found to correlate with higher yields of maize, beans, and paddy rice in Tanzania (Lokina, Nerman, and Sandefur 2011). Similarly, the use of 2.5-meter-wide combine harvesters by smallholders on rice fields not only reduces harvest losses, but also reduces the harvesting time from three days to three hours for 1 ha of paddy field (Wilson and Lewis 2015). This finding has been corroborated by the Lower Moshi Irrigation Scheme.

With respect to 2WTs, the Mmari and Mpanduji (2014) study showed variable results dependent on agroecological conditions and farming systems. Data provided by district authorities in Mbarali corroborate farmers' claims regarding increased productivity, especially of paddy. However, in areas with harder soils (particularly in Kilombero district, which accounts for 19 percent of the 237 2WTs found in Morogoro region), 2WTs are rarely used for plowing, and their effect on productivity is found to be limited. Furthermore, in the areas that have found a correlation between $2 \mathrm{WTs}$ and productivity growth, it is possible that the productivity improvements are a result of other factors. For example, in Mbarali they may be due to improved ability to 
prepare better seedbeds faster. In some cases, extra income obtained from hiring out 2 WTs is used to purchase fertilizer, thus considerably increasing the amount of paddy produced per unit area.

Effects of mechanization on overall labor use are mixed. Among Mbarali farmers using $2 \mathrm{WTs}$, greater area cultivated leads to higher demand for hired labor for transplanting. However, though farmers are working with the Mbarali District Council to explore ways of acquiring tiller-powered rice transplanters, for the time being, transplanting remains a manual activity.

The use of 2WTs seems to reduce transportation costs by substituting tractor transport for manual transportation and other, costlier transportation services. Among the respondents in the Mmari and Mpanduji (2014) study, 91 percent of the Kilombero farmers and 80 percent of the Mbarali respondents using 2 WTs reduced their transport costs as a result of tractor transport accessibility.

In terms of mechanization's impact on adoption of other technologies, such as improved seeds, planting in lines, improved seed rate, and chemical fertilizer use, there is limited empirical evidence in the Tanzanian context. A few exceptions include one by Nkonya and colleagues (1998), who studied the adoption of maize production technologies in northern Tanzania over a 20 -year period (1974 to 1994). They showed that using tractors instead of ox plows was positively associated with greater use of chemical fertilizer, although differences were insignificant between tractor and hand hoe users.

\section{Effects on Gender, Feminization of Farming, Labor Markets, and Youth}

The evidence on other socioeconomic effects of mechanization is scarce in Tanzania. However, some insights can be obtained from various case studies.

\section{EFFECTS ON GENDER}

The farming activities that Tanzanian women commonly participate in include weeding, tillage and land preparation, postharvest management, and transportation of agricultural produce. A research study conducted by the Royal Tropical Institute explored issues relating to gender and mechanization in East Africa, including Tanzania (van Eerdewijk and Danielsen 2015). The research recognized the dominant position of men within the farming community and identified male-dominated plowing as the most common application of on-farm mechanization. In this respect, increased mechanization for land preparation and plowing was seen to have relatively little direct impact on women's labor burden. 
The major impact on women depends on resource ownership and intrahousehold dynamics. Due to a complex interplay of values and assumptions, access to and control over resources, and intrahousehold decision-making, women's high labor burden does not translate into articulated demand for and adoption of mechanization. Intrahousehold power relations and decisionmaking determine how resources are accessed and allocated across household needs. The research findings showed that women in male-headed households are not given an opportunity to articulate their demand for mechanization in order to reduce labor intensity, because they are excluded from most household decisions (van Eerdewijk and Danielsen 2015). Consequently, access to machinery may not contribute to women's well-being, unless intrahousehold effects are addressed.

Discussions around 2WTs have also shown that women were willing to adopt this technology as long as they could access financial and information resources. Male household heads were more likely than women to own a 2WT, due to better access to technical information from extension agents (Mbesa 2017). A major shift in the reduction of labor and in access to and control over benefits from mechanization occurs for women who own their own resources, either through formal employment or through owning land (van Eerdewijk and Danielsen 2015). Women's low level of articulated demand for small-scale mechanization also must be understood within the broader context of low levels of adoption of mechanization in general. This is especially true considering that 2WT adoption is particularly low, and women's tasks are most likely to require 2WTs (Bymolt and Zaal 2015).

In some cases, however, mechanization may affect women indirectly. Increased production of maize as a result of mechanization is likely to create indirect benefits for women, because they can access more produce that can ultimately be sold in markets. Another indirect benefit is that mechanization of male labor tasks in farming (land preparation and tillage) reduces women's labor burden because men can help with other, non-land preparation activities (van Eerdewijk and Danielsen 2015). It has also been shown through causal empiricism and key informant interviews that $2 \mathrm{WTs}$ have reduced the time spent by families on their paddy fields during the cropping season, meaning that women can return from the farm early and work on household chores or go to the market (Agyei-Holmes 2014). This finding is also confirmed by Shetto (2016). In addition, the multifunctionality of tractors described in the previous section may be an important entry point to mechanization of nonfarm women's tasks (Misiko et al. 2013), though the costs of buying or hiring additional equipment must be taken into account. 


\section{EFFECT ON YOUTH ASPIRATIONS}

Educated and young people make up the bulk of the rural-to-urban migrants and are motivated by a desire to liberate themselves from the drudgery associated with traditional hand tool-based farming. Data collected in 1990 in Tanzania shows that more than 50 percent of heads of rural households were 45 or older (Tanzania, BoS 1992). In communities in Tanzania where successful mechanized farms have developed over time, youths are more likely to think that the sector presents economic opportunities through commercialization and "farming as a business." If mechanization is to be further expanded, the users of mechanization technologies cannot be small-scale peasant farmers who are aging. They must instead be young and educated people who can engage in agricultural activities as commercial farmers. This argument is in agreement with the Tanzania Development Vision 2025 (Tanzania, Planning Commission 1999), which states that if agriculture in Tanzania is to be expanded, the current farming community ( 80 percent of the population) needs to change from peasant-dominated to primarily commercial MSFs (Mpanduji and Salim 2008).

There is some anecdotal evidence of young people making a viable career in farming (Agyei-Holmes 2016). Examples of farmers who have succeeded in commercial agriculture could potentially serve to promote agricultural mechanization through youth engagement. Moreover, mechanization provides many other employment opportunities for youth—as mechanics, machine operators, processors, and transporters-where skilled labor demands can be met.

\section{Key Environmental Effects}

Although agricultural mechanization is indispensable for production, it can have detrimental effects on the environmental sustainability of farming through soil compaction and erosion, tillage, and chemical pollution. Soil compaction amplifies harmful physical, chemical, and biological processes, which, when combined with inappropriate soil management, lead to soil degradation. Soil degradation, in turn, can affect the amount of fertilizer and energy used in crop production, and may have additional adverse environmental consequences (Soane and van Ouwerkerk 1994). Though soil compaction is a challenge, it can be mitigated by ensuring that the power source matches the local soil and climatic conditions.

There is currently considerable awareness among policymakers that mechanization must be accompanied by adoption of environmentally friendly techniques in tillage, such as minimum tillage and conservation agriculture. To 
this end, mechanization in Tanzania is currently being promoted as part of a sustainable agricultural mechanization strategy (Mrema 2016). If the correct technologies are applied-such as climate-smart agriculture, efficient application of pesticides, precision application of fertilizers, soil compaction management, efficient harvesting, and natural resource conservationthen sustainable intensification can ensue. This has been the experience of the FACASI project, which introduced 2WTs as part of a conservation agriculture-based approach. Combined with adoption of conservation agriculture, 2WTs have a broader impact on soil and water conservation, particularly in areas characterized by steep slopes (Baudron 2014). Furthermore, equipment for seeding and minimum tillage is vital to reduce energy demands and enhance smallholder profitability.

\section{Conclusions}

Tanzania has seen a slow but steady growth in agricultural mechanization over the past few decades. The country's mechanization growth trend is fairly consistent with patterns elsewhere, with both agroecological and socioeconomic conditions as key determinants of increased mechanization.

The speed of mechanization growth varies across regions. Whereas the share of cultivated area plowed by tractors is still around 14 percent for the whole country, it has reached almost 50 percent in regions such as Arusha, Manyara, Mbeya, and Kilimanjaro. In addition, different types of mechanization are emerging in different regions, indicating the varying needs for each type of mechanization based on heterogeneous production environments. For example, 4WT use is mostly emerging in rainfed maize-legume systems in lower-latitude zones, whereas 2WTs are emerging in higher-latitude zones, where more temperate production technologies such as irrigated rice production are commonly used. DAP is emerging primarily in highland zones.

Within each of these mega-regions, demand for mechanization is linked to the availability of markets for the output of the farming enterprise. Areas that are near major population centers or at least linked to them through improved infrastructure see higher growth in demand. Mechanization demand is also raised by reduced availability of labor in rural areas due to universal primary education, availability of other employment opportunities in industry and services, migration to urban areas, and remittances from relatives in urban areas and outside the country. Although Tanzania is still an agrarian society, the share of the workforce employed in the nonfarm sector has been rising 
steadily, and it recently exceeded 30 percent. At the same time, the urban population is growing at $4-5$ percent per year and its population share is expected to rise from 30 percent today to 50 percent by 2030 .

The private sector has often led the development of machinery markets and service providers to meet mechanization demand, despite the government's interventions through THSs, which is consistent with the patterns described in the Asian chapters. Similar to what happened in a country like Ghana, both MSFs and LSFs have emerged as the self-financed owners of $4 \mathrm{WTs}$, and MSFs have become the major providers of hiring services to other smallholders. Ownership of 2WTs appears to be largely motivated by their multifunctionality, because they can be used not only for land preparation but also for shelling and transportation. Again, this pattern is consistent with the spread of 2WTs in some Asian countries. Though still small in number, combine harvester hiring service providers are emerging following the advent of small Chinese and Indian shellers as well as paddy harvesters. Similar to those in other countries, such as China, some of these service providers are specialized nonfarmers and often travel more than $600 \mathrm{~km}$ away from their home to deliver harvesting services.

The lack of available information on mechanization's impact on agricultural development is a major challenge in Tanzania. In the past, there have been many failures (especially of the public sector-operated machinery hiring services) and some successes, but records of both have been poorly maintained. This makes it difficult to draw lessons from them. Moreover, much of the information available on the supply side and on mechanization's relationship with agricultural transformation is largely anecdotal and based on case studies. Reference has been made to the TAMS study (Tanzania, MAFC 2006), and this should be taken as the baseline upon which a detailed impact assessment of agricultural mechanization interventions can be built. In addition to the general lack of information, failed agricultural mechanization projects (for example, government-operated THSs) appear to have received more research attention than the successes.

There are several knowledge gaps that need to be addressed in future studies. Despite Tanzania's transition from a socialist to a capitalist economy, there is a lack of data regarding corresponding changes in issues such as land tenure policy, which may be critical in understanding the relation between mechanization and farm size growth. The role of land tenure policy is also important in view of experiences in Asian countries like Myanmar, where land reform partly led to significant growth in the uptake of bank loans for machine purchase, for which land-use rights could be used as collateral. There is also a 
need to identify whether and how government can effectively support the private sector through agricultural finance, training of tractor operators, business management, entrepreneurship and record keeping, demonstrations and exhibitions to reduce information costs, quality control and testing of equipment, and marketing of spare parts in the country. Institutional support can also underpin the formation of tractor owners' associations that would bring farmers together to discuss issues of common interest and push their development agenda. Importantly, the government does not always have a comparative advantage in providing these supports. Experiences detailed in the Asian chapters also suggest certain dynamics and sequences that make the combination of policies effective. For example, it may be critical to reduce import restrictions in the current system whereby a government agency must inspect all imported tractors, to allow for the importation of a more diverse set of tractors that are "good enough" and affordable. Regulatory measures could be enhanced once the number of tractors in the domestic market is sufficiently high, as was experienced in several Asian countries. Future research should therefore also investigate what role the private sector has played and can play in providing such services.

\section{References}

Adhola-Migot, S. E. 1969. “The Politics of Growers Association.” Thesis, Political Science Department, University of Dar es Salaam.

Agyei-Holmes, A. 2014. “Tilling the Soil in Tanzania: What Do Emerging Economies Have to Offer?" PhD dissertation, The Open University, Milton Keynes, UK.

. 2016. “Technology Transfer and Agricultural Mechanization in Tanzania: Institutional Adjustments to Accommodate Emerging Economy Innovations." Innovation and Development 6 (2): 195-211.

Alcober, D. I., J. Cornelius, J. Medland, G. C. Mrema, S. Prayag, and G. O. Sharrock. 1983. Agricultural Development and Research Priorities for a Semi-Arid Area in Kenya. ICRA Bulletin No. 10. Wageningen, Netherlands: International Centre for DevelopmentOriented Research in Agriculture.

Austen, R. A. 1968. Northwest Tanzania under German and British Rule: Colonial Policy and Tribal Politics. New Haven, CT, US: Yale University Press.

Babu, Z. E. N. A. 2017. "Comparative Analysis of Farm Power Technologies in Rice Production for Smallholder Farmers in Mbarali District, Tanzania." Doctoral dissertation, Sokoine University of Agriculture, Morogoro, Tanzania. 
Baudron, F. 2014. “Farm Power: The 'Forgotten Resource' of Sustainable Intensification Programs in Africa?" CIMMYT News Letter, Addis Ababa, Ethiopia. Available at https://simlesa .cimmyt.org/download/farm-power-the-forgotten-resource-of-sustainable-intensification -programs-in-africa/

Baudron, F., B. Sims, S. Justice, D. Kahan, R. Rose, S. Mkomwa, P. Kaumbutho, J. Sariah, R. Nazare, G. Moges, and B. Gérard. 2015. "Re-Examining Appropriate Mechanization in Eastern and Southern Africa: Two-Wheel Tractors, Conservation Agriculture, and Private Sector Involvement." Food Security 7 (4): 1-16.

Beeney, J. M. 1975. Agricultural Mechanization Study. Dar es Salaam: United Nations Development Program and Food and Agriculture Organization of the United Nations. BoT (Bank of Tanzania). 2015. Annual Report 2014/15. Dar es Salaam.

Burch, P. 1987. Overseas Aid and Transfer of Technology: The Political Economy of Agricultural Mechanization in the Third World. Avebury, UK: Gower Publishing Co.

Bymolt, R., and F. Zaal. 2015. Moving to Mechanization: Mechanization in Maize Farming Systems in Kenya, Tanzania and Ethiopia. Amsterdam: Royal Tropical Institute.

CCM (Chama Cha Mapinduzi). 1988. Program of the CCM for 1987-2002. Dodoma, Tanzania.

- 2015. Program of the CCM for 2015-2020. Dodoma, Tanzania.

Clayton, E. S. 1972. "Mechanization and Employment in East African Agriculture." International Labor Review 105 (4): 19-44.

Collinson, M. P. 1963. Farm Management Survey Report No. 3. Ukiriguru, Tanzania: Western Research Center.

De Wilde, J. C. 1967. Experiences with Agricultural Development in Tropical Africa, Volume 1: The Synthesis. Baltimore: Johns Hopkins University Press for World Bank.

Dihenga, H. O., and T. E. Simalenga. 1989. Testing of Tinkabi Tractor. Morogoro, Tanzania: Department of Agricultural Engineering and Land Planning, Sokoine University of Agriculture.

EMRC (European Marketing Research Center). 2016. Annual Report. Brussels: Department of Agricultural Engineering and Land Planning.

Fear, D. 1976. Agricultural Mechanization in Tanzania. Project No. AGO/DP/VRT.75/018. Dar es Salaam: Food and Agriculture Organization of the United Nations.

Federico, G. 1999. Feeding the World: An Economic History of Agriculture 1800-2000. Princeton, NJ, US: Princeton University Press.

Fluck, R. C., and C. D. Baird. 1979. Agricultural Energetics. Westport, CT, US: AVI Publishing Co.

Hall, M. 1968. "Mechanization Planning in East Africa." In Agricultural Planning in East Africa, edited by G. H. Helleiner. Nairobi: East Africa Publishing House. 
Holtkamp, R. G. 1989. Small 4-Wheel Tractors for the Tropics and Sub-Tropics. Weikersheim, Germany: Margraf Scientific Publishers.

1991. "Small Four-Wheel Tractors for the Tropics and Subtropics: Their Role in Agricultural and Industrial Development." In Agricultural Mechanization Policies and Strategies in Africa: Case Studies from Commonwealth African Countries, edited by G. C. Mrema. London: The Commonwealth Secretariat.

Hyden, G. 1980. Beyond Ujamaa in Tanzania: Under-Development and Uncaptured Peasantry. Berkeley, CA, US: University of California Press.

Ingle, C. 1972. From Village to State in Tanzania: The Politics of Rural Development. Ithaca, NY, US: Cornell University Press.

Kahan, D., R. Bymolt, and F. Zaal. 2018. "Thinking Outside the Plot: Insights on Small-Scale Mechanisation from Case Studies in East Africa." Journal of Development Studies, 54 (11): 1939-1954.

Kahan, D., and B. Titus. Forthcoming. Survey of $2 W T$ Hire Service Providers in Babati, Arumeru and Mbulu Districts of Tanzania. Farm Power and Conservation Agriculture for Sustainable Intensification Working Paper. Mexico City: CIMMYT (International Maize and Wheat Improvement Center).

Kalinga, G. 2001. "Irrigation Development Plan." Paper presented at Irrigated Agriculture for Food Security and Poverty Eradication conference, Morogoro, Tanzania, March 20-22.

Kazungu, K. 2009. "Trade Liberalization and the Structure of Production in Tanzania."

Dissertation, University of Glasgow, Scotland.

Kilawe, C. J., O. Mertz, T. Birch-Thomsen, and S. M. Maliondo. 2018. "Transformation of Shifting Cultivation: Extent, Driving Forces and Impacts on Livelihoods in Tanzania." Applied Geography 94: 84-94.

Kinsey, B. H. 1976. Economic Research and Farm Machinery Design in Eastern Africa. Discussion Paper 10. Norfolk, UK: School of Development Studies, University of East Anglia.

Kjærby, F. 1983. Problems and Contradictions in the Development of Ox Cultivation in Tanzania. Research Report No. 66. Uppsala, Sweden: Scandinavian Institute of African Studies.

Lokina, R., M. Nerman, and J. Sandefur. 2011. Poverty and Productivity: Small-Scale Farming in Tanzania, 1991 to 2007. Working Paper 11/0896. London: International Growth Center, London School of Economics.

Lord, R. F. 1963. Economic Aspects of Mechanized Farming at Nachingwea, Tanganyika. London: Her Majesty's Stationery Office.

Lwesha, M. 2015. “Utilization of Tractors in Mbarali District of Tanzania.” Dissertation, Sokoine University of Agriculture, Morogoro, Tanzania. 
Lyimo, M. 2011. “Country Presentation on Agricultural Mechanization in Tanzania." Presented at Boosting Agricultural Mechanization in Rice-Based Systems in Sub-Saharan Africa, Saint Louis, Senegal, June 6-8.

Maeda, J. H. J. 1976. "Population Participation, Control and Development: A Study of the Nature and Role of Popular Participation in Tanzania's Rural Development." Dissertation, Political Science Department, Yale University, New Haven, CT, US.

Mayne, J. E. 1954. “Progress in the Mechanization of Farming in the Colonial Territories.” Tropical Agriculture 31 (3): 178-187.

- 1955. "Progress in the Mechanization of Farming in the Colonial Territories." Tropical Agriculture 32 (3): 95-99.

_. 1956. "Progress in the Mechanization of Farming in the Colonial Territories." Tropical Agriculture 33 (4): 272-277.

Mbesa, B. 2017. "A Comparative Analysis of Business Models of 2WTs in Babati, Manyara." Dissertation, Sokoine University of Agriculture, Morogoro, Tanzania.

Mgeni, T., and I. B. Yustin. 2014. "Is Kilimo Kwanza a Reliable Answer to the Paradox of Hunger in the Midst of Plenty in Tanzania? Challenges and Prospects of Kilimo Kwanza (Agriculture First) Strategy in Tanzania." Journal of Economics and Sustainable Development 5 (9): 94-106.

Misiko, M., P. Kaumbutho, W. Mariki, J. Mutua, U. Titi, P. Massawe, and F. Baudron. 2013. Drudgery and Realities of Small Mechanization among African Smallholders. CIMMYT Working Paper. Addis Ababa: International Maize and Wheat Improvement Center.

Mkoga, Z. 2010. Conservation Agriculture for Sustainable Agriculture and Rural Development and Food Security in Southern and Eastern Africa: Monitoring and Impact. Evaluation Study Report. Available at http://www.act-africa.org/lib.php?com=5\&com2=218res_id=97.

Mkubwa, H. M., B. A. Mtengwa, and S. A. Babiker. 2014. "The Impact of Trade Liberalization on Economic Growth in Tanzania." International Journal of Academic Research in Business and Social Sciences 45: 514-532.

Mmari, D., and S. M. Mpanduji. 2014. Frugal Innovation for Inclusive Development: A Case Study on Power Tillers in Tanzania. Dar es Salaam: Policy Research for Development.

Mpanduji, S. M. 2000. "Repair Cost of Tractors and Comparison of Mechanization Strategies under Tanzanian Conditions.” Dissertation, Technical University of Munich.

Mpanduji, S. M., and N. Salim. 2008. "Annual Costs of Mechanizing with Tractors in Tanzania.” The Journal of Agricultural Mechanization in Asia, Africa, and Latin America 39 (4): 81-86. 
Mrema, G. C. 1981. "Agricultural Mechanization and Farming Systems: Policies and Prospects." In Proceedings of Farming Systems Research Conference, 144-159. Dar es Salaam: University of Dar es Salaam and United States Agency for International Development.

— ed. 1991. Agricultural Mechanization Policies and Strategies in Africa: Case Studies from Commonwealth African Countries. London: Commonwealth Secretariat Publications.

— 2016. "Draft Report of the Scoping Study on Impact of Agricultural Mechanization Interventions under ASDP1." Presentation at Second Annual Agricultural Policy Conference, Sokoine University of Agriculture, Morogoro, Tanzania, February 23-25.

_ 2017. "Smallholder Agricultural Mechanization: The Role of Service Hiring Market in Developing Countries: A Case Study of Tanzania." Presentation at South-South Knowledge Sharing on Agricultural Mechanization, Addis Ababa, October 31-November 1.

Mrema, G. C., J. Kienzle, and J. Mpagalile. 2018. "Current Status and Future Prospects of Agricultural Mechanization in Sub-Saharan Africa (SSA)." Agricultural Mechanization in Asia, Africa and Latin America 49 (2): 13-30.

Mundial, B. 2012. Agricultural Innovation Systems: An Investment Sourcebook. Washington, DC: World Bank.

Nkonya, E., P. Xavery, H. Akonaay, W. Mwangi, P. Anandajaysekeram, H. Verkuijl, D. Martella, and A. Moshi. 1998. Adoption of Maize Production Technologies in Northern Tanzania. Mexico City: International Maize and Wheat Improvement Center (CIMMYT), United Republic of Tanzania, and Southern African Center for Cooperation in Agricultural Research.

Nyerere, J. K. 1967. Socialism and Rural Development. Dar es Salaam: Government Printer.

Passmore, R., and J. V. G. A. Durnin. 1955. “Human Energy Expenditure.” Physiology Reviews 35: 801-840.

Raikes, P. L. 1975. “The Development of Mechanized Commercial Wheat Production in Northern Iraq-Tanzania." Dissertation, Stanford University, CA, US.

Shetto, R. M. 2016. Study on Machinery Service Hiring Market in Tanzania. IFPRI Background Report. Washington, DC: International Food Policy Research Institute.

Simalenga, T. E. 1989. "Simulation Model to Predict Field Work Days and Its Use in Machinery Selection under Tropical Conditions." PhD Thesis, Institute of Agricultural Engineering, Royal Veterinary and Agricultural University, Copenhagen, Denmark.

Simalenga, T. E., and N. Hatibu. 1994. Draft Animal Power Use in Tanzania: Proceedings of Tanzania Society of Agricultural Engineers. Morogoro: Tanzania Society of Agricultural Engineers. 
Simalenga, T. E., and H. Have. 1992. "Estimation of Soil Tillage Workdays in Semi-Arid Areas." Journal of Agricultural Engineering Research 51: 81-89.

Soane, B. D., and C. van Ouwerkerk, eds. 1994. Soil Compaction in Crop Production. Amsterdam: Elsevier.

Stout, B. A. 1979. Energy for World Agriculture No. 7. Rome: Food and Agriculture Organization of the United Nations.

Tanzania, BoS (Bureau of Statistics). 1992. Population Census: Preliminary Report. Dar es Salaam.

_ 1999. Population Census: Preliminary Report. Dar es Salaam.

Tanzania, MAFC (Ministry of Agriculture, Food Security and Cooperatives). 2001. Agricultural Sector Development Strategy. Dar es Salaam.

—. 2005. Agricultural Sector Development Program 1 2005-2015. Dar es Salaam.

—. 2006. Tanzania Agricultural Mechanization Strategy (TAMS). Dar es Salaam.

- 2015. Agricultural Sector Development Program 2015-2022. Dar es Salaam.

- 2016. Division of Agricultural Mechanization Progress Report. Dar es Salaam.

Tanzania, MALF (Ministry of Agriculture Livestock and Fisheries). 2016. Mechanization Division Progress Report. Dar es Salaam.

Tanzania, MFEP (Ministry of Finance and Economic Planning). 1988. Annual Economic Review: 1987/88. Dar es Salaam.

Tanzania, Planning Commission. 1999. Tanzania Development Vision 2025. Dar es Salaam.

TSAE (Tanzania Society of Agricultural Engineers). 1974. Proceedings of Annual Conference of 1974 Held in Mwanza. Morogoro.

Ursus. 2016. “Current Report no. 5/2016." January 29. www.ursus.com/en/current-report /current-report-5-2016.

van Eerdewijk, A., and K. Danielsen. 2015. Gender Matters in Farm Power. Amsterdam: Royal Tropical Institute.

Wilson, R. T., and I. Lewis. 2015. The Rice Value Chain in Tanzania - A Report from the Southern Highlands Food Systems Programme. Rome: Food and Agriculture Organization of the United Nations.

World Bank. 1961. The Economic Development of Tanganyika. Washington, DC. 


\section{CONTRIBUTORS}

Xinshen Diao is the deputy director and a senior research fellow in the Development Strategy and Governance Division of the International Food Policy Research Institute (IFPRI), Washington, DC.

Hiroyuki Takeshima is a senior research fellow in the Development Strategy and Governance Division of IFPRI, Washington, DC.

Xiaobo Zhang is a senior research fellow in the Development Strategy and Governance Division of IFPRI, Washington, DC, and a chair professor of economics at the National School of Development, Peking University, Beijing, China.

Fredrick Abeyratne is a visiting lecturer at the University of Jayawardenapura, Nugegoda, Sri Lanka, and retired head of the Poverty-Governance Units of the United Nations Development Programme (UNDP).

Andrew Agyei-Holmes is a consultant in the Office of the Chief Economist, World Bank, Washington, DC.

Mansur Ahmed is an economist, Agriculture Global Practice, World Bank, Washington, DC.

Ben Belton is an associate professor in the Department of Agricultural, Food, and Resource Economics of Michigan State University, East Lansing, US.

Guush Berhane is a research fellow in the Development Strategy and Governance Division of IFPRI, Washington, DC. 
Madhusudan Bhattarai is the national project manager of the National Planning Commission of Nepal and UNDP, Kathmandu.

Rob Cramb is a professor at the School of Agriculture and Food Sciences of the University of Queensland, St. Lucia, Australia.

Hugo De Groote is a principal scientist and agricultural economist at the International Maize and Wheat Improvement Center (CIMMYT), Nairobi.

Mekdim Dereje is a research officer in the Ethiopia Strategy Support Program (ESSP) of IFPRI, under the Ethiopian Development Research Institute, Addis Ababa.

Zachary M. Gitonga was a research associate at CIMMYT, Nairobi, at the time he contributed to this book. He is currently a $\mathrm{PhD}$ candidate at the University of Cape Town, South Africa.

Scott E. Justice is an agriculture and rural mechanization consultant, Yangon, Myanmar.

David G. Kahan is a consultant, former agribusiness specialist, and principal scientist at CIMMYT, Addis Ababa, Ethiopia.

Akeem Lawal is a senior extension specialist and the former head of the Agricultural Engineering Department, National Agricultural Extension and Research Liaison Services, Federal Ministry of Agriculture and Rural Development, Abuja, Nigeria.

Yanyan Liu is a senior research fellow in the Markets, Trade, and Institutions Division of IFPRI, Washington, DC.

Cliff Marangu was an intern at CIMMYT, Nairobi, at the time he contributed to this book. He is currently an operations officer at the Diamond Trust Bank, Nairobi.

Ian Masias is a senior program manager of IFPRI's Myanmar Strategy Support Program, Yangon.

Bart Minten was the program leader of ESSP in Addis Ababa, Ethiopia, at the time he contributed to this book. He is currently the program leader of IFPRI's Myanmar Strategy Support Program, Yangon.

Geoffrey C. Mrema is a professor in the Department of Engineering Sciences and Technology, Sokoine University of Agriculture, Morogoro, Tanzania. 
Nguyen Van Cuong is a senior lecturer in the Mechanical Engineering Department of the College of Technology, Can Tho University, Viet Nam.

Thomas Reardon is a professor in the Department of Agricultural, Food, and Resource Economics of Michigan State University, East Lansing, US.

Ravindra S. Shekhawat is a scientist-economist at the Indian Agricultural Statistics Research Institute, New Delhi.

Jed Silver was a senior research assistant in the Development Strategy and Governance Division of IFPRI, Washington, DC, at the time he contributed to this book. He is currently a PhD student at the University of California, Berkeley, US.

Gajendra Singh is an adjunct professor at the Indian Agricultural Research Institute, New Delhi.

Seneshaw Tamru is a PhD candidate at the LICOS Centre for Institutions and Economic Performance, University of Leuven, Belgium.

Viboon Thepent is a senior agricultural engineering specialist, Agricultural Engineering Research Institute, Department of Agriculture, Ministry of Agriculture and Cooperatives, Bangkok, Thailand.

Myat Thida Win is a PhD student at Michigan State University, East Lansing, US.

Jin Yang is a professor at Huazhong University of Science and Technology, Wuhan, China. 

Page numbers for entries occurring in figures are followed by an $f$; those for entries in notes, by an $n$; and those for entries in tables, by a $t$.

Adama Agricultural Machinery Industry (AAMI), 346, 347, 352-53, 362, 371, 372

Africa: continental and country trends in, 32-33. See also specific topics

Africa south of the Sahara (SSA), xxviixxviii, 404-6. See also specific topics

African Union Commission (AUC), 8, 9

Africa's path forward: demand must be closely assessed, 54; eliminate distortions, 55-57; identify appropriate technology, 57-59; lessons from Asia and the past, 53; market-led hiring services must be prioritized, 54-55. See also Policy recommendations

Agenda 2063, 8

Agricultural Engineering Division (AED), $183,186-88,192$

Agricultural Engineering Research Institute (AERI), 183, 193. See also Agricultural Engineering Division

Agricultural Equipment Hiring Enterprises (AEHEs), 439

Agricultural implements, 4n2, 111

"Agricultural machinery," 4n2. See also Machinery
Agricultural mechanization. See Mechanization

Agricultural Mechanization and the Evolution of Farming Systems in SubSaharan Africa (Pingali et al.), 5. See also $\mathrm{PBB}$

Agricultural Mechanization Services Enterprise Center (AMSEC) program, 48, 387, 392-95; governmentselected "private" entities as AMSECs, 394

Agricultural production collectives, 223. See also Collectives

Agricultural Sector Development Program (ASDP), 460, 472

Agricultural Sector Development Strategy (ASDS), 484

Agricultural transformation, 6, 59, 264, 268, 380; in Ethiopia, 329, 330, $362-$ $63,365-67,369$; foreign occupation and, 140; importance for growth and privacy reduction, 4 ; industrialization, agricultural productivity, and, 35; mechanization and, 4, 6, 45, 305-7, $309,312-16,330,362-63,365-67$, $369,444-47,449,457,458,472$, 48490; in Nigeria, 444-47, 449; policies 
Agricultural transformation (continued) and, 406. See also Transformation; specific topics

Agriculture Inputs Trust Fund (AGITF), 472,482

Amec power tillers, 467, 469t

Animal traction, 21, 36, 41, 123t; benefits, 407; costs, 330, 331, 334; effects of tractor adoption on, 444, 445t; farm size and, 425-26; history, 402, 403n1; importance, 411-12; in Kenya, 404, 410-11, 416-19, 424, 428; and soil impaction, 447; tractors substituted for, 432-33, 444-47; use in rainy seasons, 424, 425t. See also Draft animals

Asia, 28-31; lessons from (see Africa's path forward). See also specific topics

Asian Development Bank (ADB), 299

Axial flow pump, $189 f$

Bangladesh, 235-36, 256-58; adoption rate of tractors/power tillers, 245-46, 247f; agricultural labor, cattle/buffalo, machinery, and wages, 237, 238f; agroecological conditions and mechanization, 245-47, 249; characteristics of tractor/power tiller adopter and owner households, 246-47, 248t; determinants of adoption and ownership/ service provision of tractors, 249, 250$51 \mathrm{t}$; drivers of mechanization adoption, 249, 252-53; evolution of economic and employment structure and mechanization in, 237-38, 239t; evolution of mechanization and supporting policies in, 236-41; land distribution among machinery adopters and owners, 243 , 244f; landownership and adoption of machinery, 243, 244f, 245; percentage of owners hiring out their tractors/power tillers, 243, 245f; profile of machines of farm households, 242, 243t

Bank loans. See Loans

Banking regulations, 279

Bhandari, P., 314

Bigot, Y. See PBB
Binswanger-Mkhize, H. P., 380. See also PBB

Boserup, E., 10, 13

Buffalo, 143, 166, 176, 238f, 249

Bullocks: tractors and, 97, 122, 123, 123t, $125 \mathrm{t}$; wage rates for, 128, 128t. See also Oxen

CAMARTEC (Centre for Agricultural Mechanisation and Rural Technology), 474

Cassava, 178-80, 191, 193-95

Cattle, 238f, 249, 334, 404, 411, 415-17

Centre for Agricultural Mechanisation and Rural Technology (CAMARTEC), 474

Centrifugal pumps, 241

China: agricultural production and input at the household level, 77-78,79t; demand for mechanization services, $86,87 f$; number of agricultural workers and amount of machinery power, $76-77,77 \mathrm{f}$; use of machinery in agricultural production, $84-85,85 \mathrm{t}$

Chinese engines, 46

Collateral: land use rights used as, 39, 55, $279,281,283,397,490$; land used as, $20,31,39,283$

Collective action problems, 40, 50

Collective actions, 50

Collectives, 221-23. See also Cooperative(s)

Combine harvester ownership, 82-83, 289-90; cost of cooperative ownership, 83, $84 \mathrm{f}$

Combine harvester service providers, 119 , 224, 305, 316

Combine harvester use, 289-90; and crop yields, 125-27, 127t, 137; and labor productivity and crop yields, 363 , 364f; seasonal changes in, 356-57, 358f; and use of human labor for harvesting and threshing, 122, 124t

Combine harvesters, 470; imports, 348, 349f; seasonal movement of, 358-59, 360f, 361f. See also specific topics 
Combine service enterprises, $86,91 \mathrm{t}$; cost per hectare and area harvested by, $92 \mathrm{f}$

Combine services, 86

Communes, 224

Completely-knocked-down (CKD) tractors, 353, 435-37

Comprehensive Africa Agriculture Development Programme (CAADP), 8,9

Cooperative and joint ownership among farmers, 117

Cooperative(s): forming a, 83, 84f; service, $87,90,223-24$

Corporation (big business)-owned machinery for big farms, 118

Corporations, multinational, 470-71

Cotton, $80,125-26,127 \mathrm{t}$

Countervailing duties, 111

Credit, 39, 40, 109, 110, 130, 352-53, 472. See also Collateral; Financing; Loans

Crop, use of machinery by, 342-43, 343t

Crop-livestock integration, 41

Crop-specific factors affecting demand for mechanization, 175-81

Crop yields, combine harvesters and, 125$27,127 \mathrm{t}, 137,363,364 \mathrm{f}$

Cross-regional mechanization services: economics of, 82-86; evolution of, 87-91

Custom hiring service centers (CHSCs), 115, 117; government-promoted CHSCs under a public-private partnership model, 118

Custom hiring services (CHSs), 17, 19, $45,51,53,97,156,157,159,236,239$, 246, 258, 478; accessibility, 296, 316, 449; big private firm-owned machinery for organized, 118; demand- and supply-side factors in the growth of, 241-43, 245; effects of tractor CHS on agricultural returns to scale in Terai, $312,313 \mathrm{t}$; extent of CHS operations, in number of days used per year, 301 ,
$303 \mathrm{t}$; for grain combines, $117 \mathrm{n} 11$; pace of the growth of, 117. See also Farmertractor-owner hiring service providers

Custom hiring services providers, 117, 119, 300-302, 315, 316

Custom hiring services provision, 220; combine harvester service providers, 224; government-run system, 222-23; individual ownership, 220-22. See also Collectives; Cooperative(s)

Customer finance, types of, 278-79

Customs duties, 111, 435. See also Import duties

Dakawa Irrigation Scheme, 481

Debaridhi pump, 187-88

Decollectivization, 221

Diesel engines, 182, 185-89, 217, 219

Diesel fuel prices (and subsidies), 112-13, 182,184

Draft animal power (DAP): emerging in highland zones, 489; share of farmers using labor or, 153t; in Tanzania, 457, 459, 460, 462, 463, 464f; and technologies, 463

Draft animal use: benefits, 407 ; history, 5, 141; mechanization and, 122-24; in Myanmar, 267-68, 268f, 274; in Nepal, 288t, 290, 291, 292f; in Nigeria, 424, 432, 444; in paddy cultivation, 140, 267-68, 268f; in Viet Nam, 221, 222

Draft animals, 21, 28, 30, 33, 380; in Bangladesh, 237, 238, 254, 257; cost, 222; farm implements and, 418 ; in Kenya, 403-7, 413f, 418; in Nepal, 286, 288t, 290, 291, 292f, 297; rising demand for, 141; in Sri Lanka, 140-41, 143; tractors substituted for, $4 \mathrm{n} 2,28$, 29, 36, 41, 267. See also Animal traction; and specific animals

Duties, 109, 111. See also Import duties

Economic structural adjustment programs (ESAPs), 459, 462, 471 
Economic transformation, 59, 225, 257; demand and, 21, 35; in Ethiopia, 32930; in Ghana, 380, 385; and the labor market, 21, 294-95, 380; and mechanization, 16, 28, 35, 449; in Sri Lanka, 145, 146, 170. See also Transformation

\section{Emigrants. See Migrants}

Energy, 4n2, 76, 112, 436, 488, 489

Energy costs, policy context and, 184, 195

Engineering Research and Development Division, 156. See also Farm Mechanization Research Centre

Engines, 115; Chinese, 46; diesel, 182, 185-89, 217, 219; smaller/small-scale, 391,393

Enumeration areas (EAs), 266

Environmental effects: of mechanization, 488-89; of tractor use, 314-15. See also Soil compaction

Ethiopia, 329-32; agricultural growth and structural transformation, 333-34, 336-38 (see also Agricultural transformation: in Ethiopia); characteristics of mechanization-intensive and other zones in, 350, 351t; combine harvesters, labor productivity and crop yields, 363, 364f; commercial farms, 337, 338f, 347-49; evolution of farm sizes of smallholders, 336, $337 \mathrm{f}$ (see also Farm size: in Ethiopia); farm size and grain area, by zone, 349, 350f; interventions to stimulate mechanization uptake, 371-73; labor and land productivity by tractor use in mechanization-intensive zones, 365-66, 366t; labor and land productivity in wheat cluster in southeast, 363, 364t; mechanization and daily wage rates, $350,351 \mathrm{f}$; reasons for growth in agricultural sector, 333-34, 336; seasonal movement of tractors between zones in, 358, 359f; seasonal movements in rural wages, 369 , 370f; supply-side analysis, 352-54, 356-62; tractor use and labor productivity, 366, 367f; tractor use and wheat yield in mechanization-intensive zones,
$367,368 \mathrm{t}$; wages of unskilled laborers in rural areas of, 334, $335 \mathrm{f}$

Ethiopian agricultural machinery: importance of machine rental services, by farm size, 354, 355t; imports of, 34546, 346f; ownership of, 339-40, 340$41 \mathrm{t}$; use of, 340-44, 342t-45t; use of machines for harvesting/threshing and wheat yield in southeast, 363,365 , $365 \mathrm{t}$

Excise duties, 108, 111, 112

Exit from farming, 446; smallholder, 307, 309

Exports: machinery, 186, 187f, 195, 218, 219; rice, 166, 173-75, 195; from Thailand, 166, 173-75, 177-80, 186, 187f, 195; tractors, 38, 98, 110n6, 217, 393; Viet Nam and, 217-19. See also Tariffs

Farm household typologies, 427-28

Farm machinery. See Machinery

Farm mechanization. See Mechanization

Farm Mechanization and Conservation Agriculture for Sustainable Intensification (FACASI) project, 480

Farm Mechanization Research Centre (FMRC), 144, 156-58

Farm power, 237; animal traction and, 424, 432; meaning, use, and scope of the term, 4n2; in Nigeria, 423, 424t, 432; in Tanzania, agricultural sector and demand for, 461-62; in Viet Nam, $208,215,226$

Farm power strategy of Thailand, 183

Farm size, 273, 274t; cooperatives and, 83, 84f; declining farm size in Sri Lanka, 146-47, 147t; in Ethiopia, 336, 337f, 338-41, 340t-42t, 349, 350f, 355t; in Ghana, 381-83, 383t; machinery use and, 209-10, 212, 215, 252, 42426, 426t; mechanization and, $271-$ $72,272 f$, 484-85; in Nigeria, 424-26, $424 \mathrm{t}, 426 \mathrm{t}, 428$; trends in machinery use and ownership by, 100, 102. 
See also Large-scale farms; Mediumscale farms

Farm size dynamics, $121 \mathrm{t}$; mechanization and, $120-21,121 \mathrm{t}, 135-36$

Farmer owner-operators, 17-18. See also Tractor owner-operators

Farmer-to-farmer, 117, 124, 301, 302, $302 \mathrm{t}-4 \mathrm{t}, 304,305,316,387,389,392$, 396, 439, 448. See also Tractor hiring services

Farmer-tractor-owner hiring service providers (4WT and 2WT), 478

Farming systems evolution, 3, 5, 13-15, $17,21,25$

Farms: commercial, 337, 338f, 347-49 (see also Medium-scale farms; Smallscale commercial farms). See also specific topics

Feminization of farming, 313-14, 486-87. See also Gender

Fertility, tractor use and women's, 314

Fertilizer, 78, 432. See also Manure

Fertilizer use, 312, 333, 486; animal traction and, 416; mechanization and, $124-25,126 \mathrm{t}, 444-45,445 \mathrm{t}$

Financial markets, interventions in, 371-72

Financing, 39, 109-10; hire-purchase, 278-79, 280t, 283; informal sources of, $174,302,316,440$; machinery purchase, import, and financing policies, 433-34; sources of, 302, 303t, 304 (see also Small Industry Finance Corporation); of tractors, 439-40, 482-83. See also Loans

Finger millet (Eleusine coracana), 152, $153 \mathrm{t}, 158$

Four-wheel tractors (4WTs), 303t; age, 465, 468f; cost components, 302, 304, $304 t$; imports, 143, 188, 194, 345, 346f, 435; in India, 100, 102, 103f, 105, 129, 130; in Myanmar, 269-71, 270f, 272f, 274-76, 277t, 279, 282; in Sri Lanka, 139, 141-47, 148f, 148t, 159, 163; in Tanzania, 458, 459f, 464, 465, 466f-68f, 477f; in Thailand, 166,
178-80, 188, 191, 194; used for transportation, 207n2; in Viet Nam, 207, $207 \mathrm{n} 2$, 220. See also specific topics

Fuel policies, 112

Fuel prices and costs, 443, 479

Fuel subsidies, 112

Gender, mechanization and, 249, 313-14, 486-87

Gendered labor use, 123n15, 127, 314, $367,385 \mathrm{t}, 487$

Ghana, 395-98; Agricultural

Mechanization Services Enterprise

Center (AMSEC) program, 48, 387, 392-95; crop area per rural person, $381,382 \mathrm{t}$; difficulties for specialized tractor services, 394-95; emergence of high demand for mechanization in, 379-86; farm size in, 381-83, 383t; farming system evolution in, 380 , $381 \mathrm{f}$; historical overview of mechanization in, 377-79; land-labor ratio in, 380, 381; limited knowledge and information about small machinery, 390-92; limited options for multipurpose tractors, 391-92; market failures in machinery investment, 388-92; private sector-led mechanization in, 38788 ; rising rural wages, $384-86,385 \mathrm{t}$; supply of mechanization in, 386-95; tractor imports, 387, 388f, 393-94; urbanization, 381-84

Ghimire, D., 314

Government failure(s), 48-49, 51, 394

Government policy, role of, 45-46; institutional development and capacity enhancement policies, 51-52; public goods policies, 49-51. See also Import policies; Promotion policies

Government-sourced (GS) tractor owners, 439, 440, 442-43

Great Groundnut Scheme (GGS), 458, 470

Green Revolution, 4, 114, 236-37; in Africa, 33-34, 402; mechanization and, $28,73,175,195-96,236-37$ 
Hand-tool technology (HTT), 460, 462, 485

Hayami, Y., 11. See also Induced innovation theory

High- and intermediate-mechanization implements (HIMIs), 333, 339, 340t

High-yielding varieties (HYVs), 175, 176, 237

Hire-purchase arrangements, 278-79, $280 t, 283$

Hire-purchase loans, 263, 273, 279

Hiring markets: machinery hiring market, 156-57; and market failures, 17-22

Hiring services, 272-73

Holding size and machinery use, 146-47, 148f, $148 \mathrm{t}, 149$

Household Income and Expenditure Survey (HIES), 236, 242, 248t, 250-51t

Household registration system, 74, 75

Import duties, 108-9, 111, 112, 143-44, $155,352,435$; absence of and waiving of, $47,56,281,352,372,435,471$. See also Tariffs

Import policies, 47, 108-11, 130, 298, 372-73; liberalization of, 236, 237, 434-35

Imported machinery, 157-58, 345-46, 346f, 371. See also Imports

Imports, tractor: in Ghana, 387, 388f, 393-94; imports of four-wheel tractors (4WTs), 143, 188, 194, 345, 346f, 435; state-influenced, 393-94; tractors imported from Japan, 182, 184, 186, 188-89. See also Imported machinery

Income, household: effects of adopting tractors on, 306, 307t. See also Wages

India: agroclimatic zones, 104, 106f; distribution of tractors across states in, $100,101 \mathrm{t}$; ownership and market institutions for mechanization service provision, 115, 117-19; policies toward inclusive growth of mechanization, 113-14
Indian agricultural machinery: agroecological conditions, cropping systems, and spread of, 104; machinery purchase, manufacturing, and import policies, 108-14; machinery used and market size of machinery, 100 , $102 \mathrm{t}$; manufacturing policies, $114-$ 15; tractor manufacturers, $115,116 \mathrm{t}$; trends in machinery use and ownership by farm size, 100, 102; twoand four-wheel tractor sales, 100, $103 \mathrm{f}$

Indian agriculture: change in use of machinery and related factors of, 98 , $99 \mathrm{t}$; correlation between tractor density and other factors, $105,107 \mathrm{t}$; demand for mechanization, 100,102 , 104-5; farm-level impacts of mechanization, 119-28; historical background and evolution of mechanization, 98-99; labor-land ratio and tractor density, 104-5; percentage of mechanization by crop and operation, 104, $105 \mathrm{t}$; status of farm mechanization industry, $115,116 \mathrm{t}$; supply-side factors, 106,108 ; tractor density and agricultural labor density across states, 104 , 107f; trends of farm holdings, 100, 101t. See also India

Indo-Gangetic Plains, 119, 288, 314, 315

Induced innovation, 316, 407

Induced innovation theory, 15, 16, 195; overview, 380; vs. PBB framework, 16-17, 21-22

Induced technological change, 15-17

Informal sources of financing, 174, 302, 316,440

International Rice Research Institute (IRRI), 183, 192

Investment: market failures in machinery investment, 388-92. See also Public goods

Investment licenses, access to, 372-73

Irrigated cereal systems, 31

Irrigated paddy farming, 144, 147, 390

Irrigation, 140, 175, 176, 180-82, 392; power tillers and, 390-92 
Irrigation infrastructure, 225-26

Irrigation pumps, 185-88, 189f. See also Water pumps

Irrigation schemes, 390, 404, 405, 481, 484-85

Irrigation systems, 139, 140, 152

Japan: tractors imported from, 182, 184, 186, 188-89. See also Kubota

Joint ownership among farmers, 117

Kenya, mechanization in, 401-2, 417-20; evolution of, 410-12, 413f, 414f; factors affecting adoption, 415, 416-17t; farm implements used, 410; history, 402-5

Knocked-down (KD) tractors, 353 , 435-37

Knowledge, 108, 129, 372

Knowledge constraints and limited knowledge, 45; on animal traction, 41; on land preparation practices, 392, 395; on machinery and mechanization, 5 , 7, 20, 390-92; on plowing, 41; on soil conditions, 37, 38, 41, 50

Knowledge gaps, xxvii, 204, 225, 395, 423, 449, 490

Knowledge transfer, 44, 52, 58, 59, 396-98

Kormawa, P., 42

Kubota, 89, 218, 220, 224, 467, 469t

Labor: mechanization and, 122-27, 125t. See also specific topics

Labor market, 268; broader economic transformation and the, 294-95; mechanization and the, 153-54, 486-88; nonfarm, 255-56 (see also Nonfarm labor supply)

Labor-saving technology, 4, 252-55; defined, $4 \mathrm{n} 2$; mechanization as a, 4 , 267-69, 380. See also specific topics

Labor use, tractor adoption and, 312, 445$47,446 \mathrm{t}$
Land-labor ratio, 104-5, 286, 288t, 380, 381. See also Land-to-worker ratio

Land preparation, 122, 144, 153t, 274, 384, 391, 462, 479-82; bullocks and, $122,123,123 \mathrm{t}$; demand for mechanization in, 432, 433; demands of, 11 , 461; households using machinery for, 269, 270t, 272f, 273, 274t; labor use for, $122,123 \mathrm{t}$; substitution of machinery for, 431-32; THSs and, 458, 465, 479; tractor use for, 11, 21, 124, 126t; use and scope of the term, $122 \mathrm{n} 13$; use of owned or rented machinery for, 272-73, 273f, 274t; wages for, 427, 429t; women and, 486. See also Bangladesh; Paddy land preparation; and specific topics

Land preparation tasks, 461

Land productivity: mechanization and, 122-27, 136-37, 309, 312, 362-63, $365-66,366 \mathrm{t}$; in wheat cluster in southeast Ethiopia, 363, 364t

Land rental markets, 363, 369

Land rental revenue, 309, 310t

Land-to-worker ratio, 173, 174f. See also Land-labor ratio

Land use rights used as collateral, 39, 55, $279,281,283,397,490$

Large-scale farms (LSFs), 461-62, 474-75, 478. See also Farm size

Licensing, 111, 299-300; access to investment licenses, 372-73

Licensing agreements, 474

Liquefied petroleum gas (LPG), 184

Living Standards Measurement StudyIntegrated Surveys on Agriculture (LSMS-ISA), 423n 1

Loans, 48, 109, 110, 261-63, 279, 280, 299, 389, 471, 472, 481; bank, 482, 490; concessional, 48, 56, 57, 298, 393-94, 396, 435-36, 472, 480; government, 48, 434, 480-82; informal, 440, 443 (see also Informal sources of financing); Oromia International Bank, 353. See also Collateral; 
Loans (continued)

Financing; Hire-purchase loans; Small Industry Finance Corporation

Local service providers (LSPs), 117

Low-mechanization implements (LMIs), $333,339,340,340-41 \mathrm{t}$

LP method, 80

Machine collectives, 222

Machine rental, 78; expenditures on rented tractors, 295-96; owned vs. rented machinery, $85,117,171,205$, 208, 209, 273f, 274t; proportion of machine rental by region in Viet Nam, 205, 207-8, 208t; rice planting and, 209-10, 211f, 212, 213f. See also Rental services

Machine utilization rates, 7, 41, 42, 54, 55. See also Power tiller utilization rates; Tractor utilization rates

Machinery: sources of, 155; terminology, 4n2; types of, 43-44, 157-58; use in South Asian countries, 238, 240f; uses of, 43-44. See also specific topics

Machinery manufacturing, 217-19; local, 157-58. See also under India

Maize, 78, 80t, 86, 416, 418-19. See also specific topics

Maize production, $78,79 \mathrm{t}-81 \mathrm{t}$; factors affecting demand for mechanization, 180-81; in Kenya, 403, 405, 408, 416, 418-19; power sources used for operations in, 152, 153t; use of machinery in, $84,85 \mathrm{t}$

Malabo Declaration, 8-9

Manufacturing. See Machinery manufacturing

Manure, 221, 407

Market failures, hiring markets and, 17-22

Market-sourced (MS) tractor owners, 439, 440, 442-43

Marshall, A., 71-72

Mbarali district, Tanzania, 466, 475-76, 476f, 476t, 477f, 483-86; distances from home to shops selling spare parts,
483, 483f; farm size in, 475-76, 477f; utilization rates per price of machines, $469 \mathrm{t}$

Mechanization: and agricultural transformation, 4, 6, 45, 305-7, 309, 312-16, 330, 362-63, 365-67, 369, 444-47, $449,457,458,472,484-90$; definition and scope of the term, $4 \mathrm{n} 2$; factors affecting adoption of, 415 , $416-17 \mathrm{t}$; factors affecting demand for, 169-81; factors affecting supply of, 181-94; helping smallholders survive and become more productive, 306-7, $309,312-15$; as a labor-saving strategy, 267-69; overview, 4-5; sequential nature of, 269-70; small- vs. largescale, 271. See also specific topics

Mechanization adoption, empirical models on, 261-62

Mechanization implementation program (MIP), 439

Mechanization service cooperatives, 87, 90. See also Cooperative(s)

Mechanization supply chain, 56-58; evolution of supply chains for agricultural machinery and implements, 470-71; key players in, 274-75; private-sector, 387,396

Medium-scale farms (MSFs), 461, 462, 474-76, 490. See also Farm size

Metals and Engineering Corporation (METEC), 332, 346-47

Migrant workers, 92, 169-70

Migrants, 268, 294

Migration, 145; rural-to-urban, 75, 181, 182,268

Migratory harvesting services, 89 , 93; cross-regional, 85

Migratory service provision, 19, 73, 389; opportunities for, $42-43$

Mingalar Than Myint compound, 276, $277 \mathrm{t}$

Multifunctionality: of machines, 3; of tractors, 12-13, 19, 31, 43-44, 144, 149, 391-92, 487, 490 (see also Transportation: tractors used for) 
Multinational corporations (MNCs), 470-71

Myanmar, 263-65, 267f; Agricultural Mechanization Department (AMD), 273, 280; demandside evidence of mechanization, 267-74; geographical expansion, 276-78; hire-purchase arrangements, 278-79, 280t, 283; machine sales, $276,277 \mathrm{t}$; machinery and draft animal use in paddy cultivation, $267,268 \mathrm{t}$; number and location of machinery suppliers, 277-78, 278f; policy environment, 280-81; regional variations in use of machinery, 273-74; share of farm households using machinery for land preparation and harvesting, 269, $270 t$; supply-side evidence of mechanization, 274-79

Myanmar Aquaculture-Agriculture Survey (MAAS), 265-66

National Agricultural Research Institute (NARI), 145

Natural gas for vehicles (NGV), 184

Nepal: agricultural wages, 295, 296t; agroecological belts in, 285-86, 286f; broader economic transformation and the labor market, 29495; demand for mechanization, 297; demand-side analysis, 286-97; determinants of tractor adoption and intensity of use, 295-96; effects of tractor use on livestock and land rental revenue and off-farm income, $309,310 t$; evolution of farm household characteristics, 291-94, 293t; evolution of scales of mechanization in, $286,287 \mathrm{t}$; farm size distribution and tractor use, 291; historical background of mechanization evolution in, 285-86; land-to-labor ratio, terrain ruggedness, and draft animal holdings, 286, 288t; machinery purchase and import policies, 298-302, 304; mechanization and agricultural input use, 309, 311t; mechanization and cropping patterns, $287-88,289 \mathrm{t}$; mechanization and revenue per hectare, 312, 313t; medium-scale farms as suppliers of hiring services, 304-5, $305 t$; ownership and market institutions of mechanization service provision, 300; role of mechanization in agricultural transformation, 305-7, 309, 312-16; supply-side analysis, 297-302, 304-5; tractor adoption and returns to scale in farming, 31213; tractor custom hiring service and agricultural returns to scale, 312-13, $313 \mathrm{t}$; use and ownership of tractors and combine harvesters, 286-90

Nigeria, 448-49; agroecological conditions, cropping systems, and farm household typologies, 426-33; area cultivated annually per tractor in, 440 , 441t; characteristics of service provision in, 440-42; demand-side analysis, 423-33; determinants of the area cultivated by tractors, 430, 430t; farmland endowments, farm sizes, labor, and animal use by region, 423-24, 424t; role of mechanization in agricultural transformation, 444-47; supply-side analysis, 433-43

Nigerian agricultural machinery: demand for wider-scale adoption of tractors, 432-33; determinants of tractor use, 430-32; industrial policy on manufacturing, 436-37; machine ownership and market institutions for mechanization service provision, 437-43; tractor use by farming activity, 440, 441 t

Nonfarm economy, 29, 35, 383, 384

Nonfarm employment, 35, 73-75, 91, 92, 236; salaries and wages, 91, 152, 256, 406, 446, 446t, 447, 462; urbanization and, 384. See also Nonfarm work

Nonfarm enterprises, 48

Nonfarm labor supply, 256-57t; mechanization and, 4, 29, 73, 92, 235, 236, 253-58, 256-57t, 446, 487

Nonfarm sector, $76,92,334 \mathrm{n} 3$; growth of and labor absorption into, 235, 256, $281,294,295,316,334 \mathrm{n} 3,428-29$, $446,460,489-90$ 
Nonfarm use of tractors, 99, 112, 149, 301, $303 t, 440$, 462, 466, 487; off-season, 102

Nonfarm vs. farm households, 290, 291, 447

Nonfarm work, 294, 301, 303t, 479. See also Nonfarm employment

Nongovernmental organizations (NGOs), 118

Off-farm income, 309, 310t, 446t

Off-farm labor use, 445-46, 446t

Other field crops (OFCs), 140, 144, 145, $147,149,151-52$

Otsuka, K., 72, 73

Owner-operators. See Tractor owneroperators

Owners: individual farmers as, 117; market-sourced (MS) tractor, 439, 440, 442-43. See also under specific countries

Ownership, tractor: barriers to, 38-40. See also under Rice planting area; specific countries

Ownership arrangements: collectives and cooperatives, 223-24; governmentrun system, 222-23; individual ownership, 220-22

Oxen, 410-12, 412f-14f, 414, 415; adoption of, 415-16; prices, 334, 335f; trained, 415, 416-17t, 417, 418. See also Bullocks

Paddy cultivation, 104, 140, 143t, 145, 149; draft animal use in, 140, 267-68, 268f; irrigated, 144, 147, 149; use of tractors for, $142 \mathrm{n} 1,143$

Paddy fields, 188-89

Paddy land preparation, 142n1, 143-45; use of machinery for, $148 \mathrm{f}, 148 \mathrm{t}, 267$, 268f, 274

Paradigm, new, 3, 6, 36; theoretical framework for the evolving, 13-22
PBB (Pingali, Bigot, and Binswanger, 1987), 16, 45, 379; hypotheses, 7, 13, $14,21,28,53,54$; on mechanization, $5,14,15,17$; sequential adoption of mechanization according to, $14,15 \mathrm{f}$

PBB framework, 3, 5, 16, 17, 27; vs. induced innovation theory, 16-17, $21-22$

Peasant subsistence farms (PSFs), 462

Peixian Bureau of Agricultural Mechanization (PBAM), 87-88

Peixian county, China, 87, 90, 91f, $92 \mathrm{f}, 93$

Pingali, P., 5; on rice harvesting mechanization in Southeast Asia, 72. See also PBB

Planters, 191. See also Transplanters

Plow-positive crops, 427

Policy recommendations, 44-45, 93, 12930, 396-98, 405-6; for African countries, 195, 226, 316-17. See also Africa's path forward

Postharvest losses, 225, 329

Postharvest machinery, 192-93, 470

Postharvest operations, 28-29, 225, 470

Postharvest processing equipment, 464, 470

Postharvesting period, 445, 445t, 446t

Power tiller utilization rates, $467,469 t$

Promotion policies, 47-49, 299

Protectionism, 115, 184

Public goods: government provision of, 7, 31, 45, 49, 93, 130 (see also Public goods policies); investments in, 226; role in mechanization development, 31

Public goods policies, 44-45, 49-51

Public sector, 7n3, 21, 55, 59, 114. See also Custom hiring service centers; specific topics

Public-sector hiring services, 404-5, 43739, 459, 474-75. See also Tractor hiring services

Public-sector investments, 145

Public-sector research and development (R\&D), 42, 52, 113, 114. See also Research and development 
Public-sector researchers, 181, 195

Public-private partnerships and collaboration, $118,157,472,473$

Quality Food Products Ltd. (QFP), 482

Rainfall, seasonal variation in, $145 \mathrm{n} 2$

Rainfall patterns in Ethiopia, 337-38, $339 \mathrm{f}$

Rainfed crop, maize as a, 180

Rainy seasons, 288-89, 289t, 412, 424, $425 \mathrm{t}, 438 \mathrm{t}, 485$

Registration of machines, 102, 112, 14142, 300, 439-40

Regulations, 111-12, 155-56, 299-300; domestic machinery, 473-74

Rental services (and programs), 117-18; direct government-implemented, 118; importance of machine rental services, 354, 355t; tractor, 222, 223f; tractor rental markets, 29. See also Custom hiring service centers; Land rental markets; Machine rental

Rented animals, 425t, 444, 445t

Research and development (R\&D), 46, 49, 50, 52, 54, 156, 391, 393-94, 396; in Ghana, 391, 393-94, 397; in India, 108, 113, 114, 130; public-sector, 42, $52,113,114$

Rice, 378; factors affecting demand for mechanization, 175-77; milled, 295, 296t; rainy-season, 288-89, 315. See also specific topics

Rice area plowed by tractors, calculation of the share of, 163

Rice exports, 166, 173-75, 195

Rice planting area (Viet Nam), 207, 222, 223f; kernel density of, 212, 215f; machine rental and, 212, 213f; tractor ownership and, 210, $211 \mathrm{f}$

Rice planting area, kernel density of, 212 , $215 f$

Rice production, 78, 79t-81t. See also specific topics
Rice transplanters, 176-77, 191. See also Transplanters

Rice transplanting, 176, 486

Rice-wheat systems, 288, 314, 315

Risk, 18, 20, 21, 35, 54, 58, 88, 158, 373; investment, 20, 21, 371-72, 387-91. See also Uncertainty

Rural industrialization, 75

"Rural labor release," 75

Ruthenberg, H., 14, 380

Ruttan, V. W., 11, 72. See also Induced innovation theory

Salaries. See Income; Nonfarm employment; Wages

Seasonal wage variability, 369, 370f; mechanization and, 127-28

Seasonality, 85-86, 359f-61f, 440-41, $442 \mathrm{f}$; seasonal changes in use of combine harvesters and harvesting charges, 356-57, 358f; seasonal labor shortages, 384-85; seasonal movement of combine harvesters, 358-59, 360f, 361f; seasonal variation in rainfall, $145 \mathrm{n} 2$

Semi-knocked-down (SKD) tractors, 353, 435

Service cooperatives. See Cooperative(s)

Siam Kubota tractors, 467, 469t

Slash-and-burn cultivation, 140, 144-45

Small Industry Finance Corporation, 183, 184

Small-scale commercial farms (SSCFs), 462, 474, 475

Small-scale farms (SSFs), 461, 462. See also Farm size

Smith, A., 71

Soil compaction, 288-89, 314-15, 488; tractor use and, 447

Soil conditions, 20, 37, 38

Soil types, 447; and tractor use, $448 \mathrm{t}$

South-South cooperation, 435

South-South knowledge exchange, xxvii 
Sri Lanka, mechanization in, 139-40, 158-59; demand-side analysis, $146-$ 47, 149-54; evolution of economic structure, employment structure, and, 141, 142-43t; farming system and machinery use, 149-53; holding size and machinery use, 146-47, 149; labor and machinery costs for selected crops, 149, 150-51t; labor market and machinery use, 153-54; ownership and hiring services, 156-57; since the 1970s, 141-46; supply-side, 154-58; up to the 1960s, 140-41

Sri Lankan Civil War, end of, 140, 145, 155

Stigler, G. J., 86

Structural Adjustment Program (SAP), $378,379,435$

Structural transformation, 16, 28, 263, 402; and agricultural growth in Ethiopia, 333-34, 336-38; agricultural wages and, 268-69. See also Transformation

Sub-Mission on Agricultural Mechanization (SMAM), 114

Sub-Saharan Africa (SSA), xxvii-xxviii, 404-6. See also specific topics

Subsidies for mechanization tools, 299

Sugarcane, 127t, 177-78, 191, 193-95, 482

Sukharomana, S., 183-84

Supply side of mechanization, 17-22

Surface-water pumps, 269, 270f, 275. See also Water pumps

Sustainable Agricultural Mechanization in Africa (SAMA), 8, 9

Tanzania: agricultural sector and the demand for farm power, 46162; demand-side analysis, 461-67, 470; effects of mechanization on agricultural transformation, 484-90; evolution of mechanization in, 45761; supply-side analysis: sourcing machinery, 470-76, 478-83; tractors in use in different years, $458,459 \mathrm{f}$
Tanzania Agricultural Development Bank, $39,472,482$

Tanzania Agricultural Mechanization Strategy (TAMS), 460-61, 471

Tanzania Tractor Manufacturing Company (TRAMA), 471

Tariffs, 47, 48, 111, 184, 298, 435, 471. See also Import duties

Tax exemptions, 158, 241, 258, 298, 299

Taxation, $354 \mathrm{n} 22$; on fuels, 112; of machinery, 47, 108-9, 111, 130, 144, $156,298,352,435,471$

Technological innovation. See Induced innovation theory

Technologies, modern, 463; identifying appropriate technology, 57-59; mechanization and the adoption of, 122-27, 485-86; using more adapted technologies, 373. See also Labor-saving technology; specific topics

Terai, 295; Hills region and, 286, 290-92, 294, 296, 297, 306, 309, 310t, 316, 323-25t, 325f; tractor use in, 286, 287, 290-92, 292f, 296, 297, 305, 306, 309, 310t, 315-17, 321, 323-25t. See also Nepal

Thai agricultural machinery: development and supply of, 186-94; harvest and postharvest, 192-93; imports and exports of parts and machinery, $186,187 f$; number of holdings using machinery and equipment by source, $166,168 \mathrm{t}$; number of machinery businesses, 185, 186t; production of, 185$86,187 \mathrm{t}$; size and structure of the machinery industry, 185-86

Thai agriculture: agricultural land, employment, and land-to-worker ratio, 173, 174f; crop-specific factors affecting demand for mechanization, 17581; factors affecting the demand for mechanization in, 169-81; factors affecting the supply of mechanization in, 181-94; factors in the rapid mechanization of, 166-67; landholdings and farming systems, 171-73; pattern of agricultural development, 
171-74; phases of agricultural growth, 173-74

Thai economy, structural change in, 169

Thailand: economywide structural and demographic change, 169-71; holding size and land use by region, 171 , 172t; National Economic and Social Development Plans, 182-83; policy context, 182-85; regions, 165-66, $167 \mathrm{f}$; wage rates by sector, $169,170 \mathrm{f}$

Tractor hiring services (THSs), 42, 296; farmer-to-farmer, 396; farmer-tractorowner hiring service providers, 478-81; in four case study districts, 475-76; in Ghana, 378, 379, 383 (see also Ghana); government, 47 , 55, 226, 404; in Kenya, 404, 405; in Nigeria, 437, 439, 443; private-sector, 439; public-sector, 404-5, 437-39, 459, 474-75; in Tanzania, 458, 459, 461, 462, 465, 471, 474-75, 478-82, 484, 490; THS operators, 474-75; THS schemes, 378, 379; 2WT, 480, 481. See also Farmer-to-farmer

Tractor hiring units (THUs), 434, 438-39

Tractor imports. See Imports, tractor

Tractor owner-operators, 17-18; profitability differences between types of, 442-43, 443t. See also Owners

Tractor services: sources of, 437, 438t. See also specific topics

Tractor size, 37-38

Tractor utilization rates, 17-19. See also Machine utilization rates

Tractorization, 4n2, 378, 379, 474

Tractors: access to spare parts and maintenance for, 372; brands, 439; financing for (see Financing); multifunctionality, $12-13,19,31,43-44,144,149,391-$ $92,487,490$; number owned, 135 , 136; subsidies on, 109; in Thailand, development and supply of, 188-91; types of, 100, 102. See also specific topics

Trade policies, 298. See also Import policies

TRAMA (Tanzania Tractor Manufacturing Company), 471
Transformation, 124, 463; in Bangladesh, 235, 257; in Nepal, 294-95, 305-7, 309, 312-16; possibility of rapid, 53. See also Agricultural transformation; Economic transformation; Structural transformation

Transplanters, 155t, 176-77, 191

Transplanting, 176, 191, 486

Transportation, 168t, 193, 194, 300, 392, $403,410,486$; tractors used for, 43 , 112, 144, 176, 193-94, 205n2, 292, $298,392,440,466-67,478,480,486$

Two-wheel tractors (2WTs), 346, 347, 419; in India, 100, 102, 103f; in Myanmar, 269, 270f, 271, 272f, 273$76,277 \mathrm{t}, 282$; to power axial flow pump to irrigate rice field, 188, 189f; sales, 100, 103f; in Sri Lanka, 14142, 142-43t, 144, 147, 148f, 148t, $149,158,159,163$; in Tanzania, 46067, 468f, 469f, 472, 474-76, 477f, $478,480-81,483-87,489,490$; in Thailand, 165, 166, 176, 184-86, 188-91, 189f, 193, 194; in Viet Nam, 207-8, 219, 221, 226

Uncertainty, 57; demand, 48-49; in the service hiring market, 389; about tariffs and other pricing policies, 48. See also Risk

Uncertainty constraints in the equipment hiring market, 40

Uncertainty in the service hiring market, 18

Urbanization, 16, 35, 336, 381-84, 428-29

Value-added tax (VAT), 298, 352, 354n22, 435,471

Viet Nam, mechanization in, 203-5, 22526; descriptive analysis of the growth pattern of, 205, 207-10, 212, 215-17; market institutions in mechanization service provision, 217-25; mechanization level and economic structure, 205, 206t; tractor ownership by region, 
Viet Nam, mechanization in (continued) $207,209 \mathrm{t}$; wages and mechanization growth, 215-16, 216f, 217t; weak government involvement during mechanization growth phase since 1990s, 224-25. See also Rice planting area

Viet Nam Engine and Agricultural Machinery Corporation (VEAM), 219

Vietnamese agricultural machinery: factors associated with use of machines, 216$17,218 \mathrm{t}$; farm size and use of, 209-10, 212,215 ; proportion of machine rental by region, 205, 207,208t; subnational variations in rental and ownership of, 205, 207-8; supply of, 219-20; trend of tractor ownership, machine renting, and labor hiring for farming operations, 208, 210f, 215

Village development committees (VDCs), 296, 307, 308f, 321, 324-25t

Village Dynamics in South Asia (VSDA), 119-20

Wage rates: for bullocks, 128, 128t, 129; mechanization and, 350, 351f; by sector in Thailand, 169, 170f

Wages, 237, 238f, 295, 296t, 428-29, $429 \mathrm{t}$; for land preparation, $427,429 \mathrm{t}$; and mechanization growth in Viet Nam, 215-16, 216f, 217t; rising rural wages in Ghana, 384-86, 385t. See also Income; Nonfarm employment; Seasonal wage variability

Water pumps, 241, 269, 270f, 275, $277 \mathrm{t}$. See also Irrigation pumps

Weeding, 176-79, 181

Wheat production, $78,79 \mathrm{t}-81 \mathrm{t}, 86$, 104; in Ethiopia, 331, 349, 352, 354, 357-60, 363, 364t, 365, 371, 373; labor and land productivity in the wheat cluster, 363, 364f; tractors and, 365-66, 368t; use of machinery in, $84,85 \mathrm{t}$; yield effects of tractor and combine harvester use on, $127 \mathrm{t}$. See also Rice-wheat systems

Women. See Gender

Working animals. See Draft animals

Yantradoot Villages Scheme in Madhya Pradesh, 118

Youth, 145, 146, 152, 249; mechanization and youth aspirations, 488

Zero-till technologies, 119, 129, 305, 315 
Agricultural mechanization in Africa south of the Sahara, which is especially important to small businesses, has evolved to require a new paradigm, beyond conventional ones based on farming-system evolution and induced innovation theories. Can Asia, which recently succeeded in similar mechanization transitions, offer a model for Africa under this new paradigm? An Evolving Paradigm of Agricultural Mechanization Development: How Much Can Africa Learn from Asia? analyzes the experiences of eight Asian and five African countries. The book discusses crucial government roles in mechanization support, across import policies, promotion policies, and public good policies. Potential approaches to prioritize market-led hiring services, eliminate distortions, and develop appropriate technologies for Africa are presented to provide effective support for agricultural mechanization in African contexts. The roles of agricultural mechanization within overall agricultural and rural transformation strategies in Africa are also discussed. An Evolving Paradigm of Agricultural Mechanization Development's recommendations and insights should be useful to national policymakers and the development community, who can adapt this knowledge to local contexts and use it as a foundation for further research.

Xinshen Diao is the deputy director and a senior research fellow in the Development Strategy and Governance Division of the International Food Policy Research Institute (IFPRI), Washington, DC. Hiroyuki Takeshima is a senior research fellow in the Development Strategy and Governance Division of IFPRI, Washington, DC. Xiaobo Zhang is a senior research fellow in the Development Strategy and Governance Division of IFPRI, Washington, DC, and a chair professor of economics at the National School of Development, Peking University, Beijing, China.

Cover photos: (top) Altrendo Images/Shutterstock; (bottom) Xiaobo Zhang/IFPRI

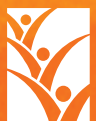

INTERNATIONAL

FOOD POLICY

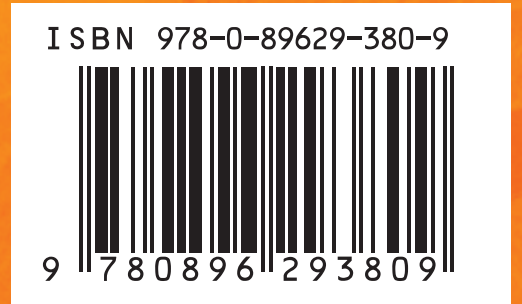

RESEARCH

INSTITUTE

IFPRI

IFPRI is a CGIAR Research Center

1201 Eye Street, NW, Washington, DC 20005 USA

T. $+1-202-862-5600 \mid$ F. $+1-202-862-5606$

Email: ifpri@cgiar.org | www.ifpri.org | www.ifpri.info 